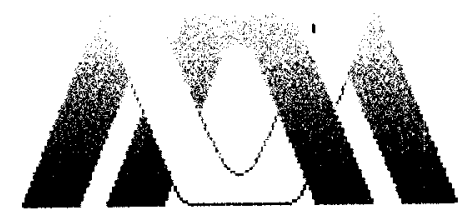

Casa abierta al tiempo

UNIVERSIDAD AUTONOMA METROPOLITANA

UNIDAD IZTAPALAPA

DIVISION DE CIENCIAS SOCIALES Y HUMANIDADES

POSGRADO EN CIENCIAS ANTROPOLÓGICAS

La cruzada indigenista en la Tarahumara

Juan Luis Sariego Rodriguez

Tesis de Doctorado en Ciencias Antropológicas

Director: Dr. Esteban Krotz Heberle

Asesores: Dra. Alicia Castellanos Guerrero

Dr. Andrés Medina Hernández 


\section{INDICE GENERAL}

PÁGINA

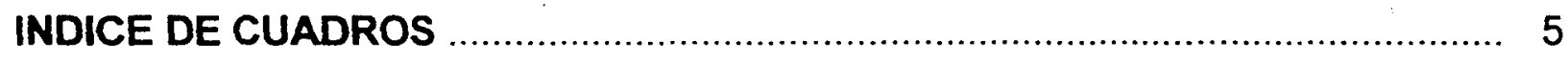

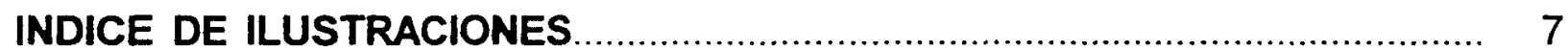

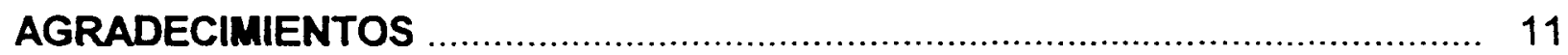

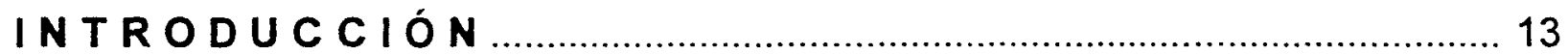

LA SIERRA TARAHUMARA: TERRITORIO Y POBLACIÓN ….............................. 13

DEBATES Y EXPERIENCIAS EN TORNO AL INDIGENISMO................................ 24

La cuestión étnica y los proyectos de nación ................................................ 28

La acción indigenista............................................................................ 36

PREGUNTAS Y SENTIDO DE LA INVESTIGACION ............................................ 40

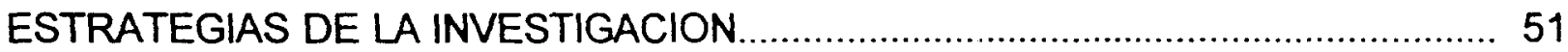

PLANTEAMIENTOS Y ESTRUCTURA DEL ESTUDIO_........................................... 56

CAPITULO 1: INDIGENISMO E IDENTIDAD EN LA SIERRA TARAHUMARA:

ENTRE LA FASCINACIÓN PRIMITIVISTA Y LA FICCIÓN REFORMADORA.......... 65

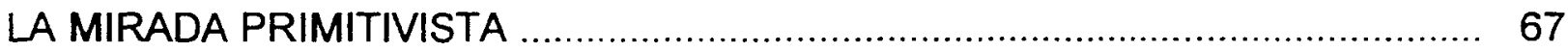

Los últimos cavernícolas americanos .................................................... 67

Mito y realidad de la resistencia física indígena.......................................... 72

Una etnografia demostrativa de la resistencia indigena al cambio.................... 79

El indio o la autenticidad del hombre natural .............................................. 89

El atraso del indio: ¿olvido o impotencia de la civilización? ................................ 94

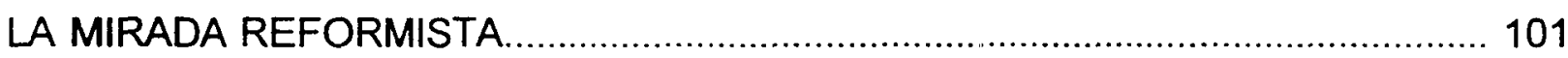

El indio como problema: el discurso indigenista .......................................... 103

El indio como símbolo: el discurso misionero ............................................. 112

El indio como imaginario y actor: el discurso postmoderno.............................. 120

CAPITULO 2: LA COMUNIDAD INDIGENA EN LA SIERRA TARAHUMARA: CONSTRUCCIONES Y DECONSTRUCCIONES DE REALIDADES Y

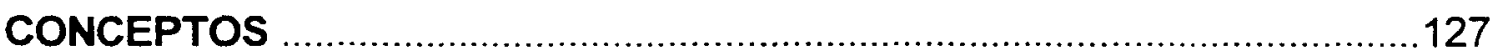

NACIONES INDIGENAS, PUEBLOS DE MISION (1600-1767) …............................. 129

LA COMUNIDAD TUTELADA: COLONIAS E INTERNADOS

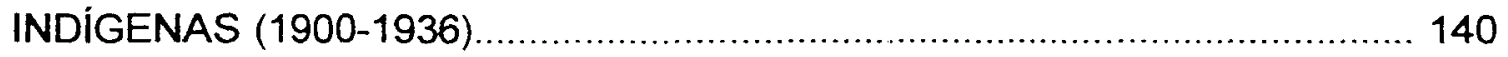

LA RAZA TARAHUMARA Y LA CUESTION DE LAS

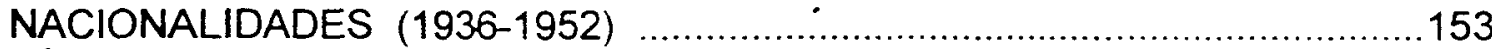

EL CARÁCTER SUI GENERIS DE LA COMUNIDAD TARAHUMARA

EN LA DOCTRINA INDIGENISTA DE LOS AÑOS CINCUENTA ................. 166

CRITICA DE LOS SUPUESTOS COMUNALISTAS DEL INDIGENISMO

EN LA TARAHUMARA... 
CAPITULO 3.- INDIGENISMO, RELACIONES INTERÉTNICAS

LA PROTECCCIÓN DEL INDIO Y PROCESOS CIVILIZATORIOS EN LA SIERRA TARAHUMARA ... 205

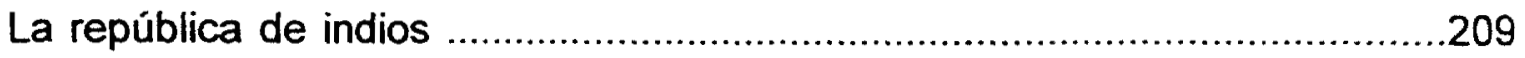

Entre el proteccionismo y el abandono liberal............................................. 211

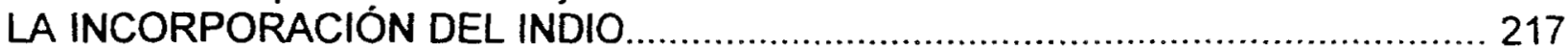

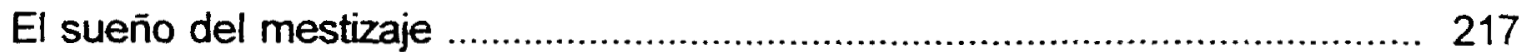

La mexicanización del indigena ............................................................ 221

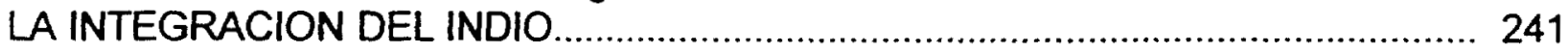

La Sierra Tarahumara ¿región de refugio? ........................................................ 241

Indigenismo y conflicto interétnico.. ........................................................... 250

CAPITULO 4.- CONCEPCIONES, MODELOS Y EXPERIENCIAS

INDIGENISTAS DE DESARROLLO EN LA SIERRA TARAHUMARA .......... 267

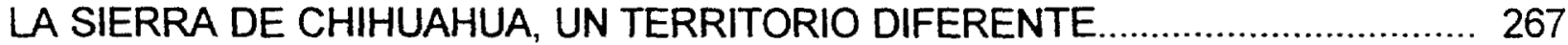

LAS PROPUESTAS RADICALES. 1936-1939................................................. 272

LA ACCION INTEGRAL: LOS TIEMPOS GLORIOSOS DEL INDIGENISMO

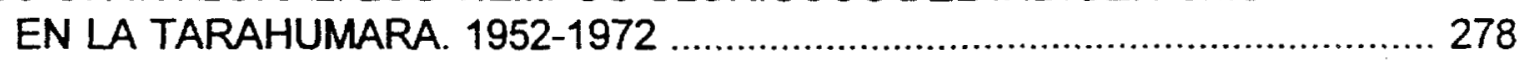

Los primeros proyectos ............................................................................... 278

La centralidad de lo forestal en el modelo indigenista del desarrollo ................ 287

Los signos del progreso indígena: escuela y salud ...................................... 302

DE LAS POLITICAS SECTORIALES A LA PARTICIPACIÓN INDIGENA:

LOS TIEMPOS DE CRISIS DEL INDIGENISMO (1972-1990) …................... 317

Neoindigenismo y programas sectoriales ................................................. 322

Los obstáculos del indigenismo de participación ....................................... 327

LAS ESTRATEGIAS EMERGENTES DEL DESARROLLO EN LA TARAHUMARA.. 340

Nuevos perfiles de la minería serrana ........................................................ 341

Turismo y desarrollo indígena.................................................................. 344

Narcotráfico y cultura de la violencia ............................................................. 347

CONCLUSIONES: DEL INDIGENISMO A LA AUTONOMIA E

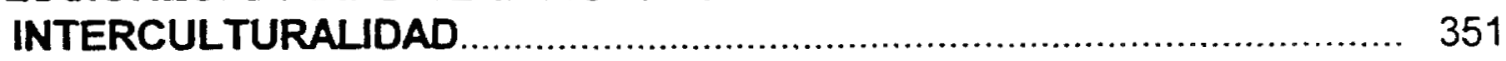

Del indigenismo a la autonomía .............................................................. 359

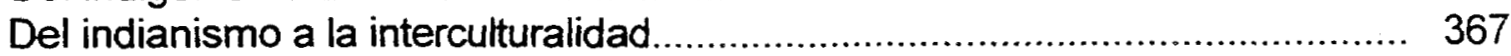

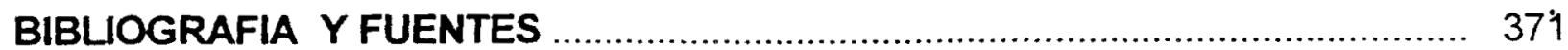




\section{INDICE DE CUADROS}

PÁGINA

CUADRO 1.- Población tarahumara, tepehuana, guarijia y pima en el estado de Chihuahua por municipio, 1990, 1995

CUADRO 2.- Altitudes de las cabeceras municipales de la Sierra Tarahumara.

CUADRO 3.- Distribución porcentual de localidades y población de 5 años y más hablante de tarahumara, tepehuano, pima y guarijío (HLI) en los municipios de la Sierra Tarahumara del estado de Chihuahua. 1995.

CUADRO 4.- Tabla comparativa de récords establecidos por corredores tarahumaras en Olimpiada de Guachochi (1-5 mayo de 1942)...

CUADRO 5.- Patologias más recurrentes de los Tarahumaras según Basauri............ 77

CUADRO 6.- Reseña de datos tarahumaras clasificados, según Bennett y Zingg........ 86

CUADRO 7.- Sinopsis de los principales rituales y fiestas tarahumaras ....................... 117

CUADRO 8.- Localidades por municipio según tamaño de la localidad................... 191

CUADRO 9.- Distribución porcentual de la población de 5 años y más que habla alguna lengua indigena en municipios de la Sierra

Tarahumara, según tamaño de localidad. 1995.

CUADRO 10.- Localidades de la Sierra Tarahumara con más de 50 hablantes de lengua indigena de 5 años y más, por municipio, 1995.

CUADRO 11.- Dotaciones de tierras en la Sierra Tarahumara por resoluciones presidenciales (1920-1933)...

CUADRO 12.- Censo de población indigena tarahumara con especificación de lugares, población escolar y escuelas existentes. (1926).

CUADRO 13.- Síntesis del Proyecto elaborado por el Profr.Filiberto Gómez González para la creación de una Comunidad experimental tarahumara (CET) en el Valle de Nabogame, mpio. de Guadalupe y Calvo.

CUADRO 14.- Cuadro demostrativo de la situación agraria de los 10 munlcipios que comprende la jurisdicción de la Sub-delegación de la Tarahumara, 1972

CUADRO 15.- Asuntos atendidos por el Departamento Legal del CCIT. $1965-1970$ y $1977-1982$

CUADRO 16.- Relación de ejidos localizados dentro de la zona de trabajo del CCIT con solicitudes pendientes en la Delegación estatal del Departamento de Asuntos Agrarios y Colonización. 1972

CUADRO 17.- Niveles de marginación en los municipios de la Sierra Tarahumara. 1995

CUADRO 18.- Recomendaciones del Departamento del Trabajo para resolver los problemas de la Raza Tarahumara (1936)

CUADRO 19.- Plan de acción para enfrentar el Problema tarahumara propuesto por Plancarte. 1954.

CUADRO 20.- Programa de los cursos de capacitación de Promotores 
culturales del CCIT. 1953.

CUADRO 21.- Superficies forestales en municipios de la Tarahumara (circa1965)... 288

CUADRO 22.- Empresas y explotaciones madereras (pino) en el área de influencia del Centro Coordinador Indigenista de la Tarahumara. 1948-1951

CUADRO 23.- Composición étnico-ejidal de los municipios de Guachochi, Nonoava y Guadalupe y Calvo. 1970 (Estimaciones hechas por el CCIT).

CUADRO 24.- Producción y utilidades obtenidas en 6 ejidos organizados por el CCIT. $1^{\circ}$ y $2^{\circ}$ ejercicios de 1959.

CUADRO 25. - Escuelas atendidas por el CCIT y movimiento general de alumnos. Septiembre 1965-Junio 1966.

CUADRO 26.- Relación de 51 defunciones atendidas por personal médico de la Clínica del CCIT en Guachochi (23 febrero de 1959 al 20 de abril de 1960)

CUADRO 27.- Esquema comparativo de la acción a partir de los Centros coordinadore indigenistas. 1951-1976 y 1977

CUADRO 28.- Resultados de la operación de los Fondos Regionales de Solidaridad en Chihuahua.

CUADRO 29.- Discursos, políticas indigenistas y respuestas indigenas en la Sierra Tarahumara. 


\section{INDICE DE ILUSTRACIONES}

PÁGINA

FIGURA 1.- Mapa de los municipios de la Sierra Tarahumara ................................ 15

FIGURA 2.- Perfil fisiográfico de las barrancas del Cobre, Batopilas y Urique.............. 21

FIGURA 3.- Vista panorámica de la Barranca del Cobre desde el Divisadero.............. 23

FIGURA 4.- Mapa del actual teritorio tarahumara ................................................ 41

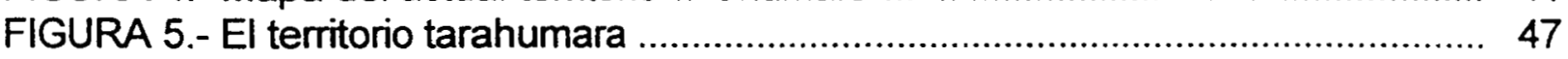

FIGURA 6.- Principales poblaciones de la Sierra Tarahumara ............................... 52

FIGURA 7.- Autoridades tarahumaras en el atrio de la iglesia de

Norogachi, Chih. Julio de 1892. Foto de la expedición de Lumholtz .......... 70

FIGURA 8.- La Conducta de metales de Batopilas hacia 1890............................... 70

FIGURA 9.- Los modernos y competitivos corredores rarámuri................................ 82

FIGURA 10.- El Tarahumara en el cine nacional.................................................. 82

FIGURA 11.- Rarámuri. Mesa de la Yerbabuena..................................................... 82

FIGURA 12.- Antonin Artaud, viajero de la Tarahumara ........................................... 96

FIGURA 13.- Fernando Jordán en la Alta Tarahumara en 1954 ............................... 96

FIGURA 14.- Músicos mestizos o "chabochis" en las calles de Batopilas.................. 110

FIGURA 15.- Escuela albergue Francisco M. Plancarte. Aboréachi......................... 110

FIGURA 16.- Iglesia de San Ignacio de Arareco................................................... 118

FIGURA 17.- Fiesta de la Virgen de Guadalupe. Rowérachi..................................... 118

FIGURA 18.- Migrantes rarámuri en la ciudad de Chihuahua.................................... 122

FIGURA 19.- Rarámuri de Samachique............................................................. 122

FIGURA 20.- Mapa de las Misiones y territorios indígenas

en la Sierra Tarahumara. Siglos XVII y XVIIII.................................. 132

FIGURA 21.- El territorio tarahumara hacia 1600 ................................................. 134

FIGURA 22.- Ruinas de la Misión de San Miguel de Tubares

municipio de Morelos, Baja Tarahumara........................................... 138

FIGURA 23.- Misión de Satevó, a orillas del río Batopilas...................................... 138

FIGURA 24.- Evangelización del indigena..................................................... 150

FIGURA 25.- Iglesia e Internado de Sisoguichi.................................................... 150

FIGURA 26.- Miembros de la Comisión del Departamento de Trabajo

escuchan al profesor Ignacio León. Norogachi (1936)........................ 162

FIGURA 27.- El Primer Congreso Tarahumara. Guachochi. 1939........................... 162

FIGURA 28.- Miembros del Consejo Supremo Tarahumara con el Gobernador de Chihuahua Alfredo Chávez (circa 1941)...................................... 166

FIGURA 29.- El Lic. Villanueva y el Dr. Aguirre Beltrán escuchan el informe de labores de Eleuterio Rodríguez, Presidente saliente del Consejo Supremo Tarahumara. Guachochi, enero de 1971............................ 166

FIGURA 30.- Vista aérea de la ciudad de Guachochi, ejemplo típico del patrón de "pueblo hispánico" en la Sierra Tarahumara...

FIGURA 31.- La Mesa de Yeguachique, en el pueblo de Aboréachi

(municipio de Guachochi), ejemplo del patrón de "diseminación 
rural" tarahumara

FIGURA 32.- Rancho tarahumara, ejemplo de la dispersión demográfica, cercano a Cusárare.

FIGURA 33.- Establo móvil tipico de un rancho tarahumara. Yeguachique, Aboréachi.

FIGURA 34.- El trabajo colectivo antes del tesgüino. Yeguachique (Aboréachi).........

FIGURA 35.- Kumérachi o cárcel rarámuri de la Mesa de la Yerbabuena, cerca de Batopilas.

FIGURA 36.- Esquema general de articulación entre los niveles de organización socio-territorial en el área indígena meso-americana y de la Sierra Tarahumara.

FIGURA 37.- Misión de Cusárare

FIGURA 38.- Túnel minero Porfirio Díaz en Batopilas hacia 1885.......................... 212

FIGURA 39.- El trabajo en las minas de Batopilas................................................. 224

FIGURA 40.- Don. José Córdoba. Aserradero de Samachique.............................. 224

FIGURA 41.- José Járis Siquirichi................................................................... 234

FIGURA 42.- Yoquivo. Iglesia y ruinas del viejo Internado indígena......................... 234

FIGURA 43.- Los primeros maestros tarahumaras. Norogachi (1936)..................... 238

FIGURA 44.- Iglesia e Internado de la Misión de Sisoguichi................................... 238

FIGURA 45.- Batopilas. Calles de un pueblo mestizo............................................. 246

FIGURA 46.- La Mesa de Guachochi. Vista panorámica........................................ 246

FIGURA 47.- Mestizos de la Sierra Tarahumara. 1892-1893 (Foto de la expedición de Lumholtz).

FIGURA 48.- Rostros mestizos de la Tarahumara. Samachique Cusárare y Norogachi.

FIGURA 49.- La Comisión del Departamento del Trabajo llega a Arareco (1936)..... 278

FIGURA 50.- Instalaciones del CCIT. Guachochi................................................. 278

FIGURA 51.- Francisco M. Plancarte, primer director del CCIT. Guachochi, 1953.... 284

FIGURA 52.- Dispensario médico instalado por el INI. Guachochi, 1953................. 284

FIGURA 53.- Area de trabajo del Centro Coordinador Indigenista de la Tarahumara. 1953

FIGURA 54.- Lugares estratégicos para las actividades del CCIT en 1953, según los planes de Plancarte y Aguirre Beltrán......................... 284

FIGURA 55.- EI Profesor Silvino Espino Loya del CCIT instruye a los promotores culturales indigenas. Guachochi, 1953.

FIGURA 56.- Tomás Méndez, rarámuri, miembro de la primera generación de promotores culturales del CCIT en 1953

FIGURA 57.- Con el arado y la wica (palo sembrador), en un magüechi, entre piedras y pinos.

FIGURA 58.- Aserradero de Samachique.

FIGURA 59.- Comedor-clase de la escuela albergue Francisco M.Plancarte. Aboréachi

FIGURA 60.- Niño rarámuri atendido por desnutrición en el Hospital infantil de Chihuahua. 1994

FIGURA 61.- Efectos de la explotación forestal en los ecosistemas 
de la Sierra Tarahumara hacia 1988.

FIGURA 62.- Readecuación de aserraderos por parte de

PROFORTARAH (circa 1974).

FIGURA 63.- Centros Coordinadores Indigenistas y escuelas albergue

en la Tarahumara.

FIGURA 64.- Mecanismos de participación indigena en el INI. 1986.

FIGURA 65.- Camiones con madera de la Sierra Tarahumara.

San Pedro, Guerrero.

330

FIGURA 66.- Cabina de transmisión de XETAR. La Voz de la

Sierra Tarahumara. Guachochi, 1998.

FIGURA 67.- Operación de la sierra banda. Aserradero de Samachique, 1999

FIGURA 68.- Camión trocero camino al aserradero, estampa típica de la Tarahumara.

FIGURA 69.- Organigrama de los Fondos Regionales de Solidaridad.

FIGURA 70.- Camión para la comercialización de chivas. Fondo Regional de Solidaridad "Repabé Rarámuri". Guachochi, 1998.

FIGURA 71.- Lugares de interés turístico. Plan Barrancas del Cobre.

FIGURA 72. - Cascada de Basaseachi, lugar de atracción turistica de la Tarahumara.

FIGURA 73.- Amanecer en la Barranca de Batopilas. 1999.

FIGURA 74.- Regiones de México con mayor incidencia de narcocultivos

FIGURA 75.- Municipios del estado de Chihuahua ubicados en elTriángulo Dorado de estupefacientes y con alto índice de homicidios. 1996.

FIGURA 76.- Áreas reincidentes de siembra de amapola en la Sierra Tarahumara.1996.

FIGURA 77.- Boludo o Helicóptero para fumigación de narcosembradíos en la Tarahumara. Aeropuerto de Guachochi. 1998.

FIGURA 78.- Descanso después de la Danza de los Matachines. Mesa de la Yerbabuena. 1999

FIGURA 80.- El canto del wikaráame pidiendo a Dios la lluvia y el maiz. 358 
mans. 


\section{A GRADECIMIENTOS}

Esta investigación es el resultado de varias búsquedas, algunas largas y laboriosas, pero todas ellas alentadas por el apoyo de amigos y compañeros. La más importante de ellas fue la que me trajo a tierras de Chihuahua, hace algo más de una década, con el empeño de participar en el proyecto de apertura de una nueva escuela de antropologia. Desde julio de 1990, cuando la ENAH Chihuahua fue inaugurada, los maestros a ella adscritos no tardamos en identificar a la Sierra Tarahumara no sólo como un territorio predilecto para nuestras investigaciones, sino también como un referente obligado para las nuevas generaciones de antropólogos que hemos tratado de formar. Nos indujo a ello tanto el peso de una sólida tradición de estudios sobre esta región indigena, cuanto el reclamo de no pocos interlocutores regionales que aspiran a encontrar en la antropología la respuesta a sus preocupaciones en torno a la situación de los pueblos indios de la Sierra de Chihuahua.

Por todo ello este trabajo es, en gran medida, fruto de una reflexión colectiva que inicié con mis colegas profesores de la ENAH Chihuahua, en especial con Luis Reygadas, Augusto Urteaga, Margarita Urias (cuya muerte aún nos resistimos a aceptar) y Eugenio Porras. A ellos y a los actuales maestros y compañeros de nuestra escuela, quiero expresarles mi reconocimiento por su aliento $y$, sobre todo, por los largos años de amistad. En diferentes épocas, a varios de mis alumnos en Chihuahua los volví cómplices de mis búsquedas a lo largo de provechosas temporadas de campo en los pueblos de la Sierra y de prolongadas jornadas de consulta en archivos. A todos ellos, con quienes he conformado un entrañable equipo de trabajo, expreso aquí un reconocido agradecimiento, deseando que nuestros desvelos compartidos hayan contribuido a su formación académica.

Para poder llevar a cabo esta investigación, conté con el apoyo financiero del CONACYT y del INAH. También los directivos del INI en la ciudad de Chihuahua y el personal del Centro Coordinador Indigenista de Guachochi (Chih.) me otorgaron su autorización para consultar sus archivos. Antes de que nos abandonaran, el Dr. 
Gonzalo Aguirre Beltrán (en Xalapa) y los profesores Francisco Hernández y Hernández y Francisco Álvarez (en México D.F.) compartieron conmigo sus experiencias de otros tiempos en la Tarahumara. También el antropólogo Agustín Romano, en las oficinas del INI en México D.F., recordó conmigo sus años de gestión en el CCIT de Guachochi. A todas estas personas e instituciones expreso mi gratitud.

En el Departamento de Antropología de la UAM Iztapalapa encontré el aliento y la tutoría para llevar a término esta investigación. De manera muy especial, quiero agradecer a Esteban Krotz, mi director, su paciencia para revisar cuidadosamente todas las versiones de esta tesis, sus enseñanzas sobre el rigor académico, su amistad y su compañia por algunos días en el territorio de los tarahumaras. En ese mismo contexto, también Alicia Castellanos, supo escucharme y ayudarme a interpretar mis datos. Con Andrés Medina pude aprender algo de lo mucho que sabe de la antropología mexicana. A Luis Reygadas, le debo, antes que nada, muchos años de fiel amistad, pero también el haberme inculcado la convicción de convertirme en doctor y su constante impulso para que ese anhelo se hiciera realidad.

Muchos indígenas y mestizos de la Sierra Tarahumara me enseñaron bastante de lo que escribo en este texto y me hicieron repensar lo que creia saber. Si alguna vez los pude ver como mis informantes, hoy los reconozco, con orgullo, como mis amigos de los que, más allá de las aulas, espero seguir aprendiendo. A todos ellos, y en especial a quienes me brindaron su apoyo y amistad en Uruachi, Guachochi, Batopilas, Samachique, La Mesa de la Yerbabuena, Morelos, Cusárare, Creel, Aboréachi y otros sitios más, les reconozco su sabiduria y les expreso mi admiración.

Lore, mi esposa y Yunuén, mi hija, fueron mi mejor compañía en estos años de búsquedas. A ellas dos les agradezco su solidaridad en esta etapa, pero sobre todo su amor fiel de toda la vida. 


\section{INTRODUCCIÓN}

Este estudio trata acerca de la politica indigenista en la Sierra Tarahumara de Chihuahua durante el presente siglo. Indigenismo, término genéico empleado en forma muy diversa y ambigua en el ámbito de la antropología y de la politica, es utilizado en esta investigación para referirse a las concepciones, justificaciones y reflexiones teóricas asi como a las estrategias y acciones institucionales que han tenido como objeto integrar económica y culturaimente a los grupos indígenas a la nación mexicana. En la Sierra Tarahumara dicha política ha sido obra, especialmente, del estado nacional y se ha canalizado a través de dependencias y agentes institucionales tanto federales como del gobiemo del estado de Chihuahua. El término "cruzada" utilizado en el título de este estudio procede del vocabulario del indigenismo mexicano de los años cincuenta y connota el carácter de lucha y contienda nacional que significó, para quienes la enarbolaron como bandera política, la tarea de la integración de los grupos étnicos a la nación.

\section{LA SIERRA TARAHUMARA: TERRITORIO Y POBLACIÓN}

En la Sierra de Chihuahua, los destinatarios y supuestos beneficiarios de las politicas indigenistas han sido los pueblos indios serranos: los rarámuri (o tarahumaras), los ódame (o tepehuanos), los warijó (o warijios) y los o'oba (o pimas bajos). Todos ellos suman cerca de 90,000 habitantes y viven dispersos en un amplio territorio de cerca de 60,000 kilómetros cuadrados designado como Sierra Tarahumara, vasta región que engloba vagamente la porción chihuahuense de la Sierra Madre occidental.

En forma más precisa, utilizaremos en este estudio el término Sierra Tarahumara - "la Tarahumara" -su equivalente en el lenguaje más común-, para referimos a un conjunto de 17 municipios chihuahuenses en donde se concentra algo más del $90 \%$ de la población indigena de estas cuatro etnias residente en el estado de Chihuahua. Los municipios en cuestión son los de Balleza, Batopilas, Bocoyna, Carichi, Chinipas, 
CUADRO 1.- POBLACION TARAHUMARA, TEPEHUANA, GUARLIA Y PIMA EN EL ESTADO DE CHIHUAHUA POR MUNICIPIO. 1990, 1995

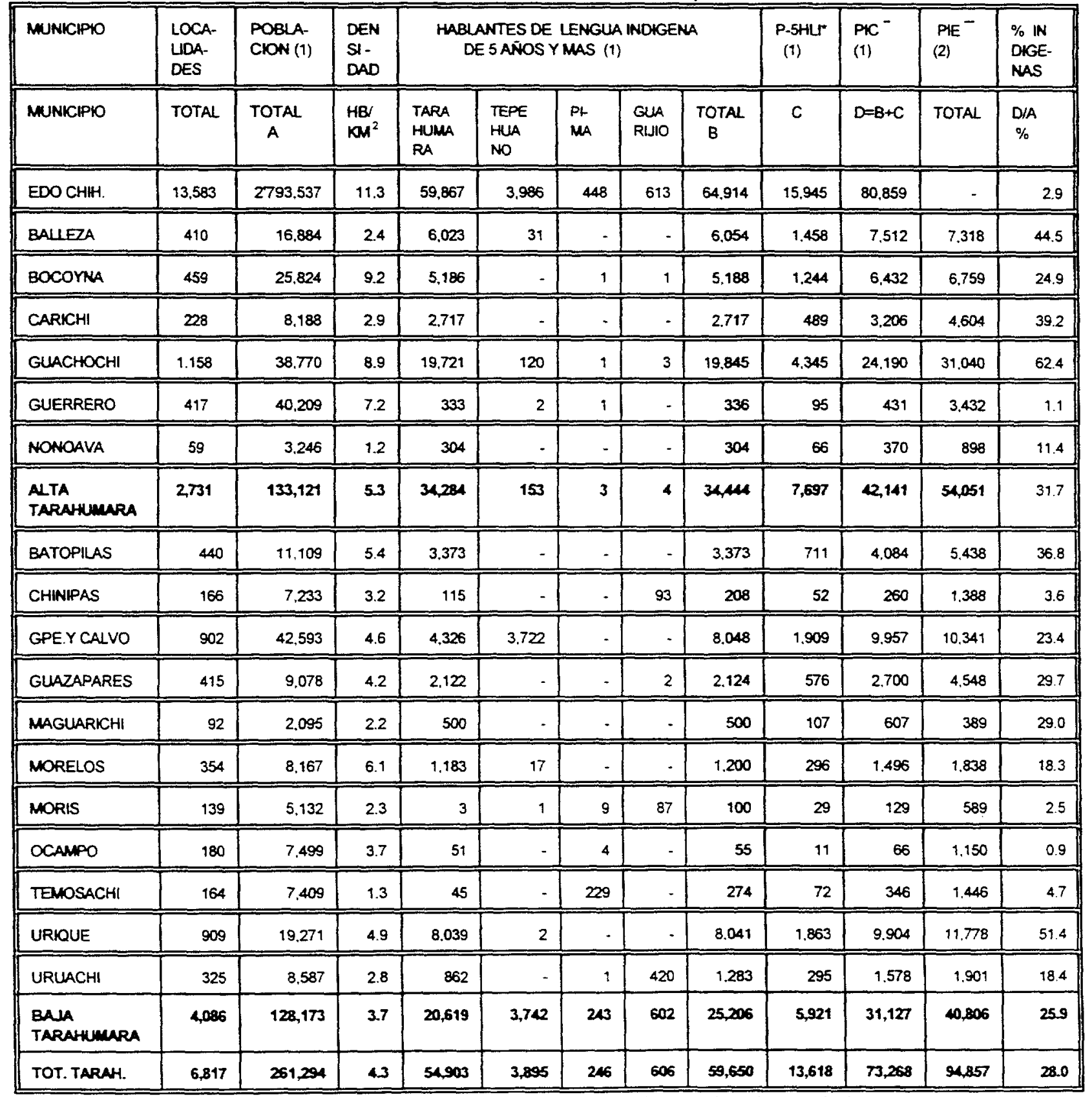

(") P-5HLI=Población de 0 a 4 años en viviendas cuyo jefe(a) o cónyuge habla alguna de las 4 lenglas indigenas (tarahumara, tepehuano, guarijio y pima).

(-) $\mathrm{PIC}=$ Población indigena (de los 4 grupos étnicos señalados) censada por el INEGI en el Conteo de Población de 1995

(*) $\mathrm{PIE}=$ Población indigena (de los 4 grupos étnicos serialados) estimada según el Instituto Nacional Indigenista. 1990.

FUENTES: (1) INEG: CONTEO DE POBLACION Y VMVENDA (1995) RESULTADOS DEFINTIVOS.

(2) WH: INDICADORES SOCKECONOMKOS DE LOS PUEBLOS INDIGENAS DE MEXICO, $1993 \mathrm{a}$. 


\section{CHIHUAHUA}

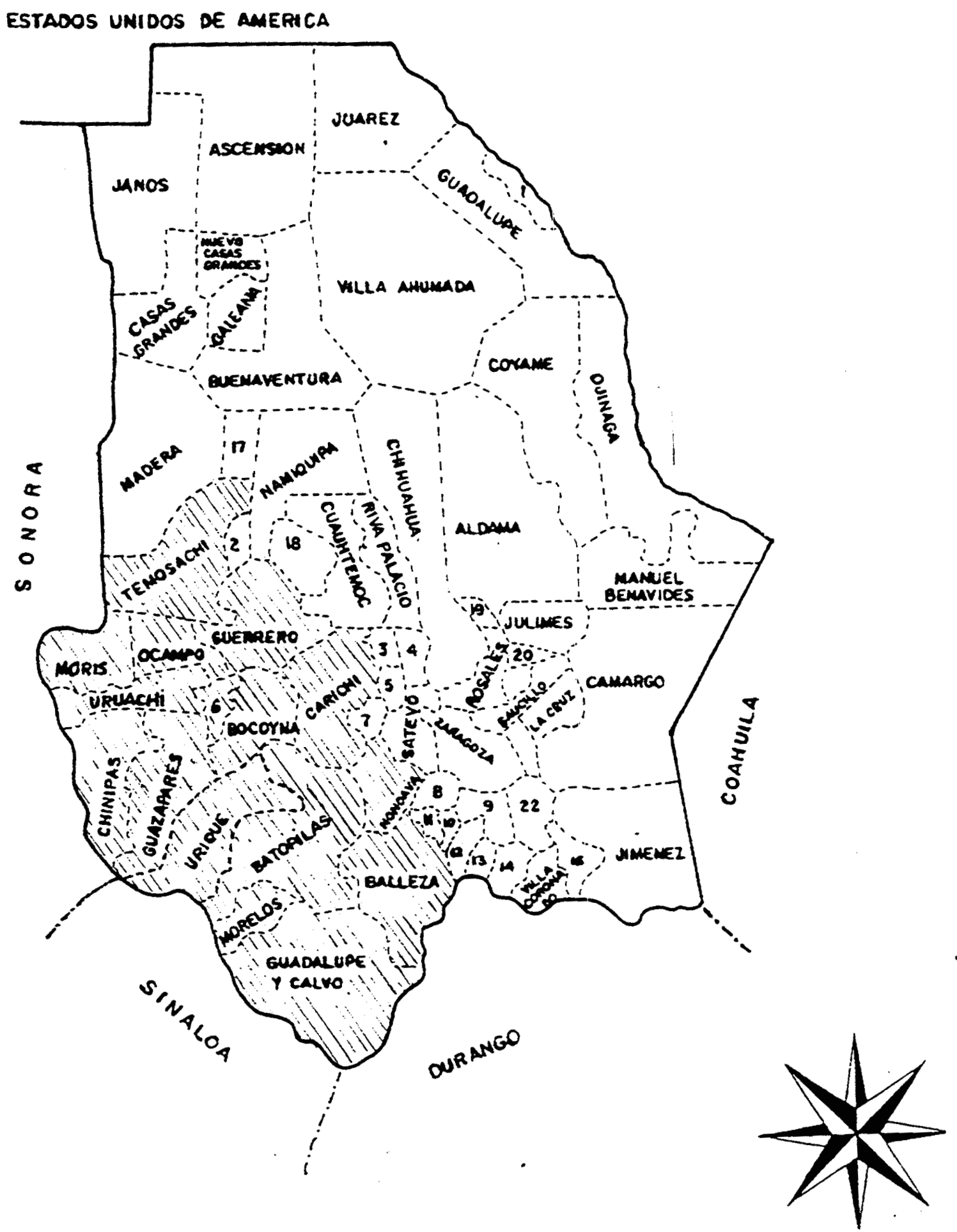

FIGURA 1.- MAPA DE LOS MUNICIPIOS DE LA SIERRA TARAHUMARA 
Guachochi, Guadalupe y Calvo, Guazapares, Guerrero, Maguarichi, Morelos, Moris, Nonoava, Ocampo, Temósachi, Urique y Uruachi. En ellos y como se puede observar en el Cuadro 1, el INEGI contabilizó en 1995 una población total hablante de alguna de estas culatro lenguas indigenas de 73,268 (90.6\% del total estatal), cantidad notoriamente inferior a la de 94,857 indigenas que estimó el Instituto Nacional Indigenista (INI) en 1993, a partir de inferencias derivadas del Censo de $1990 .{ }^{1}$

Los miembros de estos cuatro pueblos indígenas comparten su territorio con una población numéricamente casi dos veces superior de habitantes mestizos o "gente de razón", como tradicionalmente se les denomina, quienes se integraron a la vida serrana, en sucesivas olas generacionales y épocas históricas, desde los dias de la colonización española, a fines del siglo XVI, hasta los años de los repartos agrarios ejidales en las segunda y tercera décadas de este siglo.

Tres nichos ecológicos contrastantes abarca este enorme territorio serrano: al este, una serie de valles y lomeríos, cercanos a la cuenca del río Conchos, zona de transición entre el desierto de Chihuahua y las grandes cumbres, propicia para la agricultura y la ganaderia; el macizo central de cumbres frias y boscosas de alta montaña, con altitudes superiores a los 3,000 metros sobre el nivel del mar y con una gran riqueza forestal y, finalmente, la tierra caliente de las barrancas al oeste, hacia donde descargan un sinnúmero de arroyos que dan lugar a las fértiles cuencas de los ríos Fuerte, Mayo y Yaqui y que, a su fugaz paso por el territorio chihuahuense, circundan los pueblos barranqueños, muchos de ellos, de tradición minera.

En la zona de las cumbres, la temperatura media es de 18 a $20^{\circ}$, pero el frio del inviemo es inclemente cuando el termómetro llega a descender a $20^{\circ}$ bajo cero, para

\footnotetext{
${ }^{1}$ A la vista de las llamativas diferencias entre las cifras del INEGI y las del INI que se muestran en el Cuadro 1, es evidente la urgente necesidad de nuevas metodologias estadisticas que permitan un conteo más fidedigno de la población indigena serrana.
} 
ascender en verano hasta los $25 \circ 30^{\circ}$. En la región de los grandes barrancos, en cambio, el verano es extremoso con temperaturas cercanas a los $40^{\circ}$, mientras que el inviemo es benigno con temperaturas próximas a los $20^{\circ}$. Este contraste no puede ser más llamativo para el visitante que, en los últimos meses del año, puede transitar en pocas horas, de las nevadas cumbres a los cálidos rios barranqueños.

CUADRO 2.- ALTITUDES DE LAS CABECERAS MUNICIPALES DE LA SIERRA TARAHUMARA (Metros sobre el nivel del mar M.SIN.M.)

\begin{tabular}{|lc|lr|}
\hline ALTA TARAHUMARA & M.S.N.M. & BALA TARAHUMARA & M.S NN.M. \\
BALLEZA & 1,820 & BATOPILAS & 501 \\
BOCOYNA & 2,222 & CHINIPAS & 515 \\
CARICHI & 2,109 & GUADALUPE Y CALVO & 2,316 \\
GUACHOCHI & 1,687 & GUAZAPARES & 1,464 \\
GUERRERO & 2,020 & MAGUARICHI & 1,505 \\
NONOAVA & 1,676 & MORELOS & 606 \\
& & MORIS & 764 \\
& & OCAMPO & 1,732 \\
& TEMOSACHI & 1.902 \\
& & URIQUE & 549 \\
\hline
\end{tabular}

FUENTE: Almada, 1945: 28-29.

Las lluvias en la Sierra, sustento básico de una agricultura carente de grandes recursos tecnológicos, aunque inciertas, son siempre más cuantiosas que en el resto del estado de Chihuahua. En la Tarahumara, el promedio de la precipitación pluvial anual oscila entre los 550 y los 1,200 milimetros, pero es común que en la época de lluvias (de junio a septiembre), el agua caiga de forma desigual, escasa y discontinua a lo largo de todo el territorio, lo que incide directamente en la fertilidad de la escasa tierra agricola y la erosión de los suelos en las zonas de barranca. También las heladas y nevadas que permiten limpiar las tierras agricolas de parásitos nocivos para las siembras, provocan, en ocasiones, serios daños a la fruticultura y horticultura de las zonas cálidas.

La diversidad vegetal de la Sierra es notoria. En las zonas altas predominan el pino, encino, táscate, álamo, fresno, roble, manzanilla y madroño. En las barrancas son comunes el sauce, aliso, ceiba, olmo, arbolillo de chicle, tejocote, mango, plátano, 
guásima, guamúchil, capulin, tepeguaje, pitahaya, naranja, tabaco, palmilla, nopal, maguey mezcalero y palo colorado o de Brasil. En ambas regiones crecen más de 600 variedades de hierbas medicinales y comestibles, muchas de las cuales son usadas desde tiempos ancestrales por los grupos indigenas (González, 1994a: 59).

La subdivisión territorial entre la Baja y la Alta Tarahumara que tiene, como vemos, un sustento basado en referentes geográficos y ecológicos, suele ser confundida y suplantada por otra -arcaica y ambigua- entre la Baja y la Alta Tarahumara, términos acuñados en el siglo XVII por los misioneros jesuitas para distinguir administrativamente entre el territorio de las primeras misiones fundadas originalmente al sur de la sierra y el correspondiente a las del norte, que fueron instauradas con posterioridad. Desde épocas más recientes esta misma terminología se ha venido utilizando con una clara connotación topográfica, no exenta de imprecisiones geográficas: la Alta Tarahumara comprendería los municipios con mayores altitudes sobre el nivel del mar es decir, Balleza, Guachochi, Bocoyna y, en menor medida, Carichi, Nonoava y Guerreromientras que la Baja incluye la zona barranqueña, donde se ubican los municipios de Guadalupe y Calvo, Morelos, Batopilas, Urique, Uruachi, Maguarichi, Guazapares, Chínipas, Ocampo, Moris y Temósachi. ${ }^{2}$

Tras cerca de cuatro siglos de colonización mestiza, la población indigena que habita en este territorio ha asumido un patrón de asentamiento sumamente disperso, en estrecha dependencia con la ubicación de los recursos agrícolas y forestales. Las tres primeras columnas del Cuadro 1 expresan claramente esta tendencia: los 261,294. (indigenas y mestizos) que habitan la Tarahumara (cifras de 1995) viven diseminados en más de 6,800 localidades, lo que representa un promedio de 38.3 habitantes por

\footnotetext{
${ }^{2}$ Como lo señala Luis González, la distinción entre Baja y Alta Tarahumara que utilizaron los misioneros cotoniales se referia a una menor o mayor proximidad de estas zonas con relación al polo norte "al que desde el sur se iba subiendo, como entonces se pensaba" (Gonzȧlez, 1993: 234). La connotación topográfica de estos términos, de uso más reciente, adolece de claras limitaciones, puesto que dentro de muchos de los municipios de la Tarahumara se combinan las cumbres con los barrancos y, por to mismo, las altitudes de sus comunidades pueden ser muy variables (Véase Cuadro 2)
} 
localidad y una densidad de 4.3 habitantes por kilómetro cuadrado, 4 veces menor que la del estado de Chihuahua y más de 10 veces inferior a la del país.

Este patrón de asentamiento esconde sin embargo notorias diferencias: mientras los mestizos tienden a concentrarse en los núcleos más poblados y comunicados tales como cabeceras municipales, pueblos madereros, centros mineros, estaciones de ferrocarril y lugares comerciales, los indigenas prefieren dispersarse, lejos de las carreteras y próximos a sus reducidos terrenos agrícolas, conformando pequeños núcleos y asentamientos poblacionales que en muchos casos no superan el tamaño de una unidad familiar.

El Cuadro 3 , en el que se muestra la distribución de la población indígena (hablantes de lengua indígena de 5 años y más) por tamaño de localidades -según el número de viviendas en ellas existentes-, permite visualizar este comportamiento tan característico de la demografia indigena serrana. Como se observa en la segunda columna, habitan en los municipios serranos 59,650 hablantes de lenguas indígenas dispersos en un total de 6,817 localidades. Cerca de la mitad $(51.6 \%)$ de esas localidades serranas son simplemente ranchos con una o dos viviendas probablemente de una sola familia y en ellas reside el $18 \%$ de la población indígena (tercera columna). El restante $82 \%$ de los indígenas vive mayoritariamente $(54.2 \%)$ en pequeñas rancherias de 3 o más viviendas con no más de 50 hablantes de lengua indígena, de edades superiores a los 5 años, localidades que sólo representan el $31 \%$ del total. Las concentraciones de población indígena (superiores a los 50 hablantes) son sumamente escasas ( $2.6 \%$ del total de las localidades) y en ellas reside sólo el $28 \%$ de esa población (cuarta columna).

Como también se aprecia en el Cuadro $\dot{3}$, la dispersión de la población en pequeños núcleos presenta algunas diferencias municipales importantes. En general se 


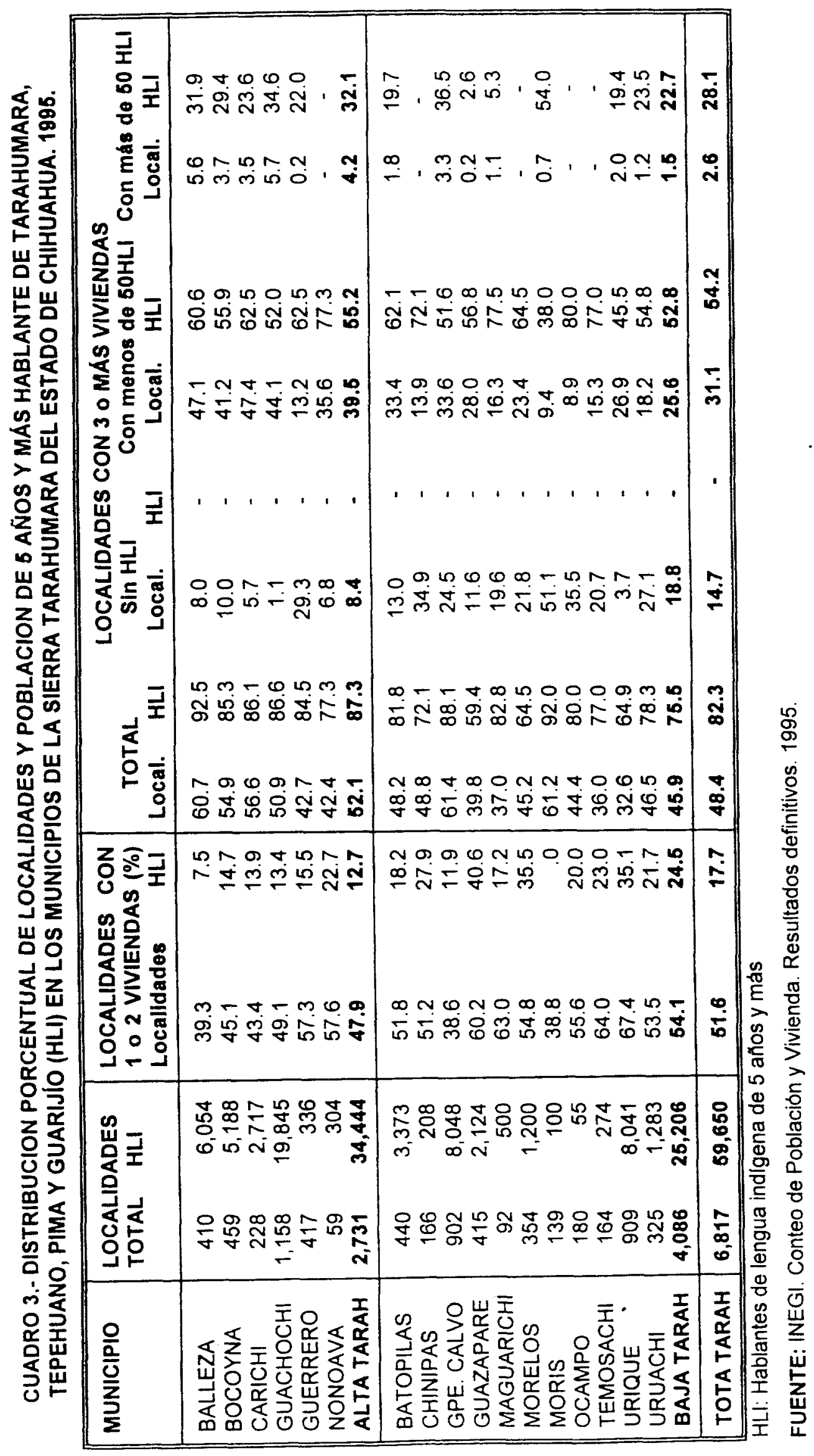

$\Omega$ 


\section{BARRANCA DEL COBRE}

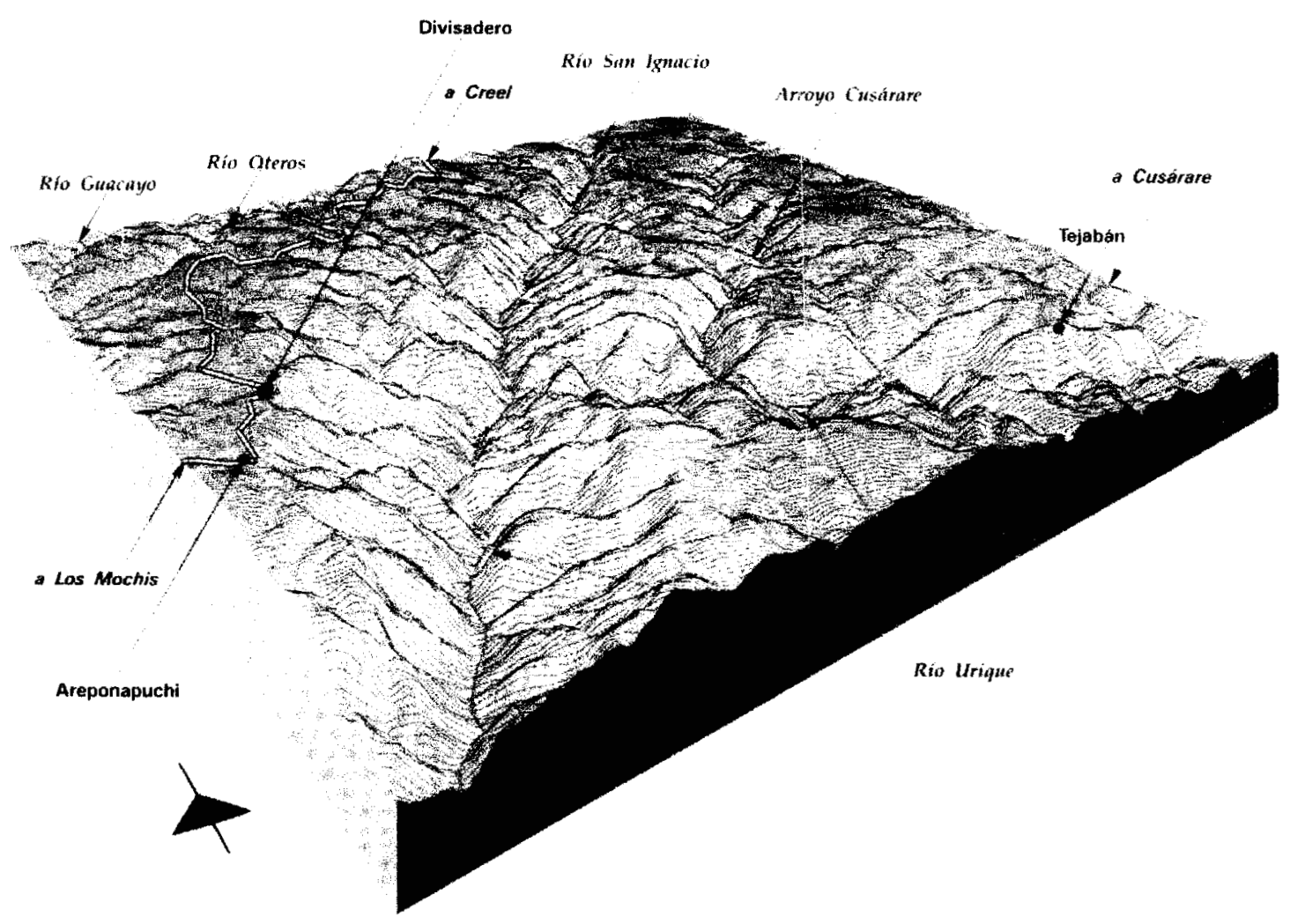

BARRANCAS DE URIQUE Y BATOPILAS

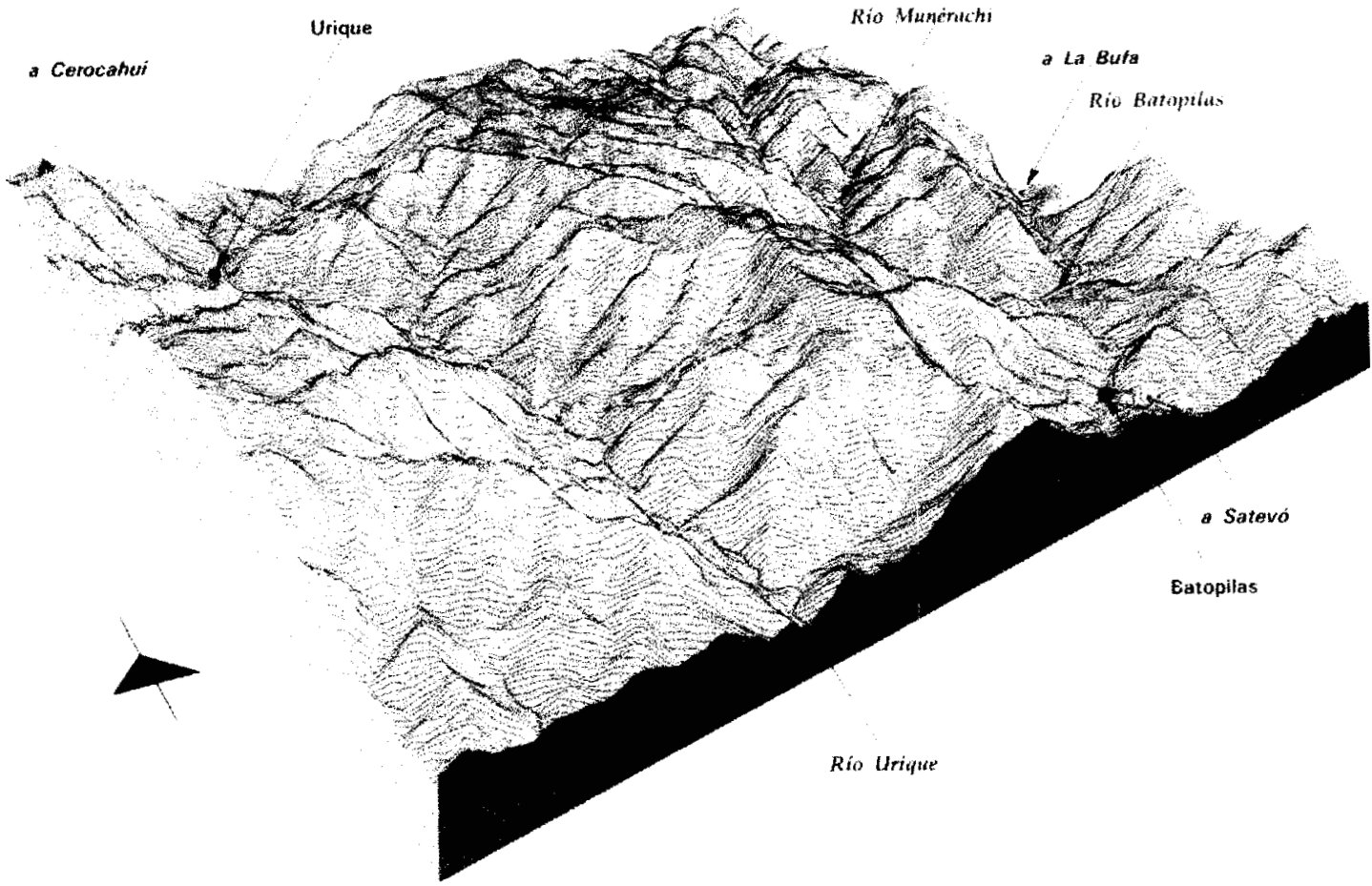

FIGURA 2.- PERFIL FISIOGRÁFICO DE LAS BARRANCAS DEL COBRE, BATOPILAS Y URIQUE (TOMADO DE SECRETARIA DE TURISMO, s/f) 
puede decir que en la Baja Tarahumara la atomización de la población indigena es mayor que en los municipios de la Alta. Además, en ambos casos, es común que las pequeñas comunidades $y$ rancherias indígenas se estructuren en torno a alguna cabecera central, otrora sede de una misión y hoy lugar de encuentro para las ceremonias y celebraciones festivas tradicionales así como espacio desde el que se ejerce el gobierno y la justicia indígenas, a través de los gobernadores y de un complejo cuerpo de autoridades autóctonas. Estas cabeceras coinciden, en términos generales, con las localidades con mayor concentración de población indígena, que registra la última columna del Cuadro 3 y que, en no pocos casos, son el centro de ejidos agroforestales.

Los más poblados de estos asentamientos rarámuri se localizan en los municipios de Balleza, Bocoyna, Carichí, Guachochi, Guerrero, Batopilas, Maguarichi, Urique y, en menor medida, en Guadalupe y Calvo y Uruachi. Los ódame se concentran en varias rancherías (Baborigame, Nabogame, Rancho de Mares, Barbechitos, Palos Muertos, Rincón del Tanque, Juntas de Arriba, La Cruz, Coloradas de la Virgen, El Túpuri) en el municipio de Guadalupe y Calvo. Los warijó se localizan en varios pequeños poblados de los municipios de Uruachi (Arechuyvo, Mocorichi, San Juan, Chagayvo, La Barranca, San Ignacio, Tojiachi, Chiltepín, Sereachi, Palmarito y Pacayvo), Chínipas (Loreto y Santa Ana) y Moris (Finca de los Pesqueira y El Gavilán). Finalmente, los o'oba viven dentro del municipio de Temósachi, en la comunidad de Yepachi y rancherías circundantes.

Este complejo y amplio territorio, con las particularidades demográficas que hemos venido señalando, ha sido a lo largo del siglo XX escenario de variados proyectos y experimentos indigenistas que han pretendido romper con el aislamiento de los pueblos indios de la Tarahumara y vincularlos económica y culturalmente a la nación. Los primeros de estos proyectos vieron la luz en la primera década del siglo XX y fueron obra 
obra de gobernantes locales impregnados de un celo reformista liberal que soñaron con la "regeneración" del indio. Desde entonces y hasta el día de hoy han sido muchos los intentos institucionales de gobiernos y organismos federales y estatales, así como de grupos religiosos y sociales que han buscado "redimir" al indio de su estado de atraso, pobreza y abandono. A través de la escuela, el desarrollo forestal, el mejoramiento de las técnicas agroganaderas, la introducción de caminos, la difusión de programas de salud y bienestar social o simplemente del asistencialismo en casos -no poco recurrentes- de hambrunas y pobreza extrema, el estado nacional ha intervenido en la Tarahumara.

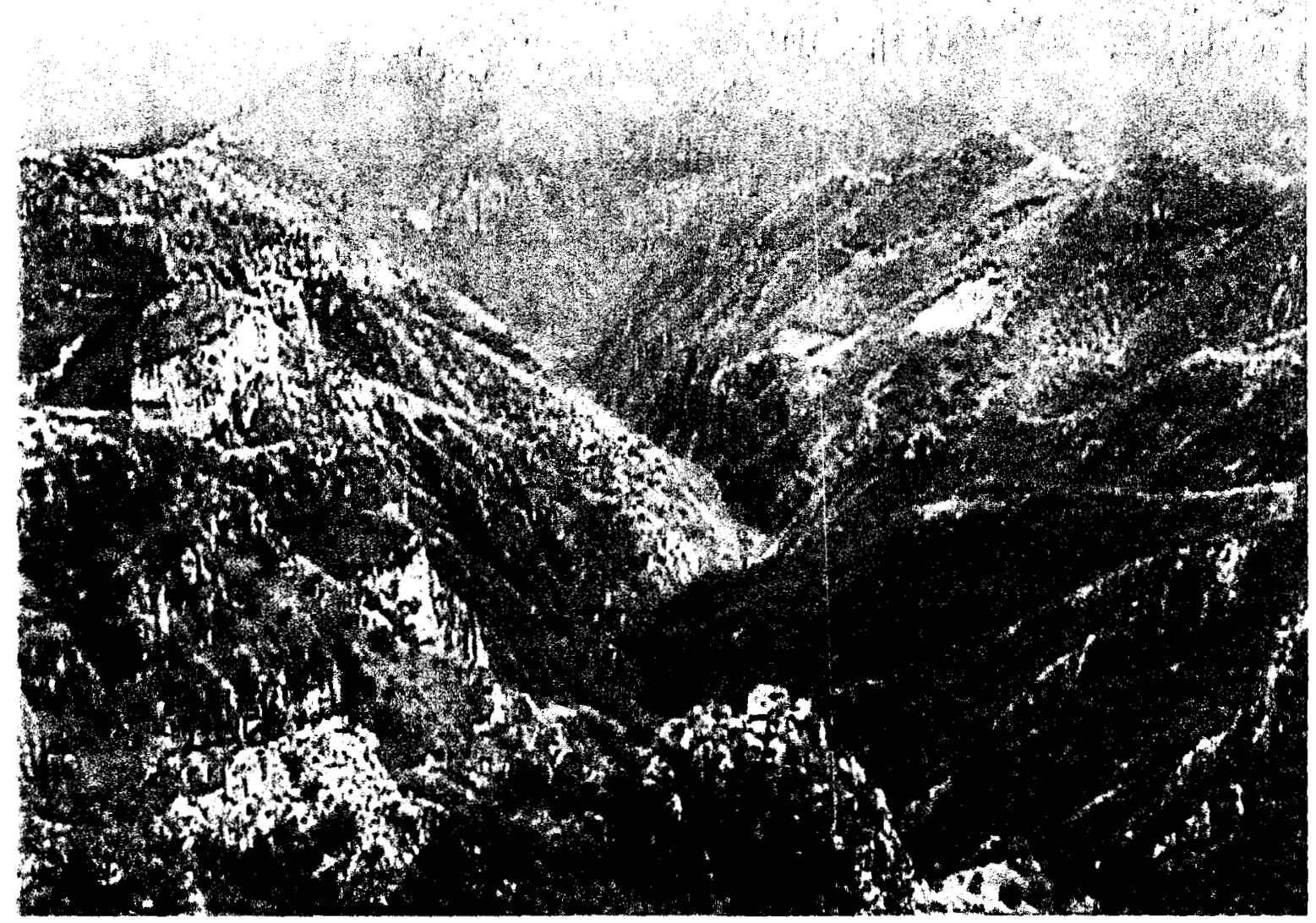

FIGURA 3.- VISTA PANORAMICA DE LA BARRANCA DEL COBRE DESDE EL DIVISADERO (FOTO DEL AUTOR. SEPTIEMBRE, 1998) 
Esta investigación tiene precisamente por objeto analizar e interpretar, más allá del discurso oficial, la acción indigenista gubernamental que ha tenido lugar en la Sierra Tarahumara durante el siglo $X X$ y, en especial, en las últimas cinco décadas. El periodo escogido no es arbitrario; toma como fecha de referencia el año de 1952, en el que el Instituto Nacional Indigenista (INI) inició sus tareas en esta región a través de la creación del Centro Coordinador Indigenista de la Tarahumara (CCIT), ubicado en la ciudad de Guachochi, uno de los dos primeros en su género en el territorio nacional. ${ }^{3}$ En forma complementaria, también se hará referencia a lo largo del texto a otros experimentos indigenistas, algunos anteriores a la llegada del $\mathbf{I N I}$, otros derivados de la intervención más reciente de diferentes agencias gubernamentales y otros más, resultado de las acciones de los misioneros jesuitas en las que se encuentra el germen de muchas de las estrategias indigenistas.

\section{DEBATES Y EXPERIENCIAS EN TORNO AL INDIGENISMO.}

El indigenismo ha sido por mucho tiempo uno de los ejes más polémicos en torno al cual se han desarrollado la teoria y la práctica profesional de la antropología mexicana. En términos generales, puede decirse que hasta el final de los años sesenta predominó en México un discurso indigenista de claro corte integracionista en el que confluyeron de forma distinta la escuela del particularismo étnico de raíces boasianas (Gamio, Sáenz), la del evolucionismo unilineal inspirado en la obra de Redfield y la del indigenismo de cuño mexicano cuyo exponente más destacado fue Aguirre Beltrán. ${ }^{4}$ Es sin duda a esta última corriente a quien debe imputarse la inspiración y orientación del Instituto Nacional

\footnotetext{
${ }^{3}$ Por acuerdo presidencial del 4 de junio de 1952, publicado en el Diario Oficial de la Federación el 16 de agosto de ese mismo año, fue creado el Centro Coordinador Indigenista de la Tarahumara en Guachochi, cubriendo inicialmente un territorio de 26,671 kilómetros cuadrados e incluyendo a los municipios de Batopilas, Balleza, Guadalupe y Calvo, Morelos y Nonoava en los que habita una parte importante de la población rarámuri (tarahumara) y ódame (tepehuanes) del estado de Chihuahua. Dos décadas después el INI decidió ampliar su radio de acción dentro de la Sierra de Chihuahua a través de la implantación de los Centros coordinadores indigenistas de San Rafael (1974), Carichi (1975) y Turuachi (1980) para atender a los rarámuri de la Baja Tarahumara, asi como a los warijó (warijios) y o'oba (pimas) del oeste del estado.

${ }^{4}$ Retomo aqui el básicamente el esquema explicativo de Hewit de Alcántara, 1988.
} 
Indigenista durante las dos primeras décadas después de su fundación en 1948.

En la antropologia mexicana existe un consenso generalizado en el sentido de que, desde el final de los años sesenta, las tesis integracionistas que sustentaron la política oficial indigenista fueron objeto de una fuerte crítica dirigida desde las teorias de la ecología cultural, el maxismo y la teoria de la dependencia latinoamericana. También desde entonces las posiciones de los antropólogos sobre la manera de entender la identidad étnica, las relaciones entre etnia-clase-nación y Estado y, por ende, las visiones sobre el sentido y el futuro del indigenismo se polarizaron, al menos en tres grandes directrices que comúnmente han sido denominadas como "manxistas", "etnodesarrollistas" y "utópicas".

Dos problemáticas diferenciadas, aunque no inconexas, surgen a partir de esta crisis. La primera tiene que ver con los nuevos derroteros que ha asumido, durante los últimos treinta años, la discusión teórica sobre el problema indígena del pais. La segunda se refiere a las transformaciones en las directrices y prácticas institucionales de la política indigenista del Estado. Si el primero de estos ámbitos se caracterizó por una renovación teórica de la cuestión étnica en el marco de una polémica entre posiciones encontradas, el segundo, en cambio, ha seguido, más allá del discurso oficial, una línea de tenues reformas que muestran más continuidades que rupturas y que han acabado por desencadenar una serie de graves conflictos sociales de trascendencia nacional. Sin dejar de señalar las conexiones entre estos dos ámbitos de la problemática indigenista, analizaremos cada uno de ellos por separado.

En un esclarecedor artículo, Rodolfo Stavenhagen identificaba en 1978 aquellos que podríamos considerar puntos neurálgicos y conceptos centrales que estuvieron en el trasfondo de la polémica sobre la cuestión ètnica que se iniciara en los años setenta. ${ }^{5}$

\footnotetext{
${ }^{5}$ Este artículo (Stavenhagen, 1978) tiene la ventaja, en relación con otros muchos que aparecieron en los
} 25 
Stavenhagen destacaba alli cinco conceptos -cultura, clase, comunidad, etnia y colonialismo intemo- alrededor de los cuales se construian cuatro distintos enfoques explicativos sobre la relaciones entre los grupos indios de México y la sociedad nacional.

El primero de estos enfoques, el culturalista, parte de reconocer que son los elementos de la cultura de los pueblos indios los que explican su atraso y concluye proponiendo su incorporación a la cultura dominante, en especial a través de las políticas educativas monolingües y bilingües. En suma, el progreso de la nación y aủn el de los pueblos indigenas pasa por la destrucción de sus culturas.

El segundo enfoque, que el autor define como clasista, explica la pobreza de las comunidades indígenas a partir de su condición especifica de clase: los indios son parte de las clases explotadas del país, pero además, su cultura constituye un agravante de su explotación y un obstáculo adicional para incorporarse a la lucha de clases. En consecuencia, la liberación de los indígenas sólo será posible en la medida en que éstos, rompiendo con su propia cultura, se integren a las luchas del proletariado nacional.

El tercer enfoque, -una variante del anterior-, caracteriza las comunidades indigenas como una supervivencia de un modo de producción precapitalista, resultado de la conquista y colonización y subordinado a un modo de producción nacional capitalista y dominante. La relación entre estas comunidades y la sociedad nacional no sólo es de explotación de clase sino de colonialismo interno. En la medida en que el modo de producción capitalista se consolide y se extienda, tenderá a desaparecer el modo de producción precapitalista y con él, todos los elementos culturales de los pueblos indios quienes acabarán por integrarse a la cultura mestiza. Sólo en la eventualidad de una transformación socialista "no tendrian por qué desaparecer los elementos distintivos

años en que el debate indigenista tomó un carácter sumamente polemico, de omitir las referencias a autores y obras especificas, desentrañando, con un análisis tipológico, los aspectos centrales del debate. 
de las culturas indigenas ya que no serian un estigma asociado a las diversas formas de explotación económica precapitalista" (Stavenhagen, 1978: 99).

La última propuesta, en fin, destaca el carácter distintivo de la identidad étnica que no puede ser reducida a una condición de clase. Las culturas étnicas de los grupos indigenas no están determinadas por las estructuras económicas del modo de producción precapitalista y del colonialismo interno a las que se asocian. Más bien, se definen "por el grado de identidad que son capaces de proporcionar a sus miembros y a su capacidad para nomar las relaciones sociales de éstos en el seno de estructuras comunitarias dadas" (Stavenhagen, 1978: 99). Así como la conciencia de clase y la conciencia étnica no se contraponen, así también la lucha de clases y la liberación étnica de los pueblos indígenas son dos fenómenos ligados entre sí dialécticamente. Por lo demás, la expansión de las relaciones capitalistas de producción en el medio indígena no provocará la proletarización sino la lumpen-proletarización, la marginalización y la desculturización de los pueblos indios, condiciones éstas las menos propicias para un cambio social del pais.

Expresados en estos términos, es probable que ninguno de estos enfoques corresponda exactamente a las propuestas concretas de todos los autores que tomaron parte en esta polémica. No me parece, sin embargo, que la mayoría de ellos estén sustancialmente alejados de algunos de estos cuatro puntos de vista. Me atrevería a pensar que, tras cerca de tres décadas transcurridas desde el inicio de la polémica, muchos de los puntos de vista implicitos en esta disidencia han sido matizados y, en algunos casos, las distancias se han reducido. ${ }^{6}$ No falta, incluso, quien piensa que este debate se ha vuelto ya caduco. ${ }^{7}$ En cualquier caso no pretendo aquí reconstruir esta

\footnotetext{
${ }^{5}$ En particular es bastante evidente que el modeto integracionista ha dejado de ser defendido, salvo en pequeños reductos académicos y es claro un relativo consenso sobre el carácter pluricultural de la nación como lo demuestra la reforma, en 1992 , al articulo $4^{\circ}$ constitucional.

${ }^{7}$ Esta parece ser la opinión de Arturo Warman, -por cierto uno de los iniciadores de la polémica-, cuando 
polémica -tarea a la que se han dedicado ya muchas páginas- ${ }^{8}$, sino más bien interpretarla y traerla hasta el presente a partir de lo que me parece ser uno de las claves de su comprensión: la relación entre las propuestas sobre el problema étnico y los proyectos de nación que las sustentan. Entre otras cosas, tal perspectiva puede ofrecer una visión más integrada de los puntos de consenso y desacuerdo que están hoy en el centro de las preocupaciones sobre el problema indígena y que se relacionan con el tema de esta investigación.

\section{La cuestión étnica y los proyectos de nación.}

En su teorización más acabada -la de Aguirre Beltrán- el indigenismo integracionista ha sido concebido como la expresión social de un fenómeno biológico, el mestizaje, como "la ideología del mestizo, método y técnica de unificación nacionaf" (Aguirre, 1992a: 96 y 1957: 111). Porque así como el mestizo representa la integración de raices biológicas y culturales distintas y por ello está en capacidad de asimilar la alteridad india, así también el indigenismo constituye la vía de articulación entre las dos fuerzas sustentantes de la nacionalidad: el indianismo y el occidentalismo. Es pues el mestizo quien es portador del proyecto de nación y no el indio, por ser éste ajeno a la idea de nación. ${ }^{9}$ Retomando los términos de Aguirre Beltrán:

afima que "los formidables debates que marcaron el desarrollo del indigenismo durante casi todo el siglo que se acerca a su final parecen agotados". Las nuevas discusiones sobre el problema, señala este autor, estarian atravesadas por una pluralidad de opiniones, una cierta indiferencia, el escepticismo y una distancia creciente entre posiciones, to que puede provocar que el debate se desgaste y se diluya. (Warman, 1991: 7 y 8$)$

${ }^{8}$ Entre los trabajos que reseñan la trayectoria de esta polémica pueden consultarse Medina y Garcia Mora, 1983; Méndez Lavielle, 1987; De la Peña, 1988; Báez-jorge, 1990. Los textos centrales de la polémica aparecen en Varios, 1970; Stavenhagen, 1969, 1978 y 1980; González Casanova, 1963 y 1965; Palerm, 1975; Aguirre Beltrán, 1992a y 1983; Medina, 1974 a y b y 1976; Cazés, 1966; Báez; 1975; Palerm. 1975, Diaz Polanco, 1978 y 1981 y Bartra, 1974 y Guerrero et al., 1978.

${ }^{9}$ Como to ha señalado Stavenhagen (1980: 66) hay en esta visión una combinación de la perspectiva decimonónica del mestizo como portador del progreso y del enfoque sobre la movilidad social de las clases medias en la sociologia del desarrollo. También Aguirre reconoce la paternidad de estas ideas en la obra de Villoro (1987). 
México transcurre por una etapa de su formación nacional y de su desarrollo capitalista, integrativo y totalizador, que le conduce necesariamente a buscar una cierta homogeneización en cuanto hace a la composición étnica, económica, social y politica mediante la fábrica de puentes que unan razas, lenguas y culturas en un interés común. El mestizaje, el bilingüismo, la aculturación y la redistribución reiterada de la dignidad, la riqueza y el poder son las instrumentalidades de la integración (Aguirre, 1994: 120-121).

Pero el anhelo del mestizaje y del indigenismo sólo pudo ser consumado a partir del programa de justicia social nacido de la Revolución y en particular de la Reforma agraria y la política educativa, expresiones ambas del sincretismo cultural. Los postulados del Congreso de Pátzcuaro, en 1940, marcaron las directrices institucionales que habria de seguir la acción indigenista para lograr la integración, combinando los principios de la justicia social con el respeto de las culturas indigenas derivado de un "sano" relativismo cultural.

Asi pues, en el planteamiento del integracionismo las ideas de la construcción de la nación y del nacionalismo están en el trasfondo de la justificación de la acción indigenista. Pero el proceso de formación de la nación que, en la lógica indigenista, es inconcluso en tanto existan grupos étnicos que no participen en igualdad de derechos en la sociedad nacional, no es ajeno a la estructura de clases y a las relaciones capitalistas de explotación que permean la vida nacional. Los teóricos del indigenismo no tardaron en percibir esta relación entre nación y clases, máxime en una coyuntura histórica como la de los años cuarenta y cincuenta en la que el país vivia una expansión acelerada del capitalismo en todos los sectores sociales y productivos. Es por eso que la integración, el mestizaje y el nacionalismo se redefinen en categorias de relaciones de clase.

El indigenismo busca entonces orientar un proceso, por lo demás inevitable, de incorporación del indio, desde una condición de explotación de casta típica de las zonas interculturales de refugio a una condición de clase, propia de una nación moderna, caracterizada por relaciones capitalistas. La primera de estas condiciones -la de casta- 
es el resultado del proceso "dominical" (segregación racial, control político, dependencia económica, mantenimiento de la desigualdad, la distancia social y la acción evangélica) con que los mestizos de las regiones de refugio, imbuidos de una "falsa conciencia" mantienen subordinadas a las comunidades indigenas. La segunda ta condición de clase-, en cambio, es signo de la integración nacional. La tarea del indigenismo habrá de consistir en desenmascarar esa falsa conciencia mestiza y en fomentar los niveles de aculturación que pongan fin al proceso dominical. ${ }^{10}$

En el paradigma integracionista, se sostiene además, -aunque nunca se logra explicar con claridad- que la proletarización del indigena no significará necesariamente la extinción de su cultura, máxime si este proceso se da en una contexto de asimilación de los simbolos indios en la cultura mestiza nacional. (Aguirre, 1992a: 121-163).

Consecuente con la idea de nacionalismo derivada de la Revolución, pero sobre todo, acorde con los postulados integracionistas, el indigenismo niega toda viabilidad a cualquier proyecto de autonomia indígena. A la revolución de 1910 se le atribuye el haber preferido un sistema unificado de gobierno antes que el principio de la libre determinación de las comunidades étnicas, por lo que las formas de gobierno indígena deberán desaparecer. Pero además la autonomía indígena resultaria incompatible con el proceso de aculturación y se convertiria en un proyecto involutivo en términos de la integración nacional, más aún si se tiene en cuenta que los paises mestizo-americanos no son estados totalmente constituidos. Finalmente la via autonomista significaria desproteger a los grupos indígenas contra los posibles embates del imperialismo. (Aguirre, 1957; 1992a y Stavenhagen, 1980).

En contraste con esta visión, de indigenismo derivada de una particular

\footnotetext{
${ }^{10}$ Como acertadamente lo ha señalado Stavenhagen, esta vision contradictoria del mestizo, -portavoz y obstáculo al mismo tiempo de la integración a la nacionalidad- no resulta del todo convincente en los planteamientos de Aguirre (Stavenhagen, 1980).
} 
interpretación del proceso de consolidación de la nación, la mayoria de los enfoques que surgieron a partir de los años setenta han planteado diversas visiones alternativas en las que se destaca la relación entre la formación nacional y la estructura de clases. Aún desde puntos de vista diferentes, todas estas perspectivas coinciden en señalar la incapacidad de la política indigenista para dar respuesta a las demandas de los pueblos indigenas.

Una de estas vertientes críticas es la que argumenta que en un contexto de crisis capitalista como la que se vivía al final de los años sesenta, era la lógica misma del integracionismo la que explicaba la exclusión de los grupos indígenas del proceso de formación nacional. Desde una concepción neoevolucionista, la postura crítica de Ángel Palerm es, en este sentido, reveladora. Tras señalar que "la contradicción esencial parece existir [...], no entre un indigenismo integracionista y otro no-integracionista, sino entre los diversos cursos posibles abiertos a la politica integracionista y la negativa a participar en ellos", Palerm sugeria una paradójica confirmación de las tesis integracionistas: la crisis económica y la reacción política derivadas del desmoronamiento del "milagro mexicano" estaban exacerbando el atraso de los sectores no capitalistas del país en cuya explotación se había sustentado el crecimiento capitalista. En tal coyuntura y en la lógica misma de los argumentos indigenistas, la crisis de expansión capitalista estaba paralizando el proceso de integración y proletarización indígenas, lo que implicaba que se acentuaran las tendencias regresivas hacia el mantenimiento de relaciones preclasistas dentro de las zonas de refugio, se activaran los mecanismos de represión frente las demandas indigenas y se regresara a un indigenismo colonialista, paternalista y burocrático (Palerm, 1992: 12-18).

Desde otra perspectiva de raices marxistas que concibe a los grupos indigenas como minorias étnicas dentro del sistema de clases del capitalismo mexicano, se construye una visión de la nación alternativa a la del indigenismo, -la nación-pueblo-, y al 
subrayarse el carácter de clase del Estado, se sostiene también la inviabilidad de toda política indigenista, como to ha planteado Gilberto López y Rivas:

El problema étnico forma parte integral de la cuestión nacional, la cual se expresa, fundamentalmente, en el conflicto entre las clases sociales que genéricamente, para el caso de nuestras sociedades dependientes, forman el pueblo y la alianza burguesia-imperialismo. Por tanto, la cuestión étnica pasa, necesariamente, por el establecimiento de un nuevo tipo de nación, la nación-pueblo, la cual redefine no sólo una nueva hegemonia, la de las clases otrora dominadas, sino que también establece una nueva relación del conjunto de los agregados étnico-nacionales, dándole a la nación un carácter multiétnico y plurilingüe [...]

Es imprescindible, por tanto, que el proyecto de la nación-pueblo asuma con claridad los programas y las plataformas de lucha de los grupos étnicos de tal manera, que las reivindicaciones de estos grupos no sean subordinadas ni subsumidas a objetivos supuestamente "estratégicos" sino, por el contranio, que estas demandas formen parte de la estrategia misma de la construcción de la nación-pueblo (López y Rivas, 1988: 63).

Un nuevo discurso se plantea aqui en tomo a la relación entre la cuestión étnica y la nación. Si en el Estado-nación sostenido en la hegemonía burguesa los grupos étnicos han sido integrados al sistema de clases como una minoria subordinada, sólo será a través de la destrucción del Estado capitalista como estos grupos, en alianza con otros sectores del pueblo, lograrán recuperar su identidad y plasmar su visión de la nación y su sentimiento patriótico que se funda "en la relación del pueblo con la producción, con la tierra, con el ternitorio, con los recursos naturales de la nación ocupada por la burguesia"11. En esta óptica, sobra decir que el indigenismo es visto como el aparato del Estado-nación burgués que busca subordinar a los grupos étnicos al sistema de explotación de clases y encubrir su opresión. ${ }^{12}$. En contraparte, se propone poner fin a

\footnotetext{
$" 11$ bid., pág. 64. Algunos de quienes plantean esta perspectiva marxista han sostenido además que la incorporación de los indígenas a la lucha de clase no necesariamente implica su proletarización -a pesar de ser ésta una tendencia expansiva en el capitalismo-, asi como tampoco la renuncia a su derecho a ser protagonistas de su liberación ni a su identidad, entendida ésta como el "complejo conjunto de sus rasgos culturales, sistemas de organización, costumbres, etc." y no como el deseo de conservar su "punto de vista de clase" manteniendo "sus condiciones de producción [...] su situación de 'propietarios libres', [...] su separación del destino general de los trabajadores, etc." (Diaz-Polanco, 1978: 30).

${ }^{12}$ Esta es la razón esencial por la que, parafraseando ese viejo dicho popular podemos afimar "el indigenismo aunque lo vistan de etnodesarrollo, indigenismo se queda" (López y Rivas, 1988: 67).
} 
todo tipo de politicas integracionistas dictadas unilateralmente por el gobiemo, impulsar la participación de los grupos étnicos en las organizaciones de clase y reconocerles a éstos el derecho a la autonomia en un estado nacional multiétnico. ${ }^{13}$

El tema de la autonomia tuvo un cierto rechazo en los años setenta entre quienes sostuvieron una óptica marxista, porque la visión del proyecto emancipador frente al capitalismo tendia a subrayar el carácter de clase de la explotación indigena en detrimento de los componentes étnicos. Esta visión reduccionista de la cuestión étnica ha sido superada. Como lo ha señalado Díaz-Polanco:

Las más recientes formulaciones permiten entender que etnia y clase social no constituyen categorias antitéticas. Es decir que no es posible entender la etnogénesis, la naturaleza cultural y el comportamiento sociopolitico de las etnias; sin considerar la matriz socioeconómica y la estructura clasista en las que se desenvuelven; pero que tampoco es posible sostener que las complejas configuraciones que constituyen los grupos étnicos se agotan en sus determinaciones económicas. Lo étnico, por tanto, no debe concebirse como un fenómeno independiente o ajeno a la estructura de clases ni las clases deben abordarse sin considerar la dimensión sociocultural, especialmente cuando tal dimensión da lugar a sólidos sistemas de identidad (Diaz Polanco, 1991: 203).

Al reconocer que los grupos indigenas constituyen una realidad social cuya identidad y demandas no se agotan en el fenómeno clasista y al constatar el papel que como sujetos del cambio social los grupos indigenas están jugando en algunos paises de América Latina, se propone en esta visión renovada del marxismo un régimen de autonomia para las etnias "precisamente porque seria insuficiente (aunque desde luego, necesario) el simple reconocimiento de los llamados derechos del ciudadano". A juzgar por las experiencias ya consumadas en algunos paises, el logro de la autonomia parece, sin embargo, impensable si no es "en el contexto de vastas transformaciones sociopoliticas a escala nacional" y a partir "de una efectiva participación de los grupos

\footnotetext{
${ }^{13}$ Puede verse al respecto la propuesta presentada al Partido Comunista Mexicano por Guerrero, Lagarde y Morales en Guerrero et al, 1978.
} 
involucrados". ${ }^{14}$ En este mismo contexto se situarian las propuestas de iniciativa de ley sobre los derechos de los pueblos indígenas que presentara el PRD en la Cámara de Diputados en la LV Legislatura, al inicio de los años noventa, entre las que se incluia la delimitación de regiones pluriétnicas con régimen de autonomía y la integración de una circunscripción electoral plurinominal de dichas regiones que ampliaria en 50 el número de diputados federales de origen indigena (Castellanos y López y Rivas, 1992 y Portal, 1995: 137-144).

El régimen de autonomia propuesto en esos años era una expresión juridica del reconocimiento del carácter multiétnico y pluricultural de la sociedad nacional. En tal reconocimiento, es indudable que las posiciones marxistas y aquellas que, en los años setenta, analizaban la cuestión étnica desde las perspectivas de la evolución multilineal, la descolonización y la autonomía ${ }^{15}$ han tendido a acercarse, aunque no a identificarse. En particular parecen coincidir en reconocer que es impensable un proyecto democrático de nación sin aceptar el carácter pluricultural y multiétnico de la sociedad. Es probable, sin embargo que las diferencias no se hayan superado en la manera como se conceptualiza la identidad indigena. En cualquier caso es evidente que esta nueva manera de entender el proceso de conformación de la nación, reconocido incluso formalmente, aunque de manera insuficiente, en la nueva redacción del artículo $4^{\circ}$ constitucional, ha vuelto caduca la vieja concepción de nación postulada por el indigenismo integracionista.

Más allá de estas concepciones defensoras de la nación plural, otra teoria del

\footnotetext{
${ }^{14}$ Retomo en esta visión de la autonomia la perspectiva de Diaz Polanco, 1991.

15 El panorama que de estas perspectivas ofrece Nahmad (1988) es quizás un poco exagerado al acentuar los aspectos "etnicistas" de estas corrientes. Bastantes de los autores en ellas incluidos por Nahmad señalaban ya para esas fechas una solución de integración de los conceptos de clase y etnia en la explicación del problema indigena. El caso de Stavenhagen al que nos hemos referido más arriba es un ejempto.
} 
fenómeno étnico vino a subvertir los términos en que la visión de la nación era formulada en el paradigma indigenista, hasta colocarlos en su posición antitética. Me refiero al modelo explicativo de Guillermo Bonfil en el que, en oposición radical a la tesis aculturacionista, es el México mestizo "imaginario" el que requiere iniciar un proyecto de reinvención de la nación, a partir de la superación de la negación del México "profundo", no reconocido, excluido, reprimido, pero vivo en la matriz civilizatoria indígena.

En sus últimos escritos Bonfil construyó una sugerente articulación entre una serie de conceptos que habian estado presentes en sus obras germinales como la autonomia étnica, el control cultural y la civilización india. La autonomía de las culturas indigenas había sido ya planteada desde sus primeras críticas al indigenismo al señalar el derecho de los pueblos indios a legitimar sus proyectos fuera de la cultura nacional.

La teoria del control cultural, en oposición al viejo concepto de aculturación, distingue los espacios de la cultura propia controlados por el grupo étnico, de los espacios de la cultura ajena que le son impuestos. Mientras los primeros son expresión de la persistencia de una matriz civilizatoria india, los segundos pueden no dejar de serlo si el sistema de dominación se apoya en el reconocimiento excluyente de la alteridad india. La matriz civilizatoria india se expresa a través de una conciencia de indianidad y se sustenta en la existencia objetiva de elementos compartidos entre las culturas indoamericanas. Portadora de principios distintivos (reciprocidad, autosuficiencia), esta civilización ha perdurado a lo largo de la historia por la lógica misma del control cultural, incluso más allá de las fronteras de los grupos étnicos. Bonfil concluye proponiendo un proyecto de nación inclusivo que implique "ver a Occidente desde la civilización mesoamericana, en vez de empecinamos en seguir viendo e interpretando nuestra realidad a través de los esquemas y parámetros occidentales". ${ }^{16}$

\footnotetext{
${ }^{16}$ Bonfil, 1991b: 141. Los principales planteamientos del autor aparecen en sus obras de 1970, 1981 y $1987 a$.
} 
Al final de esta larga trayectoria de debates, puede decirse no sólo que la cuestión indigena se ha redefinido sino también que el concepto de nación se ha deconstruido y reformulado. A pesar de los desacuerdos, son éstos los mejores logros de la polémica.

\section{La acción indigenista.}

La profunda renovación teórica experimentada durante las dos últimas décadas en los análisis sobre la problemática étnica no tuvo, sin embargo, un correlato equiparable en el ámbito de las prácticas institucionales del indigenismo. Mientras que los primeros fueron enriqueciéndose al calor del apasionado debate, las segundas se estancaron y sólo experimentaron una limitada reforma más próxima al continuismo que al cambio. La trayectoria del Instituto Nacional Indigenista (INI) durante estos años revela esta tendencia.

EI INI que desde el inicio de los años cincuenta habia experimentado y mantenido incólumes los principios de la aculturación inducida a través de una red de Centros Coordinadores en los que se institucionalizó la "acción integral" en el campo educativo, sanitario, agrario, agrícola, económico y de integración regional, comenzó a resentir en su interior los primeros sintomas de desgaste en 1970.

La causa más profunda de este desgaste era lo que Alejandro Marroquín denominaba la "herrumbre burocrática" que estaba "carcomiendo" una política indigenista "bien orientada teóricamente". En una evaluación que este destacado antropólogo hacia de las labores del INI desde su fundación hasta 1970, señalaba, entre otros, los siguientes aspectos negativos: la dispersión de la acción indigenista, la incompleta cobertura limitada sólo a una quinta parte de la población indigena nacional, la ausencia de cambios estructurales en las zonas de refugio, la falta de planificación, la carencia de estudios y asesorias antropológicos, el desconocimiento por parte de los funcionarios públicos de las tareas del indigenismo, las carencias financieras, la falta de 
coordinación con las dependencias estatales, las limitaciones en los programas de formación, la explosión demográfica en las regiones indigenas, los desajustes administrativos y la limitación de recursos. Pero de todos estos problemas, el burocratismo era, sin duda, el más grave:

Con el correr del tiempo, el burocratismo empezó a inficcionar al Instituto; a medida en que el INI crecia, crecia su planta de personal y con ello se desarrollaba el burocratismo. Los funcionarios pueden clasificarse actualmente (1970) así: científicos o técnicos, politicos y burócratas. Los politicos son aquellos funcionarios que ocupan cargos indigenistas como un escalón más en su carrera para llegar al poder. Son los más nocivos para la labor indigenista puesto que todo lo supeditan a sus particulares ambiciones o a las del grupo a que pertenecen.

Los burócratas hacen de los cargos indigenistas un simple modus vivendi sin tener la mínima emoción indigenista. Cumplen las tareas que se les asignan sin poner en su trabajo ningún sentido de creación. Procuran dar lo menos posible y en cambio, recibir el máximo de ventajas.

Los funcionarios burócratas pronto constituyeron mayoria. [...] Por otra parte, algunos burócratas decidieron hacer carrera politica, con lo que se agravaron aún más los problemas administrativos.

Los resultados han sido negativos: se perdió la mística indigenista que impulsaba la labor indigenista y ésta se convirtió en una mera rutina cotidiana (Marroquín, 1971: 221-222).

Muchas de las criticas planteadas por Marroquín, vuelven a aparecer un año después (septiembre de 1971) con ocasión de una sesión extraordinaria del Consejo del INI a la que asiste el presidente de la república y un nutrido grupo de secretarios de estado. En forma sorpresiva el periodista Fernando Benítez desata una polémica al aseverar que "buena parte de la política indigenista ha fracasado por su carencia de un decidido apoyo político y por la dispersión y duplicación de sus funciones". ${ }^{17}$

Era asi como se iniciaba el sexenio populista de Echeverria durante el cual la dirección del INI así como la Subsecretaría de Cultura y de Educación Extraescolar recaerian en la persona de Aguirre Beltrán. Paradójicamente, mientras en el entorno académico los postulados indigenistas eran seriamiente cuestionados, en el interior del

\footnotetext{
${ }^{17}$ Los detalles y el reportaje de esta polémica aparecen reseñados en Varios, 1971.
} 
INI eran fiel y rigurosamente aplicados: en sólo seis años se inauguraron en todo el país 60 centros coordinadores, 46 más que los que hasta entonces se habían creado. Además y como lo señalara el propio Aguirre Beltrán:

Se incrementa notablemente el presupuesto de la Dirección General de Educación Indigena, suprimida por Diaz Ordaz y recién renacida, para la contratación de promotores y maestros bilingües. Se construyen escuelas, albergues escolares, puestos médicos, cooperativas de consumo y producción, caminos de penetración a mano de obra y una abundancia de otros servicios -crédito, maquinaria, fertilizantes, procuraduria agraria para los cuales no siempre se cuenta con personal profesionalmente adiestrado (Aguirre Beltrán, 1988: 82-83).

Las primeras reformas en la orientación ideológica del INI comenzaron a hacerse efectivas al inicio del sexenio del presidente López-Portillo. De acuerdo con los expertos, en su programa indigenista fueron retomadas algunas de las propuestas planteadas por un grupo de los llamados "antropólogos críticos" y desechadas otras, formuladas por Aguirre Beltrán (Báez, 1990: 24-25).

El lema declarativo de la nueva política indigenista de este sexenio fue el "indigenismo de participación" derivado del enfoque etnodesarrollista pero permeado por una visión marginalista de los grupos indigenas. Cuatro objetivos orientaron esta política: el logro de una mayor participación de la población indigena en la producción y en los beneficios del desarrollo nacional; la satisfacción de las necesidades básicas de los grupos étnicos en materia de alimentación, salud y vivienda; la elevación de la capacidad de los grupos étnicos en la defensa de sus derechos individuales y sociales en materia de educación, justicia y empleo y el fortalecimiento de la conciencia nacional a través del respeto al pluralismo (INI, 1978a).

Para evitar los vicios de la descoordinación con otras dependencias gubernamentales se creó en enero de 1977 la Coordinación General del Plan Nacional de Zonas Deprimidas y Grupos Marginados (COPLAMAR) en la que quedó integrada el INI. También, atendiendo a los reclamos presentados por el Primero y Segundo 
Congresos de pueblos indígenas (1975 y 1977), el INI emprendió una serie de reformas orientadas a incorporar la participación indígena en el diseño, ejecución y evaluación de las acciones orientadas a ellos.

En la práctica y como muchos criticos lo han señalado, este ambicioso programa respondió a un intento dirigido más a encauzar y mediatizar las demandas indigenas que a resolverlas. Los postulados declarativos tampoco desembocaron en una reforma de la estructura tradicional del INI sustentada en los Centros Coordinadoras. La multiplicidad de programas COPLAMAR vino a complicar más la burocratización y la tan publicitada reforma bilingüe y bicultural de la educación no tuvo como correlato un aumento en los niveles de su calidad ni un contenido auténticamente indigena. En cambio si propició un incremento incontrolado de maestros y promotores, muchos de ellos convertidos en "indígenas profesionales" (Báez, 1978; Nahmad, 1988; Herrera, 1983 y Aguirre, 1983).

Quizás lo más novedoso de la administración indigenista del sexenio siguiente, que estuvo inicialmente dirigida por Salomón Nahmad y después por Miguel Limón, fue la creación de los Comités comunitarios de planeación (COCOPLAS), los Consejos Técnicos locales, los Comités consultivos estatales y el Consejo consultivo nacional para promover la participación de las comunidades indigenas en la política indigenista. Un decreto presidencial incorporando tales reformas fue promulgado en junio de 1986.

Dos ejes programáticos ta promoción del libre desarrollo de las culturas indígenas y la corrección de la desigualdad que lo frena o inhibe-; tres principios -la participación de los pueblos indígenas en la planificación y ejecución de los programas del INI, el traspaso de funciones institucionales a las organizaciones y colectividades indigenas y la coordinación con otras dependencias de gobierno y cuatro áreas sustantivas de acción desarrollo económico, salud y bienestar social, procuración de justicia y fomento del patrimonio cultural- conformaron el eje de las politicas y tareas indigenistas de la 
administración del INI en la era salinista (Warman, 1990). Estas se sustentaron también en el Programa Nacional de Solidaridad y en las reformas constitucionales orientadas a reconocer el carácter multiétnico y pluricultural de la nación.

La repentina irrupción en la escena política nacional del Ejercito Zapatista de Liberación Nacional en enero de 1994, la situación de guerra desencadenada en Chiapas y cinco años de infructuosas negociaciones entre un amplio abanico de representantes indigenas agrupados en tomo al neozapatismo y el gobierno de la República han vuelto a poner el tema indígena en el centro de los debates sobre el futuro de la nación. Desbordando las expectativas y los marcos conceptuales elaborados por décadas por los académicos, los insurgentes indígenas han venido a plantear como punto nodal de sus demandas el derecho a la autonomia. Esta se vislumbra como posibilidad real de los pueblos indios de acceder al reconocimiento de sus derechos colectivos entre los que se incluyen el goce y usufructo de su territorio, la vigencia del sistema de gobierno indigena, la aceptación del sistema interno normativo y de justicia, asi como el derecho de los pueblos indios a mantener su lengua y cultura y definir las modalidades de su desarrollo.

\section{PREGUNTAS Y SENTIDO DE LA INVESTIGACION.}

Aunque el indigenismo como concepto típicamente antropológico y como realidad ineludiblemente politica es, como hemos visto, un término sumamente polémico en la antropología mexicana, creo sin embargo que puede decirse que engloba una serie de elementos que estarán presentes a lo largo de este estudio. Indigenismo hace referencia, en primer lugar, a una determinada forma de ver y explicar al otro, al indio, como culturalmente distinto, ajeno, extraño y por eso, implica ineludiblemente una etnografía de lo indigena, una explicación de la diferencia cultural, una racionalización y valorización de la alteridad. 


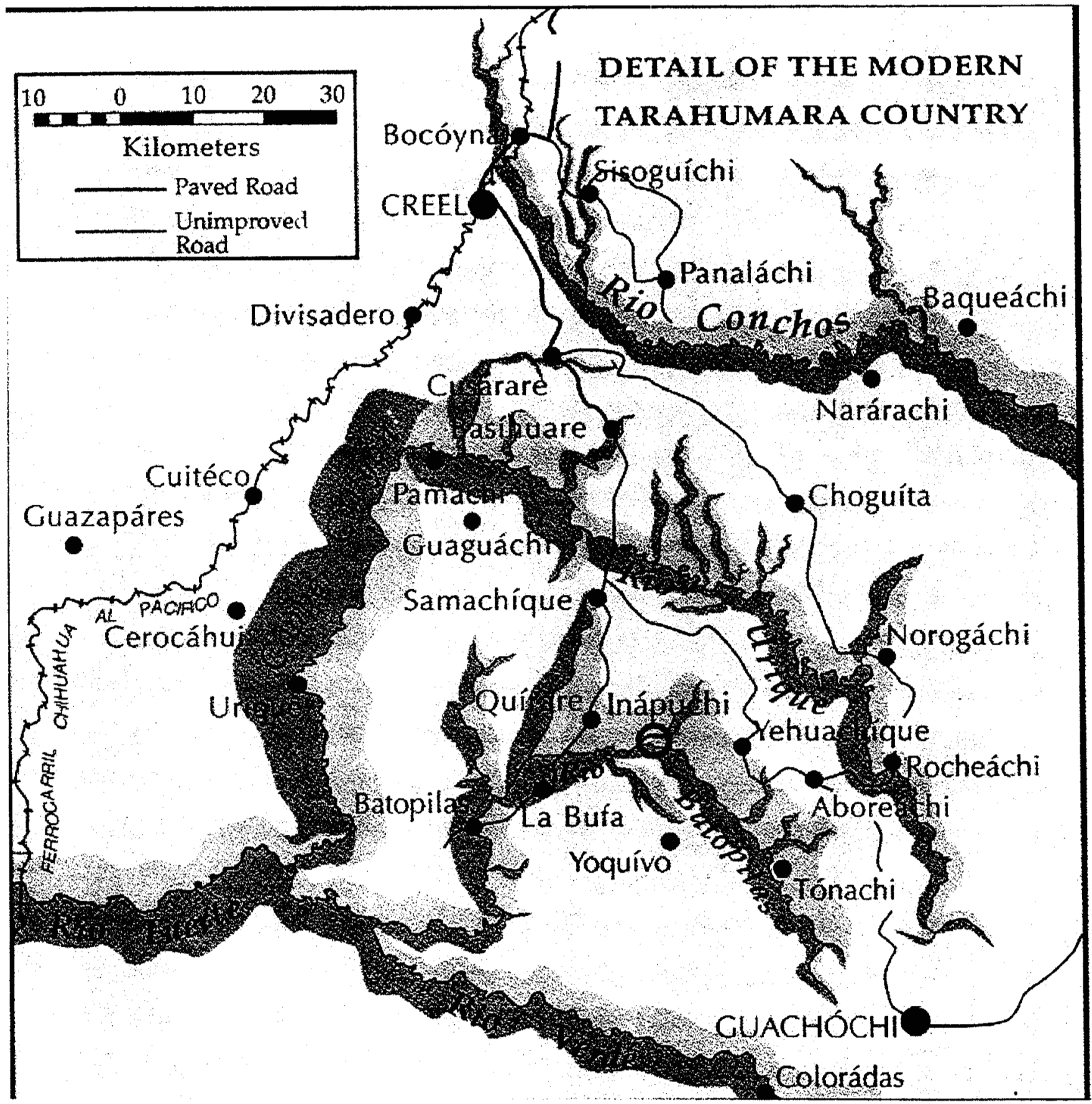

FIGURA 4.- MAPA DEL ACTUAL TERRITORIO TARAHUMARA (KENNEDY, 1996)

Pero también -y en segundo lugar- el indigenismo ha sido tradicionalmente un discurso que ha pretendido borrar la diferenciación en aras de construir - ¿artificial o forzosamente?- una unidad cuya razón de ser en los tiempos modernos, a los que se refiere este estudio, es la nación. Asi, en paises pluriétnicos, como el nuestro, el 
indigenismo nunca ha sido ajeno a las teorías de la nacionalidad, porque negados o reconocidos, los indios forman parte de la sociedad nacional no sólo como un caudal demográfico sino también como una matriz civilizatoria siempre presente en el marco de la cultura nacional. ${ }^{18}$

En México, durante este siglo, la articulación entre estas dos dimensiones del indigenismo han dado como resultado una serie de teorias explicativas asi como de experimentos institucionales orientados al cambio y a la transformación de los grupos indígenas. Dicho cambio social tiene como meta desdibujar las fronteras reales entre el mundo indio y el resto de la sociedad nacional, incorporar, integrar y asimilar a los grupos étnicos a los patrones de la cultura, la economia y la política de la sociedad nacional, mayoritariamente mestiza.

Con vista a establecer una estrategia general para esta investigación y tratando de englobar todas las dimensiones que están implicadas en el tema del indigenismo, consideramos que existen cuatro grandes núcleos de cuestiones que abarcan la mayoria de los aspectos relacionados con los debates en torno al indigenismo en México.

El primer núcleo de interrogantes es el que se refiere a la conveniencia y posibilidad del cambio cultural entre los grupos étnicos. Dicho en otros términos: ¿es necesario, legítimo y viable la transformación de las diferencias culturales distintivas de los grupos étnicos y su paulatina disolución en los patrones hegemónicos de la cultura nacional?, ¿qué principios lo justrican?, ¿tienen futuro, en la óptica indigenista, las culturas indias en tanto que diferentes? Y en el caso de admitir la necesidad del cambio cultural ¿es éste factible?

${ }^{18}$ Asumo aqui algunas de las ideas que Esteban Krotz ha planteado en tomo a la definición del indigenismo (Krotz, 1998). 
Estas preguntas tienen muchas aristas. Por una lado, nos remiten al tema de la aculturación - ¿qué tan asimilados a la cultura hegemónica occidental están hoy los grupos étnicos del país- y nos plantean la necesidad de levantar un riguroso registro etnográfico para conocer con precisión el grado de aceptación y resistencia cultural de cada etnia frente a la cultura hegemónica nacional de raices occidentales. ${ }^{19}$ Pero sobre todo, este núcleo de cuestiones se relaciona con el tema de la compatibilidad o incompatibilidad de las culturas indigenas con el proyecto de nación, proyecto que sólo es explicable dentro de parámetros culturales occidentales. Como ya lo hemos planteado en páginas anteriores, esto nos introduce en el centro mismo de los debates del indigenismo.

De una u otra forma, todo indigenismo es una justificación de que la transformación de los componentes de las culturas indias es posible e implica al mismo tiempo una propuesta de estrategias para que esta transformación sea viable. A la hora de analizar esta dimensión, claramente relacionada con la aculturación, será importante destacar especificamente cual es el carácter del cambio propuesto y en qué medida se considera que los componentes originarios de las culturas indigenas deben sobrevivir al cambio o desaparecer con él, por incompatibilidad.

El segundo núcleo de cuestiones implicadas en el tema del indigenismo es el que tiene que ver especificamente con las formas de organización social indígena y su posible persistencia, adaptación o desaparición en el marco de la integración de los grupos indigenas a la nación. Especificamente esta problemática hace referencia a dos

\footnotetext{
${ }^{19}$ Aun para quienes plantean como ineludible futuro de los grupos indigenas su integración a la nación, parece claro que ésta puede llevarse a cabo de forma distinta, teniendo en cuenta las particularidades de cada uno de ellos. Aguirre Beltrán, por ejemplo, distingue en el caso de Méxics. dos formas de integración: la de los grupos indigenas que amplian su conciencia étnica agregándota a la nacionalidad dominante y convirtiendo sus reclamaciones en demandas sociales (es el caso de los nahuas del valle de México y de la región Tlaxcala-Puebla, los zapotecas del istmo de Tehuantepec y stros más) y la de quienes amplian su conciencia étnica segregándose como una nacionalidad securviarla y planteando reivindicaciones étnicas orientadas hacia una soberania privativa, como seria el caso ce los yaxuis y seris de Sonora (Aguirre, 1994: 57-60).
} 
temas centrales: la comunidad y el gobiemo indigenas: ¿qué los caracteriza y distingue de las formas predominantes de organización social y del sistema político nacional?

En la práctica indigenista mexicana, desde los experimentos de Gamio en el valle de Teotihuacán y de Sáenz en Carapan, la comunidad aparece como el espacio privilegiado donde se plantean y proyectan las medidas de cambio social. La pertenencia del indígena a una comunidad es un hecho que es visto - $y$ a veces idealizado- no sólo como una realidad etnográfica sino también como una condición indispensable para que el cambio social entre los grupos indios pueda tener éxito. Desde esta perspectiva, el indigenismo ha teorizado sobre las formas de ser de la comunidad indigena y, a partir de ahi, ha construido una propuesta de las directrices del cambio de esa comunidad. ${ }^{20}$ Por lo mismo, para los propósitos de esta investigación es importante desentrañar el papel que el concepto de comunidad ha jugado a la hora de definir las estrategias de la acción indigenista.

El tema de las formas de gobierno indígena que tuvo alguna importancia en la doctrina clásica del indigenismo mexicano (Aguirre, 1991) ha adquirido una significativa relevancia en los debates actuales sobre la autonomia, en especial a raiz del levantamiento zapatista en el estado de Chiapas (Diaz Polanco, 1991; Castellanos y López y Rivas, 1992; López y Rivas, 1988). En cualquier caso resulta un asunto central para la práctica indigenista dilucidar cómo pueden ser compatibles el gobierno indigena y los sistemas de justicia, política y administración pública que imperan en el conjunto de la nación.

Un tercer bloque de asuntos englobados dentro del indigenismo es el que se refiere a las relaciones interétnicas. El indigenismo en México ha tratado siempre de

\footnotetext{
${ }^{20}$ La bibliografía y la etnografia sobre el tema son extremadamente amplias. Entre otras obras teóricas pueden destacarse Aguirre Beltrán, 1967, 1991; Aguirre y Pozas, 1981; Gamio, 1979; Hewit de Alcántara, 1988; Redfield, 1956 y 1973; Sáenz, 1966 y Stavenhagen, 1978.
} 
plantear un nuevo orden de relaciones en el que sean resueltas de alguna forma las confrontaciones y oposiciones culturales entre los grupos étnicos y el resto de la población y, en particular, aquella de origen ladino o mestizo con la que los indigenas interactúan cotidianamente.

A lo largo de la historia del indigenismo mexicano el tema de las relaciones interétnicas ha sido formulado especificamente para caracterizar la interacción entre indígenas y no indigenas en las zonas interculturales donde ambos conviven y, a partir de ese nivel, postular algún modelo civilizatorio que haga posible la construcción de la nación. Son fundamentales en este sentido las nociones de protección, incorporación, mestizaje, mexicanización e integración del indio, asi como los conceptos de "región de refugio" y "proceso dominical" planteados por Aguirre Beltrán (1967). A todos ellos habremos de referimos a lo largo de este trabajo.

El cuarto y último grupo de aspectos que tienen que ver con la teoría y la práctica institucional indigenistas es el de las estrategias del desarrollo ligadas a enfrentar la situación económica de los pueblos indios. En este sentido, el indigenismo ha formulado modelos del desarrollo económico que han pretendido explicar el atraso y el grado de pobreza en que viven las poblaciones indias en términos de su exclusión del sistema capitalista nacional y, por lo mismo, ha planteado formas para resolver esta situación por medio de la modernización y la integración de los núcleos de población indígena a los circuitos del trabajo, la producción y el mercado nacionales.

Tres elementos aparecen particularmente como fundamentales en estas teorias y experiencias del desarrollo: la transformación de las bases tecnológicas de la actividad agro-ganadera de las comunidades indigenas, los programas de educación que incluyen como aspecto central la castellanización y la difusión de los conceptos básicos y los servicios públicos de la medicina moderna (Aguirre, 1956). 
Este conjunto de estrategias del desarrollo ha dado lugar a un número importante de críticas en términos de la eficacia y éxito de la política indigenista. Algunas tienen que ver con la burocratización del mismo aparato indigenista (Marroquín, 1971) pero otras, más actuales y de mayor interés para nosotros, se refieren especificamente a la posible discrepancia entre las visiones occidental e indígena del desarrollo.

Estas cuatro problemáticas conforman el punto de partida de este estudio en el que tratan de abordarse y aplicarse al caso particular de la historia de la politica indigenista en la Sierra Tarahumara durante el siglo XX. Siguiendo la secuencia de esas problemáticas, las preguntas centrales que guian la presente investigación podrian resumirse en estos cuatro bloques de cuestiones:

a.) ¿Cómo ha sido concebida la identidad cultural distintiva de los grupos étnicos de la Sierra en los postulados y en la acción indigenista que en ella se ha desarrollado? Tal identidad ha sido entendida ¿como el obstáculo más serio a enfrentar? ¿como el objeto estratégico a defender y preservar? ¿como una aspecto de incidencia secundaria en las tareas indigenistas? ¿Bajo qué premisas el indigenismo ha planteado las posibilidades del cambio de estos grupos étnicos? En definitiva ¿cuál es el estatuto que el indigenismo ha otorgado a las culturas indigenas de esa región? y ¿qué formas de control cultural ha ejercido, en su caso, frente a ellas?

b.) ¿Qué concepciones sobre la comunidad y las formas de gobierno indigenas ha sustentado la acción indigenista en la Tarahumara? ¿Qué relación existe entre estas concepciones y la realidad etnográfica constatable? ¿Hacia qué tipos ideales de comunidad entre la autarquía comunal y el integracionismo cultural-se han orientado las propuestas indigenistas? ¿qué importancia ha otorgado el indigenismo a la transformación de los sistemas de gobierno y organización propios de estas etnias?. 


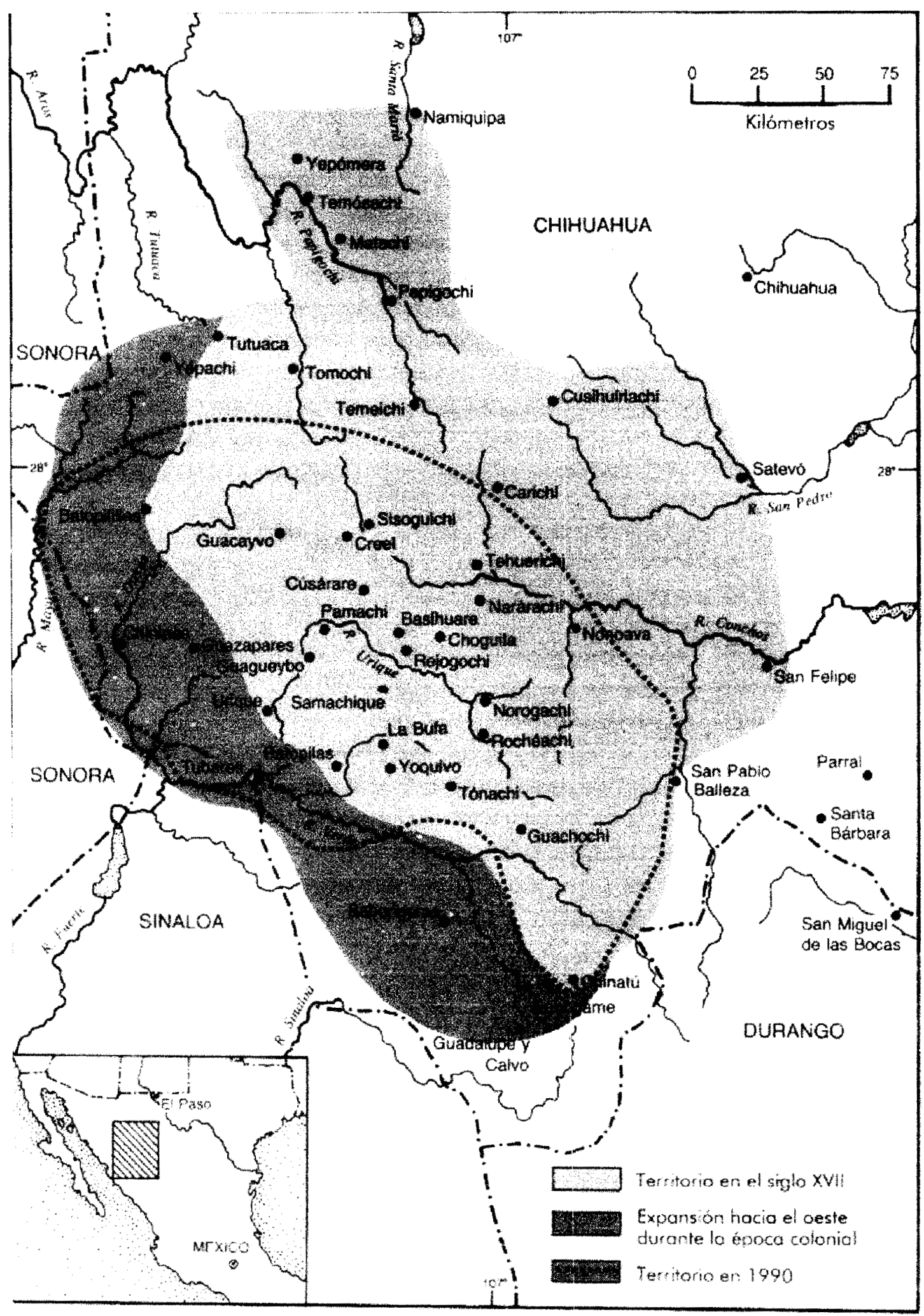

FIGURA 5.- EL TERRITORIO TARAHUMARA (PENNINGTON, 1983: 277) 
c.) ¿Cuáles han sido los términos y contenidos del discurso sobre las relaciones interétnicas que el indigenismo ha planteado en la Sierra Tarahumara? La práctica indigenista ¿ha contribuido a mantener, superar o agravar los niveles de conflictividad en que tradicionalmente se plantean las relaciones interétnicas? ¿Hacia dónde apunta, en la Tarahumara, el proyecto ideal de éstas en la perspectiva indigenista?

d.) ¿Qué modelos de desarrollo han guiado la acción indigenista en la Sierra Tarahumara? ¿De qué concepciones del bienestar social y del desarrollo derivan? ¿Han sido éstas compatibles con la cosmovisión indígena del bienestar? ¿Qué grado de autosustentabilidad han tenido estos modelos? ¿En qué forma las propuestas del desarrollo económico y del bienestar social que han presidido la tarea indigenista han modificado los comportamientos económicos tradicionales de la población indígena? ¿Qué grado de éxito o fracaso ha tenido esta tarea de aculturación indigenista en términos del logro de mejores condiciones de bienestar social y cuáles son las razones que lo explican?

Varias preocupaciones e intereses académicos, profesionales y personales están en el trasfondo del problema de investigación que me he planteado y, puesto que creo que justifican su pertinencia teórica, es importante explicitarlos.

La preocupación central que da sentido a esta investigación surge de la constatación de un hecho hoy amplia y trágicamente reconocido en México: el indigenismo, como política de gobierno frente a los grupos étnicos del país, como proyecto de futuro y aún como realidad presente ha fracasado. Prueba esta afirmación no sólo el grave conflicto -aún sin resolver- derivado del levantamiento indígena en Chiapas en enero de 1994 y su secuela en la política nacional, sino también el hecho insoslayable de que son los pueblos indígenas el sector con los más graves índices de pobreza en el país. Por lo que a este estudio concierne, es ampliamente conocida la 
grave situación de marginación y atraso en que se encuentran los grupos indigenas que habitan en la Sierra Tarahumara, considerada oficialmente como una de las regiones más marginadas y atrasadas del país. Más allá de los indices estadísticos oficiales ${ }^{21}$ y de las evidencias etnográficas que aportaremos a lo largo del estudio, el fracaso del indigenismo en la Tarahumara se evidencia si tenemos en cuenta que la eficacia de algunas de las estrategias más importantes de desarrollo promovidas por el indigenismo en la zona, como la explotación intensiva de los recursos forestales, la tecnificación de la agricultura, la expansión de la educación bilingüe, ha sido seriamente cuestionada. También la actual situación de violencia en la zona derivada del auge de la siembra y comercialización de cultivos de estupefacientes (mariguana y amapola) corroboran indudablemente este fracaso. Todo ello apunta ineludiblemente a la necesidad de revisar sistemáticamente cuáles fueron los aciertos y los errores a lo largo de varias décadas de experiencias indigenistas, para poder reformular hoy los esquemas de la relación entre el Estado y la sociedad nacional y regional, por una parte, y los pueblos indios de la Tarahumara, por otra.

Esta investigación tiene un carácter evaluativo, en un doble sentido. Me interesa primeramente conocer los alcances reales de la acción indigenista en su propia lógica, de acuerdo con los objetivos y metas por ella trazados: ¿ha sido real la integración de los indigenas de la Sierra de Chihuahua -en especial los tarahumaras- a la dinámica del desarrollo y de la cultura nacionales? ¿son palpables y en qué grado los beneficios de esta integración en forma de una mejoría en la producción agricola, salud, educación, alimentación, vivienda, ingresos, seguridad y acceso a la justicia? En caso negativo, como parece ser, ¿cuáles son las causas que explican el fracaso? Desde otra

\footnotetext{
${ }^{21}$ De acuerdo con el Consejo Nacional de Población (CONAPO), el grado de marginación de la población de los municipios de la Sierra Tarahumara corresponde al más alto del estado de Chihuahua y se ubica entre los niveles de "muy alta" y "alta" marginación en el conjunto del pais. Estos indices se cakculan a partir de variables tales como el hacinamiento en las viviendas, la presencia en éstas de agua entubada, drenaje y energia eléctrica, el salario y el analfabetismo (Véase Consejo Nacional de Población, 1990).
} 
perspectiva, la evaluación pretende analizar los logros indigenistas desde la óptica de sus destinatarios, los pueblos indios. En este sentido me interesa destacar y valorar los grados de aceptación, conflicto, rechazo, resistencia y reapropiación culturales que los indigenas de la Tarahumara han mostrado frente a las politicas integrativas: ¿para qué les han servido éstas? ¿para los objetivos que fueron diseñadas o para otros más cercanos a sus intereses?. Dicho en otros términos, buscaré examinar la eficacia o el fracaso del indigenismo a partir de su efectiva capacidad para adaptarse a la cosmovisión indigena y para responder a las demandas sociales y politicas de los pueblos indios de la Sierra Tarahumara.

En un sentido complementario, pienso que el tema y la óptica de indagación que asume esta investigación son pertinentes en la medida en que pueden contribuir a renovar la polémica teórica -desde hace tiempo trabada en referentes ideológicos- en tomo al indigenismo, ya que se introducen aquí dos novedades: el enfoque regional y la prioridad otorgada al análisis de las experiencias del indigenismo por encima del recurso al examen de la coherencia de su discurso teórico. Las dos orientaciones que planteo creo que han estado ausentes en la mayor parte de la bibliografia sobre el tema. En cuanto a la historia de más de cuatro décadas de indigenismo en la Sierra Tarahumara una de las regiones donde, por cierto, más tempranamente se ensayó- puede decirse que está por hacerse. Quizás por el descrédito en que este tema ha estado inmerso en los últimos años, la amplia bibliografia sobre la antropología de la Tarahumara con que contamos, por lo general, sólo toca de forma tangencial -si es que no omite- el tema del indigenismo y, como veremos más adelante, prefiere optar por temas como la etnografía de algunas comunidades y el estudio de aspectos tales como la aculturación, la religión, los sistemas de intercambio reciproco, las prácticas rituales y la historia de las misiones en la región. 22

\footnotetext{
22 Pueden verse al respecto, entre otros, los trabajos de Bennett y Zingg (una monografia clásica sobre los tarahumaras escrita antes de la llegada del INI a la región), Kennedy (1970), Pennington (1963 y 1969), De la Peña (1948), Velasco (1987), Lartigue (1983), Merrill (1992), Jordán (1989), y González (1988), éste último con una exhaustiva revisión bibliográfica sobre el tema.
} 
En cuanto a la pertinencia del estudio del indigenismo a partir del análisis de su práctica institucional, creo que puede ser una estrategia válida para "desbloquear" la tendencia que ha predominado de juzgar el indigenismo a partir del discurso de sus autores intelectuales. Me parece que en tal perspectiva, será de gran utilidad conocer las mediaciones entre el discurso teórico y la práctica concreta, mediaciones que sin duda están relacionadas con la práxis de los agentes históricos y regionales, tanto los promotores indigenistas como las propias comunidades indigenas. Asi pues y en contraste con los análisis que han centrado su crítica al paradigma indigenista en la coherencia de sus conceptos, aqui se pretende plantear otro acercamiento crítico que tome como punto de referencia su ubicación en un contexto étnico-regional especififico y los resultados de esta práctica indigenista.

El intento pretende ser algo más que un juego intelectual. Se encamina a encontrar, desde la óptica de la antropología aplicada, atternativas orientadas a proponer puentes de articulación entre las teorias explicativas de la problemática indígena y los marcos de acción para su transformación. No sólo encuentro en ello una tarea urgente, sino también una de las más ricas vetas de la antropología mexicana, desde el Forjando Patria de Manuel Gamio hasta el México Profundo de Guillermo Bonfil. Por lo demás, la transferencia de la conducción de esta transformación a manos de la autoría de los propios sujetos indigenas no nos excluye a nadie -y menos aún a los antropólogos- de concebirla y hacerla realidad. Espero pues, que esta investigación contribuya a esta tarea en el marco de las preocupaciones que muchas personas e instituciones, en particular del estado de Chihuahua, compartimos por la Sierra Tarahumara.

\section{ESTRATEGIAS DE LA INVESTIGACION.}

Para reconstruir esta historia regional del indigenismo tuve que recurrir a varias estrategias de investigación. La que implicó más esfuerzos y tiempo consistió en recuperar las huellas escritas de esta experiencia que, después de varias búsquedas, pu- 


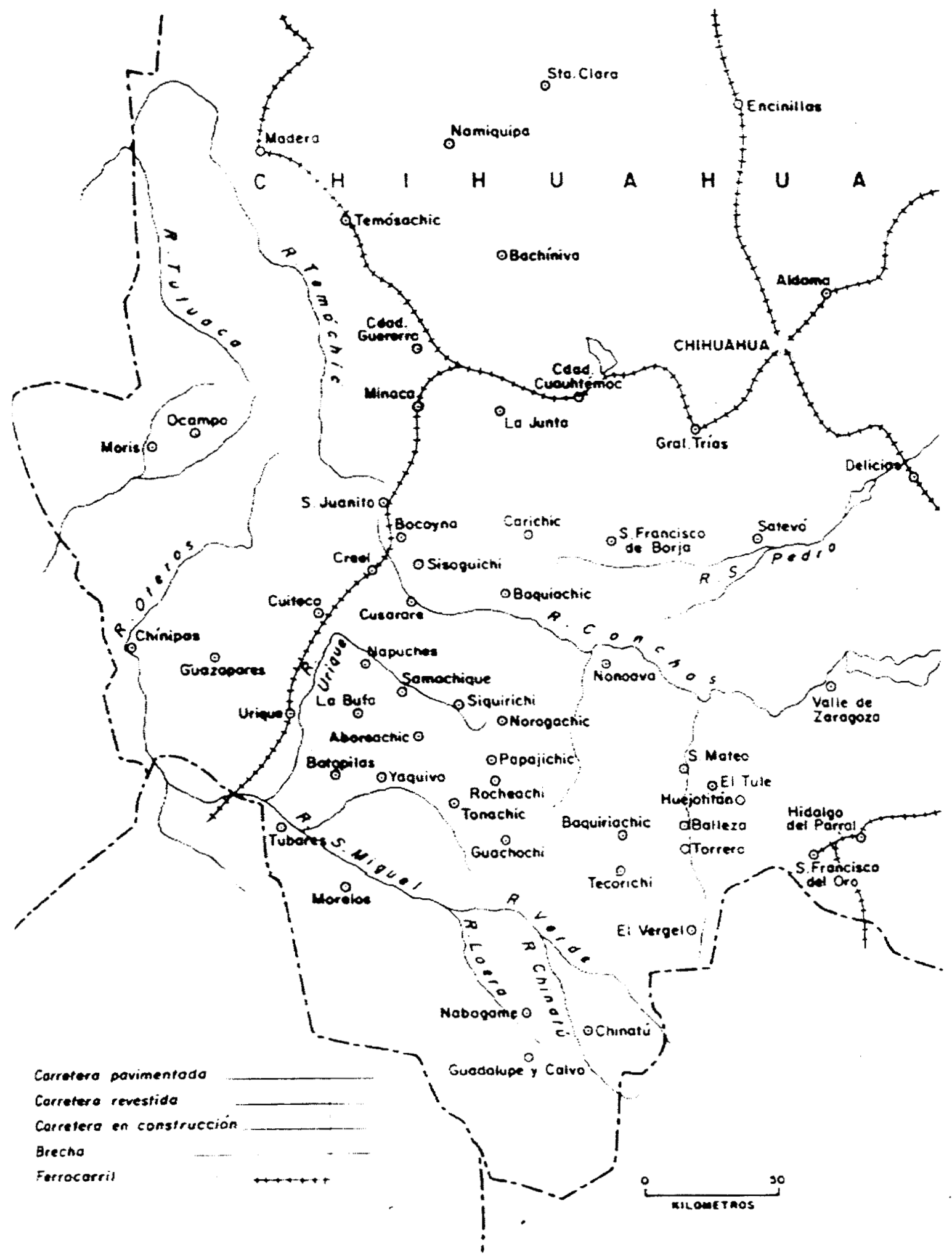

FIGURA 6.- PRINCIPALES POBLACIONES DE LA SIERRA TARAHUMARA (BENITEZ, 1967:79) 
de localizar en un viejo archivo frí, húmedo, polvoriento y lleno de papeles desordenados, amenazados por su destrucción y -peor aún- su olvido. Se trata del Archivo del Centro Coordinador Indigenista de la Tarahumara localizado originalmente en uno de los viejos edificios de este Centro en la ciudad de Guachochi, en plena alta Sierra Tarahumara. Con el apoyo y el entusiasmo de un grupo de estudiantes de la Escuela de Antropología de Chihuahua, donde soy profesor y he enseñado desde su creación en 1990, y después de varios veranos de trabajo de campo, pudimos rescatar, ordenar y catalogar este enorme archivo que reúne casi 50 años de historia del INI en la Tarahumara. $^{23}$

Tras su clasificación, en la que procedimos de acuerdo a los principios archivisticos de origen y fecha de la documentación, el ACCIT está integrado por 158 legajos divididos en un total de 3,462 expedientes. Se trata de documentos que proceden de las distintas "secciones" o áreas en que ha estado dividido el CCIT, secciones que corresponden al organigrama del CCIT y que, con el tiempo, han ido cambiando su denominación y función. ${ }^{24}$ Asi, entre sus legajos y expedientes se pueden encontrar informes de directores y técnicos de las secciones Forestal, de Educación, de Agricultura y Ganaderia, de Salubridad y Bienestar social, de Economía y Legal. También innumerables documentos relativos al Consejo Supremo Tarahumara, problemas agrarios de los ejidos serranos, informes técnicos, recortes periodisticos, solicitudes de gobernadores y autoridades indígenas, expedientes legales relativos a la defensoria de

\footnotetext{
${ }^{23}$ Desde el verano de 1995 y a raiz de un convenio establecido entre la ENAH Chihuahua y el INI, el archivo en cuestión en adelante referido como ACCIT- se encuentra en calidad de custodia en la Biblioteca Guillermo Bonfil de la ENAH Chihuahua, to que me ha permitido su ágil consulta. Además, y con el apoyo financiero del CONACYT, estamos actualmente digitalizando toda su información de forma tal que pueda ser ampliamente utilizado.

${ }^{24}$ Como resultado de este trabajo de clasificación, hemos editado un CD con el Indice del ACCIT. Es importante señalar que el sisterna que hemos seguido despertó un declarado interés por parte de las autoridades centrales del INI y de algunos otros grupos relacionados con el rescate de la documentación indigena, quienes han promovido la aplicación de nuestros procedimientos en algunos de los Centros Coordinadores del INI en Oaxaca, Chiapas y Sonora. Otro de los resultados de este rescate ha sido la publicación de una antología de textos sobre el indigenismo en Chihuahua (Sariego, 1998a).
} 
reos e inculpados indígenas en juicios de diferente tipo y, en fin, todo aquello que puede servir para documentar la historia heroica o frustrada, pero al fin real, del indigenismo en una de sus regiones predilectas, la Sierra Tarahumara.

Tomando en consideración el carácter evaluativo de esta investigación, resultaba imprescindible combinar los materiales escritos de esta historia regional del indigenismo con el testimonio vivo de quienes participaron como sujetos activos o indirectos de dicha experiencia. Fue asi que opté por realizar una serie de entrevistas largas y pormenorizadas con algunos de quienes tuvieron en sus manos la definición de las estrategias indigenistas en la Sierra Tarahumara. Muchos de ellos los visité, en octubre de 1994, en sus lugares de residencia, lejos de Chihuahua, como al Dr. Aguirre Beltrán (en Xalapa, Ver.) y a los profesores Francisco Hernández y Francisco Alvarez (en México D.F.) -los tres hoy desafortunadamente ausentes- y el antropólogo Agustin Romano. A todos ellos, así como algunos otros directivos del INI en Chihuahua y México y de la Coordinación Estatal de la Tarahumara en Chihuahua, Creel y Guachochi les agradezco su paciencia para descubrime experiencias que hoy muchos ya han olvidado.

Pero el lugar donde mejor pude constatar, problematizar y sopesar to que el indigenismo ha representado en la Tarahumara fue en las mismas comunidades indigenas, en especial en aquellas en donde la presencia del INI ha sido más decisiva. Para ello he venido realizando trabajo de campo de manera regular durante los meses de julio y agosto desde 1993 a la fecha en diferentes lugares de la Sierra Tarahumara y, ocasionalmente, algunas otras estancias más cortas en otras épocas del año. Debo decir que este trabajo ha sido parte de mis tareas como docente e investigador de la ENAH Chihuahua y que por ello ha tenido que adecuarse a los calendarios escolares. A este trabajo de campo han estado regularmente integrados, en grados diversos de compromiso, varios alumnos de diferentes generaciones, algunos de los cuales están 
elaborando sus tesis sobre temas afines al que aqui se trata. ${ }^{25}$

De esta forma pude visitar y desarrollar trabajo etnográfico en diferentes comunidades entre las que destacan Guachochi, Cusárare, San Ignacio de Arareco, Sisoguichi, Creel, Yahuirachi, Samachique, Mesa de la Yerbabuena, Batopilas, Yehuachique, Aboréachi, Tónachi, Norogachi, Batopilas, Yoquivo, Polanco, Morelos, Baquiriachi, Turuachi, Guadalupe y Calvo, San Rafael, Urique, Uruachi, Yepachi y algunas otras más. En todas ellas traté de indagar acerca del impacto que tuvo la actividad del INI y otras agencias indigenistas, para lo que entrevisté maestros y promotores indigenas de educación y salud, gobernadores y autoridades tradicionales asi como representantes ejidales y municipales. Más que estudios "de comunidad", pretendi a través de estas entrevistas y de mi observación, conocer de cerca la impronta del indigenismo en dichos lugares y recoger la opinión de sus habitantes indigenas y mestizos.

En no pocas ocasiones en estos últimos siete años he tenido la oportunidad de participar en debates y foros de discusión vinculados con problemas relacionados con la Sierra Tarahumara. En noviembre de 1993 y en respuesta a una solicitud del Congreso del estado de Chihuahua a nuestra escuela, colaboré activamente en la consulta a los pueblos indígenas para la reforma de la constitución estatal, ocupándome de coordinar las acciones que al respecto se llevaron a cabo entre la población warijó de los municipios de Moris y Uruachi, lugar éste último donde previamente tuve a mi cargo el rescate y catalogación del Archivo histórico municipal "José Maria Ponce de León”. También he participado en diferentes foros de discusión sobre la Ley Reglamentaria de

${ }^{25}$ En la actualidad un equipo de 5 alumnos está integrado a un proyecto sobre "ideologías y modelos de desarrollo en la Sierra Tarahumara" que coordino y para el que cuento con apoyos del CONACYT. Sus investigaciones de tesis versan sobre la economia agricola rarámuri (en la zona de La Mesa de la Yerbabuena), relaciones interétnicas y cultura mestiza en Batopilas, efectos del ecoturismo en la zona de las barrancas, impacto de la educación bilingüe en una comunidad tarahumara y condiciones de impartición de justicia entre presos indigenas del CERESO de Guachochi. 
los derechos de los Pueblos indigenas de Chihuahua y en reuniones de evaluación y consultas públicas organizadas por diferentes organismos relacionados con la tarea indigenista en la Tarahumara (INI, Coordinación Estatal de la Tarahumara, ENAH Chihuahua, Congreso del Estado de Chihuahua, etc.), asi como en seminarios, congresos, asesorias de tesis y trabajos de investigación que me permitieron entender mejor las complejas dimensiones de los problemas de la Tarahumara. ${ }^{26}$

La bibliografia antropológica sobre la Sierra Tarahumara es amplia y relativamente diversificada, pero el tema indigenista suele estar silenciado en ella, a pesar de que muchas de las comunidades que han sido objeto de etnografías sistemáticas fueron, al mismo tiempo, lugar predilecto de la acción indigenista. Las referencias más directas a ésta aparecen en la obra de Francisco M. Plancarte (El problema indígena de la Tarahumara, 1954) quien fuera el primer director del CCIT, asi como en articulos escritos por directivos y técnicos del INI que se localizan en las Memorias del INI y en varias de las revistas indigenistas como América Indígena y Boletín Indigenista.

\section{PLANTEAMIENTOS Y ESTRUCTURA DEL ESTUDIO.}

La tesis más importante que trato de demostrar a lo largo de esta investigación estriba en plantear que el indigenismo vivió en la Sierra Tarahumara una historia particular que resulta dificil de entender desde los moldes conceptuales clásicos que la teoria del indigenismo aculturativo planteó y que sus críticos han supuesto estuvieron presentes y se generalizaron en todas las regiones indigenas del pais. Dicho en otros términos, no fue, en estricto sentido, el paradigma académico tradicional del indigenismo lo que se aplicó en la Sierra Tarahumara, sino un conjunto de estrategias, muchas de ellas surgidas más de la experiencia cotidiana misma que del debate teórico, con las se trató primordialmente de enfrentar el problema del atraso económico y de la pobreza de

\footnotetext{
${ }^{26}$ Mis aportaciones sobre estos temas aparecen en Sariego, 1995a, 1995b, 1998a, 1999a, 1999b y Sariego y Urteaga, 1995.
} 
los pueblos indios. En la práctica, los agentes y promotores de esta política indigenista tempranamente acabaron reconociendo de hecho su incapacidad real para trastocar los componentes más nucleares de la cultura indígena tales, como los patrones de asentamiento y organización social, los sistemas de gobierno y politica, las formas de impartición de justicia, las valoraciones sobre el mundo mestizo y sus relaciones con él, las concepciones acerca del uso y aprovechamiento de los recursos naturales $y$, en general, las cosmovisiones indigenas sobre el mundo, la vida y la sociedad.

Visto desde esta perspectiva, el relativo fracaso del experimento indigenista constatable en sus resultados- sería consecuencia no tanto de sus pretendidos funestos efectos, cuanto de su incapacidad para afrontar y resolver los graves problemas de pobreza y marginación que aquejan a los pueblos indios de la Tarahumara. $Y$ este fracaso tiene básicamente dos explicaciones: en no pocas ocasiones los supuestos conceptuales que sustentaron los experimentos indigenistas estuvieron lejos de ser compatibles con la realidad etnográfica de las sociedades en que trataron de funcionar; en la mayoría de las circunstancias, en cambio, fue la resistencia -activa o pasiva- de los propios núcleos indígenas la que mitigó o anuló la eficacia de las estrategias integracionistas. Ejemplo de la primera de estas situaciones es el modelo comunalista que el indigenismo trató de imponer, derivado de la realidad mesoamericana, pero ajeno a los patrones de organización y asentamiento de los pueblos indios de la Tarahumara y posiblemente de otras regiones del norte de México. Y como muestra de la segunda de las situaciones puede aducirse la pervivencia y actualidad de la medicina indigena, asi como de las concepciones sobre la salud, la enfermedad y la muerte ligadas a ella.

Pero el indigenismo de las últimas cinco décadas en la Tarahumara no debe necesariamente concebirse o como un fiel aliado o como un perverso antagonista de la condición indígena, sino más bien como un contexto politico en el que los indígenas, en tanto que sujetos y actores sociales, se han desenvuelto teniendo que negociar sus 
propios intereses y proyectos culturales. En ese complejo marco de transacciones y acuerdos, algunas de las estrategias indigenistas han sido reapropiadas por los mismos indigenas de acuerdo a su lógica de sobrevivencia y adaptación. Creo que el ámbito donde esta situación es más patente es el de la educación indigena bilingüe y bicultural: lejos de haber logrado las metas para las que fue concebida, subsiste y hasta ha llegado a cobrar una cierta vitalidad no por otra razón que no sea la de los intereses que sus usuarios indígenas articulan en torno a ella. En particular considero que si bien es cierto que las escuelas-albergue operan con notorias deficiencias pedagógicas, cumplen sin embargo para los indígenas una función primordial en tanto que contribuyen a resolver los graves problemas de la alimentación, cuidado y salubridad de los niños asi como su capacitación para enfrentar cultural y lingüísticamente las adversas y desiguales condiciones de las relaciones comerciales y políticas con el mundo mestizo.

Teniendo como trasfondo estas tesis y lo que denominé más arriba las cuatro vertientes más importantes del concepto de indigenismo, el estudio ha sido estructurado en cuatro capitulos. En el primero de ellos, que he intitulado Indigenismo e identidad en la Sierra Tarahumara: entre la fascinación primitivista y la ficción reformadora, trato de descubrir y analizar la visión que los indigenistas que trabajaron en la Sierra Tarahumara construyeron en tomo a la identidad de los grupos étnicos de esa región en particular de los tarahumaras, la etnia más numerosa- $y$, más concretamente, la visión que plantearon acerca de las posibilidades y condiciones del cambio, la aculturación y la integración de los indígenas a la nación. Al mismo tiempo, pretendo relacionar esta concepción con las de otros autores y enfoques que han estado presentes dentro de lo que llamo la "antropología de la Tarahumara".

Sostengo que la perspectiva indigenista, partiendo de supuestos de orden más políticos que académicos, concibió las culturas indlgenas serranas abiertas al cambio y postuló entonces la vía integrativa como alternativa para que éstas pudieran expresar, 
con libertad y en plenitud, todas sus auténticas dimensiones culturales. Esta misma convicción en el cambio aparece también entre los analistas misioneros jesuitas, quienes, desde otros presupuestos, llegan también a la conclusión de que las etnias serranas han sido a lo largo de la historia y son hoy sujetos de transformación cultural. En ambos casos, me inclino a pensar que es el "celo" reformador lo que ha motivado la construcción de esta "ficción" sobre el cambio social.

En contraposición a esta concepción, un sector importante de la antropologia hecha en la Tarahumara sostiene una tesis opuesta: el valor cultural más significativo y conservable de las etnias serranas es su rechazo al cambio, su permanencia fuera de la historia, su primitivismo, origen de una auténtica fascinación etnográfica.

La conclusión a que llego en este capitulo plantearía que la visión indigenista del cambio social en la Tarahumara era quizás demasiado optimista y estaba poco apuntalada en una etnografia seria. Pero en todo caso, esta imagen apunta hacia un modelo de cambio social que parece no implicar la disolución de las culturas indigenas, sino más bien su potenciación.

En el capitulo 2, La comunidad indígena en la Sierra Tarahumara: construcciones y deconstrucciones de realidades y conceptos, trato de demostrar que uno de los principios -quizás el más importante-sobre el que se sustentaron las concepciones y prácticas indigenistas en la Sierra Tarahumara fue el de creer y plantear que los indios conforman entidades comunitarias. El supuesto "comunalista" fue al mismo tiempo un postulado teórico y una meta en la acción indigenista. Quiere esto decir que, a través de diferentes acciones, se buscó que los indigenas llegaran a conformar sistemas comunales de asentamiento, organización y representación política.

En el capitulo se plantea que esta concepción y práxis comunalista proviene de la 
experiencia misionera de los "pueblos de misión" del siglo XVII y vuelve a tener vigencia a principios del siglo $X X$, en pleno período de auge liberal en tierras chihuahuenses. Su expresión más acabada es la Ley de mejoramiento de la raza tarahumara emanada del gobierno de Creel en 1906.

La acción indigenista, que empieza a desarrollarse en la Sierra Tarahumara a partir de los años treinta y se intensifica en los cincuenta, retoma este postulado del comunalismo indigena y llega incluso a plantear, en la práctica, la conformación de un organismo político tribal, el Consejo Supremo Tarahumara, en el que se expresa, en grado sumo, la visión de los pueblos indigenas como entidades políticas cuasi autónomas. A partir de los años cincuenta, el INI trató de aplicar en la Tarahumara su concepción sobre la comunidad indígena y su desarrollo, pero enfrentó, desde entonces hasta hoy, serias dificultades para hacerlo, dadas las formas especificas de organización de los pueblos indios de la Tarahumara, que van desde la unidad nuclear del rancho a la forma difusa del "complejo del tesgüino".

Finalmente lo que el capitulo trata de mostrar es que esta visión comunalista del indio serrano (que forma comunidades, que acepta un esquema socializado de organización, que estructura su economía a través del colectivismo y que llega a organizarse en organismos de representación tribal) es más un supuesto que una realidad. Porque la etnografia mostró y sigue mostrando que los grupos étnicos serranos asumen un modelo de organización territorial, social, económica y política muy distante del esquema ideal "comunalista" que planteó en diferentes formas el indigenismo. La conclusión que se desprende del capítulo es que la falsedad del supuesto comunalista seria una de las causas del fracaso de las estrategias indigenistas.

En el capítulo 3, Indigenismo, relaciones interétnicas y procesos civilizatorios en la Sierra Tarahumara, pretendo examinar las diferentes concepciones y supuestos 
sobre las relaciones interétnicas y el proceso civilizatorio que estuvieron en el trasfondo del indigenismo en la Sierra Tarahumara. ¿Cómo se explicaron las relaciones entre el mundo indio y el no-indio? ¿Qué relación tuvieron estas explicaciones con las propuestas de cambio social encerradas en la práctica indigenista? ¿Hacia dónde apunta el sistema de relaciones interétnicas entre el indígena y el mestizo en el modelo ideal de sociedad regional que planteó el indigenismo en la Tarahumara?

Con especial énfasis se revisan en este capitulo tres discursos y experiencias institucionales distintas sobre las relaciones interétnicas: el de la protección del indio, el de su incorporación y el de su integración. También se analiza, la forma como el indigenismo definió y enfrentó en la Sierra Tarahumara el grave problema de las relaciones interétnicas, es decir, el conflicto -latente o explicito- entre el mundo indígena y el mestizo 0 , como se dice, en el lenguaje serrano, entre el rarámuri y el chabochi o entre el indigenas y el yori. ${ }^{27}$

Trataré además de enfrentar y comparar esta experiencia regional con las teorias que sobre el tema construyó el indigenismo oficial y retomo para ello básicamente documentos y materiales de campo en los que se plantean las demandas, quejas de comunidades indigenas frente al $|\mathbb{N}|$ y en general frente al gobierno por problemas derivados de la presencia mestiza.

Concluyo planteando que, en contra de lo que la teoria oficial indigenista ha postulado, en la Tarahumara la experiencia indigenista sivió más para profundizar y ahondar los conflictos interétnicos que para superarlos. También pongo en tela de juicio la aplicabilidad de los supuestos implicados en la teoria de las "regiones de refugio" y del proceso "dominical" para caracterizar el sistema de relaciones interétnicas en la

\footnotetext{
${ }^{27}$ El término "chabochi" es utilizado por los tarahumaras para referirse despectivamente a los mestizos, en tanto que el de "yori" tiene el mismo significado entre guarijios y pimas.
} 
Tarahumara.

El capitulo 4, Concepciones, modelos y experiencias indigenistas de desarrollo en la Sierra Tarahumara, se enfoca a discutir cuáles fueron los esquemas y modelos del desarrollo que el indigenismo experimentó en la Sierra Tarahumara, en qué principios se basaron y cual fue su grado de éxito o fracaso. En particular me referiré a los ámbitos más importantes de la acción indigenista en la Tarahumara que incluye, en primer lugar, lo que podriamos llamar "el agrarismo forestal", -sin duda, el área más importante de la acción indigenista en esta región, es decir la lucha del INI por crear ejidos y dotarlos de áreas de explotación forestal, así como por implantar aserraderos e incluso, llegar a pensar en la autogestión indígena en el manejo de los recursos forestales. Analizo también en este capitulo otras tareas del indigenismo ligadas a la implantación de una aparato de educación indígena así como a la creación de infraestructuras educativas, sanitarias, agropecuarias y la construcción de vias de comunicación.

En el capitulo trato de caracterizar las diferentes etapas de estas acciones tendientes al desarrollo de las comunidades indígenas y busco evaluar los resultados de dichos programas con realismo: ¿qué lograron? ¿qué no lograron? ¿qué relación hay entre las metas propuestas y las demandas y expectativas de los indigenas serranos?. Me inclino a pensar que uno de los grandes logros de ese indigenismo fue hacer realidad la reforma agraria en la Sierra, pero, por otra parte, el modelo forestal acabó por ser un fracaso, tanto desde el punto de vista ecológico como desde el punto de vista del desarrollo económico. La situación actual de pobreza de los ejidos forestales lo demuestra más que sobradamente.

En general, la critica más seria que planteó al modelo indigenista de desarrollo serrano es que siempre se sustentó en el principio de la acumulación y apropiación 
(colectiva o individual), principio que chocó con la mentalidad india. En conclusión, el indigenismo nunca llegó a postular, propiciar, fomentar o inventar un modelo indígena de desarrollo. Por otro lado y como ya antes lo señalé, sostengo que en muchos de estos ámbitos y estrategias de desarrollo hubo diferentes modalidades de apropiación indígena.

En las conclusiones trato de proponer algunas líneas directrices que sirvan de referente para construir, bajo nuevos presupuestos, un modelo alternativo de relaciones de la sociedad y el estado nacionales con los pueblos indios de la Tarahumara. En particular me ubico en la óptica de los debates actuales sobre la autonomía y planteo algunas sugerencias sobre las modalidades que ésta podria asumir en la Tarahumara a partir de principios tales como la interculturalidad $y$ el respeto a las formas de organización social y cultura política de los pueblos indígenas.

Una aclaración final: en la ortografía que utilizo en palabras y términos rarámuri, he optado por conservar los usos lingüisticos propios de los documentos de las dependencias indigenistas, en particular del CCIT de Guachochi, entre 1952 y 1980, a sabiendas de que esta grafia está actualmente en desuso. 


\section{CAPITULO 1: INDIGENISMO E IDENTIDAD EN LA SIERRA TARAHUMARA: ENTRE LA FASCINACIÓN PRIMITIVISTA Y LA FICCIÓN REFORMADORA}

...el atraso cultural [del tarahumara] [...] es tan extraordinario como para que podamos afirmar que si ocumiera un cataclismo $y$ eliminara a este pueblo, absolutamente nada dejaria tras de si; ni siquiera los toscos dibujos con que hace diez mil años se solazaban los trogloditas europeos (De la Peña, 1946: 249)

El indigenismo en la Sierra Tarahumara tiene una historia compleja. No sólo es un recuento de acciones "civilizatorias", experimentos de desarrollo y anhelos de integración; también es un discurso sobre lo que los indios son y deben ser, una propuesta explicativa sobre la identidad y el cambio social indígena, en suma, una interpretación antropológica sobre el pasado, la realidad y el futuro de los pueblos indios de la sierra chihuahuense.

Este capítulo pretende rastrear, entender y definir en sus justas dimensiones los orígenes y alcances del discurso teórico que el indigenismo construyó a partir de su experiencia en la Tarahumara. Para hacerlo nos proponemos ubicarlo en el contexto más amplio de las explicaciones etnográficas que diferentes corrientes de la antropologia han venido construyendo en torno a los pueblos indios que habitan este territorio del oeste chihuahuense.

Antes de revisar globalmente esta "antropología de la Tarahumara" y el lugar que en ella ocupan las visiones indigenistas, es oportuno hacer algunas acotaciones. La primera es que utilizaremos el término "antropologia de la Tarahumara" en un sentido amplio, incluyendo no únicamente a los etnógrafos de oficio, sino también a otro conjunto 
de intérpretes de esta realidad étnica como los misioneros, viajeros y en generalpromotores del desarrollo, cuyos planteamientos se acercan a los de los antropólogos propiamente dichos.

Una segunda precisión hace referencia a los limites etno-geográficos que abarcan las interpretaciones antropológicas: en su mayoria privilegian el análisis de una de las etnias de la región tos rarámuri o tarahumaras- y relegan a las otros tres -warijó o warijíos, ódami o tepehuanes y o oba o pimas- a un grado inferior de documentación. Cabria precisar incluso que la etnografia sobre la Tarahumara ha tendido a concentrarse en las poblaciones ubicadas en las cumbres del área central serrana (municipios de Bocoyna, Guachochi y en menor medida Batopilas) descuidando el estudio de la asi llamada Baja Tarahumara (municipios de Guadalupe y Calvo, Morelos, Chínipas, Uruachi, Moris, Temósachi, Ocampo, Maguarichi y Urique). ${ }^{1}$

El discurso etnográfico sobre la Sierra Tarahumara adolece además de otra seria omisión: el mundo mestizo, frente al que la identidad indigena se define por oposición referencial, ha sido más valorado que entendido y antes enjuiciado que descifrado. De esta valoración, de signo peyorativo, nace una especie de "leyenda negra", raras veces superada, sobre la cultura mestiza serrana ${ }^{2}$, la que, en definitiva, se convierte en un serio obstáculo para entender su contraparte, la civilización india.

Partiendo de estas premisas, nos atrevemos a proponer que la visión indigenista

\footnotetext{
"Ya hemos hecho referencia a la "clásica" distinción geográfica entre la Alta y la Baja Tarahumara. Sin que los limites sean muy precisos, es evidente que los antropólogos han preferido estudiar comunidades y grupos de la Alta donde los niveles de concentración de población indigena son más altos.

${ }^{2}$ En el capitulo 3 abordaremos con más detalle el tema de las relaciones interétnicas en la Tarahumara. Tres notorias excepciones a este olvido por la cultura mestiza son: la etnografia clásica de Francisco $M$. Plancarte, El problema indigena tarahumara, que hacia un interesante balance de las relaciones interétnicas al inicio de los años cincuenta; el estudio monográfico de Fructuoso Irigoyen sobre la región barranqueña de Urique en Cerocahui. Una comunidad en la Tarahumara y la apasionada narrativa de Victor Hugo Rascón en Volver a Santa Rosa, donde entre añoranza y memoria- trata de descubrir el alma mestiza del pueblo de Uruachi.
} 
debe ser contextualizada en el marco de una clara diferenciación entre dos grandes discursos o miradas antropológicas sobre la identidad de los grupos étnicos de la Tarahumara. La primera está permeada por lo que podriamos llamar una fascinación ante el primitivismo indio; la segunda, en cambio, agrupa las visiones de quienes han conceptualizado esta identidad india como un problema y han soñado la Tarahumara como una tierra de reformas y utopias sociales. Al analizar las diferencias y contrastes de estas dos visiones, habremos de plantear cómo y por qué la óptica indigenista se ubica en el marco de la segunda de estas dos miradas antropológicas.

\section{LA MIRADA PRIMITIVISTA.}

"La Sierra Tarahumara es famosa mundialmente por lo grandioso de sus profundas barrancas y la cultura rarámuri (o tarahumara) que se ha conservado casi intacta a pesar del impacto de nuestra cultura". Estas afirmaciones, que proceden de las páginas en el Internet de la Secretaría de Turismo ${ }^{3}$, resumen los dos postulados básicos que han caracterizado desde tiempos históricos una de las visiones más obsesivamente reincidentes sobre la Sierra chihuahuense: la Tarahumara es geográfica y culturalmente una tierra primitiva, ruda y, por ende, singular, única, fascinante y cautivadora. A pesar de su simplicidad semántica, el comercial con el que se pretende atraer al turista rememora al menos un siglo de miradas antropológicas sobre los indios de la sierra chihuahuense permeadas de esta fascinación primitivista.

\section{Los últimos cavemícolas americanos.}

En los últimos cien años, los principales portadores de esta visión fueron sin duda los viajeros extranjeros de finales del siglo XIX quienes llegaron a las serranias chihuahuenses tras el mito del hombre primitivo. El prototipo de esta búsqueda cientifica fue el noruego Carl Lumholtz quien protagonizó entre 1890 y 1898 cuatro expediciones en la Sierra Madre occidental y convivió por cerca de año y medio con los tarahumaras.

\footnotetext{
${ }^{3}$ Pueden consultarse las páginas elaboradas por la Secretaria de Turismo para difundir, a través de la Red Internet, el Programa Turistico "Barrancas del Cobre" en http://mexico-travel.com/touring/cano_esp.htm.
} 
En el Prefacio de El México desconocido, Lumholtz asienta sin ambajes que el origen de sus viajes no fue otro que el de encontrar en el noroeste de nuestro país a los descendientes de los cavernicolas que otrora poblaron el suroeste de Estados Unidos y tras su primera expedición llega a afirmar:

Esta vez llegamos a los habitantes de las cavernas. Los indios tarahumares de la Sierra Madre, una de las tribus mexicanas menos conocidas, vivian en cavemas en una extensión tal que propiamente puede llamárseles trogloditas americanos de hoy. Me resolvi a estudiar este interesante pueblo, especialmente a los gentiles $^{4}$. (Lumholtz, 1986, Tomo I, pág. XIV).

A lo largo de su obra magistral, Lumholtz construye una de las etnografias más vivas y comprensivas que se hayan escrito sobre la Tarahumara. El mito occidental del hombre primitivo cobra realidad en las descripciones de la arcaica economia cazadorarecolectora de los tarahumaras, pimas y tepehuanos, de sus sistemas de autoridad y prácticas jurídicas, de sus ceremonias agricolas, de los rituales y danzas del "rutuburi", "yumari" y "jículi" o peyote, de las prácticas curativas y de sus mitos sobre los astros, los animales, el origen del mundo y el destino del hombre. A lo largo del libro la obvia distancia cultural del etnógrafo se transforma en empatía y la desconfianza en respeto y admiración por la sabiduria de un pueblo.

Después de esa larga experiencia, Lumholtz no dudará en hacer explicitos sus presupuestos evolucionistas: los tarahumaras son únicos y genuinos no sólo por su condición de últimos trogloditas de América, sino también por estar escribiendo las páginas finales de su historia y la de otros pueblos primitivos que, como ellos, acabarán por sucumbir ante el progreso:

Los pueblos primitivos son cada dia más raros en el globo. En el continente americano aún quedan algunos en su estado oniginal. Si se les estudia antes de que ellos también hayan perdido su individualidad o hayan sido arrollados por el paso de la civilización, se podrá esparcir mucha luz no sólo sobre los antiguos

\footnotetext{
${ }^{4}$ Gentiles o simarroni (equivalente en lengua tarahumara a cimarrones) son los términos utilizados desde la época colonial para designar aquel sector de la población indigena que se resistió a la evangelización misionera. Hoy en día connota más bien a núcieos aislados y ajenos a la influencia occidental y a la acción indigenista de las agencias gubernamentales.
} 
pobladores de dicho país, sino aún sobre los primeros capitulos de la historia de la humanidad.

En el rápido progreso actual de México, no se podrá impedir que esos pueblos primitivos pronto desaparezcan fundiéndose en la gran nación a que pertenecen. Las vastas y esplendorosas selvas virgenes y la riqueza minera! de las montañas no continuarán largo tiempo siendo exclusiva propiedad de mis morenos amigos; mas espero que les habré hecho el servicio de erigirles este modesto monumento, y que los hombres civilizados serán los primeros en reconocerlo (lbid.: XVIII y $X(X)$.

Y a pesar de asumir una óptica nitidamente evolucionista, el viajero noruego no parece titubear a la hora de juzgar los efectos perversos que el progreso está sembrando ya entre los tarahumaras y así, con un lenguaje que raya con el de una profecia apocalíptica, Lumhottz sentencia:

La civilización, tal como les llega a los tarahumares, ningún beneficio les presta. Sacude rudamente las columnas del templo de su religión. El Ferrocamil Central Mexicano aplasta sus cactus sagrados, cuya ira redunda para los tarahumares en años de escasez y desgracias. En tanto que ellos se privan del placer de fumar durante el dia para no ofender al sol con el humo, arrójanlo en espesas nubes, día con dia los homos y máquinas de los blancos, dejando a los indios fuera de la vista de Tata Dios que no puede cuidarlos. En la locomotora misma, ven la representación del Diablo con larga lengua y crecida barba... Lo peor es que la civilización va destruyéndoles su patria, pues cada vez ensanchan los blancos los limites de la suya (lbid. Tomo l: 403).

Este juicio, que pareciera contradecir las convicciones de un hombre de ciencia, revela en realidad uno de los presupuestos implicitos en el pensamiento y en la mirada antropológica de la mayoría de los expedicionarios, etnógrafos, arqueólogos y naturalistas, europeos y norteamericanos que, como Lumholtz, recorrieron la Sierra Tarahumara al final del siglo pasado. Sea que se trate del arqueólogo y etnohistoriador suizo Adolph Francis Bandelier, del historiador jesuita belga Aquiles Gerste, del etnobotánico norteamericano Edward Palmer o del militar Frederick Schwatka, todos ellos parecen coincidir en identificar los rasgos culturales de los indigenas chihuahuenses con el prototipo, casi mítico, del hombre primitivo, todo ello dentro del 
paradigma tipicamente evolucionista tan expandido en la antropologia finisecular. $^{5}$

Más aún, el arcaicismo genuino y primitivista del indio serrano y de sus instituciones culturales no sóło es reconocido por los viajeros occidentales, también y sobre todo es sublimado a niveles tales que, en ocasiones esta mirada antropológica acaba por ser sesgada, en la medida en que deja de lado una serie de referencias etnográficas que testimoniarian el impacto aculturativo que una evidente modernización económica estaba sembrando por esa época en el territorio serrano.

En tal sentido cabría preguntarse si la obra de Lumholtz, tan prolija en la ilustración de los rasgos culturales típicamente primitivos de los indios serranos, no es, en cambio, parca a la hora de atestiguar la mella que un capitalismo maderero, ferrocarrilero y minero estaba dejando marcada en el rostro de la identidad india. Baste un ejemplo al respecto: en el capitulo IX de su obra, Lumholtz narra su descenso por la barranca de Batopilas y su llegada a esta población de origen colonial donde, por esos años, operaba una de las negociaciones mineras más prósperas del pais, la Batopilas Mining Co., propiedad del exgobernador norteamericano Alexander R. Shepherd. ${ }^{6}$

Y sin embargo, nada del notorio esplendor productivo de esa empresa, ni del indudable auge demográfico derivado de la fiebre del metal en esa barranca, nada en absoluto de la impronta que la modema tecnologia, el comercio y la población

\footnotetext{
${ }^{5}$ Adolph Francis Bandelier, arqueólogo y etnohistoriador de origen suizo que estuvo estrechamente ligado a Lewis Henry Morgan, recorrió en 1884 la región de Casas Grandes y Janos donde investigó las relaciones culturales entre los indios pueblo del sur de Estados Unidos y los grupos étnicos de la sierra sonorense y chihuahuense (Bandelier, 1923-1937 y Brown, 1996). El P. Gerste excavó en diferentes lugares de la Sierra Tarahumara en 1892, identificando ciertos elementos de la cultura material y simbólica de los tarahumaras (Gerste, 1914). Edward Palmer y Frederick Schwatka también recorrieron la Sierra Tarahumara a finales del siglo pasado: el primero elaboró un amplio registro etnobotánico y el segundo consignó las modalidades de la aculturación indigena entre 1889 y 1890 (Watson 1886; Schwatka, 1893).

${ }^{6}$ Como muestra de este auge minero baste decir que el pueblo de Batopilas aumentó su población entre 1880 y 1902 de 300 a cerca de 4,000 habitantes y el municipio llegó a ser el tercero más poblado del estado de Chihuahua en 1900 con 14,167 habitantes.
} 


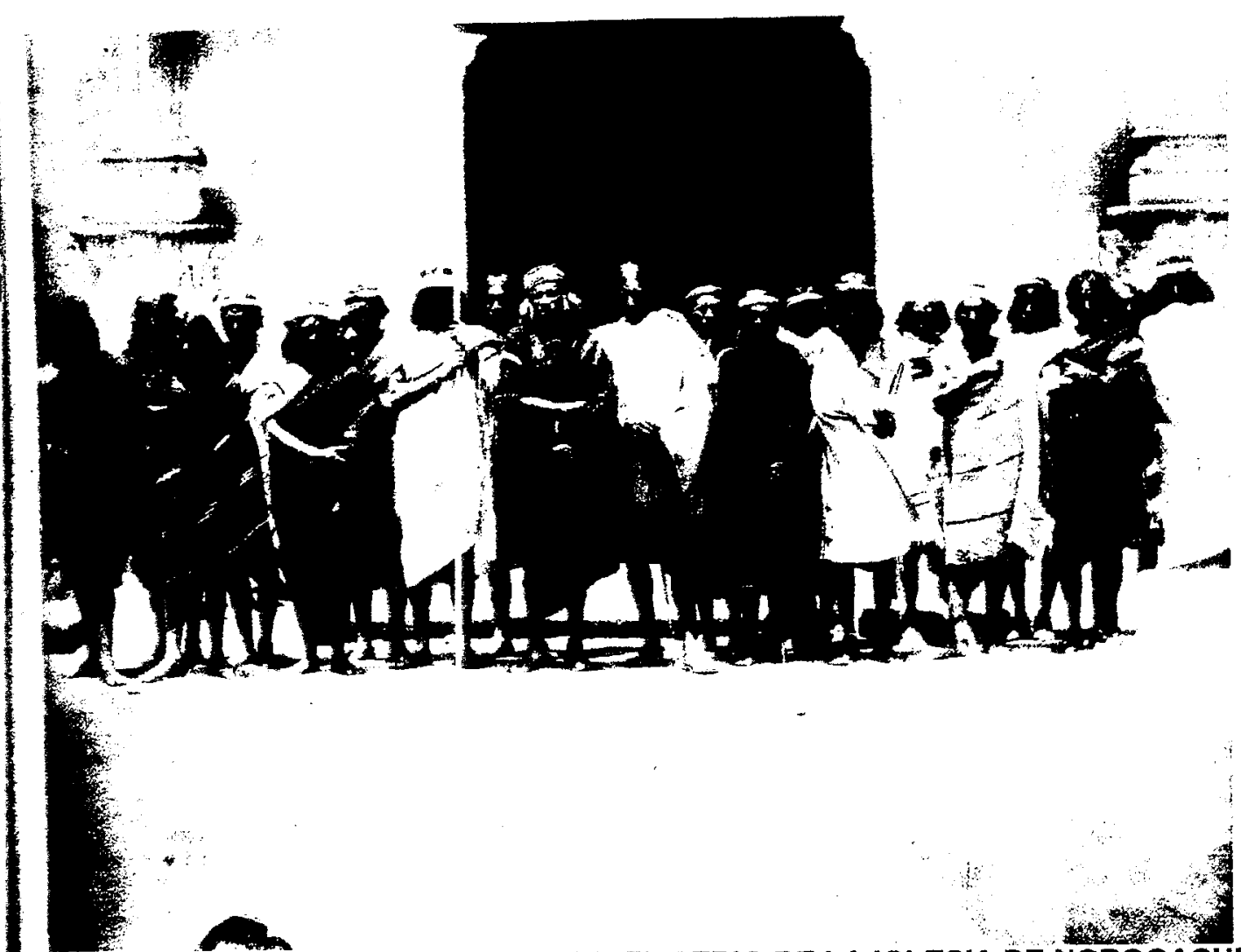

FIGURA 7.- AUTORIDADES TARAHUMARAS EN EL ATRIO DE LA IGLESIA DE NOROGACHI, CHIH., JULIO DE 1892. FOTO DE LA EXPEDICIÓN DE LUMHOLTTZ (RAMIREZ,1996: 71)

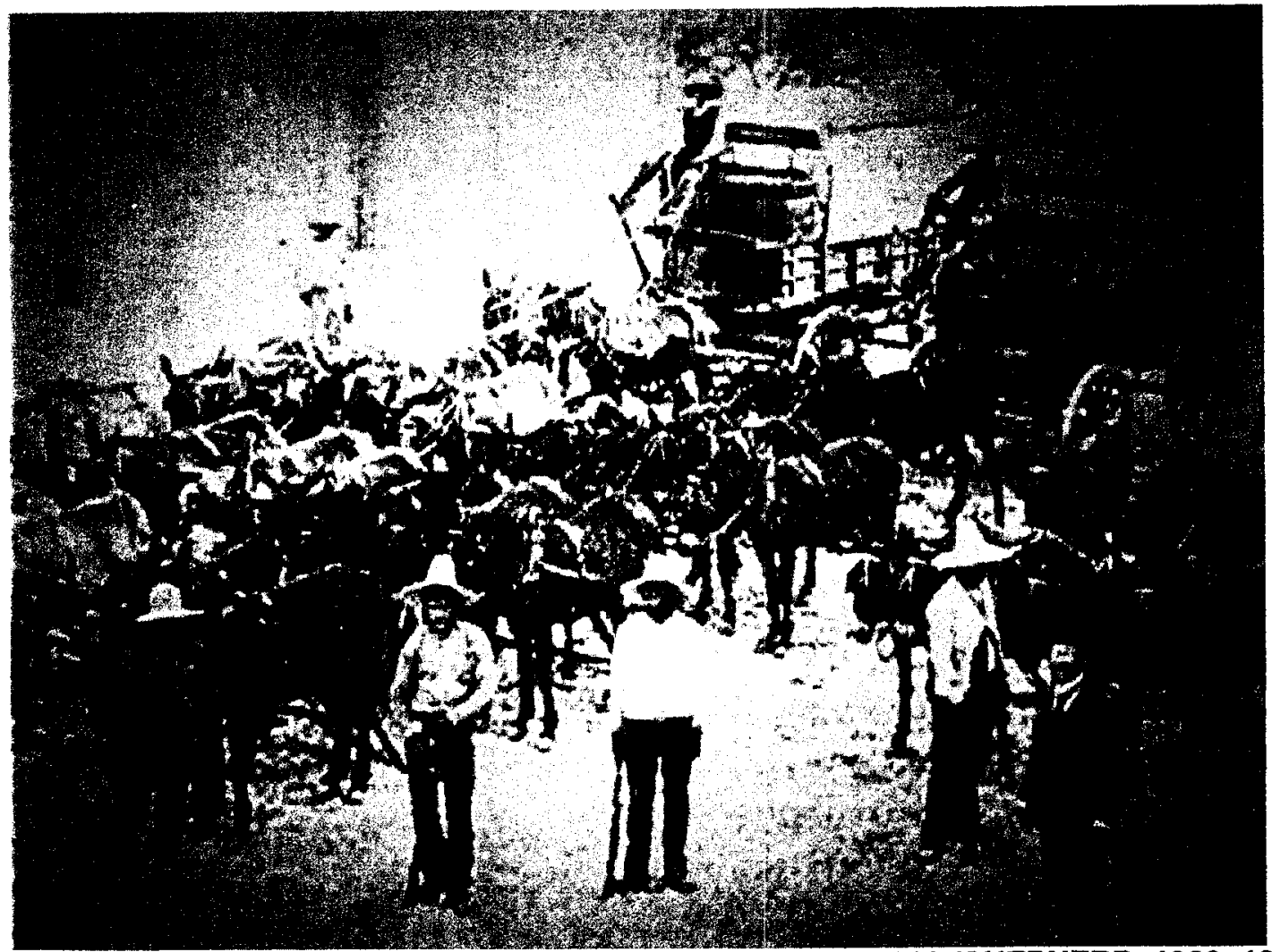


norteamericana advenediza estaban sembrando en el viejo poblado ${ }^{7}$ se reseñan en el libro de Lumholtz. Este, simplemente se limita a asentar que el Mr. Shepherd lo recibió cordialmente "cautivando con su bondadosa cortesía a todos los miembros de la expedición" (Lumholt, 1986: 178). Cabe preguntarse entonces ¿por qué el silencio del viajero noruego ante tantas evidencias de modernidad y por qué, en cambio, ese empeño desmedido por registrar hasta los más nimios detalles del primitivismo? ¿por qué no reconocer, con nostalgia, pero también con asombro, que en la tierra de los cavemicolas y trogloditas, el ruido de los malacates y molinos de metales y la imagen fugaz de la electricidad estaban deslumbrando las conciencias primitivas? ${ }^{8}$

${ }^{7}$ El auge minero de Batopilas está ligado a la llegada de Alexander R. Shepherd, un exgobemador del distrito de Columbia, EEUU, quien organizó en 1880 diez compañias mineras y las agrupó en 1887 en la Cia. Minera de Batopilas, capitalizada en 5'175,000 dólares. Un año antes el gobierno mexicano le otorgó una concesión sobre todos los derechos mineros en un área de 61 millas cuadradas. La empresa exptotó en la zona de Batopilas ocho grupos de minas y terminó de construir en 1899 un túnel subterráneo denominado tácticamente Túnel Porfirio Diaz, una de las grandes obras de ingeniería minera de la época. Además de restaurar los viejos yacimientos y descubrir otros nuevos, la Cía. Minera de Batopilas introdujo todo tipo de innovaciones metalúrgicas en las Haciendas de San Miguel y San Antonio en las que instaló la electricidad.

La organización del transporte de metales desde Batopilas hasta Chihuahua (a cerca de 280 millas) y de ahi, por ferrocarril, hasta Nueva York, constituyó una más de las hazañas de Shepherd: utilizando "conductas" de mulas y estableciendo estratégicamente una estación cada 40 millas y un sistema de vigilancia y aprovisionamiento de forrajes para los animales a lo largo del camino, los embarques mensuales de entre 50 a 100 barras de plata valuadas en 60,000 a 100,000 dólares, llegaban a Carichi en donde eran cargadas en carros de mulas con destino al Banco Minero de Chihuahua.

Para la historia de Batopilas entre 1880 y 1920 pueden verse entre otros: Pletcher, 1958: 182-218; Sánchez Pareja, 1883; LeBrun, 1933; Wilson y Panczner, 1986: 61-79; Southworth, 1905: 57-80; Bemstein, 1964: 22-23 y De la Peña, 1948, Tomo ll: 345-443.

${ }^{8}$ En contraste con la visión del viajero noruego pueden citarse los recuerdos de Grant Shepherd, hijo del "magnate de plata" de Batopilas:

Cuando mi padre instaló por primera vez la luz eléctrica en Batopilas los nativos pensaron que era cosa de brujeria, nunca en su vida las gentes del lugar habian soñado, ni idea tenian de lo que podía ser la luz eléctrica; no podian creer que con solo apretar un botón una estancia podia quedar bellamente iluminada. [...]

Cuando tuvimos la planta éctrica, grandes locomotoras con fanales delanteros fueron colocadas en lugares estratégicos, una linea de focos fue instalada dentro del túnel Porfirio Diaz dando un aspecto hermosisimo. Los indios, muchas mujeres y niños acostumbraban llegar hasta ahi únicamente para asomarse adentro y exclamar. 'ilas luces tan lindas!" (Shepherd, 1966: 138 y 139). 


\section{Mito y realidad de la resistencia fisica indigena}

Si en la visión primitivista que algunos viajeros del siglo XIX erigieron sobre la Tarahumara destacan los rasgos relativos a la cultura material y simbólica de los indios, en la de otros observadores, en cambio, cobran preeminencia los aspectos fisicos y raciales. El indio primitivo y salvaje pasa a ser visto entonces como un ejemplar de una raza única del que la resistencia fisica y la adaptación a un medio natural hostil llegan a asombrar a la ciencia médica. El prototipo de este discurso del "primitivismo racial" es la estampa del tarahumara descrito y observado como el "corredor de pies ligeros". 9

Esta imagen y el discurso ligado a ella son típicos de la etnografia de la Tarahumara. Viajeros como Friedrick Schwatka se asombran de que un tarahumara baje la Barranca del Cobre con un mensaje a las gentes de una mina y regrese con la respuesta a la cumbre una hora y media después, mientras que a cualquiera otra persona le toma diez u once horas bajar y subir, a lomo de mula, esa misma distancia con una diferencia de cerca de 1,000 pies de altitud. El mismo autor, Lumholtz y Grant Shepherd relatan con admiración las proezas de los tarahumaras capaces de recorrer como mensajeros el tramo Batopilas-Chihuahua-Batopilas (500 millas) en cinco dias, o el de Guazapares-Chihuahua-Guazapares (600 millas) en seis dias, o, más aún, de bajar a lo largo de los sinuosos caminos de la barranca de Batopilas un pesado piano o de subir, desde alli y hasta la cumbre el ataúd con los restos fúnebres de quien fuera en vida "el magnate de plata". (Shepherd, 1966: 103 y 272. Véase también Kennedy, 1996: 260).

Más allá del mito y la leyenda, el arquetipo del tarahumara corredor resistente y fisicamente superdotado comenzó desde los años veinte a adquirir fama internacional, convirtiéndose en un fenómeno digno de ser registrado cientificamente. $Y$ fueron

\footnotetext{
${ }^{9}$ Una de las significaciones más comúnmente asignadas al término "rarámuri" (utilizado desde principios del siglo XIX y probablemente relacionado con el de tarahumara) es la de "corredores a pié" y aunque esta traducción tiene dudosas bases etimológicas, lo cierto es que ha contribuido a forjar el mito de los tarahumaras como corredores de grandes distancias con una notoria resistencia fisica. (Sobre el término rarámuri véase Merrill, 1992: 123 y ss.)
} 
precisamente los antropólogos físicos, los médicos y hasta los periodistas deportivos quienes con más ahinco contribuyeron a forjar y divulgar esta imagen del indio primitivo, moldeado en el crisol de la ruda naturaleza serrana y, por ello, capaz de desafiarla.

Quizás la primera ocasión en que esta particular forma de ver al tarahumara adquirió cuerpo, debió ser una carrera pedestre entre las ciudades de Pachuca y México (100 kms.), promovida por autoridades indigenistas el 7 de noviembre de 1926, en la que participaron tres tarahumaras. Varios registros efectuados por antropólogos del Departamento de Escuelas Rurales de la SEP, aprovechando las paradas de los corredores para comer pinole, beber agua y atarse los huaraches, atestiguan que "no se encontraron sintomas de depresión física (fatiga)", a pesar de más de 9 horas continuas de carrera. ${ }^{10}$

La fama de los corredores tarahumaras no tardó en llegar a Estados Unidos. En 1927, dos rarámuris lograron recorrer en menos de 15 horas una distancia de 89.4 millas entre San Antonio y Austin, Texas y, en el estado de Kansas, otro tarahumara estableció una marca de 6 horas y 46 minutos en la carrera entre las ciudades de Kansas y Lawrence, bajando en más de 1 hora el récord anterior (Kennedy, 1996: 262 y Dedera, 1974).

Un año después, un grupo de tarahumaras compite en la prueba de Maratón de las Olimpiadas de 1928 de Amsterdan (Holanda). Tras finalizar entre los primeros puestos de la prueba, se dice que los rarámuris siguieron corriendo mostrando asi no sólo desconocer las reglas del maratón sino también tener motivaciones muy distintas a las de sus contrincantes internacionales (Kennedy, 1996: 262).

\footnotetext{
${ }^{10} \mathrm{El}$ consumo de agua y pinote es tradicional en las carreras de bola masculinas (rarajipari) y femeninas (ariweta) que practican periódicamente los rarámuri en sus comunidades. (Sobre este tipo de carreras, véase Kennedy, 1996: 259-286). El relato de la carrera y los registros efectuados por antropólogos fisicos puede consultarse Basauri, 1926: 24.
} 
En mayo de 1942, Filiberto Gómez, un maestro ligado a las Misiones Culturales, organizó una olimpiada en Guachochi, reuniendo para ello a corredores y deportistas de 15 pueblos de la Tarahumara. Los registros levantados por Dn. Filiberto son asombrosos y muestran que en materia de velocidad y resistencia los tarahumaras están a la altura de los mejores récords mundiales.

\section{CUADRO 4.- TABLA COMPARATIVA DE RÉCORDS ESTABLECIDOS POR CORREDORES} TARAHUMARAS EN OLMPIADA DE GUACHOCHI (1-5 DE MAYO DE 1942)

\begin{tabular}{|c|c|c|c|}
\hline EVENTO & TARAHUMARA & CENTROAMERICANO & MUNDIAL \\
\hline $1,500 \mathrm{mts}$. planos & 3.9 & - & 3.47 .8 \\
\hline 1,609 " & - & - & 4.01 .04 \\
\hline $3,000 "$ & 6.23 & - & 9.08 .03 (Olimpico) \\
\hline $5,000 "$ & 11. & - & 14.17 \\
\hline $5,731 "$ & 12. & - & . \\
\hline $10,000 " \quad "$ & 23.48 & 33.16 .0 & 30.6 .2 \\
\hline $17,193 " \quad "$ & 34.07 & - & - \\
\hline 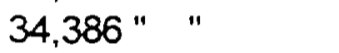 & $1 \mathrm{hr} .30 \mathrm{~min}$. & - & - \\
\hline $40.117 " \quad "$ & $1 \mathrm{hr} .43 \mathrm{~min}$. & - & - \\
\hline $42,195 " \quad "$ & - & - & hrs.29.19.4 \\
\hline
\end{tabular}

Fuente: Gómez, 1948: 200.

Las proezas de los corredores tarahumaras son algo más que una keyenda del pasado. En años recientes, varios tarahumaras han destacado a nivel internacional en las pruebas de ultramaratón (100 millas) desarrolladas en Colorado en las que han sobresalido algunos como Victoriano Churo de Panalachi, Juan Herrera de Choguita y Cirildo Chacarito, también de Panalachi. Baste decir que éste último, de 50 años de edad, recibió el 13 de marzo de 1998 el "Tepóraca de oro", presea que el gobierno de Chihuahua otorga al mejor deportista en activo del estado. ${ }^{11}$

Las capacidades attéticas de los tarahumaras son, para los observadores, la

${ }^{1}$ En su portada del 14 de marzo de 1998 El Diario de Chihuahua cabeceaba: "Chacarito se lleva la noche. En una ceremonia especial para galardonados, et tarahumar Cirildo Chacarito se llevó larga ovación al recibir el Tepóraca de oro. Cirildo, ataviado con su tradicional vestimenta, recibió aplausos por más de dos minutos". 
expresión moderna de las virtudes primitivas de una raza que ha sabido como nadie adaptarse a un medio fisico y natural hostil, hasta aprender de él a superar incluso la fuerza y la agilidad de los animales. Por eso es tan recurrente en la etnografia y hasta en la cinematografia sobre la Tarahumara ${ }^{12}$, ese relato del indio capaz de cazar al venado a base de cansarlo y agotarlo:

Yo he visto salir a un tarahumara e intemarse en la espesura del monte cierto dia al pardear el horizonte llevando, por arma, un cuchillo [...]. La suerte me deparó el verlo regresar al dia siguiente como a las veintitrés horas. Por entre aquellos mismos pinares se destacó la oscura silueta del indigena que traía sobre sus hombros un hermoso venado. Lo habia perseguido sin darle un momento de descanso durante varios horas -nos explica él con una naturalidad como si fuera esto cosa de todos los dias- y no se dejaba el chumari alcanzar. Por fin... ya no tenia pezuñas.. pues se le habian caido de tanto correr.. echó al río. y alli echó... yo llegué y enterré cuchillo... Hay otros chumari que se despeñan contra las rocas (Gómez, 1948: 199). ${ }^{13}$

La resistencia física y la fortaleza muscular de los tarahumaras no han podido por menos de asombrar y cuestionar a la ciencia médica: el doctor José A. Raynal, quien vivió entre los tarahumaras en los años cuarenta, llegó a considerar si los rarámuri no tendrian algún músculo accesorio (Gómez 1948: 196). Más allá de estas sorprendentes "hipótesis" y tras estudios y mediciones, fisiólogos, neumólogos y cardiólogos han llegado a concluir que el organismo de los tarahumaras $y$, en especial el de los corredores, es extraordinario. Sus capacidades les permiten hacer gastos de energia

${ }^{12}$ Puede verse, por ejemplo, "Tarahumara", pelicula filmada durante 1964 en la región de San Ignacio Arareco, con los auspicios del INI y en la que Luis Alcoriza, su director, presenta la forma de vivir de los tarahumaras y la labor heroica de los indigenistas.

${ }^{13}$ Como acertadamente to ha mostrado el Dr. Fructuoso Irigoyen Rascón, la explicación de esta curiosa. habilidad cazadora de los tarahumaras no hace sino remitimos a la sabia estrategia indigena de adaptación perfecta al territorio y su medio animal:

...después de oir la misma historia muchas veces decidi investigar a fondo alguna de las versiones de la misma. Una vez más los tarahumaras demuestran un impresionante conocimiento del medio que los rodea: ellos saben que el venado corre en circulos y que no rebasa nunca los límites de un determinado temitorio fuera del cual se encuentra perdido, io que les permite a los cazadores cortarle el paso o bien forzarlo a entrar en un territorio extraño para él, donde fácilmente les es posible darle alcance. De cualquier manera, la resistencia del tarahumar, que le permite trotar vanios dias consecutivamente casi sin descanso en pos del animal, es su amma fundamental para capturano (Irigoyen, 1994: 12 y 13). 
superiores a las 10,000 calorias en 24 horas y, cuando corren, su presión arterial tiende a bajar y el pulso aumenta. Todo ello muestra una alta capacidad anaeróbica de transportación de oxígeno como lo comprueban las elevadas cifras de hemoglobina que los tarahumaras registran en su sangre. La dieta alimenticia, rica en hidratos de carbono y vegetales y reducida en grasas, favorece además niveles muy bajos de colesterol y, por ende, la ausencia de cardiopatias. En fechas recientes, algunos estudios médicos en universidades norteamericanas parecen sugerir también que enfermedades neurológicas, como el mal de alzheimer, son desconocidas por los tarahumaras. ${ }^{14}$

La fortaleza física de la raza tarahumara, a pesar de ser llamativa, no deja de ser paradójicamente contrastante con los niveles de desnutrición aguda y crónica que muchos observadores atribuyen a este grupo étnico. ¿Cómo explicar este curioso contrasentido? o, como lo planteara en términos de antropologia física en los años veinte Carlos Basauri al hablar de los tarahumaras "¿cómo se explica que individuos mal alimentados y pertenecientes a una raza en decadencia, soporten tan exagerados sobresfuerzos sin menoscabo de su salud?" (Basauri, 1990: 269).

Las patologías de los tarahumaras que la ciencia médica ha sistematizado desde hace años revelan, en efecto, una sociedad con males y carencias graves de salud. Tal y como se muestra en el cuadro siguiente elaborado a partir de las observaciones del propio Basauri, los tarahumaras $-y$, en general todos los pueblos indios de la sierra chihuahuense- están expuestos no sólo a las enfermedades características de la pobreza, sino también a aquellas derivadas de un clima particularmente severo, sobre todo en invierno, y de una incidencia de hambrunas periódicas por falta de cosechas.

\footnotetext{
${ }^{14}$ Véase Irigoyen, 1994: 20-26. Sobre la potencia muscular y la capacidad anaeróbica de los tarahumaras vease Aghemo et al., 1968 y 1971. Las mediciones sobre el desgaste de energia, en Balke B. y C.Snow, 1965 y Paredes et al. 1970. Los resultados de estudios cardiológicos con tarahumaras pueden consultarse en Groom, 1971. Connor et al., 1975 y Cerqueiro, 1975. La baja incidencia de enfermedades neurológicas como el mal de alzheimer me ha sido comentada epistolarmente por el Dr. Daniel A. Pollen, del Departamento de Neurologia de la Universidad de Massachusetts en Worcester (comunicación escrita del 23 de junio de 1998).
} 


\section{CUADRO 5.- PATOLOGIAS MÁS RECURRENTES DE LOS TARAHUMARAS SEGUN}

BASAURI

\begin{tabular}{|c|}
\hline $\begin{array}{l}\text { ENFERMEDADES GENERALES } \\
\text { Sarampión asociado con bronconeumonia y bronquitis celular } \\
\text { Coqueluche que provoca alta mortalidad infantil } \\
\text { Reumatismo } \\
\text { Paludismo en forma leve } \\
\text { Tuberculosis pulmonar bastante frecuente } \\
\text { Epidemias generalizadas de viruela } \\
\text { Síflis en baja frecuencia y sin complicaciones nerviosas } \\
\text { Dermatosis: sama, prúrigo, pitiriasis y ezcema }\end{array}$ \\
\hline $\begin{array}{l}\text { ENFERMEDADES DEL APARATO RESPIRATORIO } \\
\text { Bronquitis aguda } \\
\text { Neumonia, bronconeumonia primitiva en niños derivada de sarampión y tosferina }\end{array}$ \\
\hline $\begin{array}{l}\text { ENFERMEDADES DEL SISTEMA NERVIOSO } \\
\text { Congestión cerebral por alcoholismo agudo precedida en ocasiones de Delirium tremens } \\
\text { Corea } \\
\text { Epilepsia en niños (casi siempre heredoalcohólicos concebidos durante la alcoholización } \\
\text { aguda de los padres). }\end{array}$ \\
\hline $\begin{array}{l}\text { AVITAMINOSIS Y OTRAS ENFERMEDADES POR HERENCIA } \\
\text { Raquitismo, pelagra, hemeralopia epidémica } \\
\text { Enfermedad de Barlow } \\
\text { Caquexias por hipoalimentación } \\
\text { Carencias crónicas: adelgazamiento excesivo, debilidad, apatia, palidez, diarreas, eczemas, } \\
\text { hemeralopia y manifestaciones escorbúticas }\end{array}$ \\
\hline $\begin{array}{l}\qquad \text { INTOXICACIONES } \\
\text { Alcoholismo crónico por consumo de tesgüino } \\
\text { Intoxicación por tesgüino, factor principal de la mortalidad infantil (sólo } 2 \text { de cada } 10 \text { niños } \\
\text { nacidos sobreviven) y asociada con la tuberculosis y con las enfermedades del sistema } \\
\text { nervioso. } \\
\text { Intoxicación por jicuri o peyote que provoca trastornos de la visión, alucinaciones e } \\
\text { insomnio. }\end{array}$ \\
\hline $\begin{array}{l}\text { ENFERMEDADES DEL APARATO DIGESTIVO } \\
\text { Dispepsias derivadas del consumo en exceso de hidratos de carbono } \\
\text { Enteritis agudas } \\
\text { Ictericia catarral simple o infecciosa } \\
\text { Congestiones alcohólicas } \\
\text { Cirrosis atrófica o hipertrófica del higado }\end{array}$ \\
\hline
\end{tabular}

Fuente: Elaborado a partir de Basauri, [1929]1990: 267-269. 
Además, algunas de las patologias de los tarahumaras proceden claramente de su notoria proclividad al consumo del tesgüino -cerveza fermentada de maiz- en el que no pocos observadores han visto el mal endémico de la raza tarahumara.

Como ya lo plantearan algunos antropólogos físicos desde hace cerca de setenta años (Basauri [1929], 1990: 269-270) y como lo señalan más recientemente ciertos médicos (Irigoyen, 1994: 24-26), muchas de las patologias crónicas indicadas parecen tener su origen no tanto en una alimentación deficiente cuanto en condiciones generales de insalubridad ambiental acentuadas por la extremosidad del clima serrano. Frente a estos factores que favorecen la incidencia de cuadros de tuberculosis, cirrosis, salmonela, etc., muchas de las prácticas cotidianas del tarahumara -su relativo seminomadismo, la práctica de la ganadería trashumante, la necesidad permanente de caminar para entrar en contacto con otras personas en un hábitat donde predomina un patrón de asentamiento sumamente disperso, etc.- parecen haber logrado, después de muchos siglos, una resistencia al medio con la que poder sobrevivir, hasta convertir a los rarámuri en una especie de "modernos espartanos". 15

Los mecanismos de selección natural expresados en las altas cifras de mortalidad infantil ayudan a entender que el tarahumara que llega a la edad adulta muestre signos de notoria resistencia física, nerviosa y cardíaca.

Los componentes físicos de los comportamientos cotidianos parecen, pues, los más apropiados y adaptados para poder sobrevivir en el medio serrano: la frugalidad en el consumo de ciertos alimentos y recursos escasos, la práctica de actividades rituales, deportivas, productivas y lúdicas- para mantener siempre la condición física y hasta una psicología proclive a la sobriedad, discreción e inhibición en un medio donde predominan las relaciones interétnicas conflictivas, son, entre otras, las claves de la

\footnotetext{
${ }^{15}$ término usado por Dale Groom (1971: 304)
} 
supervivencia indigena. ${ }^{16}$ En cuanto al consumo del alcohol del que parecen derivarse muchas de los más graves patologías de los tarahumaras, ya tendremos más adelante ocasión de hablar.

En conclusión de cuanto venimos diciendo, la imagen del tarahumara proyectada por la perspectiva médica no hace sino refrendar con nuevos matices la visión del indio como ser primitivo, vieja intuición de la etnografía serrana decimonónica construida por los viajeros anglosajones. La nueva argumentación estriba en comprobar y corroborar que los patrones fisiológicos y los comportamientos corporales corresponden, en efecto, a la imagen de seres humanos con aptitudes y condiciones fisicas completamente adaptadas a un medio donde es dificil sobrevivir. En suma, la imagen de un hombre biológicamente "natural" y por ello, culturalmente primitivo.

Desde cualquiera de los dos enfoques planteados, la visión primitivista del indio acaba por ser una apología de su perpetuación: en medio de un entorno civilizatorio atravesado por el cambio social, los indios sólo han podido -y podrán- pervivir a base de no inmutarse, de no cambiar, permaneciendo idénticamente fieles a la imagen de su pasado.

\section{Una etnografia demostrativa de la resistencia indígena al cambio.}

Los rasgos descarnados de primitivismo y salvajismo que predominaron en los retratos de la Sierra Tarahumara plasmados por las lentes y las plumas de los viajeros de principios de siglo, aunque pudieron parecer en ese tiempo folklóricos y extravagantes, encontraron sin embargo un respaldo sólido en la etnografia sistemática sobre los tarahumaras que comenzó a levantarse desde finales de los años veinte.

En efecto, la antropologia de la Tarahumara de esos años descubria un

\footnotetext{
${ }^{16}$ Estas y otras estrategias forman parte de lo que algunos autores han llamado los principios equisticos que explicarian la pervivencia y la razón de ser de la cultura rarámuri (ver Irigoyen, 1994: 6-9).
} 
panorama de tribalismo casi similar al que habia retratado cuarenta años antes Cart Lumholtz: a pesar de las campañas de misioneros y reformadores liberales iniciadas desde el período porfirista, los indios mostraban muy pocos rasgos que pudieran hacer pensar en un cierto grado de asimilación de las formas civilizadas.

En una de las primeras y más clásicas etnografias sobre los tarahumaras, Carlos Basauri, un antropólogo mexicano comisionado por el Departamento de Escuelas Rurales de la Secretaria de Educación Pública señalaba, a la vuelta de dos viajes a la Tarahumara emprendidos en 1925 y 1926 y entre otras de sus impresiones:

Entre otras tribus indigenas de México, si bien es cierto que se conservan muchas creencias y prácticas supersticiosas, la evolución, aunque lentisima, de sus culturas ha hecho que poco a poco las vayan abandonando, al grado de que gran parte de ellas han desaparecido; pero los tarahumaras, que se encuentran sumergidos en un estancamiento cultural prevaleciente desde antes de la conquista hasta la fecha, conservan todas las supersticiones inherentes a un tipo de civilización primitiva (Basauri, 1990: 281).

Desde varios ángulos y con diferentes argumentos, la monografía de Basauri escrita al final de los años veinte (1929) abundaba en muchos detalles que venian a confirmar la tesis de que los tarahumaras vivian en condiciones de auténtico primitivismo sobre el cual ni el proselitismo religioso ni la obra civilizadora de los misioneros habian hecho mella alguna. Como prueba de este primitivismo Basauri destacaba las costumbres de una vida familiar en la que los padres se despreocupan de los hijos desde los seis u ocho años, una vida sexual y marital que iniciaba desde el periodo de la pubertad, un sistema de gobierno indígena autónomo e independiente de la administración pública y del sistema fiscal ${ }^{17}$, sustentado en la autoridad de los

${ }^{17}$ Al respecto Basauri señalaba, entre otras observaciones:

Los indios no gustan de tratar con las autoridades municipales, constituidas siempre por gente blanca o mestiza, por lo que se hacen justicia en la forma indicada, y sólo recurren a los presidentes municipales, jueces conciliadores, etc., cuando tienen quejas contra algún blanco, siendo asesorados o patrocinados en estas ocasiones por su Gobernador [...] Los indios están exentos del pago de toda contribución al Gobiemo y, sin embargo, con toda puntualidad llevan sus tributos a los clérigos, consistentes en tres a cinco hectolitros de maíz por cada familia, cuando levantan las cosechas, y en los lomos de las reses cuando sacrifican estos animates para preparar el 'tonari' en sus fiestas (Basauri, 1929: 43 y 44). 
gobernadores y sus auxiliares (el mayora y los capitanes), una economia de subsistencia propia de agricultores, cazadores y recolectores y una ausencia generalizada de sistemas de intercambio comercial y monetario.

Pero Basauri insistía sobre todo en las creencias y prácticas "supersticiosas" de - los tarahumaras, derivadas de una teogonia sustentada en la adoración a tres dioses el peyote o Jíkuri, el sol o Raienari y la luna o Mechá-, un ritual conformado por bailes deprecatorios (como el rutuguri o baile del tecolote), sacrificios de animales, el consumo del tesgüino y el peyote, la presencia de "hechiceros" (owirúame) intermediarios entre los dioses y los hombres y una serie de creencias en torno a la lluvia, las enfermedades, la medicina y la hechiceria (Basauri, 1929).

Emisario de las autoridades de la Secretaría de Educación Pública e interesado en hacer realidad entre los indigenas los principios de la educación rural a través de las escuelas y centros de instrucción pública, Basauri confesaba al final de su estadía en la Tarahumara, mitad decepcionado, mitad incrédulo, los verdaderos obstáculos para una educación racionalista y científica entre estos indios:

[Para los tarahumaras] los más sencillos acontecimientos están ligados estrechamente a lo sobrenatural; la carencia o exceso de lluvia; las enfermedades epidémicas 0 individuales; los fenómenos astronómicos o metereológicos, etc., son manifestaciones de disgusto de Dios o de espiritus malignos, y ésta es la causa de que con mucha frecuencia practiquen ceremonias a fin de aplacar las iras de sus divinidades o de los mencionados espiritus (Basauri, 1990: 291).

La visión de Basauri sobre los tarahumaras, más allá de sus indudables méritos por su carácter pionero -se trata en realidad de la primera etnografía sistemática sobre este grupo étnico elaborada por un antropólogo mexicano- puede justificadamente calificarse de pesimista. En efecto, ante la mirada de Basauri -antropólogo comprometido con la tarea de la educación rural, derivada de los postulados de la revolución-, los tarahumaras aparecen como un grupo particularmente reacio frente a 
la tarea civilizatoria y educativa que los primeros gobiernos de la revolución estaban, por esos años, tratando de llevar a las regiones indigenas del pais. El relativo fracaso de las escuelas e internados indígenas de los jesuitas que Basauri conoció de cerca ${ }^{18}$ corroboraria esta sensación de pesimismo. Pero sobre todo, lo que más llama la atención de Basauri, lo que lo convence del futuro incierto de la tarea educativa en la Sierra, es el marcado apego de los tarahumaras a sus costumbres y creencias ancestrales diametralmente opuestas al pensamiento y al raciocinio cientifico y secular sobre los que se sustentaba la reforma educativa de la escuela rural mexicana.

La etnografia aplicada y comprometida de Basauri sobre los tarahumaras, aunque en ocasiones tendía a exagerar los rasgos de arcaicismo de la población indigena serrana ${ }^{19}$, coincidia, sin embargo, en muchos aspectos con las interpretaciones que otros antropólogos, más cercanos a la academia, construían por esos mismos años sobre el mundo indígena tarahumara. Fue éste, en particular, el caso de dos jóvenes antropólogos norteamericanos procedentes uno -Robert M. Zinggde la Universidad de Chicago y el otro -Wendell C. Bennett- de la de Yale, quienes habrian de constatar etnográficamente, como Basauri, la resistencia tarahumara al cambio social. A ambos antropólogos estadounidenses se debe la elaboración conjunta de un texto clásico - Los Tarahumaras, una tribu india del norte de Méxicopublicado originalmente en inglés en 1935 y editado en español por el Instituto Nacional indigenista en 1986.

Instalados entre octubre de 1930 y junio de 1931 en el pueblo de Samachique,

\footnotetext{
${ }^{18}$ Durante su estancia en la Tarahumaras, Basauri intercambia ideas y convive estrechamente con los jesuitas en alguna de sus misiones (Ocampo 1950: 140)

${ }^{19}$ En varios aspectos nos atreveriamos a pensar que esta etnografia peca de imprecisiones y confusiones. La teogonia tarahumara, el papel del owiriame (curandero. o doctor) y del sukurúame (hechicero o hacedor del mal), la importancia del ritual, el origen del sistema de cargos, entre otros de los elementos que describe Basauri, han sido analizados e interpretados de forma muy diferente a la suya por otros antropółogos de épocas posteriores de los que hablaremos más adelante.
} 


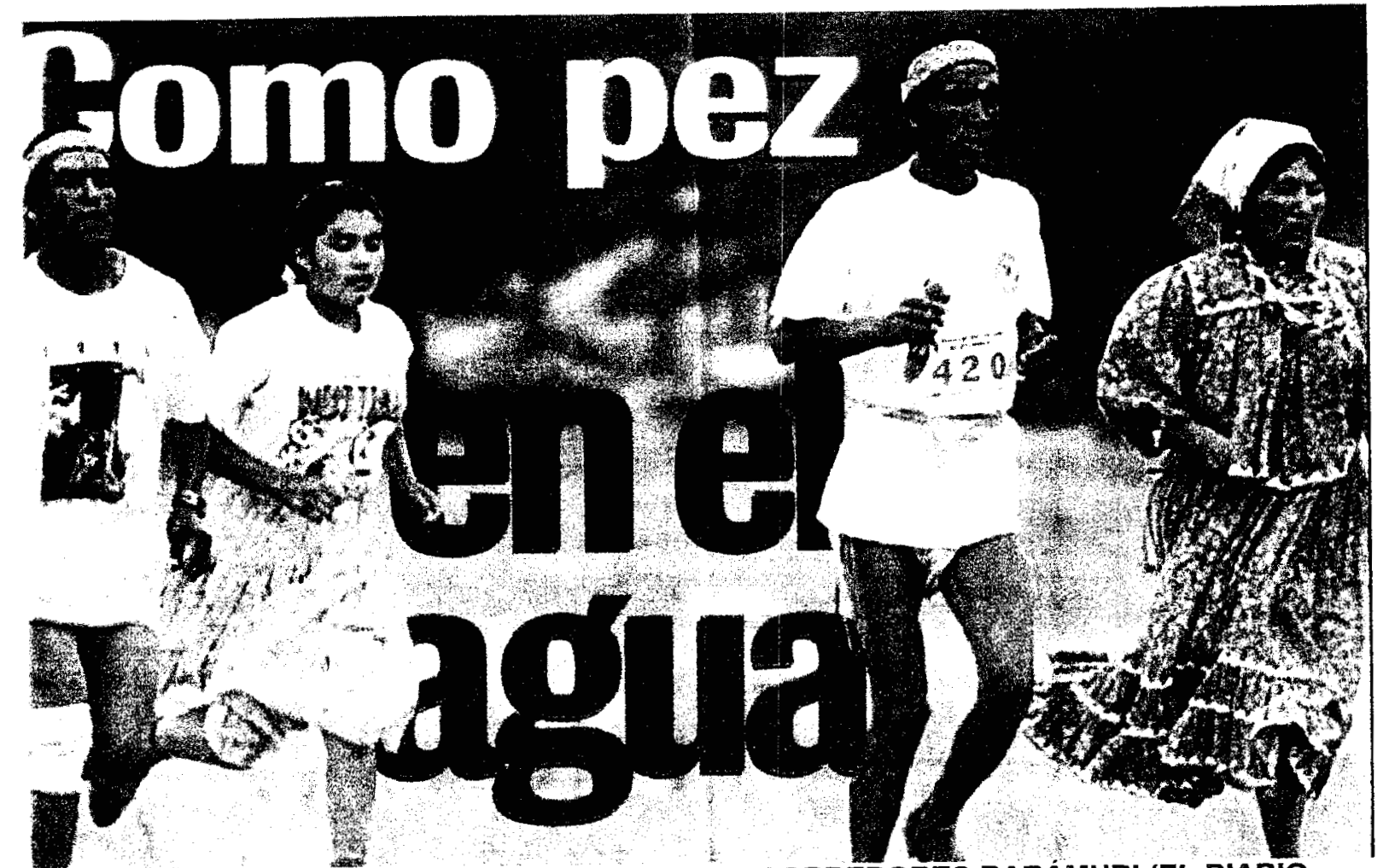

FIGURA 9.- LOS MODERNOS Y COMPETITIVOS CORREDORES RARAMURI (EL DIARIO DE CHIHUAHUA, 29 DE JULIO DE 1998)

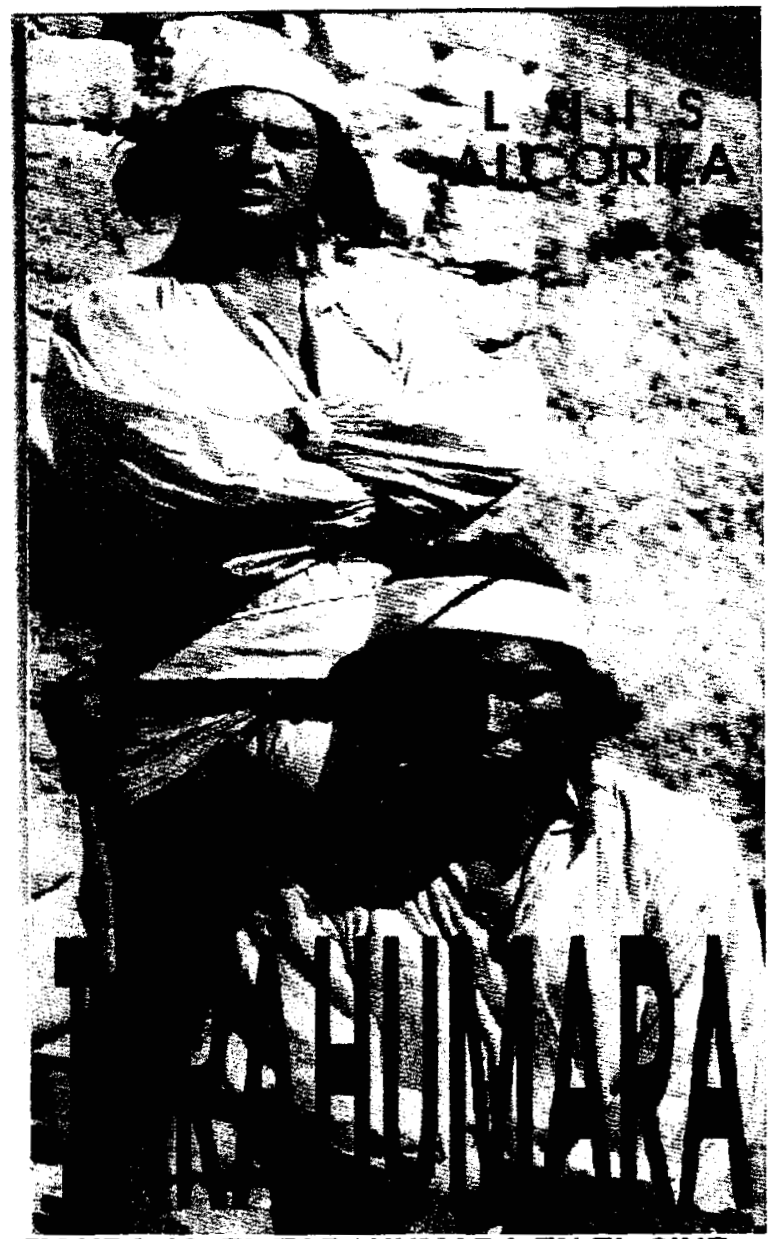

FIGURA 10. EL TARAHUMARA EN EL CINE ("TARAHUMARA" DE LUIS ALCORIZA, 1964)

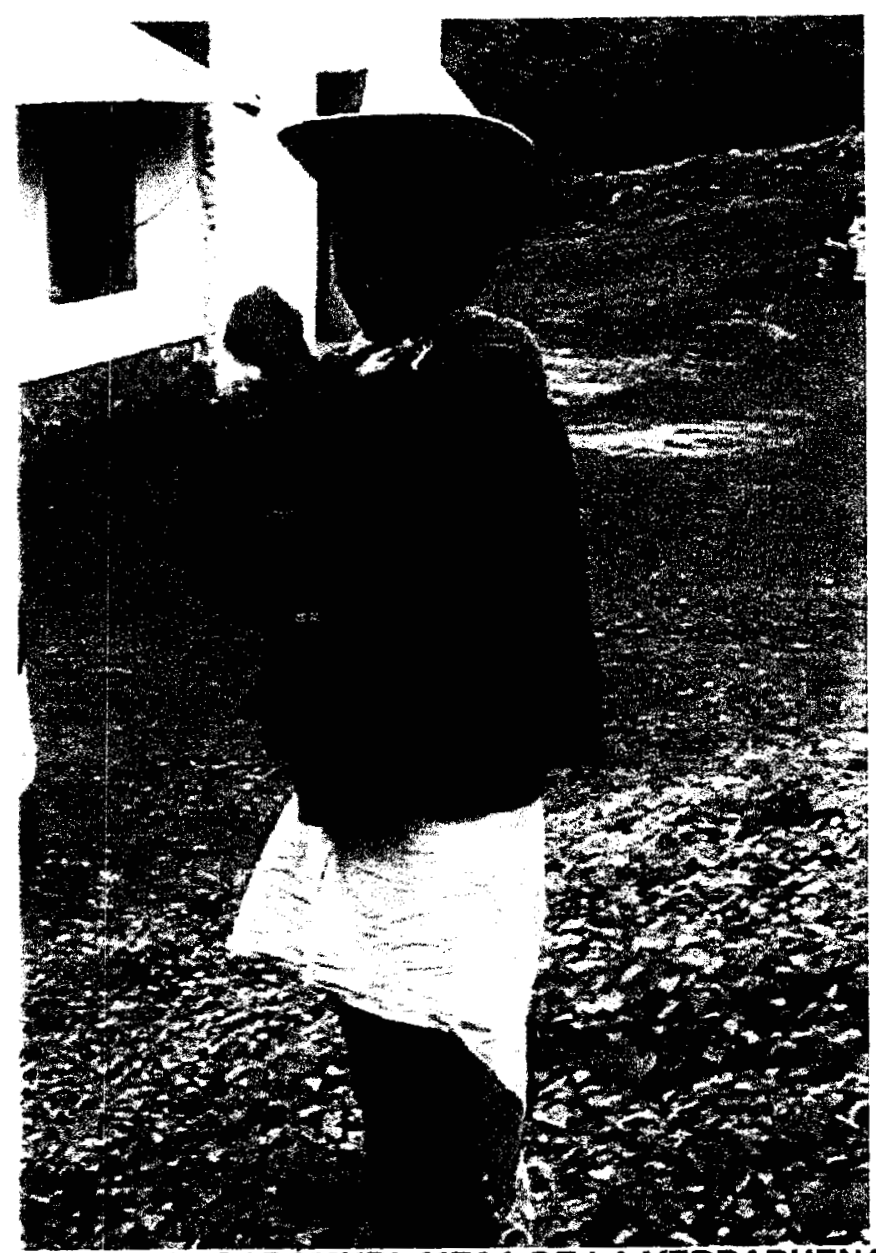

FIGURA 11.- RARAMURI. MESA DE LÁ YERBABUENA (BATOPILAS). (FOTO DEL AUTOR, JULIO, 1999) 
en el corazón del territorio de la Alta Tarahumara, Bennett y Zingg trataron de observar y analizar los elementos de la cultura rarámuri desde la perspectiva de la aculturación y el cambio social:

Ha sido nuestro propósito describir la cultura tarahumara tal y como existe en la actualidad. En lo posible, hemos procurado establecer la diferencia entre lo antiguo y lo nuevo, sin un indebido énfasis en lo antiguo. Hemos señalado los cambios de cultura que han tenido lugar en los últimos años y que todavia son evidentes. Hemos mostrado cierto interés por la cultura primitiva en cuanto funciona para que los tarahumaras se ajusten materialmente a su medio ambiente natural y socialmente, a sus semejantes (Bennett y Zingg, 1986: 44).

Entre los méritos del trabajo de estos dos antropólogos vale la pena destacar su opción por una metodologia comparativa que les permitiria captar las variantes de la cultura tarahumara. Para ello, toman como referentes de sus interpretaciones los datos etnográficos recogidos en cuatro comunidades-áreas rarámuri, estratégicamente seleccionadas: Samachique-Umirá, pueblos ambos sujetos a la acción misionera, enclavados en la alta Tarahumara e integrados estrechamente a través de la migración estacionaria de su población; Quirare, comunidad gentil localizada en el filo de la barranca de Batopilas; Guadalupe, en el fondo de la barranca de Urique y centro de notoria influencia mestiza y Norogachi, en la vertiente oriental del territorio rarámuri.

Además de esta opción metodológica, Bennett y Zingg parecen estar claramente influenciados por las tesis difusionistas y culturalistas que predominaban entonces en la antropología norteamericana ${ }^{20}$. A esta influencia habría quizás que atribuir su

\footnotetext{
${ }^{20}$ Las vicisitudes que llevaron a estos dos estudiantes de antropologia a realizar juntos una expedición y trabajo de campo en la Tarahumara son dificiles de conocer. Se trata en realidad de un arqueólogo (Bennett) y un etnólogo (Zingg) cuyo reconocimiento en la antropologia norteamericana nunca ha sido muy significativo, pero su peso en la etnografia de la Sierra Madre están fuera de toda duda. Además de su estudio en la Tarahumara, Zingg es ampliamente reconocido por sus trabajos sobre los huicholes y Bennett, por sus aportaciones a la arqueotogia andina.

Aún sin tener evidencias, nos atreveriamos a pensar que prevalece en este estudio sobre los tarahumaras un enfoque cargado de influencias boasianas y de Redfield en el que cobra especial relevancia el análisis de los "rasgos culturales", su difusión y transformación a partir del proceso de contacto y cambio cultural. Como dato digno de tomarse en cuenta hay que señalar que Zingg fue alumno de Sapir y Redfietd, a quienes los autores agradecen al inicio de su obra el apoyo y la orientación académica recibida (Bennett y Zingg, 1996: 43). Para la biografia académica de Zingg son sumamente interesantes dos articulos de Campbell y Silva (1996 y 1998). 
marcado interés por analizar los fenómenos de aculturación y cambio social entre los tarahumaras. Retomando las conclusiones que derivan sobre los estudios de arqueologia en el área uto-azteca del noroeste de México, los dos antropólogos norteamericanos proponen la existencia de tres grandes fases en la historia cultural rarámuri: un primer periodo denominado cestero con predominio de rasgos de una cultura cazadora y nómada, una segunda etapa cavernícola con un mayor grado de sedentarización, desarrollo agricola y alfarero y un tercer momento que correspondería a la etapa contemporánea. ${ }^{21}$

Pues bien, analizando pormenorizadamente los rasgos de la cultura tarahumara que Bennett y Zingg conocieron en 1930, éstos concluyen que dichos rasgos pueden agruparse en cinco bloques: en el primero estarian aquellos antiguos ya desaparecidos como resultado de la influencia de la acción misionera y la cultura nacional; en el segundo se ubicarian aquellos otros rasgos antiguos (provenientes de los periodos cestero y cavernícola) aún persistentes; en el tercero, los rasgos antiguos deteriorados; en el cuarto, los rasgos derivados de las adopciones de elementos externos y en el quinto, los elementos culturales combinados o sincréticos donde se mezclan elementos autóctonos y foráneos.

El cuadro que presentamos a continuación muestra con cierto detalle las apreciaciones de Bennett y Zingg sobre los cambios operados en los elementos constitutivos de la cultura tarahumara. Como se puede observar, los antiguos rasgos persistentes son cuantitativa y cualitativamente predominantes sobre aquellos otros que han desaparecido, se han deteriorado, han sido asimilados de fuera o se han

${ }^{21}$ El periodo cestero se caracteriza por una precaria agricultura maicera, la ausencia de alfareria, los entierros en posición encorvada, las mantas de piel de conejo y pluma de pavo, el tejido de cuerdas y pita, la carencia de viviendas y el uso de cuevas como abrigos naturales.

En el periodo cavernicola se desarrolló la agricultura del maiz, del frijol y de la calabaza; desaparece en cierta medida la caza y uso de pieles; se constuyen viviendas de piedra y graneros en forma de torres cerca de los cuales se localizan los enterramientos. Además, también cobra auge la alfareria, el tejido de tela, la cesteria trenzada y los utensilios de cascara de calabaza (Bennett y Zingg, 1986: 537-541). 
combinado con otros externos. Los rasgos culturales antiguos que han pervivido se refieren al núcleo de la cultura material, a las concepciones y prácticas sobre la salud y la enfermedad, la estructura y función de las fiestas tradicionales o "nativas", los ceremoniales de vida y muerte, la figura de los shamanes y hechiceros, los términos y estructuras del parentesco, las nociones y prácticas relativas a la propiedad y la herencia, los juegos, los deportes y la valoración sobre el consumo festivo del tesgüino y del peyote.

Entre los muchos aspectos contenidos en el cuadro que seria imposible reseñar aqui con detalle, hay dos que merecen un breve comentario puesto que ejemplifican la lógica que ha seguido la cultura rarámuri en términos de la persistencia y el préstamo cultural. Estos dos aspectos son el patrón de la cultura material, por un lado, y las modificaciones en los contenidos y ritual de las fiestas, por otro.

La introducción de los animales domésticos (vacas, bueyes, ovejas, cabras, caballos, burros, mulas y cerdos) y de las herramientas de acero (hacha, machete, cuchillo, gubia y barra) trastocaron desde la época de la colonia la tecnologia, la agricultura $y$, en general, las formas de reproducción de la sociedad rarámuri, constituyendo quizás todo esto el núcleo más significativo de los préstamos culturales.

Por el contrario, el contenido y ritual de las fiestas y celebraciones siguió una evolución muy distinta: las fiestas tradicionales o "nativas" ni desaparecieron ni se asimilaron ni se mezclaron con las fiestas "de la iglesia". Las primeras se asocian a las figuras de los shamanes (owiruame), los bailes del rutuguri y yúmari, el sacrificio de animales, la curación de tierras,animales y alimentos, el empleo de los números 3 y 4 con significados masculino y femenino respectivamente, la consagración hacia los cuatro puntos cardinales, el uso del fuego y el humo con fines purificatorios y la relación de estos rituales con el nacimiento y la muerte. 


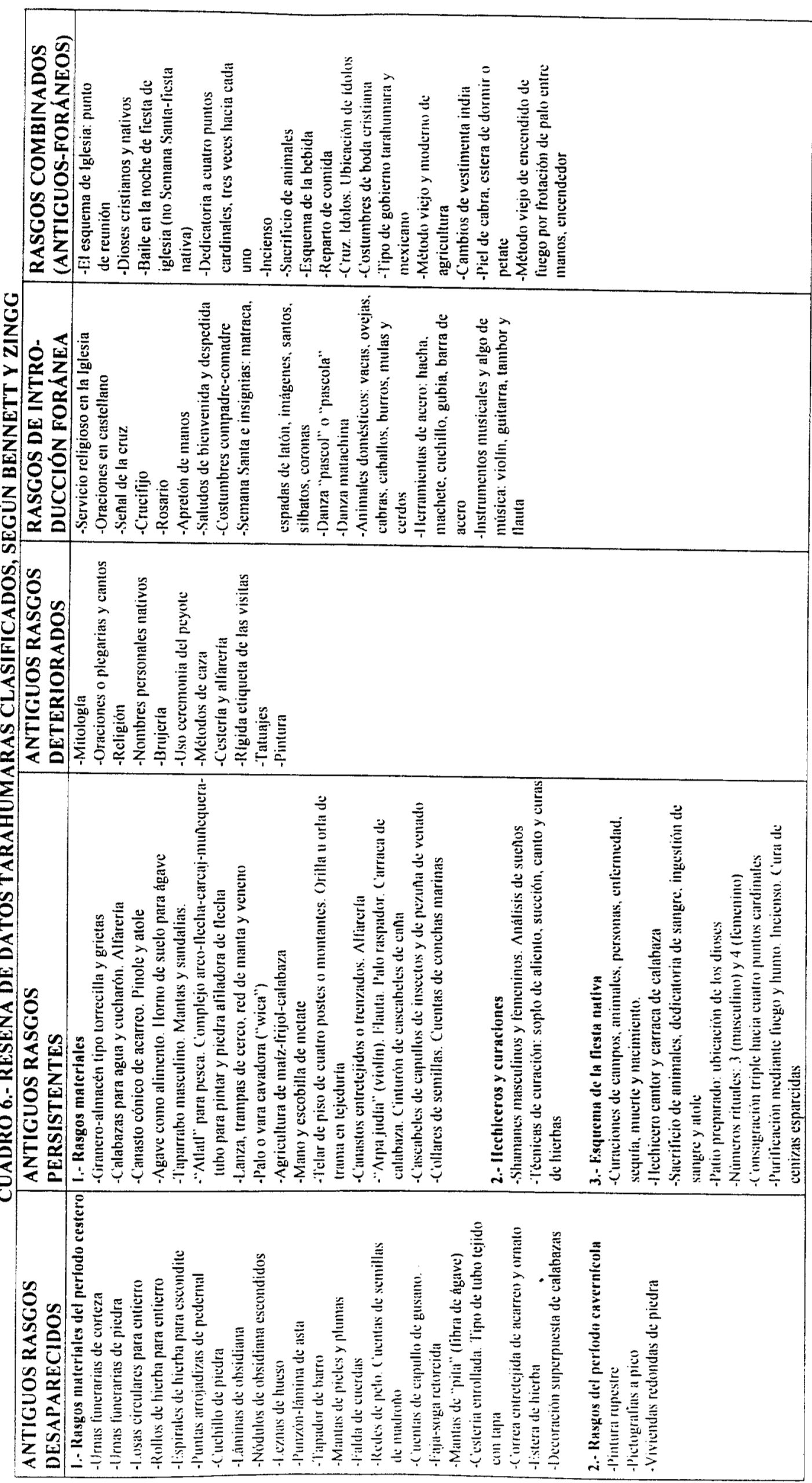




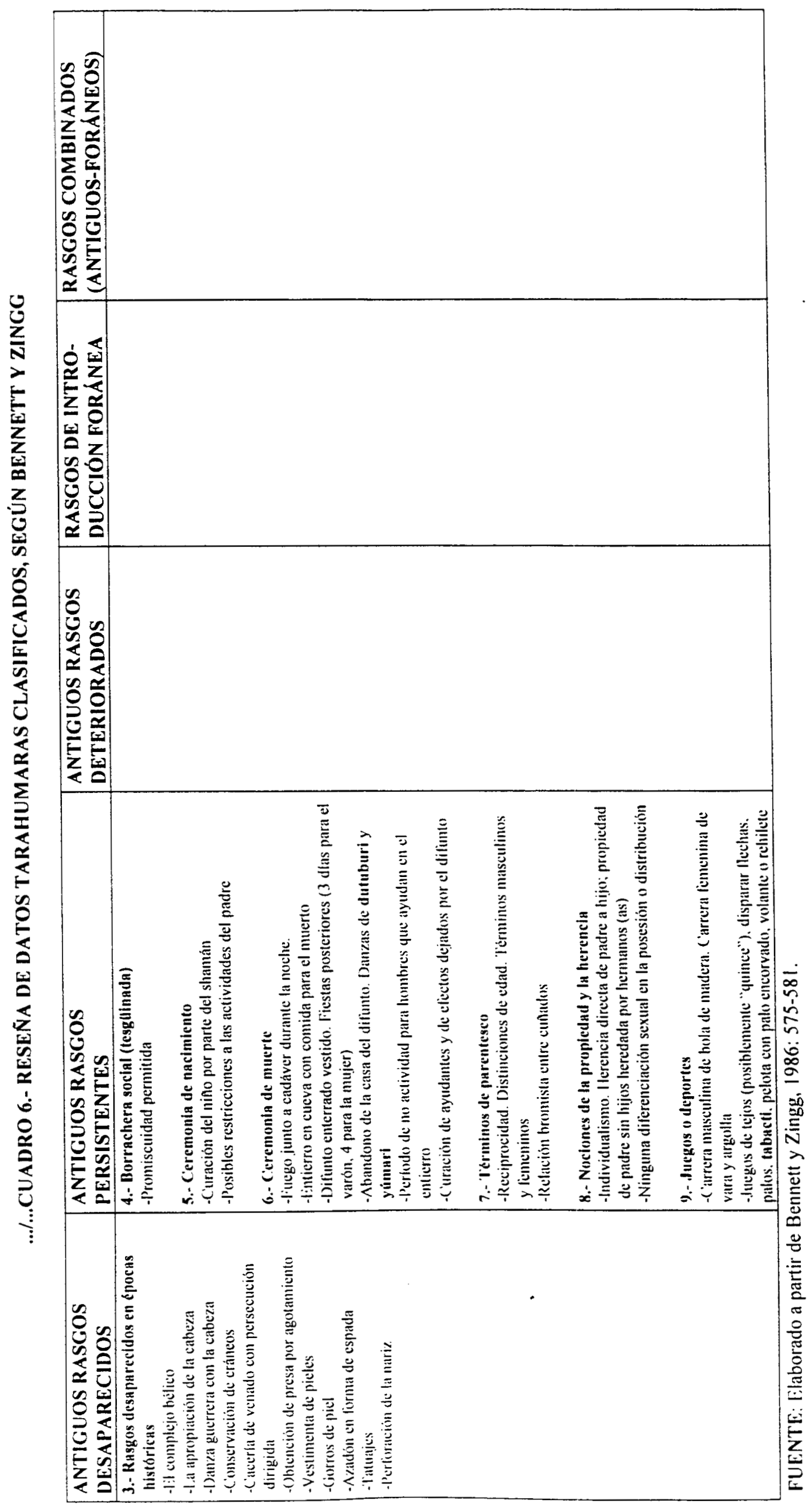


Las fiestas "de la iglesia", en cambio, tienen como origen la acción misionera y se desarrollan en torno al ciclo festivo católico (Semana Santa, Virgen de Guadalupe, Navidad, Reyes y Santo patrón local). Las danzas de matachines y pascolas 22 y el uso del violín y la guitarra y, en menor medida, la flauta y el tambor, identifican el ritual de estas fiestas en las que puede hacerse presente algún sacerdote católico.

Haciendo un balance entre to propio y to ajeno, Bennett y Zingg concluian reconociendo que la cultura tarahumara habia mostrado a lo largo de la historia una notoria capacidad de resistencia para mantener sus rasgos tradicionales e incluso para reprocesar y modificar otros rasgos apropiados a través de la influencia externa:

Si tenemos en cuenta los tres siglos transcurridos de contacto casi permanente, se puede afirmar que, tal y como era de esperar, los tarahumaras han conservado tenazmente su antigua cultura; más bien lo asombroso es que no se hayan mexicanizado más [...].

Como objeto de estudio, los tarahumaras han demostrado ser un valioso grupo, debido a que todavia funciona, entre ellos, en la forma de una gran entidad tribal, una sencilla cultura india americana. Superpuesta a esta cultura nativa, hay una delgada capa superficial de elementos españoles $e$ indios, que es posible separar, con bastante seguridad o certidumbre, de los elementos prehispánicos (Bennett y Zingg, 1986: 568 y 575).

Al inicio de los años treinta, Bennett y Zingg construian pues una visión, sólidamente apuntalada en una rigurosa etnografía, sobre la cultura tarahumara en la que destacaban los rasgos de primitivismo y tribalismo. Los tarahumaras seguian siendo casi los mismos que Lumholtz había descubierto y casi idénticos a aquellos que conocieron los misioneros jesuitas de la época colonial. Aferrado a sus tradiciones y estructuras sociales, este pueblo indio se mantenia fiel a su pasado, a sus

22 Bennett y Zingg describen el matachin como un "baile de movimientos, giros y cambios rápidos ejecutados por dos hileras de danzarines bajo la dirección de un jefe o monarco y la supervisión de los chapeones'" (Bennett y Zingg, 1986: 462). Los matachines lucen trajes vistosos con capas de color rojo, calcetines, zapatos, una corona roja con espejuetos y un pañuelo en la cabeza. El origen de este baile son las danzas de "moros y cristianos", procedentes de España e introducidas por los misioneros en la época colonial. El pascol, también de origen hispánico, es "un zapateado muy rápido" (ibid.: 483). En ambos casos, los autores insisten en que se trata de bailes ajenos a la cultura de los tarahumaras. 
cosmovisiones y a sus prácticas. El progreso, vestido de adoctrinamiento católico o de valores patrios de mexicanidad, sólo había tenido un efecto fugaz y superficial entre este grupo indio y pocas evidencias apuntaban entonces hacia una ruptura de este predominio de lo heredado sobre lo asimilado, de lo propio sobre lo ajeno.

\section{El indio o la autenticidad del hombre natural}

Si la constatación del primitivismo del indio serrano chihuahuense llega a provocar entre etnógrafos y médicos sorpresa y fascinación ¿qué decir de quienes se han acercado a la Tarahumara cargando sobre sus espaldas el desencanto de la civilización occidental y han tratado de escudriñar, en el alma indigena, la autenticidad y la pureza del hombre natural? Quizás de todos ellos nadie como el poeta y dramaturgo francés Antonin Artaud representa mejor la pasión de este hallazgo.

Miembro del movimiento surrealista (integrado, entre otros, por Aragon, Breton, Eluard, Péret y Unik) con el que sin embargo muestra desacuerdos teóricos y políticos, Artaud llega a México a principios de 1936, invitado a difundir entre la intelectualidad cardenista de la capital los conceptos del surrealismo francés y sus visiones sobre lo que denominó el "teatro de la crueldad". ${ }^{23}$ Pero el verdadero interés de Artaud estriba en lograr un acercamiento comprensivo al México prehispánico que le permita palpar de cerca la profundidad y la pureza de culturas donde el poder simbólico de la mitologia permanece vivo y donde las fuerzas de la naturaleza permean el

\footnotetext{
${ }^{23}$ Artaud contrapone al modelo estereotipado del teatro europeo la idea de un "teatro de la crueldad", entendido éste como un medio para "modificar" el mundo. Para ello propone encontrar en las viejas cosmogonías primitivas una visión pura de la cultura antes de que ésta fuera transgredida por la civilización occidental. Hacia 1933. Artaud esboza los borradores de una obra teatral titulada La Conquista de México. de la que habrá de nacer su ansiedad por conocer este pais y, en especial, su pasado indigena. Tras largas peripecias, Artaud logra una cobertura gubemamental (del agregado cultural en Francia, Jaime Torres Bodet, del Departamento de Acción social de la UNAM -dirigido por Salvador Azuela, del Departamento de Bellas Artes, de la Alianza y de la embajada francesas) y el apoyo de varias revistas y periódicos franceses y mexicanos para dictar y publicar varias conferéncias en la ciudad de México. (Estos y los siguientes comentarios sobre la presencia de Artaud en México proceden del estudio introductorio elaborado por Luis Mario Schneider y publicado como Prölogo de un libro -Artaud, 1984-que recoge los trabajos de Artaud sobre México).
} 
comportamiento humano.

Atormentado por esta obsesión, Artaud no logra sosegarse hasta que, al final de la estación de lluvias (agosto-septiembre) de 1936, viaja por ferrocarril a Chihuahua y se adentra en la Sierra Tarahumara. Como varios autores lo han destacado, los rarámuri el paisaje de su territorio, su imagen, su atuendo, su cosmogonía, sus ritos y su cotidianidad- representan para Artaud la mejor expresión viva de una cultura no contaminada por la civilización occidental:

Todo sucedia como si los Tarahumaras hubieran conservado -como si fuesen los únicos que hubieran conservado- una cultura encamada, una cultura en came, en sensibilidad, y no en concepto, una cultura con la cual los mitos no habian dejado de ser animados por las fuerzas subterráneas que los habian engendrado, en la cual el hombre volvia a encontrar al instante su yo profundo, en la cual la frecuencia sorda del espiritu dejaba de ser arbitrariamente modelada por una fuerza conceptual extraña al ser, en la cual la comunicación, para establecerse, no tenia ya necesidad de palabras, ni de palabras-signos, ni siquiera de palabras-valores. A esta cultura, la única capaz de integrar la realidad de Artaud, éste la habia localizado a priori en el pais de los tarahumaras. $^{24}$

Haciéndose acompañar de un guía y traductor, Artaud cabalga, durante varios dias, por la vertiente de los valles orientales de la Sierra a lo largo del camino que recorre desde la vieja misión jesuítica de Sisoguichi hasta Norogachi -también pueblo de implantación religiosa-, atravesando por Cusárare -poblado donde Lumholtz habia atestiguado casi cincuenta años antes los procedimientos de un tribunal de justicia tarahumara- y Narárachi -"el lugar donde lloran", comunidad renombrada entre los rarámuri por sus curanderos y "raspadores de peyote".

El paisaje de este agreste territorio desconcierta al viajero francés quien descubre en todos los trazos de la naturaleza y en las formas caprichosas de las rocas -imágenes petrificadas de gigantes salidos de la teogonia rarámuri- toda una simbología viva, consciente y creada que hace explícitos los arquetipos tarahumaras

\footnotetext{
${ }^{24}$ Comentario de Georges Charbonier en su Essai sur Antonin Artaud, citado por Sctneider, 1984: 10.
} 
de la vida. Ante su mirada penetrante y surrealista, la Sierra Tarahumara se convierte en "la montaña de los signos". ${ }^{25}$

Artaud descubre así que los tarahumaras conforman una "raza principio", ajena a la nefasta influencia de la civilización occidental y portadora "de las fuerzas que intervienen en el movimiento filosófico de la naturaleza". Los tarahumaras "tienen la obsesión de la filosofia", expresan en sus simbolos el carácter dual -macho-hembrade la deidad y sus figuras, como la cruz o el círculo presente en el baile o el maiz, remiten a los principios de la vida. ${ }^{26}$

La empatía de Artaud con los rarámuri va in crescendo. Primero logra presenciar el ritual de un sacrificio animal -probablemente un tónare- en Norogachi, que él asemeja al "rito de los reyes de la Atlántida" descrito por Platón en el "Critias" de sus Diálogos. Después, entra en contacto con la ceremonia del tutuguri, a través de la cual los tarahumaras piden a Dios les bendiga con la lluvia y las cosechas y agradecen la creación del mundo ${ }^{27}$. Finalmente y quizás como premio a su empecinada insistencia, Artaud es admitido por los rarámuri para participar en el ritual del consumo y de la danza del peyote -jikuli o jíkuri en voz de los rarámuri, ciguri en las palabras del viajero francés.

La experiencia del peyote y el intercambio posterior de ideas con el "sacerdote del ciguri" -presumiblemente el sipáame o raspador del peyote- dejarán una huella

\footnotetext{
${ }^{25}$ Titulo de uno de los textos de Artaud redactado en el transcurso de este recorrido.

${ }^{26}$ Las citas provienen de Una raza principio, texto incluido en la antologia citada, págs. 285-289. En un interesante análisis. Augusto Urteaga ha planteado cómo la narrativa etnográfica de Artaud muestra y demuestra una estrecha empatia y una experiencia interactuante entre el viajero francés y los rarámuri con quienes convivió. No pocos de los principales elementos de la cosmovisión india aparecen asi relatados y expresados en un código de significaciones propio del poeta y dramaturgo surrealista. (Urteaga, 1997).

${ }^{27}$ Tónare designa la came cocida sin sal que se consume en el yúmari, fiesta o danza que incluye et sacrificio de un animal, un baile-canto (tutuguri) y la comida-bebida de carne y tesgüino. (Véase lo que señalamos más adelante en este mismo capitulo y Velasco, 187:132).
} 
indeleble en la mente de Artaud que lo acompañará hasta sus últimos dias de encierro, de electrochoques y "envenenamientos sistemáticos y diarios" en el hospital psiquiátrico de Rodez, en Francia. El ciguri y su ritual son el camino para encontrar el principio trascendente de la vida que Artaud identifica en ocasiones con el Infinito y con Dios -"el peyote devuelve el yo a sus origenes verdaderos"-, haciendo que el hombre encuentre su camino auténtico más allá del engaño a que nos someten los sentidos y el Mal:

Porque el Rito del ciguri es un Rito de creación y que explica cómo las cosas son en el vacio y éste en el Infinito, y cómo las cosas brotaron del Infinito a la Realidad y fueron hechas. El rito termina en el momento en que, bajo la orden de Dios, ellas han cobrado Ser en un cuerpo. ${ }^{28}$

A lo largo de la vivencia alucinante y tormentosa de Artaud en la "montaña" de los tarahumaras, hay un principio que guia todas sus reflexiones: lo más valioso de este pueblo indio, lo que lo hace singular y auténtico es su rechazo a la civilización occidental y sus beneficios "siniestros" (Artaud, 1984: 51). Ya desde su estancia en la ciudad de México, Artaud observa con desconfianza y desaprueba la actitud oficial del gobierno y la intelectualidad cardenistas que pretenden "elevar a los indios incultos hacia una noción occidental de la cultura" (ibid.), siendo que "el indio, ineducado, se muestra enfrente de nosotros, europeos, semejante a un civilizado en alto grado" (ibid, pág.23).

Más adelante, en los pueblos de la Sierra, Artaud se queja de que los mandatarios del gobierno sean "de sangre mestiza" y consideren "peligrosas las creencias de los antiguos mexicanos" (Artaud, 1984: 311) y lucha contra maestros indigenistas e influencias de la evangelización jesuítica que se convierten en un obstáculo para su acercamiento a los ritos indigenas y que no hacen sino negar la

\footnotetext{
${ }^{28}$ Esta y las referencias del párrafo anterior provienen de El rito del peyote entre los tarahumaras (Artaud, 1984: 304-327) texto que fue escrito en los años de intemamiento de Artaud en un hospital psiquiátrico, al final de su vida, en Francia.
} 
autenticidad de los rarámuri ${ }^{29}$.

Frente a tales tendencias indigenistas y modernizantes tan de moda en aquellos años de fervor nacionalista, Artaud, en uno de sus momentos de mayor lucidez, se atreve a definir asi a los rarámuri:

Al norte de México, a cuarenta y ocho horas de la ciudad de México, hay una raza de puros indios rojos, los tarahumaras. Allá viven cuarenta mil hombres, en un estado como antes del diluvio. Ellos son un desafio a este mundo donde uno no habla tanto de progreso, porque sin duda uno pierde la esperanza de progresar.

Esta raza, que debiera estar fisicamente decaida, resiste desde hace cuatrocientos años todo lo que ha venido a atacarla: la civilización, el mestizaje, la guerra, el inviemo, los animales, las tempestades y la selva. En el inviemo vive desnuda, en las montañas obstruidas de nieve, desafiando todas las teorias médicas.

El comunismo existe como un sentimiento de solidaridad espontáneo. Tan increible como parezca, los indios tarahumaras viven como si ya estuvieran muertos. No ven la realidad y sacan fuerzas mágicas del menosprecio que tienen por la civilización [...].

Asi es la vida de este extraño pueblo sobre el que jamás ninguna civilización tendrá influencia" ("La raza de los hombres perdidos" en Artaud, 1987: 301-303).

\footnotetext{
${ }^{29}$ El lenguaje metafórico y las referencias vagas de Artaud nos esconden a sus verdaderos interlocutores. Sabemos, sin embargo, que en el tiempo de su viaje a la Tarahumara (septiembre-octubre de 1936) se vivia en la Sierra una etapa de persecución religiosa que provocó, entre 1934 y 1939 , el cierte y la confiscación por parte del gobierno cardenista de las iglesias y escuelas de los jesuitas. Norogachi, el pueblo donde Artaud vive sus más intensas experiencias con los tarahumaras, era precisamente y junto con Sisoguichi, un importante centro misionero y educativo, en donde el gobierno instauró una de las primeras escuelas internados indigenas, bajo la dirección de Jaris, un lider tarahumara del que hablaremos más adelante. Nos atrevemos a pensar que es precisamente este personaje al que Artaud se refiere cuando habla del director de la escuela de Norogachi -donde se alberga quien, como representante "modernizante" del gobierno, no sóto parece desaprobar la participación de Artaud en el ritual del peyote sino, en general, el mantenimiento de las costumbres indigenas:

El ministro de Educación Pública de México, de quien el ministro de Francia me hizo obtener el permiso de circulación, hizo que me hospedara en los edificios de la escuela indigena de los tarahumaras. Por consiguiente, entré en relación con el director de esa escuela, quien, además, estaba a cargo del orden en toda la extensión del territorio tarahumara y bajo cuyo mando estaba un escuadrón de caballería. Sin que ninguna disposición hubiese sido tomada [...], yo sabia que era cuestión de impedir la próxima fiesta del peyote (Artaud, 1984: 311)
} 
Desafio al progreso y a la ciencia médica, menosprecio mágico por la civilización, comunismo espontáneo. Estos son los términos de Artaud para, de nueva cuenta, volver a reafirmar lo que hemos denominado la "mirada primitivista" sobre la identidad de los indios de la sierra chihuahuense. Ante los ojos de nuestro viajero y espectador europeo ellos aparecen como únicos, como sobrevivientes de los desastres de la civilización, como genuinos actores en el "teatro de la crueldad" del mundo. Su primitivismo rebasa el plano de lo meramente etnográico; expresa el estado de pureza del hombre en el nivel y la época donde cultura y naturaleza se confundian.

Sobra decir que este descubrimiento del primitivismo indigena sólo causa en Artaud gozo, respeto y admiración. Pero ésta difiere no sólo en grado sino en cualidad de aquella otra que asumieran los viajeros etnógrafos del Siglo XIX y los médicos y naturalistas estudiosos de la Tarahumara. Para Artaud, a diferencia de Lumholtz, el primitivismo indio no es el preámbulo del progreso sino la utopia a la que nos debiera llevar la civilización, la auténtica cultura, el mejor y más deseable estado del hombre. Primitivismo indigena es sinónimo de autenticidad, originalidad y sabiduria.

\section{El atraso del indio: ¿olvido o impotencia de la civilización?}

Si la constatación del primitivismo del indígena serrano de Chihuahua despierta en la mente de etnólogos evolucionistas, médicos naturalistas y poetas surrealistas una profunda admiración y éxtasis ante el inesperado encuentro con lo más profundo y auténtico de la naturaleza humana, no es menos cierto también, que el mismo fenómeno es motivo para otros observadores y viajeros de la más profunda amargura y el más hondo desencanto: el atraso del tarahumara aparece en esta otra óptica no como un mérito, sino como un lastre, no como un signo de autenticidad sino como un reconocimiento de la impotencia de las fuerzas civilizatorias y progresistas para imponerse sobre el atavismo indigena. En contraste con la visión de los etnógrafos del final de los años veinte (Basauri, Bennett y Zingg), esta otra perspectiva insiste en achacar el atraso del indio no a la capacidad de resistencia cultural de éste, sino al olvido 
y abandono del resto de la sociedad nacional para con los grupos étnicos, lo que equivale a plantear una fuerte critica a las instituciones y programas indigenistas.

Una perspectiva de tal naturaleza ha estado presente en diferentes momentos y entre variados autores de la antropologia de la Tarahumara, pero es quizás el pensamiento de Fernando Jordán el que más fielmente refleja este pesimismo ante el indio.

Formado en la Escuela Nacional de Antropologia e Historia, Jordán llega a la Tarahumara en noviembre de 1948 convertido en periodista. Durante 40 dias, en medio de penalidades y de un crudo invierno, recorre la región de Sisoguichi, Panalachi, Norogachi el mismo camino de Artaud- y Batopilas. A lo largo de la ruta, elabora una serie de reportajes intitulada "Invierno en la Tarahumara" publicada en siete entregas por la revista Mañana. ${ }^{30}$ Seis años más tarde, Jordán regresa a Chihuahua con el propósito de investigar y escribir un libro sobre la historia de este estado. Después de seis meses de viajar y estudiar y otros tantos de encierro para redactar en el poblado de San Juanito -uno de los núcleos madereros más encumbrados y fríos de la Tarahumara-, el antropólogo y periodista saca a la luz su libro Crónica de un país bárbaro, su famoso ensayo interpretativo de la historia de Chihuahua que varias generaciones locales han

\footnotetext{
${ }^{30}$ Desde su época estudiantil Jordán mostró su preferencia y aptitudes para el periodismo, campo que años más tarde considerará el más apropiado para difundir el conocimiento antropológico. Tras elaborar algunos reportajes para La Prensa entre 1946 y 1948, ingresa a trabajar en el semanario Mañana bajo las órdenes de su director Regino Hernández Llergo. Una curiosa combinación entre su formación de etnólogo y su pasión por el periodismo hace de Fernando Jordán un viajero y cronista capaz de atraer la atención de sus lectores en sus interesantes reportajes en las páginas de Mañana sobre lugares exóticos y perdidos de Chiapas, Baja California, Puebla y Yucatán. Pero, con los años. Chihuahua, el "estado fuerte" será su predilecto.

La serie Inviemo en la Tarahumara fue publicada en Mañana entre diciembre de 1948 y enero de 1949 con los siguientes titulos: ". - Ante los mayores abismos del mundo", 18 de diciembre de 1948; "II.Ejemplares vivos de los hombres de la prehistoria", 25 de diciembre de 1948; "IIl.- En el mundo irreal de la Tarahumara", 1 de enero de 1949; "IV.- Una estancia con los misioneros", 8 de enero de 1949; "V.- La Guadalupana en la Tarahumara", 15 de enero de 1949; "VI.- Cómo trabajan los gambusinos en la Sierra de Chihuahua", 22 de enero de 1949 y "VII.-Leñadores y aserraderos en la Sierra de Chihuahua". 29 de enero de 1949.
} 
leido con pasión. ${ }^{31}$

Desde sus primeros pasos por la Sierra, Jordán percibe, desconcertado e incrédulo, el atraso en que viven los indios:

En la Tarahumara el significado cultural del siglo $X X$ deja de tener sentido. Un viaje a esta región transporta al explorador a la Edad de Piedra: lo hace retroceder mil años en la historia de la civilización y le permite encontrarse de pronto ante el hombre de las cavemas de aquellas épocas preténitas: el tarahumara de hoy, personaje principal en el grandioso escenario de la Sierra Madre de Chihuahua.

De los 40,000 aborigenes que hacen la raza tarahumara, todavia hoy un diez por ciento -cálculo conservador- habita en cavemas. El resto, exceptuando los pocos que han llegado a compartir las formas culturales de los blancos o mestizos, viven en cabañas primitivas tan sencillas en su construcción, que a menudo resultan tanto o más inadecuadas para habitación que las mismas cuevas.

Por esto, México, el mismo México de la industrialización, es el único país que conserva aún ejemplares vivos de los hombres de la prehistoria y cuenta entre sus ciudadanos - ¿o no lo son?- a los últimos cavemicolas del mundo.

Cuatro siglos de influencia cultural europea, 140 años de gobiemo autónomo, 50 años de Revolución y 10 de politica indigenista no han logrado hacer cambiar la tradición del tarahumara $y$, ni por asomo han conseguido mejorar su vida miserable ni propiciar su incorporación a nuestra civilización. ${ }^{32}$

Constatar la pervivencia de una cultura de cavernicolas prehistóricos desencadena en Jordán una mezcla de confusión, compasión y tristeza porque si bien es cierto que algunos elementos de esta cultura, como el sistema de impartición de justicia, denotan sabiduria, otros muchos, en cambio, son en realidad irracionales y destructivos. El tesgüino o batari es, según Jordán, uno de ellos: cuando el tarahumara lo consume se llega a convertir en un violador y adúltero, en un criminal peligroso para los forasteros e incluso

\footnotetext{
${ }^{31}$ Además de las referencias que se encuentran en este texto a la historia y situación de la Sierra Tarahumara (en especial en el capitulo respectivo del Libro Cuarto), Jordán escribió algunos otros articulos periodisticos sobre Chihuahua. Entre ellos nos interesa destacar "¿Serán los indios el problema? Es posible que los indigenistas sean un mayor problema", aparecido en la revista Siempre en julio de 1954.

32 "Ejemplares vivos de los hombres de la prehistoria", en Mañana, México, 25 de diciembre de 1948.
} 

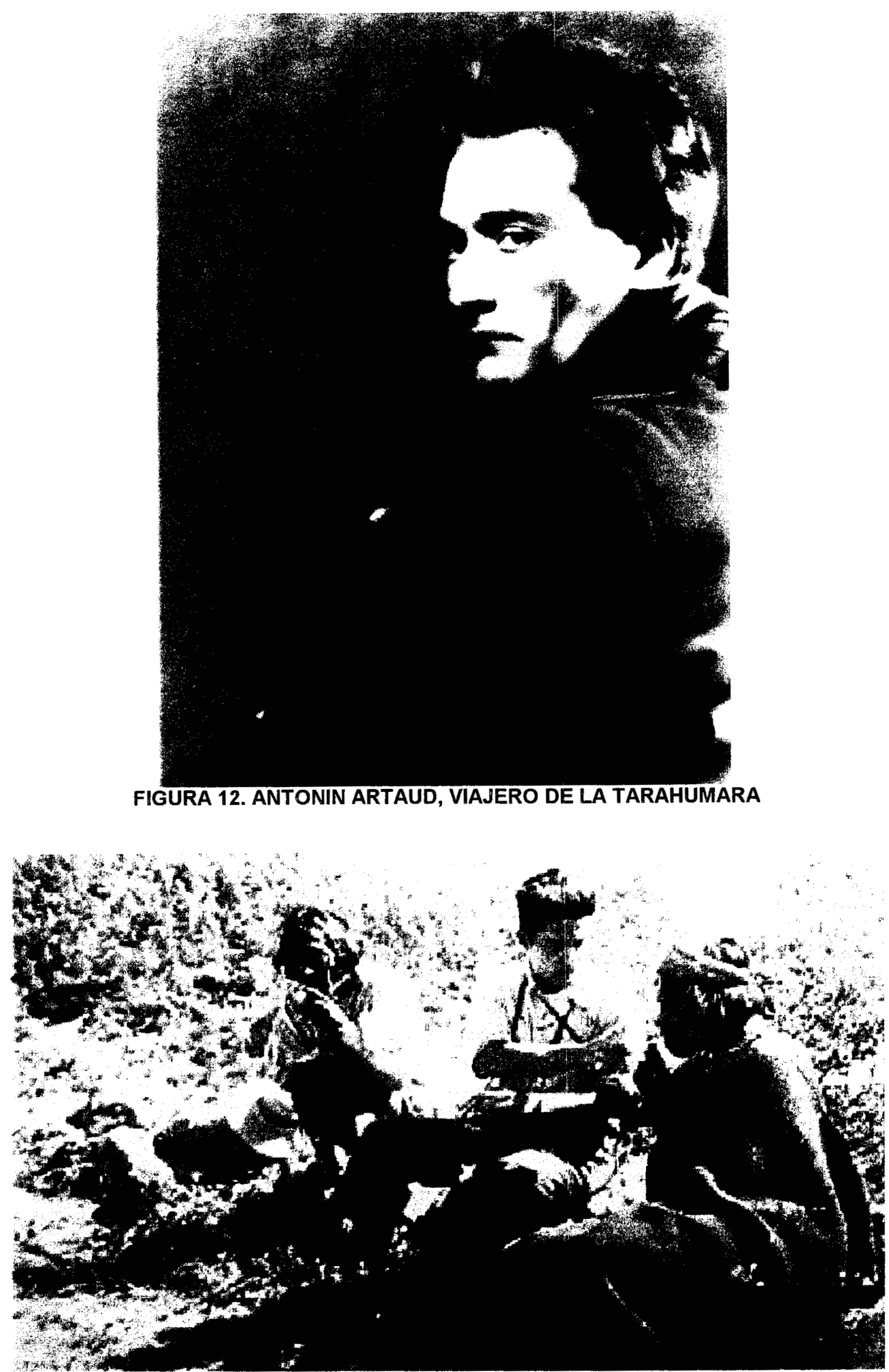

FIGURA 13.- FERNANDO JORDAN EN LA ALTA TARAHUMARA EN 1954

(FOTO DEL DR. AFRIAN QUIRÓS, TOMADA DE GÁLVEZ, 1993: 24) 


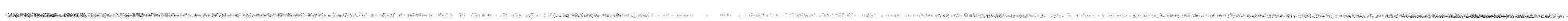


deja de ser el indio ceremonioso, honesto y sereno, convirtiéndose en el ser primitivo, en el salvaje, en el representante del último pueblo de las cavemas que exista en el mundo (lbid.: 42).

El primitivismo cultural indigena, sinónimo de oscurantismo religioso y de atraso civilizatorio ha dejado de tener sentido en la medida en que convive al lado del progreso y de la modernidad. La Sierra, observará Jordán en 1954, es contrastante hasta lo inaudito y lo absurdo:

Hay equipo mecánico modemo en las minas y [...] camiones de 10 a 12 toneladas transitando por todas partes mientras los indios corren descalzos e incansables a campo traviesa. Suena ruido de industrialización en los aserraderos y oprime una atmósfera de primitivismo en el 'tutuguri' de los tarahumaras. Cruzan el cielo los aviones [...] mientras los amieros se pasan 12 horas para llegar tan solo al fondo de un barranco (Jordán, 1954: 29).

Desde esta óptica, no tiene sentido alguno no sólo el arcaicismo y atraso de la cultura tarahumara sino tampoco cualquier modalidad de sincretismo que pretenda vaciar superficialmente contenidos culturales occidentales en moldes indios. Tal parece ser la conclusión a la que Jordán llega el 12 de diciembre de 1948 cuando observa y registra, como etnólogo y periodista, los rituales de la fiesta de la Virgen de Guadalupe entre los rarámuri de Panalachi.

Aterido de frío y con la humedad en los huesos, Jordán sigue paso a paso el ceremonial en el viejo templo, la procesión con la Virgen y las danzas de matachines, chaperones, violinistas, fiesteros y beatas. Pero ni el baile, ni el canto, ni los gritos, ni la procesión... nada parece tener sentido para él. Jordán no logra encontrarle el gusto a la excepcional comida del tónare que califica de "sebo insípido", ni a la bebida del tesgüino, ni entender el griterío de los indios al que equipara con el aullido de los lobos y acaba confesando sentirse entre salvajes con quien sólo puede entenderse por señas. Al día siguiente, mientras emprende camino de regreso a Sisoguichi, cavila:

La tristeza de Panalachi estalla en neurastenia con tanto ritmo corto y repetido y tanto aullido. [...] Cuatro horas a caballo por la senda helada bajo una lluvia 'calabobos' que no maduró en nieve. Me encuentro un venado a tiro y no saco el rifle porque estoy entumecido. Empapado hasta la camiseta, mudo y sombrio, me 
pregunto si me gustó o no la fiesta en Panalachi. Esa fiesta hibrida, extraña en su confusión de ideas, que no tiene la solemnidad de las católicas ni la angustia singular de las primitivas aborigenes; que le falta color y alegria; que trae nuevamente a colación la desorientación del indigena abofeteado por un impacto cultural que no ha sido encauzado y que ahora se materializa y manifiesta en una concepción de la vida que no entien.jen ni el indio ni el blanco.

Hibrida, confusa, desorientada, sin sentido: con tales calificativos define Jordán la torpe e inacabada apropiación cultural que los rarámuri hacen de un símbolo tan cargado de significados como el de la Virgen de Guadalupe. Y el ejemplo, por sus contenidos en términos de la cultura nacional, no es arbitrario sino que demuestra que la inevitable tarea civilizatoria y aculturativa a la que debe someterse al indigena no es fácil y necesita empeño y tiempo. Porque, en definitiva, el indio no puede tener futuro ni sentido sino como parte integrante del todo de la cultura nacional. Fuera de este marco, el indio se convierte en un problema para la nación y Jordán no vacilará en expresar con crueldad en qué consiste en realidad el verdadero "problema tarahumara":

El indio, atrincherado en la barrera de su idioma incomprensible y perdido por la movilidad a que le obliga el marco geográfico, ha considerado como úttimo refugio el aislamiento. Agoniza aqui, en la sierra de pinos y barrancos, con su cultura ancestral y su miseria crónica [...]

Desde un punto de vista absolutamente realista, la población indigena de Chihuahua obra sobre el Estado como un lastre. No es una población consumidora ni productora; son 50,000 fantasmas miserables que deambulan por la sierra, algunos pastoreando ovejas o cabras, otros sembrando trocitos de tierra de donde obtienen el puñado de maiz que convertido en pinole es su alimento preferido. Pero éstos y los que viven bajo el amparo oficial o particular, son mexicanos que no influyen en la estadistica de México y que solamente aparecen en el balance de la República en la columna del "debe". Forman parte del déficit.

Este es el verdadero significado del problema indigena, del problema tarahumara. El indio es un cero en et todo económico de la Nación, o algo peor, porque su rescate, su aculturación, su inclusión dentro de la vida nacional (en proyecto siempre) opera en costo sobre el Erario. El tarahumara cuesta dinero, ya sea arrancado al presupuesto o a los particulares mediante contribución voluntaria, sin que en nada contribuya al desarrollo económico o social de México. Parecerá cruel exponer asi el problema, pero asi es. Por, ello, más que por cualquier otra razón, se hace necesaria la resolución del problema (Jordán, 1989: 418 y 419).

33 "La Guadalupana en la Tarahumara", en Mañana. 15 de enero de 1949: 39. 
Tras reconocer y lamentar los indicios y las consecuencias del atraso cultural y la pobreza crónica de los indios de la Sierra de Chihuahua, Jordán pasa a proponer una explicación justificativa de la tarea incorporacionista. El progreso y la civilización -dirá el etnólogo y periodista- son ineludibles. En la Sierra, sus figuras sociales más representativas son las de los mestizos gambusinos y taladores del bosque que Jordán retrata en sus crónicas ${ }^{34}$. Ante esta evidencia, lo único que queda por hacer es luchar tratando de que el choque cultural para el indio sea lo menos violento posible. Nada representa mejor esta lucha que la tarea misionera de los jesuitas quienes difunden en sus misiones, escuelas e internados indígenas instrucción, progreso y técnica:

en esta Tarahumara no hay armonia sino brutal contraste. [...] Los indios, callados e indefensos, van retrocediendo a sus últimos refugios; mientras los blancos, en una conquista limpia de perversión avanzan paso a paso ocupando zonas antes virgenes, talando bosques [...] y marcando con la destrucción [...] el límite más avanzado de su conquista. Los jesuitas en su radio de acción, han tratado de armonizar (dando el humano ejemplo de llevarla bien hasta con los protestantes), defendiendo al indio y aplacando al blanco. Pero la lucha no siempre tiene éxito porque se lucha por la vida y por el derecho a vivirla, 10 cual a menudo no resulta compatible con intereses ajenos (Jordán, 1954: 29).

La afirmación de que son los jesuitas quienes con más empeño y éxito han emprendido la cruzada del progreso y de la civilización del indio parece derivar no tanto de las convicciones religiosas de Jordán, cuanto de su estrecha convivencia con estos misioneros durante una buena parte de su "Invierno en la Tarahumara" ${ }^{35}$. Y como contraparte de este reconocimiento, Jordán no dudará en calificar de populista y racista la tarea y la ideología que hacia 1952 estaban iniciando en la Tarahumara el Instituto Nacional Indigenista en particular, el profesor Francisco M. Plancarte, director del Centro Coordinador Indigenista creado por el INI en Guachochi en ese mismo año- y la Dirección de Asuntos Indigenas:

Se llega a pensar, viendo de cerca las actividades del INI en la Tarahumara, que

\footnotetext{
${ }^{34}$ En especial, en sus dos artículos ya citados "Cómo trabajan los gambusinos en la Sierra de Chihuahua" y "Leñadores y aserraderos en la Sierra de Chihuahua".

${ }^{35}$ Jordán confesará: "De los 40 días que permaneci en la Tarahumara, casi la mitad de ellos los vi transcumir entre los misioneros" ( véase "Una estancia entre los misioneros", pág. 41).
} 
el Coordinador nige su pensamiento por la divisa aquella que nació en los tiempos del indigenismo romántico: 'Hay que darle al indio la razón aunque no la tenga'. Aqui se le quiere defender asi, no por derecho, sino con base en un principio absurdo. Créase asi una especie de contra movimiento de tipo racista que ataca a todos los grupos humanos que no sean indigenas. El indio, en el campo de acción de estos indigenistas, es el ser superior, a los demás grupos puede llevárselos el diablo. El Coordinador ha llegado a afirmar, al reclamar cierta posesión de tierras, que todos los títulos son ilegales "puesto que éstas fueron antes tierras exclusivamente de los indios". A este paso, pronto tendrán que abandonar el país entero todos los mestizos y europeos puesto que México fue antiguamente tierra de indigenas. Es por actitudes y razonamientos de esta indole que se ha sembrado ef descontento y la discordia. Los rancheros mestizos o blancos, los madereros, los comerciantes, los mismos profesores rurales ven con desconfianza esta política, odian a los indigenistas y dentro de poco odiarán también a los indios. Esto último no sucedía antes. El indio, si bien expoliado y explotado como en todas las partes, lo era sólo en función de su ignorancia y de su particular idioma y no por perjuicios raciales que ahora crea el coordinador (Jordán, 1954: 29).

Como conclusión, podemos decir que Jordán ha constatado, como to hicieran antes los evolucionistas decimonónicos y los viajeros europeos de principios de siglo, que la Sierra Tarahumara es el territorio del primitivismo cultural, pero él asume en cambio una postura crítica muy distinta de la de aquellos otros: el primitivismo es sinónimo de atraso, miseria y abandono. Denota no la fortaleza, sino la agonía de una cultura indígena que, aunque no es culpable de su atraso, no tiene futuro alguno que no esté en el del progreso y la evolución de la nación. Más que condenado a desaparecer, el indio está llamado a conocer su liberación y ésta, por paradójico que parezca, sólo podrá provenir de su ineludible enemigo histórico, el mestizo y su civilización.

Aunque extremadamente critica ante el indigenismo, la postura de Jordán se ubica ya en la antesala de todas aquellas posiciones que han defendido la necesidad de la intervención y el cambio social en el mundo indigena de la Tarahumara, teorías de las que hablaremos más adelante.

Hasta aquí hemos venido hablando de una serie de visiones sobre los pueblos indios de la Sierra Tarahumara que agrupamos bajo lo que denominamos "una mirada 
primitivista". A pesar de sus diferencias en contenidos y matices, se trata sin embargo de interpretaciones que reconocen y, en su mayoria, valoran positivamente la capacidad de estos pueblos para resistir frente al cambio social que el entomo civilizatorio téase la nación, la educación, la evangelización misionera o la conversión religiosa- han tratado de imponerles a través de vías y modalidades más o menos coercitivas.

La resistencia al cambio se traduce en el mantenimiento y defensa de un corpus de concepciones del mundo, de la sociedad y de un conjunto de prácticas sociales típicamente propias, autóctonas. Primitivismo es entonces sinónimo de autenticidad y pureza. Sea por su empatía y equilibrio con la naturaleza y el entorno fisico o por su estrecha unidad y comunicación con el mundo sobrenatural, estas culturas indias primitivas no pueden despertar sino respeto, admiración y asombro, sentimientos todos ellos distantes de aquellos otros ligados a la "redención" o, en definitiva, el cambio social. Como contraparte, esta otra actitud conforma el origen y la orientación predominante de aquellas otras visiones que han caracterizado la antropología de la Tarahumara.

\section{LA MIRADA REFORMISTA}

Desde los tiempos en que el hombre occidental entró en contacto con los pueblos indios de la Sierra Tarahumara, ésta se convirtió en un territorio particularmente propicio para concebir y desarrollar reformas y cambios sociales. El indio pasó entonces a ser visto no como un sujeto residual del pasado sino como un agente en potencia de su propia transformación histórica.

Pero ¿de qué tipo de transformación? Es precisamente aqui donde radican las diferencias entre las dos perspectivas más importantes que conforman lo que hemos llamado "la mirada reformista" sobre la Sierra Tarahumara: una pone el énfasis en el cambio a partir de la transformación del indio en un ciudadano, en un miembro de la nación; la otra insiste y persigue la conversión religiosa, la cristianización del aborigen. La primera fue obra de los indigenistas y aunque tiene sus antecedentes históricos, cobró 
vigencia a partir de los años treinta. La segunda tuvo como sus principales promotores a los misioneros católicos y su vigencia, aunque con intervalos, se remonta a los tiempos de los primeros contactos en el siglo XVII.

Los discursos indigenista y misionero tienen mucho en común: ambos derivaron del principio de que los tarahumaras podian cambiar sus formas de pensar y vivir, su cultura. Convencidos de la posibilidad del cambio, indigenistas y misioneros pasaron del discurso a la acción, del raciocinio a la intervención social. Una y otra -la reflexión y la práxis- dieron lugar a una serie de nuevas interpretaciones sobre los pueblos indios que forman parte de lo que denominamos la "antropología de la Tarahumara".

Más allá de sus similitudes, estas dos versiones y experiencias históricas sobre el cambio social en la Tarahumara han mantenido entre si una cierta confrontación que se ha traducido, en ocasiones, en un conflicto de intereses. Esta aparente paradoja tiene su explicación: el cambio social que ambas postulan y promueven, aunque en ocasiones se sustenta en estrategias similares -como la educación, la aculturación, el desarrollo económico- persigue en realidad metas distintas. A lo largo de este estudio trataremos precisamente de mostrar y analizar el sentido de algunas de estas diferencias.

Una tercera alternativa que postula el cambio social entre los indios debe ser incluida en este apartado que engloba las "miradas reformistas". Me refiero a la visión de quienes sostienen que dicho cambio se ha venido dando desde hace mucho tiempo y que, en realidad, el primitivismo ha desaparecido. Pero estas transformaciones culturales no tienen $-\mathrm{y}$ aqui radica lo peculiar de este enfoque-rumbo ni sentido y parecen estar llevando a los indigenas a una especie de etnocidio cultural irreversible.

Al revisar a continuación cada una de estas tres ópticas que caracterizan la mirada reformista sobre la Tarahumara, trataremos de explicitar sus conexiones y divergencias. 


\section{El indio como problema: el discurso indigenista.}

Las tesis del indigenismo llegaron a la Sierra Tarahumara en la segunda mitad de los años treinta de la mano de un grupo de maestros formados en los principios de la escuela rural y del agrarismo revolucionario.

Hacia 1936, este grupo de maestros estuvo liderado por un joven profesor tlaxcalteca, Francisco Hernández y Hernández, quien habia ocupado un puesto de coordinación en las Misiones Culturales en la Sierra de Oaxaca y, tras haber viajado como representante del Sindicato de Maestros a la Unión Soviética donde conoció de cerca la forma como se estaba enfrentando el "problema de las nacionalidades", fue destinado por el Secretario de Educación Pública, Narciso Bassols, a dirigir una Normal Rural en el poblado chihuahuense de Flores Magón, al norte de la Sierra Tarahumara. Alli comenzó a juntar a una serie jóvenes normalistas y maestros con quienes organizó un taller de discusión sobre el problema indigena de México.

Entre ese grupo de jóvenes, al que se juntaron otros procedentes de la Normal de la ciudad de Chihuahua, pronto destacaron algunos como los profesores Francisco $\mathrm{M}$. Plancarte -maestro michoacano, por entonces profesor de la escuela Artículo 123 del Mineral de Maguarichi en el norte de la Tarahumara-, Emesto Cano Ruiz -que también habia trabajado en Maguarichi-, José Hernández Labastida -maestro "práctico" de origen

tlaxcalteca-, J. Patrocinio López -venido a Chihuahua de tierras zapotecas-, Francisco Javier Alvarez y alguno otro más.

A partir de este grupo de reflexión y hasta la legada del INI a la Tarahumara en 1952, los maestros comenzaron a diseñar y experimentar toda una propuesta indigenista que se habria de centrar en tres ámbitos: la reforma de las escuelas rurales, la lucha por la formación de los ejidos en los pueblos indios y la creación del Consejo Supremo Tarahumara. Las principales directrices de esta propuesta, cuyos pormenores analizaremos con detalle más adelante, quedaron de alguna manera plasmados en el 
trabajo etnográfico del profesor Francisco M. Plancarte, El problema Tarahumara, estudio que serviria de punto de partida para la erección, en 1952, del Centro Coordinador Indigenista de la Región Tarahumara (CCIT), el segundo en su género creado por el Instituto Nacional Indigenista en el pais y cuya sede ha estado desde entonces hasta hoy en la ciudad de Guachochi.

Quizás la novedad más importante que planteó el indigenismo oficial en la Tarahumara fue la de concebir y entender al indio como un problema. Lejos de la admiración por lo pintoresco, lo genuino y lo primitivo del indio que tanto cautivaron a los etnógrafos y viajeros extranjeros, los indigenistas mexicanos de los años treinta y cuarenta se sintieron golpeados por la pobreza, la marginación y el atraso de la Tarahumara y por ello no dudarian en afirmar que el indio constituia un problema nacional.

Desde el titulo y el inicio de su obra, Plancarte dibujaba con trazos firmes y colores fuertes los principales rasgos del problema de la Sierra Tarahumara. En ella viven -reseñaba el maestro y antropólogo michoacano- cerca de 50,000 indios de cuatro etnias (tarahumara, warijia, pima y tepehuana) dispersos en 60,000 kms. cuadrados, 23 municipios, 113 pueblos y 915 rancherias inhóspitas e incomunicadas. Su precaria economia de simple subsistencia basada en una agricultura rudimentaria y en el pastoreo de ovicaprinos, apenas permite una vida "misémima". Las inclemencias climatológicas, la topografia agreste, la ausencia de suelos agrícolas y los bajos niveles tecnológicos para el aprovechamiento de los recursos minerales y maderables han . condenado a estos grupos a vivir en los limites de la más extrema pobreza.

Pero lo más grave de esta situación radica en el carácter que asume el sistema de relaciones interétnicas en la Tarahumara porque los indios se ven cotidianamente acosados por la voracidad de los mestizos o chabochis ${ }^{36}$, quienes los discriminan,

\footnotetext{
${ }^{36}$ "Chabochi quiere decir, literalmente, el que tiene arañas en la cara. Es el término despectivo con que
} 104 
explotan y despojan de sus bienes y tierras, contando para ello con la complicidad y anuencia de las autoridades agrarias, judiciales y municipales. La situación llega a tal nivel de gravedad que Plancarte no dudará en afirmar algo que por evidente no deja de ser asombroso:

Los tarahumaras son legalmente ciudadanos mexicanos, con todos los derechos que les conceden y las obligaciones que les imponen las leyes.

Sin embargo, en lo general, desconocen su situación legal. Para ellos, sólo los miembros de su grupo son su gente, los suyos. El resto son chabochis, gente extraña que vino a meterse en su termitorio y que le acarrea molestias y perjuicios incontables; ladrones que les han arrebatado sus mejores tierras, que abusan de sus mujeres, que les roban su ganado y que, en el mejor de los casos, realizan con ellos tratos y transacciones comerciales en que mañosamente siempre les quitan lo más para darles lo menos (Plancarte, 1954: 35).

Aislados por la ausencia de medios y vias de comunicación, analfabetos por falta de escuelas y programas educativos adecuados, supersticiosos por su apego a las explicaciones mágicas sobre la salud, la enfermedad y la muerte e ignorantes de sus derechos como ciudadanos mexicanos, los indios de la Tarahumara -concluia Plancarteviven inmersos en una problemática grave y compleja de la cual nunca podrán salir si no se emprenden acciones radicales e integrales que les permitan alcanzar los niveles de desarrollo y madurez política, social y cultural del resto del pais (lbid.: 11-12).

Tras reconocer la gravedad del problema, este indigenismo asumió una actitud preocupada por promover el mejoramiento social construyendo, a partir de ahí, su propia etnografia de la Tarahumara y, dentro de ella, una particular interpretación del cambio social que estaba tratando de propiciar.

Se puede entender entonces que esta etnografia haya sido desde el principio militante y comprometida con una causa como la de la integración de los grupos étnicos de la Sierra a la nación y con una serie de tareas eșpecificas como la educación, la lucha

los Rarámuri designan a los Blancos y Mestizos. Se acuñó en la época de la conquista, a causa de las barbas de los españoles que daban a los indios -lampiños- la impresión de arañas" (Velasco, 1987: 415) 
por el reparto de la tierra, el desarrollo agrícola, ganadero y forestal, la implantación de servicios de salud, etc.

También esto explica que esta etnografia haya rehuido como estilo el academicismo, como género el relato viajero o la crónica autobiográfica y como pretexto el trabajo ocasional de campo. No, la antropología del indio que se plantearon los indigenistas de la Tarahumara entre el final de los años treinta y el inicio de los sesenta tuvo como marco de referencia la intervención directa de sus autores en programas e instituciones ligadas al desarrollo y cambio social de las comunidades indigenas.

Esta participación institucional, marco de la reflexión antropológica indigenista, tuvo su primera expresión en la activa intervención que el grupo de maestros antes citados asumió en la creación de una Escuela Normal de Especialización de Maestros Indigenas, fundada en 1938 en Guachochii. ${ }^{37}$ Un año después, en abril de 1939, y a partir de la influencia de esta escuela y sus directivos, un número importante de gobernadores tarahumaras decidieron constituir el Consejo Supremo Tarahumara. ${ }^{38}$ Como resultado de la presión ejercida por este Consejo ante el gobierno federal, en 1952 fue creado el CCIT y nombrado como su primer director el profesor y antropólogo Francisco M. Plancarte.

Durante todo este periodo que se inició en los años finales del cardenismo y se extendió hasta una década después de la creación del CCIT, me atreveria a pensar que el indigenismo en la Tarahumara fue una mezcla de teoría y mistica: teoría, porque se

${ }^{37}$ Esta escuela fue de importancia decisiva en la formación de los primeros maestros y promotores indigenas, en la experimentación y búsqueda de métodos para la educación informal indigena -incluyendo la elaboración de cartillas bilingües- y el establecimiento de algunos proyectos de desarrollo en comunidades (Plancarte, 1954: 29 y 30).

${ }^{38}$ Como mostraremos en el capitub 2, el Consejo Supremo Tarahumara jugó por cerca de tres décadas un papel importante en la resolución institucionalizada de los.conflictos y problemas de los tarahumaras, para convertirse despues en un típico organismo burocratizado, corporativista, de cupula y lejano a la realidad indigena. Durante los años setenta y siguiendo el ejemplo de los tarahumaras, el gobiemo federal promovió la creación de Consejos Supremos entre varios grupos étnicos del pais. 
construyó una explicación novedosa sobre el "problema tarahumara"; mistica, porque esa interpretación se convirtió en un credo y en una fuente de inspiración para la acción. Pero veamos, por partes, cada uno de estos dos componentes.

En cuanto a la teoria, es sin duda la obra de Plancarte la que mejor la resume. Su mayor mérito consiste, como vimos, en tratar de problematizar la situación del indio a partir del modelo imperante de relaciones interétnicas y del análisis de la marginación de los grupos étnicos a lo largo de la historia nacional. Pero además, esta monografía sobre los tarahumaras propone una explicación original del cambio social.

La cultura tarahumara -postula Plancarte- constituye una respuesta coherente, ajustada y adaptada a los condicionamientos ecológicos y sociales que impone el medio serrano. Los rarámuri han logrado, por ejemplo, combinar sabiamente la agricultura, la cria y explotación del ganado (del que obtienen fertilizantes orgánicos), la caza, el uso de los recursos maderables y la apropiación y conocimiento de una variada flora silvestre y medicinal. Sus patrones de seminomadismo, sus bajos niveles de natalidad, el reducido tamaño de sus familias, su dispersión y aislamiento geográfico y sus usos y costumbres en materia de propiedad y herencia son la clave para explicar la forma como este grupo humano ha podido sobrevivir y reproducirse en un medio tan hostil.

Pero además, las normas que rigen el trato respetuoso entre tarahumaras, sus prácticas y principios de justicia, su sistema de gobiemo, su religión, sus fiestas, rituales, deportes, juegos, discursos y sus creencias sobre la muerte, todo ello, integra un sistema coherente digno de ser respetado y promovido a la hora de enfrentar las tareas del mejoramiento y cambio social. ${ }^{39}$

\footnotetext{
${ }^{39}$ Porque, como señala el propio Plancarte:

...debe tomarse en consideración el hecho de que tos grupos indigenas tienen valores especificos que no sólo deben conservarse, sino aún estimularse de acuerdo al espiritu democrático y progresista de nuestras leyes

Tales son, para no citar otros, el respeto y la disciplina que estos grupos guardan a la 107
} 
Integrada, adaptada y funcional, la cultura tarahumara se habia mantenido, desde la época colonial hasta la actualidad, casi inmutable en sus principios y prácticas, lo cual, para Plancarte y los indigenistas, no constituia una prueba de su arcaicismo, sino de su eficacia actualizada.

Para demostrar la vigencia y coherencia de esta cultura el autor argumentaba que la dominación colonial sobre este grupo étnico nunca había logrado superar por completo la resistencia indigena, que la influencia religiosa de los misioneros católicos no habia trastocado el núcleo central de la religión primitiva, que el gobierno autónomo era también autóctono, que las diferencias entre rarámuri gentiles y pagótuame (bautizados) eran en realidad mínimas y que las fiestas primitivas nunca habian sido penetradas por las cristianas, constituyendo éstas últimas para los indios prácticas "superficiales" y profanas. En suma, pues, que más que cambios, eran adaptaciones to que la cultura tarahumara había vivido a lo largo de más de tres siglos:

Exceptuando algunas caracteristicas que se han ido perdiendo con el transcurso del tiempo, por estar en marcada oposición con las leyes, y por tanto, sancionadas fuertemente por las autoridades del pais; otras de orden económico y material principalmente aceptadas por ser de su obvia conveniencia, nacidas del trato con los mestizos, $y$, algunas más, oniginadas en la prédica del catolicismo, los patrones culturales primitivos de estos grupos y los que adoptaron como medio de autodefensa desde sus primeros contactos con los españoles, permanecen firmes y poco atterados [...].

Los tarahumaras, aún los pagótuame quienes se llaman a si mismos cristianos bautizados [...] en realidad sólo conocen y han aceptado algunas creencias y ceremonias del catolicismo [...] y sus creencias, ceremonias y ritos difieren básicamente de la religión católica, aunque algunos de sus elementos se han fijado a su cultura autóctona con un nuevo sentido de reinterpretación (Plancarte, 1954: 30 y 55).

Pero, si ni la ancestral presión colonizadora y aculturativa ejercida por los mestizos ni la tarea evangelizadora de los misioneros habian sido capaces de

autoridad y el sentido de responsabilidad y respeto que sus autoridades tienen respecto a sus pueblos; sus hábitos de solidaridad humana y de cooperación en sus trabajos; su arte popular y sus formas y hábitos deportivos (Plancarte, 1954: 81). 
transformar en su núcleo la cultura rarámuri, ¿de dónde provendrian, entonces, los cambios necesarios con los que los tarahumaras pudieran enfrentar, de raíz y con éxito, los graves problemas sociales que impedian su progreso y bienestar? ¿cuál sería el origen de esas transformaciones radicales y urgentes?

El verdadero cambio, la auténtica liberación del tarahumara y su salida del nivel de postración en que vive, sólo podrá venir de la implantación en la Sierra de los principios de justicia y libertad derivados del ideario de la revolución mexicana y éstos sólo se harán realidad cuando se emprendan acciones radicales en especial en materia de reparto de tierras y educación del pueblo:

No fue sino hasta la época constructiva de la Revolución Mexicana, cuando los gobiemos nacionales y estatales empezaron a preocuparse por la condición de miseria y atraso de los indigenas, tratando de llevar a la práctica el sentido de justicia social de la Revolución y la aplicación de nuestras leyes que consagran iguales derechos a todos los ciudadanos de México.

En la Sierra, se empezaron a aplicar las leyes agrarias, se abrieron escuelas e intemados, se establecieron misiones culturales, se promovió la construcción de caminos carreteros rudimentarios y se empezó a predicar a los indigenas la nueva teoría social e ideológica de la Revolución Mexicana; el derecho a la tierra, a la educación moderna, al trato igual y, en fin, a una mejor condición de vida (Plancarte, 1954: 29).

La defensa de la propiedad indigena sobre las tierras y bosques de la Tarahumara aparece en la obra de Plancarte como uno de los aspectos centrales de su visión sobre las tareas del indigenismo. Como mostraremos en el capitulo 3, la lucha por la tierra ha conformado uno de los puntos neurálgicos de las conflictivas relaciones interétnicas entre los indigenas y los chabochis o mestizos de la Sierra. Al menos durante las úttimas ocho décadas, los primeros han acusado insistentemente a los segundos de invasión y usurpación agranias y han solicitado de forma reiterada al gobiemo el reconocimiento de sus derechos sobre las tierras donde habitan.

La misma fe en los principios del agrarismo y la educación rural que Plancarte 
defendia en su obra comenzó a impregnar la naciente ideologia indigenista que los maestros rurales divulgaban en las escuelas serranas como lo muestra un texto de una de las primeras cartillas de alfabetización tarahumara, Repabé Rarámuri, elaborada en 1945 por los profeseres Labastida y Alvarez:

SOMOS TARAHUMARAS

Nosotros somos tarahumaras. Habitamos en la Sierra Madre de Chihuahua. Queremos estas tierras que nos heredaron nuestros abuelos y que nos vieron nacer.

Somos pobres e ignoramos muchas cosas, porque hemos sido dvidados muchos años. No tenemos buenas habitaciones porque no sabemos cómo hacerlas. Muchos vivimos miserables porque hemos sido despojados de nuestras mejores tierras y las pocas que nos quedan están gastadas.

Pero ya llegó el dia de nuestro mejoramiento. El gobiemo nos hace justicia. Nos ha fundado escuelas y misiones, envió procuradores que nos defiendan, recupera las tierras para nosotros y nos enseña a trabajarlas mejor. Aprenderemos castellano para entendernos con todas las gentes.

Nuestros hijos heredarán una vida mejor, para honra de nuestro Estado y de la Patria (Labastida y Alvarez, 1945:115).

El programa de reforma que Plancarte reseñaba en estas líneas no sólo perfilaba el camino de la liberación del indio sino que también destacaba las metas y objetivos sustantivos del indigenismo: el reparto de la tierra, la modernización de la economia, la asistencia y la salubridad, la educación, la seguridad, la acción social y la asesoria técnica a los pueblos y comunidades indigenas. ${ }^{40}$ En 1952 y para hacer realidad estos postulados, fue erigido en Guachochi el $\mathrm{CCIT}^{41}$, donde por muchos años el indigenismo se habría de convertir en institución. Pero no sólo en institución, también en mística, porque muchos de quienes participaron en este centro durante su primera década de

\footnotetext{
${ }^{40}$ Precisamente todos estos temas y las estrategias de acción ligadas a ellos constituyen el objeto de la segunda parte de la obra de Plancarte en donde, desde una perspectiva de antropologia aplicada, propone las directrices a seguir por el CCIT.

${ }^{41}$ El decreto del Presidente Alemán del 4 de junio de 1952 por el que se crea del Centro Coordinador Indigenista de la Región Tarahumara puede consultarse en Plancarte, 1954: 91 y 92 y en el Diario Oficial de la Federación, CXCIII, 41, 1952.
} 


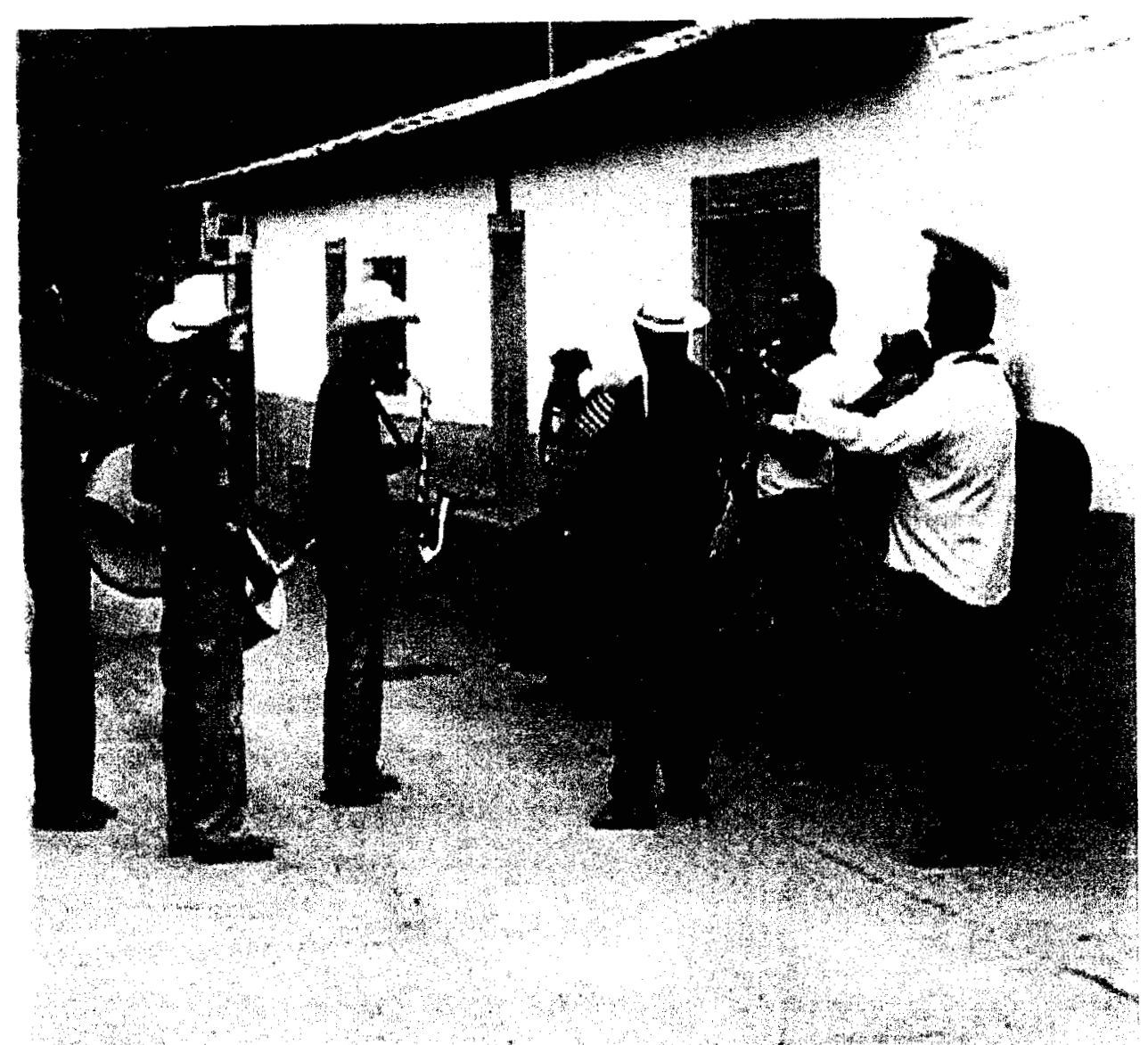

FIGURA 14.- MÚSICOS MESTIZOS O "CHABOCHIS" EN LAS CALLES DE BATOPILAS (FOTO DEL AUTOR, JULIO, 1999)
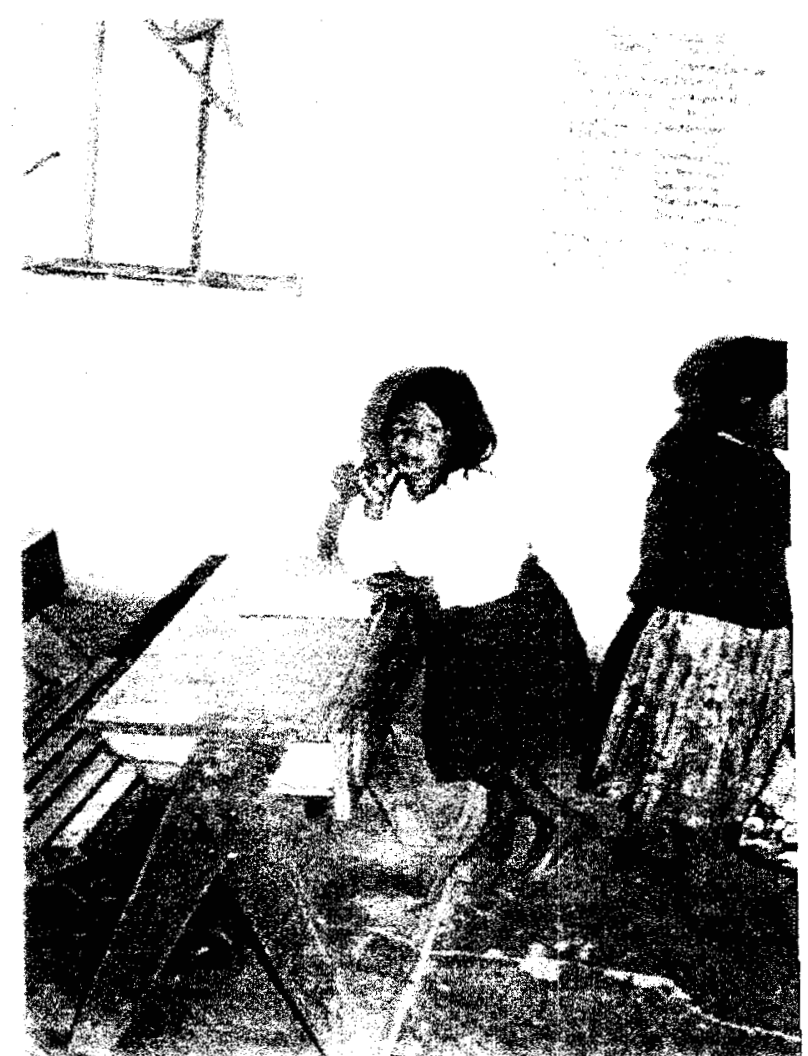
existencia asumieron como convicción ética este programa de trabajo que implicaba, por aquellos años, una auténtica mistica de redención del indio. Antropólogos, maestros, agraristas, médicos, veterinarios, agrónomos..., todos ellos llegaron a conformar lo que un escritor y periodista de la época no dudó en calificar "el pequeño ejército del bosque", para el que el único obstáculo insalvable era la burocracia gubemamental:

En la sierra trabaja un pequeño ejército de maestros, de antropólogos y de médicos. Casi todos son educadores que han pasado su vida con los indios en los internados, las misiones culturales y las montañas apartadas de México [...].

Son los únicos que aman verdaderamente a los indios, los únicos que conocen a fondo sus problemas es decir, de una manera cientifica, y los únicos que combaten a sus innumerables y poderosos enemigos. [...] La lucha de antropólogos y educadores no es contra la explotación de los indios sino contra los políticos estultos y rapaces que apoyan a los explotadores [...].

Pero es tiempo de volver al pequeño ejército del bosque. Lo encabeza Francisco Plancarte, director del Centro Tarahumara, sabio antropólogo y hombre de acción. Quien lo encuentre en la Sierra con una barba de tres dias y una camisa sucia está lejos de sospechar que ha estudiado lenguas en la Universidad de Chicago y que sea el autor del mejor libro escrito sobre los Tarahumaras. Cercano a la cincuentena, llanote y jovial, sus cien kilos de peso no le impiden guiar el camión una semana, dormir en las cabañas, comer con abundancia frijoles y tortillas, soportar las inclemencias del tiempo y vivir privado de la temura de su mujer y de sus hijos [...].

Durante las noches, después de la cena, en la casa helada, me hablaba de la vida de los indios, de los brujos, de la forma en que les son arrebatados sus bosques y sus tierras, sofocándose y dando puñetazos sobre la mesa (Benitez. 1967: 93, 94 y 95).

En enero de 1959, Plancarte moria en la ciudad de México víctima de un tumor cerebral. Su visión sobre el "problema tarahumara" y su incipiente obra en los pueblos de la Sierra constituian ya para entonces un bagaje cle teoria y experiencias para el indigenismo en Chihuahua. Con el tiempo, el vigor de ese pensamiento y la fuerza de esa mistica acabarian cediendo su lugar a una visión estereotipada de los indios y a una práctica institucional cada vez más burocratizada, pero esto será motivo de análisis en el capitulo cuarto de este texto. 


\section{El indio como símboto: el discurso misionero.}

Si la explicación indigenista sobre el cambio social en la Tarahumara pone el énfasis en el papel de los agentes institucionales externos el estado nacional postrevolucionario y sus reformas educativa y agraria-, el dissurso misionero católico, en cambio, ha insistido en reconocer la capacidad de adaptación y de apropiación selectiva que los pueblos indios de la Tarahumara han hecho valer por siglos frente a la cruzada aculturativa occidental y, en particular, frente a la evangelización católica. De esta forma, lo que en principio se plantea como una teoria sobre la conversión religiosa acaba por ser una explicación global del cambio social entre los tarahumaras. ${ }^{42}$ Pero quizás lo más sustantivo de esta explicación radica en la importancia atribuida a la capacidad de simbolización de la cultura rarámuri como mecanismo de adaptación al cambio externo.

La evangelización misionera representó en realidad la primera y más definitiva experiencia de aculturación en la Tarahumara. En el contexto de los pueblos de misión en donde fueron reducidos, los rarámuri debieron de vivir un choque cultural de enormes dimensiones que implicó, para ellos, verse forzados a aceptar un modo de sobrevivencia económica, de organización de la vida social y política y una cosmovisión totalmente ajenos a sus parámetros culturales. Desde una primera actitud de abierto enfrentamiento hostil y de rebelión armada, los rarámuri fueron transitando hacia formas variadas de resistencia pacifica y de transacción intercultural que les permitieron mantenerse integrados como pueblo sin renunciar a sus valores, aunque ello conllevara aceptar elementos externos y ajenos. ${ }^{43}$

\footnotetext{
${ }^{42}$ Los tarahumaras son, en efecto, el grupo étnico más estudiado por los analistas religiosos jesuitas, que se han ocupado -desde la época cotonial, pero, en particular en los últimos años- de interpretar, a partir de su experiencia pastoral, los rasgos centrales de la religión y la cultura rarámuri. Aunque este discurso suele autoconfesarse más cercano a la teologia que a la antropologia, es indudable que se encuentra en algún punto de esa difusa frontera que, en ocasiones, une y separa ambas disciplinas y por eso se incluye en este capitulo una reflexión sobre este discurso, cuyos principales autores son Robles, Velasco y Vallejo.

${ }^{43}$ No recurrieron a la misma estrategia ni corrieron la misma suerte otros pueblos aborigenes del noroeste de México, vecinos de los rarámuri, como los apaches, sumas, conchos, floridos y tobosos entre otrosquienes optaron por la via guerrera y el enfrentamiento contra los blancos, lo que desembocaria en una guerra etnocida y en su desaparición, como pueblos, del mapa de la moderna nación mexicana. Quizás por 
Esta estrategia de adaptación cultural tuvo también momentos y etapas variadas. En las épocas en que la ortodoxia religiosa se acrecentó, los indios o bien optaron por el aislamiento y el refugio en lugares inhóspitos lejos de la influencia misionera, o bien asumieron elementos occidentales como el nuevo complejo tecnológico agricola sustentado en el hacha, los animales de tiro y los cultivos cerealeros o como un conjunto de rituales y símbolos derivados de la liturgia cristiana.

Pero la etapa más importante de este proceso adaptativo tuvo lugar entre 1767 (fecha de expulsión de los jesuitas) y 1900 (fecha de su reingreso a la Tarahumara), periodo en el cual el sistema misional y la ortodoxia católica se relajaron al máximo, permitiendo asi una auténtica reinterpretación indígena de los elementos predicados por los misioneros o, como dice Robles, una verdadera "raramurización" del cristianismo:

Los rarámuri, que ya habian seleccionado lo compatible y enriquecedor durante los siglos XVII y XVIII, lograron gracias al vacio pastoral del siglo XIX una sintesis propia en la que raramurizaron el cristianismo recibido y cristianizaron 10 rarámuri ancestral hasta el punto de autodefinirse asi como etnia: los hombrescristianos, los rarámuri-pagótuame. Será imposible distinguir en esa integración que lograron si algo es prehispánico o fruto de la evangelización. Hay, no obstante, elementos tan ajenos a la religiosidad hispánica que recibieron que se pueden tomar como ancestrales o prehispánicos, aunque siempre estarán influidos, enriquecidos, por elementos ciertamente adoptados de la cultura invasora. Hay también elementos más acentuadamente cristianos y podremos tomartos como aportados por la evangelización sin duda, aunque siempre estarán expresados en alguna medida por simbolos y formas rarámuris y nos resultaria imposible identificarlas sin más con lo que los misioneros quisieron dar o la Iglesia actual tiene por ortodoxo (Robles, 1994: 34).

La "raramurización" de lo cristiano o la cristianización de lo rarámuri invadieron todos los ámbitos de la vida de un pueblo donde las fronteras entre los profano y 10 sagrado están borradas. Asi, si por una parte, los rarámuri mantuvieron su ancestral tendencia a la dispersión geográfica y a la autonomia, por otra parte, reforzaron sus vinculos comunales alrededor de los pueblos y las iglesias que habian sido erigidos con

eso, todavia hoy el rarámuri "se sigue preguntando por los apaches: ¿en donde están?" (Robles y Vallejo. 1995: 95). 
otros fines por los misioneros jesuitas.

Algo similar ocurrió con el sistema político de cargos: una buena parte de ellos, de origen ancestral, se mantuvieron y mantienen hasta hoy vivos incorporando algunos usos y símbolos católicos como el "sukristo" o crucifijo. Es este el caso de los enároame u owirúame (doctores o curanderos hábiles para diagnosticar y curar un sinnúmero de enfermedades), lo sipáame (raspadores del peyote y especialistas en este ritual), los waniame (expertos en extraer del cuerpo humano, a través de la succión, piedras y gusanos malignos) y los sukurúame (o provocadores del mal).

Pero además, los rarámuri retomaron todo el sistema de cargos que los misioneros les impusieron desde el siglo XVII como instrumento de control y lo convirtieron en un factor de una auténtica autonomia de sus pueblos. Desde el siglo XIX hasta hoy los siriame (o gobernadores), generales, capitanes, mayoras, alguaciles, soldados, tenanches, chapellones y bandereros, a la vez que desempeñan funciones específicas en el complejo marco de los rituales, fiestas, juicios y nawésari o sermones, perpetúan las formas de la identidad de un pueblo que ha sabido adaptarse para pervivir en la historia.

Este proceso de apropiación selectiva y reutilización de elementos occidentales en la cultura rarámuri reviste - de acuerdo con los analistas religiosos que estamos reseñando- una importante particularidad. Porque la apropiación y transmisión culturales operaron no tanto a través de contenidos civilizatorios, sino más bien por medio de los símbolos. De la religión católica predicada por los misioneros, por ejemplo, los rarámuri no retomaron los contenidos intelectuales del dogma -que hasta hoy desconocen- pero sí asimilaron un conjunto de símbolos que, en algunos casos, tenian equivalentes en su cultura ancestral y, siempre, sivvieron para reafirmar y enriquecer su propio universo simbólico asi como para dar una mayor coherencia a su interpretación de la realidad. 
Asi, paradójicamente, los viejos bastones de palo de Brasil con empuñadura metálica, que los misioneros se empeñaron en entronizar en el siglo XVII para que los gobernadores indígenas se asemejaran a los alcaldes españoles, son hoy los "tesora", el símbolo por antonomasia de la autonomia rarámuri. Y la danza de los matachines ha dejado de rememorar la guerra sagrada entre moros y cristianos, entre Pilatos y el señor Santiago y se ha convertido en una expresión viva y colorida de afirmación de los vínculos comunitarios del pueblo rarámuri. ${ }^{44} \mathrm{Y}$ en el caso de otras danzas como la de "los pintos" o "fariseos", típica de la Semana Santa, la apropiación rarámuri ha llegado a revertir los significados originales:

Por los indicios que se conservan, el rito cristiano de Semana Santa fue instituido como oposición entre soldados y fariseos. Los fariseos eran los paganos que se acercaban al bautismo que recibian en la Pascua. Los buenos eran los soldados: los españoles o los indios convertidos al cristianismo. La oposición entre el bien y el mal sigue siendo el fondo del rito, pero ahora los soldados representan a los rarámuri, vestidos con el traje ancestral en su forma actual; los fariseos siguen siendo los malos, pero el pintarse de tierra blanca ha pasado a ser simbolo de transformarse en blancos, en chabochis. Asi, en esta nueva sociedad actual, la lucha real entre los invasores y los rarámuri, el verdadero conficto social vigente, es lo expresado en el rito, y los que ayudan a Dios para que no sea vencido por el que vive abajo, los verdaderos cristianos, los pagótuame, son ellos, y no ya los invasores (Robles, 1994: pág. 83).

Estos son sólo algunos ejemplos que muestran la enorme capacidad de los rarámuri para reprocesar los simbolos que les fueron impuestos a raíz de la colonización. $Y$ puesto que se trata de una cultura donde el conocimiento se expresa no tanto en contenidos doctrinarios fijos y cosmovisiones cerradas, sino en un cuerpo de elementos simbólicos útiles y necesarios para interpretar la realidad, no es de extrañar que sean las fiestas el momento central de expresión de la cultura tarahumara:

Los Tarahumares no poseen ningún tipo de documento histórico. Carecen de escritura y de pintura; tampoco tienen ningún tipo de grabados, ni estatuas ni monumentos. Es decir, no tienen forma de "fijar" o "escribir" su historia. En cuanto a la tradición oral, las leyendas son escasas y están sumamente fragmentadas. Tampoco tienen divisiones de clanes ni listas genealógicas (ni siquiera tienen

\footnotetext{
44 Pueden verse al respecto dos interpretaciones sobre la danza de los matachines hechas por dos misioneros jesuitas en Robles, 1994: 82 y Velasco, 1987: 152-182.
} 
apellidos). Existen poquisimas referencias a hechos históricos anteriores a las generaciones todavia vivas y aun éstas son vagas y prácticamente anacrónicas. Aun actualmente hay muy poco interés por la historia (como nosotros la concebimos).

De ahi la importancia central de las fiestas y los ritos religiosos que han sido la forma de grabar o plastificar -y conservar- 10 que los Tarahumaras han 'hecho' $y$ creido. Son a la vez el contenido el depósito culturat a conservar y el medio de haceno $[. .$.$] .$

Podriamos decir que los tarahumaras han concentrado prácticamente toda su creatividad -intelectual y artística en las fiestas. Así, éstas no sólo son la casi (única) expresión de lo que los Rarámuri fueron, son y quieren ser, sino que además- polarizan otras formas y medios de expresión que, en otras culturas, tienen una autonomia propia [...].

La conservación de la identidad Rarámuri en cuanto relacionada con el compartir un conjunto de valores fundamentales (muy particularmente la experiencia de Dios como valor central), compartir tradiciones y expresiones, relacionada también con la pertenencia a un grupo cohesionado y con el hacer algo en común- depende esencialmente de las fiestas (Velasco, 1987: 268-270 y 273).

Las fiestas y los rituales en el mundo rarámuri tienen un amplio espectro. Todos son en mayor o menor grado colectivos y pueden dividirse en dos grandes apartados tal y como se muestra en el cuadro siguiente elaborado a partir del texto de Robles ${ }^{45}$ : los que acompañan los momentos centrales de la vida del rarámuri y aquellos que son estrictamente comunitarios.

Aunque en unos y otros se descubren elementos ancestrales y adoptados (cristianos), ambos, sin embargo, están integrados, raramurizados, sin poder establecerse una frontera entre esos dos componentes.

Los rituales que acompañan la vida inician a partir del nacimiento del niño con el Ba'wirochi, Morema y bautismo cristiano, a través de los cuales, el recién nacido es

\footnotetext{
${ }^{45}$ Como el propio autor to señala, la sistematización que présenta sobre el ritual y ciclo festivo procede de to observado en el pueblo de Bawwichiki o Pahuichique, asentamiento tradicional rarámuri enclavado en la región de Norogachi. Aunque el esquema propuesto varia en otras comunidades y regiones, puede servimos perfectamente de referente para lo que aqui tratamos de plantear.
}

$$
116
$$




\section{CUADRO 7.- SINÓPSIS DE LOS PRINCIPALES RITUALES Y FIESTAS TARAHUMARAS}

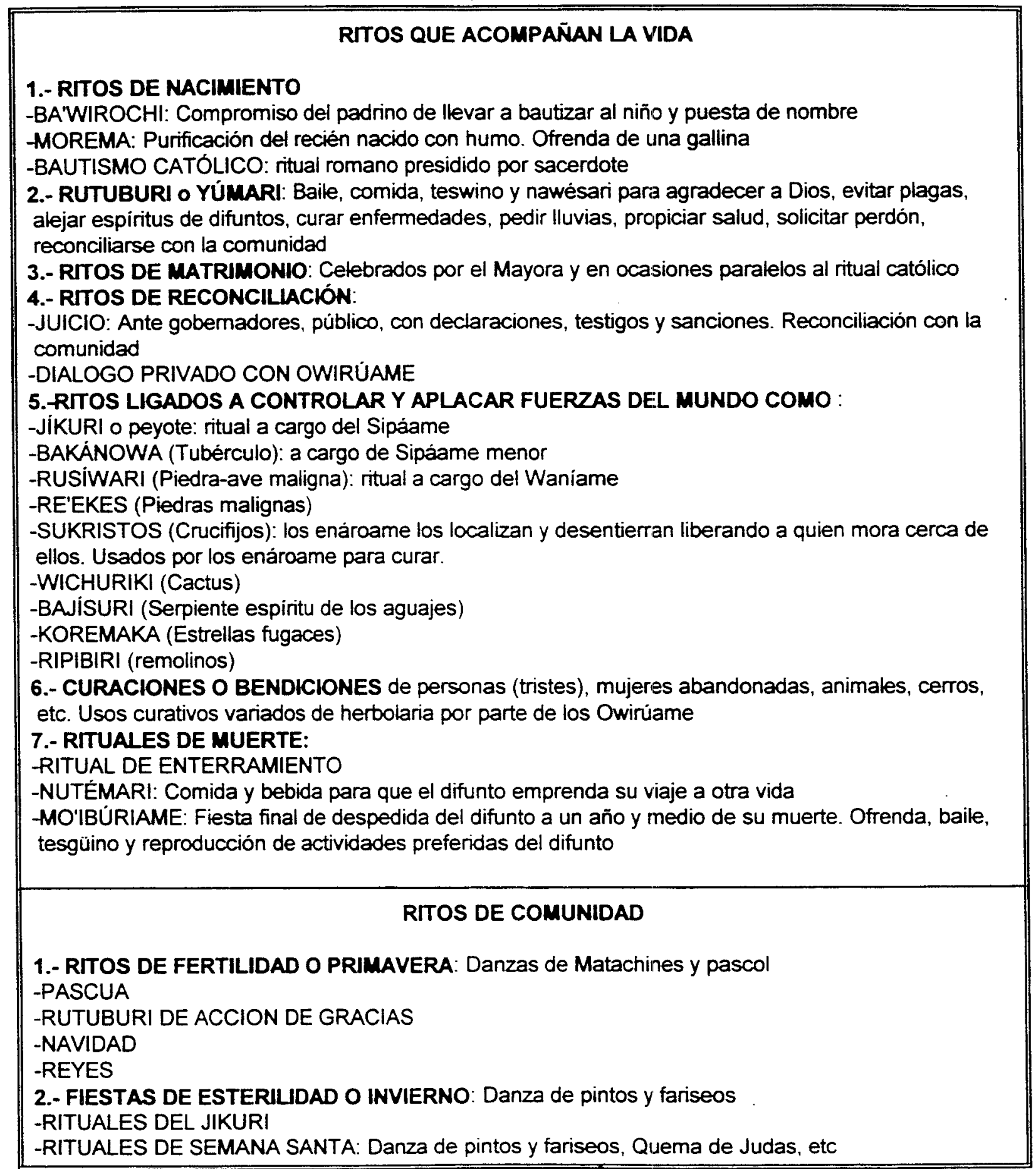

FUENTE: Elaborado a partir de Robles, 1994: 66-85 
purificado con humo y agua y recibe, de parte de sus padrinos, su nombre. El rito del matrimonio es sencillo, recae en el Mayora y, en ocasiones, se reafirma con el sacramento cristiano. El principal ritual de reconciliación es el de los juicios públicos frente a los gobernadores, en los que participan testigos, acusadores y acusados. A través de la imposición de sanciones y de recomendaciones, se busca que quien ha cometido algún delito se reconcilie con la comunidad.

Existen además una serie de rituales destinados a controlar y aplacar ciertas fuerzas poderosas de la naturaleza presentes en plantas (como el jíkuri o peyote, o como el tubérculo bakánowa), en piedras, animales, fenómenos naturales (como las estrellas fugaces, los remolinos, los rayos) o los sukristos o crucifijos (simples cruces sin Cristo) a los que se les atribuye un poder sobrenatural. También para propiciar la fertilidad de la tierra, la salud de las personas y los animales, los rarámuri acostumbran realizar ciertos rituales propiciatorios.

El rutuburi (o tutuguri) o yúmari ${ }^{46}$ es, de todos los rituales, el más importante y en cierta forma está presente en muchas fiestas. Incluye el sacrificio de un animal, comida, danza, tesgüino, baile y nawésari o sermón del gobernador. Sirve para fines diversos como agradecer a Dios o solicitarle lluvias, cosechas, evitar plagas, alejar espiritus de difuntos y propiciar que éstos prosigan en su camino hacia el más allá, lograr la salud de la familia, de la comunidad, etc.

Los ritos de comunidad son los que presentan un mayor grado de asimilación de la influencia misionera, aunque puedan combinarse con el rutuburi. Estas fiestas se dividen en dos grandes ciclos: el de la fertilidad, que abarca desde la siembra del maiz en la primavera hasta su cosecha en el otoño, y el de la esterilidad en invierno, cuando

\footnotetext{
${ }^{46}$ Dutuburi (la danza del guajolote) y yúmari (el baile del venado) son dos términos tarahumaras que designan actualmente una misma fiesta o celebración, pero todavia hace un siglo se referian a dos tipos de baile distintos tal y como lo atestiguó Lumholtz (Lumholtz, 1986. Tomo I: 329-348).
} 

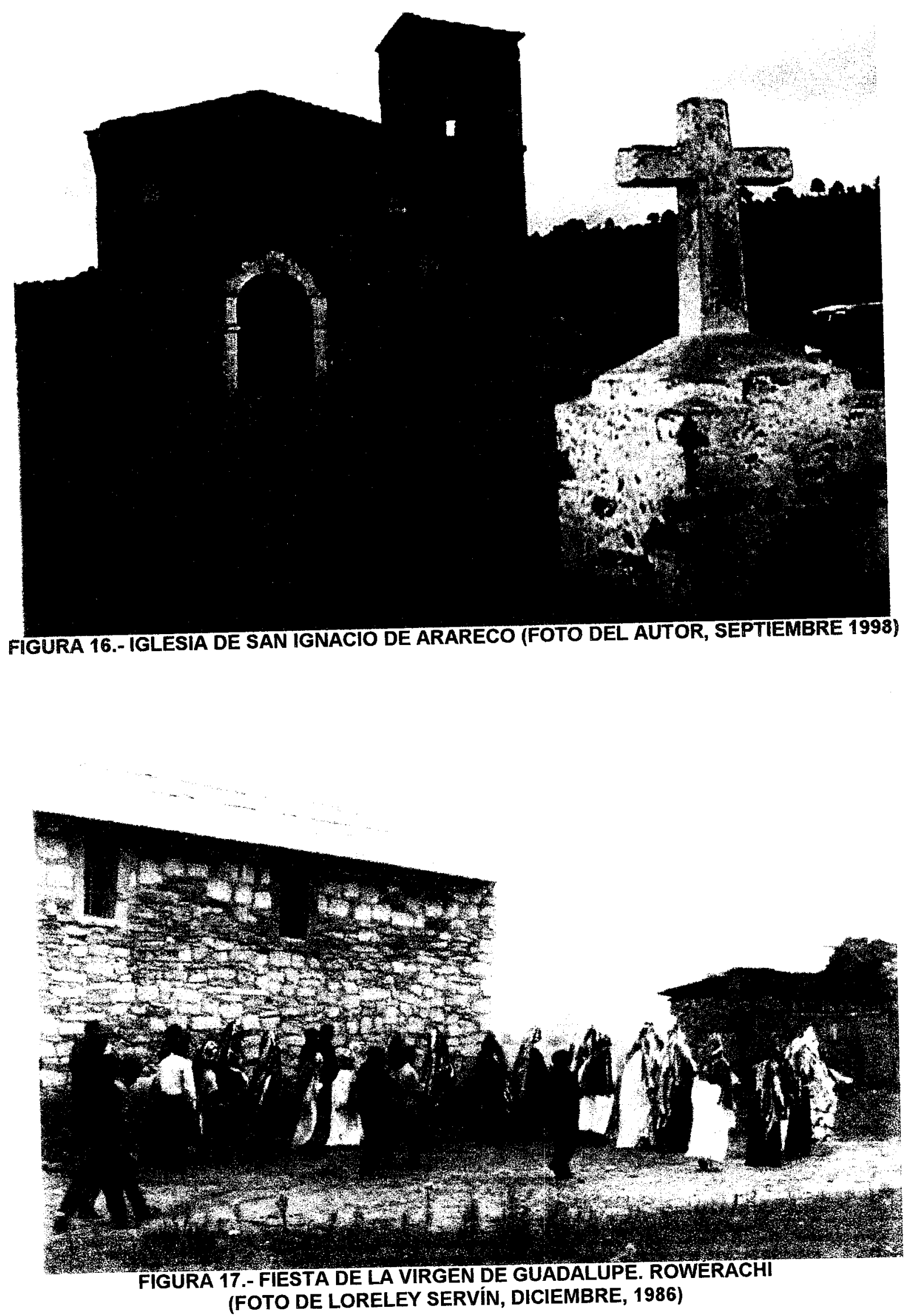
la tierra descansa en espera del nuevo año agrícola. En el ciclo de primavera, las fiestas son alegres, como lo expresa la danza, el atuendo colorido y el sonido de violines y guitarras en el baile de los matachines, típico de las fiestas de Pascua, Navidad y Reyes, asi como el baile del pascol. En el ciclo de invierno, por el contrario, las danzas son ancestrales y austeras; se baila casi desnudo al compás de la tambora y la flauta, dramatizando la lucha entre los pintos o fariseos y los soldados y rememorando el arquetípico combate entre el bien y el mal (Robles, 1994: 81-89).

En cada uno de los rituales y fiestas en que participa -trátese de momentos especiales de su trayectoria vital o de celebraciones colectivas- el rarámuri recuerda, reproduce y actualiza su visión del mundo: los hombres deben andar y comportarse con rectitud en el camino de la vida, deben celebrar y bailar para contribuir a que Onorúame -el que está arriba-, siga dándonos la vida, el maíz y el tesgüino. Porque la vida se expresa en la regularidad y fertilidad del ciclo agrícola, en el equilibrio con la naturaleza y en la reconciliación entre los hombres. Por eso hay que danzar, celebrar y beber tesgüino. Hombres, mujeres y niños lo beben en sus fiestas y labores cotidianas como símbolo de su cohesión social y, en reciprocidad con Dios, se lo ofrecen en cada una de sus ceremonias, esparciéndolo hacia los cuatro puntos del universo y utilizándolo para pedir la lluvia, curar las tierras, los animales, las enfermedades y para agradecer la cosecha. Porque sin tesgüino no se obtiene la lluvia, sin lluvia no crece el maiz y sin maíz no se puede hacer tesgüino.

La interpretación de la vida y la cultura rarámuri construida desde la experiencia pastoral de los misioneros jesuitas plantea una visión original sobre la experiencia del cambio y la adaptación sociales entre este grupo étnico. Refiriéndonos en particular a Robles y Velasco, es importante destacar que su planteamiento arriba señalado sobre la asimilación y apropiación indigenas de los símbolos cristianos resulta radicalmente opuesto al de autores clásicos de la antropologia de la Tarahumara como Plancarte, Bennett, Zingg y Kennedy quienes, como ya lo señalamos anteriormente, proponen una 
clara distinción entre el ritual autóctono y el asimilado, entre las fiestas "nativas" y las "de la iglesia". La mayoria de estos antropólogos insisten también en que ni el dogma ni las prácticas religiosas predicadas por los misioneros católicos trastocaron esencialmente la cosmovisión religiosa tradicional rarámuri.

Sin duda, lo más destacable de la perspectiva de estos analistas misioneros es que los rarámuri aparecen como un pueblo que ha vivido desde la época del contacto colonial en continua transformación de sus formas de vivir y pensar. Pero este proceso no ha significado para ellos, como algunos pudieran pensarlo, la renuncia y el olvido de sus ancestrales formas de entender el mundo y entenderse como pueblo dentro de él. Por el contrario, los tarahumaras han sabido adaptarse a la historia, han aceptado y rechazado selectivamente elementos externos y han logrado vehicular a través de los símbolos, el ritual y las fiestas, los componentes más importantes de su cultura. Herederos de una de las cosmovisiones más arcaicas del continente americano, los tarahumaras son, sin embargo, un pueblo vivo de nuestros dias porque su sabiduría les ha permitido aceptar la historia y el presente sin renunciar a su ancestral pasado.

\section{El indio como imaginario y actor: el discurso postmoderno}

Indigenistas gubernamentales y misioneros católicos, aunque difieren notoriamente a la hora de explicar las transformaciones que el contacto cultural con el mundo occidental produjo en los pueblos indios de la Sierra, y en particular entre los rarámuri, parecen sin embargo estar de acuerdo en reconocer primero que, efectivamente, se dieron cambios y segundo, que estos cambios, por su direccionalidad y sentido, permiten pensar que la cultura y la identidad de estos pueblos tienen futuro, sea que éste se fundamente en su integración a la nación como propone el discurso indigenista, o sea, como pretenden los misioneros, que la capacidad de apropiación y reinterpretación de sịmbolos y prácticas asegure a estos grupos étnicos un cierto grado de autonomía cultural. 
Pero una perspectiva muy distinta y opuesta a la de estos dos enfoques es la de quienes aseveran que los profundos cambios y transformaciones derivados del contacto con el mundo occidental han llevado a los tarahumaras por un camino irreversible hacia el etnocidio y la desintegración culturales. De quienes asi piensan quizás nada sea más representativo que los planteamientos de un antropólogo colombiano, Juan Cajas Castro, expresado en su libro La Sierra Tarahumara o los desvelos de la modernidad en México, editado en 1992.

Este autor ha escogido la Sierra Tarahumara como un territorio cultural apropiado para interpretar desde las tesis de la postmodernidad el mito de la cultura nacional y del nacionalismo y, en particular, uno de sus principales sustentos: el de la continuidad entre el México moderno y el prehispánico, el de la supervivencia contemporánea del pasado indio.

Contrapunteando la historia nacional desde los tiempos del porfiriato con los de la Sierra Tarahumara ${ }^{47}$, Cajas trata de mostrar que la definición política e ideológica del moderno estado mexicano, desde el liberalismo porfiriano hasta el populismo cardenista, tuvo como contraparte la subordinación y, en ocasiones, el aniquilamiento del indio en la Tarahumara. De ello derivó un desfase y desentendimiento entre los indios y la nación. La supuesta coherencia de un discurso indigenista, que va desde el positivismo hasta el incorporacionismo, nunca encontró interlocución entre los indios, los "sin razón", para quienes la nación sólo es un mito lejano y lo único cierto es que el mundo se sostiene porque sus columnas, que son los rarámuri, danzan y beben tesgüino. ${ }^{48}$

\footnotetext{
47 Nunca a lo largo de esta obra estas dos historias aparecen realmente integradas. El autor tiende además a sobreponderar el impacto que las fuerzas y los procesos politicos nacionales tuvieron en la Sierra tanto en el porfiriato como en la época revolucionara. La resistencia india, uno de los temas predominantes en la historiografia y etnografia tarahumaras, resulta en cambio el gran ausente en el libro de Cajas. Los indios expoliados y sumisos aparecen indefensos ante una modemidad que se va construyendo sin y contra ellos.
}

${ }^{48}$ Cajas se refiere probablemente a una concepción de los rarämuri, según la cual, la vida y el equilibrio 
Acosados económica e ideológicamente por todos los flancos, los rarámuri han perdido la batalla de la pervivencia cultural. Su identidad, su razón de ser han perdido sentido. De ellas sólo quedan símbolos, gestos y rituales que se expresan en el ámbito teatralizado de las fiestas a las que los tarahumaras son tan proclives. Pero ese teatro no es el teatro de la crueldad de Artaud en quien Cajas, sin duda, se inspira- sino, por el contrario, una representación dramática en la que los actores ni conocen ni atribuyen significación alguna a su interpretación. Es un teatro sin sentido, un teatro del absurdo:

Tres siglos de evangelización y conquista han actuado sobre el pensamiento rarámuri, erosionando su sistema de creencias, de lo cual tan sólo queda el relato corporal de sus fiestas. Los rarámuris se desenvuelven como actores de una obra que ellos mismos no pueden explicar ni en términos católicos ni en términos rarámuris. La respuesta más común, cuando uno interroga sobre el significado del sol, la luna, los yúmaris, el jikuri y las danzas es, generalmente, la misma: "asi es el costumbre" [...] Victimas del etnocidio, han sido conducidos hasta una especie de esquizofrenia cultural o pérdida del ser, que amenaza con su desaparición (Cajas, 1992: 192).

Y más adelante Cajas no dudará en plantear que la cultura teatralizada de los rarámuri más que remitirnos a sus referentes simbólicos, arquetípicos y originarios parecen expresar en forma descarnada el drama de la misma existencia del pueblo tarahumara en nuestros días:

Pese a todas las campañas ejercidas a nombre de la civilización y el progreso, las rarámuris siguen siendo seres extraños, muy pocos saben leer y escribir, escasamente siembran maiz, frijol y cuidan una que otra manada de chivas. Poseen un sistema de creencias que no saben explicar ni en españoi ni en rarámuri, han olvidado sus origenes, sus relatos, sus leyendas. No saben quienes son ni para dónde van. El sol, la luna, el jikuri, dios, Judas, la virgen, Jesús, la Semana Santa, los yúmaris, etcétera, son instancias celebratorias cuya conexión han perdido. Más que un sistema religioso coherente, católico, rarámuri o sincrético, estamos en presencia de las últimas evidencias de la cultura, donde to único identificable son los perfiles teatrales de su existencia, quizás porque sus vidas mismas han empezado a vivirse como un drama (Cajas, 1992: 214-215).

cósmico son posibles en tanto que ellos danzan el tutuguri y celebran a Onorúame pidiéndole la continuidad del mundo. $Y$ mientras los chabochis, hijos del que vive abajo, del demonio, desoyen la voz de Dios, ellos, los rarámuri, son las columnas del mundo que hacen posible que la creación perdure y el desorden no sobreviva. 


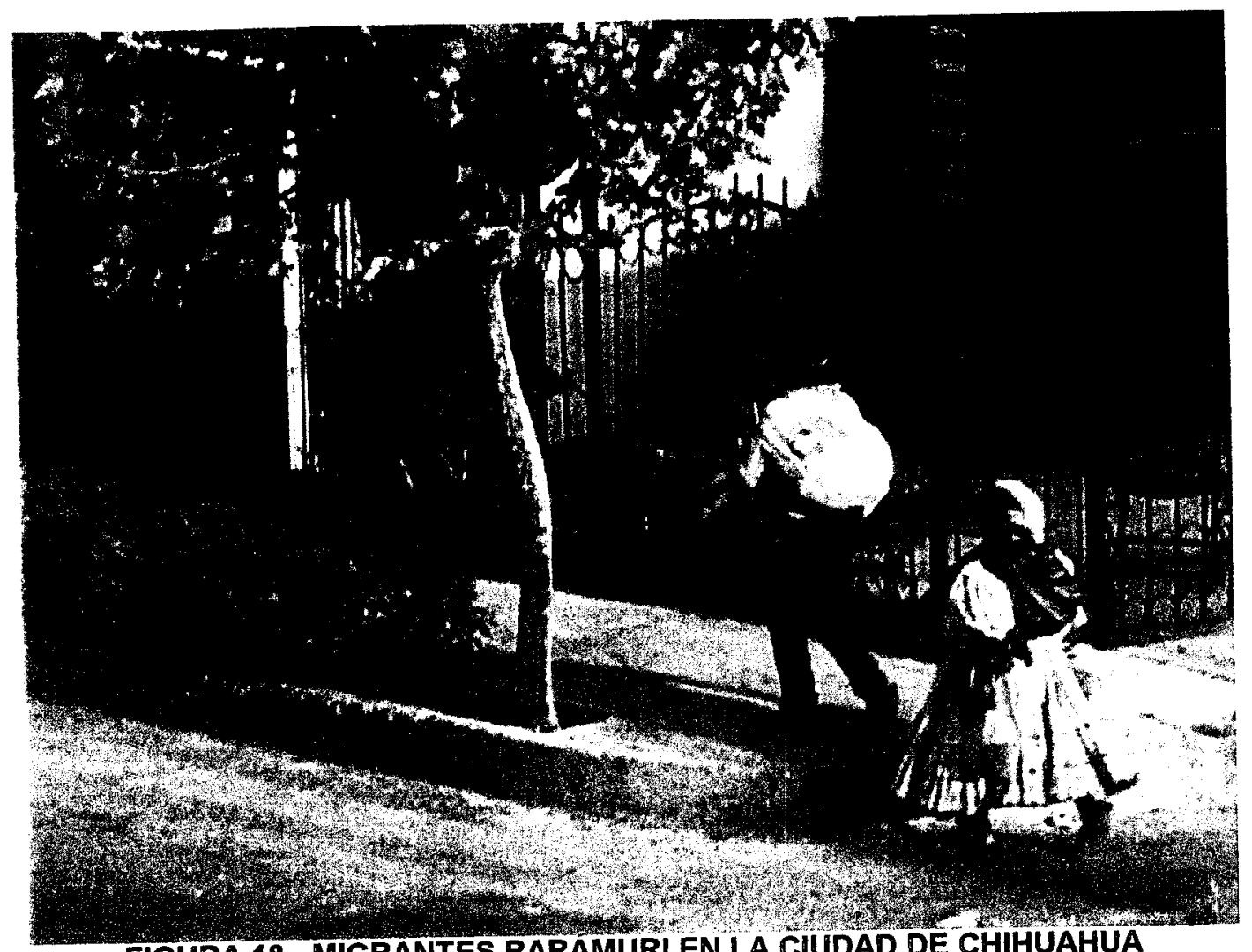

FIGURA 18.- MIGRANTES RARAMURI EN LA CIUDAD DE CHIHUAHUA

(FOTO DEL AUTOR. MAYO, 1999)

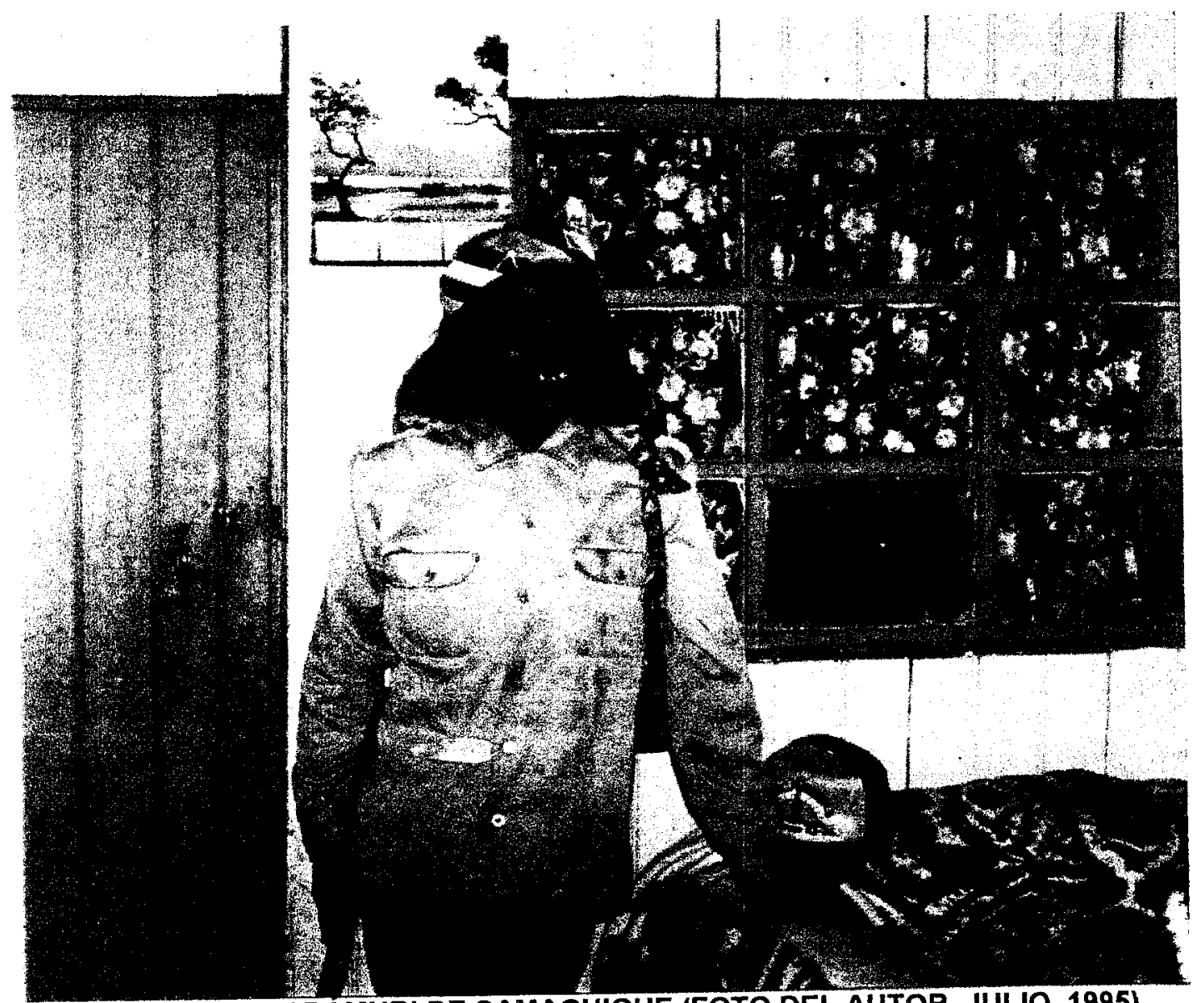

FIGURA 19.- RARAMURI DE SAMACHIQUE (FOTO DEL AUTOR. JULIO. 1995) 
Coherente con sus planteamientos -aunque, quizás, no tanto con los datos etnográficos- Cajas acaba pronosticando un futuro sin salida, un "derrumbe definitivo" para la cultura rarámuri del que ya son sintomas claros la migración de los tarahumaras y su mendicidad en las ciudades chihuahuenses, la pobreza y falta de futuro de su economía agricola y forestal, el narcotráfico y la narcosiembra en tierras serranas e incluso -como signo apocalíptico- la prostitución de jóvenes tarahumaras en las zonas de tolerancia en la ciudad de Chihuahua, germen de una posible proliferación del sida en las comunidades rarámuri de la Sierra. Nada pues de bueno encierra este incierto futuro de los indios:

Los ejidos forestales han servido para enriquecer a los mestizos y a las compañias madereras, los albergues escolares se han convertido en orfelinatos transitorios, donde más que combatir la ignorancia, se batalla contra el hambre; las raices culturales se han ido recortando; las nuevas generaciones amenazan con convertirse en nómadas urbanos; su sistema de creencias es materia de disputas teológicas entre los viejos jesuitas y las nuevas sectas evangélicas; sus míticos y legendarios organismos caen abatidos por el fuego de los soldados y los narcotraficantes y por enfermedades erradicadas en otros sitios ... y según los últimos pronósticos, el SIDA amenaza en convertirse en el nuevo Jinete del Apocalipsis, dados los altos indices que se registran en Ciudad Juárez; de ser asi, el escenario del teatro será finalmente el de la peste (lbid.: 244).

Esta lectura postmodernista del futuro indio de la Sierra Tarahumara acaba por dejar sin sentido el presente y la historia del pueblo rarámuri. Según el autor de esta interpretación, el sistema cultural rarámuri se ha vaciado por completo de sus contenidos culturales conscientes hasta devenir en un residuo en proceso de demolición etnocida. $Y$ uno se pregunta: después de cuatro siglos de contacto y transacción cultural ¿nada han creado, recreado ni resistido los rarámuri? ¿son sólo excrecencia de un pasado sin sentido, actores sin libreto de una obra sin argumento, peleles de lo más abyecto de la cultura occidental? ¿cómo explicar entonces su persistencia biológica, social y cultural? ¿cómo justificar la vitalidad de sus instituciones y el apego a sus raices? ¿no será, acaso, que los códigos en que está cifrada esta pertinaz obstinación por seguir viviendo como púeblo resultan imperceptibles a una mirada occidentalizante que ve desde el estado-nación la historia y el porvenir de los 
indios?

Sin haber pretendido ser exhaustivo, concluyo aqui este breve recorrido de las principales visiones que han caracterizado las miradas antropológicas sobre la Tarahumara y sus pueblos indios, al menos durante los últimos cien años. Al hacerlo, creo que hemos podido delimitar con más precisión cuales son las coordenadas, las proximidades y las lejanias teóricas donde se ubica el discurso indigenista, objetivo principal de este estudio.

De la diversidad de postulados y explicaciones sobre el indio serrano han derivado otras tantas propuestas de enfrentar la realidad. La mirada primitivista, como ya to dijimos, está cerca de la actitud contemplativa, respetuosa y de asombro frente al indio al que entiende como un remanente atípico del pasado que es necesario conservar, a pesar de su anacronismo. Pero esta mirada es también la vuelta autorreflexiva hacia el pasado y la profundidad más auténticos del hombre moderno. En ella se reencuentra uno con los origenes civilizatorios y los componentes más genuinos de la naturaleza humana.

Viajeros, etnógrafos, antropółogos, poetas, naturalistas, médicos y pensadores políticos construyeron a lo largo de este siglo esta visión coherente y acabada del perfecto salvaje atrincherado en los recónditos territorios de la Sierra Madre chihuahuense. Pero esta imagen, junto con su composición de lugar, no es sólo del pasado sino que sigue recreándose hoy en la mirada atónita y escondida detrás de las cámaras fotográficas de los turistas nacionales y extranjeros que descienden cada día por la escalerilla del pullman de lujo del Ferrocarril Chihuahua al Pacífico en la estación de Creel. En sus atiborradas mochilas parecen cargar, no tanto los pertrechos necesarios para soportar las inclemencias de la intemperie serrana, cuanto el peso del desencanto de la civilización occidental y las esperanzas de encontrar entre los rarámuri los secretos de la vida negados por el progreso. Como estos turistas, muchos otros viajeros presentes y 
aventureros ausentes recrean en la Sierra, por necesidad u osadia, el mito del indio primitivo que sigue vivo en medio de nuestra civilización.

Pero en ocasiones históricas este sentimiento de admiración por lo primitivo se ha trastocado en un empeño institucional por modificar y mejorar la condición del indio. De este impulso reformista han derivado visiones, teorias y explicaciones sobre el cambio del indio, los efectos de su aculturación, las estrategias para orientar este cambio de forma que logre fines preestablecidos. Es precisamente en este contexto donde surgen las visiones características de lo que hemos denominado la mirada reformista sobre la Tarahumara.

Los indigenistas y los misioneros son los mejores exponentes de esta perspectiva que implica siempre una combinación entre teoria y práctica, entre interpretación e intervención social. Creyentes en la posibilidad de la transformación del indio, los reformistas han emprendido una cruzada de salvación que responde a estrategias y modalidades diversas, pero que persigue siempre un fin: cambiar al indio, hacerlo ciudadano de la ciudad sagrada o de la nación, convertirlo, liberarlo, transformarlo, redimirlo, regenerarlo, salvarlo.

Convencidos de que el indio puede y debe modificar sus formas de vivir y pensar, los indigenistas han ensayado y experimentado todo tipo de reformas sociales enfatizando aquellas que tienen que ver con la sobrevivencia económica del indio, su socialización y su integración a la sociedad nacional.

Entre los principales postulados que han guiado este afán reformador hay uno que destaca de forma especial: el de crear y propugnar por que el indio se identifique y se asuma como sujeto comunal, como parte de un colectivo, como miembro de una sociedad. En el siguiente capítulo abordaremos precisamente las experiencias, los problemas y los debates que los indigenistas de la Sierra Tarahumara desarrollaron en 
torno a este postulado del comunalismo indio. 


\section{CAPITULO 2.- LA COMUNIDAD INDIGENA EN LA SIERRA TARAHUMARA: CONSTRUCCIONES Y DECONSTRUCCIONES DE CONCEPTOS Y REALIDADES}

Generalmente todos los que habitan esta sierra, vivian, antes de ser cristianos, una vida en lo natural poco culpable y en una politica nada bárbara, porque ni ellos entre si tenian guerras, ni cometian muertes, ni tenian hechicerias $u$ otros vicios que hasta ahora se les hayan conocido. Vivian por familias, si no congregados en pueblo y comunidad; pero nace esto de que la falta de comerciar o codicia de granjear no les atrae a buscar unos de otros lo que causa el comercio y comunicación de los hombres (Crónica anónima de Chinipas, circa 1681, citada en González, 1994:143).

Desde la época de los primeros contactos entre occidentales y "naturales" originarios de lo que hoy denominamos vagamente "Sierra Tarahumara", diferentes nociones y concepciones se han construido desde la ciencia y la ideología occidentales para justificar la urgente necesidad del cambio social de estos pueblos indigenas, tomando en consideración su alteridad cultural. De estas explicaciones, alrededor de las cuales se fue configurando el indigenismo modemo, han derivado una serie de estrategias y programas de acción a través de los cuales los agentes de la sociedad occidental ta iglesia católica y el estado nacional, principalmente- han buscado cambiar las formas de ser y vivir indígenas.

Este capitulo trata precisamente de mostrar que el principio más determinante de las propuestas indigenistas de transformación en la Tarahumara consistió en plantear la premisa de que el cambio sólo es posible a partir de que el indio asuma -de buen grado o como resultado de la imposición- formas comunales y colectivas de organización social. Este esquema ideal de convivencia implicó, entre otras cosas, propugnar por la vida en comunidad, la fijación sedentaria en el territorio, la creación de pueblos, la aceptación de un régimen centralizado de autoridad y representación políticas, un cierto igualitarismo económico y, en general, la conformación de patrones de acción en los que el individuo aparezca subordinado a la colectividad. En suma, pues, una defensa a ultranza de lo que 
podriamos denominar un "comunitarismo" indigenista.

Tomando como referente este postulado del cambio social, no es extraño que quienes, desde una visión reformadora, han creído en las posibilidades de transformación y aculturación del indio de la Tarahumara, hayan desarrollado un amplio discurso en defensa del comunitarismo indigenista. Este es visto o bien como el sistema ideal de vida al que los grupos étnicos deben aspirar o bien como una realidad etnográfica ya presente entre ellos. En cualquier caso estas visiones han tenido un doble efecto. Por una parte han idealizado el carácter, contenido y grado de socialización, articulación y unidad de los grupos étnicos y por otra, han dado pie a una serie de experimentos sociales con el objetivo de fomentar que el indio viva en forma comunitaria, justificándose asi modificaciones compulsivas o graduales en la cosmovisión, los sistemas de organización y las prácticas cotidianas indígenas.

No siempre este discurso en defensa del comunitarismo indigena ha coincidido con las concepciones que los propios pueblos indios de la Tarahumara tienen acerca de su vida en comunidad ni con sus prácticas en torno a ella. Así, la comunidad indígena en tanto realidad histórica- y el comunitarismo indigenista en cuanto modelo de interpretación y acción- han vivido procesos no sólo distintos sino incluso divergentes y en ocasiones opuestos y antagónicos.

La tesis central que trata de demostrarse aquí es que el comunitarismo indigenista, si bien permitió a los agentes occidentales justificar la acción civilizatoria y. establecer estrategias de asimilación cultural, también dio origen a variadas formas de resistencia cultural indigena. En algunas ocasiones, ésta se expresó en un rechazo y una rebelión violenta; en otras, en cambio, implicó una reapropiación por parte de los grupos étnicos de ciertas formas de organización comunalista que trataron de serles impuestas, como fue el caso, por ejemplo, del sistema de gobierno y de impartición de justicia, la organización en "pueblos" y ejidos y aún la estructura corporativa del Consejo Supremo Tarahumara. Como veremos, los grupos indigenas de la Tarahumara asimilaron y 
reutilizaron estos esquemas organizativos ajenos a su idiosincrasia, para establecer una relación pacifica e institucionalizada con el estado y la sociedad nacional, pudiendo así consolidarse como etnias dentro de la nación, aún a costa de su subordinación económica y politica.

Bajo estas premisas, se analizan a continuación cuatro momentos históricos en cada uno de los cuales el estado o la iglesia trataron de imponer a los grupos étnicos de la Tarahumara alguna forma particular de comunitarismo. El primero de esos momentos corresponde al período colonial y en especial al tiempo de implantación de las misiones de los jesuitas en la Sierra Tarahumara (1600-1767). El segundo hace referencia a las tres primeras décadas de este siglo (1900-1936), etapa en la que el estado y la iglesia ensayaron un conjunto de políticas proteccionistas orientadas a encuadrar y tutelar a los indigenas en comunidades educativas y de colonos, segregándolos de su contexto cultural para asegurar asi su civilización. El tercer momento (1936-1952) corresponde a los tiempos en los que se consolidó en la Tarahumara una propuesta radical de organizar a las etnias como una unidad politica autónoma, casi como una nacionalidad, planteamiento que derivó, entre otras cosas, en la conformación del Consejo Supremo Tarahumara. El ültimo de los intentos comunalistas fue el que instauró la política oficial del indigenismo en 1952 (fecha de creación del Centro Coordinador Indigenista de la Tarahumara) y que se ha prolongado hasta la actualidad. Esta propuesta se ha caracterizado por querer trasplantar y aplicar, sin éxito, una visión sobre la comunidad indigena de raices mesoamericanas, ajena a las concepciones y prácticas de las etrias de la Tarahumara. Tras examinar cada uno de estos cuatro momentos, concluiremos este capítulo mostrando, desde una perspectiva etnográfica, los límites reales del comunalismo indigenista.

\section{NACIONES INDIGENAS, PUEBLOS DE MISION (1600-1767)}

En 1607, apenas dieciséis años después de que los jesuitas recibieran autorización para establecer sus propias misiones en la Nueva España, tuvo lugar el primer contacto civilizatorio entre religiosos europeos e indígenas tepehuanes en el 
sureste de la Sierra Tarahumara, dando lugar a la formación de la incipiente misión de San Pablo de Balleza ${ }^{1}$, que albergó indios tepehuanes y tarahumaras. Estos esfuerzos misioneros enfrentaron, sin embargo, una violenta resistencia en muy poco tiempo: en 1616 y por cerca de dos años, los tepehuanes se rebelaron destruyendo la misión de Papasquiaro y asesinando a la mayoria de los misioneros.

Años más tarde otro intento similar de implantación misional corrió la misma suerte: la misión de Chínipas, región al oeste de la Sierra donde los mineros españoles incursionaron desde la vertiente del Pacifico por primera vez en 1589 y los jesuitas en 1601, fue destruida por los indios guazapares y warojios en 1632 dando muerte a sus dos misioneros. En ambos casos la represión militar de los españoles no se hizo esperar. Los levantiscos fueron combatidos y sus principales líderes colgados. Se iniciaba asi el ciclo típico de las tres fases de conquista -amistosa convivencia inicial, protesta reprimida militarmente y aceptación del dominio- que habria de repetirse en varias ocasiones en la Sierra Tarahumara y que fue característica de los primeros contactos de los españoles con los grupos indigenas del noroeste de México y suroeste norteamericano. ${ }^{2}$

A diferencia de los tepehuanes, guazapares y warojios, los tarahumaras, que en su mayoria se habian mantenido ajenos a la rebelión de 1616, fueron considerados entonces como sujetos más receptivos a la labor evangelizadora. Algunos de ellos, incluso, se integraron a los pueblos de misión tepehuanos restaurados en el norte de Durango a partir de 1619. Otros, se concentraron en San Pablo Balleza y en la misión de

\footnotetext{
${ }^{1}$ Hasta 1591 las misiones al norte de Zacatecas eran mayoritariamente franciscanas. En el área cercana a la Sierra Tarahumara, la primera misión jesuita fue fundada a finales del siglo XVI por Jerónimo Ramirez al norte del actual estado de Durango, agrupando a pobladores tepehuanes de la región de Santiago Papasquiaro, Santa Catalina y EI Zape. Hacia 1604, el jesuita catakán Joan Font partió de esta misión hacia los valles de Ocottán, Aguila y San Pabło, en el sureste de la Sierra Tarahumara y en las fronteras entre los territorios de tepehuanes y tarahumaras.

Para la historia de las misiones en la Sierra Tarahumara' puede consultarse Dunne, 1958 y León, 1992, pero sin duda, el trabajo más completo lo es la enorme obra de Luis González Rodriguez, por la amplitud de fuentes consultadas y el conocimiento de la zona.

${ }^{2}$ Véase al respecto la caracterización que hace Spicer (1976: 16) del modelo del "ciclo de conquista" más común en esa área cultural.
} 
San Miguel de las Bocas fundada en 1630 a la orilla del rio Florido, en el camino entre Balleza y el centro minero de Santa Bárbara. ${ }^{3}$

Nueve años después, en 1639, los jesuitas lograban ampliar su presencia en la región a través del establecimiento de cuatro nuevas misiones, todas ellas ubicadas en las márgenes del río Conchos: San Felipe, San Jerónimo Huejotitán, San Pedro de Conchos y San Francisco de Borja. Poco tiempo después se fundaron las misiones de San Francisco Javier de Satevó, Carichi, La Purísima de Papigochi y San José Temechi. Desde estos pueblos de misión, los religiosos comenzaron a desarrollar su labor en una red de pequeños asentamientos tarahumaras, -llamados en la terminología misional de la época "pueblos de visita-, hacia el ceste, configurando así un territorio designado por ellos como "Baja Tarahumara". Las misiones de la Baja Tarahumara, fundadas a raiz del avance hacia el norte desde el territorio tepehuano, fueron ampliándose y estuvieron bajo el control de los jesuitas hasta 1753. Ese año, un total de 23 misiones fueron transferidas al obispado de Durango. Entre ellas, se incluian la mayoría de las de la Baja Tarahumara y algunas de las tepehuanas del área de la Sierra de Topia, al norte de Durango. ${ }^{4}$

Entre 1644 y 1652 el trabajo misional hubo de detenerse, al enfrentar al menos tres periodos de rebeliones: de 1644 a 1645 se alzaron en armas, al sur de la Sierra, los indios salineros, tobosos, cabezas, mamites, julimes, conchos y colorados. Entre 16481649 y 1650-1652 tuvieron lugar las primeras rebeliones tarahumaras que dieron como

\footnotetext{
${ }^{3}$ Fundada en 1567 y por algún tiempo capital de la Nueva Vizcaya, Santa Bárbara constituyó el primero y más importante centro minero de Chihuahua hasta la apertura y el auge de las minas de Parral en 1631. Ambos Reales de minas conformaron la frontera cultural española al sureste de la Sierra Tarahumara y fueron durante la época colonial el punto de partida de muchas de las expediciones asi como de la gradual penetración de mineros, ganaderos y agricultores en territorios serranos. En contraste con los pueblos de misión bajo el control de los jesuitas, en los centros mineros se combinaron formas variadas de explotación de mano de obra indigena en las labores de las minas. (sobre la fundación de Santa Bárbara, véase Cramaussel, 1990). En el extremo norte de la Sierra, los primeros asentamientos de vaqueros españoles y mestizos no tendrian lugar sino hasta 1650 con la erección de la Villa de Aguilar (actualmente Ciudad Guerrero) y una misión cercana en los valles fértiles del rio Papigochi.

"Como ya to señalamos anteriormente, "Alta" y "Baja" Tarahumara hacen referencia en la terminologia colonial a los territorios situados en el sur y norte de la Sierra y no a la altitud de los pueblos donde se situaron las misiones.
} 
resultado la destrucción de la misión de Papigochi, la organización de varias expediciones punitivas en el área cercana a Tomochi y la muerte de un número significativo de indios, entre ellos algunos de sus dirigentes como el histórico líder de la resistencia Tepóraca.

A partir de 1673 y hasta la expulsión de los jesuitas de los territorios de la Corona española en 1767 se llevó a cabo la formación y consolidación de las nuevas misiones de la "Alta Tarahumara", en el norte de la Sierra Madre, proceso que fue seriamente interrumpido por la gran rebelión general tarahumara de 1690-1691 y 1696-1698 la que afectó también algunas de las misiones pimas de la frontera con el actual estado de Sonora. ${ }^{5}$ Desde las dos principales cabeceras de este territorio -San Bernabé Cusihuiriachi y San Francisco de Borja Tagüéachi- los jesuitas fueron fundando pueblos de misión y puestos de visita en el área central y noroccidental de la Sierra Tarahumara, en lugares como Carichí, Sisoguichi, Nonoava, Norogachi, Coyachi, Cocomórachi, Matachi, Yepómera, Cajurichi, Tutuaca, etc. También se incluyeron en este territorio algunas misiones de frontera entre trarahumaras y tepehuanes como Chinatú, Babogame, Nabogame, Baborigame, Cinco Señores, casi todas ellas en el actual municipio de Guadalupe y Calvo.

El tercer territorio dentro de la administración misionera colonial fue el de la región de Chinipas, al oeste de la Sierra, en los actuales límites de los estados de Chihuahua y Sonora y jurídicamente adscrito al sistema misional de Sinaloa. Tras el levantamiento de 1632, los jesuitas reiniciaron el trabajo misional en la zona en 1675, estableciendo pueblos de misión y visita en lugares como Guazapares, Témoris, San Luis de Babarocos, Batopilillas, Cerocahui, Cuiteco, Churo, Satevó, Sorichique, Yécora, etc., en el área de los actuales municipios de Uruachi, Chinipas, Guazapares y Ocampo, en

\footnotetext{
${ }^{5}$ En relación con esta tercera rebelión, se conserva el valioso testimonio del Padre José Neumann, editado, traducido y ampliamente comentado por Luis Gonzałez (Neumann y González, 1991). También puede consultarse "Testimonios sobre la destrucción de las misiones tarahumaras y pimas en 1690" en González, 1993: 237-292).
} 


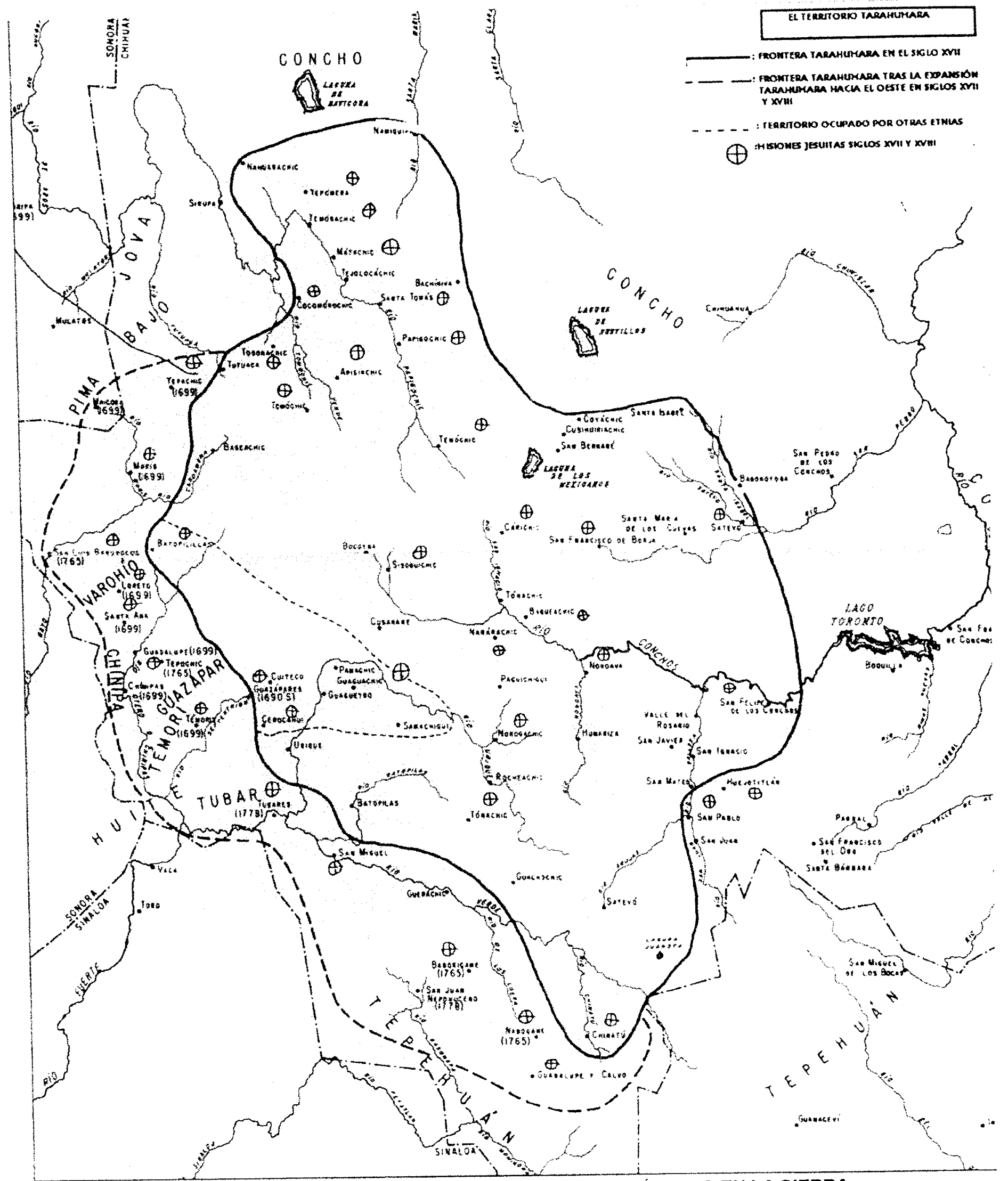

FIGURA 20.- MAPA DE LAS MISIONES Y TERRITORIOS INDIGENAS EN LA SIERRA

TARAHUMARA. SIGLOS XVII Y XVIII (TOMADO DE PENNINGTON: 1963) 
donde se asientan actualmente poblaciones de tarahumaras, warojios y pimas. ${ }^{6}$

La implantación y desarrollo de las misiones jesuíticas entre 1606 y 1767, fecha ésta última de su expulsión, tuvo un gran impacto en todos los órdenes de la vida de los pueblos indigenas de la Sierra Tarahumara. De éste nos interesa destacar aquellos aspectos que tuvieron que ver con la aparición de nuevas formas de identidad colectiva y comunitaria impuestas por los misioneros y, en mayor o menor grado, asimiladas por los indios.

A pesar de que los estudios de etnohistoria y etnolingüistica dejan hasta la fecha muchas preguntas sin contestar, es bastante fundado suponer que la colonización misionera de los grupos indígenas de la Sierra Tarahumara, -como en general, de muchos de los pueblos indios del noroeste de México- llevó a los colonizadores a asignar y crear unidades culturales y en ocasiones políticas donde éstas no existian. Partiendo de criterios lingüisticos, los misioneros utilizaron el concepto de "naciones indias" para referirse a conglomerados étnicos de una heterogeneidad muy diversa. Asi, por ejemplo, las crónicas misioneras de la Sierra se refieren en forma reiterada a la nación "tarahumara" y a las naciones de "chínipas", "guailopos", "guazapares", "tepehuanes", "témoris", "varojios", "tubares", "jovas" y otros.

Pero los datos etnográficos que contienen esos mismos documentos apuntan en un sentido muy distinto. Ninguno de esos grupos serranos puede decirse que constituyera unidades políticas ni mucho menos formas, ni aun arcaicas, de estado, similares a las de los grupos del sur mesoamericano. En una de las tipologías ya clásicas sobre los sistemas sociales de los grupos indios del noroeste mexicano y suroeste norteamericano hacia 1600, Spicer ha encuadrado a las etnias serranas de Chihuahua y Sonora dentro del modelo que él denomina "poblaciones de rancheria" ("the rancheria peoples"): pequeños asentamientos no compactos ni articulados entre sí, dispersos en las montañas y barrancas, entre las cuales las familias podian circular según las

\footnotetext{
${ }^{6}$ Puede verse al respecto "Crónicas de la región de Chinipas", en González. 1992: 23-142.
} 
estaciones agrícolas o los ciclos de la recolección silvicola. En muchos casos, la morada predominante eran simples refugios tales como cuevas en las laderas rocosas o chozas con mampostería de piedra y adobe en los valles y barrancos. Su economia se basaba en una agricultura simple soportada en tres cultivos básicos (maiz, frijol y calabaza), pero sobre todo en la recolección y la caza. Aunque se intercambiaban artículos suntuosos, no existía un comercio regular ni especializado ni mucho menos ciudades mercado.

Desde el punto de vista político no existieron instituciones que fueran más allá de las unidades familiares extensas o de los pequeños grupos de asentamientos, ni formas de control militar $o$ administrativo que trascendieran a otras comunidades $u$ otras etnias. La guerra, aunque podía ser común por épocas, no significaba conquista territorial ni subordinación tributaria de un grupo sobre otro. No hay referencias explicitas a un sistema organizado de autoridades y, en la mayoria de las crónicas sobre los tarahumaras, sólo se hace referencia a la existencia de caciques, líderes militares con ocasión de las rebeliones y shamanes -a los que los misioneros identifican con hechiceros-, pero no a una estructura religiosa-sacerdotal o militar. En suma, la Sierra Tarahumara conformaba un territorio multiétnico (tarahumaras, warojíos, pimas, tepehuanes, jovas, tubares) de pequeños asentamientos dispersos, autónomos e independientes política y económicamente unos de otros. ${ }^{7}$

Las misiones pugnaron precisamente por erradicar y sustituir el modelo de los "pueblos de ranchería". En la mentalidad de los religiosos europeos establecidos en la Sierra Tarahumara en los siglos XVII y XVII, el pueblo de misión era concebido como el baluarte de una idealizada república de indios, aislada de los vicios de la sociedad laica colonial que se desarrollaba en los centros mineros y haciendas agricolas y ganaderas,

\footnotetext{
${ }^{7}$ Este modelo de "pueblos de ranchería" -apunta Spicer- fue el más común entre los grupos uto-aztecas (pimas altos y bajos, sobaipuris, tepehuanos, hopis, paites, chemehuevis, mayos, yaquis, opatas, eudebes, jovas, tarahumaras, warijios y conchos), que constituian hacia 1600 un total de cerca de 150,000 habitantes, es decir, cerca de las tres cuartas partes del total de la población del noroeste de México y surceste de Estados Unidos. El sistema de "pueblos de rancheria" (diferenciable de los otros tres modelos: las "poblaciones de aldea", las "poblaciones de bandas" y las "bandas no agricolas") no funcionó, sin embargo, de forma homogénea en todos los lugares donde estuvo presente, pudiendose hablar, al menos, de cuatro modalidades. (Spicer, 1976: 8-15).
} 


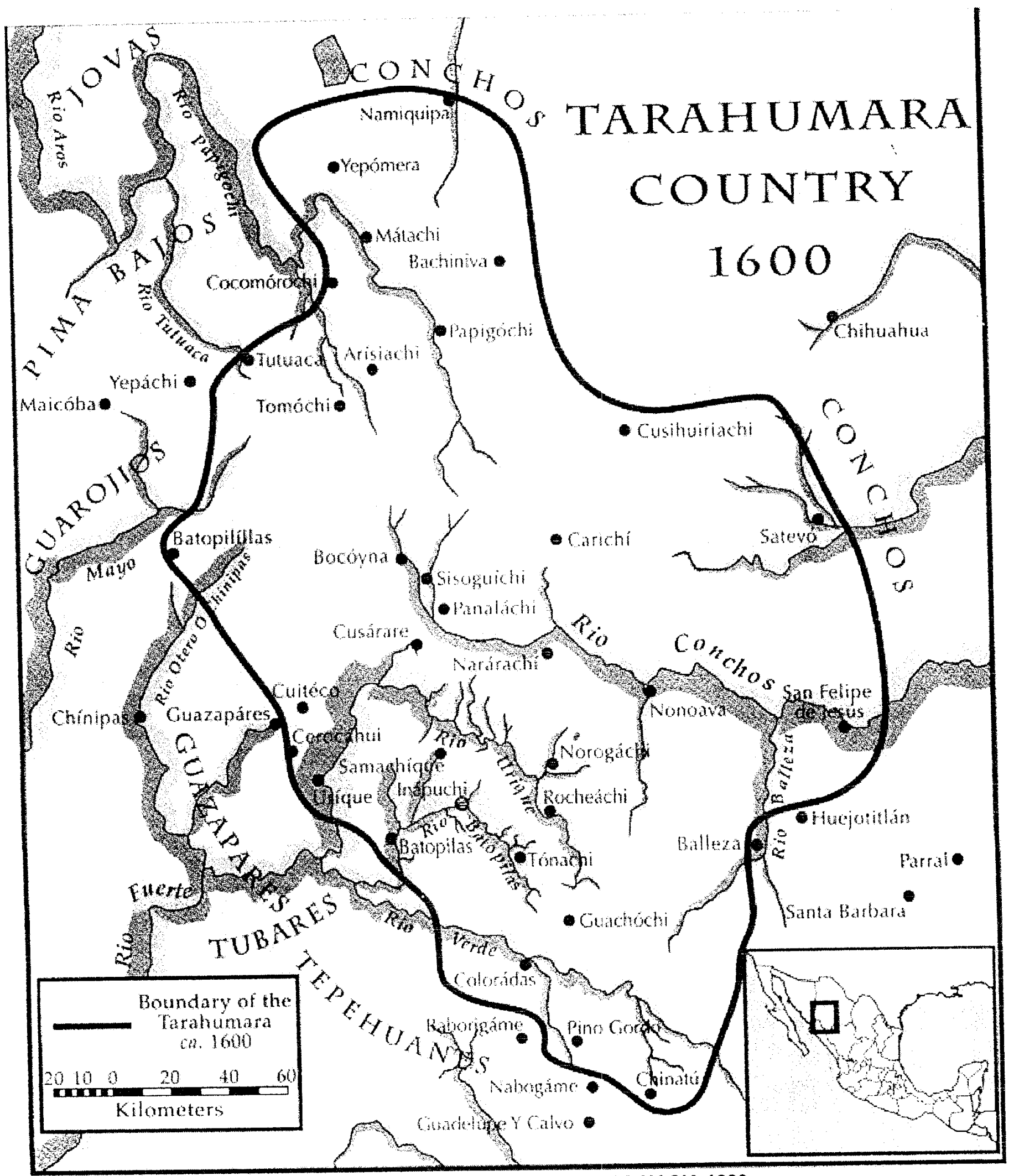

FIGURA 21.- EL TERRITORIO TARAHUMARA HACIA 1600

(TOMADO DE KENNEDY, 1966: XVIII) 

en las fronteras de las naciones indigenas. El primero de los principios implicados para hacer realidad estos pueblos de misión era "reducir" a los indios a un asentamiento estable controlado por los religiosos, es decir, evitar la libertad de movilidad espacial y estacional, tan característica de estos grupos. La reducción y adscripción de los naturales buscaba también erradicar la formación de rebeldes agrupados en bandas en un territorio agreste.

La paz era concebida como la condición más propicia para que la fe floreciera entre los nativos. Los presidios cercanos a las misiones y las expediciones militares en casos de levantamiento trataron de asegurar este clima de paz.

La catequización religiosa contó con todos los métodos pedagógicos propios de hombres ilustrados como lo eran los misioneros jesuitas: construcción de iglesias, imágenes religiosas, oraciones, ceremonias y rituales, enseñanza de los dogmas de la fe en lengua indígena y en "castilla" o castellano, uso de la música, administración de los sacramentos, vigilancia para erradicar prácticas rituales "paganas" y el consumo de tesgüino, etc.

Además de prefigurar una "ciudad sagrada", los pueblos de misión pretendieron asumir el carácter de una utopía terrenal orientada a la autosuficiencia económica, la división del trabajo y la consecuente diversidad productiva (González, 1993: 219-237 y Urías, 1994: 73-88). La agricultura arcaica y la recolección ocasional de hierbas y raices fueron sustituidas por un moderno complejo productivo basado en una nueva percepción sobre las posibilidades del medio ecológico territorial e inspirado en los ecotipos campesinos europeos: arados, animales, cereales, forrajes, molinos, trapiches, lanas, textiles, etc., a lo que se sumó una incipiente estructura de artesanos. El éxito productivo tuvo como fundamento la concesión a las misiones de sus propias tierras, tituladas como propiedad de los indios de misión y, desde luego, la fijación de los indigenas al trabajo y como contraparte, los salarios, alimentación, vestido y seguridad que las misiones les brindaron. La disciplina laboral y la cuidadosa administración de los bienes de las 
misiones hizo de éstas un negocio próspero, exento de impuestos reales y capaz de competir en los mercados de las ciudades de la Nueva Vizcaya, éxito que motivó no pocas protestas por parte de comerciantes y mercaderes.

En la construcción de este modelo de comunidad, los misioneros emplearon todos los medios a su alcance para llevar a cabo una profunda reforma de creencias, mentalidades, costumbres y formas de vida. La imposición del ideal católico de la familia monógama y de la sexualidad reducida al matrimonio, la implantación del trabajo disciplinado y productivo, el rechazo al consumo del alcohol, la prohibición de los rituales mágicos y de la hechiceria, la adopción de las buenas costumbres y, en general, el abandono de los vicios y prácticas salvajes propios de una sociedad pagana conformaron todo un programa de acción misional que, en muchos casos, estuvo lejos de convertirse en realidad y en otros dio origen a protestas y levantamientos. ${ }^{8}$

Para consolidar esta nueva estructura social, los misioneros, con el apoyo de las autoridades coloniales, suplantaron la jerarquia social de los tarahumaras basada en criterios de edad -los ancianos-, liderazgo militar -los caciques y jefes- o mágicoreligiosos -los curanderos y hechiceros-, por otra más compleja integrada por doctrineros o "tasmatianes", fiscales, capitanes, soldados, alguaciles, tenanches, "justicias", tenientes, alcaldes y generales. De este esquema habria de surgir el sistema de cargos y autoridades que sigue operando hasta la fecha entre los pueblos indios de la Sierra Tarahumara. $^{9}$

Tras varios periodos de expansión y colonización durante los siglos XVII y XVIII,

\footnotetext{
${ }^{8}$ La obra del padre José Neumann es uno de los testimonios más significativos al respecto. En ella se narran múltiples intervenciones de los misioneros en contra de prácticas culturales indigenas como ciertos ritos mágicos considerados como hechiceria-y las "tesgüinadas" colectivas, siendo hasta la fecha la ingestión del tesgüino (bebida de maiz fermentado) una práctica común de los grupos indigenas serranos ligada a un gran número de rituales y fiestas.

${ }^{9}$ Véase al respecto el interesante articulo de González (1994), en el que se caracteriza la implantación de este sistema de cargos de "autoctonización", es decir de asimilación a los esquemas indigenas del modelo de mando de los conquistadores.
} 
este sistema de pueblos de misión y el modelo de comunidad de él derivado vivió sin embargo su desarticulación y ocaso. Varias razones lo explican. En primer lugar, la resistencia militar o pasiva que asumió múltiples modalidades, desde la revuelta armada y la destrucción de los pueblos de misión a las que ya nos hemos referido, hasta el rechazo permanente a las formas de asimilación cultural y religiosa puesta en práctica por grupos que hasta la fecha siguen siendo denominados "gentiles" o "cimarrones". No menos común fue la salida de indios de las misiones para integrase a las formas de vida precoloniales y, también, la adscripción de algunos otros al trabajo, forzado o asalariado, en ranchos y minas a través de sistemas de encomienda propiciados por colonos españoles y autoridades, en contra la voluntad de los misioneros. De hecho, la presión de los hacendados y mineros, origen de varias de las rebeliones cíclicas, hizo que durante los primeros cien años de colonización de la Tarahumara, las relaciones misioneros-neófitos no llegaran a consolidarse por periodos de más de 30 años y que, durante ese siglo, el auge de los pueblos de misión, sobre todo en la Alta Tarahumara, sólo fuera intermitente (Spicer, 1976: 38)

Pero además, la sujeción de los indios a los pueblos de misión vino a relajarse a raiz de 1750, con ocasión de la gran rebelión multiétnica que asoló una gran parte de la Nueva Vizcaya. Considerada tradicionalmente como un levantamiento de los indios suma a la que siguió una larga etapa de la guerra apache, en realidad agrupó a un sinnúmero de indígenas del noroeste, entre los cuales se contaron no pocos antiguos pobladores de las misiones de la Sierra Tarahumara. ${ }^{10}$ La asimilación cultural propiciada en el seno de las misiones se volvia ahora en contra de sus artífices: los indios ponian en obra sus conocimientos aprendidos de los misioneros sobre la lógica de defensa y ataque, hasta entonces patrimonio exclusivo del aparato colonial. No sólo eso; también hacian valer una doble identidad -la de colonizados y civilizados-, capaz de permitirles atentar contra los núcleos estratégicos del poder colonial y transmititir ese conocimiento a grupos étnicos como los apaches, hasta entonces no asimilados a la obra civilizadora.

\footnotetext{
${ }^{10}$ En la explicación de esta etapa del decaimiento de las misiones, asumo aqui la interesante y novedosa interpretación de Urias, 1994.
} 
Sin embargo, la causa más definitoria de la descomposición del sistema de los pueblos de misión fue la expulsión de los jesuitas en 1767. Estos fueron forzados a abandonar las misiones correspondientes a 17 partidos de la Alta Tarahumara y otras 12 más del territorio de Chínipas. ${ }^{11}$ Dichas misiones fueron asignadas poco tiempo después al clero secular dependiente del obispado de Durango (11 partidos) y a los franciscanos del Colegio Apostólico de Guadalupe de Zacatecas (18 partidos), pero mientras los primeros no lograron mantenerlas con éxito, los segundos prolongaron hasta mediados del siglo XIX la obra de los jesuitas ${ }^{12}$. Sin embargo en toda la Tarahumara la labor pastoral decayó gradualmente debido a la falta de misioneros, la confiscación de los bienes de la iglesia, los ataques de los apaches $y$, en especial, por la apropiación por parte de españoles y mestizos de las tierras de los pueblos de misión. Todo ello impidió a los nuevos misioneros arraigar a los indios a dichos pueblos $y$, aunque en algunos lugares se construyeron prósperas iglesias y se bautizaron indios gentiles, el patrón de dispersión se acrecentó y el control de la iglesia sobre los indigenas disminuyó.

Como lo ha planteado Merrill (1995:164), el programa franciscano de reducción fracasó porque, ante la confiscación de las tierras eclesiásticas y el debilitamiento del aparato productivo de las misiones, los indigenas optaron por dispersarse y refugiarse en sus acendradas tradiciones de caza y recolección de recursos silvestres. A ello, lógicamente, se debió sumar su tradicional rechazo a vivir bajo el control de los misioneros.

La gradual desintegración de los pueblos de misión fue también resultado de una serie de reformas promovidas por la administración borbónica a través del visitador José

\footnotetext{
${ }^{11}$ De la Alta Tarahumara y región de Papigochi: Carichi, Coyeachi, Guaguachique, Matachi, Narárachi, Nonoava, Norogachi, Papigochi, Tagüèachi, Santo Tomás, Sisoguichi, Temeichi, Chinarras, Temósachi, Tónachi y Tutuaca. De la antigua misión de Chinipas: Baborigame, Babarocos, Cerocahui, Tubares, Chinipas, Guazapares, Moris, Nabogame, San Andrés, Santa Ana, Satevó y Yécora (Merrill, 1995: 157161).

${ }^{12}$ Merrill (1995: 162) señala que en 1793 sólo 1 de los 11 partidos controlados por el clero de Durango contaba con un pároco permanente. En 1859 la Ley de Nacionalización de Bienes del Clero secular y regular abolió las órdenes religiosas, por lo que los franciscanos abandonaron la Tarahumara.
} 


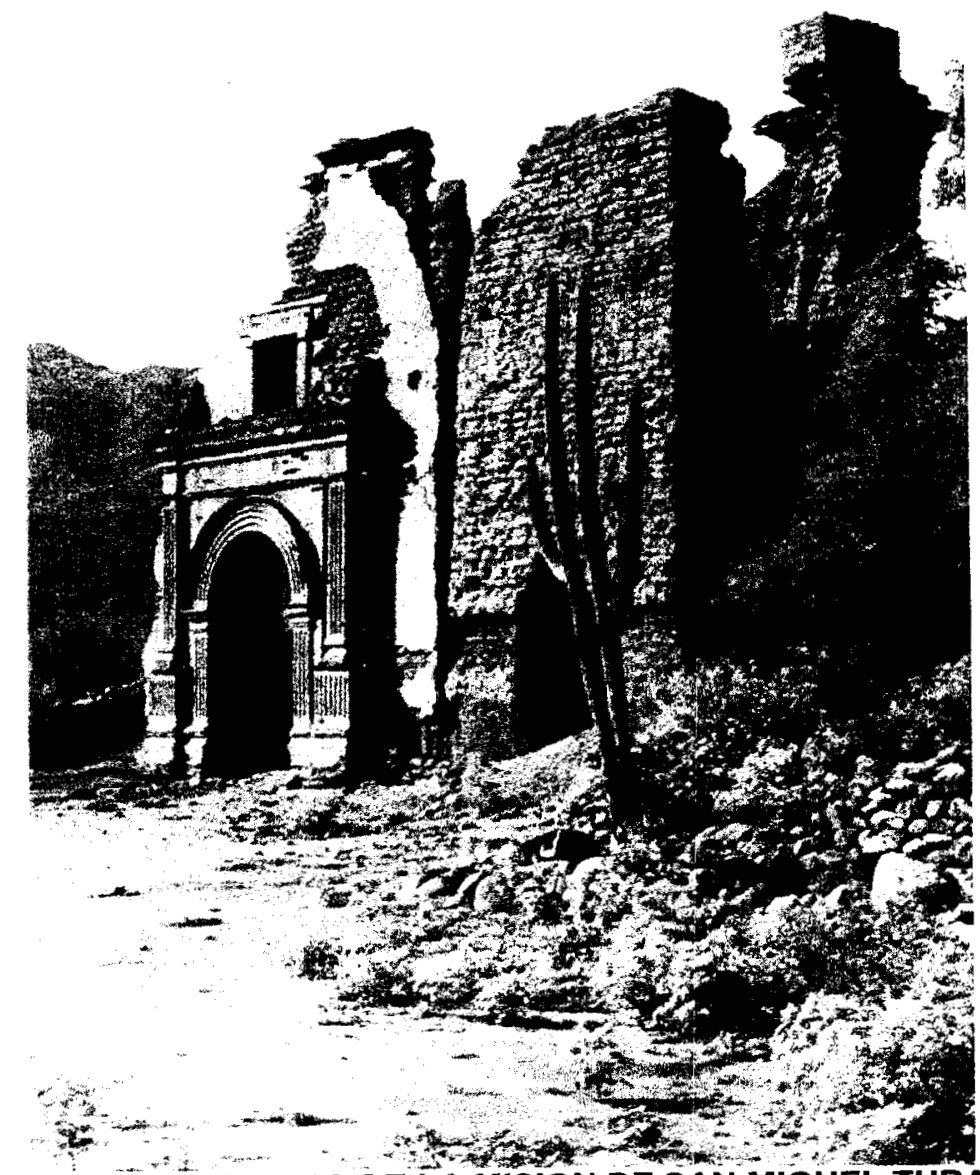

FIGURA 22.- RUINAS DE LA MISION DE SAN MIGUEL TUBARES, MUNICIPIO DE MORELOS (BAJA TARAHUMARA) (FOTO DEL AUTOR, JULIO, 1995)

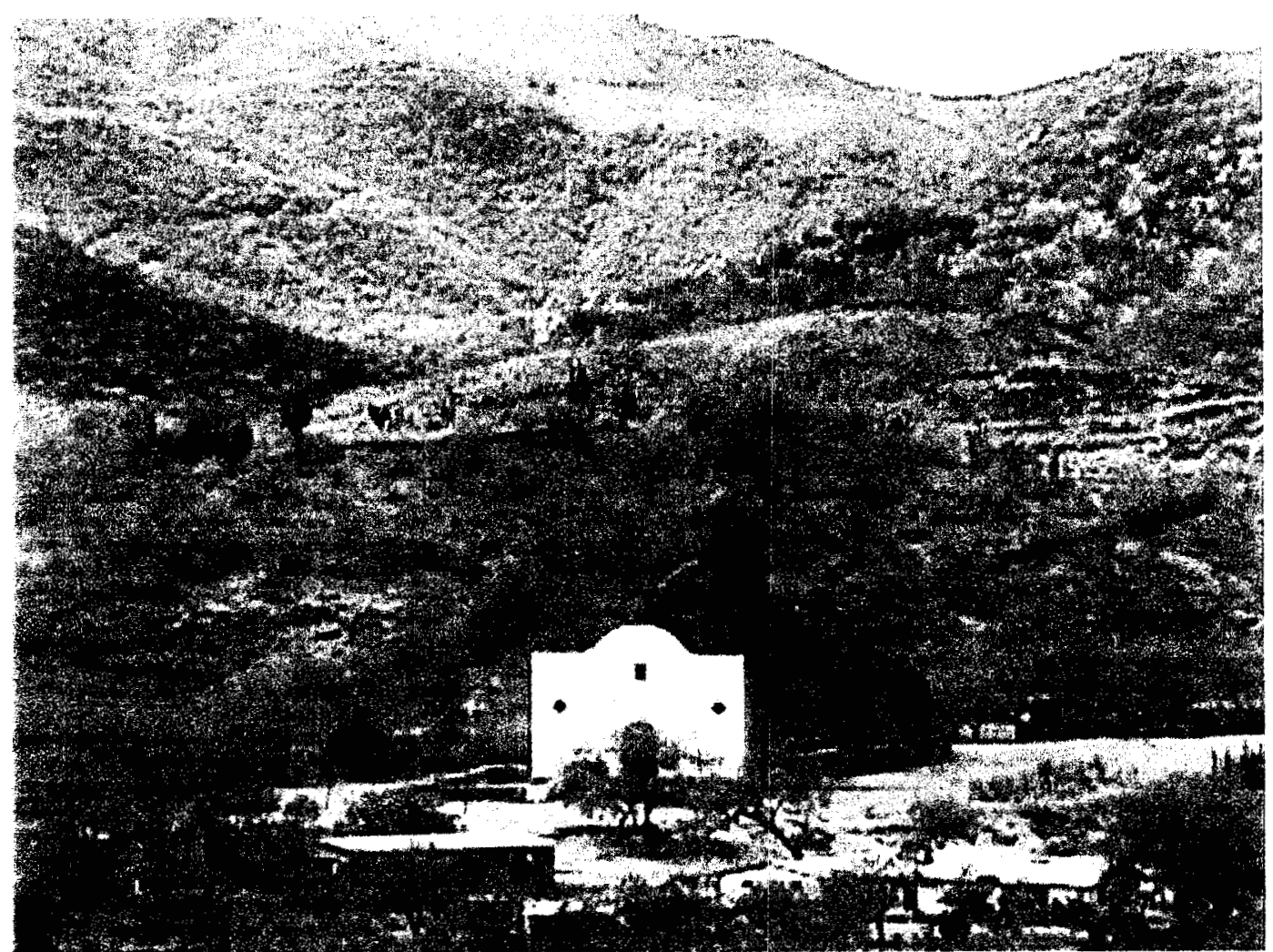

FIGURA 23.- MISION DE SATEVO, A ORILLAS DEL RIO BATOPILAS, CONSTRUIDA POR LOS FRANCISCANOS A PRINCIPIOS DEL S.XIX (FOTO DEL AUTOR, JULIO, 1999) 
de Gálvez. Con ellas y de forma temprana se implantó un sistema basado en la supresión de la adscripción territorial de los indios, en el desarrollo de pueblos conformados por españoles y mestizos (mineros, agricultores, ganaderos, arrieros y comerciantes), asentados en los viejos pueblos de misión y en la creación de nuevos asentamientos, originados a partir de la recuperación de territorios hasta entonces asolados por los apaches-, y su entrega, por parte del gobiemo, a nuevos colonos venidos de otras regiones de Chihuahua y del norte de México ${ }^{13}$.

Este nuevo modelo de comunidad supuso una ruptura radical con el que le había precedido. La utopia religiosa fue sustituida por un laicismo de estado, el comunalismo por la propiedad privada, la república de indios por el mestizaje, la segregación defensiva por la incorporación forzosa, la disciplina del trabajo comunitario por el individualismo liberal, la mística de las órdenes religiosas por el pragmatismo liberal.

En la Sierra Tarahumara, la desintegración del modelo comunitario de los pueblos de misión tuvo como correlato una cierta restauración del orden social y cultural previo a la época de la utopia religiosa: la libertad de circulación, la dispersión de la población indigena fuera del control de los misioneros, su vuelta a las prácticas paganas y el regreso a las costumbres tradicionales significaron el saldo de años de resistencia callada. Los pueblos de misión fueron en muchos casos abandonados y, en otros, convertidos en centros ceremoniales, en donde los indigenas se apropiaron del sistema de gobiemo y justicia que los misioneros les habian impuesto, adaptándolo a sus necesidades de organización interna y de relación con la sociedad mestiza circundante. Incluso, y como ya lo señalamos en el capítulo 1, fue ésta la época en la que los tarahumaras, más libres de la presión de los misioneros "raramurizaron" el contenido y el sentido del dogma, los sistemas organizativos, las prácticas productivas y, en general, las enseñanzas recibidas de los jesuitas, reinterpretándolas y reapropiándose de ellas a

${ }^{13}$ Entre 1767 y 1827, en las misiones de la Tarahumara que permanecieron bajo el control de los franciscanos, la población indigena disminuyó a 2,000 habitantes mientras que la población no indigena aumentó 10 veces, al pasar de 600 a 6,000 personas (Merrill, 1995: 167). 
partir de su cosmovisión ${ }^{14}$, porque dos siglos de catequización y adoctrinamiento no podian pasar en balde.

No es menos cierto que el aparato colonial no dejó de acosar a los pueblos indios, en especial a través de la llegada creciente de colonos mestizos y la expropiación de las tierras de los pueblos de misión. La huida hacia zonas inhóspitas y despobladas, la recreación de nuevos "pueblos de rancheria" y la refuncionalización de las viejas estrategias de sobrevivencia y cultura fueron las estrategias predominantes entre los "naturales". La utopia de los pueblos de misión habia fracasado, vencida, al fin, por la presión de una sociedad colonial de mineros, rancheros y mercaderes amparados en un régimen colonial en expansión que acababa por destruir los últimos reductos de un modelo de comunidad indigena segregada del resto de la sociedad.

\section{LA COMUNIDAD TUTELADA: COLONIZACIÓN Y EDUCACION (1900-1936)}

En agosto de 1908, el padre Gerste, un misionero de la Sierra Tarahumara, casi 250 años después de que sus hermanos jesuitas hubieran sido expulsados por el rey de España de ese territorio, escribía al Secretario del gobierno del estado de Chihuahua, manifestándole

que la única solución del problema tarahumara era nombrar al misionero como tutor del indigena, a quien habria de tratar como menor de edad.

Comentando esta opinión, otro misionero del mismo lugar, aseveraba en 1925:

Pues esto es 10 que hemos logrado con nuestra obra de colonización, con la ventaja de tener más influencia sobre el indio que tutoreamos que si hubiéramos recibido el nombramiento oficial del Supremo Gobierno. ${ }^{15}$

Los términos -tutela y colonización- y las instituciones -iglesia y supremo gobiemo-

\footnotetext{
14 Al respecto puede verse la interpretación de Robles (1994) -a la que ya hicimos mención-sobre las modalidades de apropiación y reinterpretación de los contenidos y simbolos católicos que hicieron los tarahumaras bautizados o "pagótuame" a partir de la salida de los jesuitas de la Sierra.

${ }^{15}$ Ambas cartas, la primera enviada a Victoriano Salado Alvarez el 8 de agosto de 1908 y la segunda, del padre Cordero, publicada en las "Noticias de la Provincia de México" de la Compañia de Jesús el marzo de 1925, aparecen citadas en Ocampo, 1950: 239.
} 
referidos en estos documentos parecen resumir las claves de interpretación para entender las concepciones y políticas emprendidas frente al "problema tarahumara" en el lapso histórico comprendido entre principios de siglo y el final de su tercera década. Tales concepciones y modelos de acción constituyen además el antecedente más cercano de la politica indigenista actual que llegaria a consolidarse en la Sierra Tarahumara al inicio de los años cincuenta.

En el período de referencia, 1900-1936, la visión de los agentes institucionales occidentales -la iglesia y el gobierno- que predominó fue la de concebir que las causas de la miseria del indio serrano radicaban en el atraso de su cultura. Este no sólo le impedia acceder a los elementos para convivir y desarrollarse en una sociedad modema, sino que también le convertían en una víctima de la expoliación de autoridades rurales, rancheros y vecinos mestizos de esa región.

El círculo vicioso de atraso culturatexplotación no tenia, para esos agentes, posibilidad de solución dentro de los márgenes de la mentalidad indígena. Para superarlo, era necesario una intervención externa de carácter civilizatorio que emancipara a los indios de sus costumbres oscurantistas y los introdujera, llevándolos de la mano como niños, por las sendas de la civilización y el progreso que, entonces, era el signo de los tiempos en el pais. Entre las posibles estrategias para llevar a cabo tan heroica tarea, ninguna parecia más convincente y eficaz que la escolarización y la creación de colonias agricolas indigenas. Mientras la primera permitiria inculcar en el educando los valores de la ciencia y la moral occidentales, la segunda resultaba el más eficiente método de erradicar del indígena la perniciosa influencia de su medio. En suma, se proponia al indio romper con su entorno social y sus lazos culturales de origen para convertirse en miembro activo de una nueva sociedad, la misma a la que estaba adscrita el resto de la nación.

La coincidencia de perspectivas entre iglesia y estado no era sin embargo total. Desde los días del gobiemo de Juárez y de la promulgación de la constitución de 1857 , 
los gobernantes mexicanos $y$, en particular, los liberales chihuahuenses tan dignamente representados en figuras de la talla de Luis Terrazas y Enrique Creel, no podian por menos de concebir que la civilización tenía que tener el sello de la secularidad y que la aplicación de las leyes de Reforma otorgaba al gobierno el monopolio de la acción educativa que debia de ser cientifica y laica. La iglesia, por su parte, insistía en la necesidad de combinar civilización y conversión, ciencia y fe, educación y moral. Nada como la conversión cristiana de los indios podia volverlos más útiles y adaptados a la moderna sociedad y ninguna esperanza cabría albergar de una tarea civilizadora que no estuviera regida por las convicciones morales sostenidas en la fe.

El debate entre el estado y la iglesia sobre la acción indigenista versaria pues durante cerca de treinta años no tanto en tomo a sus estrategias cuanto a sus metas finales, pero sobre todo en relación al monopolio que uno y otra pretendieron atribuirse en dicha acción. El conflicto, tenuemente planteado durante el porfiriato, se convertiria en los años de la revolución y, sobre todo, en algunos periodos de la post-revolución y del cardenismo en motivo de abiertos enfrentamientos y acciones persecutorias anticlericales de las que derivaron la suspensión temporal de la acción eclesiástica. Al inicio de los años cuarenta, cuando las aguas volvieron a su nivel, todo indicaba que los viejos pleitos habian perdido toda razón de ser: el estado comenzaba a hacer realidad una política indigenista inspirada, como veremos, en la utilización secularizada de muchos de los principios de la obra misionera que, años atrás, había perseguido.

Para religiosos y gobernantes de principios del siglo, la tarea civilizadora de los indios de la Sierra Tarahumara era a todas luces novedosa y urgente. Novedosa en primer lugar para el gobierno estatal que, durante todo el siglo XIX no había tenido oportunidad de concebir otra política indigenista que no fuera la de erradicar del territorio del norte de Chihuahua el peligro incesante de los indios apaches ${ }^{16}$, considerando por

\footnotetext{
${ }^{16}$ La guerra contra los apaches fue, desde mediados del siglo XVIII hasta finales del XIX, el problema indigena más grave y dificil de resolver para los gobernantes chihuahuenses. Las campañas y persecuciones militares tuvieron lugar, sobre todo, en los desiertos del norte del estado, territorio predilecto de las bandas apaches. Entre otras muchas estrategias para combatirlos, el gobiemo estatal promovió la formación de partidas de civiles y decretó en 1849 las "contratas de sangre", otorgando recompensas 142
} 
eso el problema de la Sierra Tarahumara como secundario. Novedoso también para la iglesia, porque tras 250 años de la expulsión de los jesuitas, las tareas misioneras entre los indios serranos habian ido gradualmente decayendo, en especial a lo largo de todo el siglo $X I X .^{17}$

El apremio, compartido en amplias esferas de la sociedad de principios del siglo, de no posponer por más tiempo la civilización de la Sierra estaba soportado en razones de peso: paradójicamente, mientras la revolución industrial, en manos del capital extranjero y encarnada en una naciente industria forestal, una pujante restauración de los centros mineros de origen colonial y una gradual expansión de la via férrea hacia el Pacifico ${ }^{18}$, comenzaba a hacer sus primeros estragos en medio del territorio serrano, los núcleos de población indigenas vivian, desde hacia cerca de un siglo, un proceso de creciente aislamiento con respecto a la población mestiza advenediza (Spicer, 1976: 44) y una consecuente "reindianización".

En efecto, la Ley de Colonización de 1825 que permitió la compra, por parte de rancheros mestizos, de las tierras comunales ociosas de los antiguos pueblos de misión

monetarias a quienes entregaran cabelleras apaches. El peligro apache sólo comenzó a ser controlado hasta 1880, fecha de la batalla de Tres Castillos en la que el coronel Joaquin Terrazas derrotó a un grupo comandado por el jefe Vitorio. (Sobre la guerra apache en Chihuahua pueden consultarse, entre otros Terrazas, 1905 y Orozco, 1992).

${ }^{17}$ A raiz de la expulsión de los jesuitas en 1767, las misiones de la Sierra Tarahumara fueron transferidas a los franciscanos, siendo éstos expulsados en 1857 y sustituidos, primero por el clero secular y, a fines del siglo XIX, por los padres Josefinos. En 1900, y tras recibir la autorización correspondiente del propio general Porfirio Diaz, los jesuitas retomaron a su cargo las misiones de la Tarahumara. (Sobre la historia moderna de esta misión, véase Ocampo, 1950).

${ }^{18}$ Durante la primera década del siglo tuvieron lugar, en efecto, una serie de transformaciones profundas en la economia serrana. Acicateados por la presencia del ferrocarril que alcanzó a tocar, en la primera década, hasta los municipios de Bocoyna y Guerrero y que soñó desde entonces con articular la frontera norteamericana con el Pacifico, numerosos inversionistas norteamericanos y europeos emprendieron una restauración de importantes centros mineros como Batopilas, Guadalupe y Calvo, Ocampo, Urique, etc. La electricidad y los medios de transporte motorizados llegaron a la Sierra junto con la metalurgia. También fue ésta la época de los primeros aserraderos destinados a abastecer la construcción del ferrocarril que se desarrollaron inicialmente al norte del distrito de Guerrero, dando lugar a la creación de Ciudad Madera. (Entre otros, pueden verse al respecto, para el ferrocamil: Almada, 1971; para la mineria: Day, 1979; Griggs. 1907; Pletcher, 1958; Shepherd, 1965 y Sonnichsen, 1976 y para la industria forestal: Lartigue, 1982). 
de la Alta y Baja Tarahumara. Además, otra reglamentación similar de 1833 garantizó a los habitantes originarios de la Sierra -mestizos o indigenas- la adquisición de parcelas familiares. Por todo ello, muchos indigenas optaron por desplazarse hacia lugares más inhóspitos, alejándose del influjo de los blancos y asegurando asi su autonomía. ${ }^{19} \mathrm{La}$ imagen de los tarahumaras que Carl Lumholtz retrataba en su México desconocido, tras sus viajes científicos en la Sierra Madre durante la década de 1890 era un claro testimonio de la persistencia de las cosmovisiones, prácticas y formas de asentamiento de origen precolonial asi como de una muy restringida asimilación de las costumbres occidentales por parte de los tarahumaras. ${ }^{20}$

Las primeras acciones "civilizatorias" por parte del gobierno y la iglesia en la Sierra Tarahumara en la primera década de este siglo fueron las escuelas. El gobiemo implantó algunos establecimientos de instrucción primaria en varias cabeceras municipales,

\footnotetext{
${ }^{19}$ La Ley de 1825 que trataba de promover el repoblamiento del territorio estatal, permitio la venta de tierras que no fueran demandadas por las comunidades indigenas o no fueran explotadas a colonos mestizos de fuera de la Sierra. Con ello se pretendia también que esta población jugara el papel de agente civilizador de cambio frente a los indios. La expropiación de terrenos que derivó de esta ley fue tal que propició otra de carácter correctivo en 1833, prohibiendo la invasión y apropiación de las tierras de las comunidades indigenas. Sin embargo la ley reconocia el derecho de las familias ya asentadas en la Sierra a adquirir parcelas, por lo que muchos mestizos regularizaron entonces sus titulos sobre terrenos previa e ilegalmente adquiridos. (Spicer, 1976: 39-40). Similar efecto tuvo la Ley de desamortización de manos muertas de 1856 y su aplicación posterior en 1859 (Almada, 1968: 164, 356 y 514).

${ }^{20}$ En el capitulo VI de su obra, en el epigrafe titulado "Los verdaderos tarahumaras" y refiriéndose al puebto de Cusárare, afirma Lumholtz:

Acampamos a pocas millas fuera del pueblo, y enviamos al guia a advertir a los habitantes de nuestra llegada. Bastante se habia hablado recientemente entre los mexicanos del salvaje pueblo que vivia en aquellas profundas barrancas, y era, en verdad precipitación de mi parte el acercarme a tales sitios. No habia mexicanos establecidos en Cusárare ni más adelante, de manera que, excepto en el reducido campo minero de Barranca del Cobre, ningunos habia en una extensión de cincuenta millas al sur y más o menos la misma distancia de este a ceste.

Los pueblos de los indios, en toda la República, permanecen casi abandonados la mayor parte del año. Me refiero, por supuesto, a los que no han tomado carácter mexicano. Lo primero que tuvieron que hacer los misioneros fue obligar a los indigenas a formar pueblos abandonando sus dispersos ranchos [...] pero el objeto de hacer que los indios permanezcan en aldeas no se ha conseguido hasta hoy, y sólo las autoridades que los naturales exigen, abligados a residencia determinada por el término de su cargo, constituyen una especie de población permanente en los pueblos. En cuanto a los naturales, sóto se reúnen para celebrar sus fiestas, y los domingos, para ocuparse del culto, según ellos lo entienden (Lumholtz, 1986: 135-137).
} 
centros mineros y localidades con mayor densidad dernográfica. ${ }^{21}$ Estas escuelas se limitaban sin embargo a atender casi exclusivamente a los hijos de colonos mestizos, descuidando por completo a la población indigena por razón de su dispersión demográfica.

También los jesuitas (en su mayoría españoles y mexicanos), recién instalados en la Sierra iniciaron por esos años la instalación de pequeños planteles escolares, normalmente anexos a la misión. A medida que los jesuitas fueron abriendo misiones y pueblos de visita ${ }^{22}$, fueron creando este tipo de establecimientos en lugares como Sisoguichi (cabecera de la misión desde 1900), Carichi, Nonoava, Norogachi, Tónachi, Samachique, etc. A diferencia de sus similares "de gabierno", en estas escuelas se enseñaba en lengua tarahumara, junto con las primeras letras y elementos propios de la catequesis católica. Pero la más importante diferencia estribaba en que estas escuelas incluian entre sus alumnos a niños y niñas indígenas y que poco a poco fueron asumiendo el carácter de internados. Concentrando a los niños en edad escolar en los towisados y tewecados, como asi fueron denominados ${ }^{23}$, no sólo se enfrentaba el problema de la dispersión geográfica de los pueblos, sino que además se alejaba a los niños del influjo de sus comunidades de origen. ${ }^{24}$

${ }^{21}$ En esa primera década las escuelas primarias de gobiemo se concentraban en Jesús Maria, Ocampo, Carichi, Nonoava, Batopilas, Bajisochi, Arenal, Cerro Colorado, Cuiteco. Guachochi, Morelos, Lluvia de Oro, Rochéachi, San Ignacio, Yoquivo y Urique, con una inscripción total de cerca de 400 niños de ambos sexos, en su mayoría mestizos (Valverde, 1989:98).

22 Rancherias y asentamientos menores, dependientes de una misión central a donde el misionero, residente en ésta última, acudia periódicamente. Véase lo que ya señalamos más arriba sobre los pueblos de misión durante el período colonial.

23 Internados de niños y niñas. Towi y Teweque en lengua rarámuri significan niño y niña respectivamente. Mientras los primeros eran atendidos por religiosos, los segundos estaban al cargo de monjas.

${ }^{24}$ El padre Gassó, jesuita que se encargó de definir el rumbo de los internados, señalaba al respecto:

... uno de los etementos de mayor trascendencia para conseguir la evangelización y civilización de los indios es la escuela, porque de esta manera se propagan los conocimientos útiles y prácticos que educan al hombre, se cultiva la inteligencia, se ensancha la esfera de los conocimientos, se enseñan las buenas costumbres, se despierta el amor, [el] trabajo y la idea sublime de la Patria [...] y tomando a los blancos y tarahumaras como un solo cuerpo, nosotros los dividimos porque son elementos incompatibles y 
Esta concepción originaria de los internados estaba integrada dentro de una visión más global de la evangelización, según la cual se propugnaba por aislar a los indios de la nefasta influencia del elemento mestizo e incluso por un cierto regreso al modelo de "la república de indios", lo que significaba conseguir del gobierno el respeto y reconocimiento de las tierras de las comunidades, el sistema de gobierno y justicia indígenas, la no interferencia de los jefes políticos dentro de las comunidades tarahumaras, la restauración del sistema de castigos corporales impartidos por los "gobemadores" (o siriames) a quienes cometieran delitos y el apoyo oficial a los internados religiosos. Este programa ambicioso tuvo, sin embargo, poco eco en las esferas oficiales y fue incluso motivo de protestas airadas de algunas autoridades mestizas serranas. ${ }^{25}$

Frente a la propuesta de los religiosos y quizás para adelantarse a ella, el gobierno de Creel dictó en noviembre de 1906 una Ley sobre la civilización y mejoramiento de la raza Tarahumara, considerada en la literatura indigenista como una de las disposiciones más avanzadas de la época ${ }^{26}$. En su exposición de motivos y en sus 16 artículos, la ley constituye todo un decálogo de la concepción incorporacionista del indigenismo y representa una clara visión del problema indigena desde la perspectiva

hacemos corno dos escuelas a diferentes horas, con diferente lengua y diferente plan de conocimientos, si bien convienen en el fin último de procurar la salvación de los alumnos.

El padre Gassó recomendaba también enseñar en las escuelas de la misión, doctrina cristiana, lectura y escritura, gramática castellana, aritmética, música y canto, pero la escritura, en letra de molde, para proteger a los indigenas de la literatura de protestantes y masones.(Referencias tomadas de Valverde. 1989: 65 y 66 )

${ }^{25}$ Las palabras con que el gobernador Creet respondió al padre Gassó con respecto a sus intenciones reformadoras ilustran más que sobradamente el pensamiento de un liberal convencido:

El plan que usted propone, es inmejorable para una nación católica como España, pero para aqui, aunque no entro a discutir si las leyes son buenas o malas, 10 tengo por punto menos que imposible. La misión de ustedes es pura y exclusivamente evangélica, asi no se han de meter en negocios de terrenos ni aun en los llamados de Misión; si necesitan Ustedes algo a titulo e enseñarles como regalos o 'útiles, se los daré con gusto; pueden poner escuelas privadas, las miraré bien y escribiré a las autoridades que les favorezcan y les procuren gente. Entresáquese un proyecto de civilización, no de Chantre, sino de modemo Humboldt (Ocampo, 1950: 67).

${ }^{26}$ Puede consultarse una versión completa de esta ley en Sariego, 1998a: $19-40$. 
liberal.

Partiendo de inicio de los graves problemas agrarios y la explotación a la que estaban sometidos los tarahumaras y reconociendo la inadecuación de la educación en ese medio asi como la importancia para la nación y las cualidades intelectuales de los indios chihuahuenses -se retomaban aqui las opiniones de Lumholtz y del padre Gerstela ley civilizatoria de Creel comenzaba por decretar la creación de una Junta Central protectora de indigenas, integrada por 5 personas nombradas por el gobernador y apoyada por un grupo de corresponsales en las cabeceras de los distritos serranos.

En su artículo cuarto, la ley precisaba las funciones tutelares de esta Junta: promover la civilización de la tribu tarahumara, su mejoramiento social, educación, bienes y régimen de colonias agricolas; realizar el deslinde de los ejidos de los pueblos tarahumaras; congregar a los indios en pueblos dotándolos de tierras y aperos de labranza "para que empiecen a gustar de la vida doméstica y civilizada, premiando a los que de grado se agrupen en pueblos o colonias"; cuidar por el reparto anual de semillas; reglamentar el régimen interior de las colonias de tarahumaras "para conservar en ellas el orden, la moralidad, las buenas costumbres y el amor al trabajo"; establecer escuelas rurales para niños indígenas que incluyan la enseñanza agricola; excitar la filantropia de la sociedad para obtener apoyos a la tarea civilizadora; "conseguir por la persuasión que los indios se desprendan espontáneamente de sus hijos varones o hembras para enviartos a las escuelas de la capital del estado y de las cabeceras del distrito"; buscar "no contrariar a los indios en sus ideas religiosas, en sus juegos, bailes, fiestas $y$ esparcimientos, asi como en sus costumbres intimas y profundamente arraigadas; pero procurar si la evolución lenta, tenaz y constante de la raza, hasta convertirla a la civilización, mediante que se la rodee de los beneficios que disfruta la gente culta, para que asi lleguen los indigenas a ser buenos ciudadanos y a contribuir con su labor al progreso de la familia mexicana"; premiar con tierras y ganado a los indios que acepten enviar a sus hijos a las escuelas, "que den pruebas de procurar y propagar la temperancia alcohólica y que se muestren más amantes de la vida politica y civilizada". 
Como ejecutores de las medidas adoptadas por la Junta Central, la ley establecia la existencia de Comisionados instalados en los principales pueblos de la Sierra a quienes asignaba, entre otras funciones, las de "ayudar decisivamente a la raza indígena protegiéndola de los que, ya por explotar sus personas, ya por deseo de apoderarse de sus cortos bienes, se introducen entre ella y abusan de la ignorancia y buena fe de los individuos que la componen"; vigilar el funcionamiento de las escuelas y colonias tarahumaras asi como "las misiones que con carácter religioso o educativo se establezcan entre los indios, procurando que en ellas se observen con la posible fidelidad todas las leyes federales y del estado y sin que lleguen a traspasarse nunca, por los sacerdotes o sus adeptos, orden ninguna de las que afecten el modo de ser generar"; vigilar que los "gobemadorcillos y capitanes" no se excedan en sus castigos y evitar a toda costa que las tierras de los indigenas sean objeto de compraventa o puedan ser embargadas.

Entre las novedades más significativas que planteaba esta ley cabe destacar la formación de colonias agrícolas tarahumaras y los contenidos de la educación indígena. En cuanto al primer aspecto, el modelo de colonias que se proponía se acercaba estrechamente al de las reservaciones norteamericanas: poblamiento con predominio de indígenas, repartos de tierra, ganado y utensilios, prohibición de ventas de terrenos a mestizos, vigilancia por parte del gobierno, prohibición del consumo de alcohol, etc. En cuanto a la orientación de la educación indigena la ley precisaba los siguientes contenidos: lecto-escritura en español, cálculos de las cuatro operaciones, nociones rudimentarias de geometria, cuentos históricos con aplicación al civismo, trabajo manual y agricola en labores tales como la elaboración de textiles, jarciería, carpinteria, hojalateria, alfareria, pintura, música, decoración, cultivo de flores y hortalizas pero "sobre todo maiz, frijol, chile y trigo", conocimientos sobre tecnologia agraria y fomento de actividades deportivas como la carrera, la lucha y el tiro al blanco (Creel, 1906).

En suma, pues, la ley del gobemador Creel, retomaba algunas de las propuestas planteadas por los misioneros, pero otorgaba al estado un papel rector en las tareas de 
civilización de los indios, aspecto éste novedoso por completo en la trayectoria histórica de las acciones indigenistas del gobiemo chihuahuense. La ley no daba lugar a dudas: ningún atisbo de atribuciones especiales era delegada a la iglesia o a instituciones privadas. La tutela de los indios quedaba en manos del estado y su "mejoramiento" era concebido a partir de la implantación de reformas agrarias y educativas tendientes a incuicar entre los indios los valores y prácticas de la cultura y la civilización occidentales. No habia que contrariar a los indios en sus "supersticiones", pero habia que luchar pacientemente por erradicarlas. La concepción indigenista de Creel era además, en algunos aspectos, particularmente perspicaz: los verdaderos detonadores del cambio y mejoramiento de la condición de atraso del indio eran la explotación moderna de la tierra y su educación y era en esos ámbitos donde la acción del estado debía concentrarse.

Para bien o para mal, la propuesta de Creel nunca llegó realmente a ser puesta en aplicación. De ella sólo se derivó la creación de una colonia agricola implantada en la ciudad serrana de Creel, a la orilla del ferrocarril y lejos del medio agreste tarahumara. Dicha colonia estaba integrada en 1907 sólo por 30 familias tarahumaras y 21 mestizas con un total de 191 personas, asignándosele a cada familia una parcela de 10 hectáreas de terreno agricola (Spicer, 1976: 41).

El estallido de la revolución vino a poner término a los sueños civilizatorios de Creel. También a los de los misioneros de la Sierra, en especial a partir de 1914 cuando el gobierno villista decretó la expulsión de los jesuitas extranjeros y el ambiente bélico impidió el desarrollo de la tarea misionera. Por eso, la obra educativa debió interrumpirse hasta el inicio de los años veinte.

Hacia 1920 las concepciones y prácticas de los misioneros de la Sierra Tarahumara sobre la educación indigena adquirieron un nuevo impulso. Los internados escolares y la creación de incipientes colonias agricolas con jóvenes parejas de matrimonios tarahumaras pasaron a ser vistas como la estrategia central de cristianización y civilización de los indios. Sin duda, el principal ideólogo y artifice de esta 
tarea fue un tal padre Mier y Terán, que, al parecer, trató de adaptar en la Sierra Tarahumara la experiencia de los jesuitas en otros paises de misión como el Congo belga ${ }^{27}$. En una carta enviada en octubre de 1923 al Director de Enseñanza primaria del gobierno del estado de Chihuahua, el padre Mier y Terán resumia en cuatro principios básicos, los lemas de la educación indigena, adelantándose por varias décadas a los que habrian de ser los postulados indigenistas:

10. Hay que formar pueblos. Los pueblos son unas entidades morales que representan a un conjunto de habitantes diseminados por vastas extensiones de muchos kilómetros. Si en cada rancho se pone una escuela (lo cual es imposible), se tropezará en menor escala, con la misma dificultad de dispersión. Son estos indios tribus nómadas, inconstantes, que van de acá para allá, buscando el texgüino, la tierra fácil de labrar y huyendo del blanco que lo extorsiona.

$2^{\circ}$. Si pueblos no se pueden formar [...] pónganse internados. Pero además [...] los tohuises continuamente se escaparán al monte, por más patemalmente que se les trate, por más que les dore la jaula y por más que se les vigile. No hay que esperar que el "tata" devuelva al muchacho; antes bien, que el muchacho, aún no alcoholizado directamente reflexione mejor que el salvaje de su padre, y vuelva de grado.

$3^{\circ}$. La instrucción rudimentaria de unos dos años, por lo menos, tiene que ser sencillamente en su "idioma" [...]; de lo contrario se quedará generalmente sin ningún idioma el niño, sin ideas sólidas, sin asimilación de las ideas abstractas y morales (que son las que más se necesitan para su regeneración y su civilización), mascullando un "castilla" imposible, sin gusto por los libros y con escritura salvaje. [...] Yo creo que toda la instrucción, pero sobre todo la del indio bozal, debe ser, más que de memoria, de entendimiento. Por eso humildemente opino que enseñar a los indios salvajes en castellano, es una atrocidad que la paidologia modema no puede perdonar.

$4^{\circ}$. Por último, entiendo que atiborrar a esas cabezas salvajes con ese fárrago de conocimientos de nuestras "modemos" programas escolares muchas veces llenos de vaguedades y pedanterías, es retardar su sólida civilización y cultura, fomentar su indolencia y pereza muscular y desaprovechar la rica vena de energia y actividades que hay en esta pobre raza degenerada. Quiero decir que las escuelas de indios tienen que ser de agricultura, de artes y oficios manuales ante todo. La tercera o cuarta generación, ya redimida, podrá entrar de lleno en la corriente de Instrucción y cultura general del pais (Ocampo, 1950: 137-138).

Los comentarios del religioso sintetizaban la tarea que los misioneros estaban

${ }^{27}$ Puede verse al respecto Valverde, 1989: 62-97, en donde se analiza con detalle la historia de los towisados y tewecados, asi como de la colonia catequista de Sisoguichi. La autora, apoyándose en fuentes de archivo de la Misión de la Tarahumara muestra cómo el modelo de las colonias estuvo 


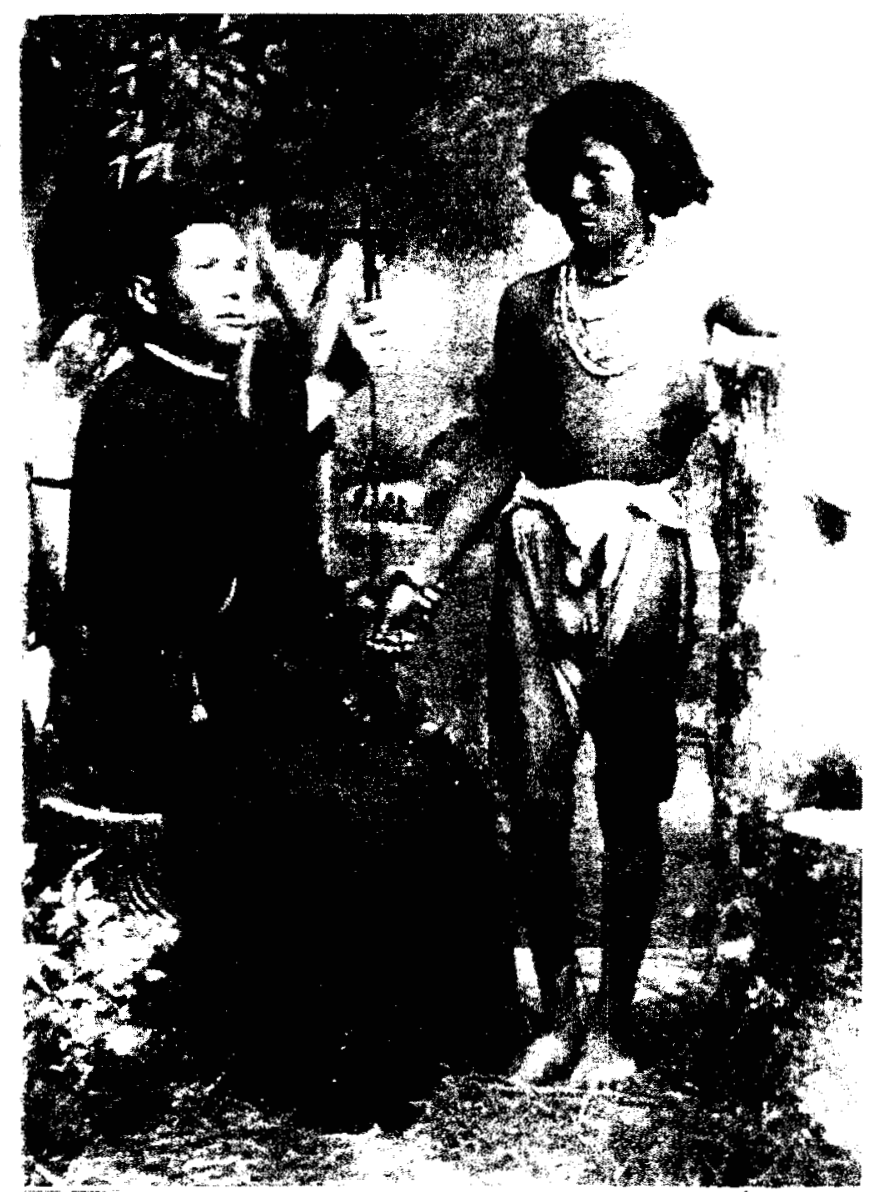

FIGURA 24.- EVANGELIZACION DEL INDIGENA (GÓMEZ, 1948: 106)

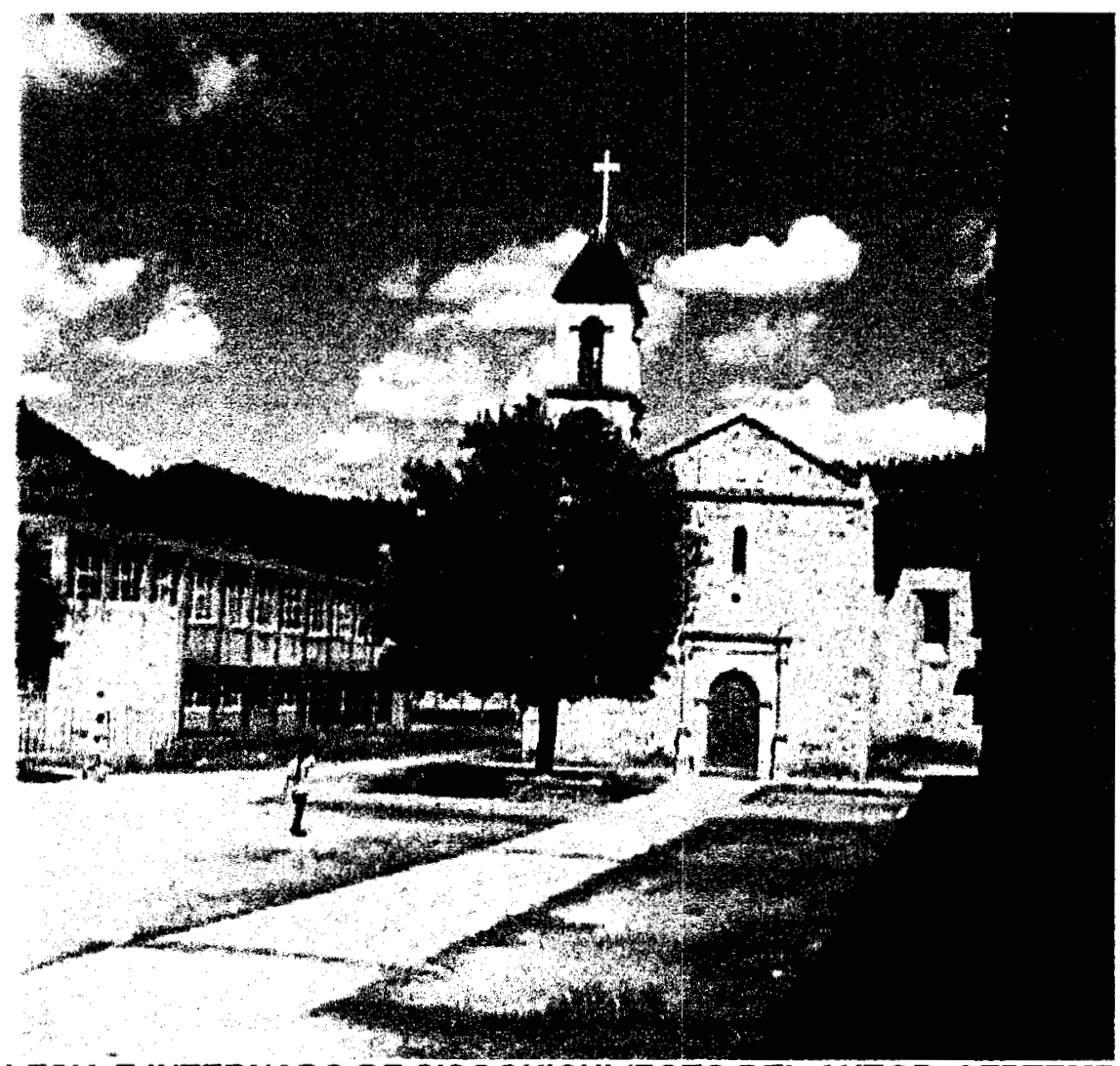

FIGURA 25.- IGLESIA E INTERNADO DE SISOGUICHI (FOTO DEL AUTOR, SEPTEMBRE DE 1998) 
llevando a cabo en sus towisados y tewecados, que por esos años se expandieron y consolidaron en Sisoguichi, Samachique, Carichi, Baquiachi y Norogachi. También en noviembre de 1924 se hacia realidad la Colonia agricola catequista de Sisoguichi integrada originalmente por cuatro familias jóvenes de tarahumaras. Tras la construcción homogénea de casas-habitación según un modelo de cabañas canadienses y su emplazamiento formando una avenida (Valverde, 1989: 80), se repartieron tierras agrícolas a las familias y se instalaron algunos pequeños talleres fomentándose asi entre los nuevos colonos la civilización y las buenas costumbres occidentales, asi como la ruptura con las tradiciones culturales indigenas. De esta forma, los jesuitas estaban logrando conciliar sus anhelos pastorales con los sueños civilizatorios del gobernador Creel, como parecia sugerir el padre Edmundo Galván, vicesuperior de la Misión, cuando escribia en 1934:

Estamos convencidos de que un indio en el estado salvaje es incapaz de ser buen cristiano por estar tan apegado a sus costumbres tradicionales, supersticiosas en la mayoría de los casos. Un indio de los pueblos del sur de la misión, sin ropa, embrutecido, con las continuas borracheras, viviendo en jacal insalubre...iqué dificil es que tome con gusto la Sagrada Comunión!; iqué raro que por su voluntad se acerque a confesar sus pecados. Digan nuestros lectores si no tenemos motivo para fomentar en los tarahumaras las aspiraciones de una vida culta y civilizada, aunque tengamos que oir algunas veces que los hacemos semejantes a los blancos. $^{28}$

El estilo de vida de esta colonia semejaba, en no pocos aspectos, el funcionamiento de las colonias de granjeros menonitas establecidos en los cercanos valles de Guerrero y Cuauhtémoc. Sin embargo, la Colonia Catequista de Sisoguichi parecia distinguirse por la injerencia paternalista y la vigilancia estrecha de los misioneros sobre la vida familiar, social y productiva de los colonos indígenas. ${ }^{29}$

Pero los esfuerzos de los misioneros, una vez más, no tuvieron el respaldo del gobierno que hubieran requerido. Primero, durante la administración callista, los jesuitas

\footnotetext{
inspirado en la experiencia de los jesuitas en las misiones del antiguo Congo belga.

${ }^{2}$ Cita tomada de Valverde, 1989: 80.

${ }^{29}$ Véase, por ejemplo, en Ocampo, 1950: 231-245, la cercana vigilancia que los misioneros ejercian sobre los colonos tarahumaras en aspectos tales como el noviazgo y la selección del cónyuge, la vivienda, los hábitos de higiene, el trabajo y, en general, la vida cotidiana
} 
fueron expuisados de la Sierra entre julio de 1926 y mediados de 1929. Después, durante el cardenismo, sus instalaciones fueron confiscadas por el gobierno entre 1934 y 1939, prohibiéndose la educación religiosa. Aunque durante esos años de persecución religiosa ni los internados ni la colonia agrícola desaparecieron, tuvieron, sin embargo, que vivir en la clandestinidad. Los colonos que se habian transformado de agricultores en artesanos industriales (carpinteros, curtidores, etc.), convirtieron sus talleres en una empresa cooperativa disfrazada bajo la denominación de Sarabéachi y Cia. que abasteció durante los años treinta a algunas empresas mineras de la Sierra y logró subsistir hasta el inicio de los años cuarenta.

Al tiempo que la acción de la iglesia se escondia en la clandestinidad, las primeras reformas sociales de los gobiemos nacidos de la Revolución comenzaban a llegar a la Sierra Tarahumara. Y mientras que se repartían las tierras de los primeros ejidos, se implantaban también las Misiones culturales de las que el gobernador Almeida informaba en 1926, habian funcionado tres en Sisoguichi, Norogachi -justo en el corazón de la zona de influencia de la misión- y Guazapares, pero que por falta de asistencia se habian concentrado en una sola en el poblado de San Ignacio de Arareco. También en 1928 y por decreto presidencial se constituyó la Junta Administradora de los Bienes de la Raza Tarahumara, integrada por representantes de los gobiernos federal y estatal y destinada a proteger las tierras de las comunidades indigenas.

Mientras hasta finales de los años veinte la acción indigenista del gobierno y la iglesia reflejó, más allá de una cierta identidad de objetivos y estrategias, una abierta competencia, a partir de los años treinta el gobierno haria valer un interés y un monopolio, hasta entonces desconocidos, por intervenir en la orientación de las comunidades indígenas. La integración de éstas a la nación y la expansión hacia el medio indigena de las reformas sociales derivadas de la Revolución se convertirian por esos años en el discurso predominante. $Y$ a la par que las instituciones educativas y las leyes agrarias eran reformadas, las viejas ideologias de la tutela de los indios comenzaron a ceder sus espacios institucionales a otras de nueva orientación en las que 
las culturas indígenas comenzaban a ser desatanizadas en el marco de un creciente nacionalismo.

\section{LA RAZA TARAHUMARA Y LA CUESTION DE LAS NACIONALIDADES (1936-} 1952)

En 1936 el gobierno cardenista creó el Departamento Autónomo de Asuntos Indígenas, reconociendo asi la imperiosa necesidad de enfrentar los graves problemas sociales de los grupos étnicos del pais a través de una dependencia que tuviera la capacidad de analizar la situación de estos grupos, proponer al Ejecutivo las soluciones más apropiadas, promoverlas, dirigirlas y estimularlas, asi como encargarse de la procuración de justicia en el medio indígena. Lo más novedoso de esta nueva medida de política indigenista consistía en reconocer que la educación y el mejoramiento social de los pueblos indígenas requerian de soluciones específicas, pero que éstas no podían tener otro objetivo que no fuera el de incorporar a los indios al conjunto de las reformas sociales que se estaban operando por esos años en todo el pais. ${ }^{30}$

Las labores del nuevo Departamento se centraron en tres ámbitos: la defensoria de los derechos agrarios de los núcleos indígenas a través de los Procuradores de asuntos indigenas, el funcionamiento de las Misiones culturales -ahora denominadas Brigadas de mejoramiento Indígena- y la operación de los Internados indígenas, rebautizados en 1938 como Centros de capacitación económica y técnica. Aunque todos estos programas se instauraron en Chihuahua, la Sierra Tarahumara vivió, sin embargo, por esos años, la experiencia de un indigenismo más radical que el que predicaba el gobierno federal y, desde luego, más enérgico que las tenues reformas y legislaciones locales que pretendieron, en 1933, revivir en Chihuahua los viejos sueños liberales de

\footnotetext{
${ }^{30}$ Puede verse en Aguirre Beltrán, 1992b: 105-109 la forma corno el Presidente Cárdenas concibió el Departamento Autónomo de Asuntos Indigenas, tratando de evitar cualquier tipo de políticas que llevaran a considerar a los grupos étnicos y sus problemas como separados del conjunto de la nación. El Departarnento habria de fungir como institución de consulta del ejecutivo para la toma de decisiones relativas a los grupos indigenas cuya ejecución pasaria a manos de las diferentes dependencias y organismos del gobierno
} 
principios de siglo, postulando de nuevo "la civilización y protección del indígena". 31

Muy en contra de este espiritu y en el contexto de los graves problemas de pobreza y atraso que se vivian entonces en la Sierra Tarahumara, aparecieron en esos años algunas propuestas radicales de un nuevo indigenismo que se caracterizaron, entre otras cosas, por propugnar una visión en la que los grupos étnicos serranos aparecian como entidades políticas unificadas y cuasi autónomas, con las que el estado nacional debía entablar una alianza, reconociéndoles el derecho a un territorio, un gobierno y una cultura propios. Asi, el viejo concepto liberal de "Raza indigena" fue adquiriendo una nueva connotación politica hasta llegar en ocasiones a confundirse con el de "nacionalidades", en el sentido en que éste fue utilizado para referirse a las minorías étnicas de la Unión Soviética después de la revolución de 1917, o lo que hoy, en el debate mexicano, se ha denominado la autonomía de indigena. Como trataremos de mostrar a continuación, este nuevo discurso se tradujo también en acciones y experimentos políticos cuya meta habría de ser la de fomentar la organización política de los indigenas a través de estructuras diversas.

La primera de estas propuestas radicales provino, en 1936, de una Comisión gubernamental integrada por representantes de los Departamentos del Trabajo, de Asuntos Indigenas, Agrario, Forestal, de Salubridad y de las Secretarias de Educación, de Comunicaciones y de Economia. Dicha comisión, presidida por el Departamento de Trabajo, fue encargada por el presidente Cárdenas de elaborar un diagnóstico económico y social de la Tarahumara, asi como de proponer las medidas necesarias para lograr elevar las condiciones de vida de los indigenas. ${ }^{32}$

${ }^{31}$ Una de estas reformas habria de ser la Ley de Protección Indigena, decretada por el gobernador Rodrigo M. Quevedo en julio de 1933, que creaba en el estado de Chihuahua un Departamento o Sección de Protección Indigena a la que se le asignaban funciones muy similares a las otorgadas en 1906 por el gobernador Creel a la Junta Central Protectora de Indígenas. Una comparación entre ambas leyes evidencia un notorio parecido, aun cuando fueron dictadas en épocas y coyunturas politicas muy distintas.

32 Dicha comisión, en la que también participó el fotógrafo Gustavo Casasola, recorrió en abril y mayo de 1936 la alta Sierra central Tarahumara conociendo de cerca los problemas de las comunidades indigenas. De ello se derivó un informe editado y remitido por el Departamento de Trabajo a la Presidencia de la República bajo el título de La Raza Tarahumara. (Departamento del Trabajo, 1936). El informe contiene una 154 
Dejando de momento a un lado las recomendaciones económicas que esta Comisión planteó (volveremos sobre ellas en el capítulo 4), quizás lo más llamativo de sus conclusiones estriba en su propuesta de organización política para la "Raza Tarahumara". Los siguientes son algunos de los principios que los funcionarios gubernamentales sugerian para ser incluidos en una nueva legislación indígena en el estado de Chihuahua:

A. La familia indigena queda facultada para gobernarse por si misma, dividiendo su gobiemo por zonas. [...]

B. Cada zona tendrá un jefe supremo, al cual obedecerán todos los gobemadores y gobemadorcillos de cada comunidad.

C. Ningún nombramiento de comisario, ni autoridad de los pueblos indigenas recaerá sobre individuos mestizos ni blancos, aun cuando residan en los pueblos indigenas.

D. No se nombrarán ni establecerán guardias blancas, defensas, $n i$ destacamentos de ningún género en pueblos indigenas.

E. Cada Gobemador nombrará la policia que sea necesaria y de acuerdo con sus costumbres, pero un reglamento claro y sencillo determinará las funciones de ésta.

F. Todas las autoridades indigenas serán nombradas por los propios pueblos de acuerdo con sus costumbres, que serán responsables, ante ellos y ante el Gobemador Supremo, quien estará facultado cuando el caso lo requiera para remitir aquellos asuntos de gran importancia a las autoridades competentes del Estado o de la Nación.

G. Las autoridades locales sólo podrán tratar asuntos indigenas por conducto del Gobemador de la Zona.

1.- Ninguna autoridad podrá detener o castigar a un indígena, excepto en el caso de homicidio comprobado, o cuando lo reciba para su castigo, por conducto del Gobemador de la Zona.

J. El reglamento de castigos debe formularse de acuerdo con la costumbre establecida por los indígenas, modificando aquellos que estuvieren fuera de 10 razonable, pero después de haber escuchado la opinión de sus gobernadores (Departamento del Trabajo, 1936: 185-186).

La propuesta del Departamento del Trabajo era una curiosa mezcla de

muy amplia y excelente colección de fotografias de paisajes y personajes de la Tarahumara, todas ellas obra de Gustavo Casasola. 
radicalismo político y de indianismo idealizado. Porque, a decir verdad, esa visión que proyectaba de los tarahumaras como una etnia con una férrea y jerárquica organización territorial y politica en torno a ciertos "patriarcas", distaba mucho de los hechos. La "familia indigena" de la que hablaba el reporte, en realidad, estaba constituida por un conglomerado de asentamientos y poblados dispersos entre los que no existía una articulación orgánica. Los supuestos "patriarcas", para quienes los comisionados cardenistas reclamaban incluso el derecho a contar con una guardia armada, conformaban una mezcla de autoridades tradicionales (siriames), de maestros indigenas y de intermediarios con un poder cuyo marco jurisdiccional resultaba muy limitado. Además, paradójicamente, la "comunidad indigena" a la que se atribuian derechos económicos e injerencia en la definición de la legislación civil, aparecia, a lo largo del informe, sumamente difusa e indefinida. En suma, pues, la "Raza tarahumara" era sublimada hasta convertirse no sólo en una entidad comunitarista sino incluso en una especie de estado autónomo indio. Como lo discutiremos al final de este capitulo, todos estos supuestos estaban lejos de retratar la realidad etnográfica de los tarahumaras.

Si una perspectiva de tal naturaleza resultó dificilmente aplicable a la realidad, varios de sus elementos, sin embargo, habrian de reaparecer al final de los años treinta en algunos intentos radicales de indigenismo que tuvieron lugar en la Sierra Tarahumara. Como lo señalamos en el capítulo anterior, el más importante de estos intentos fue obra de un grupo de maestros, formados en los principios del nacionalismo, la escuela rural y el agrarismo cardenista, quienes, desde la óptica del maxismo, comenzaron a pensar en las etnias serranas en términos de nacionalidades, planteando abiertamente una larga lucha en torno a sus derechos agrarios, culturales y políticos.

Estudiosos de la problemática étnica de México, estos profesores entre los que destacaron Francisco M. Plancarte, Emesto Cano Ruiz, José Hernández Labastida, J. Patrocinio López y Francisco Javier Alvarez- descubrieron en la experiencia soviética ${ }^{33}$

\footnotetext{
${ }^{33}$ Como ya se señaló en el capitulo anterior, el líder e inspirador de este debate fue el prof. Francisco Hernández y Hernández, quien habia tenido la oportunidad de viajar -como delegado del Sindicato de Maestros y a instancias del su dirigente el prof. Chávez Orozco- a la Unión Soviética y recorrer diferentes 156
} 
una fuente de inspiración para entender y enfrentar la situación de la Tarahumara. En el marco de las actividades de su formación como normalistas y maestros en activo, organizaron un seminario de discusión sobre el problema indigena en México y en Chihuahua. Del carácter y contenido de las discusiones que se desarrollaron en aquel taller de formación, el profesor Francisco Alvarez recordaba hace algunos años:

Organizamos un ciclo de pláticas donde nos dimos temas. Analizamos exhaustivamente todo 10 que habia de politicas de colonización... Fundamentalmente cómo había resuelto la URSS el problema nacional. Ese era el tema principal, para lo cual hubo que examinar cómo Inglaterra habia realizado su colonización, los Estados Unidos, Francia y demás. Todo...todo exhaustivamente, para llegar a la conclusión de que Rusia habia resuelto sabiamente el problema colonial y que ése era un modelo que podiamos aplicar aqui en México los "rojillos". A esa conclusión llegamos.

Al hablar del problema colonial me refiero al probiema de las nacionalidades, porque alli [en la URSS], hablaban de nacionalidades, del respeto absoluto a las nacionalidades, respeto a su idioma, a su tradición cultural, a tener el derecho a su lengua. $Y$ aunque acá [...] analizábamos que no habia verdaderas nacionalidades [...], se llegó a la conclusión de que ese modelo de respeto a los grupos minoritarios tenia que darse. Desde entonces se planteó esa cuestión aqui. ${ }^{\sharp t}$

Del discurso teórico izquierdista, los maestros no tardaron en pasar a la acción. Tras realizar varias giras por la Sierra, diseñaron una estrategia indigenista que implicaba un nuevo discurso sobre la comunidad indigena y que se sustentaba en tres pilares: el respeto por la lengua y la cultura de los tarahumaras, la defensa de su territorio y la lucha por su organización política. El primero de estos tres aspectos se tradujo en una serie de medidas tendientes a reformar la orientación y los métodos de la educación que por entonces se practicaba en los Internados indigenas de la Tarahumara. Estas reformas educativas, de las que hablaremos en el capitulo cuarto, tenian como principal meta la

regiones ètnicas de ese pais, donde pudo conocer de cerca la política soviética frente a la "cuestión de las nacionalidades". El profr. Hemández, tras haber coordinado las Misiones Culturales en la Sierra de Juárez de Oaxaca, fue nombrado por el Secretario de Educación Pública, Narciso Bassols, director de la Escuela Normal de Flores Magón (Chih.) y posteriormente Director de Educación en el estado de Chihuahua. A partir de estos puestos, propició la formación de un grupo de reflexión de normalistas y jóvenes profesores interesados en los problemas ètnicos del pais y, en particular, de la Sierra Tarahumara. (Estas y otras informaciones que se incluyen en el texto sobre el profr. Hemández proceden de una larga entrevista que él mismo me concedió en la ciudad de México el 29 de octubre de 1994, varios años antes de su triste deceso).

${ }^{34}$ Entrevista personal con el profr. Francisco Javier Alvarez. México D.F., 12 de octubre de 1994. 
de oficializar la educación bilingüe a base de crear un cuerpo magisterial autóctono.

Pero el punto nodal de este indigenismo radical gravitaba en la cuestión de la tierra, porque para aquellos maestros era impensable la liberación del tarahumara sin el reconocimiento de un territorio indígena. Reivindicar los derechos históricos de los pueblos indios de la Sierra sobre sus tierras y bosques implicaba inevitablemente entrar de lleno al ámbito conflictivo de las relaciones interétnicas. Nada, en efecto, llamó más la atención de aquellos profesores que la violencia en que se expresaban las relaciones entre indios y mestizos en torno a la propiedad de la tierra. El prof. Francisco Hernández recordaba:

Entonces vimos lo que usted ya debe saber. toda la zona tarahumara fue despojada de sus tierras y isabe usted cómo?. Entre usted despacito para que conozca. Aqui esta la Sierra.. Aqui están las familias O.., A... ${ }^{35}$ Y.., todos esos. ¿Sabe usted qué tenian?. Ganado humano trabajando sus ranchos, tomados a chingadazo limpio... machete, pistola... iA darle en la madre a los indios!. Pero para legalizar ¿sabe usted cómo le hacian? En Batopilas presentaban las escrituras o hacian el registro y eran registradas por las autoridades de ahi. Eso hacia la función de escritura. Y esas propiedades eran ya de los Y..., de los O... Cada quién tenia su rancho amparado con eso..

Entonces los indigenas no tenian nada para poder llegar... Les permitian que llegaran ahi, les daban la comida y a trabajar con ellos y a base de terror y de no tener ni su tiempo libre... Pues ia dónde se iban? A los barrancos, a las alturas y a trabajar en los ranchos que estos [mestizos] presentaban como suyos después de acreditar esas escrituras que no eran ni tienen tal valor... Y con terror, a machetazo y a chingadazo... 10, 15, 20 indigenas aqui... 10, 20, 30 indigenas alli... Asi estaba la Sierra cuando yo llegué... ¿Cómo la ve? Entonces fue cuando decidimos entrar a la Sierra. ${ }^{36}$

Para acabar con esta situación, los maestros comenzaron a presionar a las autoridades del Departamento Agrario insistiendo en que se atendieran las demandas de dotación de ejidos que muchas comunidades de la Sierra habian iniciado a tramitar desde los años veinte. Denunciando el acaparamiento de tierras por parte de la población mestiza, los profesores no cesaban de reclamar la urgente necesidad de respetar y hacer valer los viejos derechos de propiedad de los pueblos indigenas sobre

\footnotetext{
${ }^{35}$ Por razones obvias, se mantuvo el anonimato (nota del autor).

${ }^{36}$ Entrevista con el profr. Francisco Hernández y Hernández, México D.F., 29 de octubre de 1994.
} 
su territorio. Más aún, la ferviente vocación agrarista de estos promotores de un nuevo indigenismo llegó incluso a idear la posibilidad de conformar un único ejido indigena en la Sierra Tarahumara adquiriendo, mediante expropiación y compra, las tierras de los mestizos. El profesor Alvarez evocaba en estos términos aquel anhelo:

Si usted examina el mapa del estado de Chihuahua, la zona donde hay más ejidos es la región Tarahumara. ¿Por qué? Porque nosotros junto con ellos hicimos eso. Legamos a plantear incluso -no más costaba entonces quince millones de pesosexpropiar a todos los blancos de la Tarahumara, pagarles sus parcelas...y jvan p'afuera!... Y que dejaran esa zona exclusivamente para los indigenas. Estuvimos asi en un tris de conseguirto. Pero se nos rajaron a la hora buena el Agrario, el gobemador y todos se hicieron como la canela, se rajaron. Pero estaba apuntado eso y estaba ya documentado para haber hecho un gran ejido. ${ }^{37}$

El poblado de Guachochi, situado en una de las mesetas más extensas de la alta Sierra y más apropiada para la agricultura fue considerado por estos maestros como el lugar estratégico para hacer realidad su proyecto de recuperación y defensa de un territorio indigena ${ }^{38}$. $Y$ aunque Guachochi era por entonces una rancheria minimamente poblada por algunos mestizos y rodeada de pequeños asentamientos indigenas dispersos, fue ahi donde se concentraron los mayores esfuerzos de este grupo de maestros indigenistas. Para ellos Guachochi era el lugar apropiado para acabar de una vez por todas con la dispersión de la población indígena, derivada -según ellos- no tanto de factores culturales, cuanto de la presión de los mestizos sobre las tierras y comunidades indigenas.

Entre estos avanzados promotores de un nuevo indigenismo se llegó a hablar incluso del proyecto de convertir a Guachochi en una gran "metrópoli" indigena, donde se instalaran cooperativas, almacenes y talleres de maquinaria e implementos agricolas, aserraderos, escuelas, centros de salud y servicios diversos que cubrieran las

${ }^{37}$ Entrevista con el profr. Francisco Javier Alvarez.

${ }^{38}$ No es casual que en su descripción geografica de la Taráhumara, Plancarte asiente: Las mesetas más notables por su extensión son las de Guadalupe, Reforma, Agostadero, Papajichi, Cusárare, Choguita, La Juanota, Yoquivo y Tuchéachi. Sin embargo, no existe otra mesa tan extensa como la de Guachochi, de unos 40 kilómetros de largo por 30 de ancho, situada en pleno corazón de la Tarahumara, abundante en agua, pastizales, tierras de cultivo y bosques (Plancarte, 1954: 13). 
necesidades de la población indigena ahi concentrada. Este proyecto de "capital indigena" que tenia fuertes reminiscencias de inspiración soviética, representaba una perspectiva sobre la lógica del ordenamiento del territorio indigena radicalmente opuesta, a la que casi 20 años después, el indigenismo oficial pregonara bajo el concepto de "ciudad primada" y la teoria de las "regiones de refugio", planteados por Aguirre Beltrán. Porque si en esta última visión la ciudad primada aparece básicamente como un centro de poder mestizo, en la propuesta de los indigenistas de la Tarahumara de los años treinta, la ciudad aspiraba a ser la sede del poder y de la autonomía indígenas ${ }^{39}$.

Si la defensa de la lengua, la cultura y el territorio constituian, pues, los tres pilares básicos de este proyecto indigenista, su punto culminante estribaba en encontrar y promover formas de organización y representación políticas entre los indigenas serranos, que, al mismo tiempo que permitieran mantener, con una cierta autonomia, su sistema tradicional de gobiemo, tendieran también un puente entre los indígenas y el gobiemo nacional. Los maestros indigenistas se apoyaron para ello en un grupo de profesores tarahumaras que habian estudiado en la Casa del Estudiante Indigena entre 1928 y 1931 y regresado después a trabajar en la Sierra. Algunos de éstos, incluso, comenzaron a tomar parte activa en la politica serrana, llegando a ocupar puestos de representación popular en presidencias municipales y diputaciones estatales. ${ }^{40}$

De unos y otros maestros surgió desde 1935 la idea de crear el Consejo Supremo Tarahumara, pero para ello fue preciso convencer a los gobernadores de los pueblos o

${ }^{39}$ La inspiración sovietica de la propuesta indigenista de estos maestros está fuera de toda duda a partir de sus testimonios que pude recoger. En ellos, nunca se hace referencia a otras experiencias internacionales tales como las reservaciones indígenas norteamericanas.

${ }^{40}$ Las elecciones de 1940 se vivieron en Chihuahua, y en particular en la región de Guachochi, con un especial interés. Por primera vez, un partido estatal, el Partido Revolucionario Independiente de Chihuahua (PRICH), compitio en las elecciones, postulando para gobemador a Alfredo Chávez, en contra del ing. Foglio Miramontes, un candidato oficial que contaba con el apoyo del Gral. Cárdenas. El grupo de maestros indigenistas lanzaron entonces como candidatos del PRICH en la zona de Guachochi a Ignacio León Ruiz (para presidente municipal de Guachochi) y a Patricio Jaris, como diputado en el Congreso del Estado, ambos maestros egresados de la Casa del Estudiante Indigena. A pesar de la abierta oposición de los mestizos de la región, los dos obtuvieron sus nominaciones como consecuencia de los acuerdos cupulares entre el partido oficial y el PRICH. Era la primera vez en la historia contemporánea de Chihuahua que dos indigenas ocupaban tales puestos de representación popular 
siriames ${ }^{41} y$, en especial, a algunos de ellos con mayor influencia, de las ventajas que este nuevo organismo significaria:

Hasta 1930-35 no existía una interrelación entre estas unidades geográficas denominadas "pueblos"; si acaso con los colindantes, pero no más allá. Algunos gobemadores, muy pocos, lograron rebasar su autoridad fuera de su "pueblo" y para citar algunos recordamos que José Jaris logró ascendiente y autoridad sobre los pueblos de Norogachi, Choguita, Papajichi, Tatahuichi y Cusárare; Josecito Aguirre en Guachochi, Tónachi, Rochéachi, Aboreachi y toda la mesa de Guachochi y Esteban Cruz [en] Cabórachi y Tecorichi. Todos estos pueblos con sus respectivos gobernadores reconocian la autoridad de los gobemadores de Norogachi (José Járis) y Guachochi (Josecito Aguirre) pero en ningún momento se logró un control sobre toda la Tarahumara (Consejo Supremo Tarahumara, 1974: 8-9).

La idea del grupo de maestros promotores de este experimento político era realmente ambiciosa. Se trataba de crear una organización con un peso político que enarbolara las demandas indigenas:

Es decir, nosotros tratábamos de crear, paralelo con la organización tradicional, una organización un poco más modema, capaz de luchar en el orden agranio, en el orden politico, en el orden educativo; una organización más fluida y más representativa, capaz de acicatear la lucha por los intereses de los indigenas. $Y$ asi fue como se realizó el primer Congreso Tarahumara. ${ }^{42}$

Pero además se pretendia algo más: superar la atomización de los núcleos indígenas y su desvinculación con el resto de la nación, consecuencia de siglos de colonización misionera y abandono, para pasar a un modelo cuasi estatal de autonomía de la "tribu tarahumara", tal y como lo recordaba con claridad el profesor Alvarez:

Nosotros pensábamos que debia reconstruirse el poder que da integrarse en un gran grupo que es la Tribu Tarahumara, que teniamos que enmendar el entuerto que hicieron los curas al fraccionar a todos los pueblos indígenas en pequeños gobemadores fácilmente manejables por ellos. [La creación del Consejo Supremo Tarahumara] era una medida política que nosotros consideramos correcta porque, independientemente de que hubieran gobemadores indigenas, de acuerdo con las acciones politicas del Consejo Supremo Tarahumara podrian encaminarse medidas conjuntas de todos, siempre y cuando esas luchas respondieran a verdaderos intereses de los indigenas (lbid.)

${ }^{41}$ Hablaremos, en el último apartado de este capitulo, de las funciones del siriame entre los tarahumaras. También aclararemos el concepto de "pueblo" en la Tarahumara.

${ }^{42}$ Entrevista con el profr. Francisco Javier Alvarez 
Una vez convencidos estos líderes, fue posible convocar en Guachochi, en abril de 1939, un Congreso de la Raza Tarahumara o asamblea de gobemadores de pueblos y representantes indigenas. Este congreso que tuvo el apoyo del presidente Cárdenas y del gobernador de Chihuahua, Gustavo L. Talamantes quien lo presidió, sesionó por tres dias y discutió ampliamente los problemas agrarios, forestales, agropecuarios, educativos, de comunicación, de salubridad, asi como quejas contra grupos mestizos presentadas por los gobernadores tarahumaras. ${ }^{43}$

El acuerdo más importante del congreso fue la conformación del Consejo Supremo Tarahumara, concebido como un órgano de defensa y gestión de las innumerables demandas de los tarahumaras, expresadas a través de los gobernadores. El congreso acordó nombrar como dirigentes del Consejo a un grupo de maestros indígenas (Ignacio León Ruiz, Eleuterio Rodriguez Calleja, Patricio Jaris Rosalio, Santiago Recalache Garcia y Francisco Martinez Aguirre) y como delegados, a todos (cerca de 150) los gobernadores o siríame de los municipios de Guadalupe y Calvo, Morelos, Nonoava, Balleza, Carichi, Bocoyna, Urique, Batopilas, Chinipas, Ocampo, Guazapares, Uruachi y Guerrero.

Las lineas directrices del Consejo Supremo Tarahumara derivan fundamentalmente de los acuerdos tomados por los "Congresos de Pueblos Tarahumaras" que, hasta mediados de los años setenta, se celebraban con cierta regularidad y a los que asistian los gobernadores, representantes e indígenas de toda la Sierra Tarahumara, llegando a reunirse hasta cerca de 20,000 personas, lo que implicaba largos desplazamientos por varios dias de camino (Consejo Supremo Tarahumara, 1974: 14).

Desde su fundación, el Consejo celebró varios Congresos de Pueblos

${ }^{43}$ Puede verse en Gómez, 1948: XVIII-XXI el discurso del gobemador rarámuri Josecito Aguirre Aguirre, en el que se sintetizan las principales quejas indigenas. Pretendiendo atemorizar a los tarahumaras, un grupo de mestizos asesinó, unos dias antes del congreso, a Timoteo Martinez, lider agrario en la región de Guachochi. 


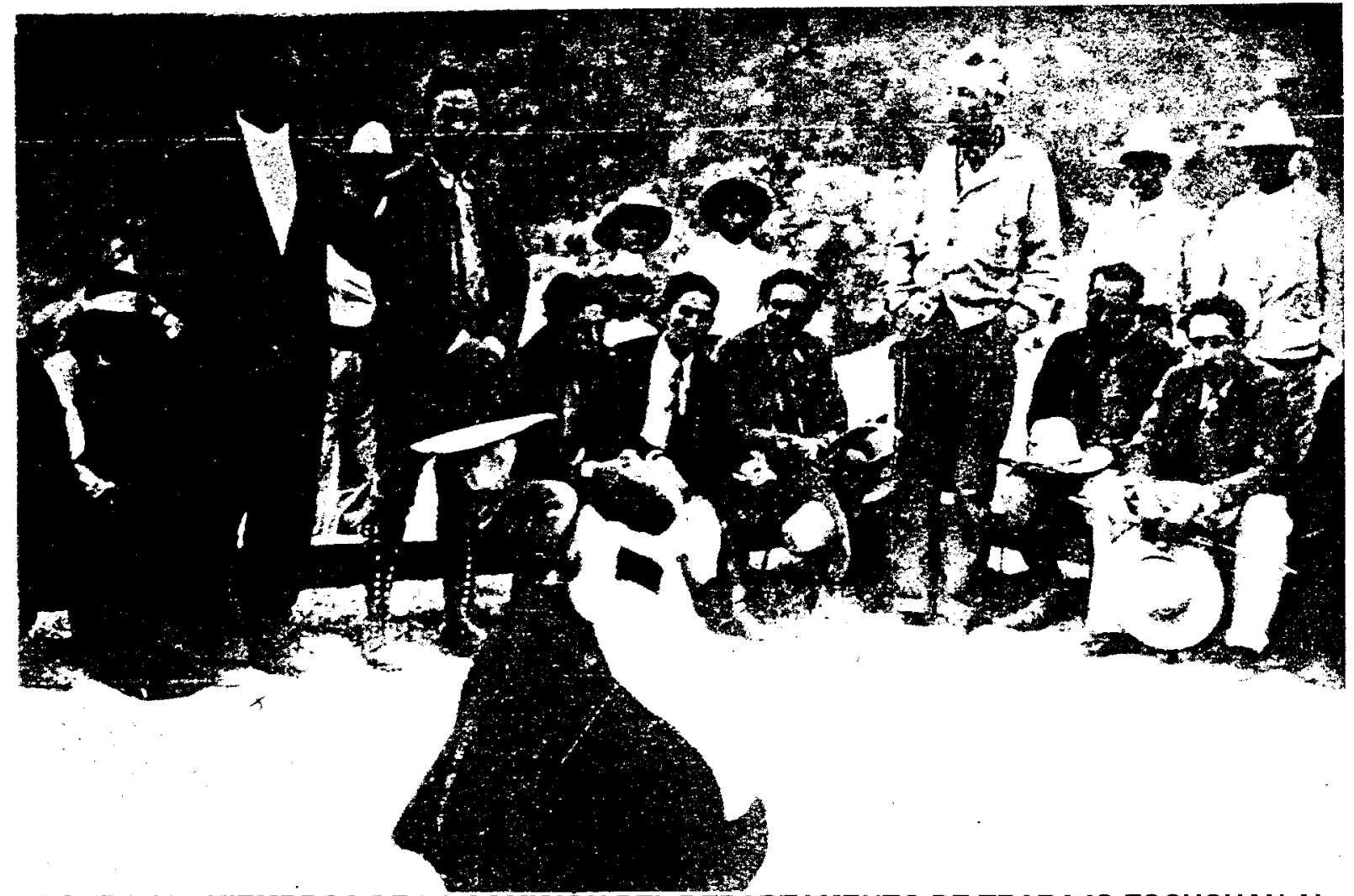

FIGURA 26.- MIEMBROS DE LA COMISION DEL DEPARTAMENTO DE TRABAJO ESCUCHAN AL PROFESOR RARAMURI IGNACIO LEÓN. NOROGACHI (1936) (DEPARTAMENTO DE TRABAJO, 1936)

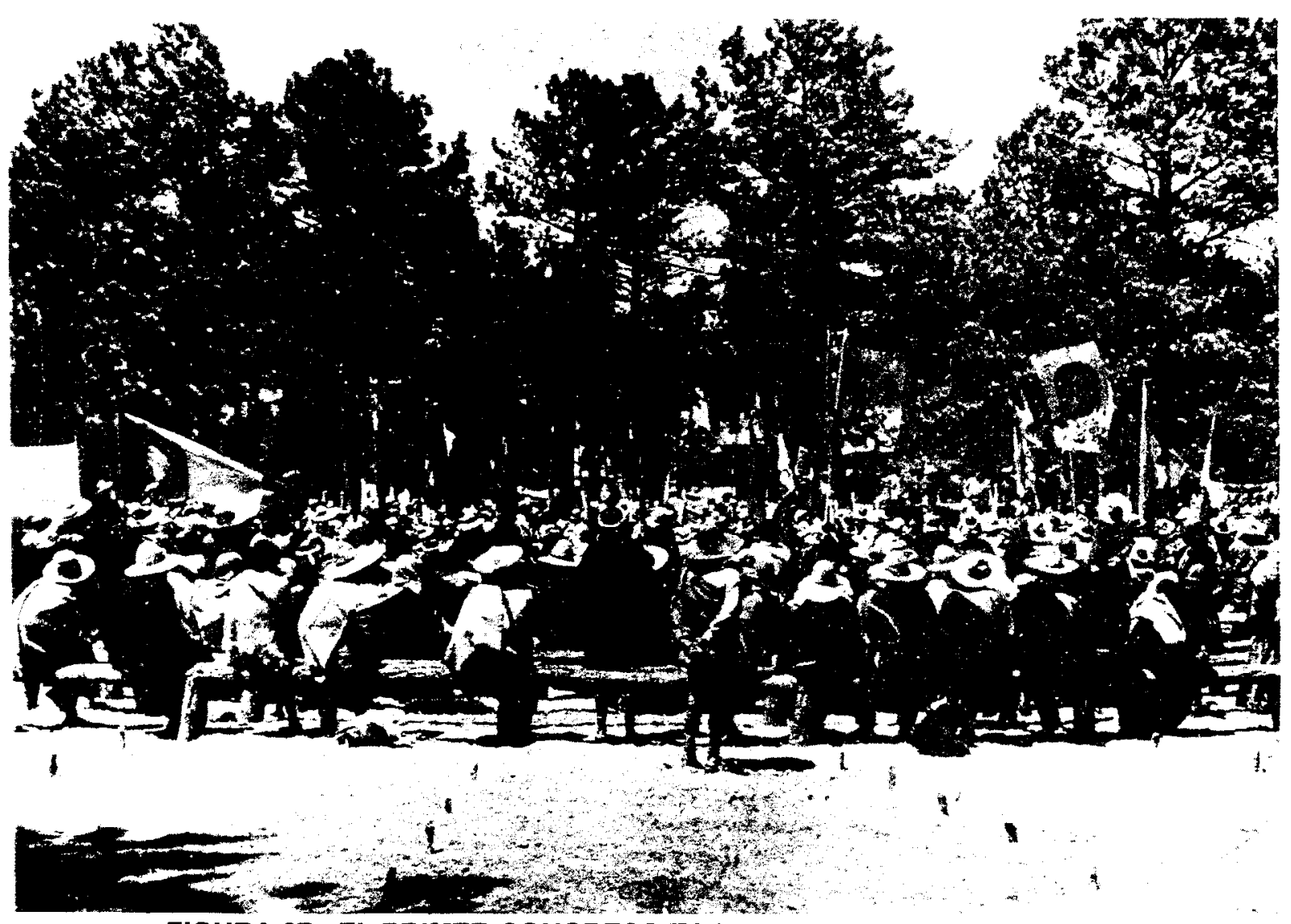

FIGURA 27.- EL PRIMER CONGRESO TARAHUMARA. GUACHOCHI. 1939

(CONSEJO SUPREMO TARAHUMARA, 1974) 
Tarahumaras (1941 en Tónachi, 1947 en Guachochi, 1950 y 1957 en Creel, 1959 y 1972 en Bocoyna y 1977 en Guachochi) y en todos ellos planteó reiteradamente una larga serie de demandas entre las que destacaron las siguientes: resolución integral de la tenencia de la tierra; creación de escuelas y plazas de maestros; construcción y mejoramiento de caminos y carreteras; instalación de teléfonos en lugares apartados de la Sierra; creación de puestos médicos y entrega de medicinas; mejoramiento de los internados; fundación de Procuradurias de Asuntos indígenas en cada uno de los municipios serranos; entrega de semillas en las épocas oportunas; aprovechamiento integral de los recursos forestales en beneficio de los ejidatarios indígenas y autodeterminación política de los pueblos indios de la Sierra. (Consejo Supremo Tarahumara, 1974:17). ${ }^{44}$

Entre 1950 y 1975 el Consejo tuvo una incidencia significativa en la representación de los indígenas y en la resolución de algunas de las demandas señaladas, estableciendo para ello una estrecha alianza con el Centro Coordinador Indigenista de la Tarahumara $(\mathrm{CCIT})^{45}$ y asumiendo el papel de gestor de los ejidos y núcleos indigenas ante diferentes instancias de gobierno.

Al respecto dos fechas resultan significativas: en 1957, el V Congreso, celebrado en Creel, decidió afiliarse y adscribir el Consejo a la CNC y en 1972, con ocasión del VII Congreso celebrado en Guachochi al que asistieron cerca de 110 gobemadores tarahumaras además de representantes pimas y tepehuanes, se acordó elegir como directivos del Consejo a un grupo de jóvenes tarahumaras (presididos por Samuel Díaz. Holguin), manteniendo a algunos de los fundadores "históricos" (Eleuterio Rodríguez, Patricio Járis, Chico Martinez y Francisco Bustillos) como asesores. Fue en este último

\footnotetext{
44 Una buena parte de los acuerdos de estos congresos puede consultarse en el Archivo del Centro Coordinador Indigenista de la Tarahumara y en la revista Boletin Indigenista. También puede verse una breve historia de los congresos y del Consejo Supremo Tarahumara, asi como su reglamento en Sariego, 1998a: 125-142.

45 A esta alianza se deben, entre otras cosas, la fundación del municipio de Guachochi en 1962, la apertura de promotorias y escuelas (más de 50 hasta hasta 1972), la regularización de la tenencia de la tierra en algunos ejidos, la defensoria de indigenas frente a los mestizos y otros asuntos de los que hablaremos más adelante.
} 
congreso, al que asistieron como representantes del presidente Luis Echeverria, Augusto Gómez Villanueva (Jefe del Departamento de Asuntos Agrarios y Colonización), Alfredo V. Bonfill (Secretario general de la $\mathrm{CNC}$ ) y Gonzalo Aguirre Beltrán (director del INI), cuando los gobemadores exigieron al presidente Echeverria una respuesta integral a un conjunto de demandas.

Dias después, los directivos del Consejo fueron convocados a la residencia de Los Pinos, donde el presidente acordó una serie de medidas emergentes (entrega de viveres, maiz y frijol en zonas afectadas por falta de cosechas), asi como el inicio del Plan Tarahumara, que incluyó la construcción de caminos, escuelas, electrificación, agua potable, becas escolares, regularización agraria, créditos agrícolas, tiendas de CONASUPO y algunos otros apoyos más en ciertas zonas de la Sierra Tarahumara (Consejo Supremo Tarahumara, 1974: 22-23).

El Consejo Supremo Tarahumara tuvo un papel importante en la creación de otros consejos similares en otras regiones del país. Desde 1957, varios directivos del Consejo visitaron algunas zonas indigenas de México persiguiendo este objetivo. También el Consejo tuvo un cierto liderazgo en la convocatoria, en octubre de 1975, del Primer Congreso de Pueblos Indigenas, que reunió en Janitzio, Mich. a representantes de 52 consejos supremos y que dio lugar al Consejo Nacional de Pueblos Indigenas.

A partir de la segunda mitad de los años setenta, el Consejo fue burocratizándose gradualmente, perdiendo su vinculación con la base de los gobernadores (siriame) y representantes indigenas, hasta convertirse en una instancia más próxima a los intereses corporativos del estado que a las justas demandas de sus representados. Hoy en dia su incidencia y su capacidad de representación son mínimas.

Una de las demandas expresadas en el IV Congreso de Pueblos Tarahumaras en 1950 fue la de solicitar al gobiemo federal la instalación de una agencia dependiente del INI en la Sierra Tarahumara. Dos años después, por acuerdo presidencial del 4 de junio 
de 1952, fue creado el Centro Coordinador Indigenista de la Tarahumara (CCIT), el segundo en su género creado entonces por el INI, después del de San Cristóbal de las Casas.

Para quienes habian conocido la historia politica del indigenismo del final de los años treinta en la Tarahumara, no pasó inadvertido el hecho de que el Dr. Alfonso Caso, director del INI, nombrara al frente del CCIT a Francisco M. Plancarte, un antiguo maestro rural de aquellos que habian propuesto algunas alternativas radicales en los años del cardenismo. El recién nombrado director del CCIT había tenido oportunidad de hacer algunos estudios de antropologia en la Universidad de Chicago y tras haber trabajado en la cuenca del Papaloapan con el Dr. Alfonso Villa Rojas, regresaba de nuevo a la Sierra. No pocos interpretaron este nombramiento como una forma implicita de continuidad entre el indigenismo radical y el nuevo indigenismo que empezaba a institucionalizarse en la sierra chihuahuense.

Como hemos tratado de mostrar, la Sierra Tarahumara conoció a finales de los años treinta un discurso indigenista innovador cuyos promotores fueron varios maestros agrupados en torno a un ideario próximo al marxismo, nacionalista, agrarista, defensor de la organización política y de una cierta autonomía de los indígenas que implicaba, entre otras cosas, el reconocimiento de su sistema tradicional de autoridad y cargos. De este discurso nos interesa especialmente destacar un aspecto: su "sublimación" del carácter comunalista y colectivista de las formas de organización de las etnias serranas. En efecto, en la óptica de este indigenismo radical las etnias aparecen como entidades con un alto grado de integración y centralización políticas, presididas por sólidas estructuras patriarcales de autoridad y gobierno y unificadas en torno a un territorio reconocido como propio. Casi podríamos decir que del sueño colonial de la autarquía comunalista de los pueblos de misión se pasó al anhelo de la autonomía tribal de las etnias serranas dentro de un estado modemo. En suma, los indios dejaron de ser vistos como meros sujetos de una comunidad para convertirse en ciudadanos de una entidad autónoma cuasi estatal. 
Si esta aspiración puede parecer acorde con toda una estrategia política de defensa de los derechos de los pueblos indios tal y como ésta fue concebida por los maestros indigenistas radicales, en cambio levanta serias sospechas en cuanto a su fidelidad con respecto a las evidencias etnográficas de los patrones de organización social y política de las etnias chihuahuenses. Como veremos un poco más adelante nada, en efecto, apunta en el sentido de que existieran entonces o existan hoy entre los tarahumaras $-y$, en general entre los pueblos indios de la sierra chihuahuense-formas de organización social y política que vayan más allá de los núcleos de los pueblos y rancherias y aún dentro de elios no son pocas las muestras de que el peso de los vínculos comunitarios -y mucho más aún los tribales- tiende a debilitarse en razón de la dispersión demográfica y la fuerza del individuo y de la familia.

\section{EL CARÁCTER SUI GENERIS DE LA COMUNIDAD TARAHUMARA EN LA} DOCTRINA INDIGENISTA DE LOS AÑOS CINCUENTA.

Si el discurso radical de los maestros agraristas del final de los años treinta concibió la transformación social de los grupos étnicos de la Tarahumara a partir de sus capacidades para constituirse orgánicamente en una estructura política tribal, autónoma y con representatividad frente al estado nacional, el indigenismo que comenzó a institucionalizarse al inicio de los años cincuenta, en cambio, centró sus expectativas en las potencialidades de cambio de la comunidad indigena.

Influido por los planteamientos de Redfield, el indigenismo integrativo postuló, en efecto, que la comunidad era el espacio propicio para la aculturación y la modificación de . los patrones de economía, organización social, gobierno, educación, medicina y, en general, las formas de vida de los pueblos indigenas ${ }^{46}$. La comunidad se convirtió

\footnotetext{
${ }^{46}$ En concordancia con los planteamientos de Redfield sobre la estructura funcional e integrada de la comunidad y sobre la conveniencia de que los cambios sociales que afectan a ésta sean graduales para evitar rupturas y conflictos, Aguirre Beltrán y Pozas Arciniega señalaban:

Se consideró a la comunidad como un todo indivisible, poseedora de un cultura cuyas constelaciones están interrelacionadas en forma tal que la modificación armónica. el mejoramiento y la modemización sólo pueden conseguirse si se atacan conjuntamente los ángulos importantes.

Asimismo se vio la necesidad de coordinar los programas especificos de acción 


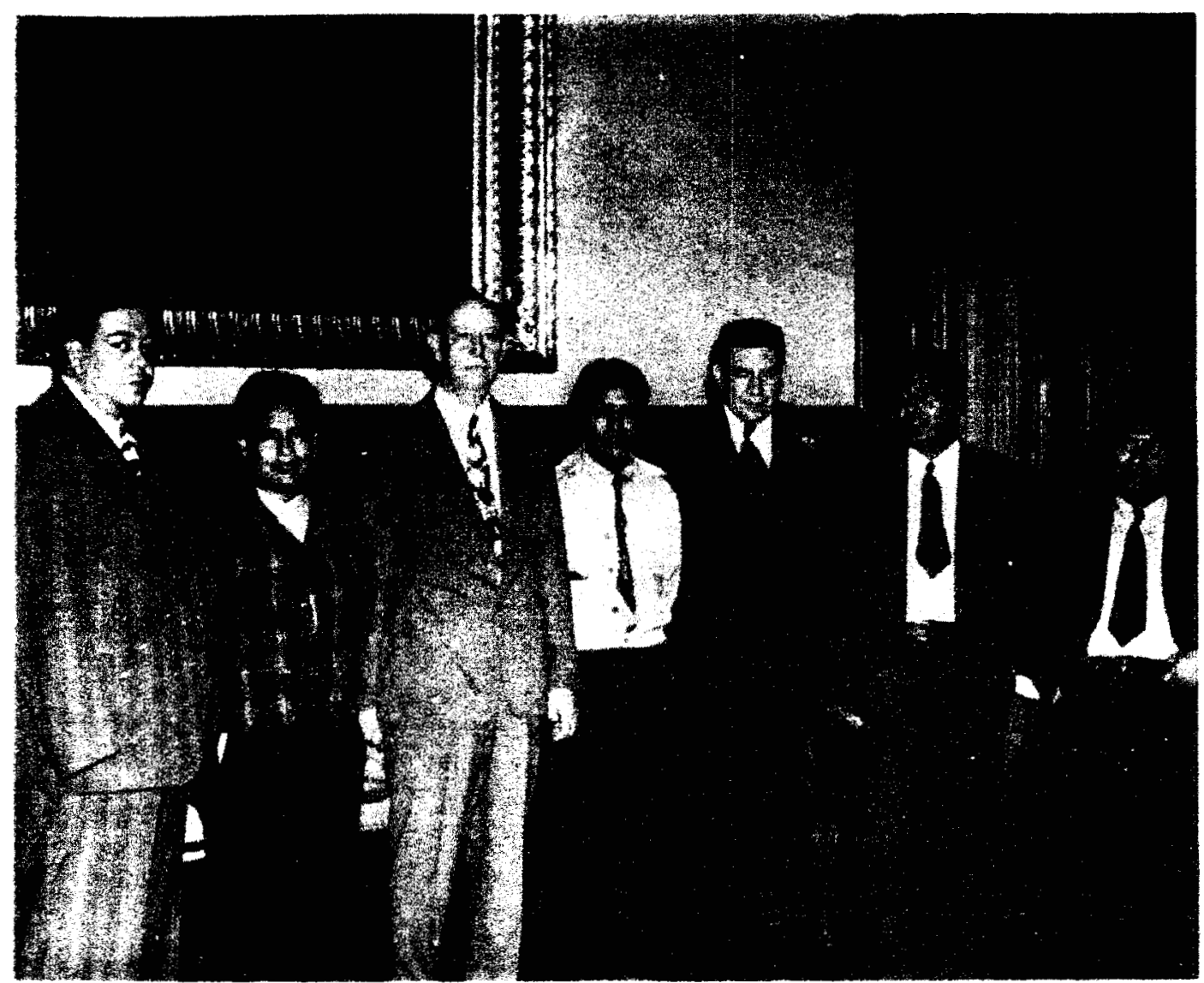

FIGURA 28.- MIEMBROS DEL CONSEJO SUPREMO TARAHUMARA CON ELGOBERNADOR DE CHIHUAHUA ALFREDO CHÁVEZ . CIRCA 1941. (CONSEJO SUPREMO TARAHUMARA, 1974) (De izdquierda a derecha: Francisco Hernández y Hernández, Eleuterio Rodriguez, Gobernador Chávez, Patricio Járis, persona no identificada, Ignacio León y Francisco Hernández Labastida)

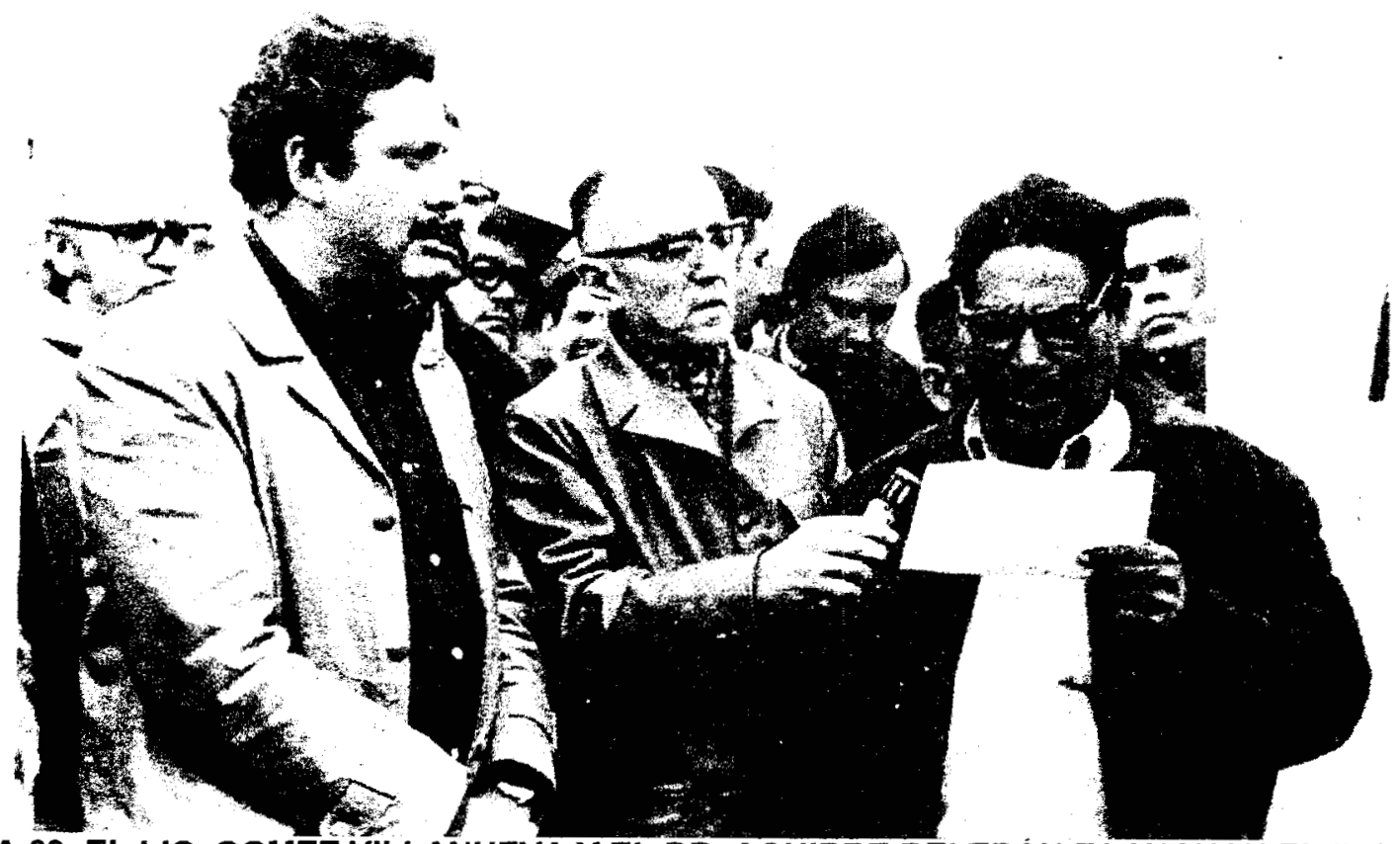

FIGURA 29. EL LIC. GOMEZ VILLAÑUEVA Y EL DR. AGUIRRE BELTRAN ESCUCHAN EL INFORME DE LABORES DE ELEUTERIO RODRÍGUEZ, PRESIDENTE SALIENTE DEL CONSEJO SUPREMO TARAHUMARA (GUACHOCHI, ENERO DE 1972) (CONSEJO SUPREMO TARAHUMARA, 1974) 
entonces en el punto crucial de la teoria y los análisis de la escuela mexicana del indigenismo integrativo. Julio de la Fuente, Alfonso Villa Rojas, Alejandro Marroquin, Ricardo Pozas, Alfonso Caso y, en especial, Gonzalo Aguirre Beltrán habrian de desarrollar, en el transcurso de los años cincuenta, un conjunto de propuestas teóricas y de planes de acción orientados a entender la estructura y funcionamiento de la comunidad indígena y a plantear su transformación.

A pesar de su supuesta solidez teórica, este esquema interpretativo, sin duda por estar sostenido fundamentalmente en bases etnográficas de origen mesoamericano, tuvo serias dificultades para poder ser aplicado a la situación de los grupos étnicos del norte de México localizados fuera de las fronteras mesoamericanas. En efecto, las formas de organización social y, especialmente, el modelo de asentamiento territorial de las etnias norteñas, se adaptaba mal al esquema levantado a partir de las etnografias en el área mesoamericana. Los indigenistas que trabajaron entre las grupos étnicos de la Sierra de Chihuahua y algunos otros que la visitaron, no tardaron en atestiguar esta contrastante diferencia:

La vida del grupo étnico tarahumara está determinada por un patrón cultural básico: el aislamiento. [...] Propiamente hablando no existen pueblos en todo el territorio; se designa asi una circunscripción de kilómetros y kilómetros de extensión donde radican familias dispersas separadas unas de otras por los inmensos bosques de pino y los profundos o elevados accidentes geográficos (Aguirre Beltrán, 1991: 67).

En la lógica de este teórico del indigenismo, el modelo de la comunidad tarahumara -y por extensión de los restantes grupos étnicos de la Sierra chihuahuenseresultaba completamente atípico. Porque, atendiendo a las características relacionadas con la base biológica de la comunidad indigena, los asentamientos tarahumaras no se estructuraban, como en el caso mesoamericano, a partir ni de la herencia patrilineal, ni de la familia extensa, ni del linaje ni del clan o calpul, sino a partir de la familia nuclear. Además de dispersarse en pequeños asentamientos, los tarahumaras resultaban, y equilibrado, a la finalidad que se habia propuesto. Educación, salubridad, agricultura, procuraduria, crédito, comunicaciones, todo es aplicado conjunta y armónicamente 
estacionalmente seminómadas, con to cual la relación entre territorio y pueblo se desdibujaba aún más.

La clave para entender este patrón demográfico de aislamiento y seminomadismo debia entenderse como una respuesta de ajuste de estos grupos étnicos a un medio donde la oferta de tierra agricola no sólo era reducida sino sumamente dispersa. A ello habia que añadir otro elemento histórico estructural: las mejores tierras agricolas emplazadas en valles y mesas habian sido objeto de la codicia de los mestizos, lo que relegaba a los indigenas a zonas inhóspitas y alejadas del influjo occidentalizador.

En contraste con la situación mesoamericana, los pueblos de la Tarahumara no parecian obedecer a formas o sistemas de asentamiento prehispánicos sino que eran resultado de las politicas de reducción forzosa de la población emprendidas por los misioneros coloniales. Tampoco este modelo disperso guardaba relación alguna con instituciones como el ayuntamiento, la mayordomía o el tequio, sustento de la organización social de los pueblos indios en el área mesoamericana. La base local o territorial de los tarahumaras -plantearia Aguirre Beltrán- constituye un tipo el de la "comunidad dispersa"- contrastadamente distinto de los otros dos que predominan en el mundo indigena mexicano, el de las comunidades intermedias o centro-ceremoniales y el de las comunidades compactas. ${ }^{47}$

Una aseveración tal no es casual; parece derivar de la impresión tan fuerte que el tribalismo y el bajo grado de aculturación de los tarahumaras causó en el propio Aguirre Beltrán cuando, hacia 1946, visitó por primera vez y con motivo de un Congreso de la Raza Tarahumara, la sierra de Chihuahua:

El impacto mayor que tiene uno cuando aborda a los tarahumaras, es que por primera vez entra uno a una organización social que es muy distinta a la de otros lugares de México, en los que la integración [de los indígenas] es mucho mayor y

(Aguirre y Pozas, 1981: 24).

${ }^{47}$ El discurso teórico del indigenismo sobre las bases biológica y territorial de la comunidad indigena puede verse en Aguirre Beltrán y Pozas, 1981: 26-46, en donde se encontrará una explicación detallada de estos tres tipos o modelos territoriales de comunidad indigena en México. 
que ya se puede identificar a los Tarahumaras como organizados tribalmente. Esa fue mi impresión. ${ }^{48}$

A pesar de este modelo de organización socio-territorial, nadie entre los indigenistas pondria en cuestión el hecho comunitario eittre los tarahumaras, quienes, a pesar de la dispersión, muestran una clara tendencia a la sociabilidad expresada en su asistencia a las tesgüinadas, las reuniones rituales y los sermones dominicales nawésari- de los gobemadores:

El aislamiento dificulta, pero no impide la vida social. Las obligaciones del trabajo cooperativo, las exigencias de la asistencia mutua y las necesidades de soporte y seguridad colectivos, hacen que el tarahumara busque la membrecia en una agrupación mayor que la simple familia nuclear. Las familias aisladas se reúnen en ocasión de las tesgüinadas que regulan el trabajo comunal, o de las fiestas religiosas que atraen y comprometen la ayuda sobrenatural; pero, a más de ello, semanariamente concurren al lugar que tradicionalmente consideran el centro o eje de la comunidad. En este centro se levantan unas cuantas construcciones. Dos son esenciales, en las comunidades tarahumaras pagótame o bautizadas: la iglesia y la cruz: entre los tarahumaras gentiles basta muchas veces un espacio abierto destinado a las asambleas y la cruz ceremonial orientada al Sol, para que el sitio tome valor de centro.

El conjunto, más o menos numeroso de establecimientos familiares aislados y este centro peculiar constituyen lo que los tarahumaras llaman su pueblo, esto es, su comunidad. Cada pueblo tiene sus autoridades e instituciones propias.[...]

Cada pueblo tiene su territorio definido que reclama como suyo. Los restantes pueblos reconocen este derecho (Aguirre Beltrán y Pozas, 1981: 48 y 49).

Asi, y de manera paradójica, la presencia de ciertos elementos espaciales y constructivos de clara reminiscencia colonial parecen ser los elementos identificadores de la comunidad. El "pueblo" entre los indígenas de la Tarahumara rememora la vieja institución colonial del "pueblo de misión". Este patrón de asentamiento contrasta con el de los mestizos serranos, lo que lleva a algunos indigenistas como Plancarte a distinguir entre las modalidades de "pueblo hispánico" y de "diseminación rural":

Consiste la primera en la erección de un centro residencial semiurbano, alrededor del cual se mueven las gentes para conseguir su's medios de vida.

Conforme a este patrón se asienta la población de las cabeceras municipales, la de otros pueblos que fueron o son centros de explotación minera, la de algunas

${ }^{48}$ Entrevista realizada al Dr. Gonzalo Aguirre Beltrán, Xalapa, Ver., 14 de octubre de 1994. 
estaciones de ferrocamil y centros comerciales y la de un limitado grupo de pueblos agricolas [...]

Los llamados pueblos indigenas no constituyen en forma alguna centros de población del primer tipo. Se componen de un número determinado de familias aborigenes cuyas casas están diseminadas sobre una gran área. En determinado lugar [...] se alza generalmente una iglesia vetusta de adobe, la casa comunal para sus juntas $y$, a lo sumo, la escuela y la casa para el maestro, éstas últimas construidas en los últimos 25 años. Cercano a este centro hay, generalmente, uno o más establecimientos comerciales de mestizos que se han radicado en esos iugares con el descontento de los indigenas (Plancarte, 1954: 18).

Para los indigenistas de los años cincuenta, otro elemento fundamental que caracteriza la "centralidad" de las cabeceras de los pueblos indígenas en relación con el hinterland de pequeñas rancherías circundantes es que dichas cabeceras se convierten en la sede del poder y la autoridad de los gobernadores indigenas. En las cabeceras de los pueblos se imparte justicia, se llevan a cabo los sermones dominicales o nawésari y se celebran los principales rituales festivos. No sin razón, un experto indigenista que laborara en el CCIT de Guachochi en su época fundacional, el antropólogo Agustín Romano, se atrevió a definir los pueblos tarahumaras como unidades políticas:

La unidad geográfica y politica la constituye el "pueblo", el cual puede definirse como el temitorio que tradicionalmente se ha considerado como la jurisdicción de una autoridad indigena autónoma llamada "siriame" o "gobernador". Esta división ternitorial parece datar del establecimiento de las misiones jesuitas, puesto que en el lugar que se considera como cabecera del "pueblo" hay una iglesia cuyo local es usado habitualmente por las autoridades para sus reuniones y ceremonias (Romano, 1962).

Acordes con las definiciones de Plancarte y Romano y hablando en particular del caso de los tarahumaras, en adelante utilizaremos el término "pueblo" para referimos a la unidad territorial conformada por una cabecera central (por lo general, sede de alguna antigua misión) y un conjunto de pequeños asentamientos (ranchos, rancherias) circundantes, lejanos entre si y con la cabecera a una distancia que puede ser muy variable. Como veremos más adelante, lo que da un carácter de unidad a estos pueblos es el hecho de que funcionan como unidades politicas, presididas por un gobernador o siriame y un conjunto de autoridades auxiliares. Las cabeceras de estos pueblos tienen en cierta forma el carácter de centros ceremoniales y de gobierno, puesto que en ellas se 
llevan a cabo los principales actos de gobiemo y justicia, al tiempo que se celebran algunos de los principales rituales del ciclo festivo. ${ }^{49}$

Esta unidad del pueblo, integrada por una cabecera y una constelación de ranchos y rancherias deriva indudablemente de la vieja estructura de las "poblaciones de rancheria" (the rancheria peoples) a la que ya nos referimos al inicio de este capitulo, pero también está en continuidad histórica con la organización territorial implantada por los misioneros en la época colonial quienes, como vimos, dividieron la Tarahumara en partidos integrados, cada uno de ellos, por una cabecera de misión y un conjunto de "pueblos de visita" (González, 1993: 221). El hecho de que los rarámuri se refieran a sus "pueblos" con el término de "póbora" demuestra que el término fue asimilado por ellos a partir de las imposiciones misioneras.

Más allá del pueblo, unidad teritorial y política básica entre los rarámuri, los indigenistas de los años cincuenta niegan la existencia de otras formas autóctonas de organización social y política. En oposición al discurso radical de los maestros cardenistas que propugnaron por la creación de organismos de representación política de la "Raza" tarahumara, los teóricos oficiales de la integración sostendrán la inautenticidad y la inviabilidad de instituciones como el Consejo Supremo Tarahumara. Inautenticidad porque el gobierno indigena en la Tarahumara nunca ha trascendido el ámbito del pueblo ${ }^{50}$ y porque, a pesar de que opere dentro de estas etnias una cierta unidad cultural y lingüística, sin embargo "no existe un sentimiento de grupo", sino más bien de "independencia" (Romano, 1962):

Las innúmeras autoridades no tienen sobre si un poder superior que las una y amalgame: no existe ni ha existido desde la penetración de los jesuitas a la sierra, un gobiemo de la tribu (Aguirre Beltrán, 1991: 71).

\footnotetext{
49 Esta noción de pueblo no sólo difiere de su equivalente en el contexto mesoamericano, sino que también de la más actual de "pueblo indigena" en el sentido de grupo étnico con una cultura distintiva dentro de la nación, tal y como lo entiende, por ejemplo, el articulo 1 del Convenio 169 de la OIT. Véase al respecto Gómez, 1995: 51-55.

${ }_{50}$ La prueba de ello es que los gobemadores indigenas ejercen su autoridad, cada uno de ellos con total autonomia y dentro de los limites jurisdiccionales de sus pueblos. (Romano, $\underline{\mathrm{op}}$. $\underline{\mathrm{cit}}$ )
} 
La inviabilidad de las formas de organización politica supracomunitarias es un postulado más complejo de la teoría integracionista según el cual no puede haber alternativas de organización indígena que no sean acordes con las instituciones de un estado modemo tales como el ayuntamiento y los tres poderes de la nación. Asi pues apostar por una forma de gobierno tribal indigena no sólo resultaria peligrosamente anacrónico sino claramente ilegitimo. Desde tal perspectiva, la crítica del principal teórico del indigenismo integrativo al experimento político del Consejo Supremo Tarahumara, inspirado en lo que hemos llamado la óptica de la autonomia de las "nacionalidades", no puede haber sido más despiadada:

Los congresos tarahumaras, incuestionablemente, han acarreado beneficios al grupo étnico [...] que han venido a paliar en parte las dificultades que confronta la población; pero no han podido conseguir esos congresos el reconocimiento legal del Consejo Supremo de la raza o tribu tarahumara, porque tal reconocimiento violentaría los ideales postulados en la Constitución. Este reconocimiento daria status legal a un gobiemo de tribu, esto es, a un gobiemo que desapareció desde los primeros contactos entre tarahumaras, jesuitas y gambusinos. Reconstruir tal gobiemo y darte unidad y forma a la tribu seria, sin género de dudas, un retroceso en la evolución politica de la nación y crear una reservación en un pais que abomina de las reservaciones (Aguirre Beltrán, 1991: 76).

Cancelada de esta manera la via de legitimidad de toda forma de identidad y organización étnica más allá del nivel básico del núcleo territorial indígena, los teóricos del indigenismo integrativo de los años cincuenta restringieron su visión y estrategia del cambio social exclusivamente al ámbito de la comunidad. Pero ésta, como la etnografia lo atestiguaba, asumía en el territorio de la Tarahumara un carácter sui generis, porque el grado de sociabilidad de estos grupos indigenas se limitaba a ciertos momentos coyunturales las asambleas dominicales, las tesgüinadas ${ }^{51}$ y las fiestas y juegos religiosos- en los que pareciera vaciarse condensadamente el espíritu comunitario y tribal de estos pueblos indígenas. Fuera de esos espacios, lo que predominaba era la dispersión, la independencia y la autonomia de los pequeños núcleos domésticos.

Sin embargo, para los indigenistas de esa época, la más importante "limitación" y

\footnotetext{
${ }^{51}$ a las que, por cierto, Aguirre Beltrán atribuye exclusivamente el papel de regulación del trabajo colectivo (Aguirre Bettran, 1991: 69)
} 


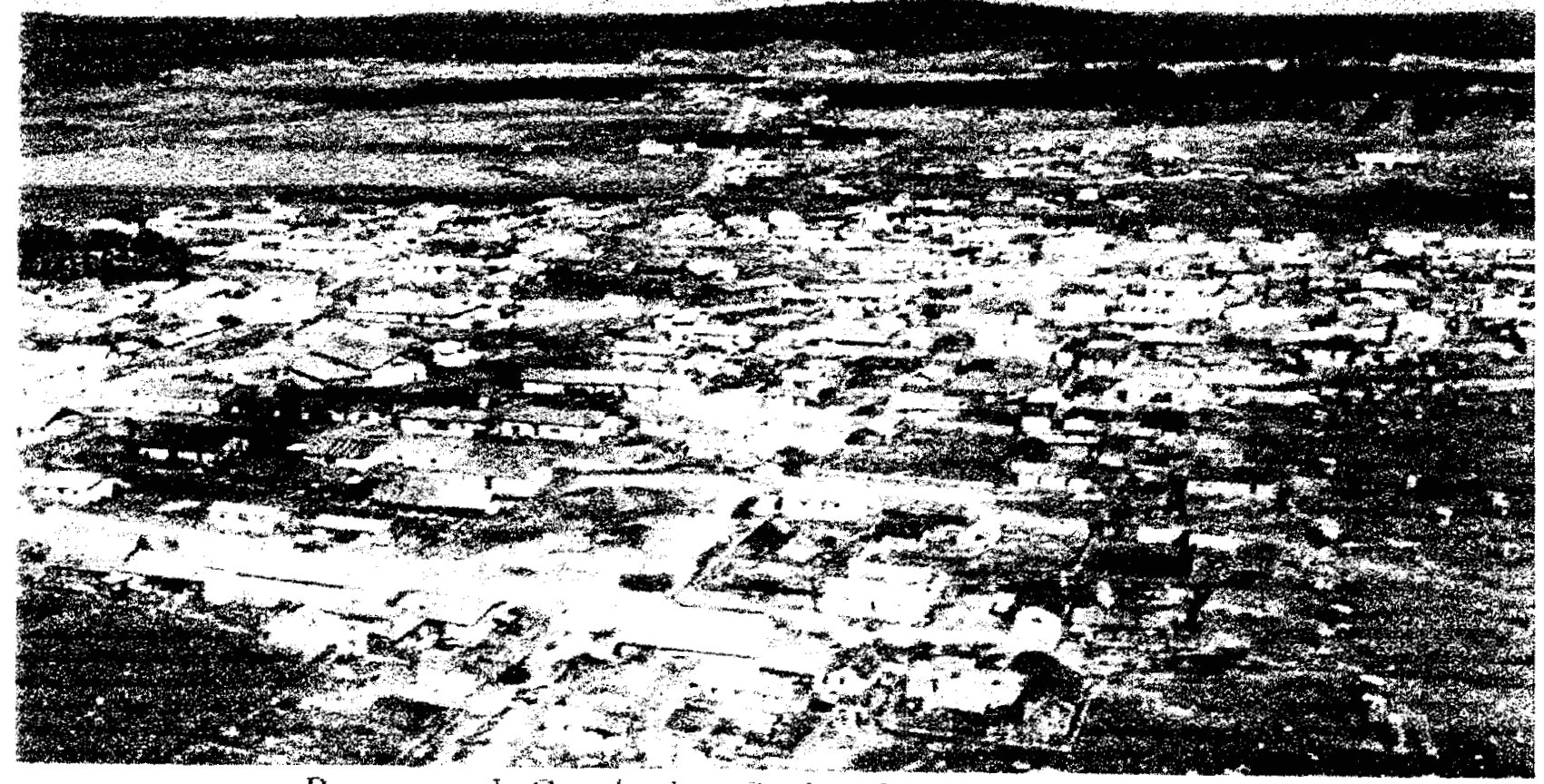

FIGURA 30.- VISTÁ AẺREA DÉ LẢ CIÚDAD́ DE GUÄCHÖCḢ, EJEMPLOO TÍPICO DEL PATRÓN DE "PUEBLO HISPÁNICO" EN LA SIERRA TARAHUMARA (FOTO TOMADA DE ANÓNIMO, 1973)

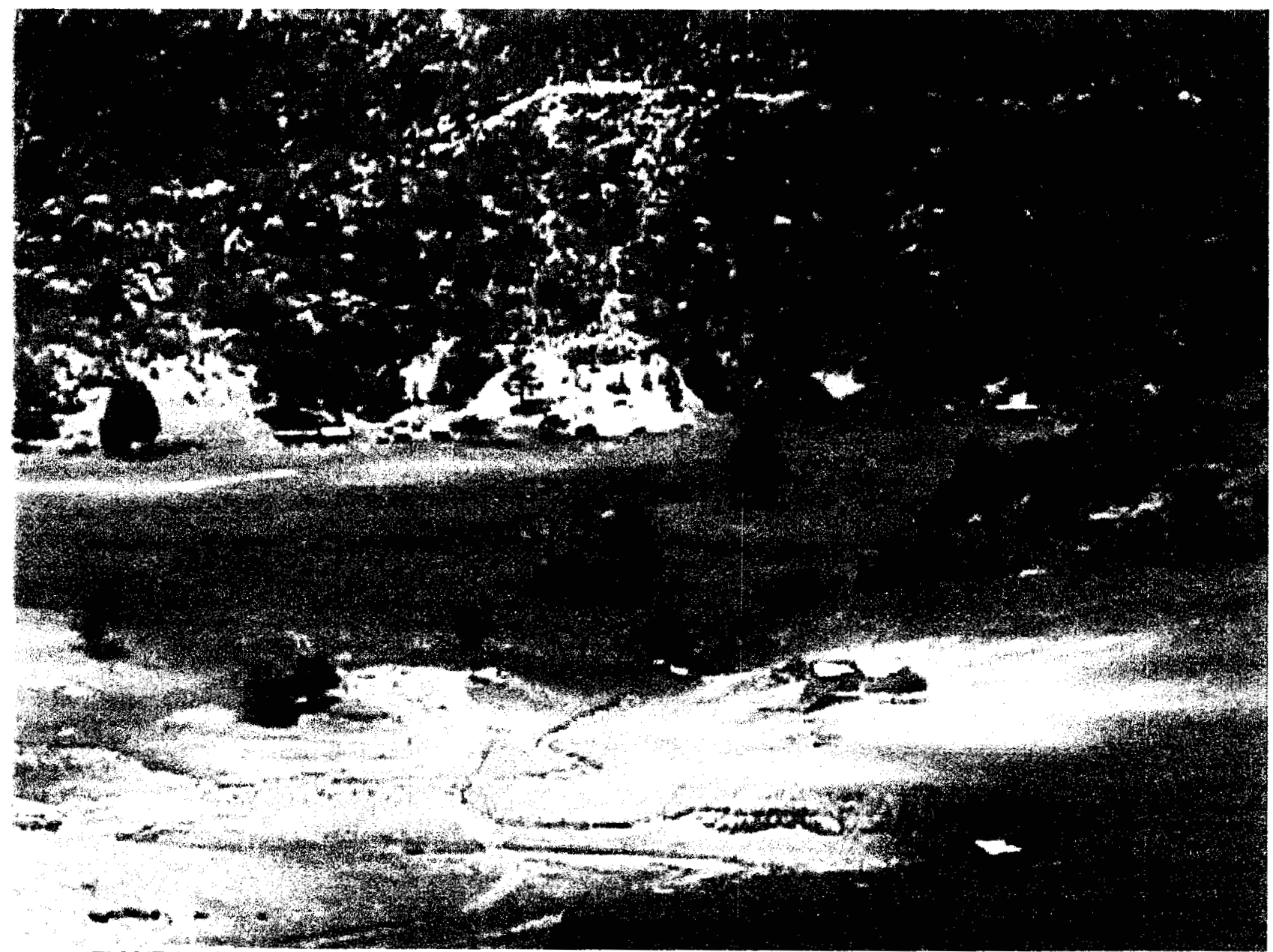

FIGURA 31. LA MESA DE YEGUACHIQUE, EN EL PUEBLO DE ABOREACHI (MUNICIPIO DE

GUACHOCHI), EJEMPLO DEL PATRÓN DE "DISEMINACIÓN RURAL" TARAHUMARA

(FOTO DEL AUTOR, JULIO 1999) 
barrera de la comunidad indigena en la Tarahumara no residia en su carácter restringido sino en su base territorial dispersa. Esta se muestra como un obstáculo no sólo para alcanzar un auténtico nivel de socialización sino sobre todo para hacer posible la aculturación, la modernización y el cambio social. En otras palabras: no podrá haber desarrollo entre los grupos indigenas de la Tarahumara si éstos no renuncian al más básico de sus patrones culturales -su aislamiento y dispersión geográfica- o si los programas de acción indigenista no eran capaces de eliminarlo, planteamiento que, por cierto, recuerda los principios de acción de los misioneros católicos.

Esta tesis aparece ya expresada en boca de Carlos Basauri, uno de los primeros antropólogos mexicanos en reconocer etnográficamente la Tarahumara, quien a final de los años veinte afirmaba:

Las familias tarahumaras viven a grandes distancias unas de otras. Esto se debe al espiritu poco sociable de la raza y a exigencias de indole económica, pues el indio se establece en aquellos lugares en los que puede encontrar facilidades para llenar las necesidades de su vida y de su familia. Y por la estructura propia de la sierra, y por los sistemas rudimentarios de explotación de los recursos naturales, empleados por los indigenas, estos sitios se encuentran muy distantes entre si. Esto constituye uno de los factores más poderosos para retener a los tarahumaras en un estancamiento cultural que corresponde a un tipo de civilización primitiva y es el principal obstáculo que presenta el problema de su educación (Basauri, 1929: 14).

En formas y grados variables, este mismo razonamiento se repite una y otra vez en boca de los indigenistas de la Tarahumara. Aguirre Beltrán considera este patrón de asentamiento indigena altamente "inconveniente para el desarrollo de una acción social efectiva" $y$, a pesar de reconocer las dificultades históricas para superarto ${ }^{52}$, no dudará

${ }^{52}$ En relación con tales dificultades señala:

El patrón de establecimiento disperso del tarahumara [...] fue motivo, durante la dominación extranjera, de grave preocupación para los evangelizadores cristianos que desesperaban al ver cómo se diluian sus esfuerzos aculturativos en la inmensidad del ternitorio. Ha sido también causa de cavilaciones sin cuento para los maestros y misioneros culturales que la Revolución introdujo en las comunidades dispersas con el fin de lograr su integración en las formas de vida nacional. Los resultados obtenidos por los jesuitas en la Tarahumara, después de una larga labor de siglos, no son ciertamente alentadores [...]. Las ventajas evidentemente demostrables que trae consigo la congregación, no son bastantes para quebrantar la fuerza del patrón de radicación dispersa cuando no se remueven integralmente los distintos factores de contexto cultural en que toma forma, contenido y 173 
en 1952, con ocasión de la realización del estudio técnico previo a la apertura del CCIT, en recomendar que se tomen acciones orientadas a fomentar la "ineludible concentración de la población dispersa, tarea que habrá de recaer sobre los hombros del Centro Coordinador si es que efectivamente desea desamollar una acción social que modifique la actual situación" ${ }^{53}$ También el mismo autor sugiere que este patrón de dispersión y seminomadismo sólo se superará cuando los beneficios de la reforma agraria se hagan efectivos en la Tarahumara y los indigenas recobren la propiedad sobre sus tierras muchas de las cuales les fueron arrebatadas por los mestizos.

Las opiniones de otros antropólogos que tuvieron a su cargo las labores del CCIT, aunque más realistas, parecen ir en el mismo sentido. Plancarte recomienda que en la medida en que el mejoramiento llegue a la población indígena, ésta adopte un modelo de asentamiento de tipo lineal a lo largo de arroyos, ríos y caminos. Sin embargo también aconseja no fomentar el tipo de asentamiento de "villa hispánica" y dotar de movilidad geográfica a los nuevos organismos de promoción cultural asi como crear escuelas que, además de instruir, puedan albergar y alimentar a los alumnos durante los cinco días hábiles de la semana. ${ }^{54}$ Otros, más atribulados por la cotidianidad de las tareas indigenistas, como el antropólogo de origen otomi Maurilio Muñoz, director del CCIT al inicio de los años sesenta, no dudan en confesar abiertamente su pesimismo ante las

acción (Aguirre Beltrán y Pozas, 1981: 49 y 50).

53 “Carta del Dr. Gonzalo Aguirre Beltrán, Subdirector del INI al Dr. Affonso Caso, Director del INI, en la que propone el Programa de trabajo que habrá de desarrollar el Centro Coordinador Indigenista de la Tarahumara en Guachochi, Chih. México D.F., 18 de junio de 1952", en Archivo del Centro Coordinador Indigenista de la Tarahumara de Guachochi (ACCIT), Legajo 17. Expediente 5.

\section{${ }^{54}$ Señala Plancarte:}

En relación con la dispersión de la población cabe pugnar por dar a los indigenas, una vez resuelto su problema económico, un nuevo tipo de asentamiento que rompa el aislamiento tradicional en que han vivido hasta hoy. Se sugiere la adopción del tipo villa lineal descrito por Lynn Smith. Este tipo de asentamiento puede impulsarse sistemáticamente en todos los pueblos a lo largo de los amoyos, rios y caminos para que, a la vuelta de unas décadas, la Sierra se haya modificado al respecto.

Se estima que otros tipos de asentamiento de la población son impracticables debido a las condiciones geográficas de la Sierra y a la resistencia manifiesta de los indigenas para seguir estos agrupamientos. En efecto, varios intentos de formación de colonias tipo villa hispánica han fracasado rotundamente en diversas épocas (Plancarte. 1954: 89). 
posibilidades de cambio en la Tarahumara:

Ya entrando en el problema, en sí, debe decirse que es muy dificil planear una rápida transformación de la región y sus habitantes, en virtud de que esta población vive dispersa, en parajes de 4, 6, 8 o 10 familias, muy distantes entre si. Estos lugares están ubicados en sitios que por lo general casi no se ven, de manera que cuando uno hace recorridos por regiones en las que no hay caminos, se puede caminar uno o dos días sin encontrar ningún poblado o paraje. Como es fácil suponer, no es posible hacer trabajos, por ejemplo, de introducción de agua potable, o de electrificación, a menos que se hicieran para ese pequeño grupo de familias (Muñoz, 1967).

Al inicio de los años cincuenta, las condiciones características en que el fenómeno comunitario se presentaba en la Tarahumara aparecian, pues, como el principal obstáculo de la acción indigenista. Aun reconociéndolo, los teóricos del integracionismo propugnaron por un cambio gradual pero definitivo de estas condiciones y plantearon como estrategia principal el reparto de la tierra entre los pueblos indigenas promoviendo la conformación de ejidos y comunidades agrarias. Además de ello, el CCIT comenzó a diseñar un programa de acción centrado en proyectos como el mejoramiento de las técnicas agrícolas, frutícolas y pecuarias, la implantación de postas zootécnicas, la formación de cooperativas de consumo y de explotación forestal asi como de trojes comunales para el abasto de semillas, el desarrollo de carreteras y caminos vecinales, la implantación de clínicas y la creación de internados escolares y promotorias educativas. $^{55}$

Al revisar estas líneas de acción así como los programas de trabajo del CCIT, desde su creación hasta nuestros dias, programas a los que nos habremos de referir con más detalle en el capítulo cuarto, llama poderosamente la atención el hecho de que todos tienen algo en común, su clara orientación "comunalista", ya que o bien presuponen la existencia de formas comunales de organización social o bien apuntan hacia ellas: el pueblo, el ejido, la cooperativa. Pero esta propuesta del desarrollo ¿resulta realmente viable y acorde con una etnografia que no ha hecho sino insistir en los limites

\footnotetext{
96.

${ }^{55}$ Los Planes de Acción del CCIT en el momento de su creación aparecen en Plancarte, 1954: 63-90 y 95-
} 
que la base territorial de la comunidad indígena presenta en la Tarahumara? ¿No es acaso excesivo esperar que los principios de la reforma agraria enarbolados por los promotores del indigenismo en los más recónditos parajes de la sierra chihuahuense, habrán de acabar para siempre con una de las raices más profundas de las culturas indigenas de la Tarahumara? Una revisión, aunque sea somera, de la etnografía académica puede quizás ayudar a despejar esta incógnita y a explicar por qué el celo de la cruzada indigenista no fue capaz de superar el que tradicionalmente ha sido considerado como el principal obstáculo al desarrollo de los pueblos indios de la sierra de Chihuahua.

\section{CRITICA DE LOS SUPUESTOS COMUNALISTAS DEL INDIGENISMO EN LA}

\section{TARAHUMARA}

La dispersión territorial de las etnias de la serrania chihuahuense que misioneros, indigenistas y agentes del desarrollo han considerado tradicionalmente como un serio obstáculo a la aculturación es sólo una expresión de una realidad más profunda, la de los límites del comunalismo o, en otros términos, la de las particularidades del fenómeno comunitario entre estos grupos étnicos. ¿Qué quiere decir, en concreto, "comunidad" en la Sierra Tarahumara? ¿Cómo han entendido y conceptualizado este término los etnólogos y especialistas en esta región? ¿Cómo viven y expresan esta realidad los indigenas serranos?

El tema de la comunidad en la Tarahumara ha asumido una doble importancia. Por un lado, constituye uno de los puntos nodales de la etnografia sobre esa región étnica; por otro, pasa a ocupar un lugar privilegiado en el diseño de las estrategias del desarrollo o, en términos indigenistas, de la "aculturación inducida", en la medida en que estas estrategias han focalizado la comunidad como el espacio central y el destinatario principal de las políticas del cambio social.

Sin pretender simplificar el problema, creo que existen al menos cinco dimensiones o perspectivas desde las cuales el tema de la comunidad ha sido visto en la 
etnografia sobre la Tarahumara. La primera de ellas se refiere a su "base biológica" ${ }^{m 56}$, es decir, la relación entre parentesco y familia, por un lado, y comunidad, por otro. La segunda dimensión considera la expresión territorial de la comunidad, es decir si la comunidad se asocia a la propiedad, uso, apropiación y transmisión de un territorio. Una tercera perspectiva ve la comunidad como una unidad económica de producción e intercambio y una cuarta, como una entidad politica y de gobierno. Finalmente una última óptica sobre la comunidad en la Tarahumara, sin duda la más englobante de todas, es la que visualiza la comunidad como el espacio y la circunstancia en los que la cultura indigena se reproduce, se socializa y se impone a los individuos.

La tesis que tratamos de plantear a continuación es que el debate abierto por la etnografia de la Tarahumara desde los años treinta sobre el significado de estas cinco dimensiones complementarias del que nos ocupamos a continuación, no fue incorporado en el diseño y concepción de las políticas indigenistas, lo que indudablemente restringió su alcance, eficacia y éxito. Porque, a pesar de haber reconocido originalmente que el fenómeno de la comunidad asumia en la Tarahumara características muy especificas, se optó en la práctica, y se sigue optando hasta hoy, por una estrategia de acción que se apoya en un modelo mesoamericano de comunidad indígena, asumiendo implicitamente que, como resultado de los programas indigenistas de desarrollo, ese modelo acabará imponiéndose al de la dispersión territorial, esperanza que el tiempo se ha encargado de condenar como falsa, tema que abordaremos en el capítulo cuarto. Analicemos pues cómo se relacionan, en la experiencia rarámuri, las diferentes dimensiones que hemos señalado sobre la comunidad.

La etnografia sobre la Tarahumara reconoce en la familia el núcleo social básico y destaca tres de su características que inciden directamente en la forma que asume la comunidad: su sistema clasificatorio de parentesco, su carácter de unidad económica y su patrón de residencia. Refiriéndonos en particular a los rarámuri, la familia nuclear constituye el foco de adscripción más estable. En la terminología del parentesco

\footnotetext{
${ }^{56}$ Retomo aqui la terminologia de Aguirre Beltrán y Pozas Arciniega (1981: 26)
} 
tarahumara resalta la tendencia a clasificar por generaciones, de acuerdo al sexo, de la edad relativa y, en ocasiones, del sexo de la persona que habla. Pero no existe en este sistema de parentesco marca alguna de agrupamientos unilaterales o bilaterales como lo muestra el hecho de que en bastantes comunidades rarámuri, todavia hasta el día de hoy, muchas personas no utilizan apellido alguno ${ }^{57}$, lo que implica que no existe la continuidad de nombres o la identificación con un ancestro, típicas de sociedades con grupos de parentesco unilineal con sistemas de linajes o clanes. ${ }^{58}$ Además el parentesco tiene una importancia sólo relativa, como lo demuestra el hecho de que los rarámuri, cuando se dirigen o se refieren a una persona, la designan preferentemente por su nombre y, sólo en casos muy especiales, por su categoría de parentesco en relación al ego (Kennedy, 1970: 174-184).

La familia nuclear es la unidad básica del trabajo y la reproducción. Existe en ella una división del trabajo por sexo y edad que, aunque flexible, orienta a los hombres adultos al trabajo agricola y de construcción de la casa, a las mujeres a las tareas de la

${ }^{57}$ sino que se designan por un patronimico acompañado de un sobrenombre que hace referencia al lugar de residencia (por ejemplo, Manuel Sitánachi).

${ }^{58}$ Retomando los planteamientos de Aguirre y Pozas, utilizo el término linaje para referirme a la unión de un número de familias extensas, ligadas por la pretensión real o supuesta de descender de un ancestro común manifestada en la posesión de un apellido indigena igual (Aguirre y Pozas, 1981: 42).

Los linajes tienen como función primordial la de regular el parentesco a través de normas exogámicas. Entre los pueblos indigenas de México donde operan (por ejemplo, los otomies), los linajes son patrilineales y están asociados a la identificación del grupo con un territorio o paraje sobre el que se reconocen derechos de ocupación ancestrales.

El clan o clan geográfico es una forma de organización social básica y común entre los grupos étnicos nahuas, mixtecos y mayences de México y Guatemala, caracterizada por la existencia de reglas de descendencia unilateral, pero, sobre todo, de una unidad territorial. Su expresión mesoamericana es et calpul o barrio cuyas principales funciones son las de constituir la unidad básica de la organización politica (ayuntamiento regional), religiosa (mayordomias) y del trabajo cooperativo (tequio) de los pueblos indigenas mesoamericanos (Aguirre y Pozas, 1981: 43-44)

La inexistencia de linajes o clanes territoriales entre los tarahumaras es reconocida ampliamente en la bibliografia sobre el tema. Sólo he podido encontrar un autor que caracteriza las rancherias tarahumaras en términos de organización social, como el conjunto de linajes segmentados asentados en porciones de la rancheria, la cual comparten con miembros emparentados con ellos por el hecho de compartir ancestros en común, por ser miembros de un linaje del cual se desprendieron, o en otras casos por quedar emparentados por la via del matrimonio (Olivos, 1997: 100) 
alimentación y crianza de los niños y a éstos, desde muy temprana edad, al cuidado de las chivas. La convivencia entre los miembros de la familia está regida por normas no sólo de cooperación sino también de profundo respeto por el individuo, libertad, autonomia, liberalidad y afecto. ${ }^{59}$

En tanto que unidad económica la familia organiza su sobrevivencia a partir de una agricultura sustentada básicamente en el cultivo del maiz, frijol y calabaza, la recolección, la caza y la pesca complementarias y la cria de cabras, ovejas y borregos de los que obtiene la lana para protegerse de los crudos inviemos y el estiércol para fertilizar la tierra. Para ello, los rarámuri acostumbran desplazar sus establos en diferentes puntos de sus tierras de labor (establo móvil), asegurando asi la fertilización de sus tierras. Este complejo agro-ganadero de origen colonial constituye el soporte básico de la economía de una unidad doméstica. Pero además, la unidad familiar es el núcleo básico de la socialización y del aprendizaje cultural del individuo. A través de la paciente enseñanza de los padres, el niño asimila los valores, los patrones de conducta y las prácticas culturales de la vida rarámuri. Quizás por ello muchos etnógrafos de la Tarahumara han insistido en el papel central de la familia en esa sociedad, hasta llegar a aseverar, como lo hacen Bennett y Zingg que "el núcleo familiar cubre perfectamente todas las necesidades de la vida aislada de los tarahumaras" (Bennett y Zingg, 1986: 298).

El espacio territorial en el que estas actividades se desarrollan se conoce con el

\footnotetext{
${ }^{59}$ En contraste con la tradición educativa de algunas sociedades occidentales, los niños rarámuri conocen más la reprensión, a través del discurso y de los consejos de los padres y mayoli, que la represión. También ejercen tal autonomia y libertad que los padres llegan a respetar sus decisiones, aun cuando éstas puedan parecer infundadas. Robles, cita por ejemplo el caso de niños enfermos que son respetados en su decisión de resistirse a tomar una medicina. (Robles, 1994: 47). Este grado de autonomia y libertad de los hijos no pudo por menos de asombrar a algunos misioneros jesuitas de la época colonial, como el padre Juan Maria Ratkay que exclamaba:
}

Los hijos no obedecen a sus padres más que cuando se les viene en gana y no hacen nunca nada para facilitarles la vida. Ni siquiera les ayudan a trabajar sus campos, a construir una casa o en cualquier circunstancia. Cualquiera que no cultive por si mismo su tierra está condenado a morir, asi sea tan viejo como Matusalén (cita tomada de Deimel, 1980: 61) 
nombre de "rancho" (kawi o bitichí en rarámuri), espacio que comprende una parcela o terreno de labor cerca del cual se asientan la casa-habitación familiar, los gallineros y corrales de chivas, las "trojes" para almacenar las cosechas, el patio para el descanso y las celebraciones rituales $y$, ocasionalmente, un área destinada a la horti-fruticultura y alguna letrina. Las condiciones ecológicas del territorio serrano y, en particular, la diseminación de las tierras propicias para la agricultura, explican la marcada tendencia a la dispersión y aislamiento de los ranchos.

También los condicionantes ecológicos y las normas que sustentan el sistema de herencia indigena explican la variabilidad en el tamaño y composición de la familia, así como su patrón de residencia. La herencia entre los tarahumaras se rige por un principio de igualdad y bilateralidad según el cual todos los hijos tienen los mismos derechos sucesorios, independientemente del sexo y edad. La herencia puede hacerse efectiva cuando los hijos se casan o tiempo después. Teniendo en cuenta estos condicionantes, los nuevos esposos podrán instalarse en el rancho de los padres o suegros en donde o bien trabajarán la tierra heredada o bien se mantendrán asociados con los padres para trabajar conjuntamente la tierra patrimonio familiar. En cualquier caso la familia nuclear pasará a convertirse en una familia extensa y el rancho ampliará su extensión para dar lugar a un número mayor de casas-habitación.

Pero también es posible que a partir del matrimonio o algún tiempo después la nueva pareja constituya una nueva familia nuclear autónoma desplazándose a otro lugar donde abrirá al cultivo, por medio de la tala, quema y roza del bosque un nuevo rancho. En suma, parece no haber una norma que determine el padrón de residencia ni la composición de la familia. ${ }^{60}$

\footnotetext{
${ }^{60}$ Retomo aqui la tesis que plantea Kennedy en su trabajo sobre Inápuchi, una zona gentil cercana al pueblo de Aboréachi. Según él -y en contra de la tesis de Murdock para quien la familia tarahumara es nuclear y neolocal- no existe una norma fija y universal que explique el patrón de residencia postmatrimonial (uxorilocal, virilocal, neolocal) ni la composición de la familia (nuclear o extensa). La familia nuclear puede pasar a ser extensa y viceversa a lo largo del año agricola a causa de las migraciones estacionales o puede variar también de una generación a otra conforme nacen nuevos miembros o van partiendo, a causa del matrimonio, otros (Kennedy, 1970: 203-210).
} 
El esquema que referimos y que explica la relación entre familia y territorio se vuelve aún más complejo si tenemos en cuenta que en muchas zonas indigenas de la Tarahumara es común que los núcleos familiares se trasladen en la época invernal de sus ranchos de la cumbre a otros situados en la barranca, para defenderse del frio y en búsqueda de pastos para el ganado, mientras que en verano el movimiento va en sentido contrario. $^{61}$ Además de eso, y dadas las prácticas de la endogamia y de la propiedad agraria derivadas de las reglas de la herencia, es común que en una familia las tierras propiedad de la esposa estén situadas en un lugar distinto al de las tierras heredadas por el esposo. Por lo mismo, la familia se desplaza periódicamente entre esos dos ranchos en las épocas de actividad agrícola. ${ }^{62}$

Aun cuando es posible que el rancho donde habita una unidad familiar -sea ésta nuclear o extensa- se encuentre relativamente aislado, lo común es que, cerca de él se asienten otras unidades residentes entre las que pueden mediar relaciones ampliadas de parentesco, conformando conjuntamente una "rancheria". ${ }^{63}$ La amplitud territorial de las

${ }^{69}$ De acuerdo con la información que hemos podido recoger en el campo, parece que esta misma práctica tambiè fue propia de núcleos mestizos en zonas como Tónachi (zona de media barranca) que, hasta los años sesenta, se desplazaban en el verano hacia la mesa de Guachochi.

62 Ello permite a las familias rarámuri diversificar sus estrategias y posibilidades de levantar cosechas en un territorio donde las lluvias son inciertas y desigualmente repartidas. Robert J.Hard y William L. Merrill (1992) han llevado a cabo un minucioso estudio sobre esta práctica cle lo que ellos llaman "agricultura móvil" en la comunidad de Rejogochi.

Como ejemplo de esta movilidad, podemos citar el caso de La Mesa de la Yerbabuena, población rarámuri barranqueña cercana a Batopilas, donde en la época de verano (junio, julio y agosto) mucha gente se desplaza a ranchos de su propiedad, distantes 1 dia de camino, con el fin de sembrar y escardar sus tierras de labor.

63 Para evitar confusiones y a diferencia de lo que hacen muchos autores, utilizo aqui el término rancheria en sentido diferente al de rancho, aun cuando en la realidad cotidiana se usen uno y otro indistintamente, para defínir las dos realidades territoriales: la del espacio de asentamiento de una familia nuclear o extensa y la de un espacio más amplio donde, en un grado variable de dispersión, se localizan varias familias o ranchos familiares.

La distancia entre las casas de una rancheria puede ser muy variable. Asi, por ejemplo, en lugares como las mesas de Guachochi y Yeguachique propicias para la agricultura, las viviendas están cercanas en un radio aproximado de distancia que se puede recorrer a pie en una o dos horas. En cambio, en lugares como Kirare (media barranca) o La Mesa de la Yerbabuena (barranca) doncle los tertenos aptos para la agricultura son escasos y están dispersos, las distancias entre ranchos puede representar un dia de camino. Kennedy (1970: 102) ubica los ranchos cercanos a Inápuchi en un radio máximo de 3 horas.

Estos factores condicionan la frecuencia de los contactos entre los ranchos. Los habitantes de ranchos próximos a la cabecera del pueblo acostumbran visitar ésta los domingos para hacer compras, asistir a la 
rancherias es muy variable y depende en gran medida de las posibilidades agricolas del lugar. Las mesas y valles son lugares propicios para la concentración; los terrenos en declive cerca de los barrancos, en cambio, favorecen la atomización demográfica.

Algunos autores (Olivos, 1997: 98) han querido ver en estas actuales rancherias la continuidad histórica del modelo del "pueblo de rancheria" postulado por Spicer y del que hicimos mención al inicio de este capítulo. Independientemente de ello, la rancheria aparece como un espacio en el que se desarrollan relaciones de cooperación, intercambio y reciprocidad entre familias, expresadas en el trabajo cooperativo en actividades agricolas, el intercambio de alimentos, la celebración de rituales festivos y, especialmente, la participación en las tesgüinadas.

Sin embargo, los perfiles de la ranchería como unidad territorial y de las relaciones de vecindad como ámbito de adscripción social no son muy definidos ya que no puede decirse que existan actividades o relaciones que sean exclusivas de estos grupos de vecinos. Quizás por ello, algunos autores como Bennett y Zingg, utilizaron el término de "ill-defined neiborhood" (mal definida vecindad) ${ }^{64}$ para referirse al perfil social de las rancherías.

En contraste con la indefinición que caracteriza al grupo de adscripción vecinal y en oposición al modelo de organización social de grupos fuertemente unidos como los linajes corporados, Kennedy ha postulado la existencia entre los tarahumaras de una

reunión o nawésari, participar en alguna fiesta o tesgüinada. Quienes residen en ranchos lejanos vienen a las cabeceras en ocasiones especiales como la Semana Santa, fiesta de la Virgen de Guadalupe y algunas otras festividades. Las visitas entre ranchos cercanos son más comunes.

${ }^{64}$ Referencia tomada de Deimet, 1980: 65 y 66. La "indefinición" de dicha vecindad se explica porque no necesariamente todos los vecinos de una rancheria participan en las actividades de cooperación y reciprocidad $y$, en cambio, familias alejadas de esas rancherias pueden hacerlo. Al respecto señalan Bennett y Zingg

Los grupos a los que un tarahumara común pertenece son: primero y antes que cualquier otro en importancia, la familia; segundo, un grupo vecinal bastante indefinido, que funciona como factor de unión en el trabajo, durante la tesgüinada y que, levemente aumentado, une en las ceremonias de la fiesta nativa; tercero, una comunidad o pueblo, que proporciona reuniones dominicales, fiestas de iglesia y gobiemo (Bennett y Zingg, 1996: 507). 


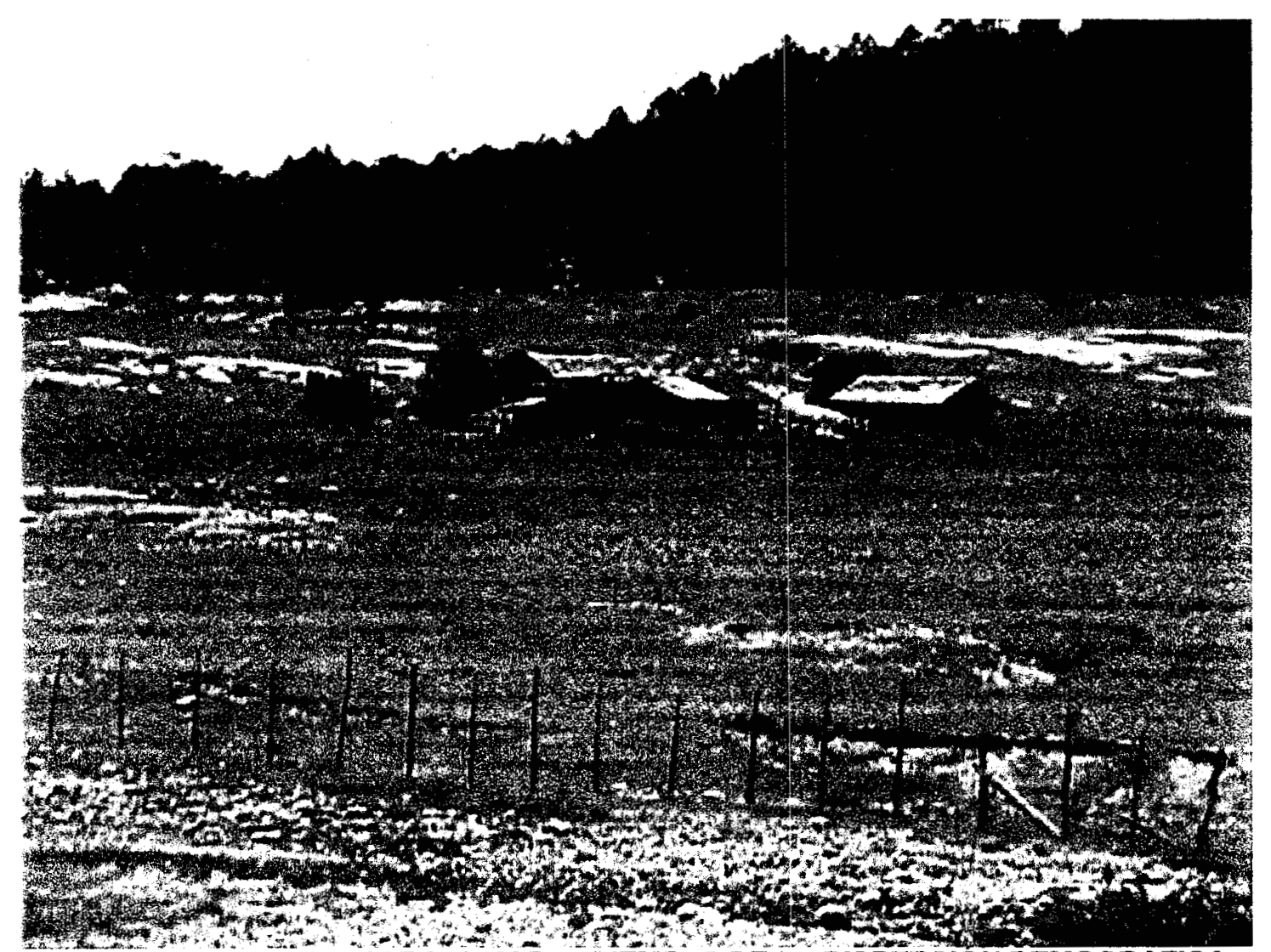

FIGURA 32. RANCHO TARAHUMARA, EJEMPLO DE LA DISPERSION DEMOGRAFICA, CERCANO A CUSÁRARE. (FOTO DEL AUTOR, JULIO DE 1999).
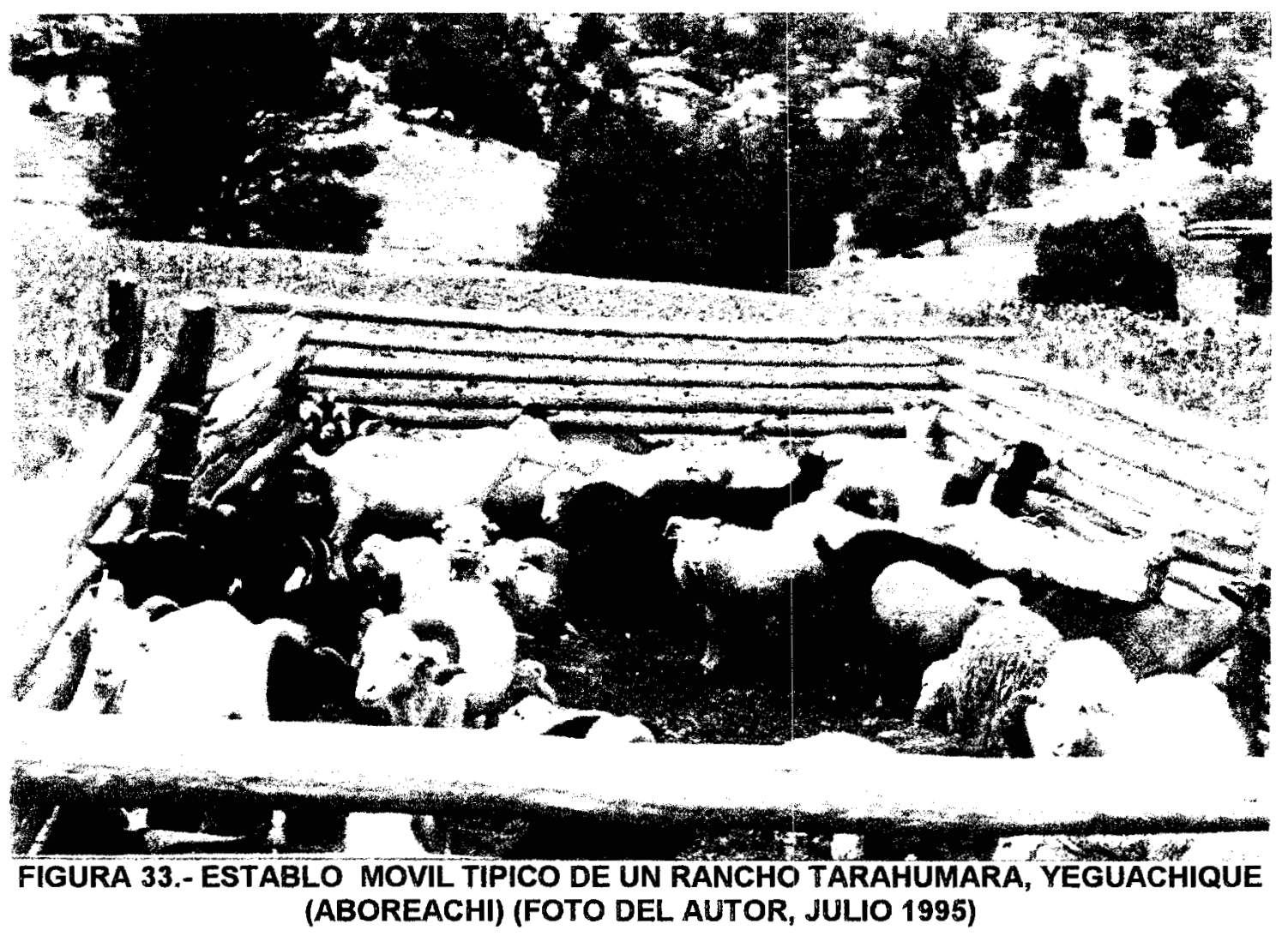
entidad social que ha denominado "red o plexus del tesgüino", integrada por el conjunto de personas que se articulan socialmente a través de las invitaciones periódicas y reciprocas a consumir tesgüino, ligadas a trabajos cooperativos o actividades rituales, como las curaciones de personas o tierras, yúmari o tutuguri. Esta comunidad de bebedores de tesgüino puede rebasar ampliamente los límites de las rancherias y no necesariamente incluye a todos los miembros de éstas.

A partir de su investigación en el área de Inápuchi, Kennedy ha propuesto que el individuo y las familias encuentran en su adscripción a esta red del tesgüino la forma más efectiva de socialización:

Para los gentiles de Inápuchi, la tesgüinada sirve [para] todas las funciones de la vida social [...]. Es el grupo religioso, el grupo económico, el grupo de recreación, el grupo en cuyo seno se arreglan las disputas, donde se conciertan los matrimonios y donde se finiquitan los negocios. Es entonces cuando, bajo la influencia del alcohol, entre el conjunto de vecinos, el individuo tiene la oportunidad de desempeñar los rotes sociales que han estado latentes durante su aislamiento. El hombre con cualidades de líder o aspiraciones a serto se pondrá de pie y pronunciará un sermón, que sivve tanto para reforzar las normas morales cuanto para dramatizar las aspiraciones de status o posición. Se verifican tratos en que se transfieren animales o maiz. Pueden concertarse entonces una ceremonia o una carrera de bola. En las tesgüinadas los solteros encuentran su pareja y los casados variación en su experiencia sexual. Los roles del parentesco que van más allá de la familia nuclear rara vez encuentran oportunidad o ánimo para expresarse, excepto en los casos en que los alcoholizados llegan a juntarse. Aqui, también, el patán construye su reputación de ser muy diablo, y despiertan mucha jocosidad sus bromas sexuales estereotipadas y sus chanzas pesadas. El rol ritual del practicante religioso nativo se desempeña también en gran parte en esta atmósfera. Las tesgüinadas proveen prácticamente las únicas oportunidades para la liberación de los impulsos agresivos; asi de frecuente es la ocurrencia de pleitos por ésta o aquella razón. El motivo más común es el celo sexual, y es corriente que provoque lesiones e incluso la muerte, lo cual contrasta con el hecho de que casi nunca suceden peleas fuera de las tesgüinadas.

El sistema de status social se encuentra también intimamente ligado con el complejo del tesgüino [...] La tesgüinada cumple la importante función de hacer astensible el rango y el poder en la comunidad (Kennedy, 1970: 119, 120).

El tesgüino sigue siendo hasta hoy un eleménto central de la vida rarámuri. En todo tiempo, se observa en los ranchos que la gente se reúne alrededor de las ollas de tesgüino, sea a causa de algún trabajo colectivo o "fáina" (agrícola o relacionada con el 
arreglo de un camino, la construcción de una casa, de un aula escolar, etc.) o con motivo de alguna ceremonia destinada a rogar y agradecer a Dios-Onorúame la bendición de la lluvia, las cosechas y el agua o para curar la tierra, los animales o los cerros. Finalmente, el tesgüino nunca está ausente cuando se celebran las "fiestas de la iglesia" (Semana Santa, Virgen de Guadalupe, Reyes), cuando se realizan carreras de bola e incluso festividades civiles. En todas estas circunstancias, la tesgüinada compendia, en muchos sentidos, la esencia misma de la vida rarámuri, tejida en torno a las obligaciones de la reciprocidad (expresada en las normas de cortesía al devolver la weja o recipiente con bebida, en las invitaciones y la ayuda mutua), el respeto por el fiel cumplimiento del orden ritual, la autoidentificación de los rarámuri frente a los mestizos e incluso la sublimación del estado de ebriedad como un estado ideal, cuasi sobrenatural del hombre. Ello, aún a costa de la conflictividad y violencia (peleas, violaciones, disputas, etc.) que, en ocasiones, se propician en el contexto de las tesgüinadas. ${ }^{65}$

El consumo social del tesgüino aparece pues como la ocasión propicia más importante para la conformación de una identidad comunitaria entre los tarahumaras. Esta no se corresponde necesariamente con las estructuras territoriales (rancho, rancheria, pueblo) sino que las rebasa. Menos aún puede decirse que corresponda a agrupaciones unilineales como los linajes, los clanes geográficos o calpules mesoamericanos. Se trata más bien de un esquema sumamente flexible y relativamente informal de organización social adaptado a las condiciones de dispersión demográfica que impone la ecología serrana. En esencia pues, el complejo del tesgüino y el conjunto de hechos sociales vinculados con él constituyen el núcleo central más cohesivo y originario de lo que podriamos denominar la comunidad en la Tarahumara.

Si el rancho, la ranchería y la red del tesgüino aparecen como niveles de organización social de raices prehispánicas, el pueblo, cuarto nivel de adscripción del indigena de la Tarahumara, es claramente un invento misionero colonial. Los pueblos

\footnotetext{
${ }^{65}$ Puede verse al respecto el interesante trabajo de Urteaga (1998) sobre el uso y significados actuales del consumo del tesgüino entre los tarahumaras.
} 
actuales son, en efecto, el testimonio más vivo de lo que fue la estructura territorial promovida por los misioneros y sustentada en la centralidad de una misión-cabecera y una constelación de ranchos y rancherias dependientes que, en conjunto, conformaban un partido. Un aspecto destaca de la vida de estas cabeceras de los pueblos de la Tarahumara: su centralidad ritual y política. Presididas por una iglesia, muchas veces de origen colonial, las cabeceras son el lugar de la reunión indigena. En el atrio del templo se llevan a cabo las celebraciones y rituales ligados al ciclo católico tas "fiestas de la iglesia" (Bennett y Zingg)-, asi como los juicios y los sermones comunitarios -nawésaridirigidos por los gobernadores. El ambiente de reunión, formalidad, ritualismo y orden jerárquico de los pueblos en días festivos no puede por menos de contrastar, a los ojos del visitante, con el aislamiento, la cotidianidad, el apremio del trabajo agricola y la informalidad de la vida de los ranchos. El orden social del pueblo rememora pues el arquetipo de la comunidad tantas veces soñado por misioneros e indigenistas.

Las cabeceras de los pueblos suelen ser los asentamientos con mayor cantidad y densidad de población pero ésta no deja de ser muy reducida. Hay que tener en cuenta que suele ser en estas cabeceras donde se asienta también una parte de la población mestiza que vive en la Sierra. En cualquier caso y desde la óptica indígena, los pueblos engloban a las rancherías y los ranchos y establecen un principio de pertenencia y adscripción. En tanto que entidad política el pueblo es la unidad básica de jurisdicción en la que se ejerce el gobierno y el sistema de justicia indígena. Analicemos con más detalle estos aspectos.

El sistema de gobierno rarámuri está presidido por el gobernador o siriame, elegido por consenso (no por votación) por la gente de los diferentes ranchos, rancherias y cabecera de cada uno de los pueblos. El principal deber del siriame es mantener la justicia, el orden público y la costumbre, asegurando asi la reproducción de los valores. Para llegar a ser gobemador se requiere, antes que nada, de un buen prestigio social. Además es preciso ser un buen orador y tener capacidad para ser justo y atender las demandas de la gente, sin recibir a cambio remuneración alguna. El tiempo de 
ocupación en el cargo es variable y es posible la remoción en cualquier momento así como la reelección si el desempeño fue bueno. El simbolo de mando del gobernador es el bastón o tesora (el siriame es "el portador del bastón") con el que asiste a los juicios y ceremonias de gobiemo. Las más importantes de éstas son las reuniones dominicales a las que asiste gente procedente de distintos ranchos del pueblo y que tienen lugar en el atrio de la iglesia de la cabecera. El siriame pronuncia entonces un nawésari o sermón para reafirmar los deberes sociales del respeto, la equidad, la solidaridad y el mantenimiento de las tradiciones y costumbres. También en otras muchas ceremonias son comunes los nawésari.

El siriame siempre es auxiliado en sus funcioines por un grupo de funcionarios, elegidos por él mismo, cuyo número y categoria es variable en cada pueblo. Asi en algunos lugares de la Sierra existen gobernadores auxiliares del siriame principal o warú siriame que se encargan del orden en un grupo particular de rancherías, mientras que en otros pueblos hay cargos de segundo gobernador. Otras autoridades auxiliares en el gobierno y ejercicio de la justicia del siriame son el general, warula capitán, teniente, fiscal y juez.

También los siriame cuentan con el apoyo de una especie de cuerpo militar conformado por el jinerari, varios igapitani y los sontárasi o soldados. El capitán mayor conserva el orden en las tesgüinadas, reuniones, asambleas, fiestas y es auxiliado por los soldados. El cuerpo de policias está integrado por los alguaciles (arowashi o alawashi) que guardan los bastones de mando de los gobernadores, vigilan el orden de las reuniones y custodian a los presos en el kumerachi o cárcel donde se encierra a los delincuentes si asi lo acuerda el siriame.

Los mayora o mayoli tienen como función contribuir a conformar matrimonios, celebrarlos, dar sabios consejos a quienes se quieren casar y vigilar la moral familiar. Pueden separar matrimonios si éstos no han funcionado o convocarlos a juicio antes de que se separen, aún sin que exista denuncia previa por parte de alguno de los cónyuges. 
En los juicios de niños y mujeres suplen al siriame amonestando a los culpables.

Existen además algunos cargos propiamente religiosos entre los que destacan el rezandero que dirige las oraciones en fiestas religiosas y en reuniones dominicales en el templo, la tenanchi, mujer encargada de limpiar el templo e incensar a los santos en la iglesia y en las procesiones. Además el fiestero (o tenanchi en algunos pueblos) es el encargado de organizar la fiesta cargando con los gastos de la compra de una res y el tesgüino. También hay jefes de moros, fariseos, bandereros y chapeyokos (o chapeyones), encargados de dirigir las danzas respectivas. ${ }^{66}$

Una de las funciones más importantes del siriame es la de impartir justicia en delitos como robo, adulterio, maltrato, agresión, violación, etc. La justicia y su aplicación juegan un papel central entre los grupos étnicos de la Sierra Tarahumara como mecanismo de conservación de la armonia en la convivencia social, máxime en sociedades como éstas donde el individuo tiene una tan notoria autonomía e

\footnotetext{
${ }^{66}$ Entre los ódami o tepehuanes el sistema de gobiemo es más complejo y tiene una particularidad, la existencia de una autoridad suprema, el moyi o capitán general. Hasta finales de los años sesenta habia un único moyi con jurisdicción sobre todos los pueblos tepehuanos del municipio de Guadalupe y Calvo y con sede en el pueblo de Baborigame. Posteriormente surgió un segundo, con sede en Nabogame, dividiéndose entre ambos el control sobre el territorio ódami. El capitán general tiene funciones de autoridad, vigilancia, control y aplicación de la justicia. Para llevar a cabo esas tareas es auxiliado por el kaitán y su suplente, un sargento y su suplente y varios sandar (soldados). Además, en cada pueblo hay un gobernador o kaiki y su suplente, puesto en el que se alteman personas de los asentamientos de la barranca (abajeños) y sierra (arribeños). Todas estas autoridades sesionan periódicamente para tomar decisiones $y$, en su caso, aplicar justicia. El verdugo es quien se encarga de aplicar azotes a quien asi sea sancionado por cometer algún delito. Existen también los phiskari (fiscales) y sus ayudantes, los. fiesteros, los kakabo (cabos), encargados de organizar las fiestas religiosas, asi como los oidigerdunukame o jueces de campo, autoridad en los ranchos o pequeñas comunidades.

Entre los warijó que habitan los municipios de Uruachi, Chínipas y Moris, los cargos tradicionales ligados al gobiemo indigena han ido desapareciendo, existiendo entre ellos un nuevo liderazgo organizado en tomo al Consejo Supremo Warijio. Los warijó participan, sin embargo, en los puestos de la administración municipal y ejidal.

Entre los o'oba o pimas bajos que habitan rancherias próximas al poblado de Yepachi, en el municipio de Temósachi, existe un sistema de cargos parecido al de los rarámuri. pero más simplificado. El gobernador u onogúshigam mantiene el orden público, la costumbre, representa a "la tribu" frente a las autoridades no-indigenas y es auxiliado en sus funciones por un segundo gobernador y por gobernadores de menor rango en cada rancheria. Es interesante señalar que en años recientes fue nombrada una mujer como gobernadora. Existe tambien la figura del justiciero y su suplente, que vigilan el orden y la justicia aunque no lleven a cabo juicios.
} 
independencia. En este sentido, la justicia cumple la función de asegurar que la libertad del individuo no choque con los intereses colectivos, pero también la de garantizar que los derechos individuales sean respetados.

El juicio es común en estos pueblos. Siguiendo la explicación de Robles y Vallejo (1995), el juicio surge a partir de una denuncia que se puede presentar, de manera informal, por el ofendido ante el gobernador con ocasión de alguna reunión o tesgüinada. Los capitanes y mayora reciben la denuncia e investigan los detalles a base de preguntar a los vecinos. Si alguno de estos dos funcionarios son parientes del acusado serán eximidos de su función y el quejoso acude directamente con el gobernador o con el general.

Los juicios se realizan los domingos después del nawésari. Si hubo violencia o robo, se traerá al acusado cuando éste se muestre renuente a venir al juicio. Esta tarea la llevan a cabo los capitanes acompañados de los sontárashi quienes llevan una lanza como símbolo de autoridad. La información sobre el caso circulará en las reuniones de trabajo y tesgüinadas. Todo ello ayudará a esclarecer el caso y avanzar la investigación.

El juicio se lleva a cabo en presencia del gobernador, alguacil y un grupo de ancianos que se sientan en línea y, frente a ellos, en otra línea, se sienta el acusado y el acusador. Alrededor de ellos se sienta el resto de la comunidad y los testigos. Durante el juicio el gobernador debe tener su bastón de mando en la mano, hasta el fin del juicio. Invita a todos a que asistan, incluyendo los niños, para que vayan aprendiendo. EI siríame interroga al acusado y al acusador. Si se trata de mujeres o niños es el mayora quien interroga pero ante la presencia del gobernador y del publico.

Cuando el delito es evidente, el acusado debe aceptarlo para llegar a un acuerdo final, pero cuando se niega, el juicio se prolonga por más tiempo y puede desembocar en la amenaza de que el acusado será enviado al sistema de justicia no indigena (agencia 
del ministerio público $)^{67}$. La gente que asiste al juicio puede opinar públicamente. Cuando el acusado acepta su responsabilidad, el gobernador le hace ver las consecuencias de su conducta frente a la comunidad. El gobernador pregunta al acusador qué pide en retribución al delito. Se negocia y se llega a un acuerdo final. El pago en dinero, especie o trabajo puede llevarse a cabo de inmediato o a plazos. En ocasiones, el acusado deberá penar por algún tiempo su culpa en la cárcel o kumerachi, donde, para su vergüenza, estará a la vista de todos. Finalmente, todos manifiestan su acuerdo con el veredicto y el acusado acepta el pago. El acusado y el acusador se saludan públicamente y saludan a los jueces y a la comunidad diciendo Matétera ba, gracias. EI juicio termina con un sermón del gobernador indicando que ya se regresó a la paz, pidiendo a todos no volver a hablar mal del acusado. El que pidió el juicio ofrece una comida (tortilla, atole, frijoles) a los ancianos.

El sentido profundo del ejercicio de la justicia tiene que ver con el restablecimiento del equilibrio entre los individuos, de éstos con el resto de la comunidad y, en general, con la naturaleza y con Onorúame, Dios. Los rarámuri se conciben a si mismos como las columnas del mundo que lo sostienen, que colaboran con Dios para mantener el orden cósmico, de las estaciones, de los astros, de la tierra. Como en todos los rituales, fiestas y celebraciones en que participan, en los juicios los rarámuri recuerdan, reproducen y actualizan su visión del mundo: los hombres deben de andar y comportarse con rectitud en el camino de la vida, deben celebrar, bailar y contribuir a que Onorúame, el que está arriba, siga dándoles la vida, el maíz y el tesgüino.

Una vez que hemos analizado la forma de funcionamiento del sistema de gobierno y justicia, podemos entender mejor la lógica socio-territorial de los grupos

\footnotetext{
${ }^{67}$ Uno de los elementos significativos de la costumbre juridica de los grupos étnicos de la Tarahumara es que existe cierto tipo de delitos que se considera deben ser juzgados exclusivamente por las autoridades mestizas. Este es particularmente el caso de delitos "mayores" como los homicidios y los delitos "de sangre". En esos casos, los propios gobernadores transfieren los delincuentes a los juzgados mestizos y dichos delincuentes siguen los procesos comunes de la justicia. Es por eso que los presos indigenas de los CERESOS, en la mayoria de los casos, pugnan penas por alguno de estos delitos "mayores", incluyendo delitos "contra la salud" (narcosiembra y narcotráfico), por los que pudieron ser detenidos y acusados dentro o fuera de sus pueblos.
} 
indigenas en la Tarahumara. Los datos que se muestran en los tres cuadros siguientes proceden del Conteo de Población realizado por el INEGI en 1995 y tienen serias limitaciones no sólo por los criterios para establecer la pertenencia a un grupo étnico, sino también por la total discordancia entre las concepciones del INEGI y las de los grupos indigenas sobre el territorio y su estructura social. Aún así, los cuadros nos permiten acercamos a una idea aproximada de cómo se articulan los ranchos, las rancherias y los pueblos en la Tarahumara.

En el Cuadro 8 aparece la distribución de las localidades de los municipios serranos según su tamaño demográfico. Como se observa, predominan los pequeños asentamientos con menos de 50 habitantes (cerca del $85 \%$ ) y sólo existe una mínima proporción (aproximadamente del 1\%) de localidades con más de 500 habitantes, en su mayoría concentraciones semiurbanas mestizas (cabeceras municipales o centros como Creel, Guachochi, etc.). La atomización de los núcleos demográficos en ranchos se presenta tanto en la Alta como en la Baja Tarahumara e incluye tanto a la población mestiza como a la indigena, aunque en forma distinta. Las localidades de nivel intermedio, de 50 a 500 habitantes, totalizan sólo cerca del $12 \%$.

Los cuadros 9 y 10 permite visualizar más especificamente la lógica territorial de la población indigena de la Tarahumara. En el primero de los cuadros se indica la forma como ésta se distribuye según el tamaño demográfico de los asentamientos. En términos generales podemos decir que algo más de la mitad de la población vive en asentamientos con más de 3 viviendas pero con menos de 50 habitantes, es decir en . localidades que corresponderian, en términos generales, a lo que hemos denominado rancherias. Aunque hay algunas diferencias notables entre municipios, las cifras globales no muestran mucha variación en toda la Tarahumara.

En cambio, la importancia relativa de los núcleos de $1 \circ 2$ viviendas que se aproximan al modelo de ranchos unifamiliares (sea la familia nuclear o extensa) es muy distinta en ambas regiones, porque mientras en la Alta Tarahumara sólo cerca del $12 \%$ 


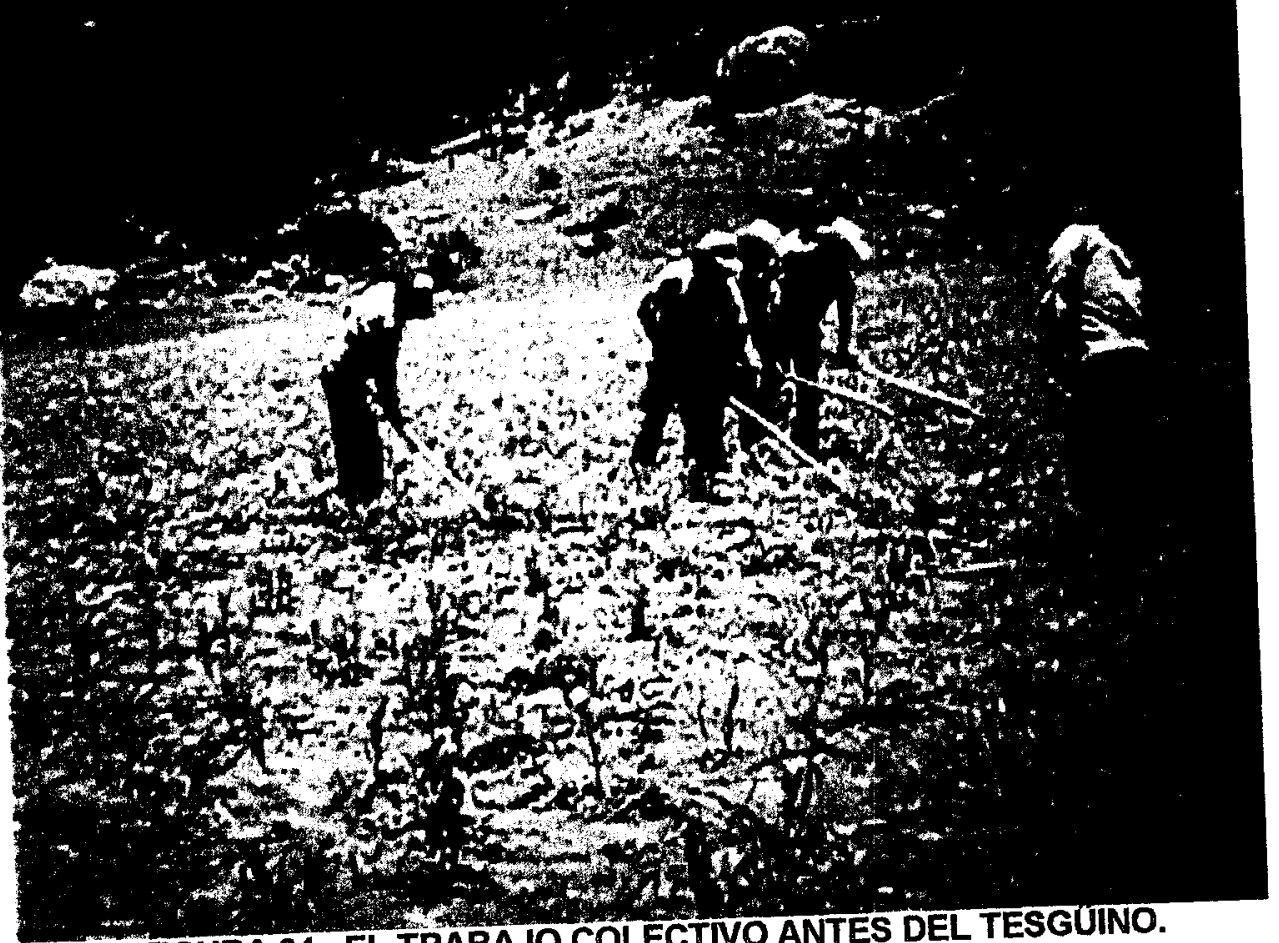

FIGURA 34.- EL TRABAJO COLECTIVO ANTES DEL TESG 1995 )
YEGUACHIQUE, ABOREACHI (FOTO DEL AUTOR, JULIO 199.

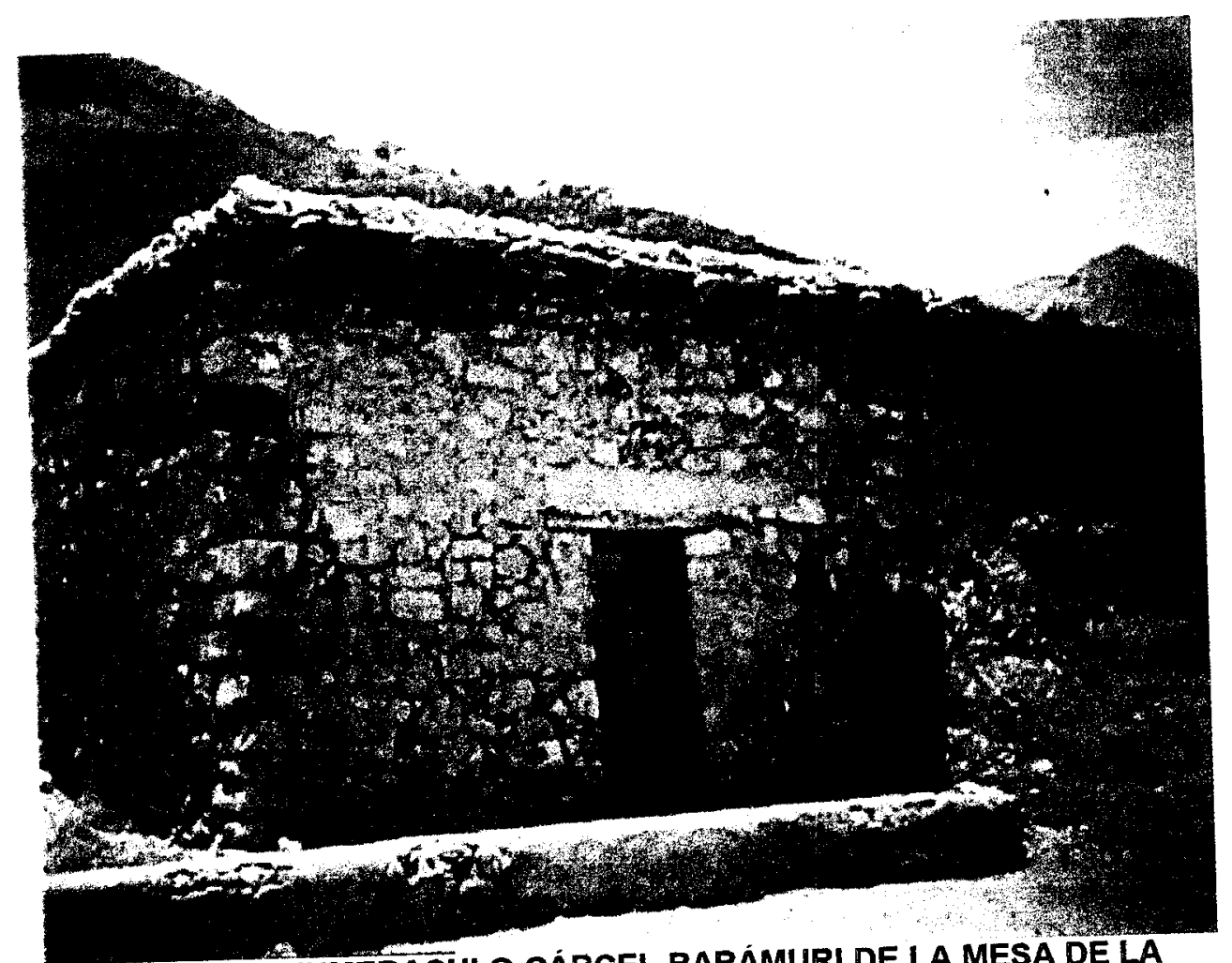
FIGURA 35.- KUMERACHI O CÁRCEL RARÁMURI DE LA MESA DE LA
YERBABUENA, CERCA DE BATOPILAS (FOTO DEL AUTOR, JULIO DE 1996). 
de los asentamientos son de este tipo, en la Baja lo son en una proporción doble, cercana al $25 \%$. Es decir, las comunidades indigenas de la Baja Tarahumara, y en especial aquellas donde reside la población warijía (Uruachi) y pima (Temósachi) son, por lo general, de tamaño más reducido, siguiendo el modelo de ranchos unifamiliares, mientras que en la Alta Tarahumara este tipo de ranchos es menos frecuente. Finalmente la proporción de los asentamientos con más de 3 viviendas y de 50 habitantes oscila entre el $22 \%$ (en la Baja Tarahumara) y el $32 \%$ (en la Alta), lo que vuelve a comprobar de nuevo una mayor tendencia a la atomización demográfica en los asentamientos indigenas de la zona de las barrancas.

CUADRO 8.- LOCALIDADES POR MUNICIPIO SEGÚN TAMAÑO DE LA LOCALIDAD. (PORCENTAJES)

\begin{tabular}{||l|c|c|c|c|c||}
\hline MUNICIPIO & $\begin{array}{l}\text { NUMERO } \\
\text { DE LOCA- } \\
\text { LIDADES }\end{array}$ & $\begin{array}{l}\text { LOCALIDADES } \\
\text { DE } 50 \\
\text { HABITANTES }\end{array}$ & $\begin{array}{l}\text { LOCALIDADES } \\
\text { DE 50 A 99 } \\
\text { HABITANTES }\end{array}$ & $\begin{array}{l}\text { LOCALIDADES } \\
100 \text { A 499 } \\
\text { HABITANTES }\end{array}$ & $\begin{array}{l}\text { LOCALIDADES } \\
\text { DE >500 } \\
\text { HABITANTES }\end{array}$ \\
\hline BALLEZA & 410 & 82.9 & 9.5 & 6.6 & 1.0 \\
BOCOYNA & 459 & 86.1 & 6.7 & 6.3 & 0.9 \\
CARICHI & 228 & 85.5 & 7.9 & 5.7 & 0.9 \\
GUACHOCHI & 1,158 & 87.3 & 9.3 & 3.0 & 0.4 \\
GUERRERO & 417 & 80.8 & 6.0 & 9.8 & 3.4 \\
NONOAVA & 59 & 83.0 & 6.8 & 8.5 & 1.7 \\
ALTA TARAHUMARA & $\mathbf{2 , 7 3 1}$ & $\mathbf{8 5 . 2}$ & $\mathbf{8 . 2}$ & $\mathbf{5 . 5}$ & $\mathbf{1 . 1}$ \\
\hline BATOPILAS & 440 & 90.5 & 5.7 & 3.4 & 0.4 \\
CHINIPAS & 166 & 82.6 & 8.4 & 7.8 & 1.2 \\
GPE.CALVO & 902 & 77.3 & 12.5 & 9.4 & 0.8 \\
GUAZAPARES & 415 & 92.3 & 4.1 & 3.4 & 0.2 \\
MAGUARICHI & 92 & 92.4 & 4.3 & 3.3 & - \\
MORELOS & 354 & 89.3 & 7.1 & 3.6 & 0.7 \\
MORIS & 139 & 78.4 & 14.4 & 6.5 & 1.6 \\
OCAMPO & 180 & 85.0 & 5.6 & 7.8 & 1.8 \\
TEMOSACHI & 164 & 86.6 & 4.3 & 7.3 & 0.4 \\
URIQUE & 909 & 93.7 & 4.2 & 1.7 & 0.3 \\
URUACHI & 325 & 87.1 & 8.6 & 4.0 & $\mathbf{0 . 6}$ \\
BANA TARAHUMARA & 4.086 & $\mathbf{8 7 . 0}$ & $\mathbf{7 . 4}$ & $\mathbf{5 . 0}$ & $\mathbf{0 . 8}$ \\
\hline GRAN TOTAL & $\mathbf{6 , 8 1 7}$ & $\mathbf{8 6 . 3}$ & $\mathbf{7 . 7}$ & $\mathbf{5 . 2}$ & \\
\hline
\end{tabular}

FUENTE: INEGI, Chihuahua. Conteo de Población y Vivienda, 1995. Resultados definitivos. Tabulados básicos. 


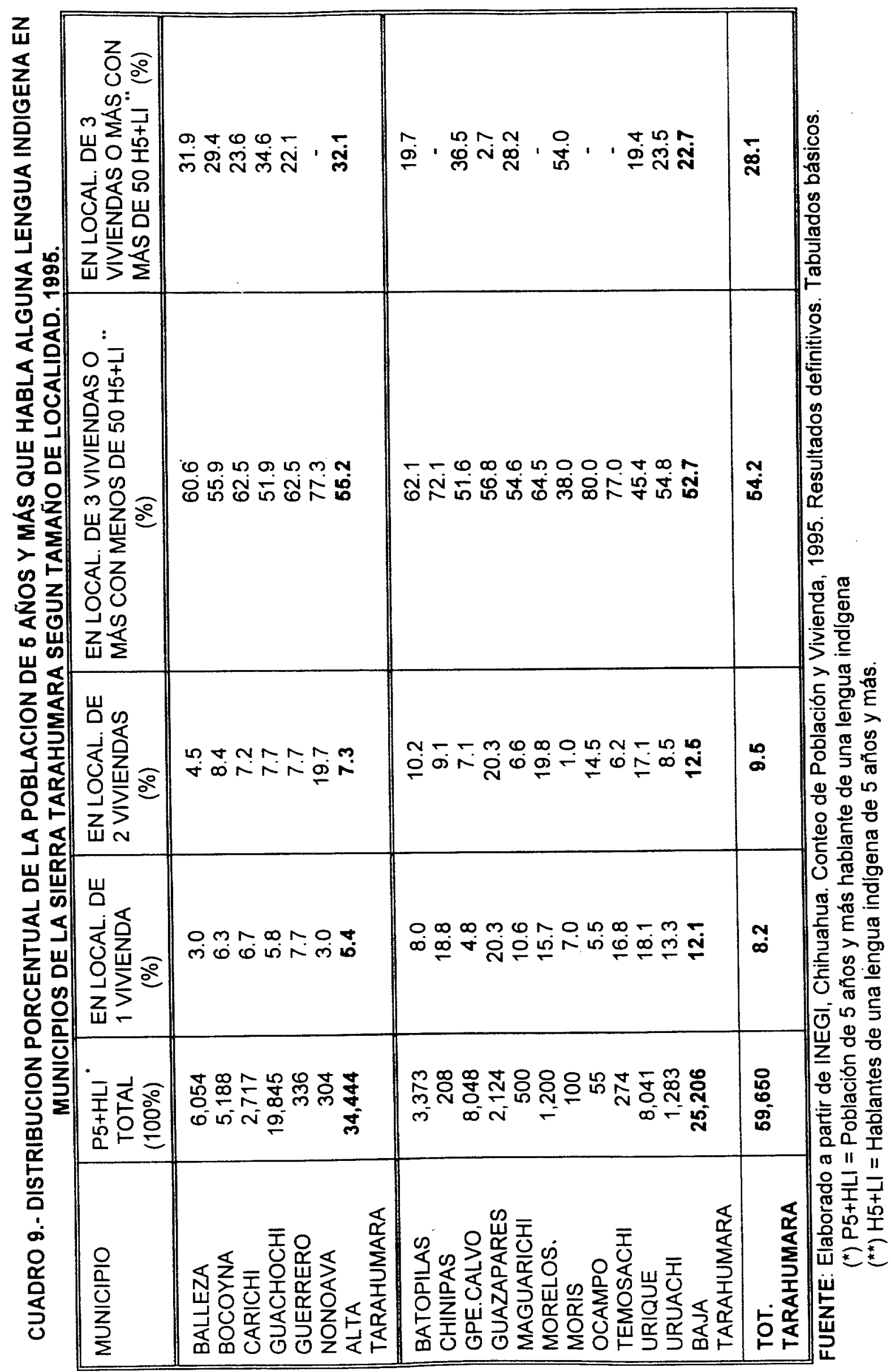




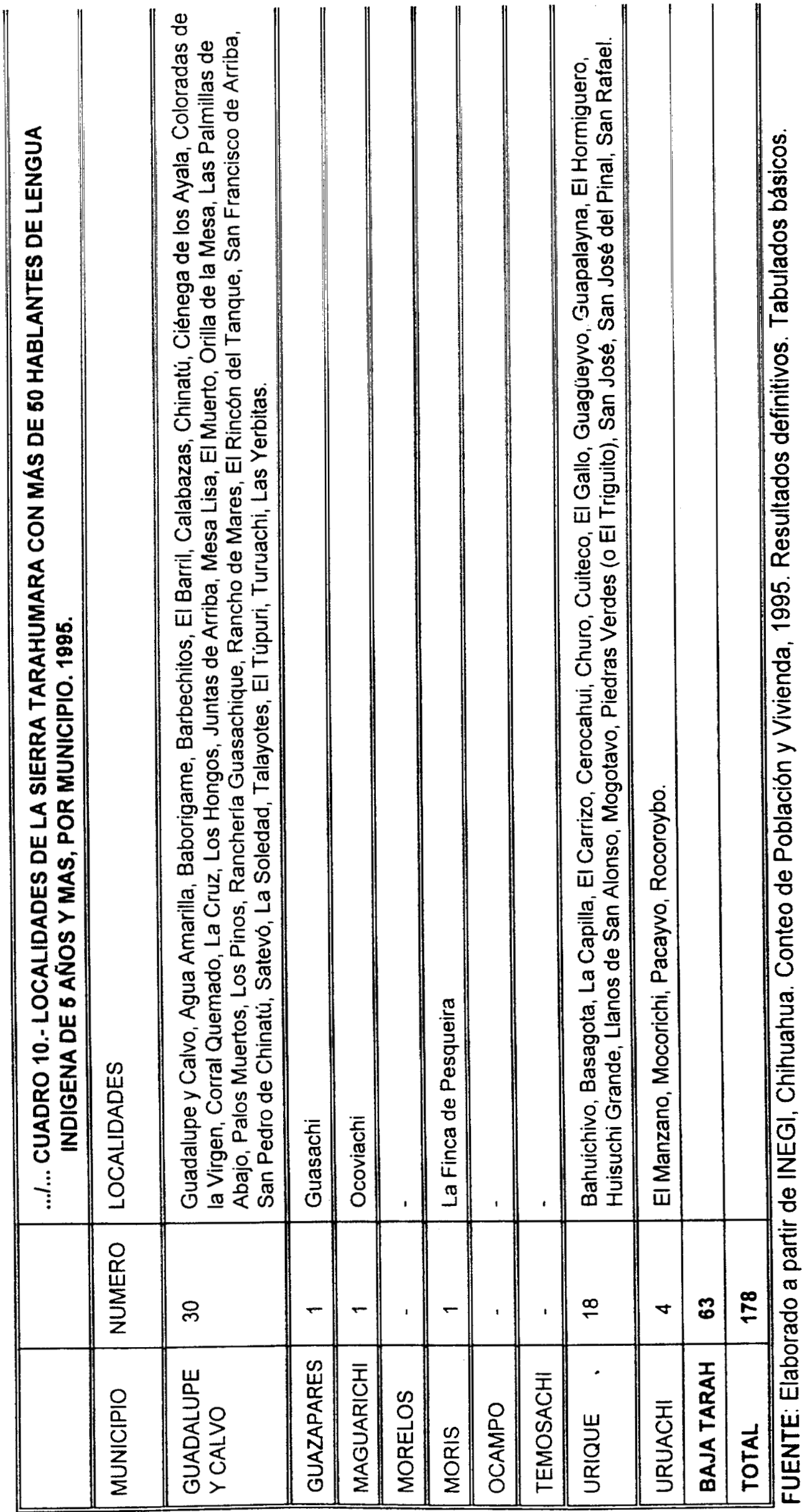


Por otra parte, podemos pensar que este rango de localidades coincide en términos generales con dos tipos de asentamientos: rancherias bastante pobladas y pueblos-cabecera. El Cuadro 10 enlista estas comunidades y, efectivamente, se pueden encontrar alli bastantes de cabeceras como Cusárare, Aboréachi, Basihuare, San Ignacio de Arareco, Santa Rosa de Ariseachi, Sisoguichi, etc., pero también aparecen en esa lista muchas rancherías con una población indigena superior a los 50 habitantes.

La forma en que se articulan los diferentes niveles de organización social y territorial de los grupos étnicos de la Sierra Tarahumara y su notable contraste con el modelo mesoamericano se muestran en el esquema siguiente. El dibujo de la izquierda sintetiza la forma como en el mundo indigena mesoamericano, y de acuerdo con los planteamientos de Aguirre Beltrán y Pozas Arciniega, se integran la familia nuclear, la familia extensa, el linaje, el calpul y el pueblo, niveles cada uno de ellos comprensivos de los anteriores. Recordemos que para estos autores, el linaje agrupa varias familias extensas que reconocen un ancestro común y un territorio de referencia; el clan geográfico, calpul o barrio integra diferentes linajes y sus respectivos territorios; el pueblo conforma una comunidad segmentada integrada por unidades que van desde la familia al calpul y que se originan en vinculos consanguineos y territoriales (Aguirre y Pozas, 1981: 26-46).

En el segundo y tercer dibujos se muestra la forma como se estructuran y articulan, según Bennett y Zingg y según Kennedy, los diferentes niveles de organización socio-territorial de los grupos étnicos de la Tarahumara. La diferencia más llamativa con el caso mesoamericano es la relativa flexibilidad de estas articulaciones, la no correspondencia estricta entre núcleo de organización social y territorialidad, por la movilidad geográfica de la familia, por la variabilidad del tamaño de los ranchos y por la amplitud -más allá de los limites de las rancherias y los pueblos- de la red del tesgüino. Por todo ello, es claro que el concepto de pueblo en uno y otro caso es muy distinto: en el primero denota concentración demográfica y articulación entre familia-linaje-clan y 
territorio; en el segundo, en cambio, significa dispersión. En el tercero de los dibujos, se incluye además el aspecto de la movilidad de la familia entre un rancho principal y otros ranchos (en otros pueblos), donde, como ya lo señalamos, se pueden ubicar otras tierras agrícolas heredadas por alguno de los miembros de la familia.

La diferencia más notable entre la interpretación de Bennett y Zingg y la de Kennedy estriba en la importancia que los primeros le otorgan al "grupo vecinal" y la que. el segundo descubre en lo que denomina el "complejo del tesgüino" tal y como ya lo hemos explicado.

El complejo esquema de articulación entre los diferentes niveles de organización y territorialidad el rancho, la rancheria, el pueblo y la red del tesgüino- constituyen la clave para entender la forma tan particular como se expresa la experiencia "comunal" entre los grupos étnicos de la Sierra Tarahumara.

Frente a esta interpretación, que nos parece la más cercana a los hechos, se han planteado en la etnografía sobre la zona lo que podriamos llamar dos visiones extremas sobre el fenómeno comunitario. La primera tiende a negar cualquier forma de identidad grupal más allá de los lazos sociales derivados del parentesco y la territorialidad. Por lo mismo, subraya el peso que el individuo, su libertad y su autonomía cobran en la sociedad tarahumara. La segunda visión extrema, en cambio, propende a sobreponderar los elementos de centralidad politica, de cohesión social y de identidad grupal entre la población indígena y es aqui donde se situó la posición indigenista.

La etnografia sobre la Tarahumara coincide en señalar que más allá de los niveles del rancho, la rancheria, el pueblo y la red del tesgüino, ninguna otra forma de identidad socio-territorial parece haber existido nunca entre las etnias de la Sierra. Las "naciones" indigenas o las "tribus" fueron, en realidad, construcciones ideológicas de los misioneros e indigenistas y no existen evidencias etnográficas que nos permitan hablar de sistemas 

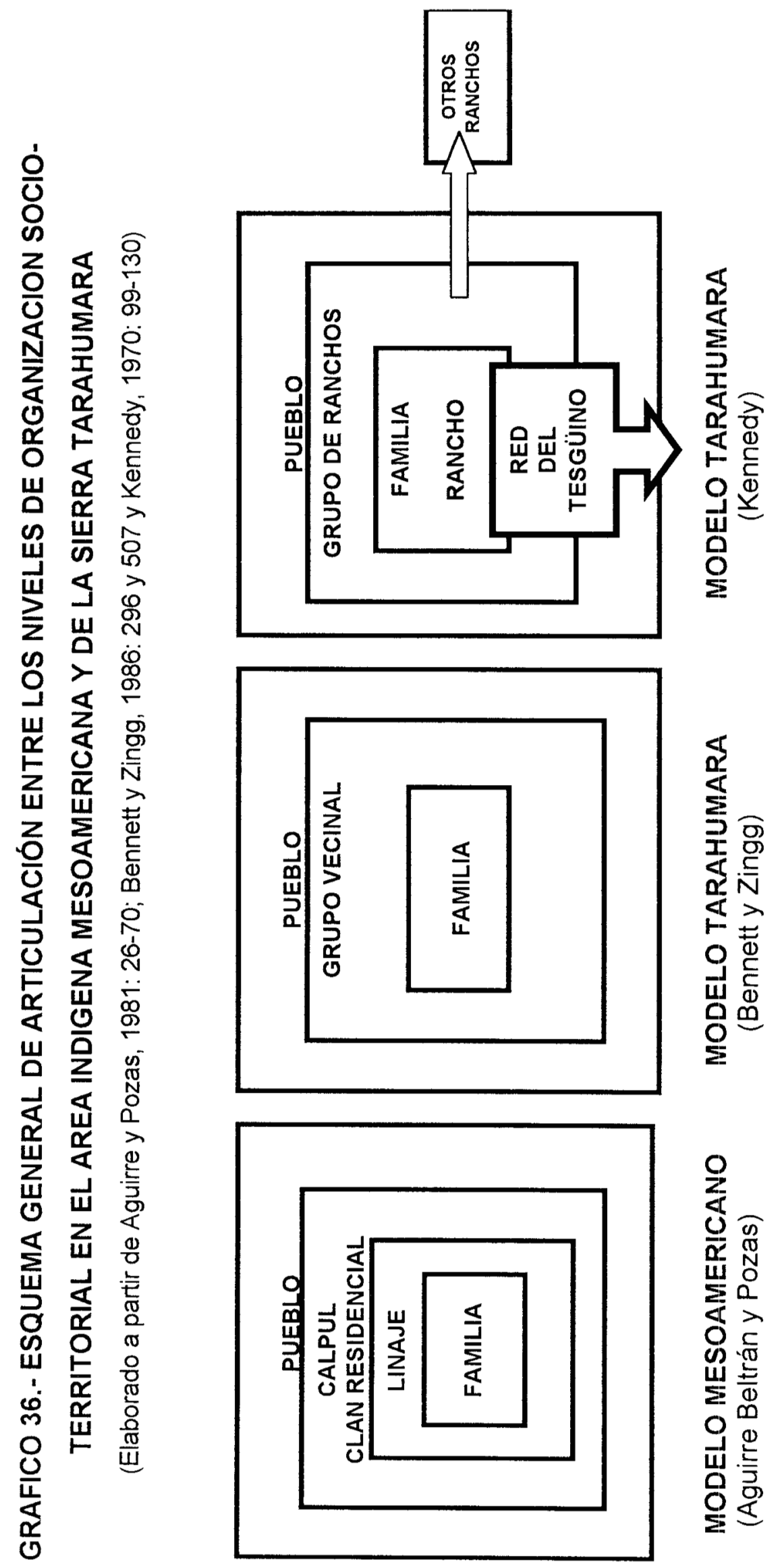

de gobierno tribal. Pero algunos autores, como el antropólogo alemán Claus Deimel, llegan aún más lejos al postular que, incluso, la idea de una comunidad étnica y de una unidad politica autoreconocida no existe entie estos grupos y que todas las formas con que éstos son designados corresponden a asignaciones externas:

La historia de los Tarahumaras comienza con la fundación de la nación y misión tarahumara al inicio del siglo XVII. Es la historia de un pueblo que, en tanto que tribu o "nación" -conceptos que suponen una unidad política-, no existe más que en las representaciones de los no-indios. Hasta el dia de hoy, los asi llamados Tarahumaras no se han forjado una conciencia que responda al ideal misionero y colonial de nación. Sólo tardiamente se dieron a si mismos el nombre de rarámuri, citado como nombre propio por primera vez en 1826 en nuestras fuentes ${ }^{68}$ [...]

Todavia hoy en día [los tarahumaras] sólo existen en las representaciones de la ciencia y de la politica en tanto que "nación" o en tanto que grupo étnico: en lo que a ellos les concieme, nunca han tomado conciencia de ser un pueblo cuyas fronteras fueran independientes de las de la misión. El intento de integración de estos seres dificilmente registrables les sobrevino en los inicios del Estado bajo la forma de un nombre -clasificable, nombrable, registrable, conceptualizado- bien determinado: los Tarahumaras (Deimel, 1980: 16 y 44-45).

Asi, y según este autor, la designación de tarahumaras o tepehuanes correspondería más bien al interés de agentes institucionales extemos (la iglesia y el estado) por encuadrartos dentro de unidades administrativo-religiosas (la misión) o de categorías étnico-nacionales compatibles con la estructura de la nación mexicana. Como prueba de esta afirmación Deimel aduce el hecho histórico de que la designación "tarahumara" y su supuesta deformación lingüistica rarámuri (que algunos, según él, infundadamente traducen como "corredores de pies ligeros") son términos de uso muy tardío, impuestos por los misioneros y ajenos a la idiosincrasia indigena. ${ }^{69}$ También

\footnotetext{
${ }^{68}$ En la versión francesa de este texto que estoy citando se señala como fecha 1926 pero ésta parece ser un error de edición, ya que más adelante, Deimel explica con detalle que la palabra rarámuri, fue citada por primera vez por el franciscano Miguel Tellechea en su Compendio Gramatical para la Inteligencia del ldioma Tarahumar (Deimel, 1980: 43).

${ }^{69}$ Su propia experiencia de campo en el pueblo de Naráachi lleva a Deimel a confirmar esta impresión de que no existe una identidad grupal:

La concepción europea de una nación unida y el sentimiento nacionalista europeo que están en la base del concepto de Tarahumara están ausentes en el nombre propio rarámuri: a quienes conoci, el hecho de que yo les llamara rarámuri, tarahumaras o mexicanos les dejaba perfectamente indiferentes: a menudo me respondian: "escoge el 
señala, retomando el estudio de Howard Gentry entre los warojios, que éstos, que no fueron integrados a la misión sino en el curso del siglo $X X$, se asumen en ocasiones como mayos (sus vecinos del oeste), en otras como tarahumaras (sus vecinos del este) y en ocasiones como mexicanos, lo que mostraria la ausencia de una identidad étnica definida (Deimel, 1980: 45 y 46).

La consecuencia de este estado de identidad asignada es que los pueblos y la estructura de gobierno y organización social que los sustenta sean en cierta forma artificiales y ajenos a la idiosincrasia indigena. En efecto, la creación de los pueblos por parte de los misioneros nunca logró modificar en esencia el patrón indígena de dispersión geográfica y una latente tendencia apolítica a rechazar cualquier tipo de autoridad y orden jerárquico. ${ }^{70} \mathrm{Y}$ el sistema de autoridad y gobiemo, por su parte, constituye más una especie de perpetuación ceremonial de un sistema politico impuesto desde fuera, que una modalidad de autonomía política. ${ }^{71}$

nombre que te guste más". Sin embargo, rarámuri representa para ellos una evidencia, se opone a chabochi (blanco o mestizo) y es igualmente posible que no se refiera únicamente a los tarahumaras sino a todos indios americanos (Deimel, 1980: 45).

${ }^{70}$ Puede verse al respecto esta tesis en Deimel, 1980: 69-84 y la critica de Thomas Hillerkuss a esta interpretación por lo que se refiere al sistema politico indigena en la época colonial y prehispánica (Hillerkuss, 1992: 33 y ss.).

${ }^{71}$ A partir de una revisión de las fuentes históricas misioneras y de su experiencia en Narárachi, Deimel insiste en plantear que el sistema de gobierno indigena fue completamente impuesto por los misioneros, que los tarahumaras desconocian la noción de jefes o autoridades, que hasta la fecha no la han asumido por completo y que los gobernadores y demás "cargos tradicionales", cuya imagen es la de los "portadores del bastón de mando", tienen como función primordial reproducir ceremonialmente un sistema de autoridad y gobiemo impuesto desde la época colonial:

El desinterés por la función jerárquica oficial es tan grande que nunca llegué a descubrir el menor signo de un prestigio marcado ligado a la función de portador de bastón. Tampoco he podido constatar diferencia alguna entre los grados de los gobemadores. [...]

Los portadores de bastón ilustran la pompa exterior de la autoridad y las presiones de ésta, pero únicamente en el interior del pueblo [cabecera]. Todo esto representa tan pocas ventajas personales, tantas penas y enojos que ningún tarahumara intriga para ocupar un cargo oficial. Para ellos, el poder politico consiste únicamente en la reproducción de las formas de autoridad politica de la sociedad blanca, de la cual sólo han integrado la parte ritual que representa para ellos la repetición de ceremonias tradicionales (Deimel, 1980: 80 y 84). 
Si el orden del pueblo y de la jerarquia de cargos simboliza una cierta continuidad histórica de una identidad forzada e impuesta desde fuera -no es casual que el término kumérachi sea usado indistintamente para designar en tarahumara la comunidad y la cárcel cercana a la iglesia de los pueblos (Deimel,1980: 68)-, el ámbito de la familia, el rancho y el plexus del tesgüino -continúa proponiendo Claus Deimet constituyen, en cambio, los espacios naturales y propios de los tarahumaras para expresar desde su nombre -que originariamente hace referencia a alguna característica geográfica del lugar de procedencia del individuo- hasta su identidad grupal:

Estas comunidades fundadas sobre la bebida y sus encadenamientos a través del juego de invitaciones constituyen el sistema social y politico esencial de los Tarahumaras, funcionando de manera satisfactoria sin la dominación de un individuo o de un grupo. Liga a las familias de la Sierra por nituales de bebida en todas partes idénticos, por tipos de comportamiento idénticos y por ceremonias muy parecidas; permite la difusión de noticias y se opone al nacimiento de una conciencia comunitaria bien delimitada recubierta con las parroquias, los ejidos 0 incluso las representaciones civilizatorias (Deimel, 1980: 66).

La identidad grupal de los tarahumaras asume pues expresiones sumamente laxas, informales, no coercitivas ni jerárquicas, respetuosas de la independencia de los núcleos familiares asi como de la libertad y autonomía de las personas. Se trata pues, de una sociedad donde predomina el individualismo por encima del comunalismo:

El individuo no puede contar por mucho tiempo con la servicialidad de la comunidad: por regla, cada uno debe ejecutar por si mismo su trabajo. Los servicios rendidos espontánea o gratuitamente son inhabituales y pueden incluso ser considerados como una falta de cortesía, porque demandan una reciprocidad no deseada. Se pueden ver viejos portando las más pesadas cargas sin que los jóvenes presentes les presten cualquier tipo de ayuda. Los trabajos ejecutados colectivamente en los campos o en la casa lo son exclusivamente en intercambio del tesgüino con ocasión de ceremonias; no es raro que los bebedores se contenten sólo con un simple gesto simbólico. Se ve frecuentemente a los viejos terminar su vida a cierta distancia de sus hijos (Deimel, 1980: 65).

La etnografia sobre la Tarahumara no sólo llega a explicar -a partir del aislamiento y del ajuste al medio geográfico- las raices de este predominio del individuo sobre la comunidad, sino que en ocasiones también se aventura a juzgarlo. Las valoraciones de Robert M. Zingg son el mejor ejemplo de ello. Para él la autonomia del individuo se inicia 
en los años de la infancia cuando los niños tarahumaras aprenden a vivir como pastores solitarios forjando desde entonces un carácter hosco, tímido, desconfiado ante el otro y propenso al individualismo:

Tanto tiempo pasean alejados de la sociedad humana, que los niños parecen compañeros de los cielos, las rocas y los árboles, más que de los otros seres humanos. Este condicionamiento en la infancia es en gran medida responsable de la actitud impasible del tarahumara adulto, que permanece sentado durante horas sobre un gran peñasco, envuelto en su manta, inquieto y tímido ante la presencia de sus semejantes. Tan acentuada es su timidez, que no hay exageración en afirmar que la vida social normal no podria prosperar sin la ayuda del tesgüino (Bennett y Zingg, 1986: 66).

La falta de sentimientos y experiencias de sociabilidad constituye, al decir de Zingg, una muestra del carácter inauténtico, espúreo y falso de los valores de la cultura tarahumara. Esta ausencia de valores y sentimientos sociales positivos se agrava aún más si se considera que las únicas circunstancias en las que la insociabilidad se supera son las tesgüinadas, pero éstas están lejos de significar un estado superior de civilización:

La cualidad verdaderamente inauténtica de los Tarahumaras por su civilización -que se organiza en tomo a la borrachera- reside en la tonalidad vacia e incolora de la vida tarahumara, carente de bagaje cultural alguno, que se muestra excesivamente primitiva en cada una de sus manifestaciones (tomado de Deimel, 1980: 63).

Justamente en el polo opuesto a esta concepción extrema del individualismo y de la ausencia de formas asociativas entre los indígenas se ubica la visión sobre la comunidad de los misioneros católicos y de los indigenistas. Los primeros han fundado su defensa del comunitarismo indigena básicamente en el peso de la evangelización ${ }^{72}$; los segundos, en cambio, han asumido una posición pragmática, nunca suficientemente

\footnotetext{
${ }^{72}$ La interpretación de los misioneros (véase Robles, 1994: 38,47 y 49-52; Velasco, 1987: 51-52 y Robles y Vallejo, 1995: 83-85) insiste en señalar que la conciencia de comunidad, aunque tiene sus antecedentes prehispánicos, deriva básicamente de la experiencia misionera y está ligada a la aparición de los pueblos y del sistema de gobierno y justicia que, con el tiempo, ha sido aṕropiado por los rarámuri:

Asi, el ser pueblo puede considerarse como aporte cristiano aun por la palabra que usan, "pueblo" o "póbora" que no es suya. Hay fiestas de corte ancestral que también crean comunidad en menor escala, familiar o vecinal, que fue tal vez el tipo de comunidad ancestral; pero la comunidad amplia, el pueblo, sólo se da en el sitio que fundaron los misioneros y en las fiestas que ellos introdujeron (Robles, 1994: 38 y 39)
} 
justificada, en el trasfondo de la cual se planteó que la acción indigenista, concebida originalmente de acuerdo a la matriz comunitaria de los pueblos indigenas mesoamericanos, acabaria por modificar las formas de vida social de los grupos étnicos de la Tarahumara, hasta asemejarlas al patrón comunitario mesoamericano.

Esta perspectiva se expresó en diferentes estrategias o programas de la acción indigenista. En cuanto a la óptica del territorio, el indigenismo optó por otorgar al ejido y a la condición ejidal de los indígenas una preeminencia por encima de cualquier otra forma de territorialidad y de adscripción social. Con ello, los perfiles del territorio indigena y la jurisdicción de los gobernadores se fue desdibujando y éstos, en tanto que interlocutores fueron poco a poco sustituidos por las autoridades agrarias de los ejidos, muchas veces mestizas. Asi pues, la defensa de la propiedad agraria, bandera capital de indigenismo militante de las primeras décadas, arrojó como costo adicional, una gradual desarticulación de la estructura territorial de los ranchos, rancherias y pueblos indigenas, asi como una notoria afectación de la autoridad de los gobernadores. ${ }^{73}$

La segunda consecuencia importante de este comunitarismo infundado tuvo que ver con las concepciones y experiencias del desarrollo que puso en práctica el indigenismo en la Tarahumara. Considerando que era la comunidad el origen, destino y agente principal de esta desarrollo y que el individuo quedaba supeditado a esta fuerza social, la tarea de las agencias indigenistas, en especial el INI, se centró en depositar en la iniciativa de una mistificada y sublimada conciencia comunitarista y colectivista las claves del desarrollo y el cambio social.

\footnotetext{
${ }^{73}$ No es raro que el territorio de viejos pueblos haya quedado dividido en varios ejidos o que un ejido englobe a rancherias de dos pueblos o situaciones similares que han venido a afectar la capacidad de ejercicio de la autoridad por parte de los gobernadores dentro de su jurisdicción territorial tradicional. Puede verse al respecto el caso de los pueblos de Guadalupe Coronado, Guapalaina y una referencia a los casos de los del Potrero, La Mesa de la Yerbabuena y Munérachi o el de Tehuerichi en Olivos, 1997: 135-143. En relación a la forma como la autoridad agraria de los ejidos tiende a desplazar y suplantar a los gobernadores y al modo indigena de tomar las decisiones véase Urteaga, 1996: 314.
} 
Fue asi como el indigenismo trató de implantar en la Tarahumara sistemas productivos y laborales colectivos y comunitarios, inspirados en instituciones mesoamericanas tan ajenas a la Tarahumara como el tequio ${ }^{74}$ y expresadas en la operación de los aserraderos ejidales y las tiendas cooperativas, la construcción de "trojes comunales" y caminos, la erección de escuelas y clínicas y la constitución de fondos regionales y empresas de solidaridad social. Además, y como to expresara un alto funcionario del INI a la hora de justificar el programa presupuesto de 1965, solicitado al Presidente Diaz Ordaz, el principio "comunalista", no sólo era culturalmente compatible sino económicamente ventajoso:

Por otra parte, el indigena está acostumbrado a trabajar en bien de su comunidad. El trabajo comunal es una de sus formas culturales que data desde la época prehispánica, $y$ esto hace que las obras que se ejecuten salgan a precios imisonios, porque la comunidad voluntariamente proporciona su esfuerzo, aportando materiales y mano de obra. Una escuela de dos aulas de mamposteria con techo de teja, que construimos en un ejido de Chiapas y que tendría un valor entre 15 y 10,000 pesos, sólo cuesta 3 o 4,000 pesos para pagar el cemento, los vidrios, etc., que la comunidad no puede proporcionar, y lo hace con todo empeño y entusiasmo porque considera que esa escuela es suya. ${ }^{75}$

Los proyectos y las ideologias indigenistas del desarrollo en la Tarahumara se sustentaron, como veremos $n$ el capitulo cuarto, en esta fe ciega en el comunalismo indigena. Al fin y al cabo, desde la época colonial, esta fe había formado parte sustancial de la creencia de que el cambio social del indígena sólo llegaria de la mano de su adscripción civilizada a una comunidad de creyentes a un estado de ciudadanos.

\footnotetext{
${ }^{74}$ Como se desprende de to que hemos venido planteando en este capitulo, no existe entre los grupos indigenas de la Tarahumara una institución equivalente a ésta de raices mesoamericanas. El trabajo colectivo en actividades agricolas y de construcción de casas u otros es un trabajo de intercambio "a mano vuelta", pero no implica la realización de obras de uso colectivo sino de apropiación individual (la cosecha, la casa). Algunos autores plantean incluso que la asociación entre tesgüinadas y trabajo colectivo no aparece sino hasta el siglo XIX (Hillerkuss, 1992: 17 y 18). Las "tesgụinadas comunitarias" y las tareas colectivas (arreglo de escuelas, caminos, sistemas de agua, etc.) son invento indigenista y algo ajeno a la mentalidad indigena (Véase al respecto, Urteaga, 1998: 526-527).

${ }^{75}$ ACCIT, Legajo 4, Expediente 1, Documento 5: "Proyecto de Plan Sexenal en relación con el problema indigena", 1964.
} 
Las justificaciones y las experiencias comunitaristas no fueron, sin embargo, el único soporte del indigenismo en la Tarahumara. Junto a ellas, se gestó también un intenso debate en torno al presente y futuro de las relaciones interétnicas que siempre, y de una manera conflictiva, han enfrentado a los indios con los mestizos $y$, en general, con el resto de la sociedad nacional. De este debate nos ocupamos en el siguiente capitulo. 


\section{CAPITULO 3.- INDIGENISMO, RELACIONES INTERÉTNICAS Y PROCESOS CIVILIZATORIOS EN LA SIERRA TARAHUMARA.}

Antes de ser ocupada la región por los nuevos amos, ignoraban los tarahumares lo que fuese la pobreza; de suerte que no es extraño que los tarahumares cristianos crean que está el infiemo tan abundantemente poblado de mexicanos que ya no queda lugar para los indios, y que los que no han cabiclo alli, se han salido a molestar a los tarahumares (Lumholtz, 1986, Tomo l: 406).

En los dos anteriores capitulos hemos examinado la manera en que el indigenismo elaboró, desde la etnografia, una visión optimista sobre las posibilidades del cambio en la Tarahumara y, para ello instrumentó, como primera estrategia, la de propiciar entre los indígenas formas comunitarias de organización social. La cruzada indigenista no se limitó, sin embargo a estos propósitos sino que también se afanó por impulsar un profundo cambio cultural entre los indigenas que los condujera a una gradual, pero irreversible, asimilación en los patrones civilizatorios occidentales. Este capitulo trata precisamente de dar cuenta de los diferentes esfuerzos que el indigenismo emprendió en la Tarahumara para auspiciar dicho cambio.

A lo largo de su historia y bajo cambiantes modalidades, el indigenismo ha construido distintos paradigmas para explicar las diferencias y las relaciones entre los grupos indigenas y el resto de la sociedad. La importancia estratégica de estos intentos explicativos es por demás evidente: de ellos han derivado justificaciones históricas que pretenden dar cuenta de los procesos de asimilación, iritegración, etnocidio, segregación e imposición culturales de que han sido objeto los grupos indígenas por parte del resto de la sociedad. También todas estas propuestas han acabado por consagrar alguna justificación ideológica acerca de la superioridad de un determinado modelo civilizatorio sobre los demás. 
El discurso sobre las relaciones interétnicas se ha desenvuelto en dos niveles. El primero se refiere explícitamente al ámbito espacial de las regiones interculturales donde la interacción entre la población indígena y no indígena (mestiza o ladina) es particularmente intensa, englobando aspectos económicos, sociales, culturales y políticos. El segundo, de un alcance más hondo, examina el papel que los grupos indigenas desempeñan -o deben desempeñar- en el proceso de construcción de la nación, y por tanto, considera las directrices del proceso civilizatorio a nivel nacional. En ambos niveles, el punto central de la discusión ha sido el de la aculturación del indio: ¿cómo hacer compatible la cultura indígena con los valores y principios de un modelo civilizatorio que se concibe a si mismo superior a los demás?

Desde los tiempos coloniales, la Sierra Tarahumara ha sido un escenario propicio para debatir en torno a este tema de las relaciones interétnicas, para construir marcos justificativos y para experimentar programas de acción en torno a la aculturación del indio. Sin pretender ser exhaustivo, creo que puede decirse que han existido a lo largo de esa historia tres grandes propuestas.

La primera de ellas que califico de proteccionista concibe a los grupos indigenas como una minoría racial en condiciones de inferioridad social, incapacidad juridica, atraso cultural, precariedad económica y, por lo mismo, necesitada de protección, ayuda, tutela y sujeta a un régimen de excepcionalidad juridica y politica. La debilidad del indio justifica que su inevitable incorporación a la civilización requiera de ciertos mecanismos de protección y aislamiento que aseguren que el enfrentamiento con la civilización externa no vaya a ser excesivamente impactante, pernicioso o destructor. Por el contrario, se proponen estrategias aculturativas que lleven gradualmente de la mano al indio a lo largo de la escala ascendente de la civilización. En esta perspectiva, las relaciones entre los grupos étnicos y ef resto de la sociedad se plantean en términos de paternalismo y segregación, lo que en definitiva favorece una cierta autonomía y persistencia cultural de los rasgos indigenas. La comunidad autosuficiente y relativamente autárquica, pero tutelada por los agentes civilizatorios -la iglesia o el 
estado- resulta ser el paradigma de sociedad mejor ajustado a esta visión de las relaciones interétnicas.

La segunda propuesta, que denomino asimilacionista 0 incorporacionista, también sostuvo, como en el caso anterior, que la única altemativa de futuro para la sociedad indigena consistía en su total incorporación y asimilación a los patrones de la sociedad no indigena (colonizadora, mestiza, nacional). Sin embargo, la novedad de esta propuesta estriba en postular, como estrategia para llegar a ese fin, la necesaria eliminación de todo tipo de barreras protectoras y de estatutos de excepcionalidad para con el indio, propugnando en favor de la igualdad -al menos formal de éste con el resto de la sociedad y por la paulatina, pero definitiva e irreversible, desintegración de los rasgos culturales e identitarios de los grupos indigenas, o lo que algunos llamaron la "mexicanización" del indio. Para que este proceso llegue a buen término, es necesario dicen quienes lo defienden- dejar que las fuerzas aculturativas se desenvuelvan $\sin$ trabas, logrando que, por su indudable superioridad, la civilización occidental -y con ella la idea de ciudadanía y la experiencia de nación- se impongan sobre los atávicos signos del atraso indio.

Una tercera vía explicativa de las relaciones interétnicas ha creído que el proceso de definición de la nación es compatible con la persistencia cultural indigena. Aquí el concepto clave es el de la integración, que reconoce el derecho de los grupos étnicos a mantener su lengua y cultura vernáculas y su dignidad como pueblos, pero siempre que éstos se integren a la sociedad nacional, proceso éste, por lo demás ineludible, que permitirá a la población indígena acceder a los logros sociales de una nación en constante progreso. Una de las preocupaciones más originales de esta tercera propuesta consiste en señalar que para que la integración indigena a nivel de la nación sea posible, es necesario modificar de raiz el carácter de las relaciones interétnicas en el ámbito de las regiones interculturales donde indios y mestizos conviven.

Esta tercera concepción de las relaciones interétnicas constituyó la visión del 
indigenismo oficial que derivó de la creación del INI en 1948 y que trató de implantarse en la Tarahumara en 1952, a raiz de la implantación del CCIT. Como trataremos de demostrar, este esquema explicativo ha tenido muchas dificultades para ajustarse a la experiencia histórica y cotidiana de las relaciones interétnicas entre indigenas y mestizos de la Sierra Tarahumara.

Estas tres altemativas de explicar y plantear las relaciones interétnicas y los procesos civilizatorios han estado presentes en la historia del indigenismo en la Tarahumara. A lo largo del tiempo y en diferentes épocas, cada una de ellas ha asumido expresiones cambiantes pero identificables. Las tres tienen dos cosas en común: han provenido del entorno occidental próximo o lejano del mundo indigena -pero no de él-y, por ello, se han enfrentado a muy variadas formas de resistencia cultural de los propios grupos étnicos. Este capitulo trata precisamente de examinar las vicisitudes de este proceso histórico de definición, imposición, rechazo y transacción de los diferentes discursos y paradigmas de las relaciones interétnicas en la Sierra Tarahumara.

\section{LA PROTECCIÓN DEL INDIO}

La visión del indio como un sujeto social requerido de protección permeó muchos de los esfuerzos civilizatorios que conoció la Tarahumara desde los tiempos coloniales. La protección se tradujo en el establecimiento de regimenes de excepcionalidad juridica y en la creación de formas de segregación socio-espacial de las que derivaria el ideal de comunidad del que hablamos en el capitulo anterior.

La estrategia proteccionista tuvo dos importantes modalidades, cada una de ellas en un momento distinto de la historia de la Tarahumara: la de la "república de indios" del periodo de las misiones jesuiticas (1600-1767) y la de las propuestas indigenistas y económicas emanadas de los gobiemos de Chihuahua entre 1880 y 1910 . A pesar de las diferencias entre estos dos proyectos, ambos coincidieron en plantear que la asimilación del indio requeria de una tutela paternalista y de una aculturación guiada que evitara su brusco enfrentamiento con la civilización occidental. Por eso, el modelo de 
relaciones interérnicas que derivó de esta vía proteccionista no fue el de la autonomia de los indigenas sino el de su separación y segregación.

\section{La república de indios}

En el capitulo anterior ya analizamos detenidamente cómo las primeras concepciones occidentales sobre el cambio social llegaron a la Sierra Tarahumara de la mano de una utopia religiosa. En ella, la fe y la civilización casi se confundieron: abrazar los contenidos del dogma cristiano implicaba asumir un nuevo ethos y con él un conjunto de normas y prácticas de vida derivadas de una concepción occidental del progreso humano. De todos los principios que caracterizaron esta experiencia ninguno tuvo un peso más definitivo que aquel que consideró que la salvación y la civilización de los "naturales" de esas tierras sólo podian ser posibles a partir de conminarlos a vivir bajo "policia", es decir, bajo gobierno, como nación o república de indios, o, con otras palabras, en un régimen de comunidad tutelada (Urías, 1994). Esta concepción, a la vez sagrada y profana, encontró en la institución de los pueblos de misión su expresión más acabada.

Los pueblos de misión constituyeron un auténtico laboratorio de experimentos de desarrollo todos ellos orientados a implantar y consolidar la autonomía productiva de la comunidad indigena. Las tradiciones de recolección y caza y la base agrícola de los pueblos indios serranos fueron sustituidas por un moderno complejo agroganadero, artesanal y comercial. En el tiempo que subsistió, este modelo de comunidad tutelada rindió, en términos de autosuficiencia productiva, sus mejores frutos.

Uno de los principios rectores de los pueblos de misión fue el de la segregación residencial: para garantizar su conversión, los indios debian vivir bajo el control patemal de los misioneros y lejos del pernicioso influjo del español a quien las fuentes eclesiásticas de la época califican

como un hombre dominado por el vicio y el pecado capital: arrogante, soberbio, lujurioso, borracho, vago y tráfago; ambicioso, codicioso e inclinado al múltiple amancebamiento, mentiroso, perjuro y ladrón (Urias, 1994: 78). 
En consecuencia, pues, el contacto cultural del indigena con la sociedad laica española y mestiza, con la "gente de razón", aparecen negadas en el proyecto misionero colonial, porque como muy bien lo ha planteado Margarita Urias:

Los misioneros anhelaban conseguir una cristianización sin presencia de hombres blancos ni militares, ni burócratas, ni comerciantes, ni propietarios particulares. Recordemos los continuos confictos entre jesuitas y colonizadores; con el gobiemo eclesiástico del obispado de Durango y con los franciscanos (Urias, 1994: 80)

En realidad y como ya lo señalamos en el capitulo anterior, este sistema de segregación residencial y de aislamiento cultural expresado en el principio de la comunidad y en la institución de los pueblos de misión nunca llegó a cuajar entre los grupos indigenas serranos. A pesar de los esfuerzos misioneros, los tarahumaras, tepehuanos, pimas y warojios expresaron durante el primer siglo y medio de contacto con los europeos, una abierta resistencia a aceptar un patrón de comunidad impuesto que venia a poner en entredicho formas de vida tan arraigadas entre ellos como la dispersión territorial, la movilidad espacial, la diversificación de estrategias productivas, el rechazo al trabajo asalariado y la ausencia de sistemas de control político, militar o administrativo.

Pero además, desde finales del siglo XVIII, el gobiemo virreinal acabó por dejar de creer en un proyecto civilizatorio sustentado en la protección, el aislamiento y el trato de excepcionalidad de los "naturales", promoviendo a cambio la colonización de la Sierra por parte de mineros, hacendados agro-ganaderos y comerciantes. Frente a esta violenta ola colonizadora y cuando los jesuitas fueron expulsados de los territorios de misión, las "naciones indias" que los misioneros habian imaginado en sus crónicas volvian a restaurar el viejo orden social y las formas tradicionales de adaptación al medio previas a la época de la llegada de los religiosos. Ante la presión de la colonización mestiza, muchos núcleos indigenas huyeron hacia żonas inhóspitas y despobladas para recrear ahi los viejos principios de la sobrevivencia y autonomia nómadas. $Y$ al tiempo que la Sierra de Chihuahua se "reindianizó", el anhelo de la autosuficiencia comunal y de la república de indios se convertian en un mito extraño. 


\section{Entre el proteccionismo y el abandono liberal}

Un siglo y medio después de que los misioneros jesuitas fueran expulsados de la Tarahumara la propuesta proteccionista volvió tener vigencia ahora por iniciativa de un gobernador de Chihuahua, Enrique $\mathrm{C}$. Creel, quien, a pesar de representar como pocos el espiritu liberal de su época, acabaria por reconocer -no sin cierta dubitación- que la única via de civilización del indio pasa por la tutela paternalista del estado.

En la exposición de motivos presentada a la Legislatura del Estado en 1906 con vistas a la aprobación de la Ley para el mejoramiento y cultura de la raza tarahumara, el gobernador Creel comenzaba reconociendo que el problema indigena era fundamentalmente un problema agrario ${ }^{1}$ y expresaba con nitidez las dos vías altemativas para resolverio:

Prolongar el estado de etema minoridad, de falta de iniciativa, de constante tutela y de perpetua dependencia del poder público, equivale a despreciar las enseñanzas de la historia [...]. Dejartes a los indios la libre y absoluta disposición de lo que se les done, es tanto como constituirtos en terratenientes interinarios, enriqueciendo a unos cuantos especuladores y aumentando los vicios, la falta de cultura y el horror que contra el blanco siente actualmente esa raza inferior.

Hay, pues, que combinar dos tendencias absolutamente distintas, si no es que absolutamente diversas y encontradas: la propiedad individual y el derecho de disponer limitadamente de ella; la protección que necesita el incapacitado y el libre goce de lo que le toca al ciudadano; la propiedad territorial, de cuyos productos puede y debe aprovecharse el dueño, y la propiedad restringida e inalienable a fin de que no pueda deshacerse de ella quien hará mal uso de su derecho luego que lo goce sin trabas ni dificultades (Creel, 1906: 10).

En esencia, mientras la primera de estas dos vías significaba seguir promoviendo mecanismos de tutela y control que asegurasen y condujeran el necesario "mejoramiento" de la "raza inferior" indigena, la segunda equivalia a esperar que los beneficios del progreso y la "mano invisible" de un mercado capitalista en expansión acabarían tarde o temprano por alcanzar a los miembros más débiles de la sociedad,

\footnotetext{
1 "El problema en los tiempos actuales -plantearia con notoria clarividencia Creel-y sobre todo respecto de la raza tarahumara, es, antes que todo, un problema esencialmente económico, esencialmente agricola, esencialmente ligado a la propiedad de tierras más o menos prósperas que los indios cultiven aprovechándose de sus productos" (Creel, 1906: 10. Véase también una edición de la Ley de Creel en Sariego, 1998a: 19-40).
} 
como lo eran los indigenas de la Tarahumara.

La indecisión de Creel frente a estas dos alternativas era más que fundada, porque aunque la Sierra Tarahumara vivia al final del porfiriato una época de verdadero esplendor económico, nada sin embargo podía hacer pensar que esa prosperidad estuviera realmente favoreciendo a los nücleos indigenas como el propio gobernador no dudaba en reconocerlo:

Desde hace muchos años ya se quejaban los tarahumares de las incursiones que entre ellos hacian algunos blancos codiciosos; pero semejante situación ha adquirido un carácter de palpitante actualidad en los momentos presentes, en que el auge de los negocios, el mejoramiento económico y la prosperidad industrial [...] y sobre todo el alza que súbitamente han adquirido las tierras en aquellas partes de nuestro Estado por la demanda que tienen ya para el cultivo, ya para la explotación de montes y bosques, ya para el establecimiento de haciendas metalürgicas o de industrias diversas, hacen que [...] los especuladores redoblen sus artimañas para conseguir que los indios les vendan a vil precio lo que ha sido siempre su habitación y constituido el centro de su vida (Creel, 1906: 5-6).

Los signos más evidentes del esplendor capitalista que vivió la Tarahumara entre 1880 y 1910 fueron la restauración, el auge productivo y el repoblamiento de los viejos centros mineros de las barrancas serranas. En todos ellos, la bonanza minera fue obra del capital extranjero, particularmente norteamericano: en Batopilas, la Batopilas Mining Company de Alexander Shepherd; en Urique, la Lluvia de Oro Mining Co., en Chínipas, la Palmarejo Mexican Gold Fields; en Guazapares, la Río de Plata Mining Co.; en Temósachic, la Dolores Mining Co., en Guadalupe, la Calabacillas Gold Mining Co.; en Ocampo, El Concheño y Pinos Altos, la Cía. de La República y el grupo de empresas de W.C. Greene asociadas en la Greene Gold-Silver Co. y así en otros puebios barranqueños. ${ }^{2}$

\footnotetext{
2 La implantación de todas estas empresas asumió un patrón tecnológico muy similar. introducción de modernos sistemas de extracción, metalurgia y fundición; construcción de sistemas hidráulicos para generar electricidad y, en su caso, de ingenios de vapor, instalación de pequeños ferrocarriles para uso local entre minas y plantas, etc. Del éxito productivo de estas empresas no sólo dan cuenta las cifras de su producción de metales preciosos sino también las evidencias estadisticas de un claro repoblamiento de estos centros que en algunos casos llegaron a adquirir una fisonomia tipicamente urbana, a pesar de estar enclavados en medio de un territorio por demás agreste. El caso más notorio fue el del pueblo de Batopilas que, de 1880 a 1902 vio aumentar su población de 300 a cerca de 4.000 habitantes entre ellos un número considerable de extranjeros- y llegó a ser en 1900 el tercer municipio más poblado del estado de Chihuahua. con algo más 

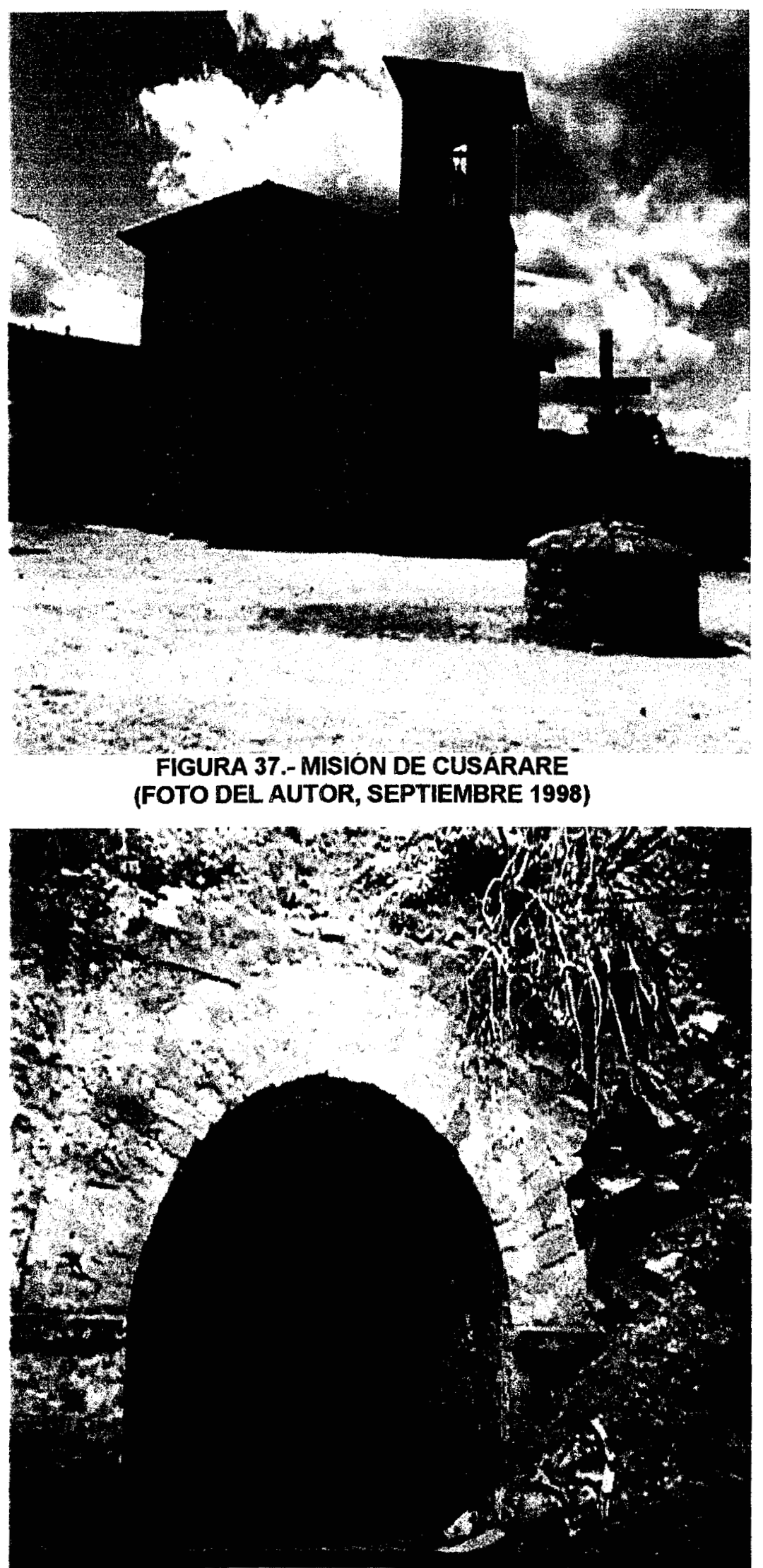

FIGURA 38.- TUNEL MINERO "PORFIRIO DIAZ" EN BATOPILAS (FOTO DEL AUTOR, JULIO 1998) 
Junto con la mineria, la colonización mestiza fue promovida también por la industria maderera y la construcción del ferrocarril que alcanzó a comunicar, en los años previos a la revolución, los valles de Guerrero y la región de Casas Grandes con la frontera de Ciudad Juárez y la capital de Chihuahua respectivamente. Desde principios del siglo varias empresas madereras, muchas de ellas de origen extranjero instalaron los primeros aserraderos y plantas secadoras dando lugar a poblaciones como Madera y San Juanito. (Lartigue, 1983 y Almada, 1971).

Pero este apogeo minero, maderero y ferrocarrilero fue en realidad limitado y efimero. Limitado porque no impactó más allá de los pueblos mineros ni fue capaz de generar un efecto dinamizador en la economía serrana. Como lo muestran las descripciones etnográficas de Lumholtz o los análisis estadísticos del historiador chihuahuense José María Ponce de León ${ }^{3}$, la imagen de modernidad y progreso que ofrecian los Minerales barranqueños al final del porfiriato no eran sino una excepción en un panorama dominado por el carácter tribal de la mayoría de la población indigena de la Sierra, dispersa en un sinnúmero de pequeños asentamientos, pertinaz en mantener sus prácticas ancestrales de caza, recolección o agricultura y claramente ajena a los signos del progreso capitalista que los hombres de empresa llevaron a la Sierra.

El auge minero fue también limitado porque no se apoyó ni generó infraestructuras ni equipamientos útiles para otras actividades económicas como la agricultura o la explotación forestal. Aunque es cierto que estos pueblos mineros conocieron tempranamente la electricidad, ello no provocó una diversificación de su raquitica actividad manufacturera, limitada casi siempre a la producción artesanal de mezcal, panocha, pieles curtidas, calzado y textiles. En muy pocos de estos centros mineros puede decirse, además, que se generara un claro proceso de proletarización de

de 14,000 habitantes. (Más detalles sobre la estadistica de empresas mineras asentadas en la Sierra en esos años pueden verse en Griggs, 1907 y Sariego, 1998b: 241-264)

${ }^{3}$ De entre sus obras pueden verse los Anuarios estadísticos editados por el Gobiemo del estado de Chihuahua en la primera década del siglo y su estudio geográfico del estado (Ponce de León, 1909). 
la población local indigena puesto que ésta se resistió al trabajo asalariado. Por eso fue preciso reclutar mano de obra entre mestizos e inmigrantes ${ }^{4}$.

El proyecto liberal encarnado en la llegada a la Tarahumara de las compañias mineras, deslindadoras y forestales despertó pues desconfianza y recelo puesto que habria de acarrear más perjuicios que beneficios a la población indigena. Como bien lo habia logrado captar Lumholtz, el progreso parecia despertar entre los viejos pobladores de la Sierra Tarahumara más desconfianza y recelo que prosperidad y fortuna, máxime teniendo en cuenta la voracidad y la codicia que el comercio de la tierra estaba desencadenando en los pueblos de la Sierra.

Quizás por eso el gobierno de Creel acabaria optando por restaurar y adaptar el viejo proyecto proteccionista de raices misioneras, proponiendo la creación de Colonias agrícolas. Más allá de sus sueños reformadores, el mandatario chihuahuense, el mejor portavoz local del pensamiento de los cientificos y liberales de la época, acababa paradójicamente por reconocer en la práctica las bondades de una propuesta claramente proteccionista y tutelar "para la civilización y mejoramiento de la raza tarahumara". Como ya lo planteamos en el capítulo 2 la ley de Creel estipulaba abiertamente la segregación de los tarahumaras en colonias agricolas donde estuviera prohibida la presencia de mestizos y la venta de tierras y donde se mantuviera el régimen de gobierno indigena y sistema especial de educación (arts. $6^{\circ}, 8^{\circ}, 12^{\circ}$ y $14^{\circ}$.) La colonia agrícola, fundada en el poblado de Creel, acabó sin embargo siendo un esfuerzo efimero como lo fueron también los sueños indigenistas de los liberales a causa del estallido de la revolución.

A finales de la primera década del siglo $X X$ tanto el proyecto económico que los liberales habia sostenido en la Tarahumara como su propuesta indigenista acabaron en fracaso. En 1906 los precios de los metales se derrumbaron afectando seriamente a

\footnotetext{
${ }^{4}$ La industria maderera no conoció en esos años sino un leve desarrollo concentrado en Ciudad Madera, poblado creado por el norteamericano W.C. Greene al norte de la Sierra con el propósito original de abastecerse de madera para sus minas del distrito de Ocampo y de Cananea. Son. (Véase Sonnichsen, 1976, en especial el capitulo dedicado a las empresas de Greene en el estado de Chihuahua).
} 
todas las empresas mineras instaladas en la Sierra. Cuatro años después, en noviembre de 1910, el ataque de Pascual Orozco a Miñaca (población ubicada en las inmediaciones de la Sierra) y los levantamientos revolucionarios subsecuentes en los pueblos y ranchos de la región de Guerrero colapsaron no sólo el tráfico ferrocarrilero sino también el de las "conductas" ${ }^{\text {n5 }}$ de arrieros. En toda la Sierra, desde Ocampo hasta Guadalupe y Calvo, la mayoria de las empresas mineras y madereras tuvieron que clausurar sus operaciones, los empresarios extranjeros emigraron y gran parte de los centros mineros se despoblaron. ${ }^{6}$

Esta estampa de abandono y olvido representaba mejor que nada el fracaso de un proyecto de desarrollo sustentado en la inversión extranjera, la modernización productiva y la ampliación del mercado regional. También simbolizaba la incapacidad de este proyecto modernizador para suplantar otro de caracteristicas más tradicionales y arraigadas en la Sierra de Chihuahua, el de la autarquía productiva de los pueblos y comunidades.

Pero el fracaso no sólo era de carácter económico. También la propuesta de civilizar a los tarahumaras a través de una estrategia de segregación no tuvo ningún éxito. Esta política sólo no logró borrar las barreras culturales entre indios y mestizos e incluso, en algunos pueblos, exacerbó el odio entre razas. Una rebelión indigena suscitada en abril de 1918 cerca del Mineral barranqueño de Morelos comprueba este repunte de la violencia interétnica:

En el mes de abril del año de 1918 en un lugar denominado Santa Inés del municipio de Morelos, se rebelaron los tarahumaras contra los mestizos de aquella región. Con dias de anticipación los indigenas celebraron juntas en un arroyo y una gran tesgüinada y, según versiones posteriores, atendiendo al llamado de un Dios que les hablaba en su dialecto y que les decia que deberian acabar con los blancos y mestizos, ya que sólo los indígenas eran los dueños de las tierras y montes, el mismo Dios les aconsejaba que tuvieran valor y fuerzas y que los que

\footnotetext{
${ }^{5}$ Tèrmino que designa en la región las recuas de mulas utilizadas tradicionalmente para el transporte de mercancias.

${ }^{5}$ Como ejemplo de ello, éstas son las cifras de población de los tres centros mineros del municipio de ocampo correspondientes a los años de 1900 y 1910 respectivamente: Ocampo: 2,404 y 1509; El Concheño: 1,069 y 412; Pinos Altos: 785 y 204.
} 
munieran en la empresa iban a resucitar el día de San Juan, o sea el 24 de junio de aquel mismo año.

Los tarahumaras tomaron por asalto una pequeña rancheria habitada por cinco familias de mestizos, a las que asesinaron brutalmente, no respetando ni a los niños de pecho, usando en el asalto tal crueldad y saña, que con mazo de madera de encino y palos con puntas de hierro, destrozaron [a] los cuerpos de sus victimas, a los niños los estrellaron contra las rocas descuartizándolos y hay quien dice que hasta se bebian la sangre.

Inmediatamente se reunieron las fuerzas que en aquella época constituian las Guardias Municipales, yendo los contingentes de los Minerales de Morelos y Batopilas a sofocar a los sublevados, a los que encontraron en número aproximado de 400 sumidos en una gran orgía en un lugar del arroyo de Santa Inés, y fue tanto lo que los habian debilitado las frecuentes borracheras, que en el primer encuentro con los "guardias", aun cuando mostraron mucho valor y ningún miedo a la muerte (por la creencia quizá de resucitar a los dos meses) fueron totalmente aniquilados, muriendo casi todos, y el resto (casi todas mujeres y niños que sobrevivieron) fueron aprehendidos y tratados como esclavos, que se repartieron como tales entre las familias acomodadas de Morelos, Batopilas y aun de Chihuahua la capital. Fue tanta la crueldad, la incultura y bestialidad de algunos de los guardias, que, haciendo ostentación de la fuerza, tiraban a los niños indigenas al viento y los atravesaban con sus cuchillos y machetes, esto, en venganza de lo que dias antes habian hecho los indigenas con los mestizos. De entonces a la fecha, no se ha registrado ningún brote de rebeldia.

\footnotetext{
${ }^{7}$ Tomado de "El Tarahumara. Estudio presentado por J. Rosario C. Martinez, Tónachi, Chih., agosto, 1947" en ACCIT, Legajo 13, Expediente 22. Es relevante señalar que el que escribió este testimonio fue maestro rural en el poblado de Potrero de Bojórquez, municipio de Morelos, en 1924, sólo 6 años después de los acontecimientos que narra.

En julio de 1995, un habitante de Morelos me narró esta otra versión sobre el mismo acontecimiento histórico:

Otra cosa que también le queria comentar [..] es el último levantamiento indigena en este municipio [.] en 1918 [...]. Hubo una masacre. Se juntaron 40 o 50 inferos de las comunidades aqui cercanas. [...] Estamos hablando de puras personas mestizas o blancas armadas con carabinas "treinta-treinta" [...]. Los indigenas se levantaron en armas, como aproximadamente 300 indigenas. Esto es muy importante que to comente con mis abuelos [...] porque ellos me lo han comentado de manera verbal y son datos que se van a perder porque se van falleciendo las personas que saben. Y si, mataron a todos los indigenas, todos los hombres. Y quedaron los niños y las mujeres. Comenta mi abuelo y mi abuela que los trajeron como si fueran animales y los juntaron aqui donde está ahora la Unidad Médica Rural. Entonces llegaron las familias y "yo me llevo ése y yo me llevo éste o éste..." y por eso volvió a cundir aqui en lla cabecera djel municlpio la raza tarahumara porque eran tarahumares ellos. Cada familia se llevaba uno o dos y los criaban como siervos, o más bien como esclavos, en las casas de los mestizos. Los criaban para tener fuerza de trabajo gratis. Mataron a todos los hombres grandes y dejaron no más mujeres y niños. A las mujeres se las llevaron para que les ayudaran en las labores de las casas y a los niños para cuidar cabras, ganado. Todo esto fue sonado. Fue en el año de 1918.
}

$$
216
$$


El estallido de la revolución vino a patentizar las contradicciones de la politica proteccionista y tutelar de los liberales chihuahuenses frente a los indígenas tarahumaras.

\section{LA INCORPORACIÓN DEL INDIO}

En el extremo opuesto de la propuesta proteccionista, los defensores de la incorporación del indio han defendido la disolución de las culturas indigenas y su total asimilación al modo de vida occidental de la mayoría de la población nacional. Esta manera de concebir y propiciar las relaciones interétnicas se presentó en la Tarahumara en dos modalidades y épocas: la primera a finales del siglo XVIII, a raiz de las reformas borbónicas promovidas por la administración virreinal y, la segunda, entre 1920 y 1952 , como resultado de la política gubemamental en materia agraria y de educación indigena. Como lo señalamos en el capitulo anterior, durante los años del cardenismo esta propuesta incorporacionista coexistió en conflicto con otra visión, la de los maestros agraristas de orientación maxista, que defendieron un sistema indigena de autonomía territorial, cultural y politica en el que los mestizos quedaban excluidos.

\section{El sueño del mestizaje}

Si la pretensión de la salvación y el progreso de los pueblos indios basado en la invención de un régimen de comunidad tutelada acabó por ser desterrado en la Sierra Tarahumara a mediados del siglo XVIII, fue en gran medida porque, frente a él, se impuso otra concepción que vino a postular que la transformación del indio sólo era concebible a partir de su asimilación a los patrones occidentales de la cultura nacional. Esta ideologia del mestizaje, que asumiria a lo largo de la historia distintas expresiones desde la versión liberal de finales del siglo XIX hasta los postulados de la mexicanización de los años cuarenta-, siempre insistiria en sostener el principio de que el indio y su cultura son incompatibles con un proyecto de nación y que el progreso sólo es viable una vez eliminados los obstáculos inherentes al modo de vida indígena. ${ }^{8}$

\footnotetext{
${ }^{8}$ Guillermo Bonfil (1991b) ha reconstruido criticamente una interesante trayectoria y perfil de la ideologia del mestizaje desde sus raices coloniales en el criollismo, destacando la contradicción entre la exaltación del pasado indio americano y la negación del presente indigena en las sociedades latinoamericanas.
} 
La política del mestizaje como estrategia del progreso y de la incorporación comenzó a ser promovida en la Sierra Tarahumara en época temprana, varias décadas antes de la consumación de la nación mexicana. Fueron las reformas borbónicas emprendidas a finales del siglo XVIII por el visitador José de Gálvez y por el Primer Comandante general de la Provincias internas Teodoro de Croix, las que fomentaron una política de repoblamiento mestizo del territorio serrano con miras a frenar toda posibilidad de rebeliones multiétnicas, como las que tuvieron lugar en la segunda mitad del siglo XVIII. ${ }^{9}$

El nuevo ideal de colonización propugnaba en favor de un modelo laico de sociedad civil integrada por pequeños "propietarios agrícolas-milicianos avecindados(Urias, 1994: 75) en la que las diferencias étnicas entre mestizos e indios fueran borradas en aras del progreso. El indio dejaba de ser visto como el "natural" segregado de la sociedad y del orden civil y político y pasaba a ser concebido como un "ciudadano" más, sujeto de derechos y obligaciones frente al poder colonial.

Fue así como el repoblamiento territorial de la segunda mitad del siglo XVIII consumó la desintegración de los pueblos de misión al establecer la libertad de adscripción y circulación de los indigenas. Pero sobre todo las políticas de fomento al mestizaje tuvieron como principal efecto legitimar la presencia de los mestizos en la Sierra, los mismos que hasta entonces habian sido ahuyentados y denunciados por los misioneros como un elemento de perniciosa influencia entre los neófitos. ${ }^{10}$

Se formaron entonces en la Tarahumara los primeros núcleos semiurbanos de población mestiza integrados por mineros y gambusinos, rancheros y vaqueros, arrieros, mercaderes, comerciantes y un sinnúmero de aventureros. El territorio que hasta

\footnotetext{
9 Sobre el impacto de las reformas borbónicas en la demografia y economia de Chihuahua se recomienda ampliamente la consulta de Navarro 1964 y Urias, 1994.

${ }^{10}$ Se estima que entre 1767 y 1827 la población no indigena en el área de las misiones franciscanas de los valles orientales y del macizo centro-occidental aumentó diez veces, pasando de 600 a 6,000 personas (Vèase Merrill, 1995: 167).
} 
entonces habia sido considerado como un área segregada y protegida se convirtió en un espacio en litigio cultural entre indios y mestizos. La apropiación de la tierra fue el principal núcleo de los conflictos interétnicos, pero la ambición por la búsqueda y explotación de los metales preciosos habria de constituir el motivo primordial de esta primera ola colonizadora mestiza. La continua inestabilidad y los caracteristicos altibajos propios de la actividad minera explican el auge y el decaimiento ciclicos de los Reales de minas y Minerales de las barrancas serranas como Batopilas, Guadalupe y Calvo, Cusihuiriachi, Maguarichi, Uruachi, Morelos, Moris, Ocampo, Urique, etc., pueblos fundados, algunos de ellos, en la época colonial y, otros, durante los primeros años del periodo independiente.

A pesar de que son escasos los estudios sobre este periodo histórico que corre de finales de la segunda mitad del siglo XVIII hasta fines del $X I X^{11}$, parece bastante probable que los propósitos de la política del mestizaje tuvieron un éxito muy limitado. La colonización mestiza promovida, o quizás mejor consentida, por las autoridades virreinales y por los primeros gobiemos nacionales, no bastó para asegurar realmente una fusión de razas y culturas. Por el contrario, todo parece indicar que más allá de una cierta permeabilidad reciproca de las culturas india y mestiza, lo que predominó fue una

\footnotetext{
11 La historiografia tradicional de la Sierra Tarahumara adolece de un grave vacio para interpretar este lapso cronológico. En general se ha considerado que fue ésta una etapa de estancamiento y aún de regresión en la tendencia "civilizatoria" que el estado habia imprimido en su obra indigenista al final de la era colonial. Frente a ella, la acción de los primeros gobiemos nacionales y estatales surgidos de la Independencia y aún de las instituciones religiosas misioneras es calificada en general de abandono. Los primeros, preocupados mayormente por las rebeliones apaches que se desarrollaron en los valles y desiertos orientales del estado de Chihuahua hasta principios del siglo habrian postergado su presencia en las regiones apartadas de la Sierra Madre. Las misiones, transferidas a los franciscanos y clero secular, habrian relajado las formas de control y adoctrinamiento sobre los núcleos de población indigena. De todo ello, resultaria -afirma la historiografia tradicional- una cierta "reindianización" del territorio serrano, expresada en el aislamiento en zonas inhóspitas de las comunidades indias derivado de su huida de los centros de población mestiza y su consecuente resistencia al mestizaje. Algunas recientes interpretaciones sugieren en cambio una visión bastante diferente. En particular Merrill (1995) plantea una cierta continuidad de los pueblos de misión con la llegada de los franciscanos hasta 1859, fecha de la Ley de Nacionalización de los Bienes del Clero Secular y Regular, que vino a abolir las órdenes religiosas y a secularizar las misiones, terminando asi la institución misional que sóto renaceria en la Tarahumara hasta principios del siglo XX. Sin embargo, el autor coincide con la historiografia tradicional al señalar el fracaso de los misioneros franciscanos en su intento, similar al de los jesuitas, de lograr reducir y concentrar a los grupos indigenas en las cabeceras de misión, evitando su dispersión.
} 
relativa autonomia y separación entre estas dos matrices y núcleos de población. Mientras los mestizos se consolidaron en los nacientes centros mineros barranqueños, los indígenas se dispersaron a lo largo del territorio, conservando sus patrones de asentamiento seminómada, perpetuando sus formas de gobierno y organización (algunas, impregnadas de reminiscencias de la época de los pueblos de misión) y manteniendo vivas sus tradiciones productivas (gradualmente más asimiladas a la agricultura que a la recolección) y su cosmovisión religiosa. ${ }^{12}$

Las políticas de repoblamiento y mestizaje fomentadas a finales del siglo XVIII tuvieron una clara continuidad a lo largo de todo el siglo XIX, cuando los primeros gobiemos locales y nacionales promovieron, de múltiples formas, la desintegración de las tierras comunales de los pueblos indigenas: a la Ley de Colonización de 1825 que permitió a los mestizos adquirir tierras ociosas no explotadas por las comunidades indígenas vino a sumarse la Ley de desamortización de manos muertas de 1856 y su posterior aplicación en 1859.

Desde finales del siglo XIX la penetración mestiza en territorio serrano tuvo un alcance mucho mayor que el de épocas anteriores. En una primera oleada derivada de un inusitado auge minero, se formaron y consolidaron, entre 1880 y 1910 , una serie de centros mineros mestizos ubicados en su mayoría en el área de las barrancas. Sin lugar a dudas fue ésta la época en la que la cultura mestiza alcanzó el más alto nivel de florecimiento en territorio serrano, como lo muestran los vestigios de la arquitectura civil e industrial que hasta hoy se reconocen en muchas cabeceras municipales serranas. ${ }^{13}$

\footnotetext{
${ }^{12}$ Este panorama general necesitaria sin embargo matizarse con mayor precisión. En general puede decirse que el mestizaje alcanzó un cierto éxito en los más antiguos puebłos de misión situados en los valles orientales de la Sierra (Nonoava, San Francisco de Borja, Satevó, Namiquipa, etc.) cercanos a los núcleos urbanos del estado de Chihuahua, donde, dadas las características del territorio propicias para la agricultura y la ganaderia los mestizos encontraron condiciones favorables para su implantación. De hecho esta región de los valles orientales es hoy una región donde la población indigena es muy escasa. En cambio en la zona de las grandes cumbres y de las profundas barrancas del centro y oeste de la Sierra, la penetración mestiza fue intermitente, discontinua y quedó limitada a los centros mineros.

${ }^{13}$ Por paradójico que pueda parecer, la Sierra Tarahumara era a principios de este siglo uno de los polos de atracción demográfica más importantes del estado de Chihuahua. En ella residian entre el 60 y el $70 \%$ de la población estatal (en la actualidad sólo habita en esa región el $20 \%$ ) y se concentraba un número 220
} 
A principios de este siglo, el auge de la mineria, la llegada del ferrocarril, el incipiente desarrollo de la actividad forestal y el crecimiento del comercio de la tierra podian hacer pensar que el progreso estaba llegando a la Sierra Tarahumara revestido de los mejores augurios de modernidad y que ésta acabaria por opacar los restos de un pasado de atraso y de incultura. También se esperaba que este avance de la civilización sumaria entre sus beneficiarios a una población indigena, gradualmente amalgamada y confundida con las capas de migrantes mestizos que, por oleadas, habian estado llegando a la Sierra desde hacia un siglo y medio. Sin embargo, y como lo constataron los viajeros y etnógrafos occidentales de la época, los signos del progreso eran contradictorios: éste, en vez de atraer y asimilar racial y culturaimente a los indios, parecia rechazarios obligándolo a vivir fuera de su alcance.

\section{La mexicanización del indio}

Después del periodo revolucionario y a la par que la presencia de migrantes blancos se acrecentaba en diferentes ámbitos de la economía serrana, una nueva modalidad de la tesis incorporacionista y de la ideologia del mestizaje comenzó a ser propuesta como estrategia para liberar al indio de su atraso y pobreza. En vez de los términos de reminiscencia decimonónica, se optó por el concepto de la "mexicanización" del indio, cuyo significado nadie, quizás, como el economista Moisés

T. de la Peña expresara mejor en 1945:

...si bien el indio ocupa el estrato social más bajo, su absorción o mexicanización es un fenómeno que cada dia adquiere mayor importancia, no sólo por medio del mestizaje, muy poco activo mientras aquél se mantiene en su estado de primitivismo, sino más bien por su lenta adaptación a los modos de vida de la

significativo de negociaciones y giros comerciales, ligados en muchos casos a un pujante desarrollo de la arrieria. Innovaciones tecnológicas tan significativas como la electricidad fueron introducidas en pueblos mineros serranos como Batopilas en la fecha en que este invento llegaba a México e incluso antes de que apareciera en muchas ciudades del estado de Chihuahua. El caso de la compañia Batopilas Mining Co. es quizás el caso más llamativo y conocido de este auge minero, pero las artes mineras y las técnicas metalúrgicas (cianuración, amalgamación, copelación, fundición. etc.) llegaron a alcanzar en muchos de los Minerales serranos niveles de desarrollo superióres incluso a los de otras regiones de México, como lo muestran, hasta la fecha, las ruinas de plantas de beneficio como las de San Miguel (en Batopilas), Guadalupe y Calvo, Ocampo, etc. Este apogeo económico tuvo también como correlato un notorio desarrollo de la cultura mestiza cristalizada en expresiones como la instrucción pública, la música del corrido, la arquitectura, etc. (Vease al respecto, Sariego, 1998b; Griggs, 1907; Pletcher, 1958. Sonnichsen, 1976; De la Peña, 1948, Shepherd, 1965 y Day, 1979).

\section{1}


población mayoritaria; de suerte que después de dos o tres generaciones de vivir este pobre ser, dotado de las muy débiles armas de su cultura autóctona, en frecuente contacto comercial con los mestizos acaba confundiéndose con éstos, una vez que alcanza a dominar la lengua nacional sin restos de acento extraño, que hace suyos los nuevos métodos de producción y viste, se alimenta y se aloja en consonancia, e inclusive acaba, en la generalidad de los casos, por olvidar la lengua materna y algunas buenas y malas costumbres que no encajan en la nueva sociedad de la que forma parte. En estas condiciones, una vez que el indio se ha salido de si mismo y se apropia el ropaje cultural de su hermano mayor, es una unidad que se resta al gran problema de la incorporación y superación indigena (De la Peña, 1945: 3).

La mexicanización del indio, entendida ésta en términos más culturales que biológicos $^{14}$, significaba aceptar con realismo el ineludible proceso histórico que enfrentaba al indigena ante el dilema de desaparecer o asimilarse a la cultura mestiza. Como el propio de la Peña lo planteaba, las estrategias más efectivas para acelerar esta mexicanización del indio -más avanzada en los estados norteños de la República ${ }^{15}$, tenían que ser de carácter económico y consistian en fomentar la construcción de vías de comunicación en las regiones indigenas, alentar su colonización mestiza en actividades como la mineria y el comercio, modemizar las actividades agropecuarios y expandir el aparato educativo.

${ }^{14}$ pues sabido es -acota de la Peña- que con sujeción a las caracteristicas puramente raciales, nadie podria decir seriamente y con certeza, en una nación donde predomina el mestizo, quien es indio y quien no to es, y aun cuando tal milagro fuera posible, careceria por completo de valor social y económico (de la Peña, 1946: 247 y 248).

${ }^{15}$ Argumenta De la Peña:

Este proceso de la mexicanización del indio, tan deseado como fecundo en resultados para la colectividad y sobre todo para los mismos actores, ha tenido su más completa realización [...] en los estados del Norte de la República, donde concurnieron varios factores [...]: uno de ellos fue el gran atraso cultural del indio nómada que vivia de la caza y la recolección; otro. el corto número de estos grupos errantes y otro más el de su libémima bravura que les mantuvo en lucha permanente con los conquistadores, y después con los mestizos, hasta su total extinción por muerte o por asimilación de cuantos cayeron prisioneros o acabaron por someterse. Fue asi como quedaron libres del problema indígena los estados de Tamaulipas, Nuevo León, Coahuila, Zacatecas y Aguascalientes, casi la totalidad de Durango, Baja Califomia y Sinaloa y la mayor parte de San Luis Potosi, Sonora y Chihuahua, donde subsisten pequeños grupos de los pocos indigenas que eran sedentarios desde los tiempos de la conquista, los que van mexicanizándose a gran prisa donde quiera que la facilidad de comunicaciones hizo posible una gran afluencia de mestizos que en parte expulsaron al indio con sus viotencias y rapacidades $y$, al constituir mayorias asimilaron al resto (De la Peña, 1945: 4-5) 
Tras los años de la revolución que en el estado de Chihuahua se significaron por las contiendas militares y la inestabilidad politica, el estado comenzó a hacerse presente en la Sierra Tarahumara en dos ámbitos estrechamente ligados con ese programa de mexicanización e incorporación del indio: los primeros repartos ejidales de la tierra y la implantación de un incipiente sistema educativo.

La primera de estas reformas sociales, el agrarismo, llegó a la Sierra en el transcurso de los años veinte en forma de repartos de tierras y dotación de ejidos. Las primeras dotaciones se hicieron, como se puede ver en el Cuadro 11, en varios pueblos de campesinos y rancheros mestizos (Pichachic, Pachera, San Isidro -o Pascual Orozco, Miñaca, Temeychi) de la región de los valles de Guerrero, donde el villismo y el orozquismo habian tenido un peso decisivo en los años de la revolución. Los restantes repartos beneficiaron a poblados de municipios de la Alta Tarahumara como Balleza, Bocoyna, Carichi, Guachochi y, en mucha menor medida, a algunas comunidades de la Baja Tarahumara, en los municipios de Guadalupe y Calvo, Ocampo, Temósachi, Urique y Uruachi. En conjunto se entregaron cerca de 600 mil hectáreas a un total de casi 5,400 ejidatarios y comuneros.

Una pequeña parte de las dotaciones benefició a ejidos tarahumaras ubicados en los valles orientales de la Sierra, en la región de Carichi y Bocoyna (Sisoguichi, San José Baqueachi, Narárachi) con terrenos propicios para la ganaderia. Otra menor proporción se entregó a tarahumaras de los pueblos de Cuiteco, Churo y Jicamórachi en la Baja Tarahumara. Pero donde las repartos fueron más cuantiosos fue en el área forestal del . actual municipio de Guachochi en esa época Batopilas- donde se concentró más de la mitad de la superficie dotada, en particular, en los ejidos forestales tarahumaras de Basihuare, Cusárare, Norogachi, Papajichi, Tetahuichi, Samachique y también en los de San Ignacio de Arareco (municipio de Bocoyna) y Chinatú (en Guadalupe y Calvo). Así, en las zonas de mayor densidad indigena, el ejido apareció desde entonces articulado a la explotación forestal, aun cuando este proyecto tardaría aún varios años en desarrollarse: más que la tierra lo que el agrarismo reclamaría en esos lugares serian las 
reservas forestales y su posibilidad de explotación. En cambio, fuera de las áreas boscosas, en la región de los barrancos, los repartos agrarios en beneficio de la población indigena fueron prácticamente nulos. En este sentido llama la atención que durante el período de 1920 a 1933 ninguna dotación fuera hecha en el territorio de los tepehuanes, pimas y warijios, ni en los municipios de Nonoava, Batopilas, Chínipas, Morelos, Guazapares, Maguarichi y Moris.

\section{CUADRO 11.- DOTACIONES DE TIERRAS EN LA SIERRA TARAHUMARA POR RESOLUCIONES PRESIDENCIALES (1920-1933)}

\begin{tabular}{|c|c|c|c|c|c|c|c|c|c|}
\hline POBLADO & B & s & AR & $A E$ & POBLADO & B & s & AR & $A E$ \\
\hline MPHO. DE BALEZA & 761 & 53.1 & & & MPIO DE BOCOYNA & 447 & 29.6 & & \\
\hline Bahuiriachi & 177 & 23.0 & 1931 & 1933 & San Ignacio de Arareco & 165 & 9.6 & 1928 & 1928 \\
\hline Gral. Carlos Pacheco & 112 & 18.1 & 1926 & 1927 & San Juanito & 114 & 0.4 & 1926 & 1926 \\
\hline San Juan Balleza & 160 & 6.0 & 1923 & 1926 & Sisoguichi & 168 & 19.6 & 1929 & 1930 \\
\hline \multirow[t]{2}{*}{ San Pabto Balleza } & 312 & 6.0 & 1926 & 1926 & & & & & \\
\hline & & & & & MPIO DE GUERRERO & 1,788 & 43.9 & & \\
\hline MPIO. DE CARICHI & 1,026 & 93.9 & & & Ariseachi & 138 & 6.8 & 1925 & 1925 \\
\hline Alamo de Ojos Azules & 33 & 0.3 & 1931 & 1931 & La Junta y Anexos & 101 & 2.0 & 1927 & 1928 \\
\hline Baqueachi & 170 & 44.0 & 1928 & 1928 & Miñaca & 142 & 0.8 & 1925 & 1926 \\
\hline Ciénega de Ojos Azul & 133 & 1.3 & 1931 & 1931 & Pachera & 150 & 2.5 & 1920 & 1921 \\
\hline Guacaréactii & 54 & 5.1 & 1929 & 1934 & Pahuiriachi & - & 0.9 & 1927 & 1927 \\
\hline Narärachi & 119 & 32.3 & 1929 & 1932 & Pascual Orozco & 131 & 1.9 & 1921 & 1921 \\
\hline Ojos Azules & 55 & 1.3 & 1932 & 1933 & Pichachic y Anexos & 146 & 2.8 & 1920 & 1920 \\
\hline Tajirachi-Norogachito & 124 & 3.4 & 1926 & 1926 & Pedernales & 149 & 3.5 & 1933 & 1934 \\
\hline \multirow[t]{2}{*}{ Carichi } & 338 & 5.4 & 1926 & 1926 & Baqueachi & 111 & 2.5 & 1927 & 1927 \\
\hline & & & & & Guadalupe & 72 & 0.6 & 1926 & 1926 \\
\hline MPIO. GUACHOCHI & 519 & 226.0 & & & Guadalupe. & - & 2.9 & 1926 & 1926 \\
\hline Basihuare & 55 & 34.0 & 1929 & 1930 & Confimación & 64 & 1.6 & 1930 & 1940 \\
\hline Cusárare & 69 & 31.0 & 1929 & 1930 & San Antonio de Sáenz & 388 & 7.6 & 1926 & 1926 \\
\hline Norogachi & 181 & 71.1 & 1929 & 1935 & Santo Tomás & 116 & 5.6 & 1927 & 1927 \\
\hline Papajichi & 103 & 21.2 & 1929 & 1935 & Tomochi & 80 & 1.9 & 1925 & 1927 \\
\hline Tetahuichi & 40 & 28.0 & 1929 & 1932 & Terneychi & & & & \\
\hline \multirow[t]{2}{*}{ Samachique } & 71 & 40.7 & 1929 & 1935 & & 295 & 5.3 & & \\
\hline & & & & & MPIO DE URIQUE & 148 & 3.5 & 1924 & 1924 \\
\hline MPHO.GPE.Y CALVO & 313 & 120.2 & & & Cuiteco & 147 & 1.8 & 1925 & 1925 \\
\hline \multirow[t]{2}{*}{ Chinatü } & 313 & 120.2 & 1929 & 1948 & Churo & & & & \\
\hline & & & & & & 82 & 8.2 & & \\
\hline MPIO DE OCAMPO & 55 & 11.6 & & & MPIO DE TEMOSACHI & 82 & 8.2 & 1931 & 1935 \\
\hline Basaseachi & 55 & 11.6 & 1931 & 1936 & Cocomorachi & & & & \\
\hline \multirow{2}{*}{$\begin{array}{l}\text { MPYO. DE URUACHI } \\
\text { Jicamórachi }\end{array}$} & 97 & 4.4 & & & & & & & \\
\hline & 97 & 4.4 & 1931 & 1934 & TOTAL & 5,383 & 596.2 & & \\
\hline
\end{tabular}

B=Campesinos beneficiados. S=Superficie dotada (miles de Has.) AR=Año de resolución. AE=Año de ejecución

FUENTE: Expedientes agrario-ejidales. SRA.

El reparto de la tierra acrecentó la presencia mestiza en muchos pueblos serranos y propició una oleada migratoria hacia los nuevos núcleos agrarios. Un mejor 


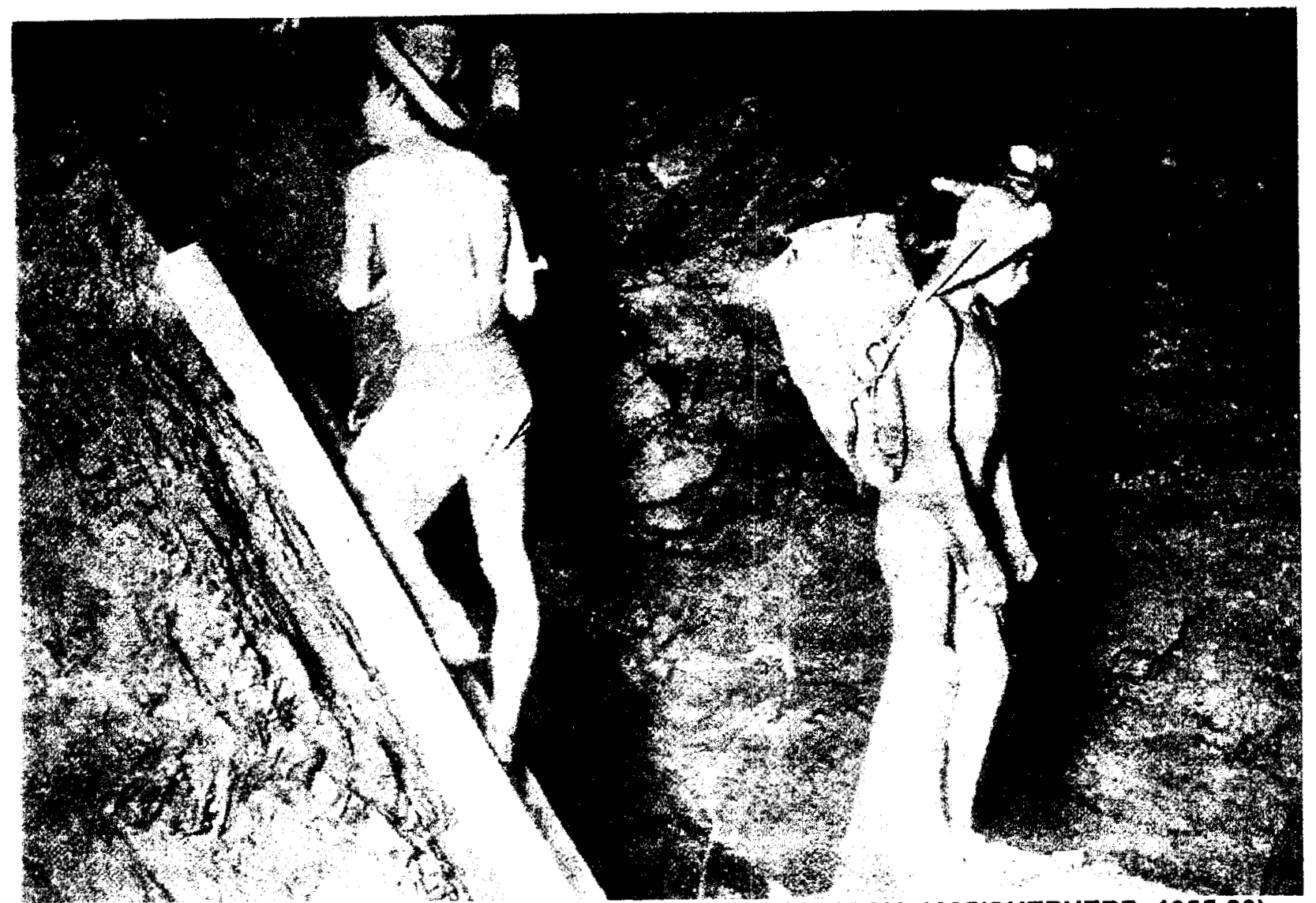

FIGURA 39.- EL TRABAJO EN LAS MINAS DE BATOPILAS HACIA 1885(SHEPHERD, 1965:80)

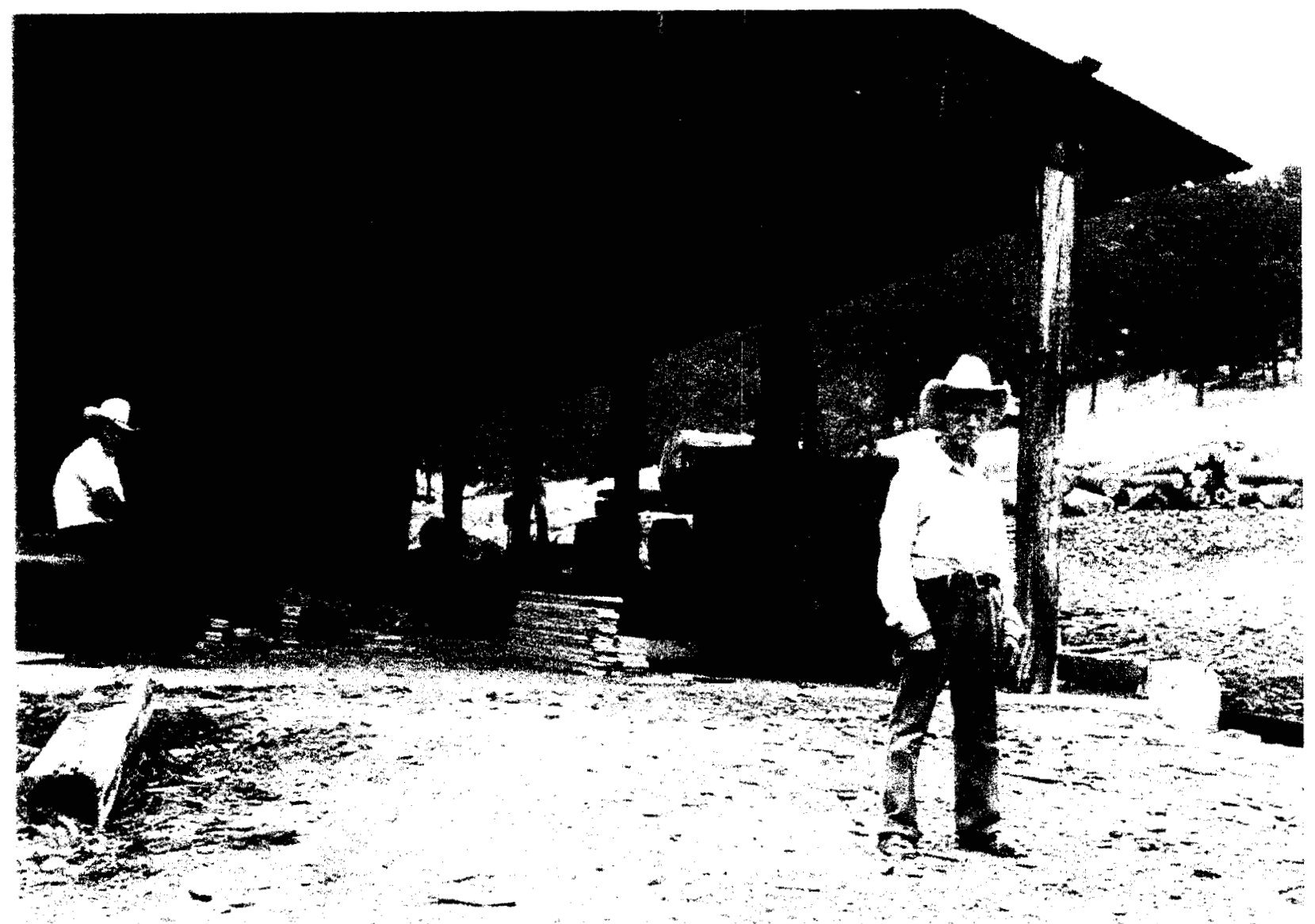

FIGURA 40.- DON JOSE CÓRDOBA. ASERRADERO OE SAMACHIQUE

(FOTO DEL AUTOR. JULIO 1995) 
conocimiento de los procedimientos y trámites y una mayor cercanía con la burocracia agraria facilitó a los mestizos integrarse a las listas de demandantes e incluso encabezar las solicitudes de tierra de los pueblos. Asi por ejemplo, en el área de Batopilas algunas familias mestizas, hasta entonces residentes en pueblos mineros de barranca por aquella época en decadencia, se desplazaron hacia las zonas altas de la Sierra para intervenir directa y ventajosamente en la constitución de los ejidos, integrándose a varias comunidades tarahumaras. Don José Córdoba, habitante mestizo de Samachique, nacido en 1925 y nieto del encargado de atender una "estación" del camino de arriería entre Batopilas y Chihuahua por donde transitaba en los años del porfiriato la conducta de metales de la Batopilas Mining Company, recordaba así la historia migratoria de su familia:

Yo naci en Norogachi, pero muy chiquito me vine aqui a La Laja que es un rancho, pero pues ya entramos de ejidatarios en este pueblo de Samachique. El finado de mi papá se dedicaba -antes no habia aserraderos- a aserrar tablas con semucho en mano, trabajaba tabla, en Norogachi o donde quiera que lo ocupaban para trabajar. Y sembraba aqui en La Laja, en el rancho. [...]

El finado de mi abuelo era "estacionero" cuando antes, en la conducta de plata que andaba acá en Batopilas. Todavía ahora se ven caminos ahi de esas conductas.. por ahi bajan. Era estacionero ahi. Trabajó mucho tiempo de estacionero en La Laja. Ahi formó él unas tiernitas, con muchas piedras, pero... Y luego él y el finado de mi papá ya se cambiaron. Se acabó el trabajo de la conducta y se fueron a Norogachi. Al fin él munó, el finado de mi abuelo y el finado de mi padre ya se acordó que el papá de él había dejado unas tiemitas y nos vinimos, se trajo la familia.[...]

Aqui en Samachique ya tenemos muchos años... Más bien cuando se hizo el ejido porque anterior no habia ejido... Hace más de cincuenta años. Vino el finado de mi papá. Ya nosotros entramos de ejidatarios, yo y mis hermanos. [...]. Cuando nos vinimos aqui a Samachique yo tenia 5 años. Todavia en ese tiempo no habia ejido. [...]

Mi papá es uno que anduvo con los ingenieros que andaban midiendo los ejidos, a ver qué tantas hectáreas tocaba a cada ejido. Mi papá anduvo en las líneas. Hacian brechas con los ingenieros y median. Y los gobemadores [tarahumaras] estuvieron de acuerdo porque hacian ellos sus juntas para platicar. ${ }^{16}$

\footnotetext{
${ }^{16}$ Entrevista con el Sr. José Córdoba en Samachique, Chih. 13 de julio de 1995. El término de "estacionero" al que hace mención et informante, se refiere al cargo que ocupaban ciertas personas mestizas como responsables de las estaciones por las que circulaba la conducta de metales de Batopilas. En ellas se cuidaban y cambiaban los animales y se detenian los arrieros para descansar al final de una larga jornada de camino. Todavia en la actualidad, el viajero puede observar en lugares como Basihuare.
} 225 
En otros lugares de la Tarahumara los repartos agrarios y el deslinde de los ejidos permitieron a grupos mestizos regularizar situaciones ilegales de ocupación indebida de tierras imponiendo el uso de éstas como pastizales y potreros, allá donde la población indigena habia practicado tradicionalmente la agricultura. Fue éste el caso de lugares como Humariza (municipio de Nonoava) y San José Baqueachi (municipio de Carichi), donde un grupo de mestizos logró que las autoridades agrarias les reconocieran la propiedad de varios predios ganaderos.

La forma en que el reparto agrario favoreció a los mestizos desencadenó un notorio descontento por parte de algunas comunidades tarahumaras, en especial en el municipio de Carichi. Alli, y de acuerdo con lo que ha investigado Mayra Meza, varios pueblos se levantaron en armas en octubre de 1927, amenazando con asesinar y expuisar a los mestizos de la zona y fue precisa la intervención del ejército para calmar los ánimos. Entre las muchas quejas que plantearon en esa ocasión los gobernadores indígenas de los pueblos de la región de Sisoguichi, Panalachi, Norogachi, San Ignacio de Arareco, Baqueachi, Guaguachérare y Carichi destacaban aquellas relacionadas con la apropiación de la tierra por parte de los mestizos y la explotación de éstos sobre los indigenas. En octubre de 1927 los dirigentes indigenas del movimiento fueron invitados a deponer las armas y a negociar con el gobierno federal en el Hotel Creel. Entre las declaraciones, destacó la del principal dirigente del movimiento, José Járis, gobernador de Siquirichi y viejo lider de la región de Norogachi quien, una década más tarde, habria de jugar un papel determinante en la formación del Consejo Supremo Tarahumara. De acuerdo con el acta levantada por el representante gubernamental, las declaraciones de . Járis no podian ser más convincentes:

...queremos las leyes de Benito Juárez, éste es el único que nos ha dado garantías y que no[s] señaló lo que nos pertenecía. Nosotros no podemos pelear con ustedes, no tenemos armas y en cambio ustedes tienen muchos cartuchos y muchas carabinas, pero digame: ies justo que los blancos se cojan lo nuestro,

viejas construcciones de piedra que fueron, hace cerca de un siglo, las estaciones donde los arrieros mineros y sus mulas encontraban cobijo y sustento. Como to muestra William L. Merrill (1992: 60-61) también en el caso de Basihuare la llegada de los primeros mestizos estuvo ligada al establecimiento de estas estaciones, siempre regenteadas por ellos. 
nuestras casas, nuestros animales, nuestras tierras y nos obliguen a trabajar sin pagamos, nos golpeen y aún abusen de nuestras familias? Al decir esto, en la cara del indio se veía la desesperación de la impotencia y gruesas lágrimas surcaron sus mejillas. ${ }^{17}$

Una de las razones de mayor peso que estuvo en el trasfondo de este movimiento fue la de presionar a las autoridades y técnicos agrarios que entonces iniciaban los deslindes de tierras y ejidos para que en sus decisiones respetaran la posesión tradicional -aunque, en muchos casos, sin respaldo documental- de los pueblos indígenas sobre sus tierras. ${ }^{18}$ Pero también es cierto que estos mismos funcionarios debieron enfrentar la presión de los mestizos, para entonces ya asentados en dichos pueblos, en especial en esa zona donde se desencadenó la rebelión de 1927. A resultas de esta situación surgieron algunas propuestas de formación de ejidos indigenas, como la que planteó el Ingeniero Patricio Fitzmaurice y otros miembros de la Comisión Deslindadora de la Alta y Baja Tarahumara, que propusieron en diciembre de 1927 repartir cerca de 2 millones y medio de has. entre 200 comunidades de la Alta Tarahumara, con parcelas de 150 a 300 has. y destinarido una parte importante de esta enorme zona a la explotación forestal. ${ }^{19}$

A pesar de este y otros proyectos, en la Tarahumara, el agrarismo del final de los años veinte estuvo muy lejos de satisfacer las demandas de regularización en la posesión de la tierra por parte de las comunidades indigenas. Como ya lo señalamos, el reparto agrario propició una migración de mestizos desde las zonas mineras de las

${ }^{17}$ Citado por Meza, 1998: 127. La cita proviene de un documento del Archivo del Cuerpo Consultivo Agrario en Chihuahua en donde fue descubierto y ampliamente analizado por Mayra Meza, para luego ser difundido en su brillante trabajo sobre la historia agraria del ejido tarahumara de San Jose Baqueachi (Meza, 1998).

${ }^{18}$ En el reparto agrario, los núcleos de población indigena no sólo se vieron perjudicados por carecer, en la mayoria de los casos, de documentación comprobatoria de su inmemorial posesión territorial, sino también por la agreste topografia del suelo y por el sistema de propiedad dispersa de ranchos, caracteristico de la cultura tarahumara y del que ya hablamos en el capitulo anterior. La institución del ejido y sus formas juridicas derivadas de la Ley Agraria se adaptan mal a la costumbre indígena de apropiación de la tierra y de movilidad territorial.

\footnotetext{
${ }^{19}$ Véase detalladamente en Meza, 1998: 69-74 y 132-133, lo que la autora llama "el proyecto indigenista de Patricio Fitzmaurice", asi como los documentos y planos del mismo.
} 
barrancas -entonces en situación de crisis productiva- hacia las áreas boscosas de las cumbres donde la entrega de la tierra implicaba también el derecho a la explotación del bosque. En otros casos, la coyuntura del agrarismo sivió para reconocer de facto la invasión ilegal que grupos de mestizos asentados en la Sierra desde principios del siglo $X X$ venian ejerciendo sobre tierras indígenas a base de introducir ganado en áreas agricolas o de explotar reservas maderables. Ádemás, en la inmensa mayoría de los casos donde se instauraron los ejidos, la autoridad de los gobernadores fue desplazada ya que los mestizos no se limitaron a gestionar y tramitar las demandas de tierras, sino que también monopolizaron los cargos directivos y las asambleas ejidales. Como ya lo señalamos en el capitulo 2, en estos nuevos ejidos en su mayoria de composición interétnica, la unidad territorial de los pueblos a la que se articula la jurisdicción de la autoridad tradicional indigena fue seriamente afectada ya que, en muchos casos no se hicieron coincidir los límites ejidales con los de los antiguos pueblos.

Si los indigenas no salieron tan bien parados de este primer reparto de la tierra, en cambio, no pocos mestizos encontraron en él una forma segura de sobrevivencia agraria. Era ésta la forma como lo que algunos autores llamaron, años después, la mexicanización del indio, se vivia en la Tarahumara. A través de su política agraria, el gobierno pretendia que la presencia mestiza favoreciera una modernización gradual de la tecnología y los usos agrícolas y ganaderos, pero sobre todo comenzaba a dar los primeros pasos que asegurasen, años después, un modelo intensivo de explotación del bosque con el que la mentalidad mestiza parecia estar más adaptada. En la década de los años veinte esta estrategia de mexicanización no produjo sin embargo los frutos esperados porque el reparto de la tierra no fue acompañado de una transformación en la economia indígena.

El segundo aspecto en el que se centró la mexicanización fue la reforma educativa, la cual tuvo por aquellos años un claro carácter incorporacionista, es decir, trató de fomentar abiertamente la homogeneización lingüistica o castellanización del indigena, así como su preparación intelectual y capacitación en actividades productivas 
CUADRO 12.- CENSO DE LA POBLACIÓN INDIGENA TARAHUMARA CON ESPECIFICACIÓN DE LUGARES, POBLACION ESCOLAR Y ESCUELAS EXISTENTES. (1926)

\begin{tabular}{|c|c|c|c|c|c|c|}
\hline PUEBLO & DISTRITO & INDIOS & GENTILES & $\begin{array}{l}\text { NIÑOS EN } \\
\text { EDAD } \\
\text { ESCOLAR }\end{array}$ & $\begin{array}{l}\text { NIN̈AS EN } \\
\text { EDAD } \\
\text { ESCOLAR }\end{array}$ & $\begin{array}{c}\text { ESCUELAS } \\
\text { PRIMARIAS } \\
.\end{array}$ \\
\hline Temósachic & Guerrero & 684 & & 70 & 80 & \\
\hline Tomochic & Guertero & 1.000 & & 130 & . & \\
\hline Matachic & Guerrero & 1.000 & & 130 & 170 & \\
\hline Yepómera & Guertero & 700 & & 70 & 90 & \\
\hline Unuactic & Rayón & 755 & & 75 & 95 & \\
\hline Yoquivo & Rayón & 500 & & 60 & 65 & \\
\hline Mahuarichic & Rayoón & 400 & & 40 & 60 & \\
\hline Mamelichic & Rayón & 750 & & 70 & 90 & \\
\hline Gorogáchic & Arteaga & 555 & & 60 & 70 & \\
\hline Tetamoa & Arteaga & 500 & & 60 & 65 & \\
\hline Témores & Arteaga & 800 & & 75 & 95 & \\
\hline Terochic & Arteaga & 462 & & 55 & 65 & \\
\hline Batosènachic & Arteaga & 600 & & 60 & 80 & \\
\hline Monterde & Arteaga & 1.125 & & 140 & 180 & \\
\hline Carichic & Benito Juarez & 435 & & 40 & 50 & \\
\hline Narárachic & Benito Juarez & 455 & & 40 & 60 & Esc. Rural Federal \\
\hline Pasigochic & Benito Juarez & 500 & & 60 & 65 & Esc. Rural Federal \\
\hline Tajirachic & Berito Juárez & 670 & & 65 & 85 & Esc. Rural Federal \\
\hline Arareco & Benito Juarez & 456 & & 40 & 60 & Escuela del Estado \\
\hline Guacayto & Benito Juárez & 400 & & 40 & 60 & \\
\hline Panalachic & Benito Juarez & 760 & & 70 & 90 & \\
\hline Baquiachic & Benito Juarez & 535 & & 60 & 70 & Esc. Rural Federal \\
\hline Sisoguichic & Benito Juarez & 900 & & 125 & 160 & Escuela del Estado \\
\hline Bocoyna & Benito Juarez & 645 & & 70 & 80 & Escuela del Estado \\
\hline Aboreachic & Andrés del Rio & 800 & 400 (1) & 130 & 160 & \\
\hline Cabórachic & Andres del Rio & 980 & $300(2)$ & 125 & 160 & \\
\hline Cusarare & Andres del Rio & 550 & $200(3)$ & 60 & 70 & \\
\hline Guahueyvo & Andres det Rio & 34 & & 40 & 50 & \\
\hline Guahuactic & Andrés del Rio & 466 & & 40 & 60 & \\
\hline Guachochic & Andres del Rio & 880 & $300(4)$ & 75 & 95 & \\
\hline Tetahuichic & Andrés del Rio & 525 & & 60 & 70 & \\
\hline Pahuichic & Andres del Rio & 900 & & 125 & 160 & Esc. Rural Federal \\
\hline Churo & Andres del Rio & 896 & & 120 & 160 & \\
\hline Cerocahui & Andres del Rio & 995 & & 130 & 170 & \\
\hline Cuiteco & Andrés del Rio & 960 & & 25 & 165 & \\
\hline Norogachic & Andrés det Rio & 1.000 & & 130 & 170 & Escuela del Estado \\
\hline Roctréachic & Andrés del Rio & 775 & & 75 & 95 & Esc. Rural Federal \\
\hline Monerachic & Andrès del Rio & 650 & & 70 & 80 & Esc. Rural Federal \\
\hline Tónachic & Andrés del Rio & 934 & & 125 & 160 & Escuela del Estado \\
\hline Zamachic & Andres del Rio & 775 & & 75 & 95 & \\
\hline Zatevó & Andrés del Rio & 425 & & 40 & 60 & \\
\hline Yoquivo & Andrès del Rio & 758 & & 75 & 95 & \\
\hline Ogüivo & Andrés del Rio & 400 & 200 & 40 & 60 & \\
\hline Baquiriachic & Hidalgo & 645 & & 65 & 80 & \\
\hline Guazàrachic & Hidalgo & 594 & & 60 & 75 & \\
\hline Tecorichic & Hidalgo & 1.400 & & 150 & 180 & \\
\hline Coloradas & Gpe y Calvo & 200 & & - & - & \\
\hline Huerachic & Gpe. y Calvo & 300 & & - & - & \\
\hline Chinatu & Gpe. y Calvo & 400 & & - & - & \\
\hline Redondeados & Gpe. y Calvo & 300 & & - & - & \\
\hline TOTALES & & 33,432 & 1,400 & 3,640 & 4,585 & 12 \\
\hline
\end{tabular}

(1) Gentiles en la Barranca de Quirare. (2) Gentiles en la Barranca de Tetejachic (3) Gentiles en Raramuchi.

(4) Gentiles en la Barranca de Sinforosa

FUENTE: Basauri, Carlos: Monografia de los tarahumaras, 1929:13. 
propias de un medio urbano, artesanal o industrial pero sumamente lejanas de su realidad cotidiana. Tras varios experimentos, poco a poco se fue imponiendo el Internado, como modelo típico de escuela indígena, modelo en el que se expresaba claramente una ruptura simbólica entre el medio indigena y el escenario educativo, entre el aprendizaje de la ciencia y la cotidianidad de la sobrevivencia, entre el pensamiento y la experiencia, entre la institución escolar y la comunidad.

Las primeras acciones educativas emanadas de los postulados de la Revolución llegaron a la Sierra de Chihuahua en una época dificil, porque tanto la propuesta liberal de Creel como los experimentos educativos de los misioneros jesuitas habian sucumbido o estaban en franca crisis a raíz de la revolución. De acuerdo con los datos censales recogidos por el antropólogo Carlos Basauri en 1925 y 1926 (véase Cuadro 12), los niveles de escolarización de la población indígena no podian ser más desalentadores para los promotores de la "escuela rural": en un total de 50 pueblos habitaban más de 33,000 tarahumaras entre los que se podia contabilizar una población en edad escolar de más de 8,000 niños y sólo en 12 de esas comunidades existian establecimientos de instrucción primaria, predominantemente frecuentados por mestizos. A ello había que añadir el carácter "casi salvaje" de cerca de 1,400 tarahumaras "gentiles" o "cimarrones", escondidos en cuevas dispersas en las barrancas de Quírare, Tetejachi y Sinforosa, cerca de los poblados de Aboreachi, Cabórachi, Cusárare, Raramúchi y Guachochi.

Fue en este medio indigena, considerado por los etnógrafos de la época como de "primitivo", en el que llegaron a la Sierra Tarahumara los primeros intentos de incorporar al indio al proyecto educativo que, desde la Secretaría de Educación Pública, comenzó a difundir el gobiemo obregonista bajo el lema de la Escuela rural y de las Misiones culturales. $^{20}$

\footnotetext{
${ }^{20}$ En 1921 se restableció la Secretaria de Educación Pública que habia sido suprimida desde el periodo carrancista. José Vasconcelos fue el primer Secretario y autor de la reorganización de la SEP. En noviembre de 1921 el Departamento de Educación y Cultura Indigena (dependiente de dicha secretaria) comenzó a realizar, a través de brigadas de maestros ambulantes, estudios sobre las condiciones culturales de algunas comunidades y regiones indigenas del pais en las que inició algunas tareas básicas de alfabetización, extensionismo agrario y un conjunto de programas de acción social tendientes a mejorar la condición 
Antes de los años veinte los esfuerzos educativos del gobierno en la Tarahumara habian sido escasos ${ }^{21}$. Desde 1922 se fundaron en la Sierra Tarahumara las primeras escuelas rurales dirigidas en muchos casos por maestros improvisados egresados de las escuelas primarias de la zona. Un viejo maestro rural comisionado por aquellos años a atender una escuela en el poblado de Potrero de los Bojórquez, en el municipio barranqueño de Morelos, recordaba asi su primer nombramiento:

Como no habia maestros para enfrentarse a esta gran cruzada [educativa], se improvisaron con jóvenes egresados de las Escuelas primarias, y en esa época solamente existian en la cabecera del municipio de Batopilas, Chih., en todo to que comprende la zona tarahumara.

Fue así como en el año de 1924, el C. Prof. don Vicente Gómez, que integró el jurado calificador en los exámenes de fin de curso (junio), seleccionó a varios muchachos y muchachas quienes, mediante un corto curso de preparación, los nombró maestros rurales, ya que en igual forma lo habia hecho los dos años anteriores, y en esa forma, el que esto suscribe, ingresó al Magisterio Rural Federal.

El lugar que se me asignó distaba de Batopilas tres dias a caballo, en la comunidad denominada Potrero de los Bojórquez, del municipio de Morelos, de esta entidad de Chihuahua, y [...] puede decirse que en el período de julio a noviembre apenas sirvió para conocer la región, y atender a poco más de sesenta niños de ambos sexos completamente analfabetos, al igual que los adultos, siendo et mayor porcentaje mestizos y unos doce indigenas: tarahumaras y tepehuanes: Los años subsecuentes de 1925, 1926 y parte de 1927 segui laborando en aquel pueblecito y, al decir del señor Inspector, con bastante éxito, pues logré aumentar la asistencia hasta cerca de cien alumnos.

Para estas fechas la educación rural en el pais era todo un éxito y el maestro era la cabeza principal de las comunidades, ya que además de mentor, teniamos que hacerle a otras actividades, tales como asesor de las autoridades, secretarios particulares de algunas gentes y hasta de médicos. ${ }^{22}$

económica de los indigenas. De ahi surgió en abril de 1923, y con la participación directa de Moisés Sáenz, el Programa de las "Casas del Pueblo", orientado a construir escuelas rurales con el apoyo de todos los vecinos de una determinada comunidad a quienes, a su vez, se ofrecian una serie de cursos prácticos y actividades de apoyo orientadas a mejorar su nivel de vida. Para capacitar a los maestros encargados de estas escuelas rurales, surgieron en 1923 las Misiones culturales, oficialmente aceptadas en 1926 e institucionalizadas en 1928. (Véase Aguirre Beltrán, 1992b: 68-91 y Aguirre Beltrán y Pozas, 1981: 187-220).

${ }^{21}$ Desde 1886 se empieza a hablar en los informes de los gobernadores de Chihuahua de la necesidad de crear escuelas para indigenas, pero en la mayoria de los casos esto no pasó de ser una buena intención. En 1899 et gobernador Ahumada estableció una escuela primaria en Tónachi y cuatro años despues se instalaron otras dos en Rocheiachi a las que asistian niños mestizos.

${ }^{2}$ Martinez Chávez, J. Rosario: "Experiencias en ef trabajo de educación indigena", Guachochi, Chih., 231 
También desde 1923 hasta 1932 funcionaron las Misiones culturales en la Tarahumara, en poblaciones como Norogachi, Sisoguichi, Batopilas, Polanco, Cusárare, Cusihuiriachi, San Ignacio Arareco, Guazarachi, Creel, Cieneguita de la Barranca, Guazapares y Rochéachi:

En 1927 fue la gran novedad que nos llenó de júbilo, pues fuimos citados urgentemente a concurrir a unos cursos intensivos de preparación. Es que llegaba a la región una de las Misiones Culturales.

En julio y agosto de dicho año, todos los maestros rurales en servicio, sin faltar nadie, ocumimos al poblado de Polanco, del municipio de Batopilas, ávidos de adquirir nuevos conocimientos.

Recuerdos inolvidables de esta Misión Cuttural en que, por primera vez en la historia, nos reuniamos con el exclusivo fin de estudiar, y nada nos hacia el levantamos antes del amanecer y todavia en la noche asistiamos a clases. Yo era el benjamín del grupo y quizá por ello guardo en la memoria toda clase de detalles, y fue ahi donde capté lo que significa la grandiosa obra de la Revolución Mexicana y sentimos la gran responsabilidad que pesaba sobre nosotros al ostentar el nombre de Maestro Rural... (lbid.)

En una región en la que la limitada acción educativa habia estado casi exclusivamente en manos de la iglesia, la aparición de los primeros "misioneros culturales" no dejó de sembrar confusión y recelo, en especial entre los sacerdotes jesuitas que se quejaban ante el gobernador del estado de que las misiones culturales operaran en los pueblos de misión y compitieran abiertamente con los towisados y tewecados, alegando que

"la mayoria de los pueblos indigenas no tienen escuelas: ¿para qué, pues, amontonar en un lugar tantos civilizadores faltando para tantos lugares, sobre todo de blancos que en vano piden escuelas y no se les puede atender? ${ }^{23}$

Pero como sucedió en otras partes de la República las escuelas rurales y las Misiones culturales habian sido diseñadas para responder más a las necesidades de los campesinos mestizos que a las de los indigenas, con quienes la castellanización forzada enfrentó serios problemas y resistencias ${ }^{24}$. En la Sierra Tarahumara a esta

20 de julio de 1961, en ACCIT Legajo 17, Expediente 10

\footnotetext{
${ }^{23}$ Carta del P. Mier y Terán al Gobernador de Chihuahua, Gral. Ignacio Enriquez, 1924 (Tomado de Valverde, 19898:100-101)

${ }^{24}$ En 1926 el gobemador J.A. Almeida informaba que, además de las escuelas oficiales comunes, ..habian funcionado tres Misiones de Civilización en Sisoguichi, Norogachi y Guazapares, pero que por falta de asistencia del alumnado, se tuvieron que clausurar para concentrar 232
} 
dificultad se añadió otra más grave: la de la dispersión de la población, lo que complicaba seriamente la ubicación y cuantia de las escuelas asi como la asistencia de los alumnos. Quizás por esta razón y tratando de fijar a los alumnos a la escuelas y evitar los traslados diarios desde éstas a sus comunidades y rancherias, los inspectores y maestros rurales serranos retomaron de la experiencia de las misiones jesuiticas el modelo escolar del internado, antes de que éste se difundiera a nivel nacional. Fue asi como en 1927 surgió en el poblado de Yoquivo el Internado Fray Bartolomé de las Casas, el primer intrernado oficial para niños indigenas creado en México:

El 27 de octubre de 1927, siendo director de educación federal en el estado de Chihuahua don Juan B. Salazar e Inspector de la $9^{a}$ zona Escolar Federal Salvador Varela R., se hizo el ensayo del Primer Intemado para los Tarahumaras, siendo quizá el primero de su tipo en la República.

Con la cooperación de algunas gentes de la región, especialmente de Batopilas, se reconstruyeron unas ruinas adyacentes a la Iglesia católica del pueblo de Yoquivo, del propio municipio [de Batopilas], y con el dinamismo que caracteriza a Varela, se agenció, no sé cómo, aperos de labranza, herramientas para talleres de carpinteria, de herrería, de zapatería y máquinas de coser "Singer", lámparas de gasolina y creo que hasta una máquina de escribir. Se improvisaron camas en bancos de madera con tablas aserradas a hacha y se consiguieron colchonetas y cobijas; y en esta forma empezó a funcionar el Internado con poco más de sesenta niños de ambos sexos. En el acto de inauguración recuerdo que lloraron de emoción Varela y Don Juan Salazar [...]

Recuerdo que entre los concurrentes, donde habia gentes que sólo conocian al indigena como pastor de cabras, peones agricolas y otros menesteres de baja ralea, todos los augurios fueron negativos a la grandiosa obra que acababa de nacer. $^{25}$

También en 1928 se fundó otro internado indigena en el poblado de Cieneguita de la Barranca, cerca de la Barranca del Cobre, en el municipio de Urique, y otro más, en 1933 en Tónachi. Durante el período cardenista, se instalaron otros dos más en

[...] esfuerzos en un solo centro de civilización [...], para lo cual se ha elegido el pueblo de San Ignacio de Arareco (Almeida, 1926: 54).

${ }^{25}$ Cfr. Martinez Chávez, J. Rosario, "Experiencias en et trabajo de educación indigena....", expediente ya citado. Puede verse tambièn "Breve historia de los Intemados indigenas elaborada por el Profr. J. Rosario Martinez, Procurador de Comunidades Indigenas, 1966" en ACCIT, Legajo 13, Expediente 11. 
Sisoguichi y Norogachi, en las instalaciones confiscadas a la Iglesia ${ }^{26}$. Estos dos últimos desaparecieron en 1940, a raiz del regreso de los religiosos, reinstalándose hacia ese año el internado de Norogachi en el poblado de Siquirichi. ${ }^{27}$ De todos ellos, los que habrian de consolidarse en los años posteriores serian los de Tónachi y Siquirichi: el primero ofreció el ciclo completo de la primaria desde 1947 y el segundo desde 1968.

La ideologia laica y el control del Estado que caracterizaron el discurso educativo oficial de los años veinte y treinta no impidieron que el modelo escolar oficial en la Tarahumara retomara de la experiencia de los misioneros jesuitas dos aspectos fundamentales: el sistema de internados y la orientación hacia la formación práctica y el aprendizaje de oficios agricolas y artesanales. ${ }^{28} \mathrm{El}$ programa escolar de los internados se estructuraba a partir de la enseñanza en castellano y de una división entre las materias "académicas" y el trabajo práctico. Las primeras eran por lo general impartidas por maestros adscritos a la SEP o al Departamento Autónomo de Asuntos Indígenas que venían de fuera de la Sierra y aun del estado de Chihuahua. Las segundas, en cambio, estaban en manos de maestros prácticos artesanos de oficio, muchos de los cuales procedian de poblaciones serranas.

Las actividades prácticas de este modelo de los intemados consistian en el trabajo en una parcela con hortalizas y frutales y en los talleres de carpinteria, textiles, curtiduria, talabartería, herreria, zapateria y albañileria, además del aprendizaje del

${ }^{26}$ Recuérdese, como ya lo señalamos en el capitulo anterior, que los misioneros jesuitas de la Tarahumara fueron objeto de persecución y expulsión y sus instalaciones cerradas y confiscadas en tres sucesivas ocasiones: en 1914, cuando el gobierno villista decretó la expulsión de religiosos extranjeros; entre julio de 1926 y mediados de 1929, con ocasión de la campaña antirreligiosa del gobierno callista y de 1935 a 1939, cuando la administración del presidente Cárdenas prohibió la educación religiosa y confiscó los edificios escolares de la Iglesia.

${ }^{27}$ Los internados indigenas dependieron originalmente de la Secretaria de Educación Pública y durante el gobiemo cardenista del Departamento Autónomo de Asuntos Indigenas para pasar de nuevo, en la administración alemanista, a la Dirección General de Asuntos Indigenas, dependiente de la SEP.

${ }^{28}$ En alguno de estos internados, como el de Siquirichi, se retomó el sistema de establecimiento de colonias agricolas con los egresados del internado, tal y como lo habia experimentado los jesuitas en Sisoguichi. 


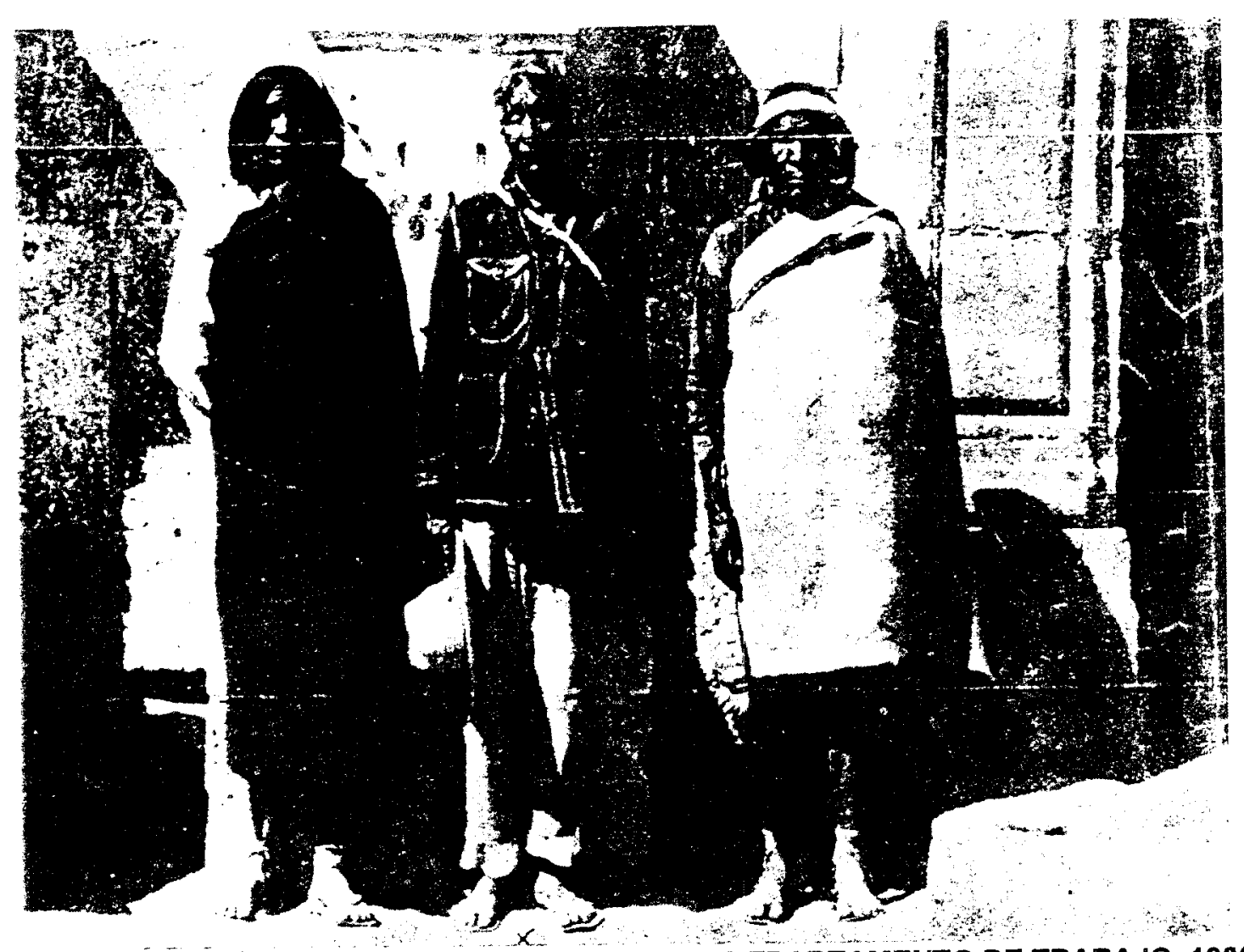

FIGURA 41.- JOSÉ JÁRIS SIQUIRICHI (EN EL CENTRO)(DEPARTAMENTO DE TRABAJO, 1936)

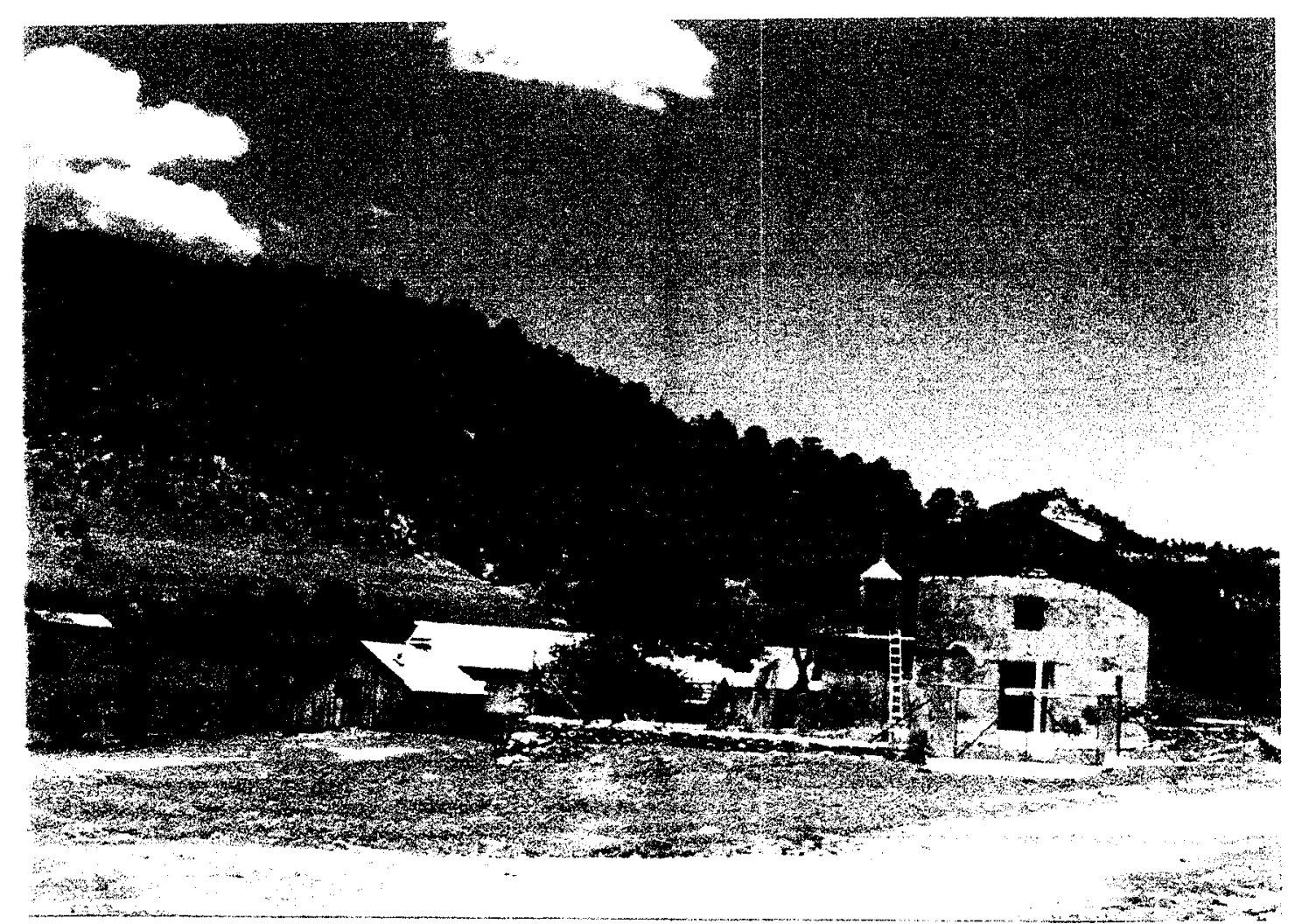

FIGURA 42.- YOQUIVO. IGLESIA Y RUINAS DEL VIEJO INTERNADO INDIGENA (FOTO DEL AUTOR. JULIO 1995) 
solfeo y de algún instrumento musical. Un maestro rarámuri, hoy jubilado, que ingresó al internado de Tónachi en 1938 nos comentaba la ventaja cle este sistema educativo:

En cierta ocasión me preguntaban si los Talleres servian para la preparación de los alumnos. Si, si sirven tes decia. Por esto. El maestro carpintero.... Lega el alumno y el maestro carpintero tiene que estar bien preparado con la cosa de las medidas. Por ejemplo la cinta métrica. Ahorita la única parte donde se practica el metro es en el aserradero. Antes en el intemado llegaba el maestro carpintero y decia: "Oiga. Hágame una mesa de $80 \mathrm{cms}$. de largo y 40 de ancho". Alli aprendia el alumno. Porque el maestro de académicas llegaba a ese tema en los últimos años. Y cuando el alumno llegaba con el maestro académico para que el maestro le enseñara la geometria, ya el alumno sabia porque lo habia aprendido del maestro carpintero. También teniamos maestros de agricultura. Nos enseñaban de hortalizas. sembrar el maiz y toda clase de semillas. ${ }^{29}$

Pero si lo que el Gobiemo pretendía era expandir la escolarización en el medio indigena, era preciso no sólo ampliar el número de planteles educativos, sino también formar maestros indígenas. La primera generación de maestros tarahumaras, cuya influencia habría de ser decisiva en los años treinta y cuarenta, se formó en la Casa del Estudiante Indígena, institución creada en enero de 1926 por el presidente Calles y con sede en el Internado de Santa Julia, ubicado en la ciudad de México.

A pesar de las críticas que se han hecho a esta experiencia educativa en la que se pretendió crear un prototipo de maestro indígena similar al resto de los educadores en términos de capacidades intelectuales y pedagógicas para convertirlo en promotor del cambio en su comunidad ${ }^{30}$, es indudable que los estudiantes tarahumaras egresados de este centro tuvieron una incidencia significativa en los proyectos indigenistas de los años siguientes, en particular en la formación del Consejo Supremo Tarahumara y en la implantación del INI en la Sierra. De la Casa del Estudiante Indígena de Santa Julia egresaron cerca de 75 maestros tarahumaras entre los que habrian de destacar Patricio Járis (hijo de José Járis Siquirichi), Ignacio León, Santiago Recalache, Quirino Salvador,

${ }^{29}$ Entrevista con el profesor Antonio Bustillos. Tónachi, Chih., 27 de julio de 1995.

30 Pueden verse al respecto las criticas de Aguirre Beltrán al experimento de la Casa del Estudiante Indigena (Aguirre Beltrán, 1992b: 97-103). Una critica a los maestros tarahumaras que se formaron ahi en Gómez, 1948: 101 
Candelario Viñiegra, Eleuterio Rodriguez, Luciano González, Eusebio Pérez y otros. La Casa el Estudiante Indigena fue clausurada en 1932 y en su lugar se crearon algunos internados en diferentes regiones del país, como los de Tónachi, Siquirichi, Cieneguita a los que nos hemos referido, en el caso de la Tarahumara.

Al inicio de los años cuarenta operaban en la Tarahumara los internados de Tónachi, Cieneguita de la Barranca, Norogachi y Sisoguichi, éstos dos últimos en las instalaciones confiscadas por el gobierno a la iglesia católica. A juzgar por el reporte de algunos visitadores, no todo era gloria en esos centros escolares. La falta de recursos, el abandono oficial, las limitaciones de una pedagogía poco adaptada al medio e incluso la corrupción llegaban en ocasiones a empañar la mistica del ideario de la educación rural. Don Filiberto Gómez, un maestro que había llegado a la Sierra como miembro de las Misiones culturales y que tuvo la oportunidad de visitar esos cuatro internados indígenas en 1941, acabaria por relatar en su Diario Tarahumara algunas de las muchas decepciones de su viaje, como la que le produjo su visita al Internado de Cieneguita de la Barranca:

A buen paso hicimos ocho horas a Cieneguita. Los maestros, atentos y amables, nos dieron alojamiento en el salón donde estudian música. [...]. La maestra Guadalupe Gutiérrez me describió cómo, por falta de vajilla, los alumnos del intemado tienen que comer con los dedos. [...]

Menú de hoy. Desayuno: frijoles, café, tortillas. Comida: frijoles, enchiladas, tortillas. Cena: frjotes, atole de maiz, tortillas. No hay vajilla de ninguna especie. Luego, por motivos que nunca les faltan, las provisiones nunca llegan a tiempo y lo sueldos se retrasan.[...]

Es bastante buena la producción de los talleres de la escuela, no obstante lo mal refaccionados que están. El curtidor y el talabartero son verdaderos expertos en su ramo, aunque no parece que hayan cursado el sexto año en la escuela. El maestro de música montó en cólera esta mañana porque un towi no tenia muchas ganas de asistir a la clase de la Banda de Guerra. Lo insultó y se le acercó amenazante, diciéndole: "iCállese el hocico!". Momentos más tarde le dio dos bofetadas, sangrándole la boca, a otro alumno que habia tenido el atrevimiento de rezongarle entre dientes a una maestra que le habia regañado. [...]

Hay sesenta y un becas autorizadas, pero sólo cincuenta y una efectivas: treinta y un varones y veinte mujeres. Antes tenian noventa becas. Durante la epidemia de abril último murieron dos alumnos. Ha transcurrido un año y ocho meses sin médico o enfermera, diez meses sin agricultor y nunca han conocido a un profesor 
de Educación Física. El exdirector está en la cárcel por haber violado a unas tewéke $[. .$.

Cada towi tiene su propia cama en esto están mejor que los otros intemados. Las provisiones se retardan, también, por la impuntualidad en llegar las órdenes de pago a Batopilas [...]. En una ocasión mandaron a México medidas exactas de cada alumno y les enviaron overoles del número cuarenta. y eso que Asuntos Indigenas exigió medidas de antemano.[...]

De nada siven las tramitaciones a base de oficios: si se piden zapatos, se envian medias: si gorras, reciben pantalones y asi sucesivamente [...] Me despedi, pensando en que tantas irregularidades y la terrible orfandad de moralidad han convertido "el problema del indio" en un lucrativo negocio (Gómez, 1948: 129 133). ${ }^{31}$

Estas limitaciones y carencias no eran sin embargo el único problema del sistema de los Internados y Misiones de Mejoramiento que operaron por aquellos años en la Tarahumara y que, pese a haber sido objeto de algunas reformas ${ }^{32}$, no dieron los frutos esperados. La debilidad más notoria de este sistema educativo residió más bien en su desconexión con otras medidas de mejoramiento y cambio social en la esfera económica y productiva, pero estos programas nunca fueron emprendidos en esa época. En realidad y hasta el inicio de la década de los años cincuenta, las acciones del Gobiemo se habian limitado a constituir en 1934 una Junta Adnninistradora de los Bienes de la Raza Tarahumara cuyos resultados fueron nulos, a disfrazar de cooperativa indigena un aserradero instalado en el Rancho de Heredia en realidad, propiedad de la Dirección

${ }^{31}$ El libro del profesor Filiberto Gómez Gonzälez, Rarämuri. Mi diario Tarahumara, constituye una de las visiones más criticas del sistema de los internados indigenas de la Tarahumara al inicio de los años cuarenta. Su tesis central pudiera resumirse diciendo que los programas educativos no pueden funcionar si antes no se resuelven las graves carencias de pobreza que enfrentan los grupos étnicos serranos. El texto acaba proponiendo un modeto de granjas -colonias.

32 En 1938 el Departamento Autónomo de Asuntos Indigenas se hizo cargo de los internados de Sisoguichi, Tónachi, Norogachi y Guachochi, creando dos Procuradurias en Creel (1936) y Guachochi. En 1942 los internados de Norogachi y Tónachi pasaron a ser Centros de Capacitación Económica (programa de 3 años de alfabetización y capacitación en talleres y actividades agricolas) trasladándose el primero a Siquirichi. El de Cieneguita de la Barranca se transformó en Misión de Mejoramiento (programas de fomento a la agricultura, ganaderia e industrias artesanales) reubicándose en Yoquivo y el de Sisoguichi fue devuelto a los jesuitas. En 1943 se fundó la Misión de mejoramiento de Baquiriachi, en el municipio de Balleza. La Misión de Mejoramiento de Yoquivo operó por un tiempo un aserradero en Mesa de Agostadero y una planta productora de Aguarrás en Mesa de Richuchi (ambas en el municipio de Batopilas). En Nabogame, municipio de Guadalupe y Calvo, se intentó, sin éxito, establecer otra Misión de Mejoramiento, pero fue abandonada por el Departamento de Asuntos Indigenas. (Véase De la Peña, 1946: 274). 
Forestal de la Secretaría de Agricultura- y a dejar incumplidas las solicitudes de dotación y regularización de tierras expresadas por los gobernadores indigenas en una concentración que tuvo lugar en Creel en 1934. A este panorama desolador se añadia además el hecho de que la construcción del ferrocamil Chihuahua al Pacifico, que tanto empuje tuvo al inicio del siglo, se encontraba por entonces paralizada. ${ }^{33}$ No es extraño pues que Moisés T. de la Peña, el defensor de la tesis de la mexicanización del indio, no dudara en discordar de la política indigenista oficial de aquellos años, al plantear abiertamente, tras un recorrido por la Tarahumara en 1944:

Porque no son escuelas ni intemados lo que más necesita el indio, sino ante todo que, protegiendo sus intereses, se le ponga en contacto con la población mestiza, que se le acerquen los mercados para dar un valor a sus productos y a su fuerza de trabajo, y se le capacite para vencer el hambre, en todo lo cual la escuela no ejerce sino una función complementaria y nunca la de panacea como se ha metido en la cabeza de los funcionarios públicos, desde hace más de 20 años [...]. Buenas carreteras ante todo y sobre todo, combate de plagas, servicio médico y asistencia social, mejoramiento de las tierras de labor, introducción de nuevos cultivos, fomento de la ganaderia mejorada, de la apicultura, de la avicultura, enseñanza de pequeñas industrias rurales [...] y escuelas a base de medios internos, quizás, y con programas ajustados a las necesidades y posibilidades regionales, más que todo destinadas a crearle necesidades al indio y a capacitarlo para satisfacenlas (De la Peña, 1944: 397-398).

Moisés T. de la Peña no habria de ser el único en reconocer que las reformas educativas aisladas y desarticuladas de un programa global de cambio social eran incapaces de modificar el panorama de atraso de los indígenas de la Tarahumara y de convencerlos de las bondades de su incorporación a los patrones de vida mestizos. Otros como Filiberto Gómez, también muy crítico del sistema de los internados indigenas, llegarian incluso a plantear algunos proyectos que buscaban vincular la. educación escolarizada con un cambio integral en la cultura y formas de vida indígena. Así, en 1948 propondria un modelo de Granjas-Colonias para establecerse en los poblados en Tuchéachi, Guachochi, Tónachi, Siquirichi, Satevó, Yoquivo, Tecorichi,

\footnotetext{
${ }^{33}$ El Ferrocarril Chihuahua al Pacifico fue formalmente inaugurado por el Presidente López Mateos el 24 de noviembre de 1961, integrándose asi las antiguas lineas férreas del Ferrocarril Kansas City México y Oriente (entre Ojinaga al noreste de Chihuahua, La Junta y Topolobampo, Sin.) con las del Ferrocarril Noroeste de México (entre Ciudad Juárez y Chihuahua, a través de Casas Grandes, Mata Ortiz, Madera, La Junta, Cuauhtémoc y Tabalaopa). Sobre la historia de este ferrocarril puede verse Durán, 1961.
} 


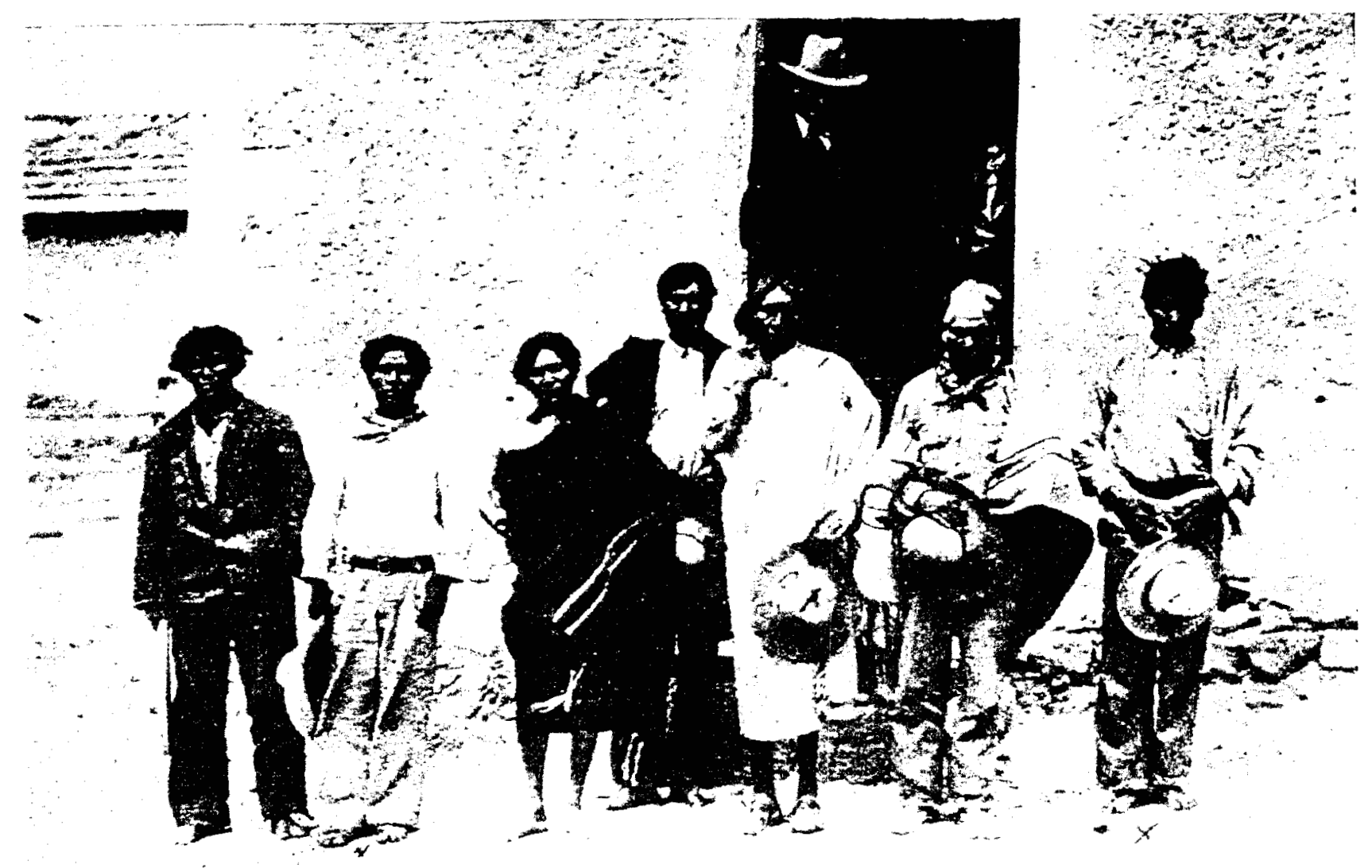

FIGURA 43.- LOS PRIMEROS MAESTROS TARAHUMARAS. NOROGACHI. 1936

(DEPARTAMENTO DE TRABAJO, 1936)

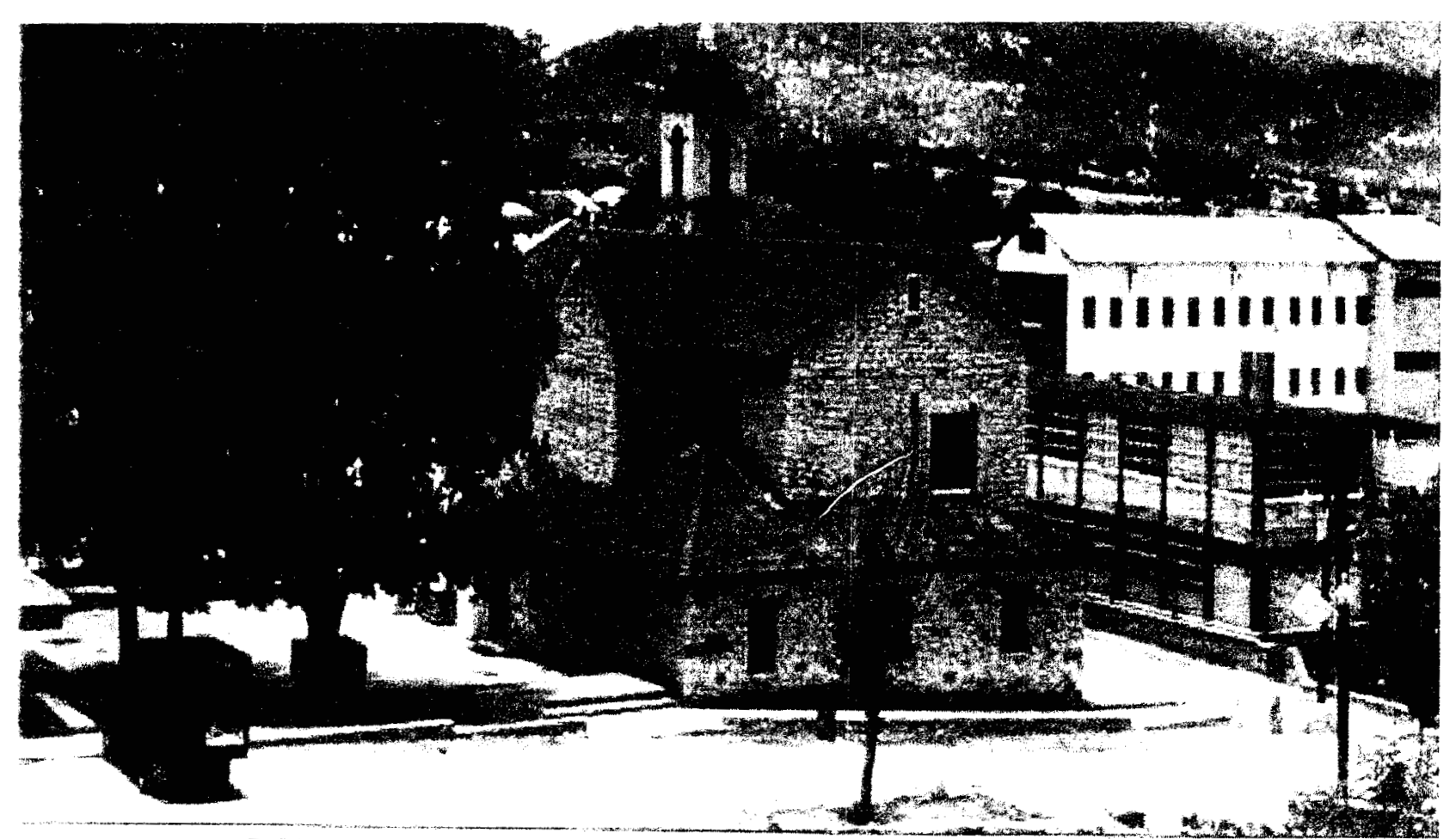

FIGURA 44.- IGLESIA E INTERNADO DE LA MISION DE SISOGUICHI.

(FOTO DEL AUTOR. JULIO 1996) 
Babicora, Alburquerque, Sirúpa, Cocomórachi, Tosánachi y Valle del Aguila y cuyos objetivos habrían de ser mejorar los niveles de vida, fomentar la modernización productiva agricola, pecuaria, forestal, pesquera y artesanal y superar las condiciones de salubridad, educación y cultura de la población indigena. ${ }^{34}$ Una derivación de este proyecto es el que el mismo autor presentaría algunos años después para crear en el poblado de Nabogame, municipio de Guadalupe y Calvo, una Comunidad Experimental Tarahumara, de acuerdo a los objetivos y estrategias que aparecen en el Cuadro 13. Como se podrá observar, el proyecto tiene como una de sus fuentes de inspiración la experiencia de las colonias catequistas organizadas desde los años veinte por los misioneros jesuitas en Sisoguichi y Norogachi.

En el período comprendido entre 1922 y 1950, la Sierra Tarahumara conoció un inusitado auge de acciones educativas emprendidas por primera vez y de forma sistemática por el gobierno federal, lo que vino a acabar con el monopolio que los misioneros habian jugado en este ámbito. A través de las misiones culturales, la escuela rural y los internados indígenas se inició un amplio programa que trataba de incorporar a los indigenas a las reformas sociales emanadas del proceso revolucionario. La orientación de este programa era por demás clara. Se pretendia la total y plena incorporación del indio a la cultura nacional, su "mexicanización" y para ello nada más útil y efectivo que la castellanización, la enseñanza de "artes y oficios" modernos y la difusión de planes de modemización productiva. Sin embargo, después de cerca de tres décadas de experimentos educativos ni la mexicanización ni la incorporación del indígena llegaron a ser realidad. No sólo porque las reformas sociales que acompañaron a este proyecto educativo fueron tibias e incompletas -como lo muestran las enormes carencias de los internados indigenas y la ausencia de una profunda transformación de la economia serrana-, sino sobre todo porque, en verdad, los grupos étnicos de la Sierra Tarahumara nunca llegaron a conocer los supuestos beneficios en términos de bienestar y desarrollo que, se suponia, debian derivar de este programa aculturativo que pretendía equipararlos con el resto de la nación.

\footnotetext{
${ }^{34}$ Puede verse la propuesta completa en Gómez, 1948: 281-296.
} 
CUADRO 13.- SINTESIS DEL PROYECTO ELABORADO POR EL PROFESOR FILIBERTO GÓMEZ GONZALEZ, PARA LA CREACION DE UNA COMUNIDAD EXPERIMENTAL TARAHUMARA (CET) EN EL VALLE DE NABOGAME, MPIO. DE GUADALUPE Y CALVO.

\section{OBJETIVOS}

- Acabar con las 5 ies en la vida del tarahumara: ignorancia, insalubridad, inseguridad,

inestabilidad, intranquilidad.

-Atender las 4 funciones de la vida: habitación, trabajo, cultivo intelectual-fisico y circulación.

- Forjar grupos compactos en su propio hábitat con mayor sociabilidad y comunicación; establecer escuelas prácticas y demostrativas asi como servicios de salubridad, electrificación, vivienda y trabajo diversificado.

- Hacer de la CET un campo de experimentación y demostración.

Despertar la conciencia comunal del tarahumara. Evitar que sea reabsorbido por un medio Primitivo y acabar con el nomadismo estacional.

- Ofrecer al tarahumara una comunidad en la que participe activamente.

Fomentar la participación del indigena en la Industria y comercio.

- Modificar la cultura, vida y costumbres del tarahumara sin destruir sus valores positivos.

-Enseñarle a enseñarse a si mismo y a ser autosuficiente. Fomentar las relaciones armoniosas entre tarahumaras y mestizos.

- Lograr que el tarahumara determine ciertos aspectos de su vida por razonamiento y eficacia e imponerle la disciplina en el trabajo. Impulsar la sociabilidad del tarahumara.

-Evitar la explotación del indio por parte de blancos y mestizos.

- Mejorar escuelas y medios de almacenamiento, combatir enfermedades, instalar sistemas sanitarios y producir más y mejores alimentos para los indigenas

\section{ESTRATEGLAS}

PERSONAL

- Instalar 20 familias en 200 has. del valle de Nabogame.

-Distintas dependencias aportarán técnicos; el tarahumara, mano de obra.

\section{PRODUCTIVAS}

-Establecimiento de cooperativas.

-Diversificación alimenticia (huertos, cria de trucha y carpa, carne, aves de corral, cerdos, productos agricolas, etc.)

-Diversificación del trabajo (agricultura, talleres. etc.).

-Diversificación de cultivos.

-Desarrollo integral del suelo, agua y minerales.

Aprovechamiento de la broza.

- Construcción de presas y lagos artificiales para riego, pesca y recreación.

-Explotación ovi-caprina intensiva.

- Telares manuales, fábricas de cajas de frutas y muebles escolares.

\section{EDUCATIVAS}

-Sistema educativo que promueva:

+Conservación del medio, la salud, la economia doméstica y la recreación comunal.

+Aprendizaje del español, de operaciones aritméticas básicas y principios básicos de salubridad.

+Orientación hacia las necesidades sociales y prácticas del indigena.

+Capacitación y especialización de maestros bien pagados en problemas indigenas. Formar maestros tarahumaras.

\section{OTRAS}

-La CET recibirá hombres de letras, artistas y científicos que ofrecerán pláticas

-Subsidio oficial mensual de 70 mil pesos.

- Estructura organizativa basada en 1 Director general, 1 Administrador. Técnicos, Maestros y 1 Comité de Vigilancia con 3 miembros.

FUENTE: Elaborado a partir de Gómez, 1965: 206-218 


\section{LA INTEGRACION DEL INDIO}

En abierta oposición al planteamiento proteccionista y en marcado contraste con las tesis incorporacionistas defensoras del mestizaje, la castellanización y la mexicanización, el INI comenzó al inicio de los años cinculenta a plantear un programa de acción declarando oficialmente su convicción de que los pueblos indígenas, sin perder sus formas de identidad (lengua y territorialidad), podian integrarse al desarrollo y a la modemidad del pais. A pesar de que este planteamiento fue objeto, desde los años setenta, de un intenso debate y crítica, en esencia, es el que ha estado presente hasta la actualidad como trasfondo de la política indigenista oficial en la Tarahumara. Analizaremos a continuación cómo esta visión de las relaciones interétnicas se expresó en las dos primeras décadas que siguieron a la implantación del INI en la Tarahumara para señalar, en el capitulo 4, la vigencia hasta la actualidad de esta perspectiva en el indigenismo oficial.

\section{La Sierra Tarahumara ¿región de refugio?}

Desde los años cincuenta, la integración se convirtió así en la divisa del discurso gubemamental sobre el indio y en el núcleo conceptual de la naciente teoria indigenista de aquellos años encabezada por Gonzalo Aguirre Beltrán y derivada de su experiencia como primer director del pionero Centro Coordinador Indigenista Tzeltal-Tzotzil de San Cristóbal de Las Casas (1951-1952) y, después, como subdirector del INI.

Entre otras cosas, esta teoria proponía una visión de las zonas indígenas del pais en tanto que "regiones de refugio" definidas éstas como

el espacio físico y moral que tiene como caracteristica una ecología en gran medida hostil, en la que interactúan poblaciones segmentadas cuyas lenguas, tecnologia, economia, estructura social, gobiemo, ideologia son distintos y asimétricos desde el momento en que los ladinos someten a los indios a explotación colonial. En esa región una ciudad primada, chef lieu o centro rector, rige a las comunidades satélites del hinterland; la ciudad ladina y las comunidades indias configuran un sistema de relaciones, inextricablemente unido, que incluye una dualidad de pueblos y culturas (Aguirre, 1994: 121).

Era, según Aguirre, en estas áreas interculturales donde se libraban las más duras batallas por la integración de los indígenas a la nación. Aisladas en su geografia y

$$
241
$$


atrasadas en su economía, las regiones de refugio conservaban un modelo colonial y semifeudal de relaciones "de casta" entre una minoria de mestizos o ladinos y una mayoría de indigenas. Los primeros seguian perpetuando frente a los segundos mecanismos "dominicales" de segregación racial, control político, dependencia económica, trato desigual, distanciamiento social y manipulación ideológica a través de la acción evangélica (Aguirre, 1967:11-17).

Para enfrentar esta situación, el teórico oficial del indigenismo proponía enclavar en las "ciudades primadas" -núcleo rector del que derivan todas las relaciones de dominación regional- sendos Centros Coordinadores del INI que llevaran a cabo todo un programa de acción integral en el campo de la educación, el desarrollo agropecuario, la creación de infraestructuras, la atención a la salud y la procuración de la justicia. El objetivo final de esta política no podía ser otro que el de hacer realidad los viejos postulados nacionalistas de la revolución de 1910 asi como el de propiciar el desarrollo capitalista de estas zonas, acelerando el tránsito de una condición de casta a otra -cualitativamente superior- de clase. En palabras del propio Aguirre Beltrán:

No hay salida independiente para el indio o para el ladino; el pase de casta a clase y la proletarización del indio corren casados con la industrialización de la ciudad primada y con la mudanza de la ideología, falsa conciencia del ladino. El camino del indio es más largo y mayor el coste a pagar -por eso se le ayuda-; pero es el mismo que el ladino recorre en procura de una sociedad comprensiva donde los conflictos se resuelvan en planos de igualdad (Aguirre, 1994: 121).

$\mathrm{Si}$ este marco interpretativo sustentado en una serie de investigaciones y estudios $^{35}$, asi como en una pionera experiencia institucional en zonas indigenas en especial en Chiapas- asumió tempranamente el carácter de formulación oficial, no es vano, sin embargo, preguntarnos si, en verdad, respondia a la situación de la Sierra Tarahumara. En concreto dos cuestiones complementarias nos parecen pertinentes: ¿era el modelo de "región de refugio" el marco más apropiado para explicar el sistema de relaciones interétnicas en la Sierra Tarahumara al inicio de los años cincuenta?. Y

${ }^{35}$ En particular los trabajos de Aguirre Beltrán sobre el proceso de aculturación (1957), las regiones de refugio (1967) y su teoria de los centros coordinadores (1956), además de algunos planteamientos programáticos de Alfonso Caso (1955 y 1958), primer director del INI. 
¿fue realmente este modelo de interpretación de la realidad el que sustentó las convicciones y la acción de los antropólogos, maestros y promotores del indigenismo de esos años en tierras chihuahuenses?. En lo que resta de este capitulo analizaremos con detalle estas dos cuestiones tratando pues de entender cómo enfrentó el indigenismo el problema de las relaciones interétnicas en la Sierra Tarahumara.

A decir verdad, el modelo de las regiones de refugio se adaptaba mal a la lógica geográfica y social del territorio serrano. Porque, en verdad, en la Tarahumara no existian "ciudades primadas" mestizas equivalentes al "arquetipo" chiapaneco de la ciudad coleta, metrópoli comercial y centro rector de San Cristóbal de las Casas que está en el trasfondo de la teoria propuesta por Aguirre Beltrán. La agreste geografía serrana ha impedido por siglos el control del territorio y la concentración demográfica. Los asentamientos mestizos importantes no sólo eran por esos años escasos sino también, en su mayoria, decadentes. Se trataba, en efecto de viejos centros mineros, muchos de ellos de origen colonial, venidos a menos desde los dias de la revolución y sobre todo desde los años de la gran depresión: Batopilas, Morelos, Urique, Guadalupe y Calvo, Ocampo, Uruachi y otros más eran -y son- ejemplo de ello.

Dado el patrón predominante de dispersión demográfica del que ya hablamos en el capitulo anterior -que también afecta a una parte importante de la población mestiza-, dificilmente podría postularse que estos pueblos, en su mayoria cabeceras municipales, funcionaran como centros "rectores" de la economia, del comercio y de las relaciones políticas de la región. Por el contrario puede decirse que en muchos aspectos las rancherías y los pueblos indígenas operaban con una relativa autonomía de la lógica de los pueblos mestizos.

El contexto geográfico de la Tarahumara resultaba tan poco acorde con la tipología de las regiones de refugio que el propio Aguirre Beltrán no tardaria en reconocerlo cuando, en 1952, tuvo ocasión de visitar la Sierra para elaborar la propuesta de trabajo del CCIT y de plantear al Dr. Alfonso Caso:

El municipio de Batopilas con 56.18\% de la población indigena es el indicado para 
comprender la sede del Centro Coordinador. Siendo la cabecera municipal una población minera mestiza, de escasos habitantes y dificil comunicación, sin tierras laborales y carente de importancia como punto de interacción entre indigenas y no indigenas, la sede del Centro habrá de buscarse en otro pueblo del aludido municipio. Con tal categoria existen los siguientes: Aboréachi, Cusárare, Guachochi, Munérachi, Cabórachi. Norogachi, Pahuichique, Papajichi, Rochéachi, Satevó, Tetaguichi, Tónachi y Yoquivo.

Al discutir con los integrantes del Consejo Supremo Tarahumara sobre el lugar que llenara los requisitos ideales para la sede del Centro éstos fijaron dos sitios de elección, a saber (1) Cusárare y (2) Guachochi. La situación central de Guachochi, el hecho de que haya sido en dos ocasiones sede del Congreso Tarahumara y las facilidades que representa la existencia de una planta de energia eléctrica no aprovechada, con la presencia de tierras, aguas y bosques, me hace proponer a Ud. y al H. Consejo se escoja este lugar como sede del Centro ${ }^{36}$

Este texto muestra claramente que incluso para el propio Aguirre Beltrán era bastante evidente que el prototipo de la ciudad primada era inaplicable en la Tarahumara. La inviabilidad de la teoría de las regiones de refugio no podía ser más obvia cuando su autor llegaba a proponer como posibles sedes del CCIT una serie de comunidades típicamente indigenas, muchas de ellas carentes incluso de población mestiza. Parece pues bastante claro que no fueron razones de orden teórico las que llevaron a los directivos del INI a escoger a Guachochi como sede del CCIT sino más bien motivos de carácter coyuntural y politico, como el hecho de que los representantes del Consejo Supremo Tarahumara propusieran esa población y ésta contara con recursos naturales y alguna infraestructura. En conclusión pues y como el propio Aguirre Beltrán me lo manifestara en entrevista en octubre de 1994, la teoria de las regiones de refugio debió adaptarse a una realidad muy particular:

...Bueno, la teoria que yo expuse, y que nos llevó a tomar como modelo para hacer Centros Coordinadores en muchos lugares, pues fue una teoria que estaba abierta totalmente a modificaciones. Asi se lo deciamos a las personas que trabajaban con nosotros y que iban a hacer una investigación para fundar un nuevo Centro. En el caso de la Tarahumara [...] a mi me tocó precisamente hacer el recorrido, por acuerdo del Director del INI, que era el doctor Caso. [Me tocó] hacer un recorrido por toda la zona Tarahumara, visitar todos los pueblos [...]. Allá la cuestión era esa: ¿cuál era la ciudad primada y dónde nos vamos a

36 "Carta del Dr. Gonzalo Aguirre Beltrán, Subdirector del INI al Dr. Affonso Caso, Director del INI en la que propone el programa de trabajo que habrá de desarrollar el Centro Coordinador Indigenista de la Tarahumara en Guachochi, Chih. México D.F., 18 de junio de 1952" en ACCIT, Legajo 27. Expediente 5. 
establecer? Entonces el doctor Caso [me dijo]: "Pues vaya Usted allá y vea donde tiene que establecerse el Centro". Entonces fui yo allá, hicimos un recornido, creo que fue cosa de dos semanas que estuve haciendo el recomido por allá e inmediatamente le dijimos al doctor Caso que nos parecia que Guachochi era el lugar para el Centro Coordinador del futuro.

Bueno esa era la idea, esa fue la idea, que se viera un lugar, en este caso Guachochi, que pudiera ser el centro de actividades de los tarahumaras por una parte, y por otra, que nos nos equivocáramos en la elección. Afortunadamente parece que no nos equivocamos. Pero no habia pueblo, no habia nada. Pues más bien eran los edificios del servicio que daba el gobiemo de educación, de escuela, un internado... cosas asi de ese tipo.

La misma percepción de que en la Sierra Tarahumara era inviable el esquema que habia propuesto Aguirre Beltrán de la ciudad primada y su hinterland indigena circundante esquema que tanto este autor como sus criticos han considerado como elemento central de la teoría indigenista de la integración intercultural ${ }^{38}$ fue claramente compartida por los primeros directores del CCIT, máxime por quienes, como el antropólogo Agustín Romano, habian tenido la oportunidad de trabajar en el Centro Coordinador Indigenista de San Cristóbal de las Casas, Chis. y no pudieron por menos de comparar ambas situaciones:

En San Cristóbal estaba muy bien definido lo que es un centro rector, porque San Cristóbal de las Casas se puede considerar que era y es la capital de toda una zona muy amplia tzeltal-tzotzil. Ahi confluian las gentes de toda un área muy grande para arreglar asuntos religiosos [...], administrativos, penales, económicos, comerciales... Todo el comercio está en San Cristóbal. Entonces prácticamente ahi está muy bien definido lo que es un centro. En cambio en la Tarahumara no hay centros rectores: ni Norogachi, ni Guachochi, ni Rochéachi pueden considerarse centros rectores [...]

Claro. Era una cosa obvia. Toda la teoria de Aguirre Beltrán está hecha en función de Chiapas [...] Realmente su teoria del proceso aculturativo es en función de la situación que prevalecia en San Cristóbal de las Casas. La situación de la zona tarahumara era totalmente diferente. Guachochi no es un centro rector: ¿qué comunidades se trasladaban a Guachochi? No habia comunicación y las

${ }^{37}$ Entrevista del autor con el Dr. Gonzalo Aguirre Beltrán. Xalapa, Ver., 14 de octubre de 1994.

${ }^{38}$ En esa teoria, la delimitación de la ciudad primada y su hinterland constituyen, en efecto, el punto de partida para decidir la ubicación del centro coordinador indigenista y planificar el impacto de sus programas en sus áreas circundantes (áreas de demostración, difusión, migración y movilización, tal y como las denominó el propio Aguirre Beltrán). Puede percibirse esta centralidad del concepto "región de refugio" tanto dentro de la teoria indigenista integrativa como en las criticas a ésta en Aguirre, 1957 y 1967. Báez, 1978 y Medina Cárdenas, 1992. 
distancias son muy grandes. No habia camiones, no habia nada. Entonces ¿cómo llegaba la gente a Guachochi?. Además ¿a qué llegaban? Ni siquiera era presidencia municipal porque Batopilas era la cabecera [...].

Yo me vi obligado, inclusive, en contra de la opinión del Dr. Aguirre, a crear la oficina del INI en Chihuahua. El no quería porque eso ya es de su teoría del centro rector de San Cristóbal. Pero ahi, en la Tarahumara el centro rector y aunque parezca increible -y no se lo pude nunca hacer entender a Aguirre- era Chihuahua y es Chihuahua. Parece increible... tan distante de la zona tarahumara. Pero ia dónde va la gente de Canichi? ¿la gente de Guadalupe y Calvo?... a Parral y Chihuahua. Inclusive dentro de la zona de lo que ahora es Guachochi, la gente de Samachique, de Basihuare, de Cusárare,.. todas esas gentes se canalizaban a Chihuahua porque era más fácil llegar a Chihuahua. Toda esa gente se iba a Creel y de Creel tomaba el tren a Chihuahua. Y en Chihuahua estaban las oficinas de gobiemo en primer lugar. Todos los asuntos se tramitaban en Chihuahua. Estaban las compañias madereras, las oficinas de las compañias madereras. Alcocer Patiño: estaban sus oficinas en Chihuahua; González Múzquiz: estaban sus oficinas en Chihuahua... todo... Asi que el centro rector, increible, pero era la ciudad de Chihuahua. Y Aguirre decía ¿pues cómo va a ser [el centro rector] la capital del estado, si es una ciudad mestiza? Pues si, es mestiza, pero ahi es donde confluye toda la gente de la zona... ${ }^{39}$

De los testimonios que hemos aportado parece pues concluirse que nadie de quienes tuvieron que ver con la decisión de instalar el CCIT en Guachochi asumió que esta población, que por aquellos años era un pequeño caserio mestizo, representara un ejemplo del modelo de la ciudad primada, sustento de la implantación de otros centros coordinadores del INI en diferentes regiones indigenas del pais. Las razones de erigir a Guachochi como el centro neurálgico del indigenismo en la Tarahumara fueron en realidad muy distintas $y$, en nuestra opinión, tuvieron que ver con las experiencias indigenistas de los años treinta y cuarenta cuando, como ya vimos, un grupo radical de maestros rurales comenzó a consolidar una propuesta agrarista y educativa tomando como centro de su acción el poblado de Guachochi. Este no sólo resultó ser el lugar más propicio para implantar la sede del Consejo Supremo Tarahumara y de una pionera escuela normal indigena sino también el centro de una vasta zona estratégica, en términos de sus riquezas agricolas, ganaderas y forestales capaces de sustentar ambiciosos proyectos de desarrollo en beneficio dé los tarahumaras. ${ }^{40}$

\footnotetext{
${ }^{39}$ Entrevista con el antropółogo Agustin Romano. México D.F., 10 de octubre de 1994.

40 En el apartado "La Raza Tarahumara y la cuestión de las nacionalidades" del capitulo 2 ya 246
} 


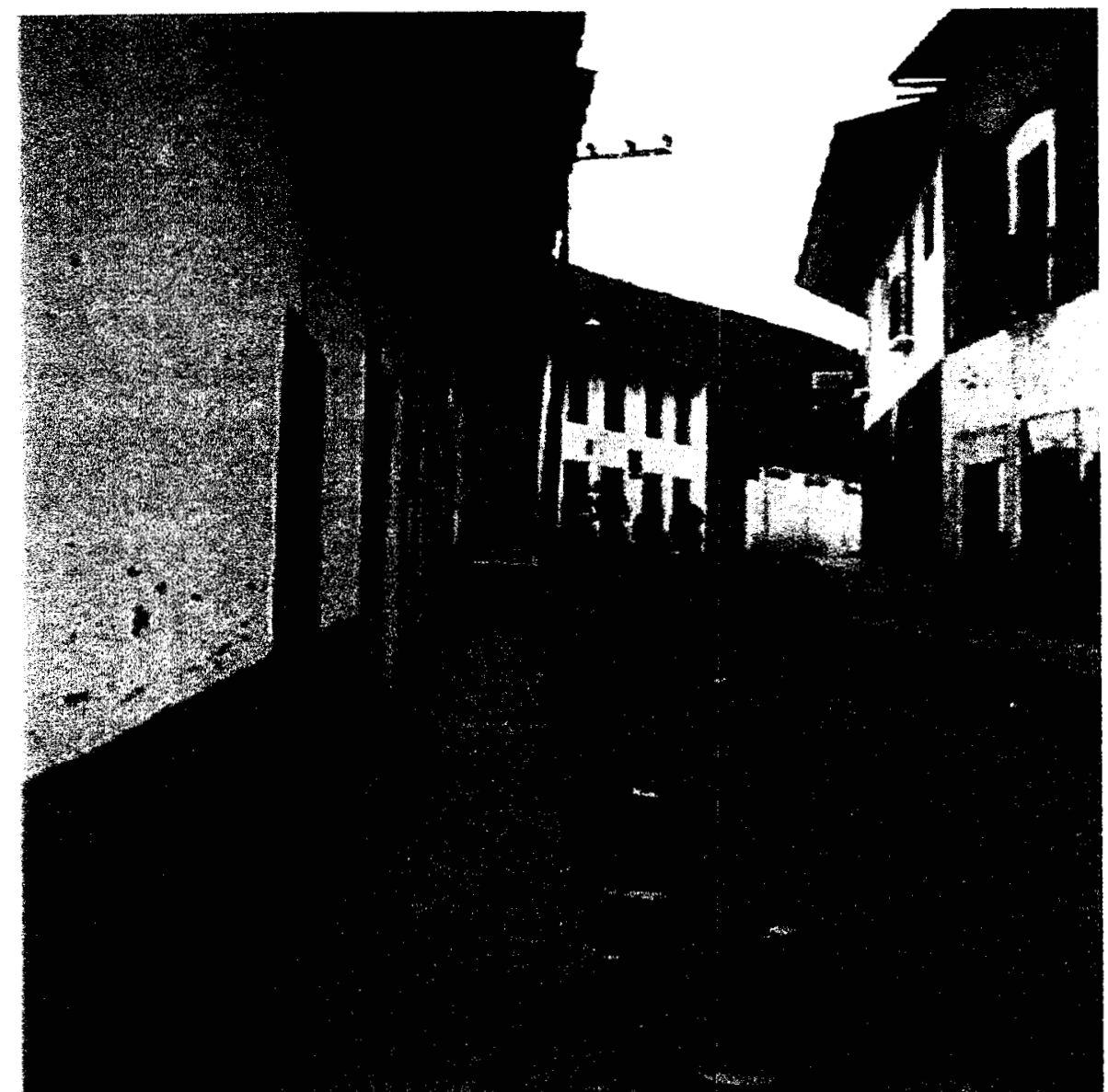

FIGURA 45.- BATOPILAS. CALLES DE UN PUEBLO MESTIZO

(FOTO DEL AUTOR. JULIO 1999)

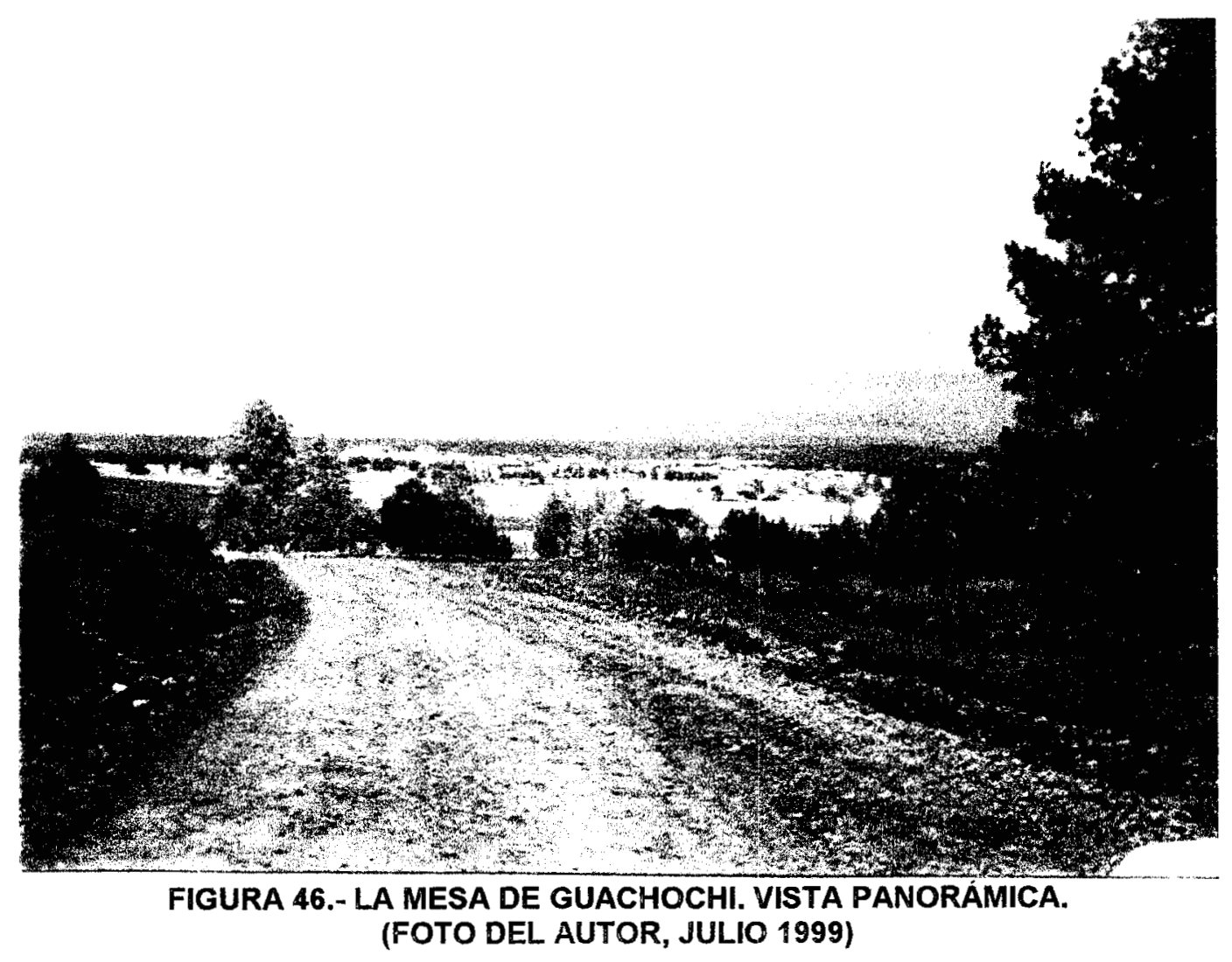


Cuando al inicio de los años cincuenta el INI llegó a la Tarahumara, su decisión institucional de instalarse en Guachochi tuvo poco que ver con argumentos de orden teórico y más bien derivó de razones de orden coyuntural y práctico: si ya, para entonces, este poblado comenzaba a adquirir el aspecto de un centro de operaciones de la acción gubernamental hacia los indígenas ¿qué sentido tendria crear artificialmente una nueva sede indigenista en una sierra carente de ciudades y vías de comunicación?

Por lo demás, y como ya lo apuntamos anteriormente, la elección de Guachochi como centro de operaciones de la acción indigenista al final de los años treinta por parte del grupo de profesores rurales no sólo fue por completo ajena a la teoria de las regiones de refugio sino que incluso derivó de una perspectiva radicalmente opuesta a los postulados de dicha teoria. Porque, en la lógica de aquellos maestros claramente influenciados por los experimentos soviéticos, Guachochi fue proyectada a futuro no como una ciudad mestiza sino como una "metrópoli" indígena, centro político y económico de un vasto territorio cuasi autónomo, como lo recordaba el profesor Francisco Hemández y Hernández:

...se llegó a la conclusión de que se creara la metrópoli -uso el término porque es el más claro- la metrópoli tarahumara, o sea un centro de población o varios centros de población escogidos por ellos mismos. ${ }^{41}$

Pero más allá de las visiones prospectivas que estos maestros pudieron tener, 10 cierto es que Guachochi se convirtió en la capital de la acción indigenista gubernamental, en contraste con Sisoguichi y Norogachi que han sido, desde principios del siglo XX, los

señalamos que el grupo de maestros rurales dirigido por el profr. Francisco Hernández y Hemández tomaron la población de Guachochi como centro de operaciones de sus proyectos de trabajo. Entre otras cosas, promovieron que ahi tuviera lugar la celebración del Primer Congreso de la Raza Tarahumara en 1939 y que alli estuviera la sede del Consejo Supremo Tarahumara. También en ese lugar fundaron en 1938 una escuela normal indigena de la que hablaremos en el capitulo 4.

\footnotetext{
${ }^{41}$ Entrevista con el prof. Francisco Hemández y Hernández, México D.F., 29 de octubre de 1994. A partir de esta entrevista, resulta dificil afimar de manera contundente. que este prototipo de "metrópoli indigena" respondia exactamente al de las ciudades de la Unión Soviética en las regiones y repúblicas pobladas por minorias étnicas que el profr. Hernández conoció a raiz de su visita a ese pais. Sin embargo es muy ctaro que lo que estos maestros tenian en mente era una ciudad y un centro regional indigena, tanto en términos demográficos como políticos y económicos. Esta perspectiva es claramente distinta y hasta opuesta a la noción de ciudad primada ladina o mestiza que Aguirre Beltrán planteó 15 años después.
} 
centros estratégicos de la actividad educativa y religiosa de la iglesia católica en la Tarahumara. Como resultado de la presión política ejercida por los directivos del Consejo Supremo Tarahumara y por las autoridades del CCIT frente al gobierno y al congreso del estado de Chihuahua, Guachochi, en tarahumara "lugar de garzas"- fue erigida en 1963 cabecera del municipio del mismo nombre que quedó integrado por las secciones municipales de Guachochi, Tónachi, Rocheáchi y Norogachi (segregadas del municipio de Batopilas) y por los poblados de Samachique, Guaguachique y Basihuare (previamente dependientes del municipio de Urique) ${ }^{42}$.

La creación del municipio de Guachochi venia a exhibir, una vez más, las discrepancias y contradicciones entre la práctica política y los postulados teóricos del indigenismo oficial, porque, desoyendo la abierta oposición que Aguirre Beltrán había expresado desde 1953 a la creación de un municipio "indígena" de la Alta Tarahumara ${ }^{43}$, las autoridades del CCIT asumieron un indudable liderazgo en dicha creación, al punto que el primer alcalde de Guachochi habría de ser el profesor Ignacio León Pacheco, hijo de uno de los fundadores del Consejo Supremo Tarahumara y persona estrechamente ligada al Centro Coordinador. ${ }^{44}$ La cercania espacial entre éste y el poder municipal no sólo permitió a los indigenistas serranos una comunicación administrativa más fluida sino

\footnotetext{
${ }^{42}$ Véase Decreto $N^{\circ} 84$ del H. Congreso del estado de Chihuahua, publicado en el Boletin Oficial del estado de Chihuahua del 9 de enero de 1963.

${ }^{43}$ La posición de Aguirre Beltrán se resume en estas palabras: Los congresos tarahumaras, incuestionablemente, han acarreado beneficios al grupo étnico [...] pero no han podido conseguir esos congresos el reconocimiento legal del Consejo Supremo de la raza o tribu tarahumara, porque tal reconocimiento violentaria los ideales postulados en la Constitución. Este reconocimiento daria status legal a un gobiemo de tribu, esto es, a un gobiemo que desapareció desde los primeros contactos entre tarahumaras, jesuitas y gambusinos. Reconstruir tal gobiemo y darte unidad y forma a la tribu seria, sin género de dudas, un retroceso en la evolución política de la nación y crear una reservación en un pais que abomina de las reservaciones.

Este pensamiento ha impedido también la erección del gran municipio de la Alta Tarahumara, ya que su establecimiento implica un aislamiento del grupo étnico, y lo que fervorasamente se desea es la integración de ese grupo dentro de la nacionalidad (Aguirre. Beltràn, 1991: 76).
}

${ }^{44}$ Sobre el apoyo decidido del CCIT a la constitución del municipio de Guachochi, originaimente propuesto como municipio de "la alta Tarahumara" pueden verse: ACCIT, Legajo 27, Expediente 5; Legajo 30, Expediente 7; Legajo 37, Expediente 2. documento 3; Legajo 37, Expediente 25; Legajo 64, Expediente 15; Legajo 150, Expedientes 2, 4 y 25.

$$
248
$$


también una intervención directa en la política local, algo dificil de lograr en la lejana y barranqueña cabecera de Batopilas, distante dos días a caballo y controlada por comerciantes y mineros mestizos, bastante renuentes a secundar la acción indigenista.

En las décadas que siguieron a su creación como cabecera municipal, Guachochi se convirtió en el núcleo urbano más poblado de la Sierra Tarahumara con cerca de 10,000 habitantes, de los cuales algo más de 1,000 son, según datos oficiales, indígenas. ${ }^{45}$ Este crecimiento demográfico que es sólo secundariamente imputable a su condición de capital indigenista más bien derivó de su carácter de centro operativo de compañias madereras y, a partir de los años setenta, de polo comercial y de "lavado" de dinero ligado al narcocultivo. Como quiera que sea, es evidente que Guachochi está lejos de ser una "metrópoli" indígena tal y como la habian imaginado los indigenistas de los años treinta. Más bien, lo que se observa es que esta ciudad se fue convirtiendo en el centro de la actividad económica, comercial y política de una vasta región en donde los intereses de la población indígena aparecen subordinados a los de los grupos de poder mestizos. En este sentido se podría pensar que, como resultado de la acción del CCIT de la que hablaremos en el capítulo 4, Guachochi se fue gradualmente convirtiendo en una ciudad primada, tesis a la que algunos autores se adscriben. ${ }^{46}$ Aunque es indudable que esta ciudad es hoy el centro del poder mestizo más importante de la Tarahumara, no necesariamente eso quiere decir que su carácter sea equiparable al de una ciudad primada, tal y como esta noción aparece definida en la teoría indigenista clásica de Aguirre Beltrán. Para esclarecer esto nada resulta más definitivo que entender el sistema de relaciones interétnicas de la Tarahumara y analizar si éste es asimilable al concepto

\footnotetext{
45 Según el Conteo de Población levantado por el INEGI en 1995, el municipio de Guachochi cuenta con una población de 38,770 habitantes de los que 19,974 son personas de 5 años o más que hablan alguna lengua indigena. En ese mismo año residian en la cabecera municipal 9,065 habitantes de los que 1,072 eran hablantes indigenas de 5 años y más. Otras fuentes contabilizan de 12,000 habitantes en la cabecera municipal de Guachochi en 1975, 16,000 en 1980 y cerca de 35,000 en 1990 (Ronquillo, 1993: 56, 62 y 83). En cualquier caso, Guachochi supera hoy demográficamente a Creel y San Juanito, pueblos más antiguos que asumen también una fisonomia de centros mestizos urbanos. Una historia detallada del municipio puede verse en Ronquillo, 1993.

${ }^{46}$ Entre otros hay quien considera que "la actual aglomeración urbana de Guachochi [...fue una invención de la razón indigenista. Allá donde no la habia se construyó una región de refugio.." (Urteaga, 1996: 297)
} 
clásico de proceso "dominical" típico de las regiones de refugio.

\section{Indigenismo y conflicto interétnico}

Una aproximación descriptiva a este sistema de relaciones interétnicas puede encontrarse en un documento dirigido en julio de 1960 por los representantes del Consejo Supremo Tarahumara al gobemador de Chihuahua y al director del INI. En dicho comunicado los directivos del organismo indígena denunciaban las formas de "incomprensión, explotación y vejación" de las que eran objeto los tarahumaras por parte de los mestizos enumerándolas en los siguientes términos:

1.- Invasión de tierras:

a.) Movimiento de cercos, que como su nombre lo indica hace que la extensión de la tierra cultivable vaya disminuyendo en contra de sus propietarios indigenas, llegando a ser tal este movimiento que paulatinamente la tierra cambia de propietario. Sobre este renglón pueden presentarse innúmeros casos que suceden desde hace muchos años en todos los ejidos y rancherías de esta Sierra en poder de los indigenas, sin que hasta la fecha y no obstante el clamor general de justicia no se ha conseguido absolutamente nada.

b.) Arrebato de propiedades [...]

c.) Arrebato de propiedades y de ganado. Se valen de los siguientes medios para logranto:

A.) Amenazas: Nos infunden miedo, amenazándonos de muerte a nosotros y a nuestras familias para lograr sacamos de nuestras tierras o simulan ventas que de nuestra propia voluntad y sin amenazas nunca conseguirian.

B.) Robos: Cuando no hacemos caso de sus amenazas, nos roban nuestras pertenencias: tierra y animales.

C.) Despojos por la fuerza: tanto de tierras como de ganado.

D.) Asesinatos: Cuando no se les hace suficiente to anterior y no consiguen quitamos todo lo poco que tenemos no se detienen en asesinamos, tanto a hombres como a niños, recurriendo a actos de una gran crueldad, como ha sido castrar, cortar la lengua, machucar la cabeza, etc. De esto se pueden presentar muchísimos casos [...].

E.) Violación de mujeres: es frecuente que sacien sus apetitos sexuales con nuestras mujeres, no importándoles edad, ni estado. [...]

F.) Explotación de la mano de obra: Aprovechándose de la escasez de maíz nos contratan para desempeñar toda clase de trabajos. A la hora del pago nos dan una pequeña cantidad de maíz o nos embriagan para que no exijamos lo justo de nuestro trabajo. sino que por el contrario salimos debiendo y tenemos que 
permanecer más tiempo desquitando con nuestras manos lo que dicen que les debemos.

G.) Arrebato de cosechas: Cuando se dan cuenta de que vamos a levantar algunas, por medios pacificos $y$ amistosos nos venden $y$ regalan bebidas embriagantes, haciéndonos creer que les debemos determinadas cantidades por estas bebidas o por manta y jabón que dicen vendemos. En esta forma se quedan también con el producto de nuestro trabajo, pues nuestras deudas con ellos nunca terminan.

H.) Altos intereses: Cuando obligados por el hambre tenemos que conseguir maiz, con un tono amistoso nos lo prestan, pero a la hora del pago nos cobran un $300 \%$ de intereses [...] Por miecio tenemos que aceptar todo lo que quieren los mestizos.

1.) Explotación del trabajo de las mujeres: Cuando obligadas por la necesidad nuestras mujeres e hijas tienen que trabajar al servicio de los mestizos como criadas, nunca reciben un sueldo, ya que siempre tienen que estar desquitando con su trabajo el jabón que utilizan para su aseo, la comida exigua que les dan y uno que otro trapo viejo que les proporcionan para vestirse. Además de lo anterior las violan y no son para reconocer en ninguna forma a los hijos que les engendran.

EJIDOS:

[...] C.) Denuncio indebido de terrenos. Varios mestizos adinerados, respaldados por madereros, contratan técnicos que les miden tierras que ellos desean. Después presentan ante el juez respectivo estas medidas y piden la propiedad de tierras que dicen no tener dueño. Los afectados, nosotros los indios y algunos mestizos tan pobres como nosotros, por más que gritamos y pidamos clemencia no se nos hace caso. El dinero gana, el mestizo es dueño de nuestras tierras y como una pequeña caridad nos dejan nuestra humilde casa y el chiquero que la rodea. Las tierras cultivables y los deseados bosques pasan a manos de nuestros enemigos, llamados asi porque sólo desean nuestro mal tanto a nosotros mismos como a los mestizos pobres e ignorantes. Algunos casos concretos: toda la mesa de Guachochi se encuentra en estas condiciones y las comunidades afectadas son: Cieneguita de Guachochi, Otóvachi, Loma del Manzano, La Cumbre de Güerachi, Los Tuceros, Agua Zarca y el propio ejido de Guachochi que se acaba de dotar y que tiene 600 ejidatarios con 22,000 has. en su mayor parte tierras inaprovechables por ser de cerro. ${ }^{47}$

Las quejas del Consejo Supremo Tarahumara venian a confirmar en cierta manera la tesis del indigenismo oficial de que las relaciones interétnicas en las regiones de refugio estaban permeadas por un sistema de explotación racista de los indígenas por

\footnotetext{
47 "Carta que representantes del Consejo Supremo Tarahumara y un grupo de gobernadores y comisarios ejidales indigenas dirigen a los CC. Gobernador del Estado y Director del INI, Guachochi, 25 de julio de 1960", en ACCIT, Legajo 126, Expediente 24.
} 
parte de los mestizos. La expresiones de esta dominación y segregación racial eran por demás variadas como el propio Consejo Supremo Tarahumara lo expresara abiertamente al General Práxedes Giner Durán, candidato a gobernador de Chihuahua en 1962:

Como es de todos sabido, nosotros los tarahumaras, por la ignorancia, o por el abandono en que nos encontramos desde tiempo inmemorial hemos venido siendo explotados en todas formas por los mestizos sin escruipulos; nos roban nuestro poco ganado, semillas, invaden nuestras tierras, asesinan a los compañeros, violan sus mujeres y en fin no nos dejan vivir tranquilos. Con los tarahumaras se cometen las peores injusticias, somos obligados a trabajar sin pagamos el salario minimo, tenemos muchos que trabajar las tierras del mestizo "a medias"; existe en la mente de nuestros explotadores el siguiente adagio: "no importa que se le haga un pequeño o gran mal, en fin son indios" y con esto de que "en fin son indios" tratan de justificar todas sus fechorias.

Este cuadro de violencia interétnica era probablemente más grave entre los tepehuanes del municipio de Guadalupe y Calvo, lo que explica su declarado rechazo al mestizo y su cultura, repudio que todavia en 1967 constataba con asombro el subdirector del CCIT a raiz de una visita a la cabecera ódame de Baborigame:

La razón de que los tepehuanes no asistan a la escuela, es que existe un completo desentendimiento entre ellos y la gente mestiza. Además tienen el deseo vehemente de que no haya ningún blanco por toda esa región y dicen: "igual que ellos no nos quieren, nosotros tampoco". [...]

Es tanta la desconfianza que los tepehuanes tienen al mestizo, que aunque éste actúe de buena fe ya no le creen ni le hacen caso, actitud que considero lógica por la ancestral explotación que han sufrido. Aparentemente delante de los funcionarios del gobiemo los mestizos se conduelen de la situación del tepehuano, pero en cualquier momento expresan que están asi porque son perezosos, no les gusta vivir bien, se conforman con muy poco, etc. ${ }^{49}$

Entre 1950 y 1970 , esta desconfianza del indigena serrano ante el mestizo se manifestaba en reiteradas quejas y protestas por robo, discriminación, estafa; acoso sexual, venta de alcohol y otros agravios propios de un contexto de caciquismo y

\footnotetext{
${ }^{48}$ Cita tomada de una "Carta dirigida por el Consejo Supremo Tarahumara al C. Gral. Práxedes Giner Durán, candidato a gobernador del estado de Chihuahua; el 14 de junio de 1962", en ACCIT, Legajo 37. Expediente 2, Documento 2.

49 Véase "Informe de la Visita realizada a la localidad tepehuana de Baborigame, municipio de Guadalupe y Carvo, Chih., por el Profesor Ignacio León Pacheco, Subdirector del CCT, 17 de marzo de 1967", en ACCIT, Legajo 10. Expediente 2.
} 
explotación racial. Los siguientes referentes ejemplifican este clima de protestas: en 1967, mientras los siriame de Quirare demandaban justicia al gobemador del estado acusando a dos mestizos de intervenir en sus fiestas y abusar de sus mujeres, el presidente del Comisariado ejidal de Guaguachique solicitaba al mismo funcionario la expulsión de un comerciante mestizo a quien acusaba de estafar y obligar a los tarahumaras a pagar sus deudas con trabajo o animales. Una demanda similar levantaban los rarámuri de Guapalayna (Urique) en contra de su comisario de policia mestizo a quien culpaban de cobrarles en maíz un impuesto por la venta de alcohol y de comprarles también con maiz sus animales. En otros casos, la venta indiscriminada de alcohol ejercida por mestizos y -derivada de ella- la explotación del indígena fueron motivo de airadas denuncias como la que presentaban en 1961 los miembros del Consejo Supremo Tarahumara refiriéndose a las vinatas clandestinas de mestizos en La Mesa de Guacaybo, el aserradero del Yamuco, los minerales de Coraréachi y Potrero de Bojórquez, La Gayta, Los Tajos, Los Placeres y Guapalayna. Con no menor irritación un grupo de rarámuri de Sebárachi rechazaban los argumentos racistas con que sus vecinos mestizos los juzgaban de desconocer la causa natural de la lluvia. ${ }^{50}$

${ }^{50}$ El caso de Quirare en "Carta de Benito Pérez y Mauricio Palma, primer y segundo gobernadores de Quirare al gobermador constitucional del estado de Chihuahua, 13 de agosto de 1967" (ACCIT Legajo 35, Expediente 33). Las protestas contra el comerciante en "Carta del presidente del comisariado ejidal de Guaguachique Miguel Rascón C. al gobemador constitucional del estado, 16 de octubre de 1967" (ACCIT Legajo 35, Expediente 33) en donde acusa al señor Antonio Dager de que: ...no conforme con vendemos a precios elevadisimos, nos ha estado molestando para conseguir le demos animales a cambio de su mercancia o que trabajemos para él a cambio de retribución alguna.

Las quejas contra el comisario de policia de Guapalayna aparecen en ACCIT Legajo 29, Expediente 34 y los problemas derivados de la venta clandestina de alcohol en "Carta del Consejo Supremo Tarahumara al Lic. José Luis Siqueiros, Secretario general del gobiemo dell estado de Chihuahua, 26 de junio de 1961" (ACCIT, Legajo 126, Expediente 24).

Las respuestas de los rarámuri de Sebárachi se resumian en una carta dirigida al Secretario de Agricultura el 18 de junio de 1957 donde apuntaban :

...Por otra parte, hacemos constar que nuestro nivel cultural no es el de hace veinte o más años, y que ya sabemos aquilatar el valor de nuestros bosques de pino y medianamente tenemos conocimientos de la forma de conservar estas riquezas, tales como evitar la tala injustificada de él, asi como cuidar que no se registren incendios, y cuando desgraciadamente se registren, estar prestos para combatitos, pues queremos desmentir categónicamente que nosotros los provoquemos intencionalmente, como se nos calumnia con frecuencia, disque porque creamos que las nubes se forman con el humo.

La cita procede de "Carta de los vecinos de la rancheria de Sebárachi, jurisdicción de Tónachi dirigida al Secretario de Agricultura y Ganadería en donde se quejan de la invasión de sus tierras por 253 
Pero si en estos aspectos el sistema de relaciones interétnicas en la Tarahumara convalidaba la teoría del proceso de subordinación racista semifeudal y de explotación "dominical" de la minoria mestiza sobre los grupos indígenas, en otros, en cambio, dibujaba con marcada nitidez las contradicciones y los conflictos propios de una sociedad capitalista azuzada por una voracidad desmedida por los recursos naturales. Estos otros aspectos que conformaban y siguen constituyendo en la actualidad el núcleo central de los agravios y demandas planteados por los pueblos indigenas en contra de los mestizos tienen que ver básicamente con dos temas: el control sobre los recursos naturales (la tierra, el agua, el bosque y el subsuelo mineral) y la aplicación de la justicia.

Los reclamos y querellas en torno al control de la tierra y sus recursos son quizás tan viejos como la llegada del mestizo a la Tarahumara. Para el período que nos ocupa estas inconformidades $y$ exigencias asumieron una mayor gravedad a raíz de dos fenómenos casi contemporáneos: la dotación ejidal y la llegada de las compañias madereras a la Sierra desde los años treinta. Estos dos hechos desencadenaron una inusitada voracidad de los mestizos, nuevos y advenedizos, por la tierra, los bosques y un despojo agrario en contra de muchos ranchos y pueblos indios, tal y como to denunciaba el Consejo Supremo Tarahumara en 1952:

Toda la vida y desde nuestros antepasados hemos venido ocupando tierras, de las cuales en su mayoria carecemos de títulos, algunos otros [...] tienen titulos expedidos unos, por el C. Licenciado Benito Juárez [...], otros por concesiones o informaciones Ad Perpetuam. Tanto unos como otros no escapan a las maniobras de nuestros explotadores, pues a los primeros se les despoja de las tierras que por justo derecho de posesión les pertenecen, valiéndose de los denuncios o solicitudes que hacen ante las autoridades correspondientes, contando con el apoyo y ayuda de elementos oficiales e ingenieros Deslindadores, ya que [...] se certifica que el terreno se encuentra baldio a sabiendas de que lo ocupamos los indios y los ingenieros deslindadores por los beneficios económicos que les reporta su falsedad, hacen aparecer en sus informes que las tierras deslindadas se encuentran desocupadas y que los solicitantes carecen de bienes $y$ están perfectamente acotadas y ocupadas por el solicitante. De los segundos, o sea quienes tienen títulos comunales, también son despojados de sus pocos bienes, bien sea por resoluciones agrarias o bien por déslindes que de tierras Nacionales hacen a favor de los mestizos [...].

parte de varios mestizos del lugar. 18 de junio de 1957", en ACCIT Legajo 126. Expediente 24 
En suma, seguimos siendo los etemos parias que se nos obliga a vivir como animales en la Sierra y en cuevas alejados de toda civilización como único medio para defendermos de nuestros explotadores. ${ }^{51}$

En el periodo del que nos estamos ocupando, las demandas indigenas por cuestiones agrarias fueron innumerables. Sirvan como ejemplo algunos como los siguientes casos. Entre 1956 y 1963 diversas querellas y demandas fueron presentadas ante autoridades municipales, agrarias y judiciales a causa de invasión de tierras, derribo de cercas, introducción de animales en sembradios, imposición de autoridades mestizas en ejidos con mayoria indigena y tala inmoderada e ilegal de madera. Estas quejas procedian de rarámuri de Pilares, Los Lirios, San Juan y Anexas, Guachamóachi, Guazarachi, San Cartos y Tecorichi (del municipio de Balleza); San Miguel, Norogachi, Ajolotes, El Ranchito, Cieneguita, Cumbre de Sinforosa, Mesa de Papajichi, La Soledad, Agua Zarca y Mesa del Barro (en Guachochi); Ciénega de Guacaybo y Santa Anita (en Batopilas); Guaguachérare y San José Baqueachi (en Carichi); Los Voicanes, Hornitos y Tosánachi (en Bocoyna); Villéachi (en Maguarichi), Guadalupe Coronado y Cieneguita de la Barranca (en Urique); Pino Gordo, Redondeados, Chinatú y Coloradas (en Guadalupe y Calvo) así como por indígenas warijó del municipio de Uruachi y por ódame de Baborigame. 52

En cuanto a la explotación de los bosques por parte de compañias madereras y particulares mestizos, el Consejo Supremo Tarahumara resumia en estos términos la forma como dicha explotación perjudicaba a los indigenas:

Podemos decir que la explotación de los bosques se ha efectuado en una forma irracional, principalmente por las compañias particulares, cuyo único interés es obtener la mayor ganancia posible [...].

\footnotetext{
51 "Carta que el Consejo Supremo Tarahumara envia al Lic. Adolfo Ruiz Cortines, candidato del PRI a la presidencia de la República, exponiéndole la situación de la Sierra Tarahumara. Chihuahua, Chih., 27 de abril de 1952" en ACCIT, Legajo 2, Expediente 1

52 Estas quejas y demandas pueden consultarse en ACCIT, Legajo 1, Expedientes 30 y 44; Legajo 9 , Expediente 4; Legajo 10, Expediente 2; Legajo 30. Expedientes 3 y 10; Legajo 33, Expedientes 10, 12 y 17; Legajo 36, Expediente 6; Legajo 37, Expedientes 2, 20 y 21; Legajo 38, expediente 7; Legajo 48, Expediente 28; Legajo 57, Expedientes 3, 11 y 14; Legajo 58, Expediente 5 Legajo 59. Expediente 3; Legajo 60 , Expediente 1; Legajo 97. Expediente 4; Legajo 104, Expediente 9; Legajo 112. Expediente 4; Legajo 130, Expediente 17 y Legajo 143, Expediente 59.
} 
Los ricos mestizos hicieron grandes denuncios de terreno, no para utilizar sus tierras en agricultura, sino para abarcar gran extensión de bosques que ahora explotan y obtienen enormes ganancias, mientras los tarahumaras estamos esperando que se nos entreguen los ejidos solicitados y se nos otorguen créditos y asistencia técnica para explotar nuestros bosques, tal vez para cuando esto nos llegue, yâ no tendremos en qué emplear esos créditos y onientación técnica, pues los bosques se habrán terminado ${ }^{53}$

Desde los años de los repartos ejidales y la llegada de las empresas madereras, el foco más importante de los conflictos interétnicos en la Tarahumara ha sido el de la tenencia de la tierra. Los tres cuadros siguientes dan una idea de ello. En el primero se muestra de forma altamente ilustrativa hasta qué punto la situación agraria de los diez municipios serranos con mayor porcentaje de población indígena era irregular aún al inicio de la década de los años setenta: más de la mitad de los ejidos y comunidades tenian deslindes pendientes abarcando algo más de 1 millón de has. (casi el 50\% del total), un total de 124 expedientes agrarios esperaban ser sustanciados y algo más de 1.4 millones de has. estaban sujetas a investigación.

Las demandas pendientes de ser resueltas y las solicitudes de los núcleos agrarios eran, como se expresa en el cuadro 16 muy variadas: en algunos casos los ejidos pedian la ejecución de viejas resoluciones presidenciales y en otros, la ampliación, la resolución de juicios por invasión o el establecimiento de deslindes y reglamentos de uso de pastos. La cuantía y acumulación de estas demandas explica, por otra parte, que el CCIT, a través de su Departamento Legal o Sección Jurídica, se viera obligado desde sus años de fundación a concentrar sus esfuerzos en el campo de las demandas y consultas agrarias, tal y como se puede concluir del análisis de los datos del cuadro 15. Pero no siempre los reclamos indigenas de justicia tanto en materia agraria como en el ámbito penal o civil recibieron la atención que exigían. Por el

\footnotetext{
${ }^{53}$ Vèase "Carta dirigida por el Consejo Supremo Tarahumara al general Práxedes Giner Durán, candidato a gobernador del estado de Chihuahua, 14 de junio de 1962", en ACCIT, Legajo 37, Expte. 2, dcto. 2.
} 


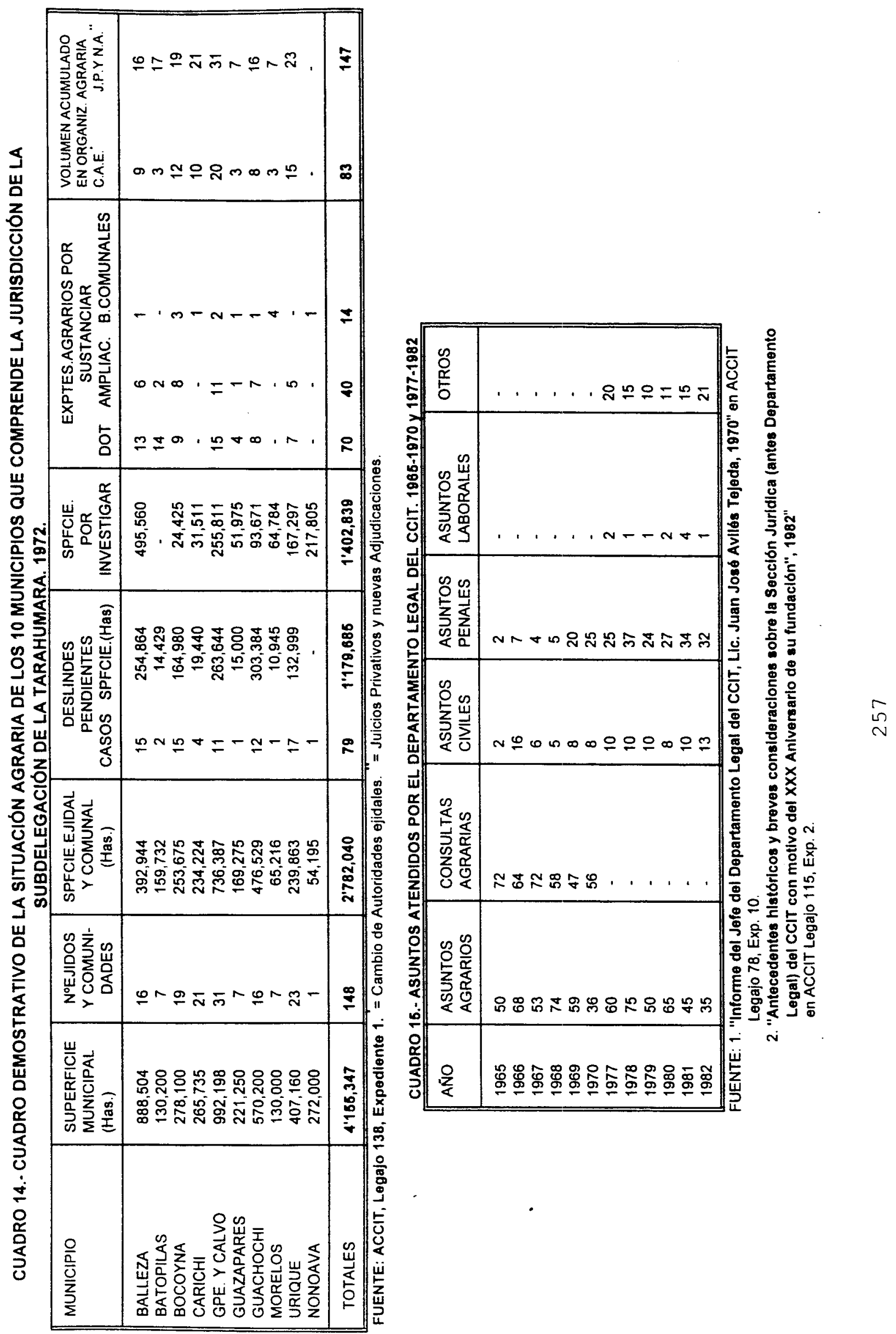




\section{CUADRO 16.- RELACIÓN DE EJIDOS LOCALIZADOS DENTRO DE LA ZONA DE TRABAJO DEL CCIT CON SOUICITUDES PENDIENTES EN LA DELEGACIÓN ESTATAL DEL DEPARTAMENTO DE ASUNTOS AGRARIOS Y COLONIZACIÓN. 1972.}

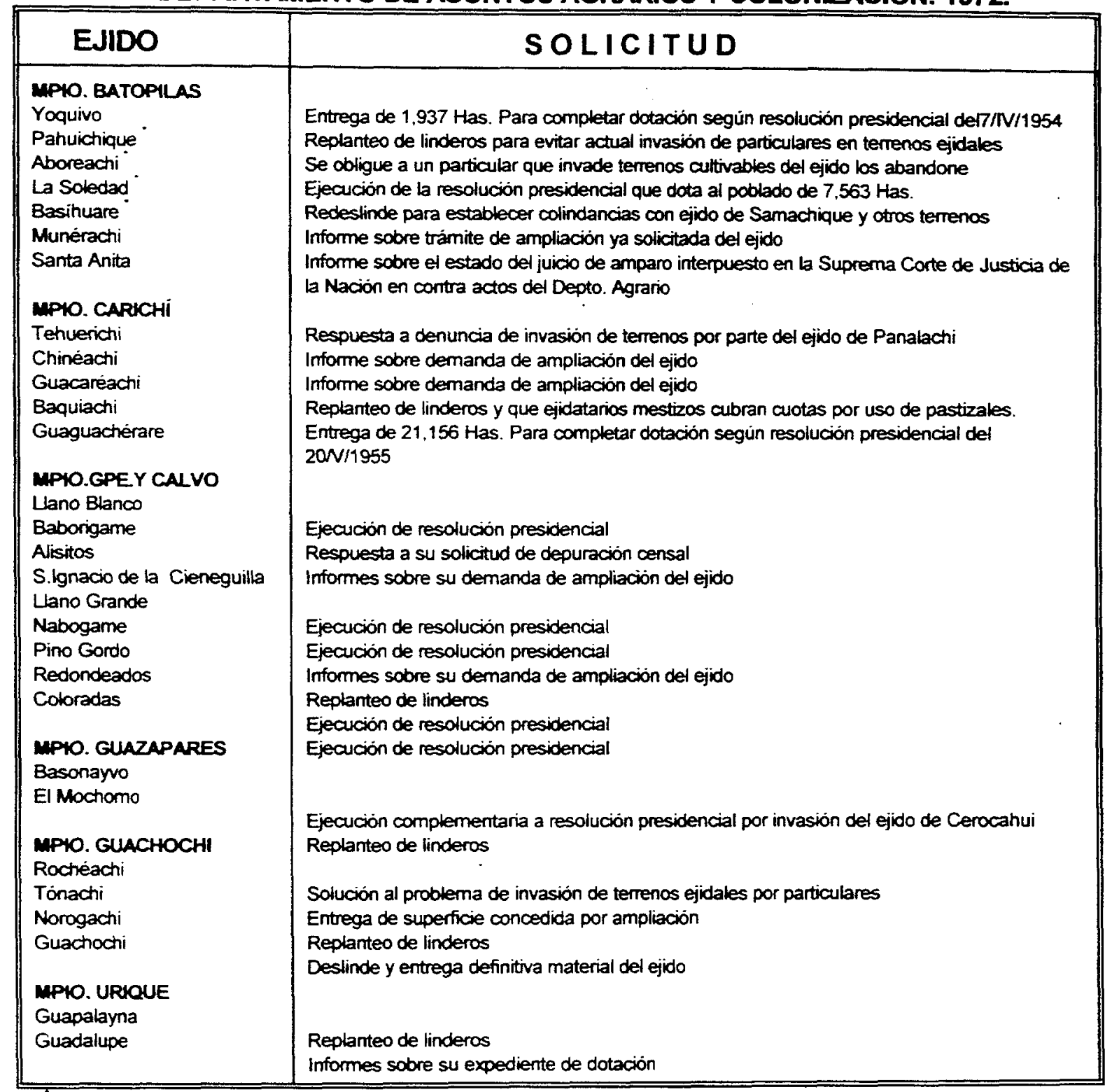

() Poblaciones actualmente pertenecientes al municipio de Guachochi.

FUENTE: ACCIT, Legajo 138. Expte. 1

contrario, la demanda de justicia y su arbitraria aplicación se convertiria en el segundo principal motivo de la conflictividad en las relaciones interétnicas, máxime si se tiene en cuenta que el ejercicio institucional de la justicia há sido tradicionalmente monopolio de los mestizos en la Tarahumara. En 1962 un procurador de asuntos indigenas ${ }^{54}$

\footnotetext{
${ }^{54}$ Los procuradores de asuntos indigenas surgen en 1936 a raiz de la creación del Departamento de Asuntos Indigenas del que dependen. Se trata de personas pertenecientes a las propias etnias indigenas
}

$$
258
$$




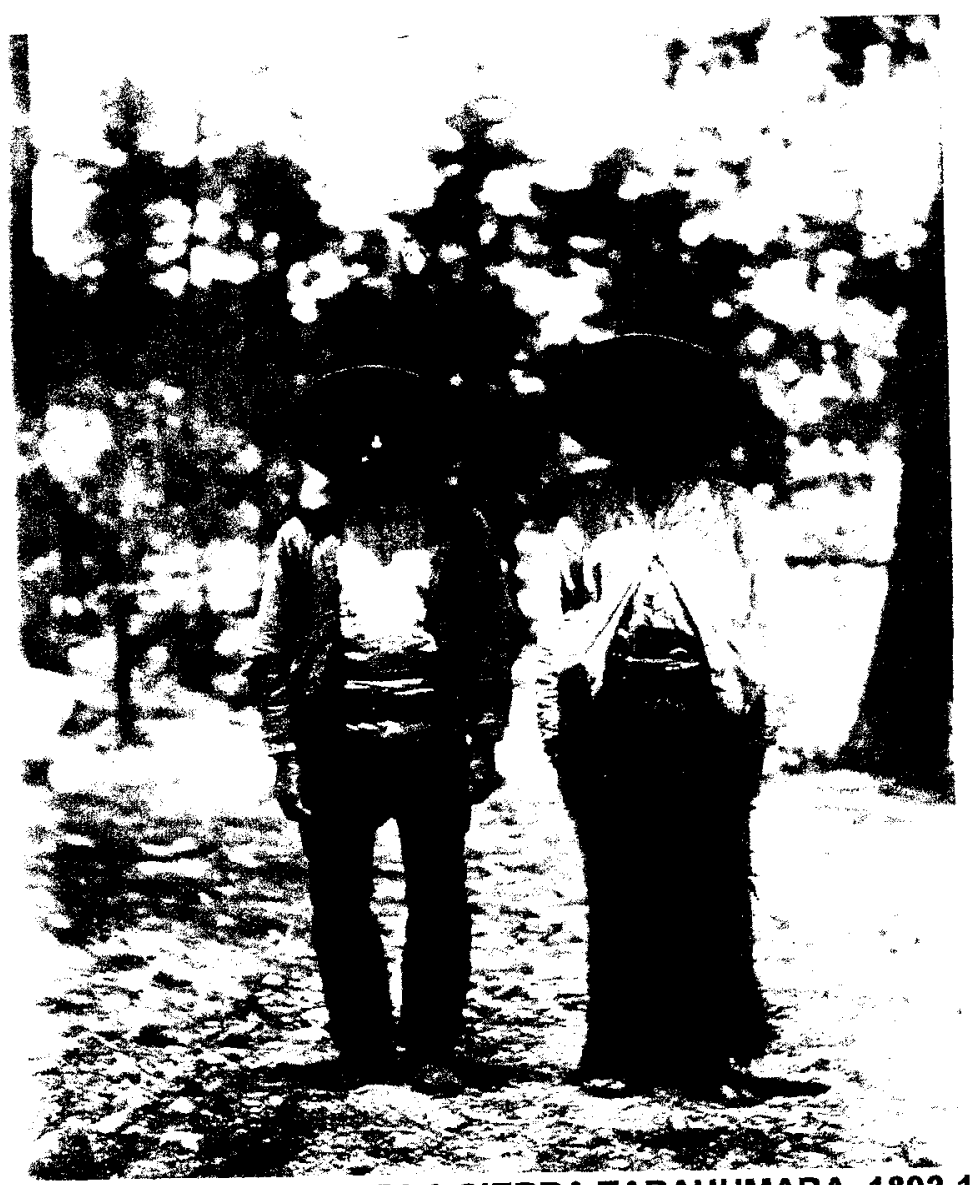

FIGURA 47.- MESTIZOS DE LA SIERRA TARAHUMARA. 1892-1893 (FOTO DE LA EXPEDICIÓN DE LUMHOLTZ) (RAMIREZ, 1996: 87)

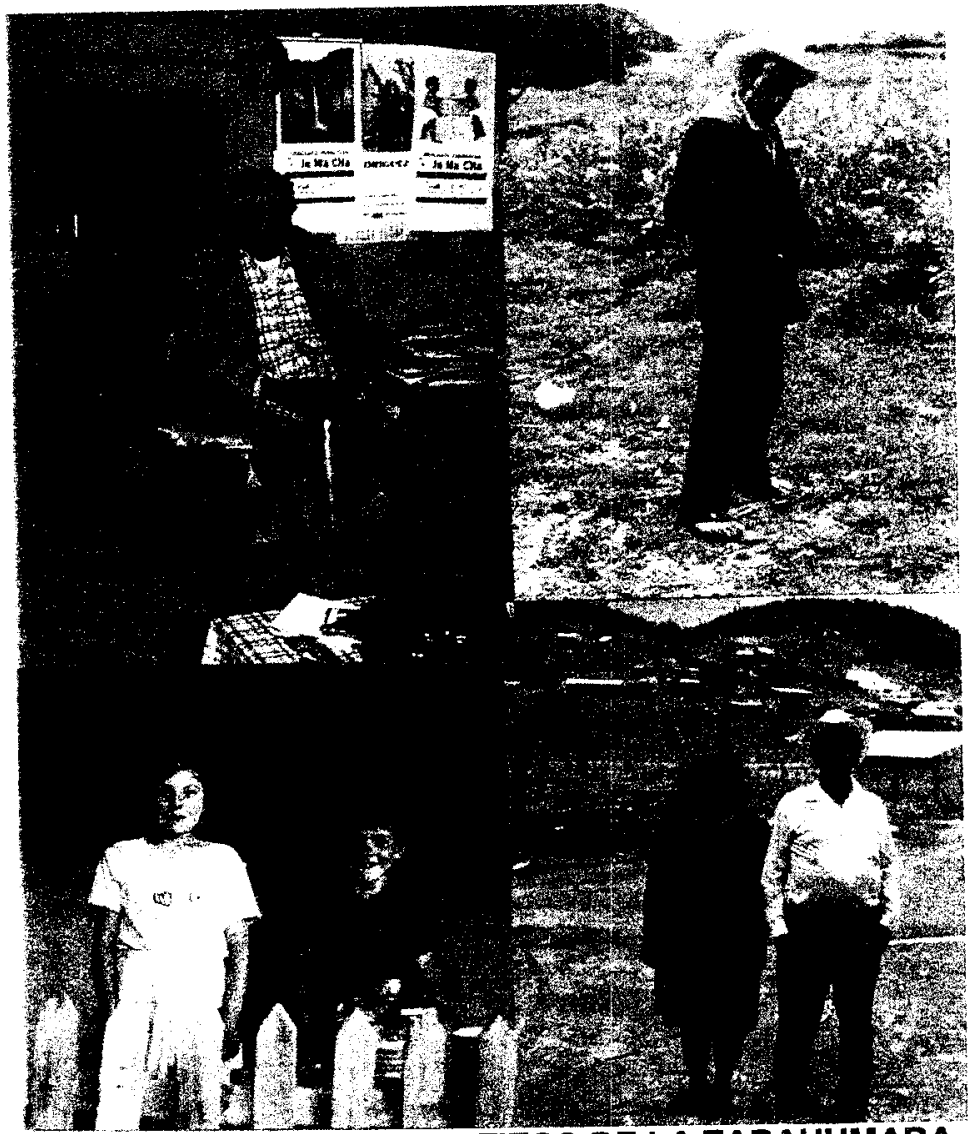

FIGURA 48.- ROSTROS MESTIZOS DE LA TARAHUMARA

SAMACHIQUE, CUSÁRARE, NOROGACHI (FOTOS DEL AUTOR. 1995) 
contrastaba asi la impunidad de que los mestizos gozaban frente a la ley con la dureza aplicada a los indígenas:

Las cárceles de las cabeceras Municipales las ocupan en un $90 \%$ indigenas, y generalmente son los que pasan a la Penitenciaria del Estado a sufrir largas condenas, y quienes los usaron de "gancho" para cometer crimenes, viven felices y tranquilos aprovechando lo que nunca les perteneció.

Las autoridades de las cabeceras, díganse Jueces de Primera Instancia, Jueces Menores, de Paz, asi como las Administrativas nada pueden hacer, porque en la SIERRA NO EXISTEN AUTORIDADES AUTORIZADAS LEGALMENTE para ordenar una aprehensión y las detenciones que por las setenta y dos horas constitucionales se hacen, no bastan para diligenciar en debida forma los delitos, y es la causa de que casi siempre [los presuntos delincuentes] van a las cabeceras con errores y en la mayoria de los casos regresan primero los presuntos malhechores que los policias que los condujeron, por ello todos aspiran al PASE a Batopilas, Urique, etc., porque están enterados de estas cuestiones. ${ }^{55}$

cuya principal función consiste en gestionar y promover restituciones, promociones, dotaciones, ampliaciones y conformaciones de ejidos y tierras comunales en zonas indigenas. (Aguirre, 1992b: 110)

55 Tomado de "Ponencia relacionada con el Capitulo VII del Temario presentada al Centro de Estudios de los Problemas de la Tarahumara de Guachochi por J. Rosario Martinez Chávez, Procurador de Comunidades Indigenas, Guachochi, Chih., junio de 1962, en ACCIT, Legajo 37, Exp.2, doc. 3.

Una muestra, entre muchas más, de la connivencia entre las autoridades locales y los mestizos en contra de los indigenas, aparece en la siguiente queja del Consejo Supremo Tarahumara al Gobernador Teófilo Borunda en 1961 solicitando prácticamente la desaparición de poderes en Batopilas y Morelos:

Rogamos que la Administración a su cargo intervenga para hacer la detención de Jesús Ramirez, quien vive indistintamente en Tierras Verdes y en Sitánachi, de los municipio de Guadalupe y Calvo y Morelos, respectivamente, por los siguientes delitos:

A.).- Jesús Ramirez ordenó a un grupo de resenvistas a sus órdenes, la detención y asesinato de los niños Tarahumaras Francisco y Alejandro Carrillo. Los parientes de estos niños, este Consejo Supremo Tarahumara y los dirigentes del Centro Coordinador Indigenista Tarahumara se han dirigido a diferentes autoridades para el castigo de estos crímenes. Hasta ahora la justicia nada ha hecho sobre el particular, el sr. Ramirez se ufana de su impunidad. [...].

B.).-El Sr. Jesús Ramirez está despojando por medio de la violencia las tierras de varias familias tarahumaras. En los primeros dias de este mes arrebató las tierras de las casas de los tarahumaras Hipólito Camillo, Mauricio Valentino y Juan Quiñonez. A muchas otras familias les ha arrebatado por el mismo procedimiento sus tierras en los últimos meses.

Rogamos a usted también ordene la destitución det Recaudador de Rentas de Morelos. Esta persona ocupa el puesto desde hace 20 años y no le interesan nuestras quejas, toda vez que él tiene funciones de Subagente del Ministerio Público en la cabecera municipal de Morelos.

El Juez Menor deberá también ser destituido porque carece de criterio, además de que solamente firma toda clase de papeles que le lleva el Recaudador de Rentas, sin saber el 
No es extraño pues que la acumulación de agravios y la arbitrariedad en la aplicación de la justicia desencadenaran en algunos casos auténticos movimientos indigenas en contra de la minoria mestiza y de su aliado, el poder gubernamental. Así por ejemplo, en septiembre de 1964, un grupo de tarahumaras del poblado de Humariza lidereados por un tal José Mina, hartos de ser desoidos por las autoridades agrarias, enfrentaron a balazos a un grupo de mestizos invasores de sus tierras dando muerte a un ingeniero representante del Departamento de Asuntos Agrarios y Colonización, lo que provocaria la detención de los indígenas. Ese mismo año los rumores de agitación y levantamientos entre los rarámuri de Nahuisuchi y Piedras Verdes (Urique) eran insistentes. Dos años después, en 1966, setenta indigenas de Memelichi en el municipio de Ocampo se dirigían al presidente de la República amenazando levantarse en armas por no haberse resuelto sus demandas agrarias. ${ }^{56} \mathrm{E}$ incluso, entre 1971 y 1976 este

contenido de los mismos. Además porque no tiene interés en la investigación de los delitos que frecuentemente se cometen en jurisdicción de Morelos.

Que el Gobiemo del Estado tome medidas conducentes a fin de que el Presidente Municipal de Batopilas encarcele efectivamente a los delincuentes. Estos tienen por cárcel la población de Batopilas, se emborrachan, portan armas y se fugan cuando quieren. De esta manera muchos asesinatos quedan impunes, tanto del municipio de Morelos como de Batopilas, porque al remitirse a la cabecera judicial del Distrito de Andrés del Rio (Batopilas) se fugan al siguiente dia de ser entregados. Esta situación ha dado auge a una criminalidad desmedida, especialmente en Morelos.

Suplicamos a usted igualmente se investiguen los asesinatos cometidos desde mediados del año pasado, en jurisdicción de Morelos y que han permanecido impunes....

(Tomado de "Carta que el Consejo Supremo Tarahumara dirige al sr. Teófilo Borunda, gobemador del estado de Chihuahua. 22 de junio de 1961", en ACCIT Legajo 126, Expediente 24.

${ }^{56}$ La referencias al conflicto de Humariza en ACCIT, Legajo 9, Expediente 4; Legajo 10. Expediente 2; Legajo 38, Expediente 13; Legajo 48. Expediente 21; Legajo 70, Expediente 10; Legajo 81, Expediente 17; Legajo 97, Expediente 4 y Legajo 110, Expediente 10. Al respecto resultan tambien interesantes los comentarios de Arturo Orpinel Holguin, técnico del CCIT en un articulo (quizás periodístico) del 22 de julio de 1964 intitulado "Los Sucesos de Humariza. José Mina y los del Agrario" donde entre otras cosas señalaba:

Quizá entre los que tienen prisioneros en Nonoava estén los verdaderos culpables del ASESINATO, del cual no tienen otras personas la culpa nada más que los funcionarios del Agranio, por un lado, y los mestizos de esa región por el otro. Todos estos mencionados son gentes que razonan debidamente para bien de sus intereses sin importarle los ajenos y eso fue lo que los llevó a la tumba y no creo que pare alli el detalle, por mucho que los asusten las autoridades estatales y federales. Los indigenas seguirán defendiendo 10 que legalmente les comesponde y que por espacio de muchos años no han podido disfrutar plenamente porque nunca los dejan en paz (ACCIT, Legajo 38, Exp. 13)

$$
260
$$


clima de conflictividad interétnica se convertiria en el mejor caldo de cultivo para propiciar un incipiente levantamiento de guerrilleros de la Liga 23 de Septiembre en los poblados de Monterde, Rocoroyvo y San Rafael de Orivo, estos dos últimos en los municipios de Uruachi y Chínipas respectivamente. ${ }^{57}$

El contexto generalizado de conflictividad interétnica que hemos venido analizando significó y sigue representando hasta la actualidad un serio obstáculo para lograr la integración intercultural entre indios y mestizos, objetivo que constituye una de la metas declaradas de la política indigenista integracionista. Esta conflictividad explica que,

La demanda de los indigenas de Memelichi en ACCIT Legajo 10, expediente 2; los rumores de levantamientos en la zona de Urique en Legajo 28, Expediente 10; Legajo 37, Expediente 20; Legajo 48.

${ }^{57}$ En cuanto al ataque guemillero a Rocoroyvo, el propio comisario de policia del lugar certificaba el 17 de febrero a las autoridades educativas que

...la gente en este pueblo [...] se encuentra en guerrilla contra el gobiemo y los capitalistas por eso desedimos mandar a el maestro y a sus ayudantes para que no corran ningún peligro aqui

También, el director del CCIT informaba con urgencia, el 26 de febrero de 1974, al Dr. Aguirre Beltrán, director general del INI que los maestros de dicho lugar habian tenido que cerrar la escuela-albergue desde hacia una semana, puesto que habian sido "amenazados por un grupo de personas que se dicen guemilleros", quienes habian

estado hablando con la gente de Rocoroyvo y lugares cercanos tanto indigenas como mestizos incitándotes a la rebelión y que [...] les están proporcionando armas, además[...] las gentes están de acuerdo con la presencia de este grupo pues les facilitan alimentación

Ese mismo dia, los maestros de Rocoroyvo testimoniaban oficialmente ...que tuvieron que cerrar la Escuela Albergue ya que fueron amenazados por un grupo de campesinos armados, los cuales les dijeron que cerraran la Escuela porque no querian gente del gobiemo y porque estaban luchando contra los Capitalistas. [...]que por informes de los tarahumaras de esa zona, existe un gran número de campesinos armados y que hay también varios estudiantes de algunas Universidades del pais. Conforme a un manifiesto mimeografiado que exhiben, el grupo que está dirigiendo este levantamiento campesino es el Comité Politico Militar Arturo Gámiz, en dicho manifiesto se invita a unirse al movimiento a los campesinos y a los obreros contra las Empresas Madereras y contra el Gobiemo haciendo una Revolución Socialista. [...jque el día 6 de Febrero estuvieron en Rocoroyvo varios elementos del Ejército y que se dirigian a la Rancheria de La Paz, pues en ese lugar es donde se sabe hay un campamento de los campesinos levantados. Supieron que habia habido un combate y que algunos soldados habian salido heridos. También agregan que hay como 500 campesinos unidos a ese grupo principalmente de las regiones de Rocoroyvo, La Paz y San Rafael de Orivo del Municipio de Uruachi y algunas zonas del Municipio de Chinipas.

Estos y otros testimonios y documentos sobre el levantamiento en la zona de Monterde y Rocoroyvo en ACCIT Legajo 47, Expediente 12 y Legajo 97. Expediente 7.

$$
251
$$


después de casi cinco décadas de presencia, el INI no haya podido lograr destrabar el ancestral y arraigado antagonismo interétnico, a pesar de que éste haya sido uno de los propósitos declarados de la doctrina indigenista oficial. Pero sobre todo -y aqui es donde radica la principal diferencia entre esa doctrina y la experiencia política en la Tarahumara- el conocimiento y la práctica cotidiana de las alianzas estratégicas entre los mestizos y el poder público provocaron entre los funcionarios indigenistas de la zona, al menos hasta los años setenta, una clara toma de posición de lado indígena, lo que no sólo les acarrearia conflictos con aquellos sino aun con las autoridades locales y, en especial, con las dependencias agrarias. Dicho en otros términos: para hacer extensivos los logros sociales de la revolución que el indigenismo proponia llevar hasta los más recónditos lugares de esta "región de refugio", los aliados estratégicos no sólo no resultaron ser los mestizos -principales legitimadores del statu quo- sino tampoco el poder público local y regional, supuestamente emanado de los mismos emblemas de la revolución mexicana.

El enfrentamiento entre los agentes indigenistas y la minoria mestiza serrana no se inició con la llegada del INI sino que se originó al final de los años treinta, a raiz de las primeras experiencias de los maestros cardenistas. Estos habian pugnado por enfrentar el monopolio político de los mestizos en los puestos públicos contribuyendo, primero, a la creación del Consejo Supremo Tarahumara y, posteriormente, a ubicar, por primera vez en la historia, a dos tarahumaras -Patricio Járis e Ignacio León Ruiz- en puestos de representación popular (como diputado local y alcalde de Batopilas respectivamente, municipio éste último en el que estaba encuadrada por aquellos años la población de Guachochi). Ambas medidas desencadenaron una abierta reacción de los grupos mestizos de la región de Batopilas y Guachochi. ${ }^{58}$ La llegada del INI a Guachochi no fue

\footnotetext{
58 Entre 1939 y 1940 se generó en el estado de Chihuahua una intensa actividad política en tomo a la sucesión a la gubernatura del estado influenciada, además, por la postulación presidencial de Almazán. En ese contexto surgió el Partido Revolucionario Independiente de Chihuahua (PRICH) proponiendo la candidatura gubernamenteal de Alfredo Chávez, en contra de la de Fernando Foglio Miramontes, candidato del centro. En la Sierra esta pugna se tradujo en la polarización entre los núcleos de poder mestizo (que apoyaban a Foglio) y el sector indigenista lidereado por los maestros cardenistas y los dirigentes del Consejo Supremo Tarahumara (en favor de Chávez), llegando akgunos grupos a armarse. El bloque indigenista que postuló algunos candidatos a alcaldes y diputados, debió enfrentar una fuerte oposición de los mestizos de 262
} 
tampoco muy bien vista por estos grupos puesto que sintieron que la defensa agraria que Plancarte y su equipo de trabajo emprendieron en favor de las comunidades tarahumaras ponia en entredicho su control sobre tierras y bosques de la región. Todo ello explica las reacciones airadas contra los dirigentes del CCIT que un grupo de poder de familias mestizas de la Mesa de Guachochi, aglutinado en torno a una tal Asociación de Pequeños Propietarios Agricolas, desencadenó, presionando infructuosamente al director del INI, al gobernador de Chihuahua y, aun, al presidente de la república para que los funcionarios indigenistas fueran destituidos. ${ }^{59}$

la región de Guachochi y Batopilas, máxime cuando los maestros organizaron con antelación un "ensayo" de elecciones para concientizar a los indigenas. El profesor Francisco Javier Alvarez recordaba asi aquellos dias tensos:

... Una semana antes hicimas un ejercicio de votación, es decir con papel y todo [...] para que distinguieran y votaran efectivamente como debia votarse. Pues hicimos nuestro ejercicio en toda la Sierra, en todos los poblados. [...]

Fue por primera vez que hicimos un ejercicio, pero los blancos sacaron la calumnia de que nosotros habiamos ya realizado las elecciones. Y el dia de las elecciones [...] viendo la enorme cantidad de indigenas que habia, optaron por ir a asaltar la mesa electoral y llevarse casillas y votos y todo. Todo se lo llevaron en Guachochi. [...] Legaron pistola en mano y luego, luego me afocaron a mi. Teniamos diez tiradores amiba.. Nos habrian matado pero se habrian muerto muchos de ellos también.. muchos, muchos... (Entrevista con el profesor Francisco Javier Alvarez, México D.F., 12 de 1994).

${ }^{59}$ El 26 de septiembre de 1958 la autodenominada Asociación de Pequeños Propietarios Agricolas de Guachochi integrada por las más poderosas familias de comerciantes y ganaderos mestizos daba a conocer a traves de un desplegado dirigido al gobemador Borunda y al presidente Ruiz Cortines y publicado en El Norte de Chihuahua:

estamos siendo hostilizados por la labor disolvente desarrollada en esta región por el Profesor Francisco M. Plancarte, Director del Centro Coordinador de la Tarahumara, dependiente del Instituto Nacional Indigenista, labor que realiza visiblemente al margen de la ley, supuesto que el grupo que manda el Sr. Plancarte se comporta en esta región como si fueran amos y señores, sin que a la fecha haya habido autoridades que frenen sus actividades en contra de nuestros pequeños intereses y de la tranquilidad social. (Cfr. "Denuncia en contra de quien resulte reponsable por delito de falsedad presentado por el Francisco M. Plancarte al C. Agente del Ministerio Público Federal en Chihuahua, Chihuahua, Chih., 6 de octubre de 1958", en ACCIT, Legajo 37, Exp. 25).

Hacia 1960 uno de los lideres de este mismo grupo se dirigia al dr. Affonso Caso, director del INI denunciando asi a los directivos del CCIT:

.. Es notorio que el Centro Coordinador de la Tarahumara, padece desde hace tiempo grave quebranto en su economía [...]. Ha colocado. en los puestos públicos de la administración municipal a los empleados del Instituto, quienes reciben sus sueldos como tales y el que les asigna el presupuesto municipal. Han creado un fondo político ignominioso un "Petit" Estado dentro del Estado. Todas estas irregularidades se han producido debido a la confianza que et Sr. Presidente de la República ha depositado en Usted, como responsable de un organismo descentralizado, como to es el INI. Responsabilidad a la que no hacen honor sus encargados. pues se han empeñado en hacer labor disolvente y 263 
Lejos de propiciar la mediación y la avenencia interétnicas la presencia del INI en la Tarahumara contribuyó a acrecentar la vieja conflictividad entre rarámuri y chabochi. A los ojos de los promotores del indigenismo, los mestizos y sus prácticas de apropiación de la tierra y el bosque, lejos de constituirse en un acicate para el desarrollo de las comunidades indígenas, se convertirian como hemos visto en el mayor obstáculo para el mejoramiento de las condiciones de vida de éstas.

De cuanto hemos venido diciendo hasta aqui acerca de la forma en que se planteaban las relaciones interétnicas en la Tarahumara en la época en que el INI se instaló alli y del análisis de la orientación que los programas del CCIT tuvieron -tema del que hablaremos con detalle en el siguiente capítulo- concluimos que existió una distancia real entre la doctrina oficial del indigenismo de la época sobre las regiones refugio y las relaciones interétnicas y la práctica institucional del INI en la Tarahumara. Esta última se

sembrar la cizaña entre indigenas y mestizos.

Esta labor no es extraña para nosotros, pues se trata del mismo grupo que durante el Régimen presidencial del Gral. Cárdenas, predicaron e impusieron aqui la doctrina COMUNISTA y continúan en su propósito, sólo que en forma encubierta, enquistados dentro del régimen democrático que encabeza el indiscutible patriota, Sr. Lic. López Mateos. Los encargados de redimir al indio to torturan y lo asesinan cuando no se plega a sus designios. Tenemos las pruebas. Sin que las autoridades hayan querido castigar estos delitos.

Los habitantes mestizos de la zona tarahumara hemos hecho esfuerzos por la unificación de las dos razas destinadas a convivir en paz y armonia, pero en vano, pues se interponen los intereses del grupo a que me refiero. Han hecho consentir a los indigenas que las pequeñas propiedades agricolas les pertenecen pretendiendo ignorar los mandatos de nuestra constitución política y nuestros derechos como hijos de la misma tierra y como mexicanos [...].

Observamos que como una ironía del destino en tanto que un grupo de COMUNISTAS, particularmente ferrocamileros purgan en las penitenciarias el delito de disolución social y negación de la lealtad a la patria, nosotros, mexicanos ciento por ciento, con fuerte y hondo arraigo en la tierra que nos vio nacer, estamos soportando el atropello y la amenaza a nuestros legitimos derechos e intereses. Estoy seguro de que Usted, cuya lealtad a nuestra patria es sincera, dentro de su gabinete de trabajo, no se ha percatado del engaño de que lo están haciendo víctima, la CEDULA COMUNISTA a que me refiero tiene su matriz en esa capital y ramificaciones en los estados, particularmente en este Estado de Chihuahua, en donde es muy influyente. Todos poseen Camet del Partido Comunista Intemacional; no se relacionan con el grupo descubierto que jefaturan Dionisio Encinas y Vallejo: son muy bien señalados por la opinión pública y más peligrosos que aquellos para nuestra libertad e integridad. (Legajo 10, Expediente 2, Documento 24). 
inspiró más en la experiencia acumulada desde los años treinta por el grupo de maestros radicales que en los postulados teóricos que algunos autores como Aguirre Beltrán comenzaban a difundir por esa época. ${ }^{60}$

Al menos durante las dos primeras décadas que siguieron a su implantación y de acuerdo con los datos que hemos planteado, el indigenismo inaugurado en la Tarahumara en los años cincuenta al calor de los postulados de la integración, acabaria por reconocer en la práctica que las distancias culturales entre las cosmovisiones y los patrones de bienestar y desarrollo indio y mestizo eran irreductibles. Más aún: que las acciones encaminadas a superar esas diferencias, acababan por provocar su mayor ahondamiento. A la luz de esa experiencia institucional, el viejo postulado de la doctrina oficial del indigenismo de que no habia salida independiente para el indio o para el ladino pareció derrumbarse ante la fuerza demostrativa de otro distinto: la única salida de progreso para el indio pasa por el enfrentamiento con un sistema de dominación, más capitalista que feudal, del que el poder político es el mayor aliado. Alrededor de esta premisa habrian de tejerse todo un conjunto de ideologías, experiencias y modelos indigenistas de desarrollo en la Tarahumara, tema del siguiente capitulo.

$\omega^{\circ}$ Algunos de los primeros directivos del CCIT habrian de surgir precisamente de ese grupo de maestros cuyo encuadramiento dentro del INI debe explicarse más por su cercania con el Dr. Alfonso Caso, que por su afinidad con los planteamientos teóricos y politicos de Aguirre Beltrán, por entonces subdirector del INI 



\section{CAPITULO 4.- CONCEPCIONES, MODELOS Y EXPERIENCIAS INDIGENISTAS DE DESARROLLO EN LA SIERRA TARAHUMARA.}

Ríos tumultuosos, caídas de agua capaces de abastecer de energía eléctrica al noroeste del país, riquisimos pinares, extensos yacimientos minerales, $y$ en medio de este paraiso, de esta opulencia intocada, cincuenta mil indios vestidos de harapos tienen como único patrimonio el hambre, el alcohol y el suicidio (Benitez, 1967, pág. 138).

\section{LA SIERRA DE CHIHUAHUA, UN TERRITORIO DIFERENTE.}

En los capitulos anteriores hemos venido analizando la historia del indigenismo en la Sierra Tarahumara desde tres perspectivas complementarias: la convicción que sobre el cambio cultural de los grupos étnicos construyeron y mantuvieron los agentes (la iglesia y el estado) del indigenismo (capitulo 1), su firme convicción- -no del todo apegada a las evidencias etnográficas- de que la mejor manera de promover ese cambio consistía en propiciar formas de organización comunalistas -desde los pueblos de misión hasta el ejido- (capitulo 2) y la constatación reiterada de los promotores gubernamentales del indigenismo en la zona, de que la conflictividad de las relaciones interétnicas constituia un grave obstáculo para hacer realidad la tan anhelada incorporación de los indigenas a la nación (capitulo 3).

A lo largo del siglo $X X$, las tres perspectivas señaladas han confluido en un conjunto de estrategias orientadas a modificar las condiciones de pobreza y marginalidad de las poblaciones indígenas, dando lugar a una serie de concepciones, modelos y experiencias del desarrollo, instaurados por diferentes agencias gubernamentales en la Sierra Tarahumara, aunque también por otro tipo de instancias y organismos sociales. Las concepciones hacen referencia a las visiones sobre el futuro ideal de los grupos étnicos construidas por el indigenismo; los modelos aluden a políticas de organización y gestión diseñadas por las instituciones gubernamentales para hacer efectiva su acción en este medio indigena. Las experiencias, en fin, nos remiten a la concreción y 
adaptación de las concepciones del desarrollo en forma de proyectos especificos, tal y como éstos fueron aplicados.

Este capitulo trata precisamente acerca de estas concepciones, modelos y experiencias del desarrollo que han sido el sustento de la acción indigenista en la Tarahumara. En particular nos limitaremos a analizar la acción de las dependencias gubernamentales (federales y del gobiemo de Chihuahua) ${ }^{1}$ y nos centraremos en el periodo comprendido entre 1952 -fecha de implantación del INI en la Sierra- y la actualidad, haciendo una breve mención de algunas propuestas de desarrollo que se plantearon en la zona durante los años del cardenismo. Éstas, a pesar de no haberse hecho realidad en ese momento, constituyen un antecedente importante de los programas del INI. ${ }^{2}$

Durante el período al que nos referimos, la acción indigenista orientada al desarrollo se centró principalmente en tres aspectos: el impulso a la actividad forestal y agrícola, la expansión del aparato educativo y la difusión del sistema de salud. Nuestro propósito en el capitulo es revisar la obra indigenista en estos tres ámbitos y evaluarla en dos sentidos: su real eficacia y efectividad para resolver los problemas de pobreza y marginación de los grupos étnicos de la Tarahumara y su compatibilidad con las concepciones indígenas sobre el desarrollo y el bienestar social.

En muchos sentidos, el desarrollo de la Sierra Tarahumara es un problema complejo. Se trata, en efecto, de un territorio con características que lo distinguen del

\footnotetext{
'Excede los propósitos de este trabajo analizar el papel que las iglesias (católica y protestante), las organizaciones no gubemamentales, algunas fundaciones empresariales y organismos de beneficencia y ayuda social desarrollan en la Tarahumara. Por su complejidad, este otro tema merece un estudio amplio y detenido que, al menos parciaimente, hemos comenzado ya a realizar.

${ }^{2}$ En los capitulos 2 y 3 ya hemos habladó de las propuestas sobre educación y desarrollo agricola planteados a principios del siglo XX por el gobernador Creel y plasmadas en la Ley de civilización y mejoramiento de la Raza Tarahumara, cuya aplicación quedó trunca a raiz del estallido de la revolución. También señalamos que la política de implantación de varios internados indigenas en la Tarahumara al inicio de los años treinta tuvo un alcance limitado, ya que esta medida no fue acompañada de otras, como la creación de programas orientados a modificar la situación económica de la región.
} 
resto del estado de Chihuahua y aún de muchas regiones del norte de México. Sin lugar a dudas, la geografia ha contribuido en forma significativa a esta singularidad. La Tarahumara abarca una extensa área de cerca de 65,000 kms. cuadrados, en la que se entremezclan los paisajes de bosques fríos de alta montaña cercanos a los 3,000 metros de altitud, con los de la "tierra caliente" en la profundidad de los cañones y barrancas, en ocasiones por debajo de los 500 metros.

La disparidad entre este territorio serrano y los que lo rodean no puede ser más llamativa. Si en la Sierra la tierra agricola, dispersa en medio de rocas y andesitas, es escasa, por el contrario, en los valles del oeste hacia el Pacifico sonorense y sinaloense, se concentran los graneros más productivos del pais por los que corren las aguas que provienen de los arroyos serranos, ahora convertidas en grandes corrientes fluviales como las del Yaqui, el Mayo y El Fuerte. En contraste, hacia el este de la Sierra, se abren las grandes planicies y los valles del Papigochi y del Conchos y más allá, el gran desierto de Chihuahua.

El clima, la orografia, los bosques, las cumbres, los ríos, las distancias, la altitud y todos los elementos de este medio físico de la Sierra de Chihuahua han contribuido por siglos a aislar y a poner barreras entre este territorio y los que lo circundan. Quizás eso explique por qué la Sierra ha constituido desde tiempos coloniales un territorio propicio para la marginalidad social (de bandoleros, rebeldes, levantiscos y narcotraficantes) pero, sobre todo, una región de refugio y olvido para grupos indígenas que sobrevivieron al exterminio y la persecución y de los que hoy sobreviven cerca de 90,000 habitantes.

Este contexto de aislamiento y marginalidad aparece como el escenario más propicio para la pobreza. Porque, en efecto, desde el punto de vista económico y por encima de todo, la Sierra de Chihuahua es famosa por la pobreza de sus habitantes. Más allá del amarillismo con el que la prensa nacional y extranjera suele teñir las noticias sobre este territorio, la Tarahumara está oficialmente considerada como una de las regiones de México donde los indices de marginación y pobreza crítica son más severos. 
En sus municipios, y de acuerdo con las cifras gubernamentales, se concentran bastantes de los niveles más drásticos del país en materia de analfabetismo, desnutrición, mortalidad infantil, dispersión geográfica y falta de servicios de educación, salud, energía eléctrica, agua entubada y drenaje.

El Cuadro 17 muestra algunos datos oficiales de 1995 sobre el nivel de la pobreza y la marginación en la Tarahumara. Como se observa, de los 17 municipios que la integran, 4 están calificados por el Consejo Nacional de Población (CONAPO) dentro de la categoria de "muy alta" marginación, 10 en la de "alta", 2 en la de "media" y sólo 1 en la de "baja". ${ }^{3}$ También se puede observar que los 4 municipios con más alta marginación se ubican en la zona de las barrancas donde las condiciones para la agricultura son poco propicias y donde la mineria, actividad tradicional de sus cabeceras, ha decaído.

Los datos son también reveladores de una clara correlación entre el grado de marginación y el nivel de dispersión y atomización de la población en pequeños asentamientos, tema del que ya hablamos en el capitulo 2 . Asi, a medida que aumenta el porcentaje de población total e indígena que habita en localidades de más de 1,000 habitantes, disminuye el indice de marginación. Puesto que el patrón de asentamiento disperso es particularmente caracteristico de la población indígena, se concluye que es ésta la que padece los más graves niveles de pobreza. A pesar de las limitaciones en los criterios estadísticos utilizados, las cifras del cuadro confirman ampliamente esta aseveración: en muchos municipios cerca del $90 \%$ de la población tiene ingresos inferio-

${ }^{3}$ CONAPO ha establecido el grado de marginación de acuerdo con los porcentajes de 7 indicadores: población analfabeta de 15 años y más, población sin primaria completa de 15 años y más, ocupantes en viviendas sin saneamiento ni excusados, ocupantes en viviendas sin energia eléctrica, viviendas sin agua entubada, viviendas con hacinamiento, ocupantes en viviendas con piso de tierra, población en localidades con menos de 5,000 habitantes y población ocupada con ingresos inferiores a 2 salarios minimos. Con base en estos medidores, CONAPO plantea 5 grados de marginación: muy alta, alta, media, baja y muy baja. 


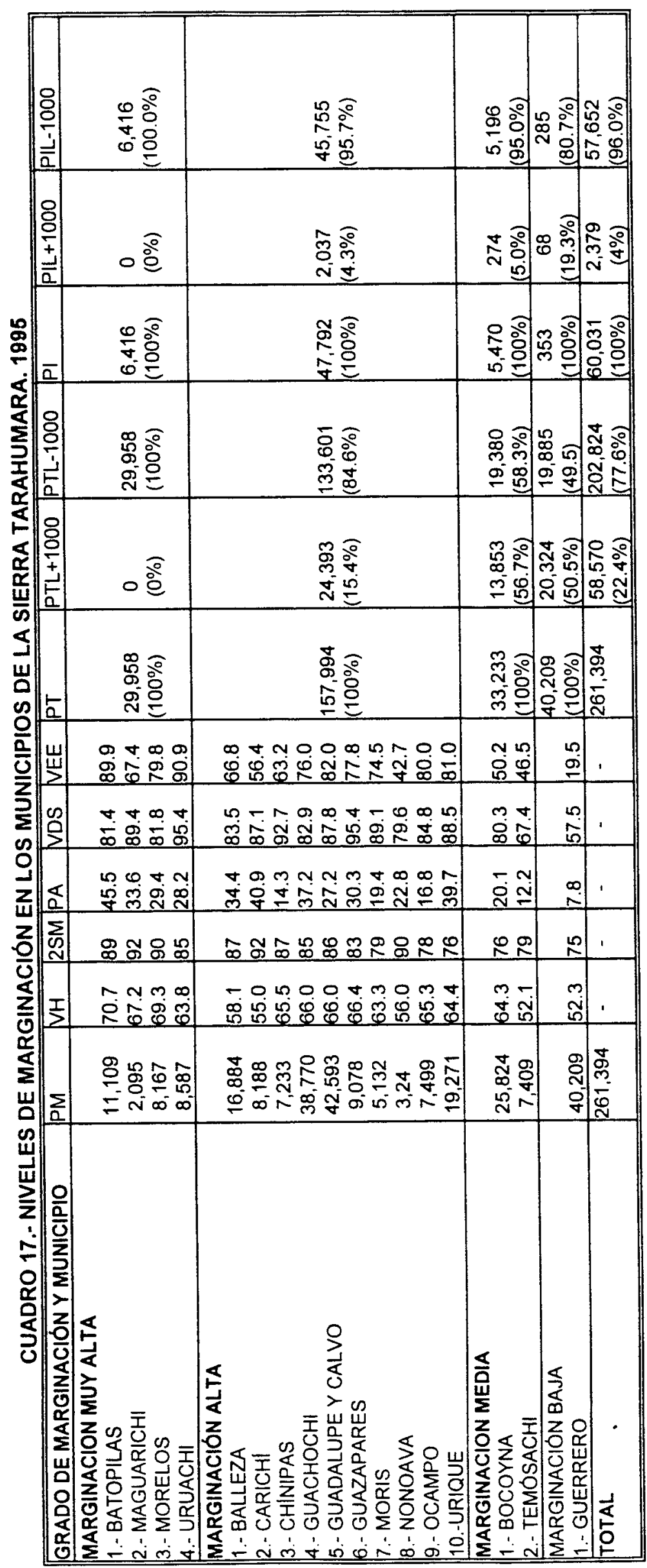


res a 2 salarios mínimos, entre el 70 y el $80 \%$ es analfabeta, cerca del $80 \%$ de las viviendas carecen de drenaje y energía eléctrica y en más del $60 \%$ de ellas hay hacinamiento. Todas estas cifras resultarian más aitas si el análisis se hiciera a nivel de los ranchos y rancherias indigenas. ${ }^{4}$

Este perfil de pobreza crítica nos hace pensar en los límites a la sobrevivencia impuestos por un medio natural extremoso, pero también nos evoca el recuerdo de una larga acumulación histórica de experiencias de desarrollo. Para revisar y evaluar las más importantes de estas experiencias, hemos dividido el capitulo en 4 partes, cada una de ellas correspondiente a una etapa distinta. La primera corresponde al periodo cardenista, en el que tanto el Departamento del Trabajo como el grupo de maestros rurales, del que ya hemos hablado, plantearon una serie de propuestas que nos atrevemos a calificar de "radicales"; enseguida nos referiremos a los programas derivados del modelo de la "acción integral" que el CCIT ensayó en la Tarahumara entre 1952 y 1972. La tercera etapa, en cambio, está caracterizada por el principio de la "acción sectorial" y corresponde al período 1974-1990. Finalmente revisaremos las más recientes y actuales estrategias del desarrollo en la Tarahumara, muchas de ellas surgidas desde fuera de las dependencias oficiales indigenistas.

\section{LAS PROPUESTAS RADICALES. 1936-1939.}

Durante los años del cardenismo los proyectos de cambio social adquirieron en muchas regiones de México un carácter radical. En la Sierra Tarahumara, que no fue una excepción a ello, dichas propuestas surgieron básicamente de dos grupos, a los que ya nos hemos referido. El primero, una Comisión gubernamental aglutinada en torno al

\footnotetext{
${ }^{4}$ Las estadisticas oficiales sobre morbilidad y mortalidad indigenas resultan de dificil manejo porque generalmente toman como referentes los municipios y no los ranchos, rancherias y pueblos indigenas. Además, en la Tarahumara, los registros de enfermedades y defunciones en el medio indígena resultan menos fiables por la carencia de centros de salud en muchas-zonas, la poca operatividad del Registro civil entre los indigenas y la falta de interés de éstos por acudir a aquel. A pesar de todo ello, son reveladoras algunas cifras oficiales como la siguiente: en 1990 la tasa bruta de mortalidad en los municipios de Chihuahua con población indigena fue de 9.3 defunciones por cada mil habitantes. es decir casi 2 veces superior a la nacional (5.2) y a la del conjunto de los municipios indigenas del pais (5.8). (Datos tomados de INI, Perfiles de los Pueblos indigenas de México).
} 
Departamento del Trabajo que recorrió en 1936 la Sierra Tarahumara para plantear una propuesta integral de desarrollo. El segundo, un núcleo de maestros del estado de Chihuahua, próximos al ideario marxista, que, entre otras medidas, plantearon una reforma integral del modelo educativo de los internados. Unos y otros configuraron lo que nos atreveriamos a calificar como un indigenismo "radical" del que surgió, al inicio de los años cincuenta, la institucionalización del indigenismo expresada en la creación del CCIT de Guachochi. Para lograr entender éste último quizás no sea vano examinar, de forma breve, los planteamientos de este indigenismo "radical" en relación con el progreso de los pueblos indígenas de la Tarahumara.

Por lo que se refiere a la propuesta que el grupo ligado al Departamento del Trabajo formuló en materia de desarrollo económico -ya hablamos en el capítulo 2 de sus propuestas en términos de autonomía política- los miembros de la Comisión remitieron al Presidente Cárdenas un informe final en el que planteaban cinco medidas indispensables para enfrentar el atraso económico de los tarahumaras. ${ }^{5}$ En conjunto, estas medidas equivalian a reconocer que el esquema tradicional de la economia indígena basada en la agricultura y el pastoreo en tierras erosionadas y profundos

${ }^{5}$ Las propuestas eran las siguientes:

Primero. Maderas. La formación de grandes aserraderos garantizando su consumo en las tres siguientes formas: a.)constituyendo a los indigenas en proveedores de este articulo al Gobiemo Federal; b.)constituyendo una gran fábrica de muebles escolares para surtir toda la República; c.)construcción de una fábrica de casas para obreros.

Segundo. En la región señalada como productora de oro y de plata, establecer un sistema de beneficio adecuado para la extracción del oro y dar asi ocupación a los indigenas. Además seria conveniente estudiar una legislación adecuada que garantizara a los indigenas una participación en los beneficios del subsuelo de sus tierras [...]

Tencero. La zona imigada del Conchos se ha entregado a personas acomodadas que han acaparado lotes, bajo los nombres de todos los miembros de la familia. Si se hace un reajuste se puede incluir ahi un $25 \%$ de indigenas puros.

Cuarto. La zona por imigar entre el río San Pedro y la sierra de Bachimba, puede destinarse exclusivamente para establecer una gran colonia tarahumara.

Quinto. Se pueden establecer dos grandes colonias, una en San José de Alburquerque y otra en Babicora, poniendo menonitas como directores de las colonias. Se ganarán asi dos cosas: resolver el problema económico de los indigenas y hacer que los colonos extranjeros principien a rendir su contingente y cooperación al progreso del pais en que viven.

Si a cada uno de estos resortes se aplica un promedio de dos mil individuos, resultarán beneficiados diez mil jefes de familia, número que responde aproximadamente a los defectuosos censos que actualmente existen (Departamento del Trabajo, 1936: 21-22).

$$
273
$$


barrancos no tenia salida. La única alternativa era introducir economías de escala, cooperativas y empresas organizadas sostenidas por el Estado en los sectores forestal y minero y, por ende, proletarizar a una parte de la población indigena. Para el resto de ella, el territorio serrano no ofrecia ninguna alternativa ${ }^{6}$ y por eso se proponia crear colonias agricolas en tres lugares estratégicos de los valles chihuahuenses lejanos de la sierra: las cuencas irrigadas de los ríos Conchos y San Pedro y la Hacienda de la Babicora, entonces propiedad del norteamericano Hearst. ${ }^{7}$ Además de éstas, el informe del Departamento del Trabajo recomendaba una serie de medidas más especificas en materia de comunicaciones, carreteras, teléfonos, correos, colonias y alhóndigas, salarios, comercio, "guardias indigenas", organización política, libertad económica y organización social (ver Cuadro 18).

A decir verdad, la propuesta del Departamento del Trabajo era una curiosa mezcla de radicalismo político y de indianismo a ultranza. Porque si por una parte no dudaba en trazar todo un modelo de transformación radical y modernización de las bases de la economia indígena hasta equipararlas a las del país, por otra, en cambio, abogaba explícitamente por la autonomía y el reconocimiento del gobierno indigena, retomando asi la vieja utopía misionera de la autosuficiencia comunalista y la autarquia de la "república de indios".

\footnotetext{
${ }^{6}$ Al respecto el informe señalaba:

No hay en la Sierra Tarahumara problema de tierras porque no hay tierra. No se puede confiar el futuro de una raza a una región donde ni hay tierra ni hay seguridad en los cultivos. Si se quiere atacar en firme el problema de la raza tarahumara habrá que recumir a estos solos recursos: transplantación de la población; grandes fábricas de productos madereros; gran desarrollo de la industria minera del oro (Departamento del Trabajo, 1936: 176)
}

${ }^{7}$ Sobre la historia del distrito de riego del Conchos y San Pedro creado a finales de los años veinte y localizado al este de la Sierra Tarahumara, en la región de Delicias y Meoqui puede verse Aboites, 1987. Sobre la conformación del latifundio de la familia Hearst en ta región de la Babicora, al norte de la Sierra, cerca del cual se instalaron a principios de los años veinte una serie de colonias agricolas de inmigrantes menonitas, véase Palomares, 1994.

\footnotetext{
${ }^{8}$ Véase al respecto lo que ya señalamos en el capitulo anterior y Departamento del Trabajo, 1936: 185-
} 186. 
Quizás por causa de las convicciones izquierdistas de sus promotores, las recomendaciones del Departamento del Trabajo adolecian también de un fuerte componente idealista. ¿Era acaso comparable la situación de la Tarahumara con la de Suiza, el Tirol austriaco, el Pais Vasco o Rusia como para poder importar las experiencias de esos paises -tal y como proponia la Comisión gubernamental- y aplicarlas en la Sierra de Chihuahua? ¿Cómo pensar que sería posible la migración masiva de la población indigena fuera de la Sierra? Restaurar los viejos centros mineros barranqueños, implantar alhóndigas, erigir una Casa de Moneda, modernizar los internados, concluir la línea del Ferrocarril Chihuahua al Pacífico, construir largos trazos carreteros, implantar fábricas de madera, aserraderos, cooperativas mineras y otras aspiraciones más ¿no era un programa demasiado ambicioso para una región como la Tarahumara que mostraba los estigmas más claros del atraso y la miseria? ¿O acaso no eran estos símbolos y aún los del primitivismo indigena los que ese mismo año de 1936 , cuando los miembros de la comisión gubernamental recorrían la Sierra, tanto habían impresionado a otro visitante, Antonin Artaud?

En pleno cardenismo y al mismo tiempo que el Departamento Autónomo de Asuntos Indigenas experimentaba en sus Internados y Misiones de Mejoramiento sus programas de clara orientación incorporacionista, un grupo de maestros comenzó a plantear y difundir en la Tarahumara una nueva visión de la educación indígena que representaba una crítica de los métodos oficiales y proponía una concepción integral del problema indigena en la que el tema de la educación se ligaba al de la autonomía lingüistica, cultural y política y al de la lucha agraria de los grupos étnicos de la Sierra de Chihuahua. Ya hemos analizado anteriormente la orientación que asumió la acción agrarista y politica de este grupo de jóvenes maestros lidereado por el profesor Francisco Hernández y Hemández e integrado, entre otros, por los profesores Francisco Javier Alvarez, José Hernández Labastida; Francisco. M. Plancarte, J. Patrocinio López y Ernesto Cano Ruiz. De ellos provendría la segunda propuesta, ésta más realista que la de la Comisión del Departamento del Trabajo, de un nuevo indigenismo. 


\section{CUADRO 18.- RECOMENDACIONES DEL DEPARTAMENTO DEL TRABAJO PARA RESOLVER LOS}

PROBLEMAS DE LA RAZA TARAHUMARA (1936)

\author{
RELACIONES EXTERIORES \\ - Consulta con cónsules de sistemas económicos en \\ regiones frias como Vizcaya (España), Rusia, Tirol \\ austriaco, Suiza, Escocia.

\section{EDUCACION} \\ - Nombrar a Ignacio León como director del Internado \\ de Tónachi \\ - Dotar a los internados de maestros casados \\ preparados, personal de apoyo, maestros textileros. \\ calderas para baños de vapor, lavadoras (para \\ erradicar el piojo blanco), molinos de nixtamal, talleres \\ de fabricación de instrumentos musicales. \\ - Crear Casas del Maestro. Pagar a los maestros \\ mejores salarios.
}

\section{ECONOMIA NACIONAL}

- Fundar aserraderos y fábricas de muebles escolares. de casas para obreros y de papel.

- Fundar 10 cooperativas mineras y plantas de fiotación en la Baja Tarahumara. Asesorar a gambusinos de Cerro Colorado, Batopilas y Tres Hermanos. declarando caducas las concesiones ociosas. - Asesorar una cooperativa maderera de Bocoyna.

\section{HACIENDA}

- Compra por parte de un Banco oficial del oro de gambusinos.

- Estudiar la conveniencia de fundar una Casa de Moneda en Batopilas.

\section{CONUNICACIONES}

- Fusionar los Ferrocarriles del Noroeste y Kansas City - construir una carretera a Sinaloa.

- Concluir la carretera Parral-Rochéachi.

-Instalar 1,000 kms. de líneas telefónicas y 50 aparatos.

- Fijar tarifas populares para servicio postal y fletes madereros.

\section{AGRICULTURA}

- Fundar colonias en Babicora y San José de Alburquerque con directores menonitas.

-Dotar de tierras al $25 \%$ de los tarahumaras en el

Distrito 05 de riego del rio Conchos en el área de

Ciudad Delicias.

\section{GUERRA}

-Establecer destacamentos militares para protección del indigena en Norogachi, Tónachi, Rochéachi, Cerocahui y Churo.

\section{DEPARTAMENTO INDIGENA}

-Establecer alhóndigas en Norogachi, Tónachi y Rochéachi para compraventa de semillas, ganados y mercancias de los indigenas.

- Iniciar cooperativas de consumo.

- Celebrar congresos indigenas anuales.

\section{DEPARTAMENTO DEL TRABANO}

- Designar un Inspector del Trabajo residente en la Tarahumara, en coordinación con lideres indigenas. - Organizar sindicatos de trabajadores mixtos (indigenas y mestizos)

\section{DEPARTAMENTO AGRARIO}

- Concluir expedientes de dotaciones agrarias a núcleos indigenas.

- Enviar agrónomos que asesoren en materia de cultivos y pastos.

\section{DEPARTAMENTO FORESTAL Y DE CAZA Y PESCA}

- Autorizar a indigenas de Bocoyna, Arareco y

Cusárare para elaborar tableta, pilote y viga.

- Dotar a cada comunidad de una sierra de sardina para fabricar tabla y evitar deforestación.

- Organizar cooperativas madereras.

-Poblar de peces los rios Septentrión, Batopilas y Urique.

\section{DEPARTAMENTO DE SALUBRIDAD}

- Enviar varias brigadas sanitarias con especialistas odontólogos.

- Cambiar la Unidad Sanitaria de Batopilas a Norogachi.

- Enviar al menos un enfermero a Tónachi, Choguita y Rochéachi.

-Campaña para erradicar enfermedades venéreas.

\section{GOBIERNO INDIGENA}

-Autoridad de un Jefe supremo y de gobemadores de cada comunidad.

- Policia al servicio de gobernadores

- Vigencia del sistema de justicia indigena

FUENTE: Elaborado a partir de Departamento de Trabajo, 19.36: 185-193.

En cuanto a la educación y desde sus primeros recorridos por las escuelas rurales y los internados de la Tarahumara, estos maestros no tardaron en advertir dos graves 
problemas: la falta de arraigo de los maestros y las dificultades de pretender enseñar a partir de la castellanización de los niños indigenas. La primera de estas dificultades sólo podria resolverse a base de formar y arraigar en la región maestros indigenas. ${ }^{9}$

El proyecto de formar maestros indigenas pronto se hizo realidad a partir de la fundación en 1938 de una Normal indigena que operó en Guachochi en los años cuarenta. Lo más novedoso no fue sin embargo su creación sino su orientación pedagógica: por primera vez, dentro de la enseñanza normal oficial, se empezó a promover la educación en lengua indigena. Varios de aquellos maestros, en efecto, conocian algunos de los primeros intentos que, desde 1939, se estaban realizando en México para reorientar la educación indígena tomando como principio la alfabetización en la lengua materna ${ }^{10}$, principio que fue asumido en las orientaciones del Congreso de Pátzcuaro al que algunos de estos maestros tuvieron la oportunidad de asistir. Así es que no dudaron en invitar a su proyecto a uno de los lingüistas que más abiertamente proponía esta nueva directriz pedagógica, el Dr. Mauricio Swadesh. ${ }^{11}$

${ }^{9}$ El profesor Francisco Javier Alvarez recordaba:

Nos dimos una vuelta por la parte central de la Sierra, que era la más poblada desde el punto de vista de población indigena, la zona de Norogachi, Guachochi, Rochéachi y hacia el norte hasta Cusárare y luego toda la zona de la Barranca.. Entonces si consideramos necesario realizar un curso para capacitar a los maestros, porque el problema de los maestros era fundamentalmente que el personal foráneo no aguantaba allá y conseguian la plaza, los nombraban y luego, si era personal de fuera, al año se valian de cualquier medio para lograr su cambio a una parte más central o a otro estado y se iban con todo y plaza y entonces siempre habia un déficit de personal.

Entonces consideramos que el primer problema era arraigar al personal educativo en la zona sobre la base de que fueran maestros nativos de la propia zona y... que algunos tenian primaria completa, otros habian estudiado en un Intemado, otros... que tenian hasta cuarto año... pero era preferible ese personal al personal que estaba como castigado alli y se iba de cualquier manera. [...] Entonces para atacar el problema educativo, la solución que nosotros apuntamos fue la de arraigar el personal, porque sin eso no se puede pensar en nada, no se puede pensar en ninguna acción, y lo segundo era capacitar a los jóvenes que debian ser los que lucharan por resolver el problema agrario... (Entrevista con el profesor Francisco Javier Alvarez, México D.F., 12 de octubre de 1994).

${ }^{10}$ Fue en la Primera Asamblea de Filólogos y Língüistas reunida en la ciudad de México en mayo de 1939 donde se empezó a plantear abiertamente esta posición. De ahi surgió, ese mismo año, el experimento del Proyecto Tarasco dirigido por Mauricio Swadesh, del que derivaria, en 1944 la creación del Instituto de Alfabetización en Lenguas Indigenas. (Aguirre Beltrán, 1992b: 120-131)

${ }^{11}$ De nuevo el profesor Alvarez

Lo que yo deseo resaltar es que nosotros en 1939, por primera vez. planteamos la 277 
A partir de las enseñanzas de Swadesh los maestros de la Normal de Guachochi confeccionaron una de las primeras cartillas tarahumaras (Hernández Labastida y Alvarez, 1945) que habria de contribuir durante varios años a desarrollar en las escuelas e internados de la Sierra Tarahumara la enseñanza en lengua indigena. Algunos de los impulsores de esta incipiente reforma educativa fueron varios de los maestros tarahumaras formados en la Casa del Estudiante Indigena que habian regresado a la Sierra y comenzaron a trabajar en escuelas e internados. Ellos, junto con los maestros radicales cardenistas, comenzaron a promover una visión sobre el problema indígena que superaba el marco cerrado del incorporacionismo y la mexicanización del indio y planteaba la urgente necesidad de enfrentar de forma integral los problemas de pobreza y marginalidad de la Tarahumara sin negar la autenticidad de las formas de identidad indígenas. Eran los tiempos en los que el principio del respeto a las lenguas y culturas indígenas promulgado por el Congreso de Pátzcuaro desde 1940, comenzaba a ser aplicado.

\section{LA ACCION INTEGRAL: LOS TIEMPOS GLORIOSOS DEL INDIGENISMO EN LA TARAHUMARA. 1952-1972.}

Los primeros proyectos.

Entre el inicio de los años cincuenta y el de los setenta el indigenismo conoció en la Sierra Tarahumara lo que podriamos denominar tiempos gloriosos porque nunca como entonces se emprendieron tantos programas en favor de las comunidades indígenas pero, sobre todo, porque nunca nadie como quienes los propusieron y dirigieron tuvieron una convicción tan profunda en la validez y eficacia de tales acciones.

El principal protagonista de esta gesta fue el Centro Coordinador Indigenista de la Tarahumara (CCIT), organismo dependiente del Instituto Nacional Indigenista (INI), creado por acuerdo presidencial el 16 de agosto de 1952 e instalado en la población de

necesidad de la enseñanza en lenguas indigenas, casi simultáneamente con Swadesh en Michoacán. El estuvo en Michoacán en el Proyecto Tarasco y luego se fue con nosotros. A invitación nuestra se fue a Chihuahua y estuvo allá como unos 4 o 5 meses con nosotros. Y en el trabajo de conjunto se elaboró el alfabeto para escribir en tarahumara. el alfabeto que llamamos cientifico, con las grafias internacionales (Ibid.)

$$
278
$$




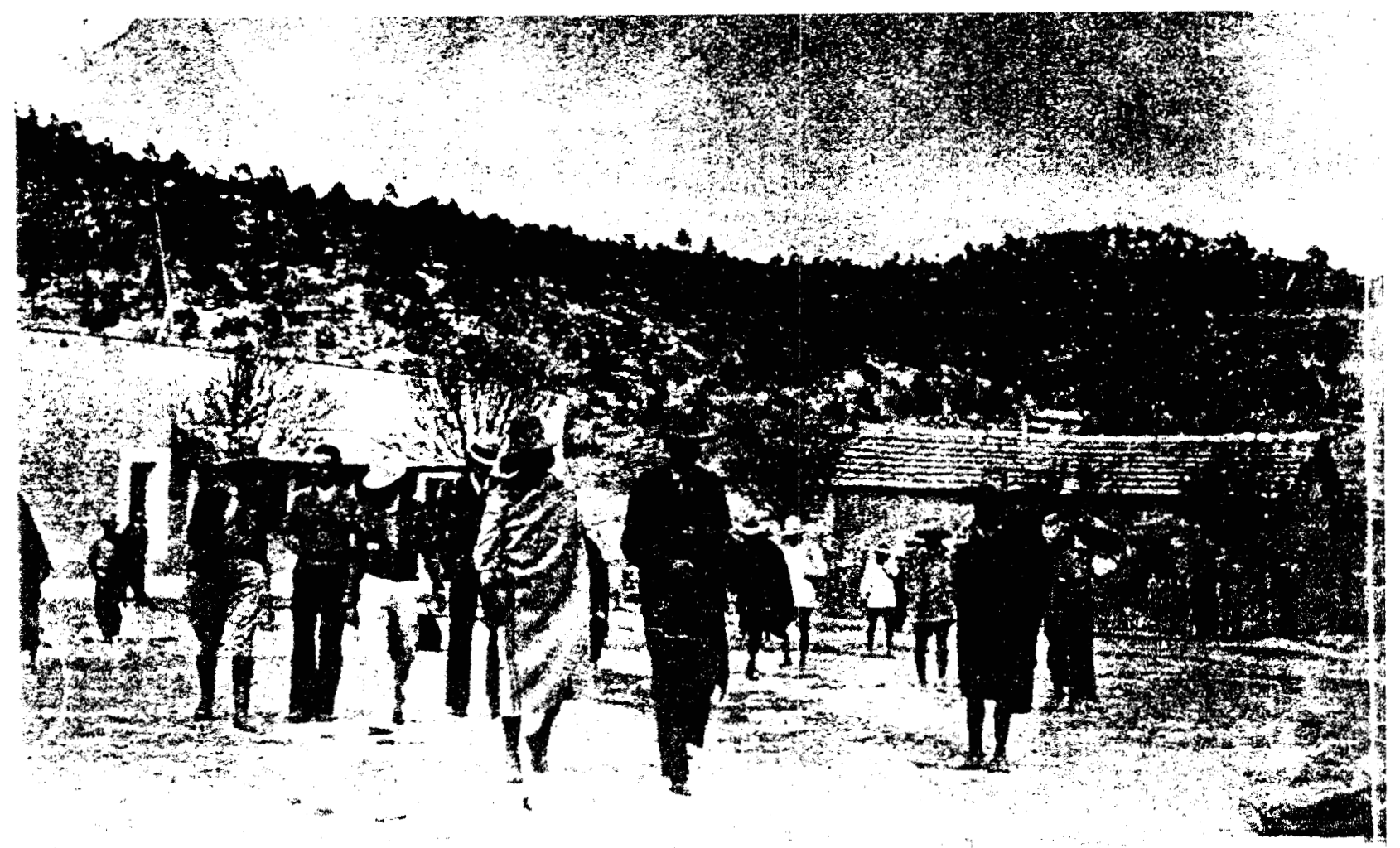

FIGURA 49.- LA COMISION DEL DEPARTAMENTO DE TRABAJO LLEGA A ARARECO (1936)

(DEPARTAMENTO DE TRABAJO, 1936)

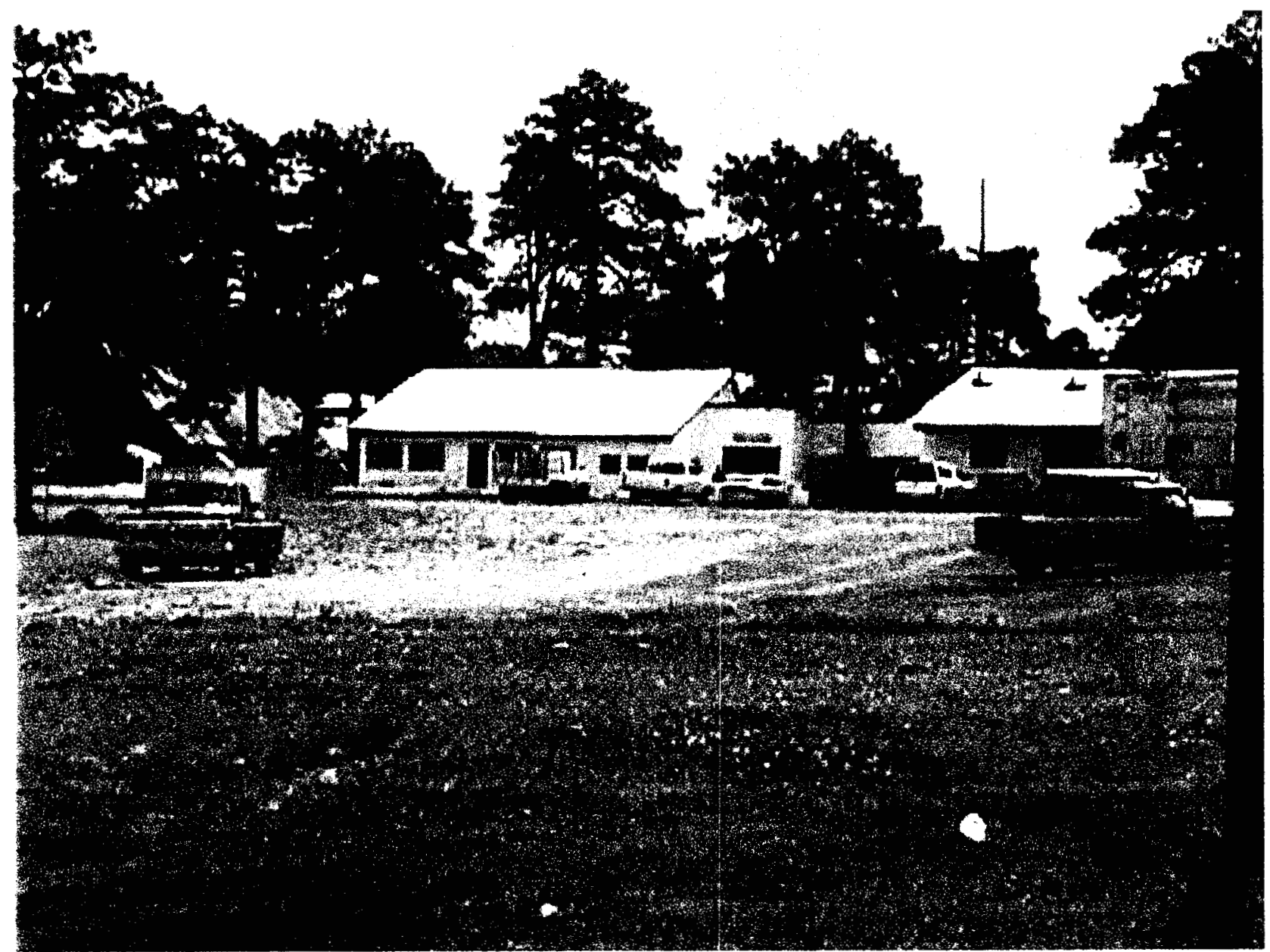
TARAHUMARA EN GUACHOCHI (FOTO DIEL AUTOR, JULIO, 1998) 
Guachochi. EI CCIT fue dirigido entre 1952 y 1959 por el profesor y antropólogo Francisco M. Plancarte quien, desde los años treinta, había trabajado en la Tarahumara y tras una estancia de estudio en la Universidad de Chicago y un período de trabajo en el área del Papaloapan bajo la dirección del antropólogo Alfonso Villa Rojas, regresó a Chihuahua para hacerse cargo del Centro de Guachochi.

El primer programa de actividades del CCIT derivó de dos propuestas complementarias: la que presentó su primer director y la que, en forma general, esbozó Aguirre Beltrán, por entonces subdirector del INI. En un estudio previo a la apertura del $\mathrm{CCIT}^{12}$, Plancarte retomaba muchos de los aspectos que habian constituido el programa del grupo de maestros rurales de los años treinta en el que él había participado activamente $y$, acorde con él, sugería una estrategia de acción integral articulada en torno a ocho líneas programáticas (véase Cuadro 19). En primer lugar se proponía crear un organismo central coordinador con representación de las secretarías de estado, el gobierno federal y los propios indígenas cuya función fuera la de coordinar acciones para resolver efectivamente el "problema indigena tarahumara", esquema que habria de plasmarse en la estructura del CCIT. Además de éste, Plancarte planteaba la creación de un segundo organismo, con sede en la ciudad de Chihuahua con capacidad para centralizar y administrar de forma racional y productiva las donaciones y apoyos crediticios de la iniciativa privada y de la sociedad civil destinados a la población indigena.

La defensa de tenencia de la tierra y los bosques en manos de las comunidades indígenas constituia el eje vertebral de la propuesta de Plancarte. En tal sentido el maestro y antropólogo michoacano planteaba no sólo la conformación de una brigada de ingenieros agrónomos y topógrafos que llevaran a cabo los estudios técnicos necesarios para delimitar las tierras comunales 0 ejidales de las comunidades indigenas sino también la suspensión de denuncios de tierras por parte de grupos de mestizos en

\footnotetext{
${ }^{12}$ El estudio fue publicado en 1954 por el INI como una monografia bajo el titulo de EI Problema Indigena Tarahumara.
} 
terrenos nacionales y áreas tradicionalmente ocupadas por los propios indígenas. La labor de los técnicos de la Reforma Agraria debia ser complementada, según Plancarte, con la vigilancia y acción legal de los Procuradores de Asuntos indígenas cuyo número y presencia se requeria incrementar en los diferentes municipios serranos.

El desarrollo de la Tarahumara se debia sustentar, en la óptica de Plancarte, en una modernización sustancial de las técnicas agropecuarias tradicionales indígenas: mejoramiento de semillas, nuevos cultivos, uso de fertilizantes quimicos y orgánicos, introducción de postas zootécnicas, creación de pequeños talleres textiles, instalación de tiendas cooperativas con precios populares, implantación de una filial del Banco de Crédito Ejidal, capacitación técnica de jóvenes indigenas y construcción de nuevas carreteras. De todos estos programas, habría uno que, con el tiempo, se convertirá, como veremos, en el más estratégico: la explotación de los recursos forestales de los ejidos indigenas.

El plan de acción diseñado por Plancarte contemplaba también otros rubros como la atención médica y de salubridad a las poblaciones serranas, la reorganización del sistema educativo a partir de una unificación de criterios y objetivos entre las diferentes instituciones educativas (internados, escuelas públicas, Misiones de Mejoramiento, etc.) de forma tal que la educación contribuyese a acelerar la integración cultural de los indigenas a la nación. La propuesta era además insistente en recomendar la asesoría de los antropólogos para evitar la elaboración de proyectos indigenistas carentes de una dimensión étnico-cultural. Por último el plan de acción trazado por quien habria de ser el primer director del CCIT esbozaba una visión original sobre el sistema tradicional de gobierno indigena: éste debería ser mantenido y respetado en tanto los indigenas "no se hayan incorporado plenamente a los patrones nacionales de organización politica, civica y sociaf" (Plancarte, 1954: 89), sin menoscabo de fomentar que los indigenas ocuparan puestos en la administración pública de los municipios serranos. 


\section{1.- MODELO ORGANizATIVO}

1. Creación de un Organismo publico coordinador de las acciones orientadas a resolver el "problema indigena tarahumara"

1.- Creacion de un Orasio civil en Chinuahua para canalizar a traves de un fondo la cooperación de empresarios y particutares a la Tarahumara.

II. TERRA. Asegupr a los indigenas la propiedad de sus tierras base de su sobrevivencia-de las que son despojados sistembticamente.

11.- Conformar una Brigada de ingenieros agrónomos para la regularizar la tenencia de la tierra en la Sierra Tarahumara.

2. Suspender la aceptacion de denuncios de tertenos, bosques nacionales y supuestas tierras ociosas, revisando las informaciones "ad perpetuam".

3.- Suspender la aceplacion de denún de Asuntos indigenas en la ciudad de Chituzhua y establecer Procuradurias de Asuntos indigenas en Creet, Batopilas.

Urique. Carichi y Guachochi para atender los conflictos imteretricos en materia de propiedad y explotación de tierras y bosques.

III- ECONOMiA. Mejoramiento de técnicas agropecuarias a traves de los siguientes programas:

1 - Capacitación de jóvenes indigenas en las modernas técnicas agricolas y pecuarias, utilizando para ello su tengua materna.

2. - Introducir nuevos cultivos remunerativos (papa, ajo. cebolia, trigo. avena. frutales finos como la manzana y el durazno) y mejorar los de maiz y frjol. Crear campos experimentales y viveros en Guachochi y otros lugares.

3. Difundir y promover el uso de abonos quimicos y orgánicos, tradicionales o modemos. Abolir el sistema de desmonte y querna de tierras

4.- Establecer postas zootécricas con ganado caprino. ovino. vacuno. cerdos y gallinas de raza y capacitar a jóvenes indigenas en su manejo.

5. - Crear un programa de capacitación en manejo de telares. teñido de lana. hechura de cobijas y sistemas de conservación y aprovechamiento de frutas, cames, pieles y lecthe de cabra.

6.- Instalar una gran Cooperativa central de consumo en Guachochi. con subsidiarias. con productos de primera necesidad a bajos precios.

7. - Crear una Agencia del Banco de Credito Ejidal para el otorgamiento de créditos a los indigenas.

8. - Instalar en los ejidos y con asesoria técnica cooperativas madereras indigenas, integradas por un aserradero y un taller de carpinteria.

9.- Promover la pequeria inrigación y electrificación aprovectando las caidas de agua de muchos lugares de la Sierra.

10. Construir 13 carreteras de terraceria: Terrero de Balleza-Guachochi: Creet-Bocoyna: Sisoguichi-Carichi-Cuauthemoc: Balteza-Verget-Guadalupe y CalvoBaborigame-ramales; GreetCuiteco-Guazapares-Chinipas; La Bufa-Batopilas; Guachochi-Tönachi; Guachochi-Yoquivo: Carichi-Baquiachi: RoctreachiNorogachi-Choguita-Creel; Nonoava-Guachochi; La Junta-San Juanito-Bocoyna. Establecer un sistema postal eficiente. teléfonos y radiotelefónos. para asegurar el comercio. el control gubernamental sobre las poblaciones y ia extensión de los servicios asistenciates.

\section{IV.ASISTENCLLA Y SALUBRIDAD.}

1.- Entrega urgente y en calidad de prestamo de maiz. frijol, sal, manta y jabon a pueblos sin cosechas. Creación de trojes comunales.

2. Asistencia a la niñez escolarizada con alimertos. ropa y utiles escolares.

3.- Establecimiento de dinicas y hospital ofreciendo servicios medicos a precios acordes con las posibilidades económicas de los pacientes

4.- Asistencia médica higiénica y preventiva de enfermedades a través de enfermeras y trabajadoras sociales que realicen una amplia labor educativa.

V.- SEGURIDAD

1.- Estabtecer nuevos grupos de Policia Rural con capacidad de rapida movilización

2- Sustituir las reservas del Ejército que no son indigenas y sueten amedrentar a éstos. por guarniciones moviles de soldados de linea que den instuctión militar a los jóvenes serranos, indigenas y mestizos.

3.- Restringir al maximo la portación de amas en la Sierra para evitar los frecuentes hechos de sangre.

VI.- ACCIÓN EDUCATIVA

1.- Unificar criterios y objetivos entre las diferentes instituciones educativas que trabajan en la Sierta tarahumara.

2- Crear el grado pre primario para alfabetizar a los niños en lengua matema e introducirios en la castellanización.

3. Intensificar la acción social de la escuela entre los adultos. fomentar la educación prática en actividades agropecuarias y manuales. Crear las Jurtas de mejoramiento comunal. Sociedades de padres de tamilias y comisiones de alumnos.

4. - Reorganizar los internados de forma que. a través de sus actividades manuales y agropecianios. sean económicamente autosuficiernes.

5. Las instituciones de educación intormal deben dirigir su acción al mejoramiento det hogar y de la farnilia, en sus mültiples aspectos.

6.- Dotación de materiales, equipos. salarios y medios requeridos por las escuelas y planteles educativos.

7 - Estabtecimiento de instituciones educativas que formen Promotores en areas de alfabetización, agropecuaria, enfermeria. albañileria, ete.

8. Crear en cada comunidad una Junta de Mejoramiento que promueva el progreso y la superación de los niveles de vida de sus habitantes

VII.-ASESORIA TÉCNICA ESPECIFICA

1. - Asesoria de antropólogos sociales y língüistas en la formulación de los planes de trabajo indigenista. para incorporar los aspectos culturaies.

VIII.- OTROS ASPECTOS.

1. - Concentrar la acción indigenista en municipios con mayor población indigena y trabajar con nucleos concentrados y con pobiacion dispersa.

2. Fornentar el asentamiento lineal a lo largo de arroyos. rios y caminos. sin forzar la tradicional dispersión indigena.

3.- Dorner de movilidad a los organismos educativos y a las escuelas sistemas de alojamiento y manutención para los educandos de zonas lejanas.

3.- Dotar de movilidad a los organismos educativos y a las escuelas sisternas de alojarmiento y manutención alimentar y vestir a los nirios que asisten a las escuelas.

4.- Emprender una campana para obdionales indigenas en tanto no se hayan incorporado plenamente a los patrones de la politica nacional.

5.- Reconocer a las autoridades tradicionales indigenas en tamto no se hayan incorporado plenamentos

7.- Fomentar la participación de los indigenas en puestos administrativos de elección popular.

8 - Reorganización por parte del Gobierno del estado de Chituahua del Servicio de Inspección de Municipios de la Sierra

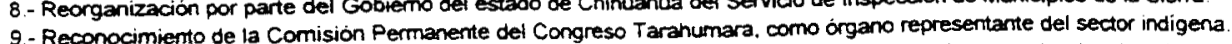

10. Difundir entre mestizos e indigenas serranos el conocimiemto sobre la patria mexicana, asi como sobre los derectios y obligaciones del ciudadano

FUENTE: Elaborado a partir de Plancarte, 1954: 83-90 
Los planteamientos de Aguirre Beltrán sobre el programa de trabajo del CCIT derivaron de una visita realizada por él a la región serrana a mediados de 1952 y de una serie de consultas con el propio Plancarte, el gobernador de Chihuahua Oscar Soto Maynez, el delegado en el estado de la Dirección de Asuntos Indígenas y varios de los directivos del Consejo Supremo Tarahumara. Con fines operativos Aguirre proponia enfocar la acción del CCIT hacia el "área de trabajo" con mayor población tarahumara (municipios de Batopilas, Carichi, Balleza, Urique, Bocoyna, Morelos, Guazapares y Guadalupe y Calvo), estableciendo también una "área de influencia" (municipios de Uruachi, Nonoava, Chínipas, Maguarichi, Ocampo y Moris) sujeta al influjo de la acción "móvil" del CCIT. Tras sondear la opinión de los miembros del Consejo Supremo Tarahumara sugeria como sede del centro la población de Guachochi, por su ubicación central en la Sierra, por haber sido en dos ocasiones sede del Congreso Tarahumara y por la presencia de tierras, aguas, bosques y una planta eléctrica no aprovechada.

Dada la extensión y lógica orográfica de la Tarahumara, Aguirre sugería la creación de 5 puestos periféricos ubicados en Baqueachi, Cusárare, Cuiteco, Baborigame y El Vergel. Para enfrentar la dispersión demográfica proponia acelerar el proceso de la reforma agraria esperando que la posesión de la tierra fomentaria la concentración demográfica. La promoción del desarrollo de la Sierra debía sustentarse, según el antropólogo veracruzano, en cuatro directrices: la acción agraria y forestal, la construcción de caminos vecinales en particular el circuito Cuauhtémoc-CarichiSisoguichi-Bocoyna-Creel-Rochéachi-Guachochi-El Terrero-Parral, con una extensión de 654 kms.-, la creación de un servicio sanitario y médico retomando la experiencia del INI en Chiapas y la implantación de métodos educativos uniformes a partir de la alfabetización en lengua nativa. ${ }^{13}$

En los primeros años de existencia del CCIT, el grupo de antropólogos, maestros,

\footnotetext{
${ }^{13}$ La versión original de esta propuesta aparece en ACCIT, Legajo 27, Exp. 5: "Carta del Dr. Gonzalo Aguirre Beltrán, Subdirector del INI al Dr. Alfonso Caso, Director del INI, en la que propone el programa de trabajo que habrá de desarrollar et CCIT en Guachochi, Chih. México D.F., 18 de junio de 1952".
} 
médicos, prácticos agricolas, promotores y auxiliares que lo integró enfrentó con más mistica que medios las innumerables necesidades previamente detectadas en el medio indigena serrano. ${ }^{14}$ Su programa de trabajo se resumía en el principio de la acción integral: una vez investigadas las condiciones culturales y las posibilidades de desarrollo de la zona, era preciso emprender acciones conjuntas y articuladas en materia de promoción económica, fomento educativo, integración geográfica, impartición de servicios médicos, atención de los asuntos agrarios y de justicia y en todos aquellos aspectos ligados al mejoramiento de las poblaciones indigenas. ${ }^{15}$ En muchos sentidos, los directivos locales del CCIT gozaron de una relativa autonomía para establecer prioridades de trabajo y para seleccionar los lugares más propicios para iniciar su programa de acción. Alfonso Caso, por entonces director general del INI, reconocia asi que la experiencia y el conocimiento del equipo de Plancarte sobre los problemas de la Tarahumara resultaban la mejor garantía de éxito para las labores del INI que, por entonces, sólo tenia como único referente de un trabajo similar el que habia iniciado, sólo un año antes, el Centro Coordinador Indigenista de San Cristóbal de las Casas, Chiapas. Así, en estos primeros años de su existencia, el CCIT, aunque asumió de la experiencia chiapaneca algunas líneas generales de trabajo, también adaptó otras y creó algunas más, a partir de la situación particular de la Tarahumara, como fue el caso del programa forestal y la creación de las escuelas albergue, temas de los que hablaremos más adelante.

En diciembre de 1956 y después de 4 años y 3 meses de operaciones, el CCIT trabajaba con un presupuesto anual de 1 millón de pesos y una planta de 106 empleados, habia construido varias oficinas, casas para sus empleados, clinicas, aulas, salones de actos, talleres, caballerizas y gallineros en Guachochi y Baquiriachi. Además

\footnotetext{
${ }^{14}$ En enero de 1953 Plancarte informaba a Caso que desde noviembre de 1952 las oficinas, salón de clases, comedor y lugar de habitación del personal del CCIT estaban provisionalmente instalados en una casa desocupada de la Colonia de Promoción Indigena de' Guachochi que su director, "viejo conocido y amigo" de Plancarte les habia prestado. ("Informe de labores del CCIT correspondiente a noviembre y diciembre de 1952, Guachochi, 5 de enero de 1953", en ACCIT Legajo 148, Expediente 5).

${ }^{15}$ El principio de la acción integral aparece en muchos de los textos de su principal teórico. Aguirre Beltrán. Por lo que a la Tarahumara se refiere puede verse Romano, 1962.
} 
habia habilitado 42 pequeñas escuelas o promotorias y otras tantas viviendas para sus promotores culturales y edificado 15 escuelas modernas de mamposteria en los poblados de Nacásorachi, Pesáchi, La Nopalera, El Cuervo, Ohuivo, Sepórachi, Agua Zarca, El Almagre, Bahuéachi, Tecorichi, Pahuiránachi, Cuechi de Pilares, Cuechi de la Ciénega, Murachárachi y Cumbre de Huérachi, donde se repartían diariamente $\mathbf{4 8 0}$ desayunos escolares.

Las actividades de promoción económica del Centro se habian orientado a la plantación de 5,000 manzanos en 25 huertos escolares y 11 comunidades, la instalación de 23 trojes comunales con semillas por valor de 80,000 pesos, la asesoría agricola a comunidades y la distribución en ellas de semillas mejoradas de papa, frijol y avena por un valor de 40,000 pesos, la inversión de 250,000 pesos en la conservación y mejoramiento de caminos (de Guachochi a Agostadero de Aguirre y de Terrero a Arbolito en la carretera Guachochi-Parral, además de las brechas Siquirichi-Norogachi y Guachochi-Rochéachi) y de otros 8,000 pesos en la construcción del campo aéreo de Guachochi (estableciéndose una ruta aérea, con dos vuelos semanales, entre Chihuahua y Guachochi), la fabricación de muebles escolares, la instalación de 6 costureros comunales y 1 taller de enseñanza de tejidos de lana, la organización de 1 unidad de explotación forestal en Cusárare, la instalación de 4 dispensarios médicos en Baquiriachi, Tónachi, Cusárare y Guachochi, cada uno de ellos, sede de campañas de combate a endemias y epidemias, de dedetización y desparasitación así como de impartición de más de 7,200 consultas médicas anuales a indigenas y mestizos. ${ }^{16}$

\footnotetext{
${ }^{16}$ El personal del CCIT estaba distribuido en las secciones de Dirección (1 director maestro y antropólogo, 1 antropólogo auxiliar, 1 administrador, 1 encargado de ayudas audiovisuales educativas y 2 auxiliares), Salubridad (4 médicos y 12 enfermeras y enfermeros), Educación (1 director, 3 supervisores y 51 promotores tarahumaras de ambos sexos). Economia ( 2 ingenieros, 4 prácticos agricolas, 1 administrador forestal y otro de caminos, 1 maestra de tejidos, 4 carpinteros y 5 albañiles) y Servicios generales (2 mecánicos, 4 choferes, 1 almacenista y 4 veladores). Todos estos datos sobre la operación del CCIT provienen de "Informe general resumido de labores que el personal del Centro rinde al C. Presidente Constitucional de los Estados Unidos Mexicanos, Don Adolfo Ruiz Cortines, con motivo de su visita a Chihuahua, 20 de diciembre 1953" ACCIT, en Legajo 27, Expediente 5.

Los detalles sobre todas estas actividades pueden verse tambien en los informes mensuales y anuales rendidos por el profesor Plancarte al doctor Caso entre 1952 y 1955 en ACCIT, Legajo 155. Expediente 36, Legajo 148, Expediente 5. Legajo 11, Expediente 11. Legajo 150. Expedientes 18 y 27 y Legajo 144, Expediente 6. También en Anonimo, 1954 y 1955 a y $1955 \mathrm{~b}$.
} 


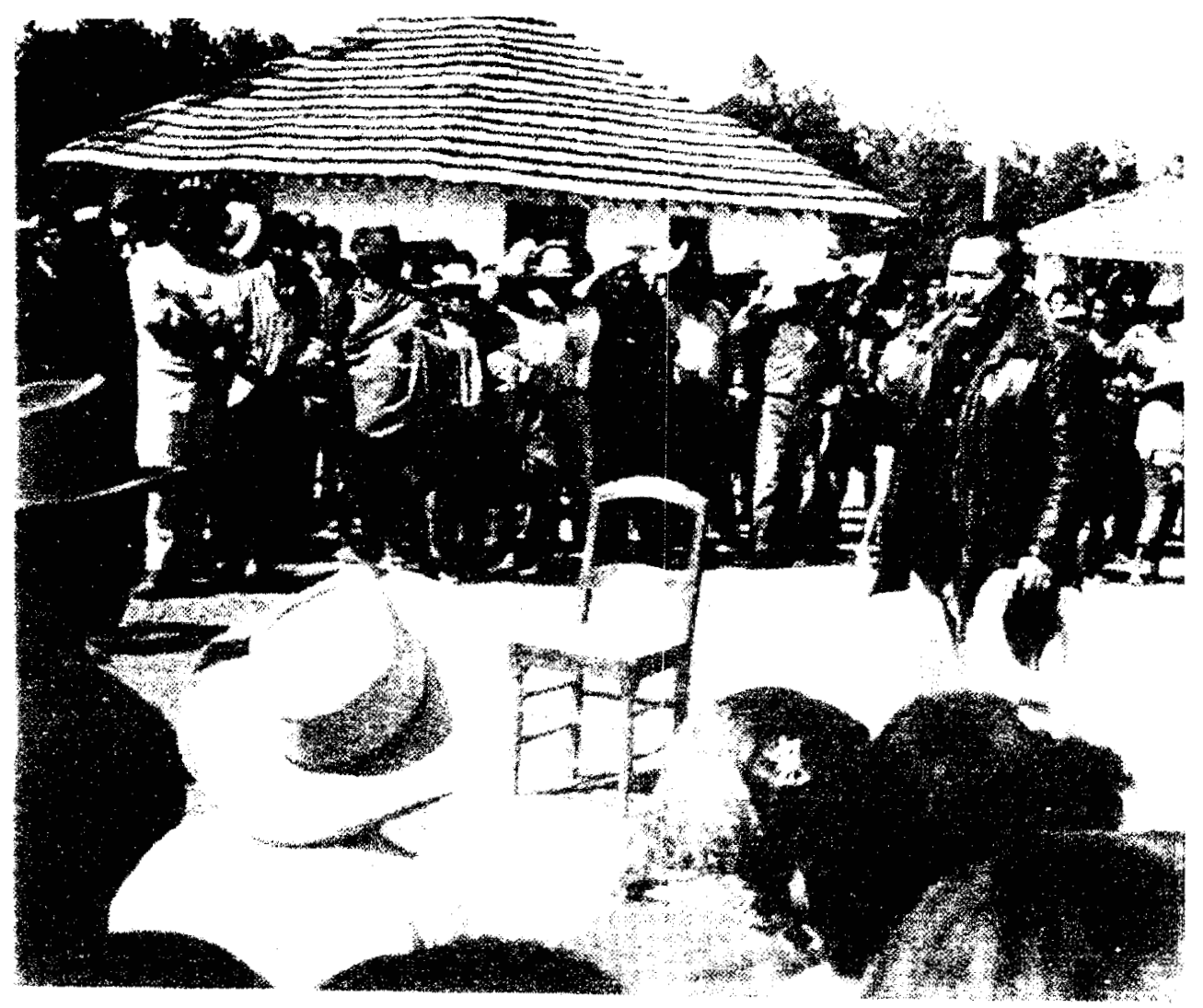

FIGURA 51. FRANCISCO M. PLANCARTE, PRIMER DIRECTOR DEL CCIT. GUACHOCHI, 1953 (PLANCARTE, 1954)

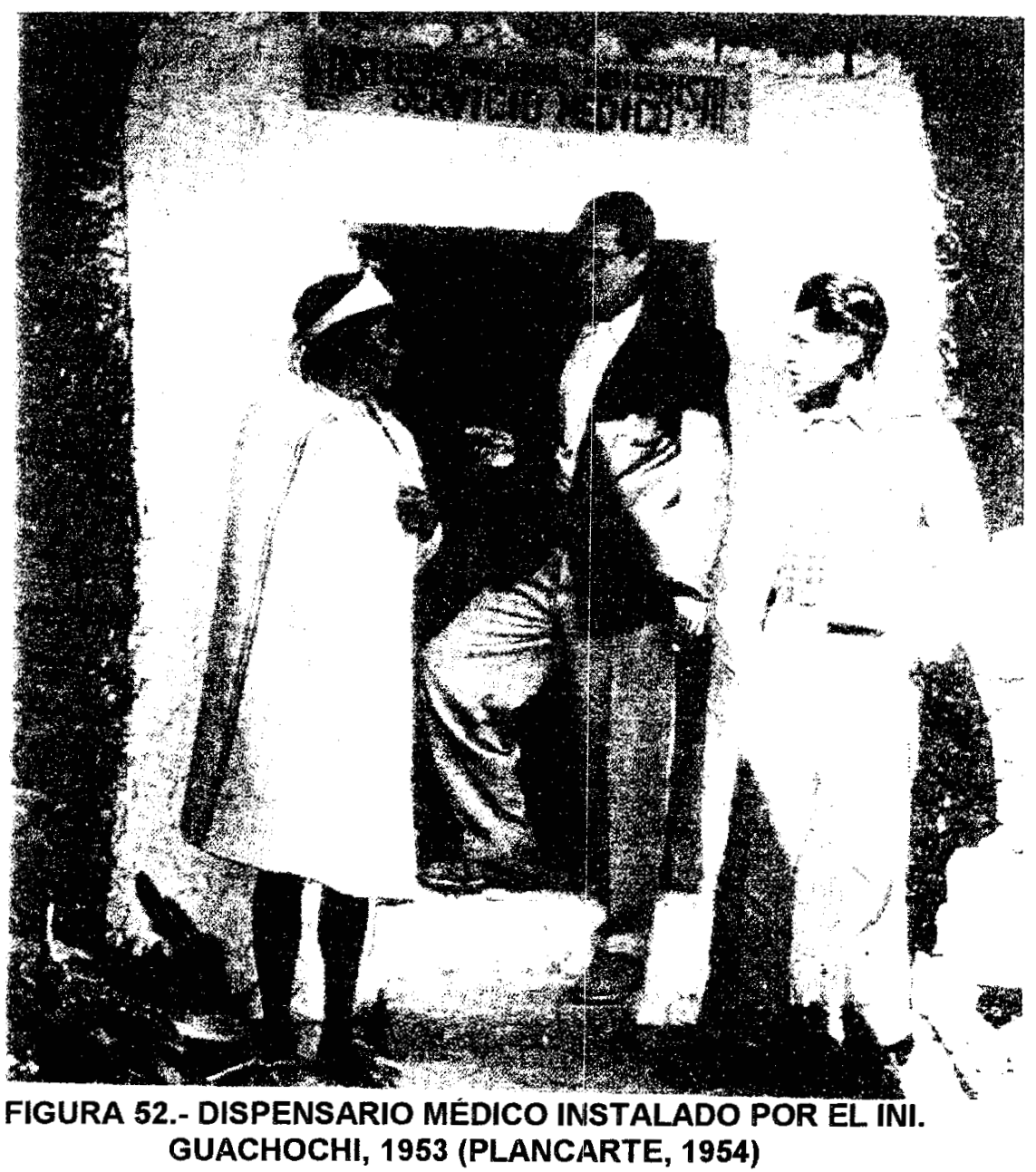




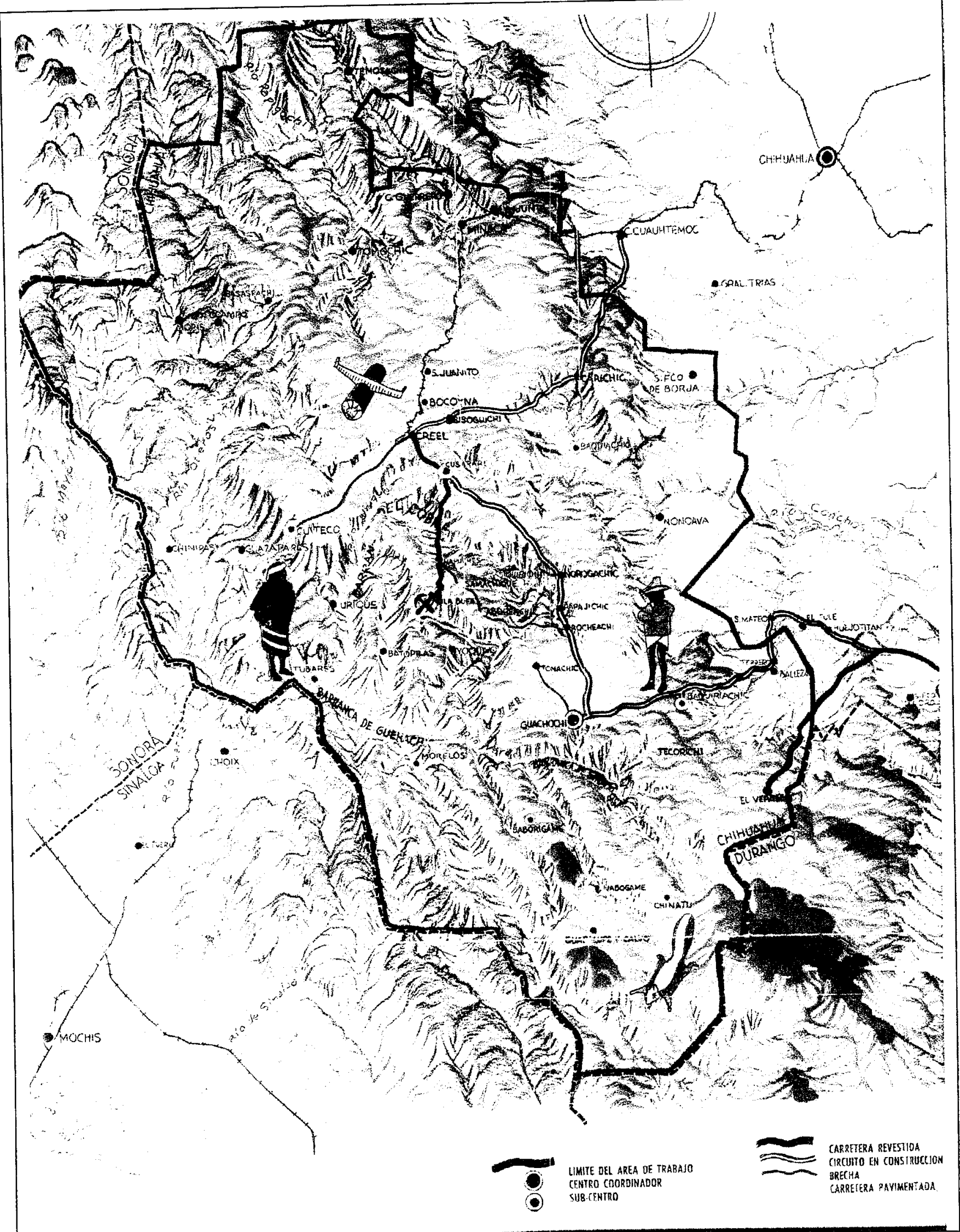

FIGURA 53.- AREA DE TRABAJO DEL CENTRO COORDINADOR INDIGENISTA DE LA TARAHUMARA. 1953 (PLANCARTE, 1954) 


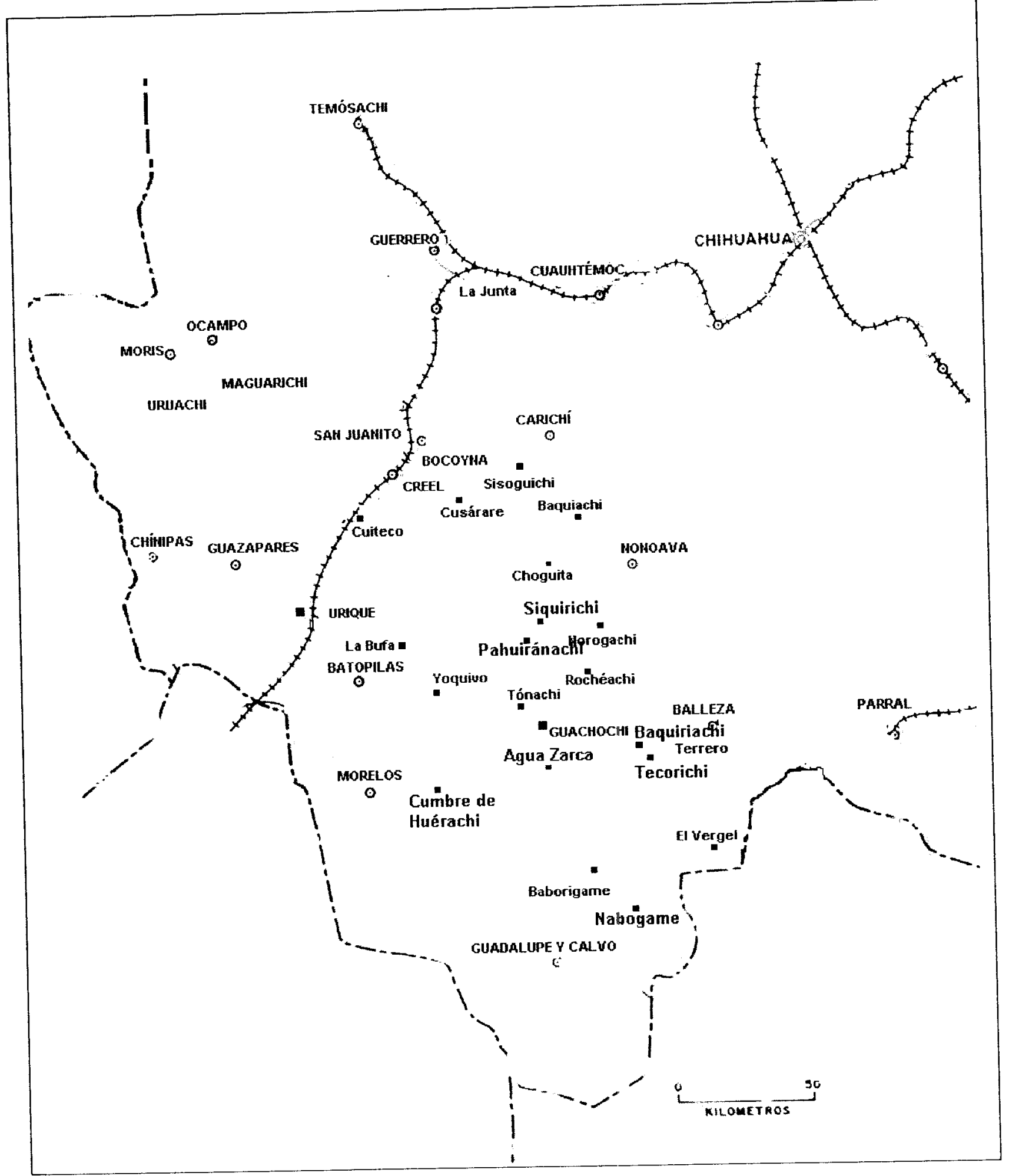

FIGURA 54.- LUGARES ESTRATÉGICOS PARA LAS ACTIVIDADES DEL CCIT EN 1953, SEGÚN LOS PLANES DE PLANCARTE Y AGUIRRE BELTRÁN 


\section{I.- LENGUANE.}

a. Reglas generales fonético-fonémicas del tarahumara.

b. Alfabeto tarahumara. Ejercicios de lecto-escritura.

c. Expresión de ideas y composición en tarahumara. Traducción.

d. Redacción de correspondencia en tarahumara y español.

e. Expresión oral en tarahumara sobre aspectos del trabajo del promotor.

g. Enserianza a niños y adultos de la lectoescritura en tarahumara

h. Preparación de la guia fonética en tarahumara.

i. Preparación de material didáctico para enserianza de lecto- escritura.

j. Manejo y uso de la cartilla tarahumara. (monolingues).

k. Técrica de enseñanza del español a monolingües tarahumaras.

1. Preparación del método de enserianza de espariol a monolingües.

m. Preparación del material didáctico para enserianza de español oral.

n. Preparación de material didáctico para enserianza de lecto-escritura a tarahumaras bilingües.

ก. Técrica de enseñanza de la fonetica y fonemica del español.

II.- CALCULO.

a. Cálculo y expresión numérica de relación y proporción en tarahumara b. Mecanismo oral de ejecución de operaciones basicas.

c. Técnica enseñanza de nociones primarias de cálculo en tarahumara.

d. Preparación del material didáctico para enseñanza del cálculo.

\section{III.- CIENCLAS NATURALES}

a. Conocimiento del medio geofisico: plantas, animales, minerales. fenómenos naturales, accidentes geográicos. recursos naturales y su aprovechamiento, etc.

b. Conocimiento del cuerpo humano: partes, sistemas óseo. circulatorio y nervioso, aparatos, órganos y funciones.

c. Nociones generales y hábitos de higiene: baño, corte de pelo, empleo del peine. combate de parásitos. aseo de las manos y boca. etc.

\section{IV.- CIENCLAS SOCLALES.}

a. Civismo: El grupo indigena tarahumara, otros grupos indigenas del pais, otros sectores de población nacional. Patria mexicana y ciudadania. Leyes que dan plena categoria de ciudadanos a los indigenas y demás sectores de población nacional sin distingos raciales. Autoridades indigenas. Autoridades constitucionales. Gobiemo municipal. Gobierno del estado.Presidente de la Republica. Centro Coordinador de la Tarahumara y sus dependencias. INI. Escuelas primarias, internados. procuradurias. brigadas de mejoramiento indigena, comunidades de promoción indigena. Secretaria de Educacion. Actividades que tiendan a la formación de hábitos de solidaridad ciudadana y humana

b. Historia: Biografias de héroes indigenas y otros héroes nacionales. Biografias de personas significadas por su labor indigenista. Fechas de conmemoración patriótica y civica.

c. Geografia: Rancheria. pueblo. pueblos vecinos, municipio. Sierra estado de Chihuahua y sus lugares más significativos. La patria mexicana y su capital.

\section{ORGANIZACIÓN ESCOLAR.}

a. Problemas de orden material: edificio escolar. casa para el maestro, muebles, útiles escolares. de aseo y de trabajo escolar Anexos: excusado, baño. campos deportivos. huerto y parcelas escolares. gallinero, porqueriza, apiario. etc.

b. Problemas técnicos: Censo escolar, libro de inscripcion, libro de asistencia, estadistica, informes, arctivo, periódico mural, biblioteca. control. gobierno y administración del alumnado. clasificacion de grupos. horarios de trabajo y calendario escolar, preparación de clases, pruebas. contro de resultados, manualidades. su importancia.

c. Trabajo de extensión educativa a la comunidad: affabetización de aduttos, extensión de actividades educativas agropecuarias y de saiubridad e higiene. Organización de la comunidad. Elaboración y realización de planes concretos de superación comunal, utilizando la organización actual de los indigenas para mayor simplicidad. Actividades con la comunidad: Trojes comunales, viveros frutales. posta zootécnica. campañas profilácticas, selección de semillas. conservación-abono de terrenos, arreglo vias de comunicación, etc.

\section{V.- ACTIMDADES AGROPECUARIAS.}

A. AGRICOLAS. Preparación de las tierras para la siembra.

a. Barbechos: Épocas adecuadas para arar. Arado en terrenos con declive. Cruzado del barbecho. Arrastrado

b. Protección de los suetos: La erosión: qué es y cómo combatirla. Forma de cultivos para proteger los suetos. Rotación de cultivos. Reforestación.

c. Abonos: El guario y modo de empleario. Empleo racional de abonos de cabra. oveja. res y caballo. Abonos verdes.

d. Seleccion de semillas: maiz. frijol, papa. calabaza y otras

e. Cuttivo racional de estas plantas.

f. Plantas horticolas: Su importancia en la alimentación indigena. Pequeñas hortalizas caseras. Cultivo de repollo, lechuga. rábano, ajo. cebolla y espinaca.

g. Pruebas de germinación de semillas y combate de plagas.

h. Combate de incendios.

i. Nuevos cultivos.

j. Apertura de nuevas tierras

k. Implementos agricolas.

1. Arboles frutales: Cultivo de manzano y durazno. Semilleros. Viveros. Injertos. Variedades. Trazo de huertas. Podas. Plagas. Riego. Cosecha.

B. PECUARIAS

a. Las mejores razas: Vacunos. Ovicaprinos. Porcinos. Gallinas.

b. Viviendas de animales: Su construcción e higiene.

c. Alimentación y cuidado de los animales anotados.

c. Enfermedades: La mancha. Fiebre carbonosa. Septicemia hemorrágica. Piroptasmosis bovina. Bola de Gurma. Cótera porcino. Compticaciones mixtas.

e. Sintomatologia. prevención y combate de dichas enfermedades.

f. Modo de aplicar inyecciones a los animales.

h. Mètodos para dirigir campañas por medio del convencimiento entre los indigenas para impartir los conocimientos antes expuestos. (La enseñanza de los anteriores puntos se llevará a cabo por medio de clases prácticas. orales y resuimenes escritos. adaptados al lenguaje tarahumara en cuanto sea posible)

\section{VII.- EDUCACIÓN MÉDICOSSANUTARIA.}

a. Higiene: Personal, alimenticia, del agua. de enfermos y habitacional.

b. Concepto de esterilización: Ebullicion y flameo.

c. Uso del termometro y aplicación de inyecciones: Hemostasia. Antibiosis. Analgesia.

d. Tratamiento de infecciones: Abcesos superficial y profundo.

e. Método de recolección de diversos sintomas: Digestivos. respiratorios y articulares

f. Uso de diversos antibióticos y analgésicos: Penicilina. sulfas. emetina. aspirina. cibalgina, etc.

g. Primeros auxilios: Vendajes, curaciones primarias de quemaduras. fracturas. hemorragias, chocks. traslado de heridos y enfermos, etc.

h. Planeación y conducción de campañas médico-sanitarias: Endernias. epidemias. medios de control. etc

\section{VIII.- NOCIONES RÁSHCAS DE PSKCOLOGIA EDUCATIVA.}

Qué es el hombre desde el punto de vista de la psicologia educativa. Genotipo. paratipo. fenotipo. Sistema nervioso. Clasificacion de alumnos. Pruebas de inteligencia. Defectos principales de los sentidos

Temperamento. carácter. complejos. infivencia del medio fisico y de la cultura en la conducta. Vaiores y controles sociales.

FUENTE: Elaborado a partir del "Informe de Labores del CCIT en febrero de 1953, de F.M.Plancarte". ACCIT. Legajo 150. Expediente 7. 
El proyecto estratégico del naciente centro fue sin embargo el de la formación de un grupo de 51 promotores culturales indigenas, concebidos por el equipo de Plancarte como los verdaderos extensionistas y agentes del cambio cultural en la Tarahumara. Tras un periodo de un año de formación, estos promotores fueron distribuidos en 41 rancherias indigenas donde comenzaron a difundir de manera escolarizada e informal entre 1,099 alumnos sus conocimientos básicos en materia de alfabetización en rarámuri y español, operaciones básicas de cálculo, principios médica-sanitarios, mejoramiento agropecuario y derechos agrarios.

El programa de formación de estos promotores, que se resume en el Cuadro 20, muestra con claridad la impronta que la vieja experiencia de la educación rural y de las misiones culturales dejó en el proyecto educativo que el INI instauró en la Tarahumara al inicio de los años cincuenta. Se trataba de crear un nuevo liderazgo indígena, integrado por jóvenes tarahumaras semi-scolarizados, conocedores y respetuosos de su propia cultura pero formados también en la creencia de las bondades del progreso y la modernización que el INI predicaba. Sin embargo, no siempre el dificil equilibrio entre estas dos alternativas parece haber sido logrado por estos nuevos intermediarios culturales tal y como lo detectaba por entonces el antropólogo norteamericano John G. Kennedy:

El programa educacional del Instituto difiere en cuanto a métodos del de Asuntos Indigenas. En lugar de llevar a los niños a escuelas donde viven permanentemente (internados), ha iniciado un sistema de entrenamiento por medio del cual los jóvenes tarahumaras fungen como promotores (maestros) en las escuelas diarias de la comunidad. Me parece que este sistema ha tenido mayor influencia sobre los mismos promotores que sobre los estudiantes a los que deben instruir. Muchos promotores se han constituido dentro de su propia comunidad en "hombres marginales" faltándoles además el conocimiento requerido para enseñar efectivamente. Estos marginales fluctúan entre los intentos por emular a los mestizos y asociarse con ellos, y la participación sincera en las tradicionales tesgüinadas, con el consecuente abandono de las responsabilidades docentes.

También se encuentran en la posición ambivalente de ser mediadores de los contactos necesarios entre las dos culturas, debido a su habilidad para leer $y$ escribir el español. En ocasiones se encuentran rechazados por la comunidad debido a su asimilación a ciertos rasgos mestizos no aceptados. (Kennedy, 1970: 25). 


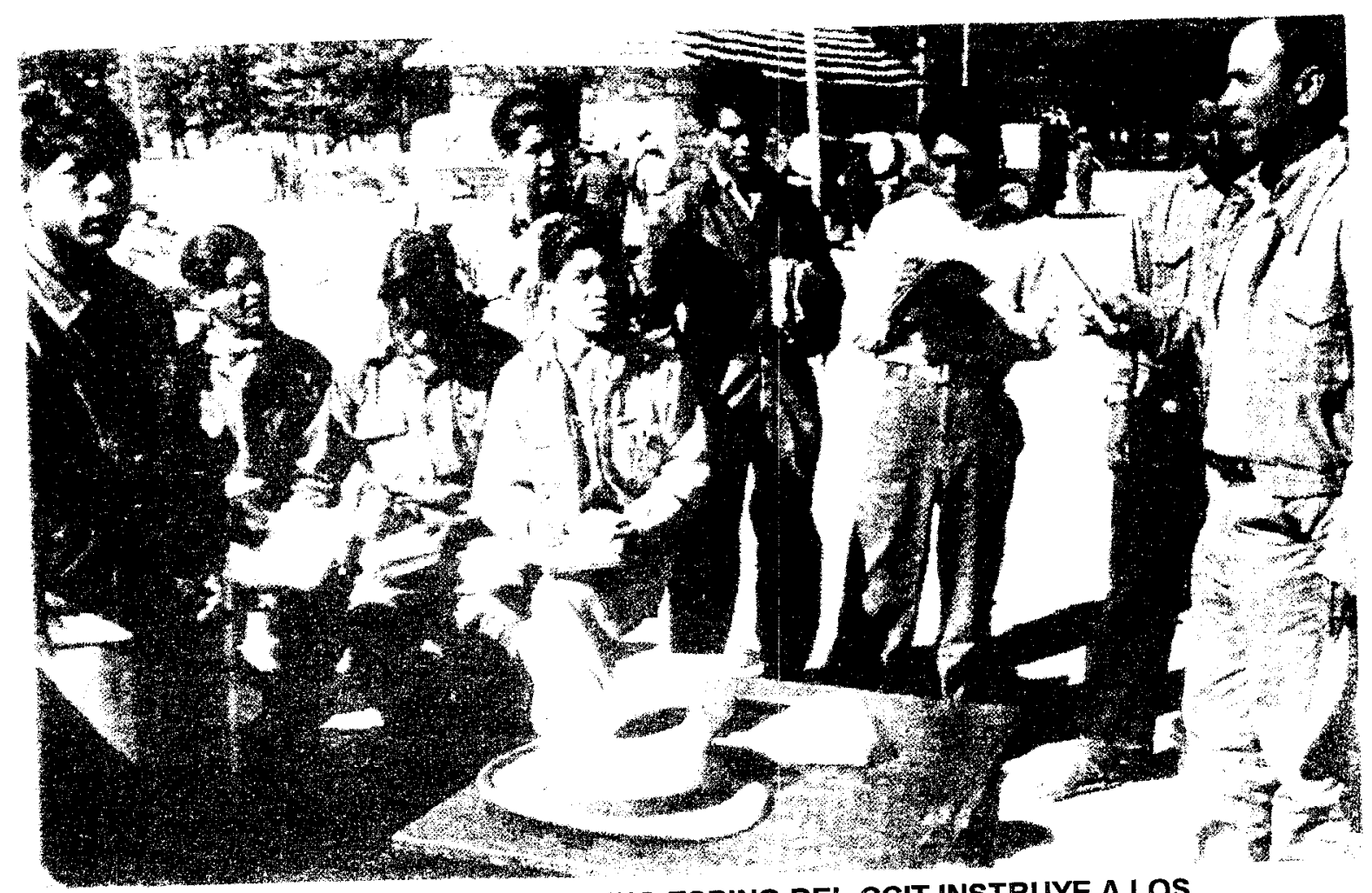

FIGURA 55.- EL PROFESOR SILVINO ESPINO DEL CCIT INSTRUYE A LOS PROMOTORES CULTURALES INDIGENAS. GUACHOCHI, 1953 (PLANCARTE, 1954)

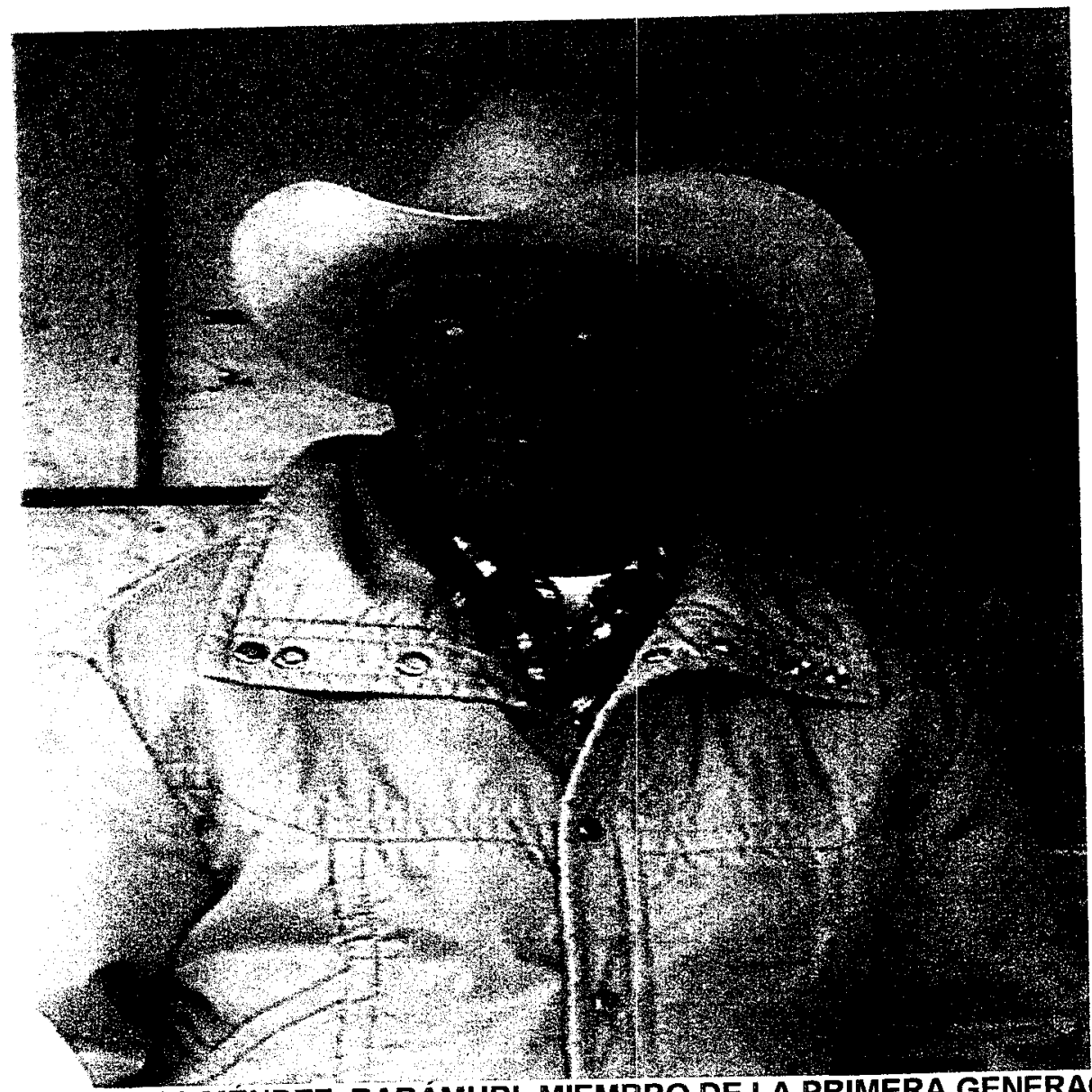

FIGURA 56.- ANTONIO MÉNDEZ, RARÁMURI, MIEMBRO DE LA PRIMERA GENERACIÓN DE PROMOTORES CULTURALES DEL CCIT EN 1953. (FOTO DEL AUTOR, JULIO, 1998) 
El programa educativo del CCIT sustentado en la labor de los promotores culturales indígenas representaba una ruptura con el sistema de los internados que el Departamento Autónomo de Asuntos Indígenas habia instalado en la Tarahumara, desde el inicio de los años treinta y que han seguido funcionando hasta la actualidad. En efecto, la figura del promotor se acercaba más a la del "misionero cultural" -por sus tareas de extensionista agrario, agente de salud, impulsor del desarrollo de los pueblos y gestor de sus demandas sociales- que a la del maestro "de aula" caracteristica del sistema de educación formal y escolarizada de los internados. También el hecho de que todos los promotores fueran indigenas, tuvieran que residir en los lugares de trabajo y trataran de conseguir el apoyo de los gobernadores locales, permitió una más estrecha vinculación entre la escuela y los pueblos (Tello, 1994: 140-144)

Si desde el punto de vista de la escolarización y la educación informal el nuevo proyecto indigenista se sustentó en la creación de un nuevo liderazgo personificado en la figura de los promotores culturales, en cuanto a su orientación productiva la propuesta del CCIT derivó de una filosofia del desarrollo indigena cuyo pivote fundamental habria de ser la apropiación y explotación de los recursos forestales.

\section{La centralidad de lo forestal en el modelo indigenista del desarrollo.}

A diferencia de lo que sucedió en otras regiones del pais, el indigenismo oficial de los años cincuenta planteó unánimemente en la Sierra Tarahumara una estrategia del desarrollo indígena centrada básicamente en la vía forestal, lo que, como veremos, otorgó a este modelo indigenista, a la vez, una notoria fortaleza y debilidad.

Chihuahua es uno de los estados de la República con mayores riquezas forestales. Sus bosques y áreas arboladas se extienden en efecto por una extensión de cerca de 5 millones y medio de hectáreas, lo que casi equivale a la superficie conjunta total de los estados de Puebla, Querétaro, Tlaxcala y Colima. La mayor parte de esta masa forestal está compuesta por cerca de 4 millones de hectáreas de coniferas mezcladas con latifoliadas (pino, encino, táscate, pinabete y madroño) y se localiza en la 
Alta Sierra Tarahumara, en el territorio de los pueblos rarámuri y ódame y en, menor medida, en el de los warijó y o'óba. Sólo en los municipios de influencia del CCCIT una fuente estimaba en 1965 algo más de 3 millones de hectáreas de bosques en su mayor parte propiedad de ejidos y comunidades. (Cuadro 21).

\section{CUADRO 21.- SUPERFICIES FORESTALES EN MUNICIPIOS DE LA TARAHUMARA. (CIRCA 1965)}

\begin{tabular}{|c|c|c|c|c|c|c|}
\hline MUNICIPIO & $\begin{array}{l}\text { SUPERFICIE. } \\
\text { BOSCOSA } \\
\text { (Has.) }\end{array}$ & $\begin{array}{l}\text { PINO Y } \\
\text { CONIFERAS } \\
\text { (Has.) }\end{array}$ & $\begin{array}{l}\text { PINO } \\
\text { ENCINO } \\
\text { (Has.) }\end{array}$ & $\begin{array}{l}\text { PARTICULAR } \\
\%\end{array}$ & $\begin{array}{c}\text { EJIDAL } \\
\%\end{array}$ & $\begin{array}{l}\text { COMUNAL } \\
\%\end{array}$ \\
\hline BALLEZA & 319.137 & 217.046 & 102,091 & 21.95 & 78.05 & - \\
\hline BATOPILAS & 122,062 & 57,585 & 64,477 & 22.99 & 77.01 & - \\
\hline BOCOYNA & 238,497 & 163,392 & 75,105 & 20.02 & 77.19 & 2.90 \\
\hline CARICHI & 29,677 & 7.948 & 21,729 & 53.71 & 34.91 & 11.38 \\
\hline GUACHOCHI & 320,758 & 191,621 & 129,137 & 10.87 & 88.69 & 0.44 \\
\hline GUERRERO & 219,002 & 38,566 & 180,436 & 27.15 & 70.95 & 1.90 \\
\hline NONOAVA & 43.098 & - & 43,098 & 100.00 & - & - \\
\hline TEMÓSACHI & 222.177 & 51,256 & 170,921 & 31.82 & 62.12 & 6.06 \\
\hline CHINIPAS & 10.808 & - & 10,808 & 71.87 & 18.75 & $9.38^{\circ}$ \\
\hline GUAZAPARES & 226.248 & 113.305 & 112,943 & 80.39 & 19.61 & - \\
\hline GPE CALVO & 679.174 & 281,178 & 397,996 & 37.50 & 62.50 & - \\
\hline MAGUARICHI & 48.074 & 37,263 & 10,811 & 71.98 & 28.11 & - \\
\hline MORELOS & 66.763 & 29,717 & 37,046 & 76.72 & 23.28 & - \\
\hline MORIS & 122.831 & 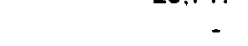 & 122,831 & 17.32 & 82.68 & - \\
\hline OCAMPO & 271.075 & 138.775 & 132,300 & 47.85 & 52.15 & - \\
\hline URIQUE & 164.150 & 111.557 & 52,593 & 24.28 & 75.72 & - \\
\hline URUACHI & 97.905 & 32.148 & 65,757 & 13.07 & 86.93 & - \\
\hline TOTAL & $3 \cdot 201,436$ & 1471,357 & $1,730,079$ & & & \\
\hline
\end{tabular}

FUENTE: Alcocer, 1987: 39-48

Desde principios de este siglo, algunos pueblos de la Tarahumara comenzaron a explotar sus bosques como consecuencia de la demanda de madera que derivó de la expansión de los ferrocarriles y la apertura de minas. Pero puede decirse que no fue sino hasta principios de los años cuarenta cuando los ejidos y pueblos con población indigena del estado fueron incorporados formalmente a la actividad forestal. Recordemos que en ese período, la madera tuvo un gran mercado en los Estados Unidos a causa de la Segunda Guerra Mundial.

Desde los años treinta, una diversidad de compañías madereras, algunas medianas y otras grandes, pero en su mayoria locales, comenzaron a adentrarse por esos años en la Sierra Tarahumara, a partir de lugares como Guachochi, Madera, Creel y Parral. El Cuadro 22 muestra una visión global de la situación de las explotaciones 
forestales en el momento en que el INI se instaló en Guachochi. En el cuadro se enlistan las compañias madereras que operaban en la zona de influencia del CCIT entre 1948 y 1951. Se trata de grandes y medianas empresas regionales (como las compañías Maderas de Chihuahua, Industrial Maderera, González Múzquiz, Alcocer Godoy, Aserraderos González Ugarte, etc.) y sólo en muy pocos casos de cooperativas ejidales (como fue el caso del ejido de Heredia y del de Cusárare). Estas compañias explotaban reservas forestales en diferentes predios o áreas boscosas, algunas de ellas propiedad de las mismas empresas, otras de mestizos serranos, otras de ejidos y otras muchas más en trámite de resolución agraria. ${ }^{17}$

La codicia de estas empresas desencadenó un sinnúmero de conflictos con los habitantes indígenas y mestizos de la región, por causa de invasiones de tierras, talas clandestinas y destrucción del bosque. Al mismo tiempo, esta situación provocó que muchas poblaciones indigenas cobraran conciencia de sus derechos sobre la tierra y los bosques y emprendieran una lucha ante las autoridades agrarias para que se crearan, dotaran de tierra y reconocieran legalmente los ejidos y comunidades agrarias de la Tarahumara.

No siempre esta lucha fue exitosa. En algunos casos, los ejidos que habian sido decretados "en el papel", comenzaron a ser una realidad. En otros casos, en cambio, personas y empresas advenedizas obtuvieron la propiedad sobre terrenos nacionales, bosques y suelos agricolas que habian sido ocupados desde tiempos arcaicos por los grupos étnicos serranos. Pero casi siempre, el bosque con el que antes la gente de la Sierra habia vivido pacificamente aprovechándolo para enfrentar sus necesidades

\footnotetext{
${ }^{17}$ Es importante señalar que, por esos años, muchos núcleos de población serrana (indígena y mestiza) estaban gestionando sus demandas agrarias, proceso que implicaba largos y costosos trámites para conseguir la dotación de tierras, la resolución definitiva, la ejecución de los acuerdos por parte de las autoridades agrarias y el reconocimiento oficial de los ejidos y comunidades agrarias. En muchos casos, este proceso burocrático se complicaba aún más por causa de conflictos de limites entre ejidos o por la depuración de las listas de los solicitantes de tierras. Hasta la llegada del INI en la Tarahumara, los indigenas no contaron con ningún tipo de apoyo legal para emprender estos trámites, lo que explica que la constitución de ejidos con mayoria de población indígena fuera tardía. En todo caso, esta situación de irregulanidad en la tenencia de la tierra propició la voracidad de las compañias madereras.
} 
básicas, comenzó a ser objeto de codicia, explotación desmedida, depredación, conflictos con las empresas madereras y antagonismos interétnicos. ${ }^{18}$

Cuando los ejidos forestales con población indigena ${ }^{19}$ fueron legalmente reconocidos, se vieron sin embargo imposibilitados de explotar de forma costeable sus reservas madereras porque para ello se requerian fuertes capitales y costosas maquinarias y equipos además de una compleja administración y comercialización de la madera. Fue por ello que las empresas monopolizaron la actividad forestal, estableciendo con las autoridades de la Secretaria de Agricultura contratos que estipulaban el pago a los ejidos, dueños de los bosques, de una pequeña participación en las utilidades de las empresas, la que, en realidad, equivalía a raquiticas cantidades

${ }^{18}$ Entre los numerosos testimonios escritos de reclamos de indigenas serranos contra empresas madereras pueden consultarse, a modo de ejemplo: "Queja que expone el indigena Juan González en relación a la explotación forestal que ha realizado cierta empresa en terrenos de su comunidad en Cabórachi, 12 de marzo de 1969" en ACCIT, Legajo 9, Expediente 24, Documento 1; "Enfrentamiento armado entre ejidatarios de Tónachi y personal de la compañia maderera Industrial González Ugarte S.A. y conflicto entre ejidatarios de Nachácachi y las empresas forestales del señor Alcocer Patiño, 1963" en ACCIT, Legajo 10, Expediente 2; "Quejas y denuncias de ejidatarios en contra de compañia maderera IGUSA por despojos, 1954" en ACCIT, Legajo 130, Expediente 17; "Queja del gobernador de San Carlos, Balleza en contra de personas invasoras que explotan indebidamente bosques del ejido, 30 de diciembre de 1961" en ACCIT, Legajo 3. Expediente 25 y "Quejas del Comisariado ejidal de Pahuichique en contra de compañia maderera por no cumplir con estipulaciones de contrato, 21 de febrero de 1961" en ACCIT, Legajo 3, expediente 40

La codicia por la explotación forestal desencadenó también conflictos interétnicos como el que surgió en Baborigame en 1968, cuando el Capitán general y gobemador local (véase lo que señalamos sobre el sistema de cargos entre los tepehuanes en nota 66 del capitulo 2) se quejaban ante el INI de que los mestizos locales estaban tratando de acordar a sus espaldas con las compañias madereras desconociendo el sistema tradicional de toma de decisiones entre los tepehuanes:

... Y también si quiere saber cuales son los cargos que hacen los ejidatarios en contra del Comisariado ejidal es que nosotros tenemos estos cargos: el de gobemadorcillo y dos Cabos y un Capitán General que son puestos [que existen] desde principios de este pueblo. Ahora los mestizos quieren explotar los bosques sin tomamos el parecer [para saber] si estamos de acuerdo todos y dicen que cuando se trate de contratar la madera que lo que reciban de la madera será para ellos, los de clase mestiza y separamos de ellos, que no tengamos derecho. Por eso es que pedimos que nos pongan un Comisariado ejidal de clase indigena... (ACCIT, Legajo 58, Exp. 5).

${ }^{19}$ Utilizamos el término de "ejidos con población indigena" y no "ejidos indigenas", porque en la Tarahumara son muy pocos los ejidos integrados exclusivamente por población indigena y lo normal es que ésta conforme entre el 60 y el $90 \%$ del padrón de ejidatarios. Este hecho confirma lo que ya señalamos en el capitulo 2: las leyes agrarias posteriores a la revolución no respetaron la estructura de los territorios indigenas. 
CUADRO 22.- EMUPRESAS Y EXPLOTACIONES MADERERAS (PINO) EN EL AREA DE IMFLUENCIA DEL CENTRO COORDINADOR INOIGENISTA DE LA TARAHUMARA. 1948-1951.

\begin{tabular}{|c|c|c|c|c|c|c|}
\hline \multirow{2}{*}{$\begin{array}{l}\text { EXPLOTADOR } \\
\text { Cia Hispano Mexicana S.de R.L. }\end{array}$} & \multirow{2}{*}{$\begin{array}{l}\text { PREDIO (1) } \\
\text { Alamo Mocho }\end{array}$} & \multirow{2}{*}{$\frac{\text { MUNICIPIO }}{\text { Ocampo }}$} & \multicolumn{2}{|c|}{$\begin{array}{l}\text { VOLUMEN AUTORIZAD } \\
\text { Metros cubicos Fecha } \\
\text { en rollo (2) del estudio }\end{array}$} & \multicolumn{2}{|c|}{$\begin{array}{l}\text { VOLUMEN EXPLOTADO } \\
\text { (mts. cúbicos) (3) } \\
\text { ASERRADOS LABRADOS }\end{array}$} \\
\hline & & & 28.000 & 1944 & 10.200 & 3.200 \\
\hline Vidal Batista & Baburechi y Sagochito & Bocoyna & 8.013 & 1945 & 2.000 & 7.000 \\
\hline Ing. Raúl Chávez & Batuybo & Bocoyna & 17.163 & 1946 & 11.160 & 8.359 \\
\hline Raúl Gonzàlez Múzquiz & Cuevas Blancas & Ocampo & 30,091 & 1947 & 33.986 & 2,709 \\
\hline Raúl Gonzàlez Müzquiz & Sono y Rocomachi & Bocoyna & 8,187 & 1946 & 6.452 & 723 \\
\hline Cia. Maderas de Chihuahua S.A. & Calaveras & Guerrero & 10,178 & 1943 & 6.723 &. \\
\hline Cia. Maderas de Chihuahua S.A. & Ejido de Talayotes & Bocoyna & 5.000 & 1944 & 2.000 & 169 \\
\hline Cia. Maderas de Chihuahua S.A. & Ejido Panalachi & Bocoyna & 42.646 & 1943 & 4.500 & 2.000 \\
\hline Cia. Maderas de Chihuahua S.A. & R.Nacional Papigochi & Bocoyna & 140.446 & 1945 & 75.435 & 1.520 \\
\hline Cia. Maderas de Chihuahua S.A. & San Pablo Sierra Lote E & Guertero & - & 1944 & 1.365 & - \\
\hline Juan Oscar Villazón & Calabazas & Bocoyna & 3.741 & 1946 & 5.470 & 913 \\
\hline Othón Diaz Quesada & Enaina Núñez & Guerrero & 14,600 & 3. 1946 & 8.575 & 624 \\
\hline Jesus Maria Pèrez & Ejido del Porvenir & Temósachi & 5,324 & 1945 & 1.432 & - \\
\hline Jesús Maria Pérez & Potrero de Rumurachi & Bocoyna & 3.000 & $\cdot$ & 3.500 & - \\
\hline Jesús Maria Pèrez & Ciènega de Guacaybo & Bocoyna & 4.163 & 1946 & 4.995 & 1,092 \\
\hline Abelardo S. Amaya S. en P. & Ejido de San Alonso & Urique & 24.143 & 1949 & 6.660 & 773 \\
\hline Soc. Coop. Ejidal de Cusarare & Ejido de Cusàrare & Batopilas & 8.424 & 1943 & 2.000 & 4.000 \\
\hline Sociedad Ejidal de Sisoguichi & Ejido de Sisoguichi & Bocoyna & 21.406 & 1944 & - & 2,500 \\
\hline Antonio Guerrero Peralta & Ejido San Luis Majimachi & Bocoyna & 6,000 & 1944 & 383 & 90 \\
\hline Antonio Guerrero Peralta & La Martha & Temósacti & 3.300 & 1945 & 1.407 & 375 \\
\hline Pilar Gonzàlez & Ejido de Creel & Bocoyna & 1.500 & 1946 & - & 502 \\
\hline Pilar Gonzàiez & Eno & Bocoyna & - & 1949 & - & 3.000 \\
\hline Pilar Gonzàlez & Ciènega de Guacaybo & Bocoyna & - & - & - & 3.000 \\
\hline Comisariado Ejidal & Ejido S.Ignacio Arareco & Bocoyna & 22,965 & 1944 & 2.010 & 618 \\
\hline Soc. Coperativa Ejido Heredia & Ejido Heredia y Anexas & Guerrero & 24.656 & 1941 & 6.841 & 1.006 \\
\hline Gabino HerTera & Eno & Bocoyna & 6.000 & 1944 & 3.093 & 980 \\
\hline Gregotio Cuesta & Eno & Bocoyna & 2.000 & 1948 & 1.800 & - \\
\hline Francisco Pérez & Ejido Arroyo de la Cabeza & Bocoyna & 6.000 & 1946 & 5.538 & 756 \\
\hline Comisariado Ejictal & Ejido de Huechovétavo & Bocoyna & 9.830 & 1943 & 2.107 & 554 \\
\hline Fernando Alcocer Godoy & Ejido de Tetahuichi & Batopilas & 45.442 & 1947 & 2.191 & - \\
\hline Fernando Alcocer Godoy & Ejido de Aboréactii & Batopilas & 31,424 & 1947 & 1.180 & - \\
\hline Cia. Maderas de Namiquipa & Hacienda Babicora & Temosachi & 5.500 & 1945 & 1.610 & - \\
\hline Hernàndez Gómez y Socios & Las Lagunas & Balleza & 61.347 & 1949 & 226 & 150 \\
\hline Cia. Nacional Maderera & Ejido de Samachique & Urique & 59.000 & 1947 & 5.387 & - \\
\hline Asertaderos Gonzàlez Ugarte & La Renga y Anexas & Urique & 18.891 & 1949 & 7.829 & 1.423 \\
\hline Aserraderos Gonzalez Ugarte & La Luciana & Guerrero & 59.571 & 1945 & 73.549 & 4,264 \\
\hline Aserraderos González Ugarte & Tuctieachi y Sapareachi & Bocoyna & 4.776 & 1944 & 2.026 & 1.223 \\
\hline Ing. Cipriano Estrada & Tónachi & Guerrero & - & 1946 & 2.412 & 225 \\
\hline Ing. Cipriano Estrada & Hacienda Babicora & Temósachi & 20.700 & 1945 & 8.150 & - \\
\hline Efrain Estrada & La Generala & Guerrero & 4.170 & 1946 & 3.147 & - \\
\hline Fèlix González B. & Los Triguitos & Guerrero & 4.650 & 1945 & - & - \\
\hline Odorico Garcia Yáñez & La Laja & Balleza & 2.553 & 1947 & 1.396 & - \\
\hline Odorico Garcia Yáñez & Mesa de Agua Blanca & Baileza & 3.090 & 1946 & 1.540 & 400 \\
\hline Fèlix Torres & La Cacariza & Bocoyna & 5.000 & 1945 & 2.000 & 300 \\
\hline Roberto de Castillo & Las Canoas y las Cuevitas & Carichi & 24,200 & 1950 & 726 & 188 \\
\hline Cia. Rio Verde Agricultural & Mesa del Corteo & Temósachi & 28.716 & 1949 & 3.500 & 600 \\
\hline Ing. Efrain Sandoval & Mesa de la Barranca & Bocoyna & 500 & 1946 & - & - \\
\hline José Dolores Gonzàlez & Meguachi & Bocoyna & 5.000 & 1946 & 1.397 & - \\
\hline Guadalupe Parra & Repórachi & Bocoyna & - & 1946 & 2.568 & . \\
\hline Cia. Maderas del Rio Verde & Reserva Nacional Tutuaca & Temósachi & 5.000 & 1943 & 13.973 & 1.875 \\
\hline Benjamin Gonzàlez & San Miguel de Garachi & Boooyna & 5.000 & 1946 & 3.841 & 7.822 \\
\hline Maderas de Los Pinos & Sierra de los Pandos & Ocampo & 34.245 & 1943 & 22.165 & - \\
\hline Jacobo Pérez & San Miguel de Sapechichi & Bocoyna & 5.395 & 1944 & 2.742 & 1.145 \\
\hline Cia Maderera Ordóñez & Unichique & Bocoyna & 6.000 & 1944 & 537 & - \\
\hline Elias Gonzajez & Tónachi & Guerrero & 5.000 & 1944 & 1.000 & . - \\
\hline Cia. Industria! Maderera & San Elias & Bocoyna & 16.800 & 1944 & 1.208 & 19.145 \\
\hline Cia. Maderera de Tejogórachi & Tejogórachi & Maguarichi & 4.530 & 1944 & 3.327 & - \\
\hline
\end{tabular}

FUENTE: "Datos Oficiales de las explotaciones forestales en el estado de Chihuahua. 1952". ACCIT. Legajo 37. Expediente 6 .

(1) incluye propiedades particulares de propietarios no indigenas. ejidales y terrenos en trámite de demandas ejidales.

(2) Metros cijbicos de madera talada. en forma de troncos

(3) Aserrados = en forma de tabla cortada en aserraderos. Labrados= Cortados manualmente con hacha. sin aserrar. En algunos casos el volumen explotado es inferior al autorizado dado que las concesiones de explotación estaban aún vigentes en 1951. fectia de tos datos. 
de dinero por concepto de "derechos de monte". ${ }^{20}$

Este sistema de trabajo no sólo no beneficiaba a los ejidatarios indigenas sino que además tenía otros inconvenientes. Los madereros, ajenos a la conservación del bosque, buscaban talario para obtener, en el menor tiempo posible, la mayor ganancia. Los ejidatarios prácticamente no eran ocupados en los trabajos asalariados de las compañías. Por otra parte y de acuerdo con la ley agraria de la época, los ejidatarios no podían cobrar directamente de las empresas los "derechos de monte", sino que éstas los depositaban en el Banco de Crédito Ejidal y sólo, después de una complicada secuencia de trámites, los ejidatarios podian recuperar esas sumas de su propiedad. ${ }^{21}$ Por aquellos años operó incluso en Chihuahua un Comité de Recuperación de la Raza Tarahumara encargado de controlar y decidir el destino de estos fondos ejidales, suplantando en realidad a los propios ejidatarios indigenas. ${ }^{22}$ En suma pues, podemos decir que durante todo este periodo, las comunidades indigenas fueron excluidas de las ganancias de la explotación de sus bosques.

Por esa razón, el INI consideró a partir de 1952 que era necesario emprender acciones que modificaran esta situación, promoviendo que fueran los propios indigenas los auténticos beneficiarios de sus riquezas forestales. Fue así como los primeros directivos del CCIT, con el apoyo de las autoridades centrales del INI, formularon una propuesta indigenista de explotación forestal en la Tarahumara. Como punto de partida y premisa fundamental, esta propuesta asumia que ni la agricultura ni la ganaderia podian

\footnotetext{
${ }^{20}$ Asi por ejemplo, en los años cincuenta, por un millar de pies de madera de pino se pagaba a un ejido de la Sierra Tarahumara por concepto de derechos de monte entre 60 y 90 pesos, suma insignificante comparada con las ganancias del negocio maderero.

${ }^{29}$ En 1956 Plancarte informaba que el CCIT habia logrado recuperar de las empresas madereras Aserraderos González Ugarte S.A., Tomás Beall, Odorico Garcia, Nacional Maderera y F. Alcocer una suma cercana al medio millón de pesos retribuida a diferentes ejidos tarahumaras por concepto de derechos de monte pendientes de ser saldados en el Banco de Crédito Ejidal. (ACCIT, Legajo 27. Expediente 5)

${ }^{22}$ Al respecto, pueden verse las criticas de los ejidatarios de Samachique a la operación de ese comité, al que culpan de haber gastado sus ganancias forestales en otros fines ajenos al ejido. en Benitez, 1967: 128131.
} 
representar una altemativa viable y sostenida de desarrollo para las comunidades indigenas, dada la pobreza de los suelos y las condiciones climáticas de la Sierra Tarahumara. $^{23}$

Esta tesis aparece abiertamente expresada en un interesante artículo publicado en 1956 en la revista Acción Indigenista que resume brillantemente la visión del INI sobre el único posible futuro de progreso para los tarahumaras. Tras analizar las bases de la economia de este grupo étnico ${ }^{24}$, el autor del texto concluia:

${ }^{23}$ Al respecto ya la Comisión del Departamento de Trabajo que recorrió la Tarahumara en 1936 habia planteado:

No habiendo tierras ni pudiendo efectuar cultivos de importancia; sin pastos para el fomento de la cria de animales; siendo una región azotada por el hielo la mayor parte del año; no teniendo jamás la seguridad de la cosecha ni los frutos de los pocos árboles ni en las sementeras siempre amenazadas por la helada o las nevadas tardias o prematuras es absolutamente necesario afirmar sin el más insignificante temor de equivocarse: Jamás podrá desarrollarse una raza fuerte y vigorosa en esa zona porque está constituida por un océano de roca improductiva (Departamento de Trabajo, 1936: 32).

Esta misma impresión prevalece entre otros observadores que llegan a señalar.

Mi afirmación relativa a la inexistencia de suelo agronómico en la Sierra Tarahumara es axiomática y evidente, si se considera la configuración fisica de esta zona (Vega, 1943)

${ }^{24}$ Éstas se resumian en estos presupuestos:

Cada 5 años es el promedio- [el agricultor tarahumara] puede contar con una buena cosecha. De cada hectárea recoge $400 \mathrm{kgs}$. de maíz. Si recordamos que el rendimiento medio de todo el país es de $850 \mathrm{kgs}$. por ha., el de los tarahumaras es uno de los más bajos de México. La cosecha de frijol la consume la familia en tres meses; la de maiz fluctúa entre 4 y 7 meses; a partir de esos plazos el hambre 10 impulsa a otros medios de subsistencia [...]

El auxilio inmediato es el que le proporciona la ganaderia ovicapnina. ¿Pero cómo puede tener una ganaderia suriciente para sus necesidades en una región que carece de pastos? A la minoria que puede sobrevivir se agrega la degeneración de las cabras [...]

En la época de escasez del maíz, el tarahumara come encino, saucillo, encino colorado, tatemas de maguey, bellotas, gusanos, lagartijas, etc., toda esa fiora y fauna a la que se debe, sin duda que no hayan desaparecido desde hace siglos [...]

Y ¿cuál es el capital de que dispone uń tarahumara?. Un jacal valorado en 10.00 pesos; enseres en 15.00 pesas. En estas condiciones consume a lo largo del año 15 pesos, incluyendo 2 o $3 \mathrm{kgs}$. de sal. Es decir que el tarahumara aporta al comercio nacional y al consumo de los articulos nacionales con 3.00 pesos al año. En el caso de los trabajadores de cualquier ciudad el egreso anual es de 200.00 pesos. [...] El tarahumara contribuye al incremento de la renta nacional con UN CENTAVO AL DIA (Anónimo, 1956) 
Los estudios realizados por el INI indican que el cambio social y cultural de los tarahumaras debe apoyarse en las siguientes realidades:

1.- El programa económico debe apoyarse en el mismo ambiente geográfico y dar un cambio radical a la economia tarahumara.

2.- Debe desecharse la tendencia a reforzar la economia del maiz ya que el ambiente hace imposible su cultivo sobre bases costeables.

3.- Debe desecharse también la explotación de la ganaderia lanar ya que los pastos de las serranias no son adecuados. La ganaderia capina no resolvería el problema ya que la concentración de las familias no podria lograrse por las necesidades de recumir a las zonas de pastoreo y esta circunstancia es indispensable para las finalidades de la promoción indigenista.

4.- La única riqueza potencial de la región tarahumara son los bosques: en ellos está el eje sobre el que puede descansar una riqueza que haga posible el mejoramiento social, económico y cultural de los habitantes (Anónimo, 1956).

Fue asi como se fue generando, desde las instancias centrales del INI, la idea de que la única alternativa económica con futuro para los pueblos indígenas de la Tarahumara residia en sus riquezas forestales: la explotación maderera, racional, sistemática y a gran escala permitiria a los pueblos indigenas no sólo controlar sus propios recursos sino también generar la riqueza necesaria para costear su anhelado desarrollo. Con las ganancias derivadas de la explotación y venta de la madera, los ejidos con población indigena estarian en condiciones de obtener beneficios que serian destinados a la construcción de trojes para almacenar semillas, escuelas, clínicas de salud y caminos así como para comprar alimentos y mejorar la agricultura y la ganadería. $^{25}$

${ }^{25}$ Un texto indigenista de la época sugiere incluso que la Tarahumara era una zona privilegiada en relación con otras regiones indigenas del pais sobrepobladas y carentes de tierras y recursos naturales. Mientras en la primera la actividad forestal podía permitir una salida al desarrollo, en las otras. la migración parecia el camino más recomendable. Este último era el caso de los Altos de Chiapas, la Mixteca norte y la Sierra tarasca para las que se proponia, respectivamente, fomentar la migración y colonización de nuevas tierras en el área de Las Margaritas y Marqués de Comillas y en las costas de Oaxaca y Michoacán. La propuesta concluia diciendo:

En consecuencia, nos parece que una de las formas fundamentales para resolver el problema indigena, no es tratar de desarrollar económicamente regiones improductivas, sino utilizar la gran niqueza que representa el trabajo de los indigenas en regiones virgenes en donde la producción seria mucho mayor. Naturalmente que esta acción tiene que hacerse como una migración planificada y controlada.. ("Proyecto de Plan sexenal en relación con el problema indigena, 1964", en ACCIT, Legajo 27, Expediente 5).

$$
294
$$


Retomando lo que señalamos en el capítulo 2 es importante insistir en que el INI tomó como referente para su programa forestal los ejidos y no los territorios de los pueblos tarahumaras, es decir que todas las acciones (de asesoria, financiamiento y gestión administrativa) tuvieron como destinatario formal el ejido y como interlocutores principales, las autoridades ejidales. Ahora bien, en su mayoría, los ejidos de la Tarahumara fueron constituidos desde los años treinta, sin tomar en consideración los limites tradicionales de los pueblos que incluyen, como ya los explicamos, una cabecera central y una serie de rancherias y ranchos circundantes, por lo que, en algunos casos, quedaron incluidos dentro de un ejido, una parte o la totalidad de los territorios de varios pueblos. Pero también se dio el caso de que el territorio de un pueblo quedara escindido en varios ejidos. En suma, la división agraria no tuvo en consideración la estructura ancestral y la lógica de los territorios indigenas, lo que ha dado lugar a muchos problemas relativos a la propiedad de la tierra.

Por otra parte, también hemos señalado en el capitulo 3, que la presencia mestiza en los territorios indigenas de la alta Sierra (donde se concentran los recursos forestales) fue en aumento desde el final de los años veinte, entre otras razones por la decadencia de la minería en la región de las barrancas. Muchos de estos mestizos se convirtieron entonces en promotores y gestores de los repartos agrarios ejidales, incluyéndose también entre sus beneficiarios. En cualquier caso, el sistema agrario impuesto desdeñó la autoridad tradicional de los siriame en los pueblos tarahumaras quienes, fueron desplazados de sus funciones tradicionales de control sobre la propiedad y uso de la tierra por parte de las autoridades ejidales. Además, en no pocos ejidos, los cargos . directivos ejidales (presidencia del comisariado y del comité de vigilancia) recayeron en personas con cierto grado de escolarización y con mayores posibilidades de acceder y entender la compleja trama de la burocracia agraria. No es extraño pues que, en algunos ejidos, estos puestos fueran monopolizados por mestizos.

Todo ello dio como resultado una configuración pluriétnica en la composición de los censos ejidales. Aunque no hemos podido obtener cifras precisas de ésta para los 
años de los repartos agrarios, los datos que mostramos en el Cuadro 23 que corresponden a estimaciones hechas por el CCIT en 1970 de los ejidos de los municipios de Guachochi, Nonoava y Guadalupe y Calvo, nos permiten darnos una idea de este fenómeno tan característico de la estructura de la propiedad ejidal en la Tarahumara. Como se puede observar son muy pocos los ejidos y comunidades agrarias dotadas bajo el régimen de "Bienes comunales" en los que la totalidad de los ejidatarios o comuneros sean indigenas. Por el contrario, lo más común es que estos compartan las tierras con mestizos.

Partiendo de esta estructura de la propiedad agraria y considerando como destinatario de sus programas al ejido, en 1954, el INI ensayó en el ejido con mayoría de población rarámuri de Cusárare, un proyecto piloto de autogestión indigena en la explotación forestal. En un lugar del ejido conocido como Yahuirachi se instaló el aserradero y las oficinas administrativas del ejido de donde salieron enormes cantidades de durmientes destinados a los Ferrocarriles Nacionales, así como muebles escolares fabricados para la Secretaría de Educación Pública. En cuatro años sucesivos, los ejidatarios rarámuri de Cusárare, asesorados por técnicos del INI y con un crédito inicial de 190,000 pesos del Banco de Crédito Ejidal lograron obtener cuantiosas ganancias que beneficiaron a cerca de 180 familias y permitieron no sólo pagar el crédito sino repartir utilidades, construir una clínica y una escuela, abastecer de medicinas al pueblo y de ropa y una comida gratuita al día los niños de la escuela. Incluso se construyeron algunas casas para ejidatarios trabajadores del aserradero que, después de más 50 años y hasta el dia de hoy siguen siendo ocupadas. ${ }^{26}$

Cusárare resultaba entonces el ejemplo a seguir en toda la Tarahumara. Sin embargo este modelo de autogestión suponía una fuerte inversión inicial que ninguna

\footnotetext{
${ }^{26}$ Tan sólo en los dos primeros años los ejidatarios obtuvieron repartos de utilidades por 115,000 y 125,000 pesos respectivamente. (Benitez, 1967: 114). El experimento de Cusárare llamó la atención de la opinión pública a nivel nacional. Algunos periodistas como Fernando Benitez vinieron a atestiguar el reparto de utilidades de Cusárare y las fotos de sus reportajes reunidos en su "Viaje a la Tarahumara" dan fe del asombro que produjo entre los asistentes la distribución de llamativos fajos de dinero entre los ejidatarios indigenas. Era la primera vez que una cosa asi se veia en la Tarahumara.
} 
CUADRO 23.- COMPOSICIÓN ETNICO-EJIDAL DE LOS MUNICIPIOS DE GUACHOCHI, NONOAVA Y GUADALUPE Y CALVO. 1970 (ESTIMACIONES HECHAS POR EL CCIT)

\begin{tabular}{|c|c|c|c|c|c|c|c|c|c|}
\hline \multirow[b]{2}{*}{ EJIDO } & \multicolumn{3}{|c|}{ POBLACION EJIDAL POR ETNIA } & \multirow{2}{*}{$\begin{array}{l}\text { STTUA } \\
\text { CION } \\
\text { AGRA } \\
\text { RIA }\end{array}$} & \multirow[b]{2}{*}{ EJIDO } & \multicolumn{3}{|c|}{ POBLACION EJIDAL POR ETNLA } & \multirow{2}{*}{$\begin{array}{l}\text { SITUA - } \\
\text { CION } \\
\text { AGRA - } \\
\text { RIA }\end{array}$} \\
\hline & $\begin{array}{l}\text { TARAHU- } \\
\text { MARA }\end{array}$ & $\begin{array}{l}\text { TEPE- } \\
\text { HUÁN }\end{array}$ & MESTLZO & & & $\begin{array}{l}\text { TARAHU } \\
\text { MARA }\end{array}$ & $\begin{array}{l}\text { TEPE- } \\
\text { HUÁN }\end{array}$ & MESTIZO & \\
\hline MPHO. GUACHOCHI & & & & & S.Juan Nepomuceno & & 15 & 85 & D.E. \\
\hline Guachochi & 60 & & 40 & D.E. & Laguna de los Cano & 15 & & 85 & D.E. \\
\hline Aboreachi & 90 & & 10 & D.E. & Llano Grande y Anexas & & 90 & 10 & D.E. \\
\hline Caborachi & 90 & & 10 & D.E. & Llano Blanco & 10 & 15 & 75 & D.E. \\
\hline Norogachi & 85 & & 15 & D.E. & Sta Rosalia de Nabogame. & & 80 & 20 & D.E. \\
\hline Cieneguita de Sinforosa & 100 & & & D.E. & El Nopal & 50 & & 50 & D.E. \\
\hline Cusárare & 90 & & 10 & D.E. & El Pinito & 5 & 10 & 85 & D.E. \\
\hline Guaguachique & 90 & & 10 & D.E. & Pino Gordo & 100 & & & D.E. \\
\hline Cumbres de Hueracti & 90 & & 10 & D.E. & La Quebrada & 5 & & 95 & D.E. \\
\hline Loma del Manzano & 90 & & 10 & D.E. & Redondeados & 50 & 40 & 10 & D.E. \\
\hline Nachàcachi & 90 & & 10 & D.E. & Tepehuano & & 50 & 50 & D.E. \\
\hline Otövactii & 100 & & & D.E. & Santa Rosa & & 64 & 35 & D.E. \\
\hline Papajichi & 80 & & 20 & D.E. & San Simon & 15 & & 85 & D.E. \\
\hline Rocheachi & 60 & & 40 & D.E. & Tohayana & & 15 & 85 & D.E. \\
\hline Tatahuichi & 100 & & & D.E. & Trinidad y Anexos & 20 & 80 & & D.E. \\
\hline Los Tuceros & 90 & & 10 & D.E. & Tule y Portugal & 25 & 30 & 45 & D.E. \\
\hline Tónachi . & 70 & & 30 & D.E. & Barbechitos & & 60 & 40 & B.C. \\
\hline Santa Anita & 90 & & 10 & D.E. & Colaradas de los Chavez & 20 & 60 & 20 & B.C. \\
\hline Sehuerachi & 75 & & 25 & D.E. & Llano del Salado & 50 & 10 & 40 & B.C. \\
\hline Basihuare & 90 & & 10 & D.E. & El Nopal & 90 & 10 & & B.C. \\
\hline Samachique & 90 & & 10 & D.E. & Nuestra Señora & 100 & & & B.C. \\
\hline Pahuichique & 90 & & 10 & D.E. & El Trigo & & 15 & 85 & B.C. \\
\hline Agua Zarca & 100 & & & D.E. & Tuaripa & 10 & 60 & 30 & B.C. \\
\hline Corralitos. & 95 & & 5 & D.E. & El Venadito & 50 & 40 & 10 & B.C. \\
\hline La Soledad & 100 & & & D.E. & Casa Quemada & 50 & & 50 & D.E. \\
\hline Cerro Grande y La Gloria & 100 & & & B.C. & Cruz de Piedra & 80 & & 20 & D.E. \\
\hline Huinchique & 100 & & & D.E. & Mesa del Tule & 25 & 30 & 45 & D.E. \\
\hline Choguita & 95 & & 5 & D.E. & Milpillas de Arriba & 20 & 60 & 20 & D.E. \\
\hline & & & & & La Onza & 10 & & 90 & D.E. \\
\hline MPHO. GPE. Y CALVO. & & & & & Rancho de Enmedio & 50 & 40 & 10 & D.E. \\
\hline Alisitos & 20 & & 80 & D.E. & La Soledad & & 75 & 25 & D.E. \\
\hline Catedral de S.Antonio & 80 & & 20 & D.E. & El Tigre & & 5 & 95 & D.E. \\
\hline Chinatú & 90 & & 10 & D.E. & Agua Amarilla & 90 & & 10 & B.C. \\
\hline Cinco Llagas & & 30 & 70 & D.E. & El Potrero & & 50 & 50 & B.C. \\
\hline Ciènega de Ortiz & 20 & & 80 & D.E. & Tejamanil y Arroyo & 90 & & 10 & B.C. \\
\hline Baborigame & 20 & 60 & 20 & D.E. & La Fragua & 10 & & 90 & B.C. \\
\hline Coloradas de la Virgen & & 85 & 15 & D.E. & Llano de Guadalupe & & 70 & 30 & B.C. \\
\hline E. Zapata-Sto.Domingo & 15 & & 85 & D.E. & & & & & \\
\hline El Encina! & & 40 & 60 & D.E. & MPIO.NONOAVA & & & & \\
\hline Galeana & 5 & & 95 & D.E. & Humariza & & 60 & 40 & B.C. \\
\hline S. Ignacio de la Cieneguilla & & 30 & 70 & D.E. & Nonoava & & 60 & 60 & B.C. \\
\hline
\end{tabular}

()Ejido con población tepehuana flotante no mayor al $5 \%$ del total. D.E.= Dotación Ejidal. B.C.= Bienes Comunales.

FUENTE: Carta Etnoagraria. INI, en ACCIT, Legajo 138, Expediente 2

dependencia del gobierno estaba en condiciones de hacer y requeria, además, de personal técnico para la supervisión administrativa de los ejidos con el que el CCIT no contaba. Por eso el INI optó por plantear otro esquema de explotación forestal para los ejidos con población indigena, que consistió en recurrir a la iniciativa privada, seleccionando entre las empresas madereras aquellas que ofrecieran mayor garantia y 
aceptaran la supervisión del INI en la operación de los contratos entre ejidos y compañias. ${ }^{27}$ Para asegurar su estrecha vigilancia sobre la operación de los ejidos y las empresas madereras, el INI presionó a las autoridades federales y obtuvo, en julio de 1957, un Acuerdo del Gobiemo federal que delegaba en su favor la organización general y particular de los ejidos, de los nuevos centros de población agrícola y de los núcleos comunales localizados en la Tarahumara. ${ }^{28}$ (Sariego, 1998: 147-149).

Dos sistemas de contratos entre ejidos y empresas madereras ensayó el CCIT. EI primero que se denominó "de financiamiento" funcionó en los ejidos de Samachique, Guaguachique, Choguita, Basihuare, Rochéachi, Papajichi, Norogachi, Guachochi, Narárachi, Tehuerichi, Yoquivo, Pahuichique y Cabórachi y establecia que las empresas financiaban a los ejidos aportando el capital necesario para la compra de equipo (maquinaria para los aserraderos y camiones de carga), instalación, hechura de caminos, asistencia técnica y administración, mientras que los ejidos aportaban el recurso bosque y los técnicos forestales del INI formulaban los estudios dasonómicos y supervisaban los aprovechamientos. Las utilidades netas se distribuian en la proporción de un 55\% para los ejidos y un $45 \%$ para las empresas financiadoras. El Cuadro 24 expresa claramente cómo este sistema permitió en 1959 a los ejidos de Samachique, Cabórachi, Norogachi, Choguita y Basíhuare incrementar entre 171 y $396 \%$ las utilidades que hubieran obtenido

\footnotetext{
${ }^{27}$ Luis Torres Ordoñez, economista y director del Departamento de Promoción Económica del INI, quien tuvo a su cargo el diseño de los programas forestales del INI en la Tarahumara y otras regiones indigenas del pais, señalaba al respecto en 1963 :

Con los resultados obtenidos en el ejido de Cusárare, se despertó el interés en la Tarahumara y llovieron en el INI las solicitudes para que esta institución estableciera aprovechamientos semejantes en otros ejidos, procedimiento que no se pudo hacer extensivo con las mismas caracteristicas, por limitaciones presupuestales para el financiamiento y por falta de personal capacitado e idóneo en el manejo administrativo, que de inmediato pudiera cubrir todas las promociones que, en forma apremiante, tenian que ponerse en movimiento.

El INI se vio precisado a recumir a la iniciativa privada, seleccionando entre las empresas aquellas que ofrecieran una verdadera garantía por su solvencia económica, moral y técnica y, sobre todo, las que mostraran disposición de asociarse con los ejidos mediante normas que se establecieron en contratos, aceptando invariablemente la supervisión e intervención del Instituto (Torres. 1963).

${ }^{28}$ Véase el decreto correspondiente del 25 de julio de 1957 en Sariego, 1998a: 14-149.
} 


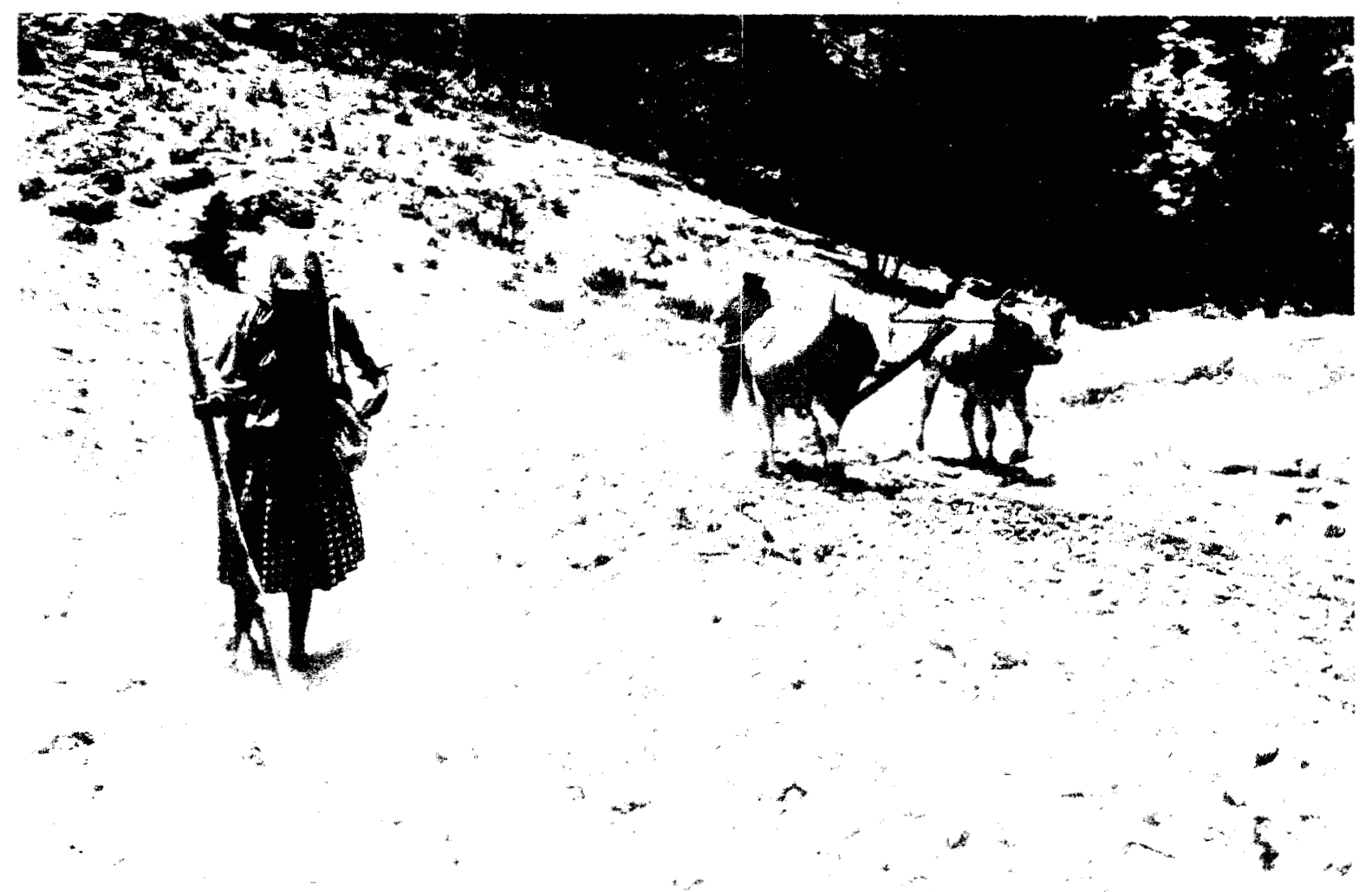

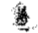

FIGURA 57.- CON EL ARADO Y LA "WICA" (PALO SEMBRADOR), EN UN MAGÜECHI, ENTRE PIEDRAS Y ESPINOS (FOTO DE FRANÇOISE BROUZĖS, TÚRACHI, EJIDO DE PINO GORDO, 1982

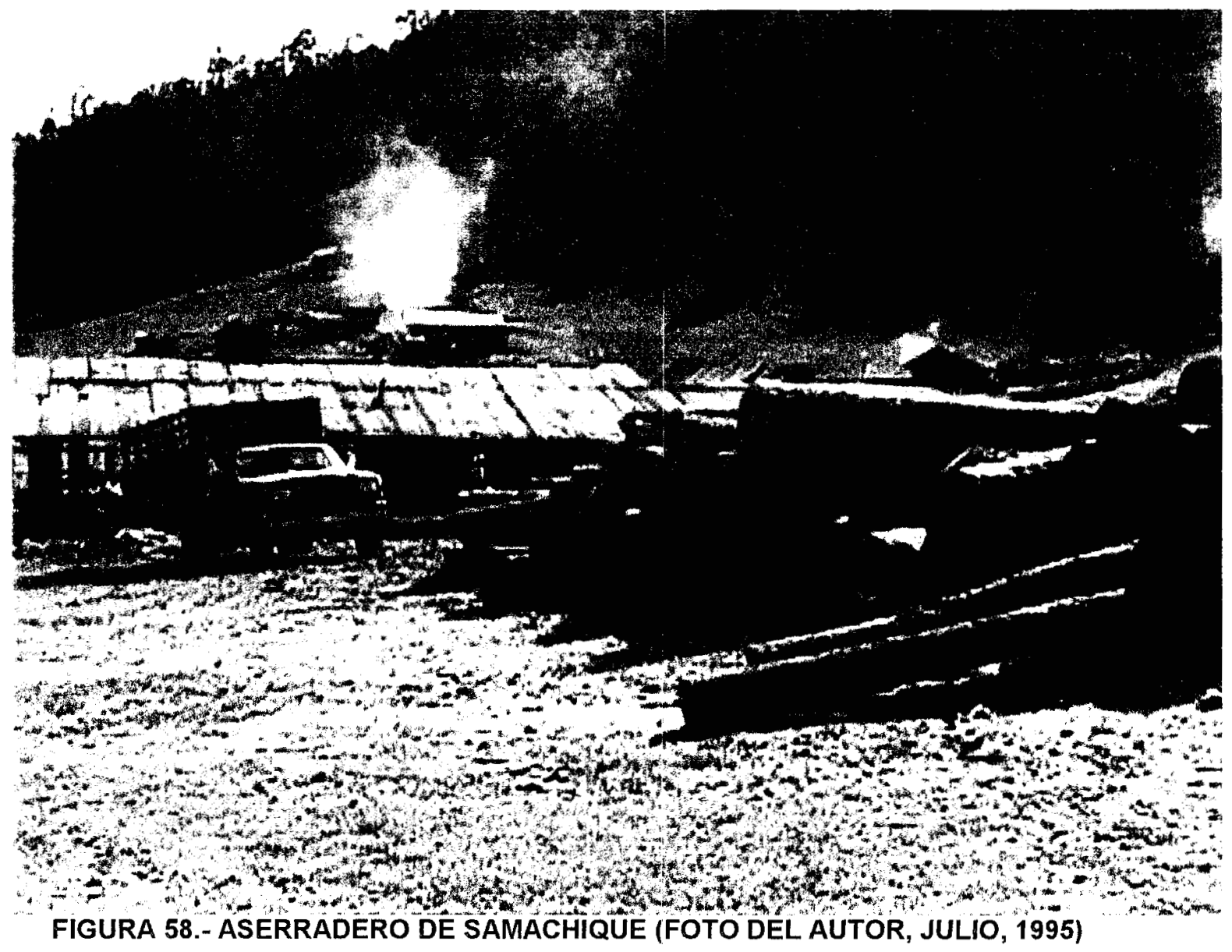


de haber seguido trabajando con el sistema de explotación forestal anterior, consistente en la venta directa de la madera y cobro por derechos de monte.

CUADRO 24.- PRODUCCIÓN Y UTILIDADES OBTENIDAS EN 6 EJIDOS ORGANIZADOS POR EL CCIT. $1^{\circ}$ y $2^{\circ}$ EJERCICOS DE 1959.

\begin{tabular}{|c|c|c|c|c|c|c|}
\hline CONCEPTO & SAMACHIQUE & CABORACHI & NOROGACHI & CHOGUITA & BASIHUARE & CUSȦRARE \\
\hline $\begin{array}{l}\text { Produc.de Madera (pies } \\
\text { tabla) } \\
\text { Utilidad del Ejido ( } 55 \% \\
\text { totai) } \\
\text { Utilidad por Millar pie de } \\
\text { tabla } \\
\text { Salarios erogados } \\
\text { Total en salarios y } \\
\text { utilidades } \\
\text { Jefes de familia ejidatarios } \\
\text { beneficiados } \\
\text { Total personas } \\
\text { beneficiadas } \\
\text { Percepción por ejidatario } \\
\text { en cada ejercicio } \\
\text { Percepción mensual por } \\
\text { ejidatario }\end{array}$ & $\begin{array}{r}11680,335 \\
200,090.70 \\
120.00 \\
458,601.00 \\
658.692 .00 \\
180 \\
900 \\
1,830.00 \\
305.00\end{array}$ & $\begin{array}{r}2451,637 \\
237.553 .05 \\
115.20 \\
651,854.00 \\
925.407 .00 \\
170 \\
480 \\
2,871.00 \\
478.50\end{array}$ & $\begin{array}{r}3,000,000 \\
240,000.00 \\
110.00 \\
580,000.00 \\
820,000.00 \\
600 \\
1,800 \\
1,360.00 \\
226.66\end{array}$ & $\begin{array}{r}2082,380 \\
199,822.25 \\
105.10 \\
418.710 .00 \\
618,532.00 \\
150 \\
750 \\
2.061 .00 \\
343.50\end{array}$ & $\begin{array}{r}2 ' 193,530 \\
217.158 .07 \\
116.90 \\
646.888 .00 \\
864,046.00 \\
165 \\
825 \\
2,618.00 \\
436.33\end{array}$ & $\begin{array}{r}3795,000 \\
889,000.00 \\
236.00 \\
751,830.00 \\
1 ' 640,830.00 \\
183 \\
915 \\
2.988 .00 \\
498.00\end{array}$ \\
\hline $\begin{array}{l}\text { Ingreso que hubiera } \\
\text { obtenido el ejido por } \\
\text { contrato compraventa } \\
\text { Incremento logrado bajo el } \\
\text { sistema del INI }\end{array}$ & $\begin{array}{l}70.00 \\
171 \%\end{array}$ & $\begin{array}{l}50.00 \\
230 \%\end{array}$ & $\begin{array}{l}50.00 \\
220 \%\end{array}$ & $\begin{array}{l}26.80 \\
392 \%\end{array}$ & $\begin{array}{l}29.50 \\
396 \%\end{array}$ & $\begin{array}{l}80.00 \\
295 \%\end{array}$ \\
\hline
\end{tabular}

OBSERVACIONES: En el ejido de Norogachi la empresa financiadora recibe únicamente el $40 \%$ de las utilidades netas. En consecuencia la cifra de utilidades que aparece corresponde al $60 \%$ del ejido. En el resto de los ejidos corresponde el $55 \%$ al ejido y el $45 \%$ a la empresa maderera financiadora, con excepción de Cusárare que trabaja con capital propio y en cuyo caso la cifra es el $100 \%$ de las utilidades obtenidas.

FUENTE: "Informe sobre la organización y resultados en ejidos forestates organizados por el INI, 1960" en ACCIT, Legajo 15, Expediente 9.

El segundo sistema fue el "de maquila" instaurado a principios de los años sesenta inicialmente en 9 ejidos (Samachique, Rochéachi, Papajichi, Cabórachi, Guaguachique, Choguita, Basihuare, Cusárare y Yoquivo). Por medio de este sistema los ejidos acordaban con alguna empresa la maquila de sus maderas, cobrando dicha empresa una cuota fija por millar de pies. Una vez hecho este pago, el ejido vendía o comisionaba la venta de sus maderas a alguna empresa comercializadora asegurándose una cantidad fija de utilidad. Este sistema permitió garantizar un ingreso fijo como utilidad, hizo más accesible a los ejidatarios el control de la operación y permitió obtener ingresos superiores en cerca del $12 \%$ sobre los del sistema de financiamiento y en más del $200 \%$ en relación con los del sistema de contrato de compra-venta. 
A mediados de los años sesenta y tras varios años de experiencia el CCIT llegó a la conclusión de que lo ideal era que los ejidos indígenas explotaran por su cuenta sus bosques, ya fuera con fondos propios o con créditos de bancos oficiales, y dispusieran de la capacidad técnica, administrativa y de conocimiento del mercado, pero si estas condiciones no se reunian, el procedimiento más recomendable era el sistema de maquila que implicaba destinar una cantidad de las ganancias forestales para el maquilador, en pago de las prestación de sus servicios.

En cualquiera de los sistemas descritos, el mecanismo para la aplicación de utilidades fue el mismo: una vez establecidos los balances de utilidades se acordaban entre las autoridades del INI, del sector agrario federal y de los ejidos, el destino y la aplicación de los fondos en inversiones para actividades productivas (como compra de ganado o animales de trabajo, maquinaria e implementos agrícolas, establecimiento de huertos de árboles frutales, etc.), distribución de dinero en efectivo entre todos los ejidatarios, por partes iguales, para beneficio de las familias (entre otras cosas, para cubrir el déficit de las insuficientes cosechas) y obras de servicio colectivo (como trojes, tiendas comunales, escuelas, clinicas, medicinas, ropa, etc.). ${ }^{29}$

A diferencia de lo que sucedió en otras regiones indigenas del pais, el INI otorgó poca importancia estratégica al desarrollo agropecuario de la Tarahumara, máxime si lo comparamos con la que recibió el proyecto forestal. De muchas formas y a lo largo del tiempo los directivos y técnicos del CCIT fueron convenciéndose de que, como ya lo habian planteado los expertos de la Comisión del Departamento del Trabajo en 1936, no valia la pena emprender esfuerzos e inversiones muy ambiciosos en una tierra que por

\footnotetext{
${ }^{29}$ En el primer ejercicio forestal de 1959 los ejidatarios de Choguita, Basihuare, Cabórachi, Samachique y Norogachi decidieron destinar sus utilidades forestales por una suma de $608,647.80$ pesos en los siguientes rubros: distribución en efectivo (39\%), construcción de escuelas $(5 \%)$, desayunos escolares $(3 \%)$, material escolar $(1 \%)$, puestos médicos $(2 \%)$, medicinas e instrumental médico $(4 \%)$, implementos agricolas $(2 \%)$, alambre $(12 \%)$, semillas y fertilizante $(1 \%)$, insecticidas $(1 \%)$, frutales $(2 \%)$, sementales $(1 \%)$, adeudos $(2 \%)$, fondo para ejidos $(2 \%)$, compra de maiz $(13 \%)$, construcción de trojes $(2 \%)$. casa del maestro de Samachique $(1 \%)$, instalación eléctrica en Samachique (1\%), ropa para ejidatarios de Samachique (3\%), lavadora en Samachique (1\%), tienda en Samachique (1\%), caminos en Norogachi (1\%). (Anónimo, 1959)
} 
sus características fisicas y climáticas es poco propicia para la agricultura ${ }^{30}$. El CCIT desarrolló sin embargo algunas actividades de apoyo a la agricultura como la creación de trojes o graneros comunales dotados de semillas de maiz, frijol y papa cedidas en calidad de préstamo temporal a diferentes rancherias y pueblos y con las que poder enfrentar situaciones de sequias y destrucción de cosechas. También se realizaron algunos experimentos agricolas de mejoramiento de semillas de maíz, trigo, frijol y de hortalizas y se trató de introducir razas finas de ganado porcino, ovino y bovino en algunos ejidos. $^{31}$

Aunque las tareas agricolas de investigación de semillas, creación de huertos de leguminosas y verduras en parcelas escolares, mejoramiento de suelos, uso de fertilizantes y plaguicidas se mantuvieron por mucho tiempo en los programas de trabajo del CCIT, éstos fueron derivando gradualmente sus prioridades hacia tres otros rubros

\footnotetext{
${ }^{30}$ Las siguientes referencias proceden de diferentes informes de directores del CCIT: ...ni las condiciones del medio, ni el presupuesto con que cuenta la Sección [de agricultura] permiten desamollar un trabajo agricola de importancia ("Comunicación del Director del CCIT al Dr. Affonso Caso, febrero de 1959", en Legajo 40, Expediente 3)
}

La economia del indigena debe canalizarse hacia aspectos diferentes, ya que las actividades agricolas continúan predominando en la economia del tarahumara. La tierra es 10 más importante en su vida material y sobre la economia de cambio continúa prevaleciendo la economia de subsistencia.

Los delgados suelos de la Tarahumara son inadecuados para el cultivo del maiz, pero los resultados obtenidos en la fruticultura y piscicultura asi como las perspectivas ganaderas [...] son renglones que nos han impulsado a buscar el desarrollo de estas actividades para el mejoramiento de la economia tarahumara ("Datos para el 3er. Informe del C. Gobernador constitucional del estado, general de división Práxedes Giner Durán, 1965" en ACCIT Legajo 21, Expediente 29).

${ }^{31}$ Entre 1953 y 1957 fueron beneficiadas con trojes comunales las siguientes poblaciones: Guachochi, Agua Zarca, Nacásorachi, Huichavóachi, La Laguna, Aboréachi, Cabórachi, Siquirichi, Baqueachi, Sibárachi, Ramuchéachi, Guazarachi, Tecorichi, Ruruchácachi, Murachárachi, Pesachi, Yoquivo, Santa Anita, Boquimova, Pahuiránachi y Agua Puerca. Entre 1957 y 1958 la sección de agricultura del CCIT investigó en campos experimentales localizados en Baquiriachi, Guachochi, Coloradas y Papajichi diversas variedades de maiz (10 tipos), trigo (20), frijol y hortalizas ob́teniéndose resultados positivos con algunas de ellas y, en especial, con las hortalizas. También en esos años se prestaron 2 cerdos sementales Duroc Jersey al ejido de Rochéachi, 12 toros sementales Hereford al de Choguita y cerca de 1,700 cabezas de ganado ovino a los de Guachochi, Samachique y Sehuérachi obteniéndose rendimientos respectivos del $100 \%$ en los dos primeros ejidos y del 26, 30 y $75 \%$ en los tres últimos. ("Informes de la Sección de Agricultura" en ACCIT Legajo 2, Expediente 31). 
más estratégicos: la ganadería, la fruticultura y la piscicultura.

La ganaderia se comenzó a ensayar a partir de algunos estudios en los ejidos de Tecorichi (Balleza), Tehuerichi, Narárachi, Baqueachi, Guacaréachi (Carichi) y Papajichi (Guachochi). Sólo en el último de estos ejidos el programa llegó a consolidarse por un tiempo a través de la creación de un proyecto modelo de ejido silvicola-ganadero y de la experimentación y siembra de algunos cultivos forrajeros de alfalfa, sorgo, cebada, avena y remolacha en Guachochi. ${ }^{32}$

La fruticultura fue el renglón más alentado por el CCIT. Para ello se sembraron en viveros experimentales y trasplantaron en casi todos los ejidos tarahumaras atendidos por el INI árboles de manzano y durazno. La piscicultura, por su parte, se concentró en la creación de una estación trutícola en Guachochi asi como en la siembra de alevines de trucha y black bass en los presones y lagunas de Arareco, Aboréachi, Humariza y Panalachi. Para muchas de estas actividades se utilizaron como capital de inversión las ganancias obtenidas por los ejidos en sus operaciones forestales.

\section{Los signos del progreso indigena: escuela y salud.}

A raíz de la reorganización de la actividad maderera, el CCIT promovió que las utilidades forestales de los ejidos por él controlados además de otras inversiones gubernamentales fueran primordialmente orientadas en dos rubros considerados como estratégicos en su visión del progreso indígena: la educación y la salud.

Desde sus años fundacionales el CCIT otorgó una notoria importancia a la labor educativa, máxime teniendo en cuenta que una buena parte de su personal procedía del magisterio y de la filosofía de la escuela rural que sostenía que ésta no debia limitarse a los aspectos docentes sino ampliarse a todos los ámbitos del desarrollo integral de la

\footnotetext{
${ }^{32}$ Pueden verse entre otros "Propuesta para crear ejidos silvicola-ganaderos, 1960", "Estudio del ejido de Papajichi, 1962" y "Estudio del ejido de Narárachi, 1964" en ACCIT Legajo 2, Expedientes 29, 32 y Legajo 3, Expediente 46.
} 
comunidad. El sistema de las promotorias fue, como vimos, la primera estrategia de alfabetización bilingüe y educación integral ${ }^{33}$ utilizada. En efecto, en dichas escuelas dispersas en medio centenar de rancherias se ofrecia originalmente el grado "Preparatorio" que cubría un nivel básico de lecto-escritura en lengua tarahumara, nociones elementales de cálculo, castellanización minima y algunos conocimientos elementales sobre higiene, medicina y prácticas agropecuarias. Estos conocimientos debian permitir a los niños incorporarse posteriormente a las escuelas primarias rurales federales o estatales así como a los internados de la Dirección General de Asuntos Indígenas de Guachochi (para niñas), Siquirichi y Tónachi (para niños).

La falta de escuelas primarias con los seis años completos ${ }^{34}$ fue provocando que las promotorías se fueran transformando en escuelas ofreciendo primero hasta el segundo grado y posteriormente el ciclo completo. Pero además, la dispersión demográfica, la crudeza del clima invernal y la pobreza de las familias indígenas, causantes de los altos indices de ausentismo escolar, llevaron al equipo directivo del CCIT a implantar en 1959 un nuevo sistema escolar que con el tiempo se convertiría en el modelo educativo del INI en todo el país: la escuela-albergue. Uno de sus creadores resumia asi esta experiencia:

Descartamos por los inconvenientes que presenta, principalmente el económico, el Internado y tomando en cuenta las experiencias adquiridas en las escuelas de Aboréachi, Samachique, Hueleyvo y Otóvachi, en las que los niños con sus propios recursos permanecian los dias de trabajo en las escuelas, llevando consigo su pinole y cobija, pensamos en un sistema de SEMI-INTERNADO que permitiera el control del niño cinco días a la semana de trabajo y retornara a su hogar los sábados y domingos de cada semana, sistema que no desliga al niño de su familia.

Como presupuestaimente no disponemos de recursos suficientes [para] estos

\footnotetext{
${ }^{33}$ Utilizo el término integral para referirme a la labor de extensionismo agrario, atención a la salud y gestión social que llevaban a cabo los promotores culturales indigenas en las rancherias.

${ }^{34}$ El Consejo Supremo Tarahumara se quejaba en junio de 1962 ante el candidato priista al gobiemo del estado de Chihuahua, general Giner Durán de que en toda la Sierra sólo existian escuelas oficiales con educación primaria completa en Guachochi, Rochéachi, Tónachi, Creel, Témoris. Guazapares, Moris, Uruachi y Chinipas, la mayoria de ellas ubicadas en cabeceras municipales y, por ello. sölo frecuentadas por niños mestizos. (ACCIT, Legajo 37, Expediente 2, Documento 2).
} 
semi-intemados que llamamos ALBERGUES o ESCUELAS-ALBERGUE y como el objetivo fundamental es proporcionar atención educativa al mayor número de niños, las escuelas se equiparon modestamente, los locales escolares se adaptaron con los anexos indispensables: cocina, comedor, dormitorio y aulas. La cocina con estufas construidas de 'tambos' de $200 \mathrm{lts}$., el comedor con mesas para 12 niños cada una, el dormitorio con literas dobles, sirviendo como aulas en casi todos los casos el comedor.

En la imposibilidad de mejorar la alimentación habitual del niño tarahumara, se calculó el sostenimiento de cada alumno en la cantidad de 1.00 peso diario, proporcionándoles pinole, avena, tortillas, papas y frijol, aumentadas estas raciones con la materia prima que envia el INPI IInstituto Nacional de Protección a la Infancia], harina de trigo, leche y frijol $^{35}$

Estas incipientes escuelas-albergue fueron construidas por las propias comunidades y funcionaron con un promotor (que fungia como director e impartia el grado preparatorio), una promotora (responsable de la alimentación, el almacén, las actividades femeniles y el dormitorio de niñas), uno o varios maestros federales (cada uno de ellos encargados de atender un grado escolar) y una cocinera. Entre 1961 y 1964 el número total de alumnos inscritos en las escuelas del INI en la Tarahumara aumentó de 1,060 a 1,570 y eso se debió, en buena medida, al sistema de las cuatro escuelasalbergue, con un total de 358 alumnos, en las que se logró regularizar los indices de asistencia en un $84 \%$ y de aprobación en un $62 \%$. Aunque en realidad la cobertura de estas escuelas se concentraba en el área de Guachochi y no llegaba a cubrir otros municipios de la alta y, sobre todo, de la baja Tarahumara, el INI habia logrado hacer realidad un prototipo de escuela que perduraria hasta nuestros dias.

El trabajo de los promotores y maestros no fue nada sencillo. La dispersión y las distancias entre los asentamientos indígenas dificultaron enormemente su tarea. El Inspector federal de la trigésimo octava zona escolar con cabecera en San Juan

\footnotetext{
35 "Informe que presenta el profesor Fulgencio Gutiérrez Morales a la Junta de Directores de Educación de los Centros del INI, 6 de junio de 1964" en ACCIT, Legajo 38, Expediente 13. Las cuatro primeras escuelas-aibergue fueron emplazadas estratégicamente en Agua Zarca, Nacásorachi (éstas dos en 1959), Aboréachi (las tres en el municipio de Guachochi) y Teconichi (Balleza). La primera se incendió y fue reinstalada en Loma del Manzano y la última se reubicó en Cabórachi. Posteriomente se instalaron otras cinco en Bahuéachi, Samactique, Basihuare, Cusárare y Choguita, las cuatro últimas sostenidas con las utilidades de dichos ejidos madereros.
} 
Nepomuceno (Guadalupe y Calvo) resumia en 1969 de esta manera los que él consideraba

Factores desfavorables en el desarrollo de la obra educativa:

a.) El estarse organizando y estructurando la zona escolar por ser de nueva creación.

b.) La incomunicación y el aislamiento total que existe en las comunidades donde se encuentran las Promotorías.

c.) El analfabetismo y crisis económica que predomina en las comunidades.

d.) La situación económica actual del Inspector y la falta de una bestia de silla para trasladarse con más facilidad a las diferentes comunidades [...]

e.) La tardanza con que se recibe la correspondencia y se expide ésta, precisamente por la falta de comunicación ya que es ésta totalmente nula.

f.) La situación geográfica en que se encuentran estructurados los pueblos y comunidades, ya que las casas habitación están distantes las unas de las otras, motivo entre otros muchos como la pobreza y el clima por el cual se observan la inasistencia, los retardos y la deserción escolar.

g.) El retardo con que se presentan los Promotores, después de que son asignados a las comunidades, citados a reuniones o después de haber disfrutado de sus vacaciones debido a lo incomunicado ${ }^{36}$

Las distancias y la lejania de las rancherias además de la movilidad territorial de la población indígena no habrian de ser sin embargo el único obstáculo importante a la tarea de los promotores. También el rechazo cultural a la institución escolar y a la figura del maestro se hizo explícito en algunos lugares como en Pino Gordo (Guadalupe y Calvo) donde el inspector reconocia en 1970 que "la raza indigena no atiende el llamado del maestro y no tiene suficiente confianza para este tipo de trabajo", o en Tuchéachi (Carichi) donde una promotora se quejaba de que el siriame la habia amenazado con expulsarla del lugar o en Chinéachi (Carichi) donde los padres de los niños, obligados a emigrar por una hambruna causada por la sequía, se negaban a mandar a sus hijos a la escuela o, en fin, en la zona de Guachochi donde un supervisor escolar tenia que reconocer ante el director de la Sección de Educación del CCIT:

con toda sinceridad hago de su conocimiento que no quedé satisfecho con esta gira, pues no realizamos mucho trabajo, fue muy poco, la nieve, la falta de los Promotores en sus escuelas, la ausencia de los niños, las fiestas religiosas (en

\footnotetext{
${ }^{36}$ "Informe trimestral de las actividades desarrolladas" en las Promotorias culturales bilingües pertenecientes a la XXXVIII zona escolar con cabecera oficial en la sección municipal de San Juan Nepomuceno, municipio de Guadalupe y Calvo, del estado de Chihuahua, en el presente año lectivo escolar de 1969-1970, Profesor Manuel Cárdenas Reyes, 31 de diciembre de 1969" en ACCIT, Legajo 4, Expediente 7.
} 
Tecorichi mataron 13 reses).. todo estuvo en nuestra contra.

En algunas escuelas los problemas derivaban de otro tipo de situaciones como en El Almagre donde un comisariado ejidal mestizo rechazaba entregar parte de las utilidades forestales para el mejoramiento de local escolar o en Boquimova, donde los rarámuri se resistian a mandar a sus hijos a la escuela de La Dura, a 5 horas de camino y en donde a los padres tarahumaras "los hacen trabajar mucho, mientras los mestizos se pasean muy contentos porque tienen a los tarahumaras que les arreglen su escuela", o en Pino Gordo, donde los padres de familia, para alimentar a sus hijos escolares, debian viajar hasta la sede del INI en Guachochi y transportar desde alli los costales de maiz y frijol sobre sus espaldas a través de la abrupta barranca de La Sinforosa.

En fin, no fueron menores tampoco las dificultades derivadas de carencias de material didáctico el promotor de la mencionada escuela de Pino Gordo declaraba tener que limitarse a usar como tal semillas, cartulinas con dibujos, piñas de pino, piedras u hojas- o la falta de adaptación en los sistemas pedagógicos, como en la escuela de Bahuéachi donde los promotores no utilizaban la cartilla tarahumara o en la Ciénega de Cabórachi, donde el inspector escolar reportaba que

...en la enseñanza de la lectura y escritura [el promotor] utilizó la forma bilingüe y el método natural, que abarcó casi todos los puntos que marca el programa del grado preparatorio y notó que los niños tienen alguna dificultad en las lecciones de primer año en que aparecen palabras como marino, barco, elefante y otras cosas que se recomiendan y que el niño, aunque quisiera, no las puede hacer porque en sus casas carecen de lo más indispensable ${ }^{37}$

A pesar de todas estas dificultades maestros, inspectores y promotores del CCIT asumieron con celo ${ }^{38}$ las tareas educativas y por primera vez en la historia algunos

\footnotetext{
${ }^{37}$ Todas las referencias sobre las dificultades operativas de las escuelas provienen de Informes de Inspectores escolares presentados al director de la Sección de Educación del CCIT entre 1964 y 1970 y contenidos en ACCIT, Legajo 4, Expedientes 1, 2 y 3 y Legajo 151, Expediente 21.

${ }^{38}$ De este celo casi misionero en las tareas de difusión y extensión educativa es muestra el siguiente reporte de un supervisor escolar en diciembre de 1964:

En la escuela de El Cuervo la trabajadora social [...Jvisitó algunas casas de los vecinos $y$, según me pude dar cuenta, platicaba con las madres de familia dándoles consejos varios y echaba DDT para acabar con los insectos propios de las casas (Informe del Supervisor, 
poblados indigenas conocieron la institución escolar. Aconsejados o presionados por los técnicos del INI, los ejidos decidian invertir parte de sus utilidades forestales en el arreglo de sus escuelas y no pocas rancherías y poblados colaboraban con trabajo manual en la construcción de las escuelas, el acarreo de los alimentos para los albergues o el arreglo de los caminos de acceso a los centros escolares, lo que muestra, al menos, un cierto grado de asimilación y apoyo por parte de la población indígena frente a la implantación de las escuelas. ${ }^{39}$

CUADRO 25.- ESCUELAS ATENDIDAS POR EL CCIT Y MOVMIENTO GENERAL DE ALUMNOS. SEPTIEMBRE 1965-JUNIO 1966

\begin{tabular}{|c|c|c|c|c|c|c|c|c|c|}
\hline \multicolumn{9}{|c|}{ 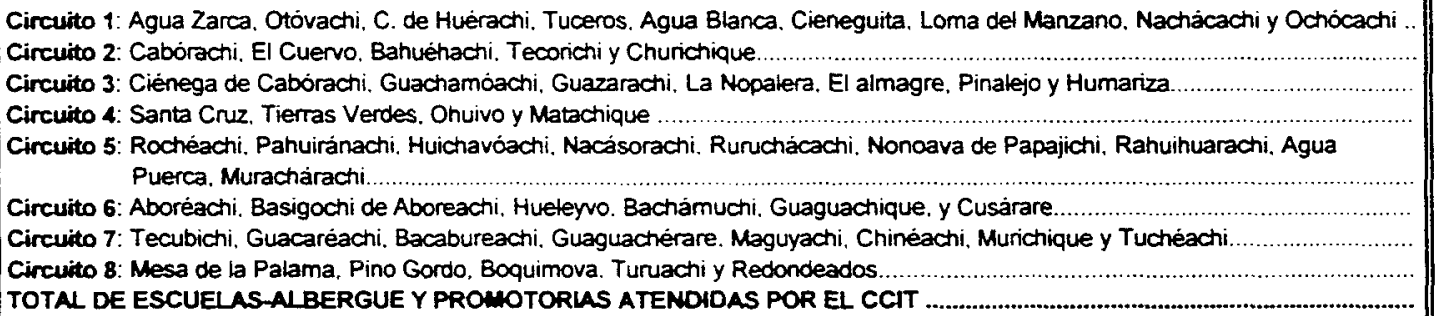 } & $\begin{array}{c}9 \\
5 \\
7 \\
4 \\
\\
9 \\
6 \\
8 \\
5 \\
53\end{array}$ \\
\hline & \multicolumn{3}{|c|}{ TOTALES } & \multicolumn{2}{|c|}{$\begin{array}{l}\text { GRADO } \\
\text { PREPARATORIO }\end{array}$} & \multicolumn{2}{|c|}{$\begin{array}{l}\text { GRADO } \\
\text { PRIMERO }\end{array}$} & \multicolumn{2}{|c|}{$\begin{array}{l}\text { GRADO } \\
\text { SEGUNDO }\end{array}$} \\
\hline & TOTAL & $H$ & $\mathbf{M}$ & $\mathrm{H}$ & $\mathbf{M}$ & $\mathbf{H}$ & $\mathbf{M}$ & $H$ & \\
\hline INSCRIPCION & $2,139(100 \%)$ & 1.254 & 885 & 668 & 460 & 468 & 343 & $\$ 18$ & 82 \\
\hline BAJAS & $168(8 \%)$ & 107 & 61 & 40 & 16 & 47 & 29 & 20 & 98 \\
\hline EXISTENCIA & $1.971(92 \%)$ & 1.147 & 824 & 628 & 444 & 421 & 314 & 98 & 66 \\
\hline EXAMiNaDOS & $1,609(75 \%)$ & 905 & 704 & 482 & 398 & 343 & 252 & 80 & 54 \\
\hline APROBADOS & $1.359(54 \%)$ & 761 & 598 & 402 & 338 & 297 & 212 & 62 & 48 \\
\hline REPROBADOS & $250(12 \%)$ & 146 & 106 & 80 & 60 & 46 & 40 & 18 & 6 \\
\hline ASISTENCLA MEDLA & $1,459(68 \%)$ & 850 & 609 & 454 & 311 & 318 & 246 & 78 & 52 \\
\hline PROMOVIDOS A OTRAS ESCUELAS & $181(8 \%)$ & 124 & 57 & - & - & - & - & - & - \\
\hline
\end{tabular}

$H=$ Niños. $M=$ Niñas

FUENTE: "Informe Anual. Sección de Educación. CCIT. 1965-66"en ACCIT Legajo 151, Expediente 2.

El Cuadro 25 permite darnos una idea de lo que representó esta "cruzada" educativa que llegó a muchos recónditos lugares de la Tarahumara, en los municipios de Batopilas, Guachochi, Balleza, Urique, Nonoava, Morelos, Guadalupe y Calvo, Carichi y

profesor B. Oramás, diciembre, 1964, en ACCIT, Legajo 4, Expediente 1, Documento 7).

${ }^{39}$ Los siguientes datos procedentes del reporte de junio de 1970 del director de la sección de educación del CCIT son reveladores de este tipo de aceptación: en el periodo comprendido entre septiembre de 1969 y agosto de 1970, los ejidos de Yoquivo, Guaguachique, Cabórachi, Guachochi, Basihuare, Tehuerichi, Choguita, Tecorichi, Narárachi, Tónachi, Pahuichique y Aboréachi destinaron un total de 314,050.21 pesos de sus ganancias forestales a la construcción o reparación de instalaciones escolares. ("Informe de la Sección de Educación. 12 de junio de 1970" en ACCIT, Legajo 151, Expediente 5.). También puede verse el "Informe anual de Labores del Prof. B.Oramas correspondiente al Sector escolar sur de julio de 1964" (ACCIT, Legajo 151, Expediente 21) en donde se enlistan los diferentes apoyos en trabajo y dinero aportados por las comunidades a las escuelas de esa zona. 
Bocoyna. A mediados de la década de los años sesenta, el CCIT había logrado consolidar y operaba 53 escuelas (48 promotorías, 5 escuelas albergue y en 26 de esas escuelas con apoyo de la SEP) en las que enseñaban cerca de un centenar de maestros y promotores a algo más de 2 mil alumnos inscritos en dos grados escolares con índices de asistencia (68\%) y aprobación (64\%) más que justificables si se consideran las hostiles condiciones para la escolarización que imperaban en la Tarahumara. Aunque la mayoria de estas escuelas no contaban con el ciclo completo de la educación primaria, el esfuerzo educativo del INI era notorio: en las principales rancherias rarámuri de la alta Tarahumara se instalaron promotorías y operaban las primeras escuelas albergue.

Las dificultades para expandir la tarea educativa, aun siendo muchas, fueron en realidad pocas si se comparan con las que enfrentó el CCIT para iniciar y consolidar programas médicos y de atención a la salud en una región en la que, como lo reconociera abiertamente en 1952 Aguirre Beltrán, subdirector del INI, en materia de salubridad todo estaba por hacerse ${ }^{40}$. Cuatro años después Plancarte informaba sin embargo que se habia realizado una "investigación primaria médico sanitaria y epidemiológica de la región tarahumara" y operaban una clínica en el Subcentro de Baquiriachi y 4 dispensarios médicos, capacitándose 2 enfermeros "nativos ${ }^{\prime 41}$. En 1961 el INI operaba en la Tarahumara 5 clínicas o unidades médicas (en Guachochi, Baquiriachi, Samachique, Rochéachi y Norogachi), otros 5 puestos médicos (en Cusárare, Basihuare, Choguita, Aboréachi y Cabórachi) y una red de botiquines permanentes localizados en comunidades indígenas. En total, laboraban en la Sección de Salubridad del CCIT 6 médicos y 11 promotores indígenas de salud. Pero ¿qué podía

\footnotetext{
${ }^{40}$ En su informe de recomendaciones para abrir el CCIT, Aguirre Beltrán reconocia que: no existe en la actualidad agencia sanitaria alguna en toda la extensión de la Sierra con excepción del Hospital -de carácter eminentemente asistencial- que los jesuitas poseen en Sisoguichi y que recibe un subsidio del gobiemo del estado. En lo relativo a salubridad todo está por hacerse: la experiencia de Chiapas nos suministra, sin embargo, el modelo para llevar adelante esta acción. (ACCIT, Legajo 27, Expediente 13, tambien compilado en Sariego 1998: 56-64)

41 "Informe que el CCIT presenta al Presidente Ruiz Cortines con motivo de su visita a Chihuahua ef 20 de diciembre de 1956" en ACCIT Legajo 27. Expediente 5. Plancarte plantea también que anualmente se invierten 40,000 pesos en medicinas y se imparten 7,200 consultas médicas.
} 


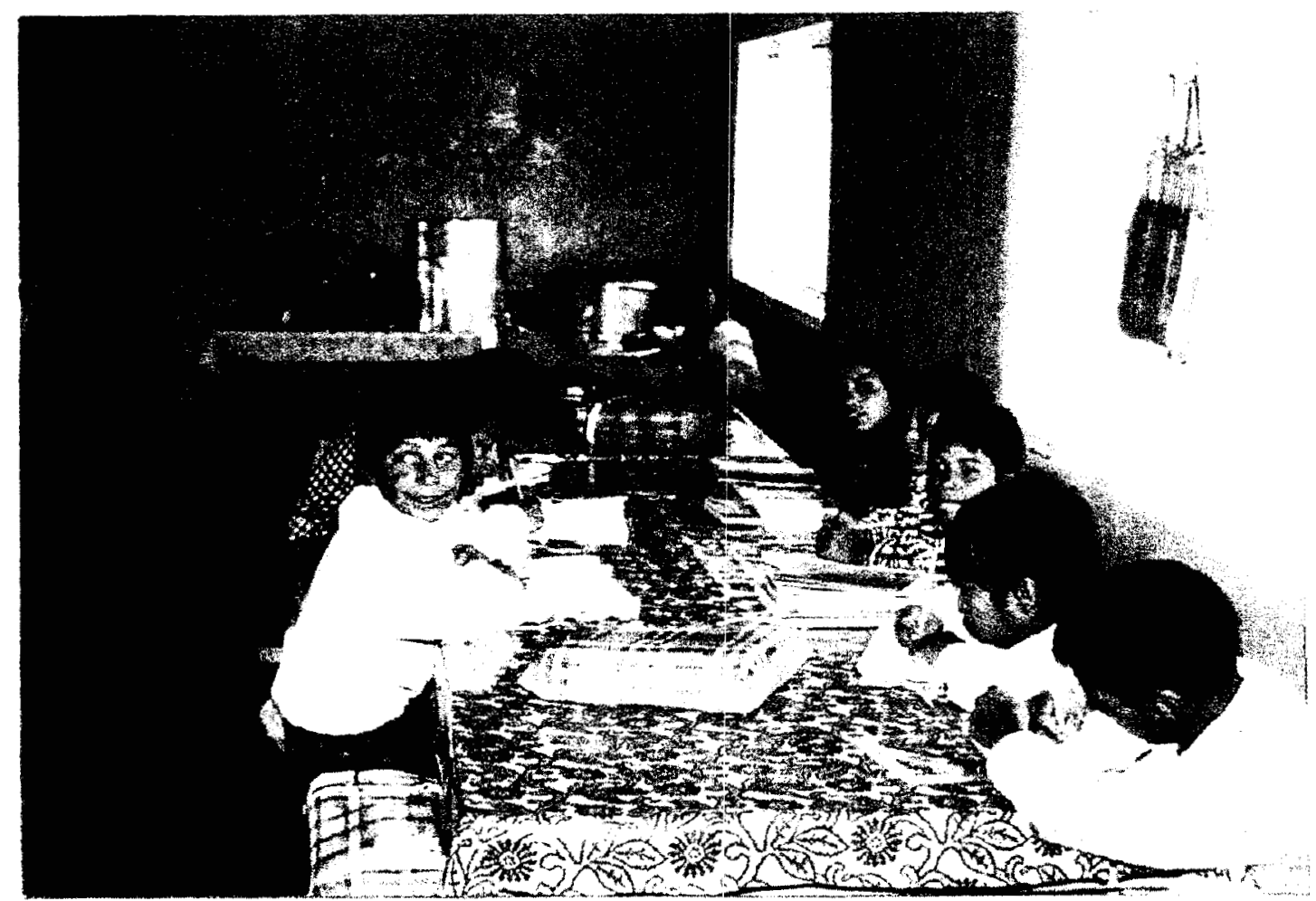

FIGURA 59.- COMEDOR-CLASE DE LA ESCUELA ALBERGUE FRANCISCO M. PLANCARTE. ABORÉACHI (FOTO DEL AUTOR, NOVIEMBRE, 1994)

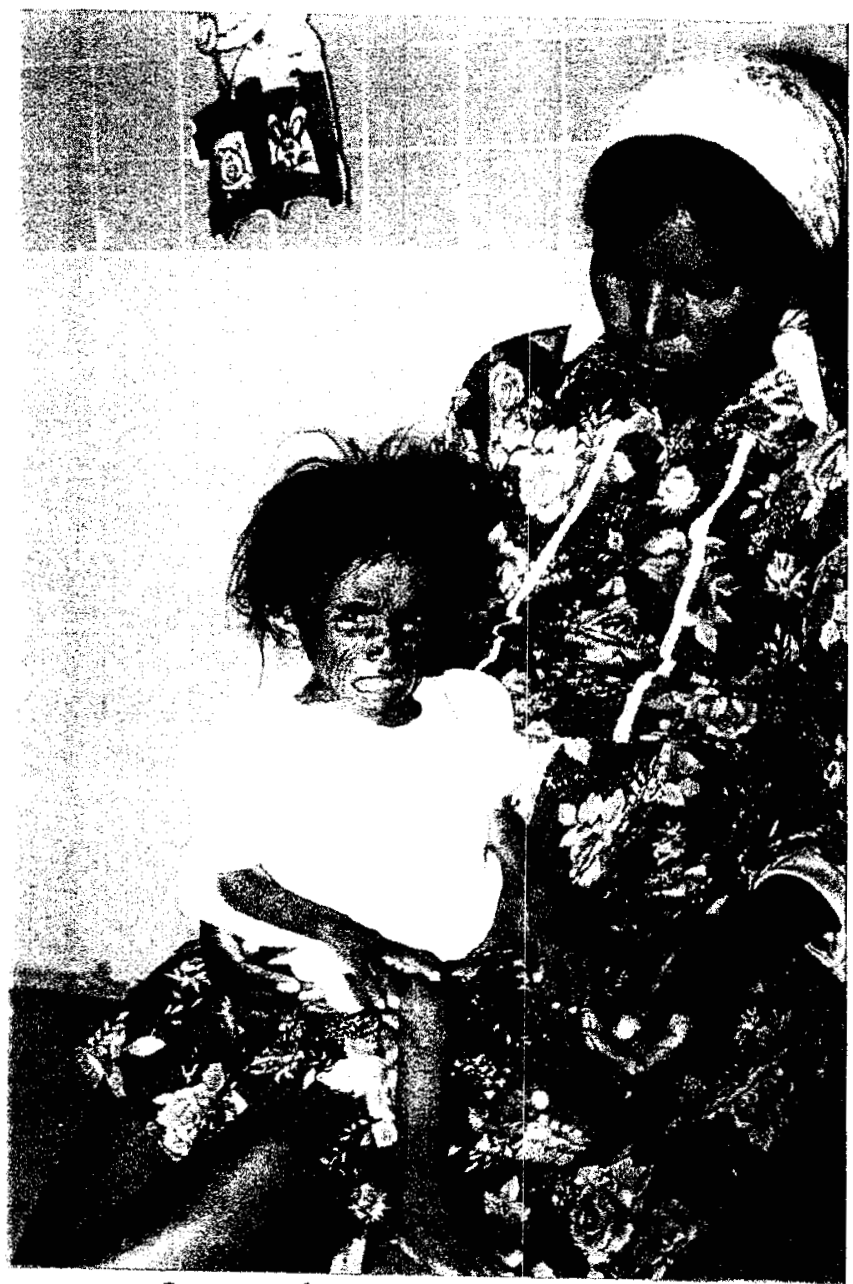

FIGURA 60.- NIÑO RARÁMURI ATENDIDO POR DESNUTRICIÓN. HOSPITAL INFANTIL DE CHIHUAHUA (FOTO DE LORELEY SERVÍN, 1994) 
representar ese esfuerzo teniendo en cuenta las enormes carencias y necesidades sanitarias de una población de cerca de 50,000 habitantes donde la medicina "científica" brillaba por su ausencia? ${ }^{42}$

El perfil de la patologia predominante que los médicos indigenistas comenzaban a registrar era el típico de regiones de pobreza extrema: diarrea y enteritis (11\%), sarampión $(7 \%)$, avitaminosis y otros estados carenciales $(6 \%)$, bronquitis, artritis y reumatismo -salvo la fiebre reumática- ( $5 \%$ cada una de ellas), rinofaringitis aguda (o resfriado banal), disenteria en todas sus formas y tosferina ( $4 \%$ cada una), faringitis aguda, amigdalitis y otras enfermedades del aparato digestivo ( $3 \%$ cada una). ${ }^{43} \mathrm{El}$ Cuadro 26 en el que se registra los casos de defunción atendidos por la Clínica del CCIT en Guachochi entre 1959 y 1960 confirman la misma impresión -la alta incidencia de las enfermedades respiratorias y gastro-intestinales- pero también la presencia de muertes imputables al clima de violencia y al consumo de alcohol.

Además de este grave perfil patológico, los doctores del INI no tardaron en percibir que los principales obstáculos para llevar la salud hasta las recónditas rancherias indígenas derivaban de aspectos nodales de la cultura y de la forma de ser de los tarahumaras $^{44}$. Asi por ejemplo un informe de la Sección de Salubridad del CCIT del año

\footnotetext{
${ }^{42}$ Incluso, en 1959 el antropólogo Romano que se habia hecho cargo del CCIT tras la muerte de Plancarte reconocía abiertamente que el funcionamiento de la Sección de Salubridad del Centro era deficiente "dados los pocos recursos con que ha contado, y a la mala distribución de las clínicas y el personaf". Recomendaba además seleccionar mejor la ubicación de futuras clínicas, reorganizar las tareas de los dos únicos médicos con que contaba el centro y adquirir el equipo médico de la compañia minera que estaba por cerrar operaciones en La Bufa, Batopilas. ("Informe del Director del CCIT al Dr. Alfonso Caso, 27 de febrero de $1959 "$ en Legajo 40, Expediente 3).

${ }^{43}$ Los datos proceden del informe anual de 1958 de la Sección de Salubridad del CCIT y fueron tomados de ACCIT, Legajo 9, Expediente 9, Documento 3

44 Desde luego el más importante de ellos, la presencia de un cuerpo de especialistas médicos owirúames entre los tarahumaras- con quienes algunos médicos del INI reconocian abiertamente estar en competencia, como el Dr. de la Rosa quien informaba en diciembre de 1959 haber tenido muchos problemas para atender enfermos en el ejido de Basihuare. donde la cultura médica es muy baja debido a que se ha trabajado muy poco en este terreno y el curanderismo y la brujeria están muy arraigados. (ACCIT, Legajo 9. Expediente 9)
} 
CUADRO 26.- RELACIÓN DE 51 DEFUNCIONES ATENOIDAS POR PERSONAL MEDICO DE LA CLINICA DEL CCIT EN GUACHOCHI (23 FEBRERO DE 1959 AL 20 ABRIL DE 1960)

\begin{tabular}{||l|l|l||}
\hline CAUSA DE DEFUNCION & NUMERO DE CASOS & EDADES DE LOS DIFUNTOS \\
\hline Agotamiento & 1 & 85 \\
Anginas & 3 & 2,3 y 70 \\
Asma & 1 & 82 \\
Ataque cardiaco & 3 & 1,7 y 20 \\
Bronquitis & 3 & 1 y $3(2)$ \\
Arma de fuego & 3 & 22,23 y 25 \\
Colapso cardiaco por alcohol & 2 & 46 y 56 \\
Colapso cardiaco-respiratorio & 3 & 1,62 y 68 \\
Cólico & 1 & 20 \\
Congestión alcohólica & 1 & 16 \\
Diarrea y anemia & 1 & 1 \\
Dolor en todo el cuerpo & 1 & 70 \\
Embolia cerebral & 1 & 18 \\
Estrangulamiento & 1 & 30 \\
Fiebre y Fiebre intestinal & 11 & $1(4), 2,3,13,32,45,54$ y 58 \\
Gripe & 2 & $90(2)$ \\
Instrumento Punzo Cortante & 1 & 40 \\
Meningitis & 1 & 4 dias \\
Pulmonia & 6 & $1,4,45,50$ y $60(2)$ \\
Quemadura & 1 & 6 \\
Tosferina & 2 & 1 y 3 \\
Toxicosis por parasitosis intestinal & 1 & 90 \\
Ulceración intestinal & 1 & 90 \\
\hline
\end{tabular}

FUENTE: "Informe de la Sección de Salubridad del CCIT, 1960" en ACCIT Legajo 9, Expediente 9, Documento 2.

1959, enumeraba así las dificultades más graves para interesar a la población indígena en los servicios médicos:

1. La vigencia de una cultura diferente que continúa orientando fuertemente a la población hacia los servicios de los especialistas nativos.

2. El poco conocimiento que nuestra Sección de Salubridad tiene del funcionamiento de la cultura indigena en su aspecto médico [...]

3. La gran dispersión de la población es un problema que continúa, sin presentarse ningún principio de solución [...]. A la dispersión de la población se agrega cierto grado de nomadismo.

4. La imposibilidad de llevar en grandes proporciones el servicio médico a los hogares indigenas, por la escasa disponibilidad de recursos humanos y técnicos. Un médico para atender a un enfermo en su casa puede necesitar todo un dia. Un médico o un promotor en gira, si los caminos son transitables, visitará en un día unas diez familias.

5. Ha habido una precaria búsqueda de técnicas para salvar las distancias fisicas y culturales que separan al servicio médico de la población indígena.

6. El personal auxiliar, los promotores, tienen una preparación muy deficiente, to que da lugar a que tengan un insuficiente papel de enlace entre el programa y la comunidad. 
7. La poca afortunada localización de las unidades médicas de Baquiriachi y Cusárare que son puntos periféricos del área de trabajo del Centro $y$ corresponden a zonas de muy baja densidad de población ...].

De lo anterior resulta que hay un desconocimiento reciproco de las motivaciones de los indigenas y de las del programa. Por ejemplo es opuesto el ambiente familiar y el ambiente de la clinica y es en el primero donde se hace la medicina tradicional. El Dr. González cree que el moderno edificio de la clínica de Baquiriachi más que atraer, rechaza a los indigenas y propone que se obtenga una rústica casa vecina para internar enfermos. Por otro lado, en esta medicina tradicional, es invariable el tratamiento del enfermo en el hogar del paciente $\dot{y}$ jamás fuera de él. ${ }^{45}$

Estas y otras limitaciones similares no tardarian en hacerse evidentes cuando las coyunturas extremas, pero reincidentes, de epidemias y hambrunas se hicieron presentes. Así por ejemplo, entre finales de 1959 y mediados de abril de 1960 se desencadenó en la Sierra una fuerte epidemia de gripa ocasionando al menos 165 defunciones registradas por el CCIT y un número adicional no definido. Los tres médicos y los promotores del CCIT fueron insuficientes para atender el llamado de los enfermos e incluso se acabaron en tres meses la partida de antibióticos asignados al centro para todo el año. Pero además esta coyuntura evidenció la incapacidad del sistema médico indigenista para enfrentar la situación de la Tarahumara, en donde

como en cualquier zona indigena cuya población ha permanecido aislada por mucho tiempo, el trabajo que se desarrolló [...] fue muy complicado. Los indigenas tienen sus propios conceptos sobre la causa de las enfermedades y disponen de sus propios métodos curativos que, al no funcionar, como último recurso ocurren al médico quien, en la mayoría de los casos poco o nada puede hacer por la gravedad de los enfermos.

La incidencia cíclica de epidemias y hambrunas (derivadas de sequias y de la consecuente carencia de cosechas) significó desde entonces hasta hoy un reto continuo

\footnotetext{
${ }^{45}$ Tomado de "Informe de la Supervisión a la Sección de Salubridad del CCIT realizada del 7 al 19 de junio de 1959" en ACCIT Legajo 9, Expediente 9 (compilado también en Sariego, 1998: 203-211)

${ }^{46}$ El texto procede del "Informe del Dr. Leopoldo Saucedo Tinajero, Jefe de la Sección de Salubridad, de mayo de 1960" en ACCIT, Legajo 9, Expediénte 9. De acuerdo con la misma fuente, desde principios de febrero hasta el 2 de abril de 1960, se tenian registradas 161 defunciones en los siguientes lugares: Aboréachi (23), Bahuéachi (16), Tecorichi (20), El Cuervo (2), Nacásorachi (4), Cieneguita (1), Santa Anita (9), Tónachi (12), Cabórachi (10), Norogachi (9), La Laja (5), Guachochi (7), Samachique (8), Baquiriachi (5), Bachámuchi (2), La Unión (1), Somárachi (10), Hueleyvo (2), Rancheria de Rochéachi(8), Ruruchácachi (1), Huérachi (6).
} 
a los servicios médicos oficiales. ${ }^{47}$ Para hacer frente a él, la Sección de Salubridad fue ampliando de manera modesta la cobertura de sus acciones. Hacia 1967 éstos se centraban en cinco grandes programas: asistencia médica en 5 clínicas, higiene materno-infantil, vacunación, saneamiento del medio y educación higiénica con el apoyo de audiovisuales y del teatro guiñol. ${ }^{48}$

Lejos de sus aspiraciones, la labor médica del CCIT nunca logró opacar la vitalidad y fuerza de la medicina indígena. Incluso algunos de los médicos indigenistas acabarian por reconocer no sólo el fracaso de sus esfuerzos sino también la eficiencia de prácticas ligadas a la curación como el ancestral consumo del tesgüino entre los pueblos indios de la Tarahumara. ${ }^{49}$

\footnotetext{
${ }^{47}$ Las campañas periodisticas sobre hambrunas y epidemias en la Sierra Tarahumara son reincidentes y a menudo infundadas, dado que, como ya lo señalamos anteriormente, resulta dificil precisar las tasas de morbilidad y mortalidad en una región donde la cobertura de los servicios médicos institucionales es escasa. En los registros documentales del CCIT he podido sin embargo encontrar referencias precisas a los siguientes casos: hambrunas en Guaguachique, Basihuare y Choguita (1959-1960); Pino Gordo (1961); Sisoguichi (1961); Coraréachi, Munérachi, Guapalayna y Guadalupe Coronado (1962); Otóvachi, Cieneguita y Tuceros (1963-1964); Nacásorachi (1964); Santa Ana y Matachique (1969-1970); Nabogame (1971); Real de La Dura, Quirare, Sisoguichi y San Luis de Majimachi(1973). Epidemias de sama en Choguita (1957); de fiebre y tifoidea en el municipio de Guadalupe y Calvo (1960); generales de gripe (1959-1960 y 1965), tuberculosis, gastro-enteritis y bronco-neumonia (1965-1966); de tifoidea en zona de Baquiriachi (19631964); de sarampión en Yoquivo (1965), San Miguel (1966). Guaguachique (1969-1970) y zona de Guachochi (1981) y de viruela en Tatahuichi (1965-1966). (Véanse los siguientes Legajos y Expedientes: 3$38,9-1,9-8,9-9,10-1,10-2,15-2,33-7,33-11,33-13,41-26,99-4,100-6,101-11,103-1,107-7,110-9,116-$ $8,139-4,144-18,153-8$ y $156-10$.

${ }^{48}$ Las 5 clinicas estaban establecias en Guachochi, Baquiriachi, Rochéachi, Samachique y Cusarare y en conjunto ofrecian un volumen anual de cerca de 15,000 consultas. El programa de higiene materno-infantil cubria la atención anual de cerca de 70 partos, el examen periódico de embarazadas y recién nacidos y un adiestramiento de parteras empiricas. La vacunación incluia la antivariolosa a 10,000 personas, la triple a 2,000 niños, la antipolio a 2,000 y la antitubeculosa. El programa de Saneamiento del medio comprendia labores de protección de pozos, manantiales, letrinas y mejoramiento de viviendas asi como asesoria para obras de saneamiento en ejidos. (Véase "Programa-Presupuesto del CCIT para 1967"en ACCIT Legajo 27. Expediente 5). En agosto de 1968 el CCIT ofrecia asistencia médica en 7 puestos médicos y 4 clinicas, los primeros a cargo de promotores culturales y las segundas a cargo de médicos, todos dependientes de la Sección de Salubridad del CCIT. Entre septiembre de 1967 y agosto de 1968 se construyeron 4 puestos médicos en Yoquivo, Guaguachique, Cabórachi y Otóvachi.("Informe del director del CCIT al gobemador del estado de Chihuahua, agosto 1968", en ACCIT Legajo 150, Expediente 16).
}

49 Véase por ejemplo "Informe de octubre de 1960 del Dr. Cuéllar sobre el alcoholismo en la Tarahumara" (en ACCIT Legajo 9, Expediente 9 y en Sariego, 1998: 216-219). Según este médico el tesgüino o batari

es una bebida energética de baja gradación alcohólica (igual o menor a la de los vinos generosos). asi que al privar a los rarámuri de su bebida bajaria su aporte calórico y 
Hacia 1970, después de veinte años de búsquedas y experiencias, los principios de la acción integral que el INI habia ensayado en la Tarahumara daban ciertos frutos. En algunos poblados, los ejidos y el reconocimiento de la propiedad indigena de la tierra habian pasado "del papel" a los hechos; la explotación de los bosques, aunque no era del todo ajena a los empresarios madereros, revertía en algunas ganancias para sus propietarios indígenas; las escuelas y las clínicas, todavia muy escasas, comenzaban a hacerse presentes en medio del paisaje de bosques y rancherias dispersas y en fin, era evidente, en opinión de los promotores del indigenismo oficial, que los grupos étnicos estaban modificando sus arraigadas actitudes frente a la sociedad nacional. Alguno de esos promotores indigenistas se atreveria incluso a decir:

El logro más importante, a mi parecer, ha sido el conseguir que el tarahumara haya abandonado su habitual fatalismo y pasividad. Hoy en dia plantea, con toda libertad sus problemas y exige su resolución aun cuando en algunas situaciones presente reclamaciones que no es posible satisfacer (Romano, 1962).

Esta percepción optimista no podia esconder, sin embargo, las variadas formas de indiferencia, discrepancia y aún de resistencia que muchos núcleos de población indígena exhibian frente a las estrategias de la acción integral. En realidad, la política agraria y forestal del INI venía a trastocar muchos de los elementos centrales de la cultura tarahumara. En primer lugar erigía en centro neurálgico del desarrollo la explotación forestal, siendo que ésta es sólo uno de los componentes del complejo productivo indigena ${ }^{50}$ que, aunque no siempre asegura los recursos necesarios para la alimentación, se sustenta en una cierta diversificación entre la agricultura, la ganaderia,

vitaminico. Además de 10 anterior viene todo el efecto farmacológico del alcohol, que proporciona un escape de la realidad hacia un mundo mejor, de euforia artificial

El doctor Cuéllar concluye que no debe desterrarse el uso del batari entre los raramuri teniendo que considerario como no alcohólico. En cambio lo que si hay que desterrar, porque es fuente de alcoholismo, es el consumo de licor y cerveza asociado a la economia monetarizada de los aserraderos y al caciquismo en pueblos como Guachochi, Cusárare, Basihuare y Choguita. También propone crear un impuesto especial para subir el precio del alcohol y usar esas ganancias para obras de beneficio colectivo, evitar la venta de alcohol los dias de pago en aserraderos y acabar así cón la "borrachera sabatina" en lugares como Guachochi, además de controlar su transporte por carreteras serranas.

\footnotetext{
50 Eso explica el rechazo de aigunos ejidos a entrar en los programas forestales o a destinar las ganancias de la operación maderera en los rubros establecidos por el INI, a pesar de la insistencia de los técnicos indigenistas. Puede verse al respecto los comentarios de Benitez en relación a la oposición de los ejidatarios de Aboreachi a los planes de inversión que el INI les propone en 1957 (Benitez, 1967: 132-135).
} 
la recolección, la caza y la explotación del bosque.

En efecto la economía indigena depende principalmente de la producción de maiz, frijol y, en menor medida, papa, calabaza, chícharo, haba, avena y trigo. Para poder sembrar, los rarámuri llevan a cabo rozas y desmontes en áreas boscosas y zonas de alta vegetación y en las pendientes laderas construyen terrazas o mawechis con piedras, zacatales, magueyes y nopales, impidiendo asi el deslave y la inundación del suelo. Utilizan semillas criollas que seleccionan y diversifican de acuerdo a los gradientes de altitud, los tipos de suelo y el grado de humedad de la tierra. La tecnologia agrícola combina instrumentos indígenas como la wica o palo sembrador con el arado de madera o de acero, el azadón y el cotense y apropiaciones occidentales como el hacha de metal, el yugo español, la hoz, el cuchillo, la barra, el arado de punta de fierro, la escardilla y el pizcador.

A partir de la influencia occidental, muchos animales se incorporaron a la vida indígena. Los bueyes se ocupan para arar la tierra en terrenos pedregosos 0 arcillosos. Los caballos, las mulas y los machos se aplican al transporte y a la agricultura cuando las condiciones topográficas lo permiten. Para abonar sus tierras de cultivo, los rarámuri utilizan el estiércol de las cabras y ovejas valiéndose para ello de la técnica del establo móvil. De todo ello deriva la importancia que los rarámuri otorgan al pastoreo de las chivas, tarea que es encomendada a los niños. Además, las ovejas son un recurso muy apreciado al proporcionar la lana para tejer las mantas con que soportar el frío invernal.

Además de recurrir a la recolección de plantas alimenticias y medicinales, asi como a la caza y pesca (González, 1994a: 105-107), los rarámuri se convirtieron, desde la época de la introducción del hacha en tiempos coloniales, en expertos artesanos madereros. Desde entonces, el trabajo de la madera invadió todos los ámbitos de la cultura material: las especies de pino que en tarahumara se denominan wiyóko, matigo y sawáka se utilizan para la construcción de casas, graneros, corrales, gallineros, cercas y artesas. Con el fresno se elaboran violines, guitarras, tambores y mangos de hacha. EI 
madroño sirve para hacer bateas, cucharas y cabezales de monturas. El encino proporciona una madera muy dura y resistente para la construcción de arados, puntas de arados y mazos. El uso indigena del bosque a pequeña escala y para usos domésticos no sólo responde a razones de indole económica, sino que también apunta hacia una actitud de respeto y preservación de raices profundamente religiosas. Cuenta un relato extendido entre los grupos étnicos de la Tarahumara que al principio del mundo Dios juntó a todos los seres vivos del bosque y les dijo:

Vengo a preguntarles qué opinan sobre si quieren que haya muerte o no. Los animales y las plantas pensaron y dijo un puma gordo y enorme: "Los animales grandes no queremos que exista la muerte". Entonces los animales chiquitos protestaron: "Nosotros, los camaleones, las lagartijas, los sapos y muchos otros, si queremos que exista la muerte porque si[no, habrá] muchos animales grandes y nos van a pisotear todo el tiempo".

Dios pensó un rato y finalmente tomó en cuenta a los animales pequeños. "Si, va a haber muerte", les dijo, "pero los que van a tener más larga vida van a ser los pinos, los encinos y otros árboles más porque ellos no caminan, no pisan ni hacen daño a nadie". Y es por eso que existe la muerte y los ámoles duran tantos aก̃os... ${ }^{51}$

Esta breve explicación de la economia rarámuri ayuda a entender las limitaciones del proyecto forestal del INI. Pero además, este experimento, aunque repartió algunos dividendos entre los ejidatarios indigenas eliminando el injusto procedimiento del pago irregular por "derechos de monte", también benefició ampliamente a las empresas madereras en la medida en que el sistema de contratos por maquila se fue imponiendo a la propuesta original del equipo del CCIT de hacer de la explotación forestal una actividad económica de estricto control ejidal ${ }^{52}$. Dicho en otros términos: por sus limitaciones financieras y administrativas, los ejidos se limitaron a controlar la fase

${ }^{51}$ Relato de Josefina Rivas Vega, maestra tepehuana del municipio de Guadalupe y Calvo tomado de SEDESOL, 1998: 45. Una versión rarámuri similar puede verse en Anónimo, 1995: 87

52 De hecho, el experimento autogestivo de Cusárare el único ejido con población indigena que habia venido trabajando con el sistema de "explotación directa", es decir, controlando todas las fases del proceso productivo y de comercialización de su madera-, fue suspendido en 1966, fecha en que el ejido se adscribió al sistema de explotación por contrato de maquila con una empresa forestal privada. El INI justificó la medida, alegando falta de créditos e incapacidad del ejido para explotar toda la "anualidad" o cantidad de madera autorizada, lo que apunta a una cierta oposición e incompatibilidad -que se dio también en otros ejidos- entre la dedicación de los ejidatarios indigenas a las labores forestales y a su ocupación tradicional agricola y recolectora (Vatant, 1979: 47-63 y Anónimo, 1971). 
extractiva del proceso maderero (tala y aserrio primario en forma de tabla y palillo), dejando a las empresas el monopolio de los precios, la comercialización de la madera y su transformación en productos manufacturados y celulosa. Sin duda, esta situación reportó a los ejidatarios algunos ingresos, pero la presencia del INI sirvió para institucionalizar una forma de subordinación de los ejidos al monopolio de los intermediarios forestales, quienes obtuvieron de ello cuantiosas ganancias. ${ }^{53}$

Desde otra perspectiva, el proyecto agrario y forestal del INI venia a colocar en una situación de subordinación al gobierno indígena en relación con la autoridad ejidal muchas veces de mayoria mestiza- desconociendo, en la práctica, la estructura de los territorios étnicos y la jurisdicción sobre ellos de los viejos siriame rarámuri.

En cuanto a los programas del INI en materia de educación y salud, ya hemos documentado la resistencia en muchos casos pasiva, pero efectiva- que debieron de enfrentar por parte de gobernadores y owirúame locales que, por cierto, nunca perdieron su hegemonia a pesar de la presencia de la medicina indigenista.

En su concepción, modelo y experiencias, la acción integral exigió de los indigenas de la Sierra de Chihuahua aceptar formas organizativas como el ejido, la propiedad comunal de la tierra, el trabajo colectivo -para la construcción de escuelas, trojes, caminos, clínicas-, las asambleas para decidir el destino de los fondos de inversión, el comité escolar de padres de familia y el municipio, todas ellas ajenas por completo a la idiosincrasia y a la tradición de dispersión y de autonomia política de los grupos étnicos de la Tarahumara. En repetidas situaciones, la aceptación de estas formas de organización respondió más a la presión de los agentes externos que a la convicción de los propios indigenas. En todo caso, puede decirse que más que buscar un enfrentamiento directo con el aparato indigenista, los rarámuri (a quienes se dirigió casi exclusivamente la acción indigenista de esos años) optaron, como to han hecho por

\footnotetext{
53 Sobre la historia de la explotación forestal en la Tarahumara véase Lartigue, 1983; Vatant, 1979 y 1990 , Alcocer, 1987; Molinari, 1993 y Porras, 1996 y Enriquez, 1988.
} 
siglos, por reapropiarse de muchos de los elementos de los programas que les fueron impuestos readecuándolos a sus propios intereses. Asi por ejemplo, encontraron que la defensa del ejido, enarbolada por el CCIT, era la mejor forma de proteger sus tierras del acoso de los mestizos y de las empresas madereras y que el celo indigenista por inculcar en sus hijos los elementos de la cultura y de la lengua nacionales podía trastocarse en una valiosa arma para la obligada convivencia con los "chabochi" en una sociedad cada vez más penetrada por el estado nacional.

\section{DE LAS POLITICAS SECTORIALES A LA PARTICIPACIÓN INDIGENA: LOS TIEMPOS DE CRISIS DEL INDIGENISMO (1972-1990).}

Desde la mitad de la década de los años setenta hasta la actualidad, el pensamiento y la práctica indigenistas han vivido una profunda crisis en México de la que no ha sido ajena la Sierra Tarahumara. Dos procesos se conjuntaron a lo largo de todo este periodo. En primer lugar la política indigenista conoció una importante reforma institucional que se expresó en una notoria pérdida del poder que el INI y sus centros coordinadores habian detentado en términos de la toma de decisiones, la coordinación y la aplicación de programas y proyectos de acción en las asi llamadas regiones de refugio. En contraparte, estas atribuciones fueron transferidas a una serie de programas y organismos federales que sustituyeron los principios de la acción integral por el de las politicas "sectoriales" destinadas a atacar los problemas de pobreza y marginación en las regiones criticas del pais.

El segundo proceso que corrió paralelo al de la reforma institucional fue el de la impugnación y crisis teórica del integracionismo aculturativo. En efecto, el paradigma indigenista que habia sido el soporte de la obra institucional del INI fue seriamente cuestionado, en especial desde el medio de la academia. Asi, la caracterización del indio que habia sido construida desde la óptica de su integración comenzó a desmoronarse. Como lo ilustrara de manera brillante Stavenhagen ${ }^{54}$, en el debate sobre la cuestión étnica en México se identificaban, hacia en 1978, cinco conceptos clave-cultura, clase,

\footnotetext{
${ }^{54}$ Véase al respecto lo que ya señalamos en las pajgs. $25-28$ de la introducción.
} 
comunidad, etnia y colonialismo interno- alrededor de los cuales se construian cuatro distintos enfoques explicativos sobre las relaciones de los grupos indios con la sociedad nacional. El primero de ellos era el enfoque clásico integrativo-culturalista que hasta entonces habia inspirado la política oficial. Una segunda corriente de orientación marxista insistia en el carácter clasista de la identidad étnica afirmando que los indios son parte de las clases explotadas del pais tendiendo así a desdibujar los rasgos culturales distintivos de este sector de la población. Una tercera línea de interpretación descifraba el atraso y la pobreza de las comunidades indigenas a partir de su carácter de colonias internas subordınadas al modo de producción capitalista dominante y pronosticaba su integración a la cultura mestiza dominante. Una última propuesta, caracterizada de indianista, anteponía la identidad étnica a la condición de clase y apuntaba germinalmente hacia el debate sobre la autonomía. (Stavenhagen 1978).

Ante esta diversidad de enfoques, los nuevos directivos del INI optaron por sustentar sus programas en una versión atenuada y corregida del integracionismo aculturativo que fue conocida con el término de "indigenismo de participación" concepción y modelo se resumen en el Cuadro 27 . En él, se puede observar que la nueva estrategia insistía en sustituir el viejo concepto de la integración por el de la participación de los grupos étnicos en la dinámica de la economía y desarrollo nacionales, lo que les permitiria satisfacer sus necesidades básicas, defender sus derechos individuales y sociales y fortalecer una conciencia nacional pluriétnica. Las tesis de la dependencia y del colonialismo interno permeaban la nueva definición del indio sustituyendo la antigua concepción culturalista. En cuanto a la orientación de las estrategias de acción, el nuevo indigenismo enfatizaba la defensa de los derechos indigenas y la incorporación en los programas de desarrollo, educación bilingüe-bicultural

55 El concepto de "indigenismo de participación" surgió en 1977 en ruptura con las tesis del integracionismo y como punto nodal de la definición de la nueva orientación asumida por el INI al inicio del gobierno del presidente López Portillo. (INI, 1978a; Báez, 1978 y Ovalle, 1977 y 1988. Véase también lo que ya señalamos en págs. 38 y 39 ). Este mismo concepto fue también utilizado por el principal critico de esta nueva orientación. Aguirre Beltrán, quien siempre vio e ella una derivación de las tesis del colonialismo interno y la marginalidad de González Casanova y Stavenhagen. (Aguirre, 1983: 333-355; 1994: 136-140 y 65-75). En cuanto a la educación bilingüe y bicultural véase Nahmad, 1978. 
CUADRO 27.- ESQUEMA COMPARATIVO DE LA ACCION A PARTIR DE LOS CENTROS COORDINADORES INDIGENISTAS

\begin{tabular}{|c|c|c|}
\hline & $1951-1976$ & 1977 \\
\hline OBJETIVOS & $\begin{array}{l}\text {-Borrar la distancia evolutiva que separa al in- } \\
\text { dio del ladino, introduciendo gradualmente } \\
\text { nuevas técnicas y pensamientos que puedan } \\
\text { sustituir los valores negativos de su cultura e } \\
\text { integrarlos a la sociedad nacional. } \\
\text {-Formación de una nación culturalmente ho- } \\
\text { mogénea (1). }\end{array}$ & $\begin{array}{l}\text { 1.- Lograr una mayor participación del indígena en la pro- } \\
\text { ducción y los beneficios del desarrollo nacional. } \\
\text { 2.- Satisfacer sus necesidades básicas. } \\
\text { 3.-Elevar la capacidad de los grupos étnicos en la defen- } \\
\text { sa de sus derechos individuales y sociales. } \\
\text { 4.- Fortalecer la conciencia nacional a través del respeto } \\
\text { al pluralismo (9). }\end{array}$ \\
\hline $\begin{array}{l}\text { PROBLEMAS A } \\
\text { RESOLVER } \\
\text { (DIAGNÓSTICO) }\end{array}$ & $\begin{array}{l}\text { La población indigena se encuentra atrasada } \\
\text { con respecto al resto de la población pues no } \\
\text { acepta las innovaciones técnicas y se aferra } \\
\text { a su cultura y sus costumbres anacrónicas } \\
\text { (2). }\end{array}$ & $\begin{array}{l}\text { Los grupos étnicos han sufrido un proceso histórico de } \\
\text { persecución, despojo y explotación de sus bienes y de su } \\
\text { fuerza de trabajo. La condición del indigena es resultado } \\
\text { de una relación socioestructural (10). }\end{array}$ \\
\hline $\begin{array}{l}\text { SUJETO DE LA } \\
\text { ACCION } \\
\text { INDIGENISTA }\end{array}$ & $\begin{array}{l}\text { Economia de mercado subdesarrollada que } \\
\text { comprende a indigenas y mestizos ( } 3 \text { ). }\end{array}$ & $\begin{array}{l}\text { Los sectores de la población que han quedado margi- } \\
\text { nados de los beneficios del desarrollo nacional (11). }\end{array}$ \\
\hline $\begin{array}{l}\text { SEDE DEL } \\
\text { CENTRO } \\
\text { COORDINADOR }\end{array}$ & $\begin{array}{l}\text { Ciudad Metrópoli, cabecera de la región indi- } \\
\text { gena centro rector. En contacto con las agen- } \\
\text { cias e instituciones de la ciudad (4). }\end{array}$ & $\begin{array}{l}\text { Plaza de } 2^{\circ} \text { orden, ciudad mercado indigena. Se ofrece a } \\
\text { las dependencias espacio contiguo al centro coordinador } \\
(12)\end{array}$ \\
\hline $\begin{array}{l}\text { AREA DE } \\
\text { TRABAJO }\end{array}$ & $\begin{array}{l}\text { Regiones interculturales de refugio: } \\
\text { 1.- Área de demostración } \\
\text { 2.- Área de difusión } \\
\text { 3.- Arrea de migración. } \\
\text { 4.- Área de movilización. } \\
\text { Aumentar la relación entre el àrea e refugio y } \\
\text { la metrópoli mestiza. (5) }\end{array}$ & $\begin{array}{l}\text { Criterios de regionalización acordes con la Secretaria de } \\
\text { Programación y Presupuesto. Integración de la región } \\
\text { marginal. disminuyendo su dependencia con la } \\
\text { estructura de poder local (13). }\end{array}$ \\
\hline TIPO DE ACCION & $\begin{array}{l}\text { DIFUSIÓN DEL DESARROLLO A LAS } \\
\text { REGIONES SUBDESARROLLADAS. } \\
\text { Asegurar el sentimiento de posesión de la } \\
\text { parcela. }\end{array}$ & $\begin{array}{l}\text { APOYO AL DESARROLLO DE LOS GRUPOS } \\
\text { ÉTNICOS. } \\
\text {-Apoyo a la defensa de sus derechos. }\end{array}$ \\
\hline Agropecuaria & -intraducción de tecnologia. & $\begin{array}{l}\text { - Aportar su producción disminuyendo su dependencia, } \\
\text { desarrollo de tecnologia apropiada y agroindustrias. }\end{array}$ \\
\hline Infraestructura & $\begin{array}{l}\text {-Caminos para romper la autosuficiencia de } \\
\text { la región de refugio. }\end{array}$ & -infraestructura de apoyo. \\
\hline Educación & $\begin{array}{l}\text {-Castellanización y enseñanza de los valores } \\
\text { de la sociedad nacional. }\end{array}$ & -Bicultural y bilingüe. \\
\hline Salubridad & $\begin{array}{l}\text {-Secularizar las prácticas médicas tradiciona- } \\
\text { les }(6) \text {. }\end{array}$ & $\begin{array}{l}\text { - Extender la cobertura sanitaria en colaboración con los } \\
\text { médicos tradicionales y parteras empiricas (14). }\end{array}$ \\
\hline COORDINACIÓN & $\begin{array}{l}\text { Consejo del Centro, integrado por represen- } \\
\text { tantes de las distintas Secretarias y Departa- } \\
\text { mentos de Estado (7) }\end{array}$ & $\begin{array}{l}\text { Participación de los centros coordinadores indigenistas a } \\
\text { través de la oficina coordinadora, en los Comités de De- } \\
\text { sarrollo de los Estados (COPRODE) } \\
\text { Convenios programáticos con las Secretarias y Departa- } \\
\text { mentos. COPLAMAR (15). }\end{array}$ \\
\hline $\begin{array}{l}\text { FUNDAMENTO DE } \\
\text { LA ACCIÓN }\end{array}$ & $\begin{array}{l}\text { Necesidad de expandir el desarrollo capita- } \\
\text { lista y ampliación del mercado. } \\
\text {-Modernizar la agricultura, compra de insu- } \\
\text { mos. } \\
\text { - Integrar a la vida nacional. } \\
\text { - Aculturativa (8). }\end{array}$ & $\begin{array}{l}\text { Necesidad de la búsqueda de las alternativas del desa- } \\
\text { rollo. Confianza en la capacidad de los grupos étnicos. } \\
\text {-Participación } \\
\text {-Pluralismo } \\
\text {-Autogestión (16). }\end{array}$ \\
\hline
\end{tabular}

(1)INI, 1964: 11-17 y Aguirre, 1957: 23 y 50; (2) INI, 1964: 21; (3) Aguirre, 1957: 68-69 y 1-17; (4) INI, 1964: 19; (5) Aguirre, 1967: 255; (6) INI, 1964: 20-24; (7) INI, 1964: 177-186; (8) Caso, 1958 y Aguirre 1957 y 1967; (9) INI, 1974; (10) y (11), Ovalle, 1977; (12) INI, 1978 b; (13), (14), (15) y (16) INI 1978 a FUENTE: Tomado de Báez, 1978: 293

$$
319
$$


y salud de la autogestión y de los valores propios de las culturas indígenas. El nuevo modelo propugnaba, además, por la coordinación del INI con las dependencias públicas y convenios programáticos de los sectores federal y estatal.

Sin embargo, en la práctica, las concepciones del indio derivadas del neoindigenismo fueron pragmáticamente suplantadas en especial, después de 1982-, por categorias generales como las de marginación y pobreza extrema a la par que la acción indigenista se asumió como parte de una política sectorial más amplia, diseñada para atender las demandas de los grupos más desfavorecidos de la sociedad. Progresivamente, esta carencia de un discurso y de un programa de acción especificos sobre la población indigena fue característica de los organismos y planes sectoriales para los que lo indigena sólo era asimilable y manejable en términos de marginalidad social, es decir, de carencias. Fue así como una visión peyorativa y excesivamente economicista del mundo indígena fue postergando aquellos otros aspectos que, más allá de connotar la pobreza, explican las diferencias de este sector con respecto al resto de la población nacional y dan razón de las causas profundas de su marginación y pobreza. ${ }^{56}$

La nueva politica indigenista que derivó de esta transferencia de funciones del INI a estos organismos sectoriales, aunque contó con importantes recursos presupuestales, por su propia naturaleza, fue burocrática, centralista y de alcance sexenal, en la medida en que volvió más lejana la relación de la población indígena con las dependencias de gobierno, eliminó la relativa autonomía que habian tenido los centros coordinadores y experimentó continuas modificaciones con cada cambio de gobierno. ${ }^{57}$ Dictada desde las

\footnotetext{
${ }^{56}$ Aguirre Beltrán, refiriéndose al cambio de orientación del INI en 1978 y a la creciente adopción en el indigenismo de la categoria de marginación, no dudaria en señalar:

El concepto económico de marginación emerge de la Comisión Económica para Latinoamérica, CELA, encabezada por Raúl Prebisch. La nueva doctrina se difunde entre economistas, sociólogos, científicos políticos y antropólogos que se afilian a la teoria del capitalismo dependiente en substitución de la teoria de la cultura y el funcionalismo estructural. Los indios, consecuentemente, dejan de ser pueblos étnicos, con cultura y personalidad propias, para convertirse en marginados, pobres, expropiados y dependientes (Aguirre, 1994:169)

${ }^{57}$ La transferencia de funciones del INI a otros organismos federales y la gradual dependencia de aquel con respecto a éstos se evidencia en un análisis de la evolución presupuestal. Entre 1949 y 1972 el 320
} 
esferas federales y en aras de la uniformidad, desconoció las particularidades de las regiones y las diferencias entre los grupos étnicos y aún las de éstos con otros grupos de la sociedad. Todo ello dejó a los viejos organismos indigenistas el INI y sus centros coordinadores- en ura situación precaria de ejecutores, pero no de instancias de decisión de esas políticas que les fueron dictadas desde arriba y desde fuera. Si a este proceso de despojo de atribuciones se añade el fracaso de muchos de los nuevos programas, se podrá entender la actual crisis del indigenismo y de sus instituciones y preguntarse, como lo hacen muchos hoy: ¿para qué mantener el INI y otras agencias similares si su quehacer institucional ha sido por completo transferido a otras instancias de gobierno cada vez más carentes de un discurso sobre lo indio?

En el largo período que va desde mediados de los años setenta a la actualidad, en el que el indigenismo vivió este doble proceso de reforma institucional y crisis teórica, cabe sin embargo distinguir dos etapas que están en continuidad. La primera, hasta 1982, en la que imperó la concepción del combate a la marginalidad y la pobreza, implantándose para ello el modelo de "planes" y "comisiones" sectoriales que desembocaron en la creación de la Coordinación General del Plan Nacional de Zonas Deprimidas y Grupos Marginados (COPLAMAR). La segunda etapa, se inauguró en 1982, cuando se introdujo de manera más orgánica en la concepción y en el modelo indigenista el principio de la participación y la autogestión indígenas, elemento éste que ya había sido planteado desde el final de los años setenta en el discurso indigenista oficial. El resultado más visible de este nuevo modelo de acción en el medio indigena fue la creación del Programa Nacional de Solidaridad (PRONASOL) en 1988 y del Programa .

presupuesto de operación del INI pasó de 0.5 a 27.3 millones de pesos corrientes. Desde entonces, el total de los recursos operados por el INI se ha incrementado de forma espectacular: 220 millones en 1975, 1,119 en $1980,3,119.8$ en $1983,65,615$ en $1988,267,591.3$ en 1990 y 283,879.9 en 1994 (INI, 1978c: 392 y 1994 : 36). Sin embargo una gran parte de los presupuestos operados de 1978 a la fecha han provenido de recursos extraordinarios derivados de acuerdos con secretarias de estado y programas del ejecutivo federal como COPLAMAR, IMSS, CFE, SAHOP, CONASUPO, SARH, SEP, PRONASOL, CFE., etc. y no tanto del presupuesto propio del INI.

En nuestro trabajo de campo pudimos recoger esa percepción indigena de desconocimiento y lejania con respecto a las dependencias y programas indigenistas de esta época. En cambio, entre muchos tarahumaras, el recuerdo de quienes laboraron y dirigieron el CCIT entre 1952 y 1977 sigue aún vivo. 
de Educación, Salud y Alimentación (PROGRESA) en $1997^{58}$

\section{Neoindigenismo y programas sectoriales}

El proceso que, en términos generales, acabamos de describir tuvo su propia trayectoria en la Tarahumara y se expresó de una manera clara en un resquebrajamiento del modelo de la acción integral. El primer ámbito donde esta ruptura se hizo manifiesta de forma temprana fue el de la explotación forestal y su control por parte de los ejidos, eje neurálgico del indigenismo de los años cincuenta.

Este modelo de explotación forestal fuertemente dependiente del aparato indigenista dejó de estar vigente en 1972, fecha en que se constituyó, por decreto presidencial del 10 de agosto, Productos Forestales de la Tarahumara (PROFORTARAH), organismo público descentralizado cuyo objeto fue promover el aprovechamiento integral de los recursos forestales localizados en los 20 ejidos que componen la Sierra Tarahumara. También se estableció como una de las metas centrales de esta empresa paraestatal la de formular y coordinar programas sociales, comerciales y de financiamiento que regularan la participación de los diferentes sectores involucrados en la actividad forestal.

La creación de PROFORTARAH obedeció a varias razones y coyunturas. En primer lugar, la mayoría de los ejidos forestales de la Tarahumara comenzaron a manifestar su descontento frente al sistema de subordinación que mantenian con las compañias madereras a través de los contratos de maquila, aduciendo que eran éstas quienes salian más beneficiadas de la explotación forestal. Los ejidatarios alegaban además irregularidades y falta de atención a sus demandas de regularización de la tenencia de la tierra (véase Cuadro 14). Por otro lado, esta misma situación de descontento agrario comenzaba a desencadenar brotes de violencia y guerrilla en

\footnotetext{
${ }^{58}$ Retomo aqui, en términos generales, la periodización que plantea Guillermo de la Peña (1998) al referirse a las politicas sociales hacia los indigenas en México entre 1948 y 1998. Como veremos más adelante, esta periodización se adapta a la Tarahumara con algunos pequeños matices. Dado que el PROGRESA está actualmente comenzando a trabajar en la Tarahumara, lo excluiremos de nuestro análisis
} 
diversos puntos del estado de Chihuahua, entre ellos, la Tarahumara. ${ }^{59}$

Todas estas razones se conjuntaron para que entre los ejidos y las propias autoridades agrarias y forestales se fuera imponiendo la conveniencia de adoptar un nuevo modelo de explotación forestal en el que se eliminara la dependencia de los ejidos con respecto a las compañias madereras. Pero, dado que los ejidos carecian de los créditos y de los cuadros técnico-administrativos necesarios para hacer rentable la operación forestal, el presidente Echeverria, tras analizar la situación y escuchar las demandas del Consejo Supremo Tarahumara $^{60}$, decidió conformar una gran empresa paraestatal que manejara como un todo el conjunto de las operaciones madereras de los ejidos y sus aserraderos.

PROFORTARAH estableció una cadena de centros industriales madereros ${ }^{61}$ en San Juanito, Creel, Tomochi, Guachochi, Bahuichivo y Parral cuyo propósito era competir directamente con las empresas y ofertar mejores condiciones económicas a los ejidatarios indigenas dueños del recurso forestal. En los 17 años que operó, PROFORTARAH no logró en realidad superar los problemas para cuya resolución había sido creada ${ }^{62}$. Por el contrario, subordinó los intereses de los ejidatarios indigenas a la

\footnotetext{
${ }^{59}$ Véase lo que señalamos en págs. 260-262. Es oportuno recordar tambièn que el 23 de septiembre de 1965 un grupo de guerrilleros intentaron tomar por asalto el cuartel militar de Madera, al norte de la Tarahumara, población vinculada a las operaciones del monopolio forestal Bosques de Chihuahua. El asalto que acabó en masacre de los guerrileros, daría lugar a la creación de la "Liga 23 de Septiembre", movimiento insurgente en el que participaron campesinos y maestros de la región.

${ }^{60}$ En febrero de 1972, el presidente Echeverria mantuvo una reunión en Los Pinos con representantes del Consejo Supremo Tarahumara en la que se discutió ampliamente la problemática forestal. Tres meses después, el presidente viajó a la Sierra y volvió a reunirse con el Consejo y con gobernadores tarahumaras. En esa ocasión, anunció que el gobiemo federal estaba considerando la creación de un organismo forestal que asumiera la organización de los ejidos de la Sierra. (Véase el discurso del presidente Echeverria en Anónimo, 1972 y ACCIT. Legajo 40, Expediente 7: "Recortes periodisticos con notas relativas a la región tarahumara, 1972-1975").

${ }^{61}$ es decir, plantas para la elaboración de productos de madera secundarios como palo de escoba, cajas o "rejas" de empaque e incluso muebles.

62 Un estudio hecho en la zona señala como principales problemas de la situación forestal de la Tarahumara en 1988 los siguientes: sobreexplotación del recurso maderable, desmontes e incendios forestales, inadecuado manejo técnico del recurso, insuficiente o incompleto aprovechamiento del potencial 323
} 
lógica paternalista de una empresa pública y cayó en muchos casos en graves problemas de burocratismo, conflictos laborales, ineficiencia productiva y corrupción. ${ }^{63}$

Por todas estas razones, PROFORTARAH fue liquidada en 1988 y sus activos quedaron transferidos a 7 Uniones integradas por 152 ejidos de 2 municipios del estado de Chihuahua que se constituyeron en 1989 como la Asociación Rural de Interés Colectivo General Felipe Angeles (INI, 1993b).

La creación de PROFORTARAH significó el primer golpe asestado al modelo de la acción integral, en la medida en que restó al INI y al CCIT injerencia directa sobre un sector de la economia indígena que habia considerado, desde 1952, estratégico para su

productivo y del volumen maderable derribado, subordinación de los ejidos a la articulación económica y politica entre los grupos industriales regionales y la SARH, SRA y PROFORTARAH, descoordinación e inoperancia de las dependencias encargadas de resolver dotaciones de tierras y organización de productores, burocratización excesiva en los trámites de aprovechamientos forestales y "nula participación directa de los posesionarios del recurso forestal en organización, capacitación, asistencia técnica y financiamiento" (Enriquez, 1988: 129)

${ }^{63}$ Como expresión del descontento que PROFORTARAH provocó entre la población indigena, baste señalar algunos de los acuerdos del VIII Congreso de Pueblos Tarahumaras celebrado en Creel en abril de 1977 que concluia haciendo entre otros, los siguientes reclamos a la empresa forestal:

1.- La Institución ha provocado división en los ejidos y comunidades entre mestizos e indigenas y entre los mismos indigenas.

2.- Ha sustituido autoridades ejidales y gobemadores indigenas por autoridades incondicionales para sus propósitos.

3. - Carga a los ejidos el costo de la asesoria técnica [...]

4.- Las utilidades que han obtenido los ejidos que maneja PROFORTARAH, no obstante los precios de garantia, han sido mínimos $[.$.

5. - Ha alentado la multiplicación de pseudo organizaciones llamadas "uniones" para enfrentarlas a la Unión que ya existia, causando con esto la desorganización en la explotación forestal.

6.- Ha bloqueado las gestiones que los ejidos tienen que hacer en la Subsecretaria Forestal [...]

7.- Existe el despiffarro del presupuesto en politicas equivocadas de repoblación forestal.

8. - PROFORTARAH [...] ha mantenido y propiciado la subordinación de los ejidos a empresas particulares mediante los contratos de participación y compraventa, los cuales ya estaban superados hace años. [...]

11. La incapacidad y falta de sensibilidad de los empleados de PROFORTARAH para entender lo que quieren los indigenas.

12.- Agresión abierta y sistemática a los esfuerzos realizados por los ejidos y comunidades para realizar sus programas [...]

20. El destino de fondos y personal para el patrocinio de campañas políticas de funcionarios de la institución (Anónimo, 1977: 4-5). 


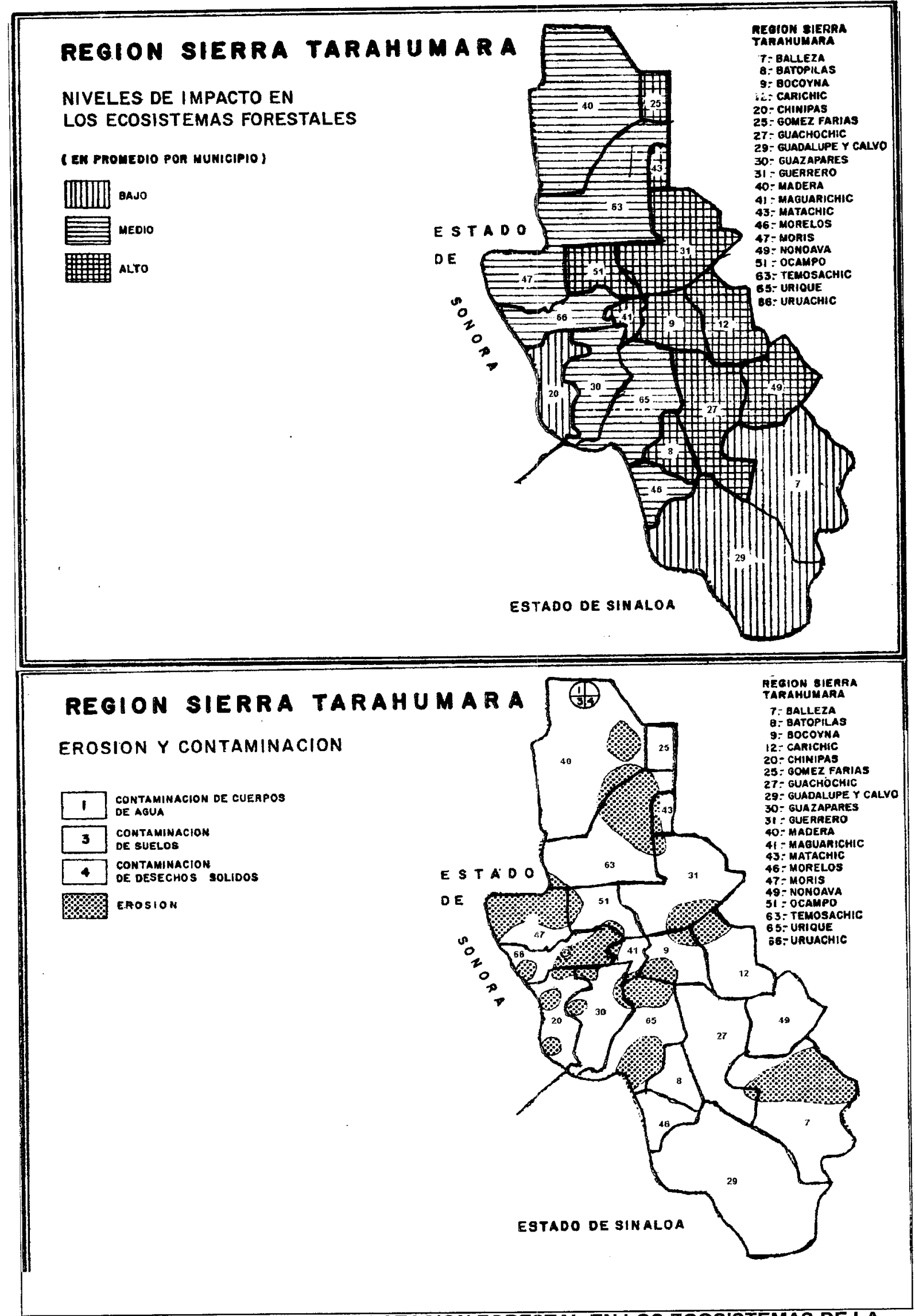

FIGURA 61.- EFECTOS DE LA EXPLOTACION FORESTAL EN LOS ECOSISTEMAS DE LA SIERRA TARAHUMARA HACIA 1988 (TOMADO DE ENRIQUEZ, 1988: 131 Y 132) 


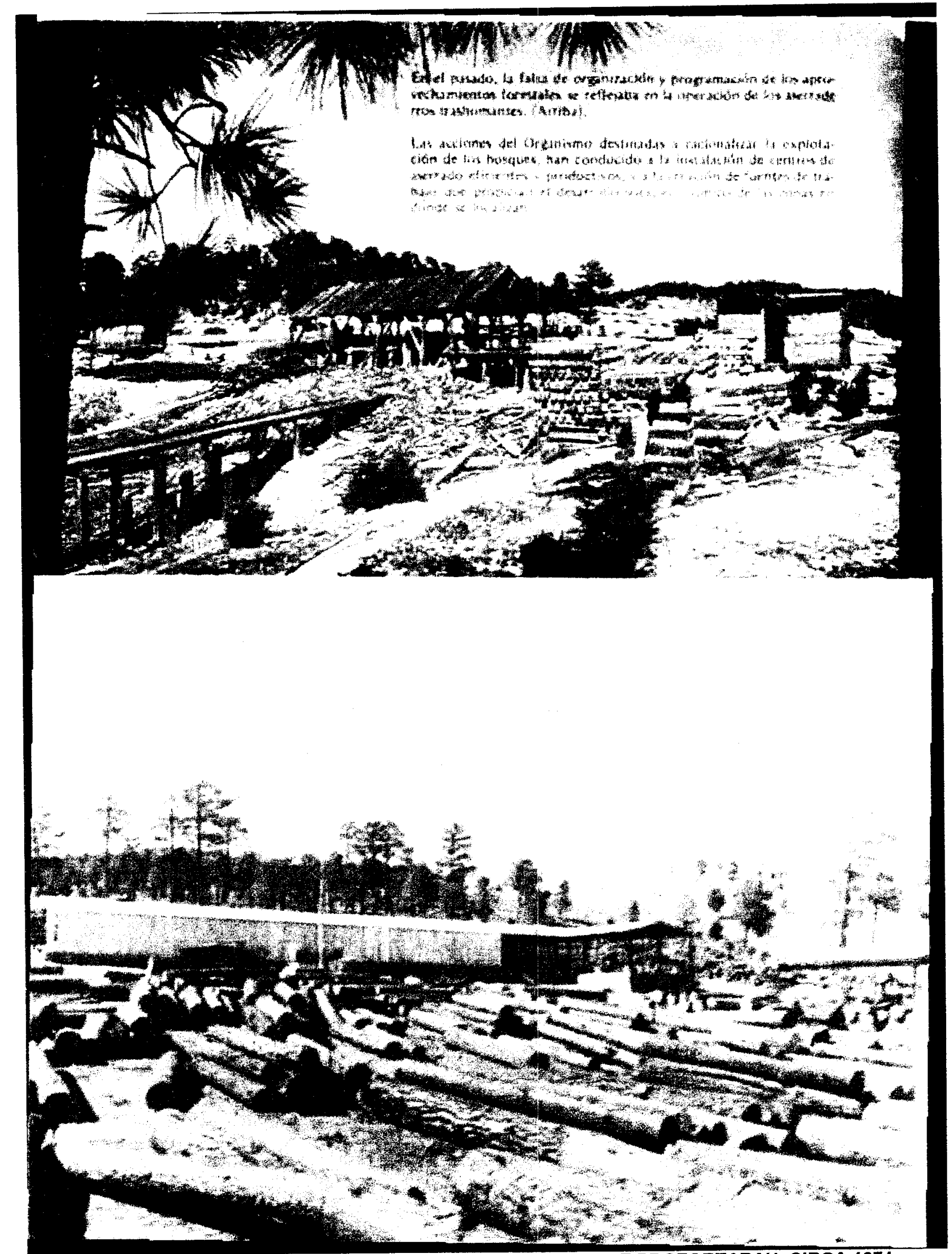

FIGURA 62.- READECUACION DE ASERRADEROS POR PARTE DE PROFORTARAH. CIRCA 1974 (TOMADO DE PRODUCTOS FORESTALES DE: LA TARAHUMARA, 1976: 61) 
concepción y modelo de integración aculturativa. ${ }^{64}$ Pero sin embargo, el derrumbe de la acción integral se consolidó a partir de la creación, el 21 de enero de 1977 de la Coordinación General del Plan Nacional de Zonas Deprimidas y Grupos Marginados (COPLAMAR), organismo dependiente directamente de la Presidencia de la República en el que quedaron integrados el INI, la Comisión Nacional de Zonas Aridas (CONAZA), Patrimonio Indigena del Valle del Mezquital, La Forestal F.C.L., el Fideicomiso del Fondo Candelillero, el Fideicomiso para Obras Sociales a Campesinos Cañeros de Escasos Recursos, el Fideicomiso de la Palma, la Promotora del Maguey y del Nopal, el Fondo Nacional para el Fomento de las Artesanias, la Compañia Forestal de la Lacandona y la empresa paraestatal Productos Forestales de la Tarahumara (PROFORTARAH).

Entre 1977 y 1982, COPLAMAR coordinó los más importantes programas del gobierno federal en zonas indigenas a través de convenios interinstitucionales con diferentes dependencias federales. Asi operaron el programa IMSS-COPLAMAR para el establecimiento de Unidades Médicas Rurales (UMR) y Clinicas Hospital de Campo (CHC), el de CONASUPO-COPLAMAR para comercializar a bajos precios alimentos y productos básicos, el de SARH-COPLAMAR de capacitación y empleo cooperativo para el fomento de recursos naturales, el de SAHOP-COPLAMAR para el mejoramiento de la vivienda rural, la dotación de agua potable y caminos rurales, el de SEP-COPLAMAR para la creación de casas-escuelas y albergues educativos, el de CFE-COPLAMAR de electrificación y otros menores. ${ }^{65}$

La mayoría de estos programas funcionaron hasta el final del sexenio del

\footnotetext{
${ }^{64}$ A partir de la creación de PROFORTARAH, el INI suspendió la asesoria que venia prestando a los ejidos en materia forestal. El Dr. Aguirre Beltrán, por entonces director general del INI, no dudaria en expresar, unos años despues y relevado ya de sus funciones directivas, su desacuerdo con esta transferencia de atribuciones:

La ofensiva [contra el INI] terminó al constituirse un organismo forestal descentralizado destinado a ayudar a los indios. En el consejo directivo se dio un asiento a las grandes empresas madereras que no tardaron en apoderarse del nuevo organismo. Los tarahumaras permanecen en el estado de siempre (Aguirre, 1994:47).

${ }^{65}$ Puede verse un recuento pormenorizada de las actividades realizadas por el INI entre 1976 y 1982, a través de los diferentes planes sectoriales y programas prioritarios en INI, 1982.
} 
presidente López Portillo, en 1982. En todos ellos, la participación del CCIT quedó siempre subordinada a las directrices emanadas desde las instancias centrales de las secretarias de estado que integraban COPLAMAR. De hecho la presencia del INI que habia tenido un cierto repunte al inicio de los años setenta y aún hasta 1980 con la creación de los centros coordinadores en Carichi (1974), San Rafael (1975) y Turuachi (1980) el primero para cubrir la zona este de la Sierra con población tarahumara y pima, el segundo para atender a la Baja Tarahumara y el tercero para cubrir la región tepehuana del municipio de Guadalupe y Calvo- disminuyó notoriamente.

En el sector de la educación, también la incidencia del INI y el modelo de la acción integral fueron en retroceso. En 1964 y en cumplimiento de una recomendación hecha por la VI Asamblea del Consejo Nacional Técnico de la Educación (en noviembre de 1963), los promotores culturales bilingües y los maestros que habian venido trabajando en los centros coordinadores del INI fueron transferidos a la SEP y en 1973 a su Dirección General de Educación Indigena, la que en 1978 definió como programa central la educación bilingüe y bicultural. El carácter bilingüe hacia referencia a la necesidad de enseñar a los educandos la estructura y la lecto-escritura de las lenguas materna y castellana, contribuyendo así a un más equilibrado desarrollo psicológico del educando y un afianzamiento de los nuevos conocimientos. El aspecto bicultural implicaba retomar en la planeación, contenidos y métodos educativos, la filosofía y los valores de cada etnia, vinculando a ésta con la sociedad nacional (Tello, 1994: 40). Tanto en sus contenidos como en su diseño, la educación indígena dejó de estar controlada por el INI desde 1971, corrrespondiéndole exclusivamente la administración de los recursos destinados a la alimentación en las escuelas-albergue, gastos de operación, asistencia médica y promoción de actividades agropecuarias en los huertos escolares (INI, 1994: 189).

A pesar de su expansión, la práctica de la educación bilingüe y bicultural tuvo $\sin$ embargo muchas limitaciones en la Tarahumara, porque la ampliación del número y de la cobertura de las escuelas albergue, no tuvo como correlato una suficiente capacitación 

del magisterio en los nuevos métodos ni una producción de materiales pedagógicos acordes con la nueva filosofia educativa. Además, a resultas de la expansión del aparato escolar, surgió en la Tarahumara toda una capa de maestros indígenas bilingües que se convirtió en un cuerpo de intermediación cultural y comenzó a suplantar, en algunos lugares, a las autoridades del gobierno indígena (Lartigue, 1988 y 1989).

\section{Los obstáculos del indigenismo de participación}

Desde principios de los años ochenta se puso de moda en las oficinas gubernamentales y entre los funcionarios del indigenismo la tesis del etnodesarrollo que propugnaba por considerar las capacidades organizativas y productivas de las comunidades indígenas como el activo más importante para superar su situación de marginación y pobreza. ${ }^{66}$ Esta nueva filosofia sobre el desarrollo se tradujo en la creación, mediante decreto presidencial de junio de $1986^{67}$, de una serie de instancias de participación indígena en los programas del INI, tales como los Comités Comunitarios de Planeación (Cocoplas), los Comités Consultivos Estatales y el Comité Consultivo Nacional.

En esencia, esta propuesta estaba encaminada a que las propias comunidades, a través de los Cocoplas, decidieran colectivamente los proyectos a emprender y la forma de participación en la ejecución y evaluación de las actividades implicadas en dichos proyectos. De esta forma se aseguraban dos cosas: serian las propias comunidades, y no el INI, quienes definirian sus prioridades y los proyectos contribuian a consolidar la organización y la participación comunitarias. La operatividad de este programa se

\footnotetext{
${ }^{66}$ Esta tesis fue particularmente reafirmada en la Segunda Reunión de Barbados (1977) en donde se insistió en la autogestión y autodeterminación de las comunidades indigenas. Surgió asi el concepto de etnodesarrollo que se ha definido como

el ejercicio de la capacidad social de un pueblo para construir su futuro, aprovechando para ello las enseñanzas de su experiencia histórica y los recursos reales y potenciales de su cultura, de acuerdo con un proyecto que se defina según sus propios valores y aspiraciones (Bonfil, 1982: 133)

${ }^{67}$ Puede verse el decreto correspondiente en INI, 1988: 578-582.
} 
completaba con la creación, en junio de 1986, del Fondo Comunitario de Proyectos Productivos. Dicho fondo se habria de integrar mediante la aportación de recursos en efectivo o en especie erogados, por partes iguales, por el INI y por las propias comunidades. (Véase en Figura 64 la estructura de los mecanismos de participación indigena en el (NI).

En la Tarahumara este enfoque participativo tuvo serias dificultades para ser aplicado. En primer lugar entró en contradicción abierta con la lógica de trabajo de PROFORTARAH, empresa pública que controlaba el rubro más rentable de la economia serrana, lo que desencadenó una oposición entre el INI y este consorcio paraestatal. ${ }^{68}$ Pero además, la propuesta del etnodesarrollo contó en realidad, en aquellos años de crisis económica, con muy pocos recursos financieros. Al respecto, el análisis del presupuesto del CCIT en 1986 es revelador: de un total cercano a los 200 millones de pesos autorizados, 107 se destinaron al aparato administrativo del centro (sueldos, salarios, mantenimiento), 60 a la operación de los albergues y sólo 27 (cerca del 13\%) al financiamiento de pequeños proyectos productivos (asistencia técnica agropecuaria, piscicultura, invernaderos horticolas, talleres escuelas de carpinteria y apoyo a la producción de artesanias). ${ }^{69}$

El único proyecto de envergadura emprendido en esos años por el INI en la

${ }^{68}$ El director general del INI, Miguel Limón Rojas no dudaría en afirmar:

Una de las realidades más dramáticas, que no podemos dejar de mencionar aqui, es la Tarahumara. Se ha querido sostener que el indio está condenado a ser pobre mientras no deje de ser indio, pero en cambio, no se ha llevado a cabo un esfuerzo serio y sostenido para capacitario en el manejo de herramientas, en la operación de talleres y en la adquisición de la habilidad técnica necesana para recibir el beneficio de su trabajo, a partir de sus recursos. La liquidación reciente de la empresa PROFORTARAH implica su incapacidad para servir al desarrollo social de la región; la verdad en este sentido es que nunca hizo un intento serio con la participación de las comunidades. El destino que continua teniendo esa riqueza y la situación económica y social de sus pobladores revelan la persistencia de afrentosas expresiones de explotación colonial (Limón, 1988: 94)

${ }^{69}$ Puede verse "Informe anual de actividades del CCIT de enero a diciembre de 1986" en ACCIT Legajo 155, Expediente 17. 


\section{MECANISMOS DE PARTICIPACION}

INOIGENA EN EL INI

INTEGRACION

ESTRUCTURA INI

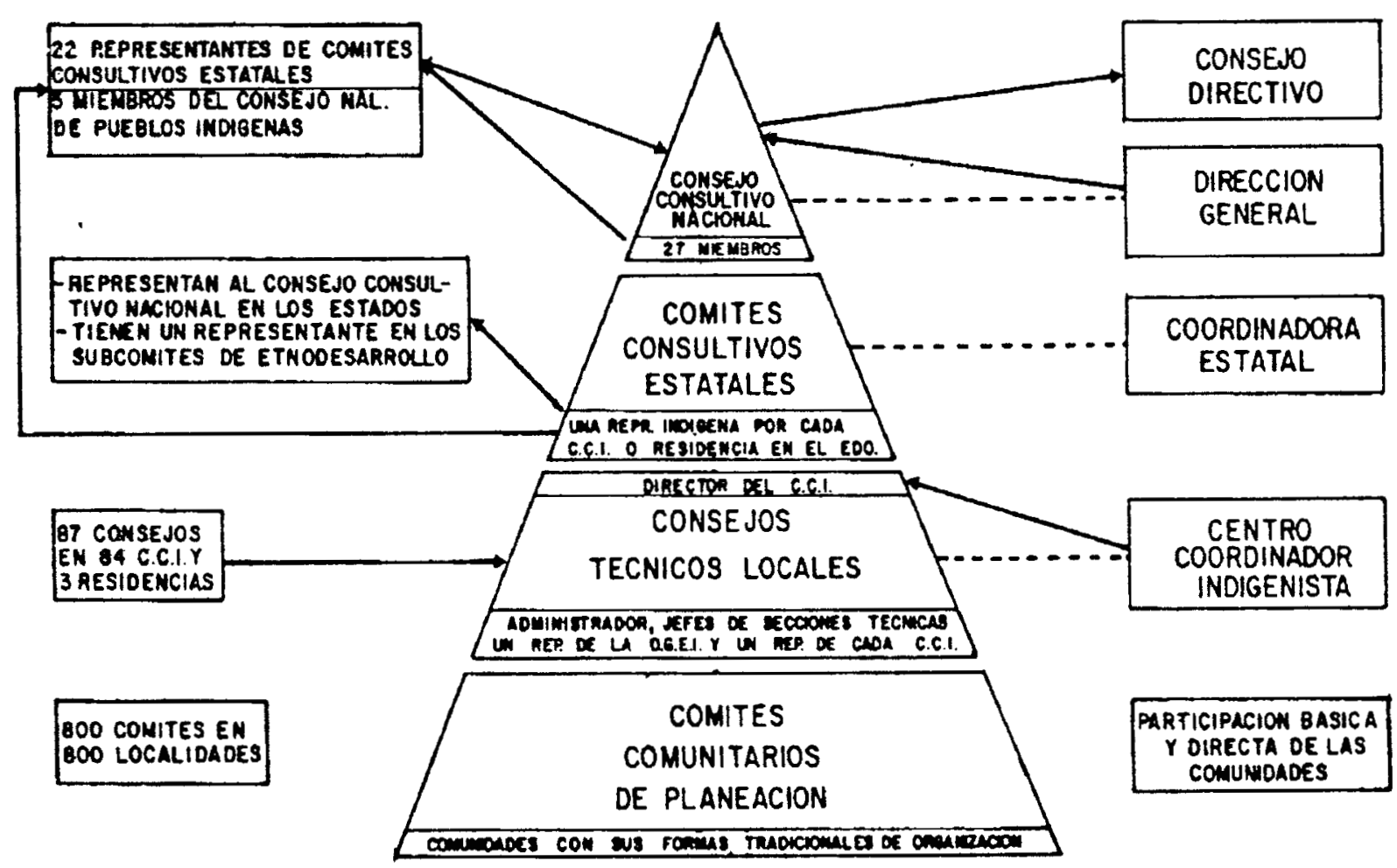

FIGURA 64.- MECANISMOS DE PARTICIPACIÓN INDIGENA EN EL INI, 1986 (INI, 1998: 524) 

Tarahumara fue la instalación en $1982^{70}$ de la estación de radio XETAR "La voz de la Sierra Tarahumara" con sede en Guachochi, que, desde entonces a la fecha, ha jugado un papel muy importante en términos de la comunicación entre los pueblos, ranchos y rancherias, manteniendo primordialmente como vehiculo de difusión la cultura y las lenguas autóctonas de la Sierra. XETAR transmite en las 4 lenguas indigenas de la Tarahumara además del castellano. Su programación es variada, destacando en ella los noticieros nacionales y locales y los programas de educación no formal, promoción de la salud, asesoria en materia de derechos indigenas $y$, en general, difusión y fortalecimiento de las culturas indias de la región. En un contexto de marcada dispersión demográfica, XETAR se ha convertido en uno de los principales canales de comunicación cotidiana entre la gente de la Sierra de Chihuahua.

Aunque en 1986 se empezaron a constituir los 10 primeros Cocoplas en otras tantas comunidades, lo cierto es que el esquema tan marcadamente "comunitarista" que permeó este programa encontró muchas resistencias entre la población indigena dadas sus formas características de organización de las que ya hablamos en el capitulo segundo. En particular, el esquema de los comités de planeación requería de un ejercicio asociacionista continuo y de un número de socios relativamente grande, aspectos que chocaron con los patrones de atomización demográfica y autonomia de los ranchos y rancherias y que hicieron dificil la operación y la toma de decisiones de los comités.

En agosto de 1987, e indudablemente como resultado de una valoración negativa de la efectividad de las acciones del INI en la Sierra, el gobierno del estado de Chihuahua bajo la administración del gobernador Fernando Baeza, decidió crear la Coordinación Estatal de la Tarahumara, organismo encargado de ejecutar y orientar los esfuerzos y las acciones educativas, de desarrollo, salud y bienestar social que el ejecutivo estatal lleva a cabo en las poblaciones indigenas de Chihuahua. Desde entonces a la fecha, la Coordinación ha dirigido proyectos de desarrollo agrícola y

\footnotetext{
${ }^{70}$ La instalación de esta emisora habia sido decidida y planeada desde 1981 con la aprobación de fondos provenientes de COPLAMAR (INI, 1982: 171).
} 
ganadero, de construcción de caminos y puentes, un plan estratégico de reforma de los contenidos de la educación indigena que incluye la elaboración de libros de texto en tarahumara estandarizado, tepehuano, pima y warojio para la educación básica y un programa de atención a los indigenas migrantes en ciudades y centros agrícolas del estado.

En 1997 trabajaban en esta dependencia cerca de 60 personas repartidas en las oficinas centrales de Chihuahua y otras tres dependientes, localizadas en Creel, Guachochi y Guadalupe y Calvo. La Coordinación se hacia presente en la Sierra a través de un equipo conformado por una veintena de "técnicos" (en su mayoría, ingenieros agrónomos y zootecnistas), cada uno de ellos adscritos a una microregión a la que atendían con asesoría agropecuaria, entrega de fertilizantes, implementos agrícolas, despensas, construcción de sistemas de agua potable y puentes colgantes. También la Coordinación contaba con una Oficina de Estudios Especiales y Educación Bilingüe y Bicultural integrada por una docena de maestros indigenas que tenía a su cargo la elaboración y edición de materiales didácticos y libros de texto para la educación primaria en las 4 lenguas y la capacitación de maestros y supervisores. Completaban la planta de la dependencia el equipo directivo, 3 personas adscritas al Departamento de Atención a Migrantes Indígenas en diferentes ciudades del estado y otras más en las áreas de apoyo legal, médico, supervisión y de oficina. ${ }^{71}$

El proyecto de la Coordinación ha sido en muchos sentidos novedoso. Representa uno de los pocos esfuerzos realizados en el país para que sean los gobiernos de los

\footnotetext{
${ }^{71}$ En el año de 1997 la Coordinación reportaba las siguientes acciones realizadas entre 1992 y 1997: instalación de agua potable en 278 localidades indigenas, entrega de medio millón de despensas alimentarias, construcción de 33 puentes peatonales colgantes en 19 municipios, 5,429 obras de rehabilitación de casas con techos de lámina para evitar la deforestación, entrega en crédito de más de 10,000 toneladas de fertilizante en 200 localidades, distribución de las variedades "Vanra" y "Vanta" de semilla mejorada de maiz a 900 productores, 30 auditorias a empresas madereras y ejidos forestales, más de 1 millón de pesos anuales destinados a la entrega gratuita de medicinas a enfermos indigenas, entrega de viviendas para 500 indigenas en las colonias Tarahumara, Dale y Oasis de la ciudad de Chihuahua y otras en colonias de Ciudad Juárez. Parral y Ciudad Cuauhtémoc y la edición de más de 200 mil libros de texto en lenguas indigenas para 19,325 niños en nivel pre-escolar y primario (Coordinación Estatal de la Tarahumara, 1997)
} 


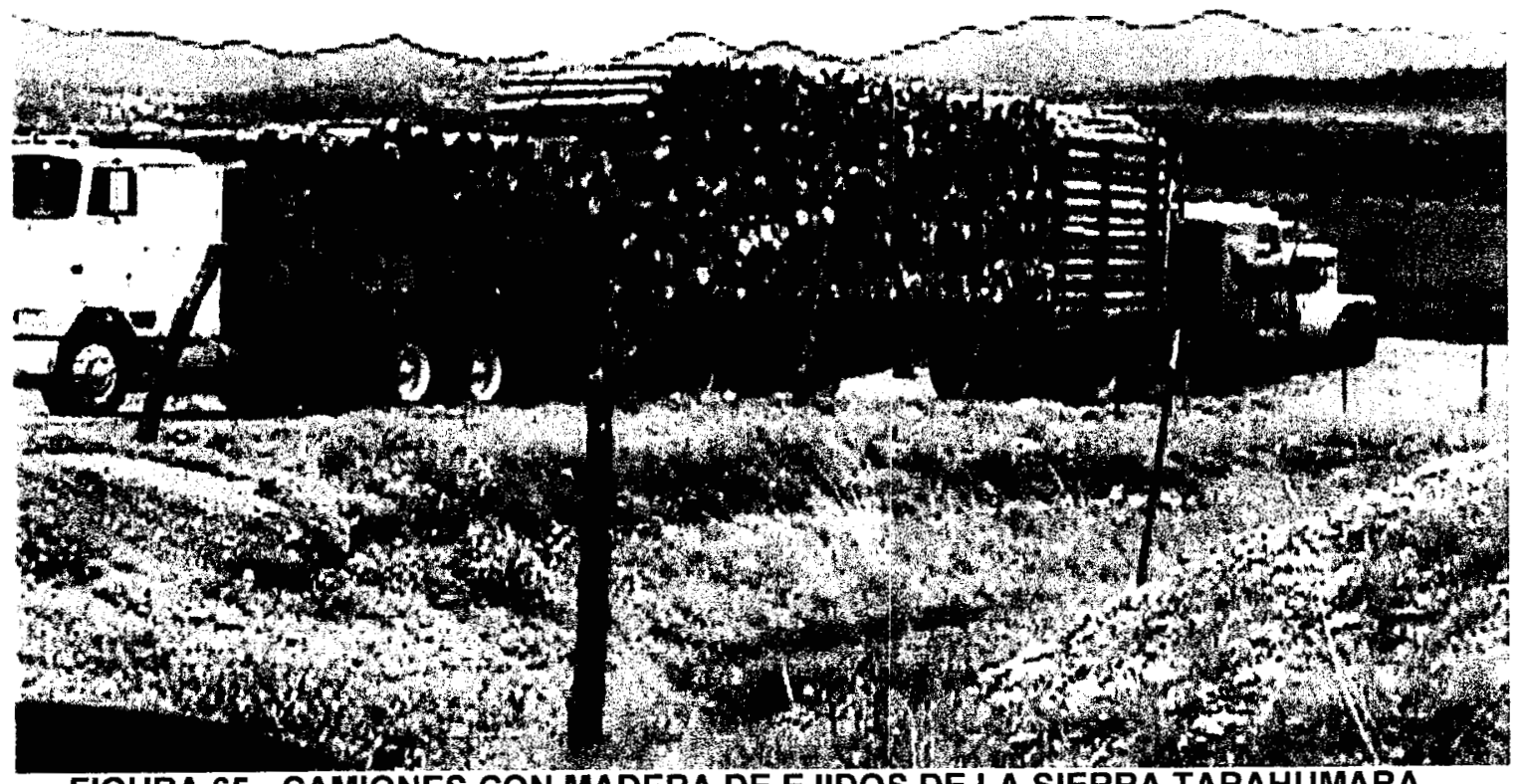

FIGURA 65.- CAMIONES CON MADERA DE EJIDOS DE LA SIERRA TARAHUMARA. SAN PEDRO, GUERRERO (FOTO DEL AUTOR, JULIO 1998)

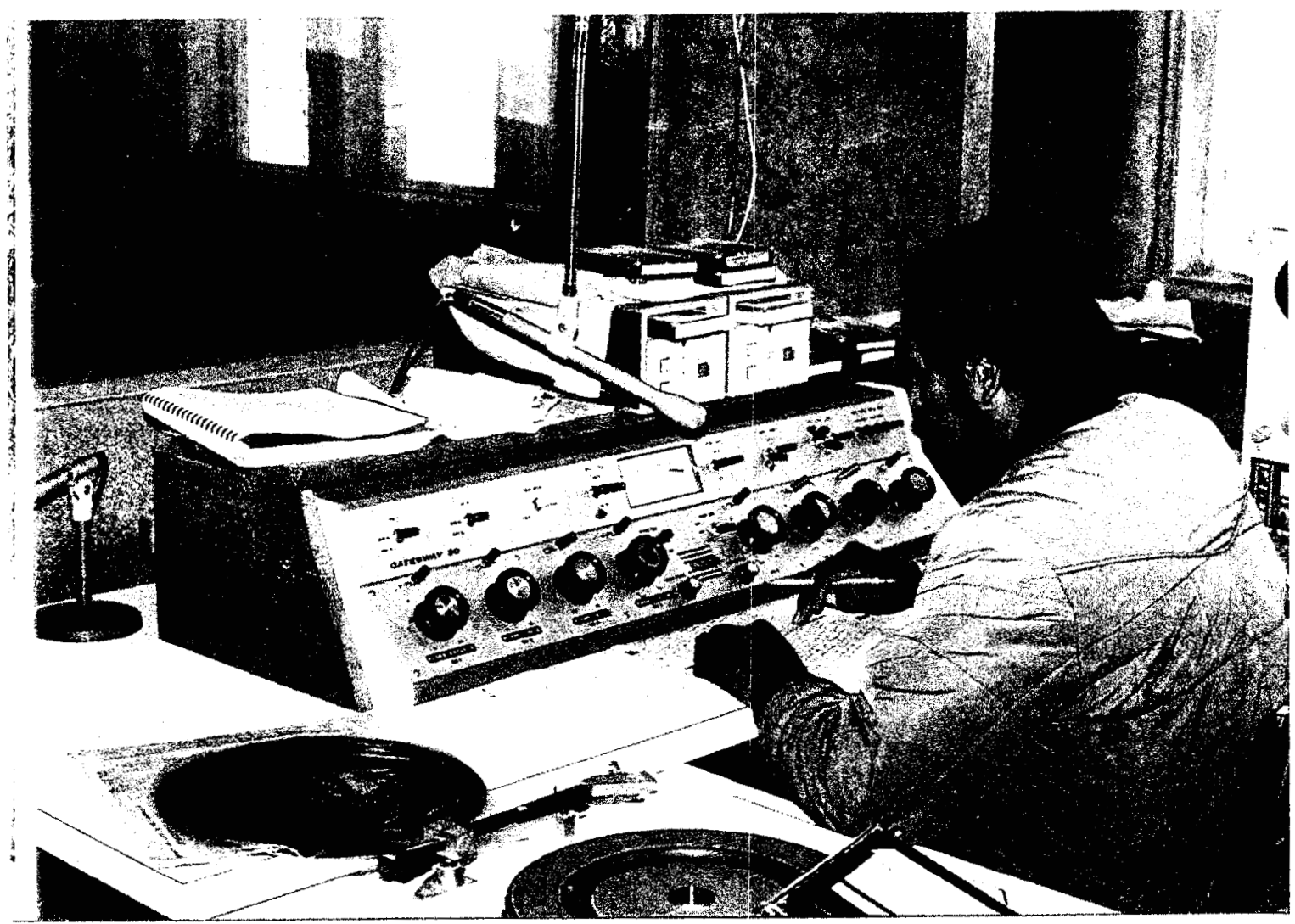

FIGURA 66.- CABINA DE TRANSMISIÓN DE XETAR, LA VOZ DE LA SIERRA TARAHUMARA. GUACHOCHI (FOTO DEL AIJTOR, IULIO, 1998) 
estados quienes asuman la concepción y ejecución de los programas de atención a la población indígena. En sus inicios, la Coordinación fue vista como una dependencia que entraba en una cierta competencia de atribuciones con la delegación estatal del INI, en especial a la hora de recibir y manejar partidas y participaciones presupuestales de origen federal destinadas a la atención de los pueblos indigenas del estado de Chihuahua. En la actualidad, aunque no ha sido legal y orgánicamente establecida con precisión una división de funciones entre una y otra dependencia, existe en la práctica una relación respetuosa de autonomia y, en ciertos asuntos, de colaboración. A los ojos de muchos observadores de la política local, la presencia de un organismo indigenista de carácter estatal apunta ineludiblemente a la transferencia gradual de funciones del gobiemo federal al del estado, proceso que, sin embargo, requiere de un cambio en la estructura y funciones de la administración pública federal.

Después de varios años de labores, este organismo ha logrado una forma de operación que permite la presencia ágil y el trabajo directo de sus técnicos y promotores en los pueblos de la Sierra ${ }^{72}$. Como todos los organismos indigenistas, la Coordinación resiente también la crisis de legitimidad que viven hoy los modelos de acción y los programas de desarrollo en el medio indígena.

En la administración del presidente Salinas de Gortari (1988-1994), dos fueron las líneas prioritarias de la acción indigenista en la Tarahumara: el Programa de Desarrollo Forestal Chihuahua-Durango y la puesta en operación de los Fondos Regionales de Solidaridad.

Tras la liquidación de PROFORTARAH (1988) y la transferencia de sus activos a

\footnotetext{
${ }^{72}$ Resulta dificil evaluar con precisión las concepciones que han guiado el modelo de acción de la Coordinación Estatal de la Tarahumara porque en su operación, y quizás por tratarse de una dependencia joven que además ha vivido la alternancia politica entre gobiernos del estado surgidos del PRl y del PAN, ha prevalecido el espíritu práctico sobre las definiciones teóricas, máxime si se tiene en cuenta que entre su personal predominan profesionistas de áreas técnicas. Sin embargo, es claro que la Coordinación ha venido a reformular en nuevos términos algunos aspectos de la acción indigenista, como el de la educación y la atención a la población migrante. (Puede verse. por ejemplo, el diseño original de reforma de la educación indigena en Tello, 1994: 165-182)
} 
7 Uniones integradas por 152 ejidos de 2 municipios del estado de Chihuahua constituidos en 1989 como Asociación Rural de Interés Colectivo General Felipe Angeles, ésta decidió asociarse por cerca de tres años con la empresa Ingenieros Civiles Asociados (ICA), pero el proyecto de industrialización de la madera establecido entre ambas fracasó en 1993 por falta de acuerdo en la distribución de utilidades. ${ }^{73}$

Por esos mismos años, una empresa maderera chihuahuense, Ponderosa Industrial, propuso un gran proyecto de reforestación conocido como Plantaciones Comerciales, que implicaba la siembra de grandes extensiones de eucalipto y pino radiatra, especies ambas ajenas al ecosistema serrano y con efectos ecológicos muy negativos en los suelos, aguas y asociaciones animales y vegetales. Todo ello y la presión pública provocaron la cancelación de este proyecto (INI, 1993b: 34).

Ante el fracaso de estos intentos y el interés del gobierno federal por integrar el sector de los productores ejidales de las regiones forestales del norte del pais al mercado nacional y extranjero, hacia 1985 surgió en las esferas gubernamentales la idea de un gran proyecto forestal con apoyo financiero externo. Esta propuesta se volvió realidad en 1989, año en fue firmado un convenio entre la Secretaria de Hacienda y el Banco Mundial por el que el segundo ofrecía un apoyo financiero por un monto global de 96 millones de dólares, destinados a crear el Programa de Desarrollo Forestal ChihuahuaDurango. Su objetivo principal consistía en relanzar la producción maderera de esa zona, a través de la capacitación y crédito a productores forestales del sector social, la rehabilitación de caminos, el impulso al desarrollo institucional, la elaboración de estudios de impacto ambiental, la promoción y capacitación de comunidades indígenas.

\footnotetext{
${ }^{73}$ Un estudio del INI calificaba asi el funcionamiento de la ARIC Felipe Angeles:

Pronto la ARIC comenzó a mostrar los signos de su posterior derrumbe: ausencia de capacidad gerencial, carencia de procesos modernos de administración y control de calidad, incapacidad para la integración horizontal y vertical de la empresa, problemas para insertarse en el mercado regional y nacional, indefinición de proyectos de diversificación productiva $y$ endeudamiento creciente. Sin embargo, los principales problemas fueron los desacuerdos intemos entre las dirigencias de las Uniones de Ejidos integrantes del proyecto (INI, 1993b: 33)
} 
Para llevar a cabo el programa fueron designadas las siguientes dependencias: la SARH como cabeza de sector, la SCT para la rehabilitación de caminos forestales, la SEDUE (que después se convirtió en SEDESOL) para evaluar los impactos ambientales, los fideicomisos FIRA y FICART encargados de la gestión de los créditos a productores, Nacional Financiera como agente financiero de la operación y el INI como responsable de los componentes de diagnóstico, promoción del proyecto entre los pequeños productores y capacitación de los mismos así como del monitoreo de sus impactos sociales. La presencia del INI derivaba del hecho de que la zona de acción del programa incluia la Sierra Tarahumara y algunos municipios del estado de Durango con población tepehuana. $^{74}$

La delegación del INI en Chihuahua incorporó un equipo amplio de consultores y técnicos (geógrafos, antropólogos, técnicos forestales, administradores y otros) repartidos en las oficinas centrales y en cuatro residencias localizadas en Guachochi, Tomochi, Guadalupe y Calvo y Bahuichivo. Este equipo tuvo a su cargo la realización de tres tareas básicas: el diagnóstico, la promoción-capacitación y el monitoreo del impacto sociocultural del programa. El primero incluyó una serie de 109 estudios de localidades indígenas y otros 4 más sobre aspectos forestales que permitieron subregionalizar la Tarahumara de acuerdo con criterios económicos, étnicos, ecológicos, topográficos y de disponibilidad de recursos. El segundo se dirigió a los ejidos organizados en la ARIC Felipe Angeles y se enfocó a aspectos administrativos y contables de la operación forestal, la formulación y evaluación de proyectos productivos en forma de empresas sociales con mayoria de socios indigenas y al marco legal. El tercer aspecto trató de . considerar los posibles impactos que el programa pudiera causar en el ámbito cultural y organizativo de las etnias afectadas y se tradujo en algunos estudios de caso sobre los problemas ligados a la dinámica de las relaciones interétnicas, la participación real de los

\footnotetext{
${ }^{74}$ Estos y los demás datos que presentamos sobre el Programa de Desarrollo Forestal ChihuahuaDurango proceden de la evaluación que sobre él hicieron sus responsables, a raiz de un Seminario celebrado en Chihuahua en diciembre de 1993 (INI, 1993b) asi como del informe de actividades del INI al final del sexenio del presidente Salinas (INI, 1994: 158-162) y de una tesis sobre el monitoreo de los impactos socio-ambientales del programa (Porras, 1996).
} 
indígenas en los procesos forestales y las formas de organización y capacitación más apropiadas en ese contexto étnico.

Entre los resultados más importantes a los que el equipo de consultores del programa llegó destaca esta conclusión:

se observó que la mayoría de la población indigena no está interesada en el aprovechamiento industrial de sus bosques, incluso pensaban que podian generarse impactos desfavorables en caso de llevarse a cabo un Programa de tal magnitud. A parecidas conclusiones llegaron los estudios de impacto ambiental, en donde se menciona que la mayoria de los habitantes de la región forestal, incluidos los indigenas, posee una cultura agricola o campesina donde se considera que su actividad principal para su subsistencia es la agricultura y la ganadería y no la explotación del bosque, al que sólo ven como parte de su hábitat y abastecedor de bienes complementarios.

La explotación forestal no es considerada como una actividad tradicional indigena, sino como una de las imposiciones fundamentales extemas, cuyos efectos reconocidos han sido la destrucción de las relaciones mantenidas con los ecosistemas, la pérdida de control indigena de sus recursos naturales, la consolidación de cacicazgos, la pobreza y la marginación (INI, 1994: 160)

A partir de estas premisas y dado que el Banco Mundial retrasó la entrega de los créditos a los productores, el programa reorientó sus acciones en 1990 y 1991 a promover la organización indígena en torno a los Fondos Regionales de Solidaridad de los que enseguida hablaremos. Asi se llevaron a cabo varios talleres de capacitación y encuentros regionales sobre asuntos forestales, agrarios, usos alternativos del bosque, autogestión y fortalecimiento del gobierno indígena.

La presión ejercida por grupos ecologistas nacionales y norteamericanos ante el gobiemo mexicano y el Banco Mundial, la postergación en la entrega de estudios de factibilidad encargados al subsector forestal y los resultados del diagnóstico elaborado por el INI propiciaron, en fin, que la liberación de los créditos se postergara y que el Proyecto forestal fuera oficialmente cancelado por el Banco Mundial y por la Secretaría de Hacienda y Crédito Público el 31 de diciembre de 1993.

En buena medida la cancelación del Programa de Desarrollo Forestal representó 


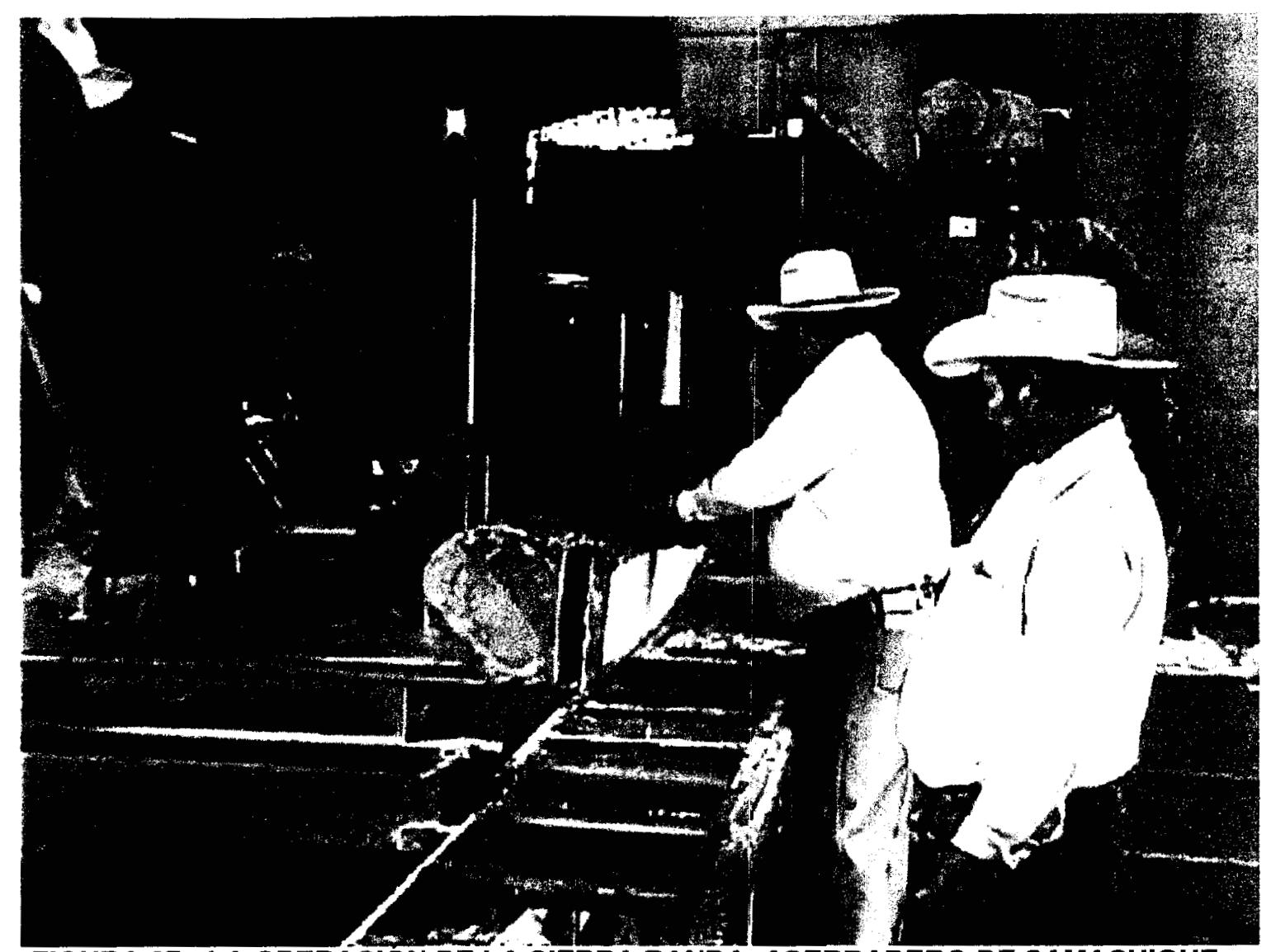

FIGURA 67.- LA OPERACION DE LA SIERRA BANDA. ASERRADERO DE SAMACHIQUE.

(FOTO DEL AUTOR, JULIO, 1999)

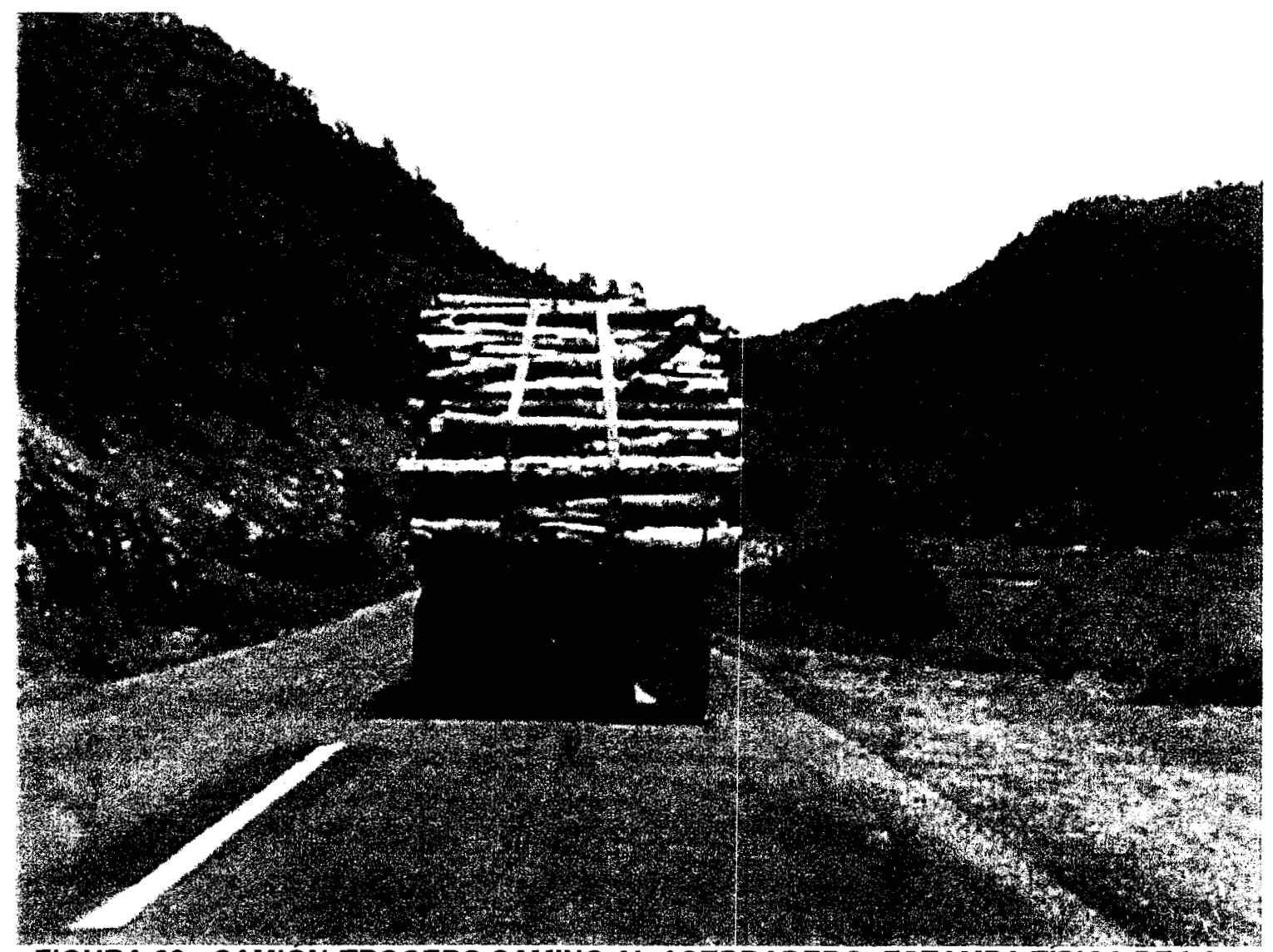

FIGURA 68.- CAMION TROCERO CAMINO AL ASERRADERO, ESTAMPA TIPICA DE LA TARAHUMARA. (FOTO DEL AUTOR, JULIO, 1999) 
el fracaso del último gran esfuerzo gubernamental por incorporar a la Tarahumara a la lógica del mercado mundial de la madera y un triunfo de los ejidos indígenas, ante la amenaza de un nuevo modelo de explotación intensiva del bosque con una grave secuela de daños ecológicos. Un estudio de la situación forestal de la Sierra realizado por la SEDUE en 1991 mostraba, en efecto, datos alarmantes:

De 2'202,350 Has. monitoreadas: 100,650 Has., que representan el 5\% del total, se encuentran en estado critico; 769,440 Has., el 35\%, en alto riesgo; 12291,100 Has., el $58 \%$, en mediano riesgo y 41,200 Has., el $2 \%$, en bajo riesgo.

En estas zonas se apreció una reducción del potencial productivo con bajas densidades de arbolado de diámetros troncales superiores a los $45 \mathrm{cms}$. y cambios en la estructura del arbolado, resultado del enfoque netamente extractivo de los aprovechamientos forestales, lo cual ha modificado los hábitos naturales.

Se encuentran 52 especies de fauna silvestre amenazadas de extinción entre las que destaca el lobo gris mexicano, la zorra norteña, el carpintero imperial y el venado cola blanca.

Por su parte, en relación a la calidad del agua, se observa que se ha alterado su composición físico-química, por el incremento de residuos tóxicos industriales generados por la actividad forestal. Las cuencas que han sufrido mayores impactos ecológicos son las del río Conchos, rio Culiacán y río Mayo.

Con respecto al suelo, se observan tres impactos ecológicos: la erosión que es el impacto de mayor gravedad y es propiciado por la reducción de la cobertura arbórea, el método de extracción de madera, la construcción de caminos, la maquinaria pesada, el tránsito de camiones y las técnicas de demibo (matarrasa y aclareo), el cambio en el uso del suelo y su uso combinado, ambos propiciados por la apertura de nuevas tierras al cultivo y uso combinado (forestal y de agostadero), donde el sobrepastoreo genera altas tasas de erosión (Tomado de Comisión de Asuntos Indigenas, 1992: 18-19).

Los Fondos Regionales de Solidaridad (FRS) representaron el modelo más acabado de la administración salinista para hacer realidad el principio de la participación indígena en las directrices del Programa Nacional de Solidaridad (PRONASOL). ${ }^{75}$

\footnotetext{
${ }^{75}$ En marzo de 1990 el presidente Salinas anunció en Xochiapa, Ver. el inicio del Programa de los Fondos Regionales de Solidaridad (FRS) cuyos objetivos más importantes son: promover la participación activa y autónoma de las comunidades en la definición, ejecución y evaluación de proyectos mediante el fortalecimiento de procesos organizativos, crear una agrupación de organizaciones y comunidades que actúe como interlocutora del INI y de las dependencias gubernamentales y desarrollar proyectos productivos rentables, diversificados, con beneficios capitalizables y con generación de empleo.
} 
Aunque fueron vistos como un proyecto novedoso, en realidad nacieron en marzo de 1990 en continuidad con las experiencias de participación indigena que ya se habian dado desde 1986, a partir de la creación dentro del INI de los COCOPLAS. La diferencia más notoria fue el hecho de que los FRS contaron con un apoyo financiero significativamente mayor que el que tuvieron los Cocoplas. ${ }^{76}$ Los objetivos más importantes de los FRS han sido promover la participación activa de comunidades indigenas en la elaboración y ejecución de proyectos productivos, fortalecer los procesos organizativos y mejorar las condiciones de vida de los pueblos indigenas.

A partir de 1990 PRONASOL transfirió, a través del INI, una serie de financiamientos para proyectos productivos dirigidos por organizaciones integradas a su vez dentro de Fondos. Dichas organizaciones debían asumir un modelo organizativo que incluia Asamblea de representantes, Consejo directivo, Secretariado técnico, Comisión de contraloría, Vocales de control y vigilancia y otras instancias menores, de acuerdo al organigrama que se muestra en la Figura 69. Los financiamientos serian operados a través de los centros coordinadores del INI, tratando de ajustar la operación de los proyectos a los lineamientos fiscales establecidos por SEDESOL. ${ }^{77}$

En diciembre de 1992 operaban en la Sierra Tarahumara 7 Fondos Regionales de Solidaridad (Napawika Nochama Rarámuri, Rarámuri-Pima Omaka Nochaba, Organización Solidaria Baja Tarahumara, Jassika Napawika Nochama Rarámuri, Repabé Rarámuri, Comunidades Unidas del Mohinora y Laguna de Juanota) cuyos resultados entre ese año y 1994 se resumen en el Cuadro 28. Como se observa, estos .

\footnotetext{
${ }^{76}$ Baste decir que el presupuesto ejercido por el INI entre 1983 y 1988 fue de N\$132,037.6 miles de nuevos pesos y que éste ascendió entre 1989 y 1994 a NS 2'074,972.8 miles de nuevos pesos, es decir $1,571.5 \%$. Casi la mitad de este último presupuesto fue destinada a actividades del Programa Nacional de Solidaridad (INI, 1994: 37).

${ }^{77}$ La operación de los FRS hubo de enfrentar serios obstáculos burocráticos derivados del sistema de fiscalización y comprobación de gastos establecidos por la reglamentación federal. No fue sino hasta 1994 cuando se logró encontrar un esquema ágil que permitiera a las organizaciones indigenas convertirse en sujetos de crédito del gobierno federal. (Para una revisión de cómo se fueron modificando los procedimientos administrativos de los FRS, vease INI, 1994: 99-119).
} 
CUADRO 28.- RESULTADOS DE LA OPERACIÓN DE LOS FONDOS REGIONALES DE SOLIDARIAD EN CHIHUAHUA (1990-1994)

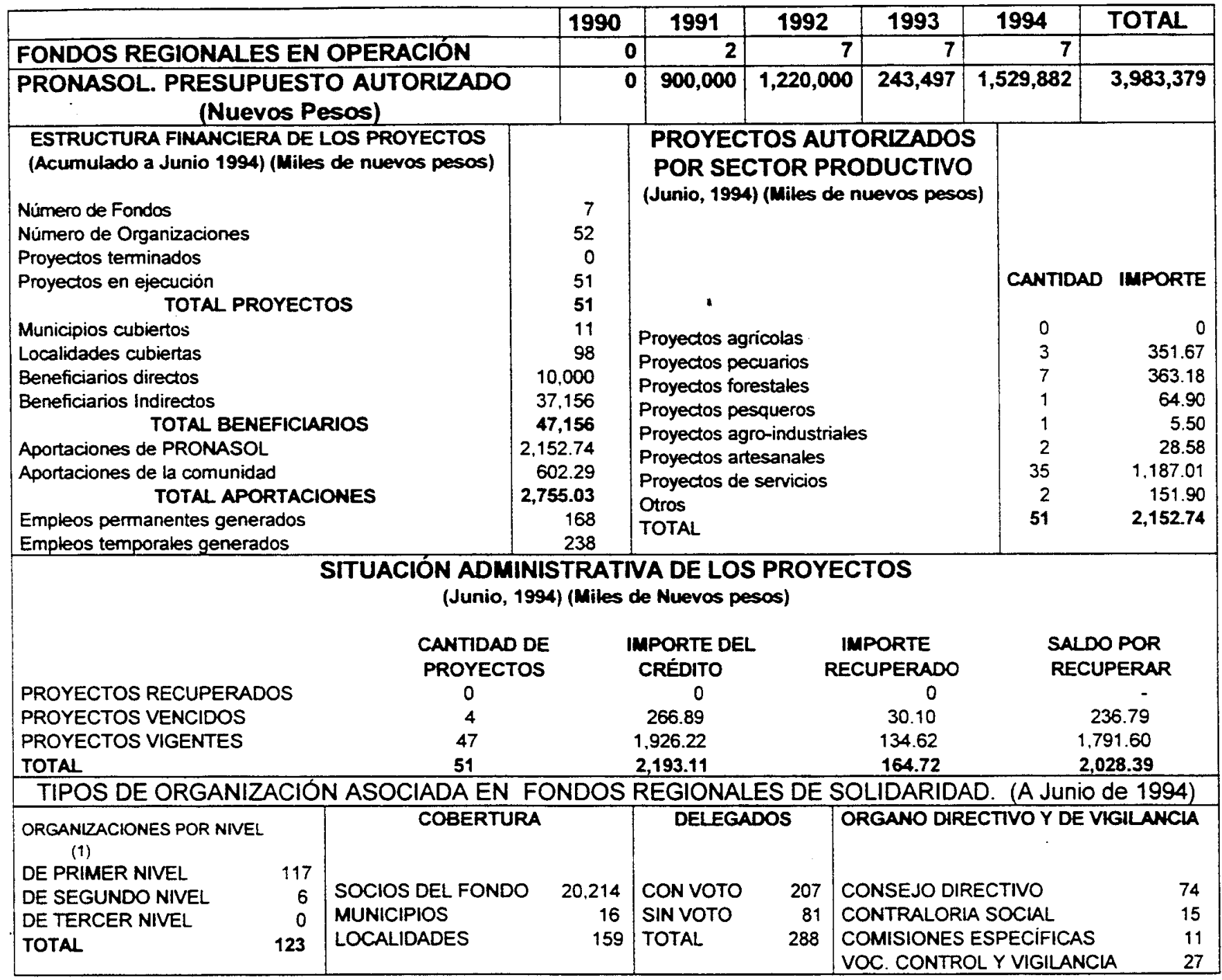

(1) Organizaciones de primer nivel= organizaciones locales (grupos de trabajo o comunidades).

Organizaciones de segundo nivel = agrupaciones de localidades o de grupos de trabajo.

Organizaciones de tercer nivel $=$ organizaciones regionales o estatales.

FUENTE: Elaborado a partir de INI, 1994: 100, 101, 111, 112, 114 y 116.

7 fondos agrupaban a 52 organizaciones dispersas en 11 municipios y 98 localidades. Hasta 1994 habian emprendido 51 proyectos con un financiamiento de PRONASOL por cerca de 2 millones de pesos, a los que se sumaban aportaciones de los propios socios por otros 600 mil. De estos 51 proyectos, los más numerosos (35) consistían en pequeñas tiendas de abasto de mercancias básicas a precios de CONASUPO cuyo costo representaba cerca de la mitad de los recursos erogados. El resto se distribuia en 
proyectos pecuarios (venta de chivas), forestales, pesqueros, agroindustriales y de artesanías, pero ninguno de carácter agricola. En conjunto, y de acuerdo con las estimaciones del INI, estos proyectos tenian 10,000 beneficiarios directos y 47,156 indirectos.

La situación financiera de todos estos proyectos a mediados de 1994 revelaba serias dificultades: de algo más de 2 millones de pesos entregados en crédito sólo se habian podido reintegrar 164 , lo que apunta indudablemente a problemas de operación. Aunque los datos del cuadro relativos a los tipos de organizaciones asociadas dentro de los FRS no concuerdan del todo con los que se muestran en el renglón de la estructura financiera (quizás debido a que corresponden a años y meses distintos), lo cierto es que la mayoria de estas organizaciones eran núcleos de primer nivel, es decir, grupos de personas pertenecientes a pueblos y rancherias agrupados bajo la estructura de consejos directivos, contralorias sociales, comisiones y vocalias de control y vigilancia.

Los datos que hemos presentado y nuestra propia experiencia de campo permiten pensar que en la Tarahumara, el programa de los FRS ha tenido, como sus antecesores, problemas serios para adaptarse a la economía y la dinámica organizativa de los grupos indigenas. Los proyectos se han orientado hacia un aspecto importante el abasto de mercancias básicas, a bajos precios, en pequeñas tiendas de consumo- pero no han podido incidir en el núcleo central de la economia indígena, es decir, en el complejo agricola-ganadero y recolector. Además, la concepción de estos fondos, sustentada en modelos organizativos asociativos, asambleistas y cooperativistas que presuponen una constante interacción entre sus miembros, no tardó en chocar con los patrones indigenas, como el propio INI acabaría por reconocerlo:

...entre los rarámuri (tarahumaras) existe una forma de organización social basada en los grupos de parentesco que se reúnen con cierta regularidad con fines ceremoniales. Entre sus miembros prevalece una alta movilidad ciclica que se dirige hacia la barranca en época de frio y hácia la sierra en estaciones de calor. Mantener el esquema organizativo basado en asambleas periódicas para la toma de decisiones, implicaba forzar a los miembros de ese grupo a adoptar un modelo que no les pertenece y que no se ajusta a sus formas de organización social [...]. 


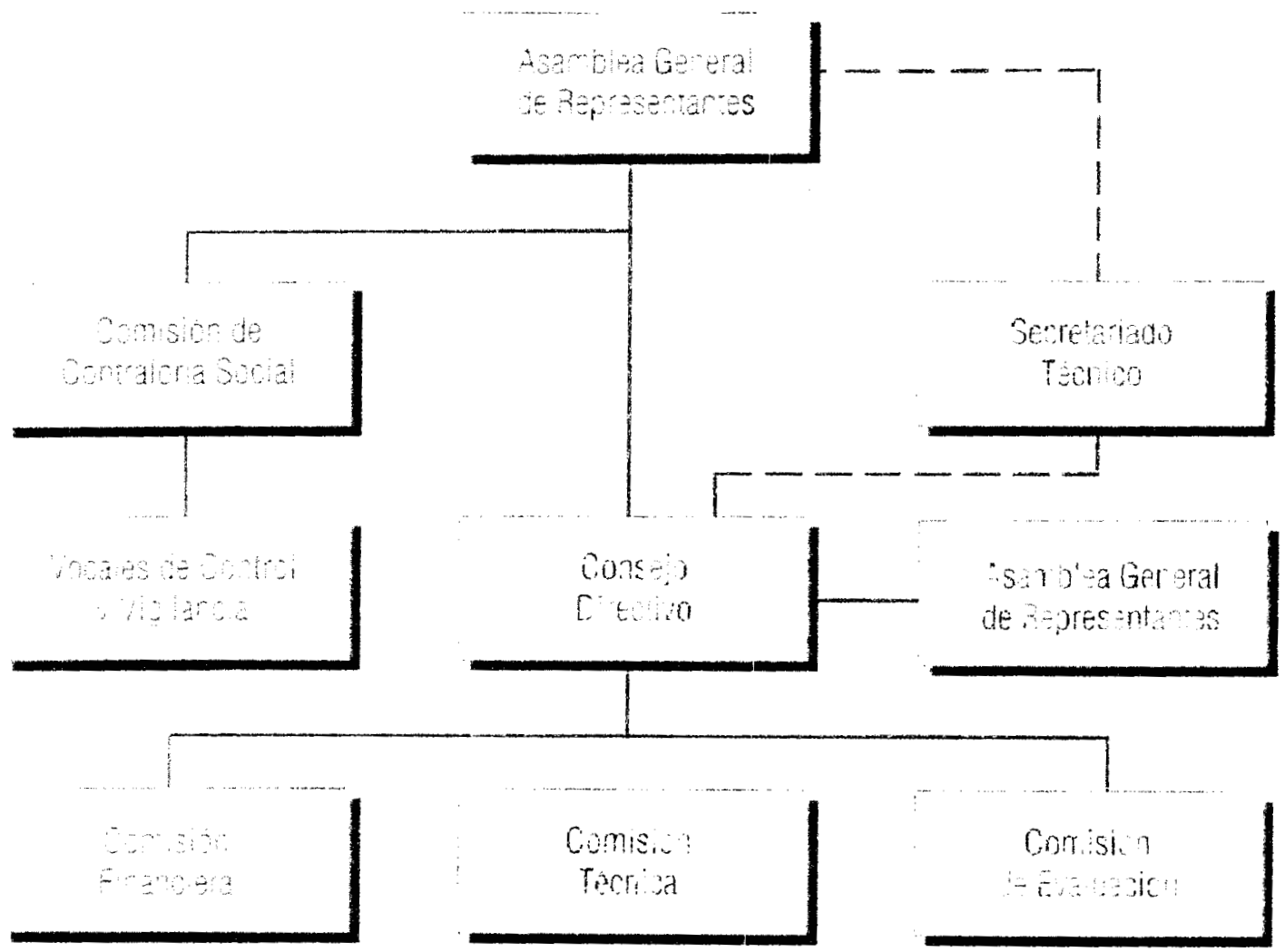

FIGURA 69.- ORGANIGRAMA DE LOS FONDOS REGIONALES DE SOLIDARIDAD (INI, 1994: 103)

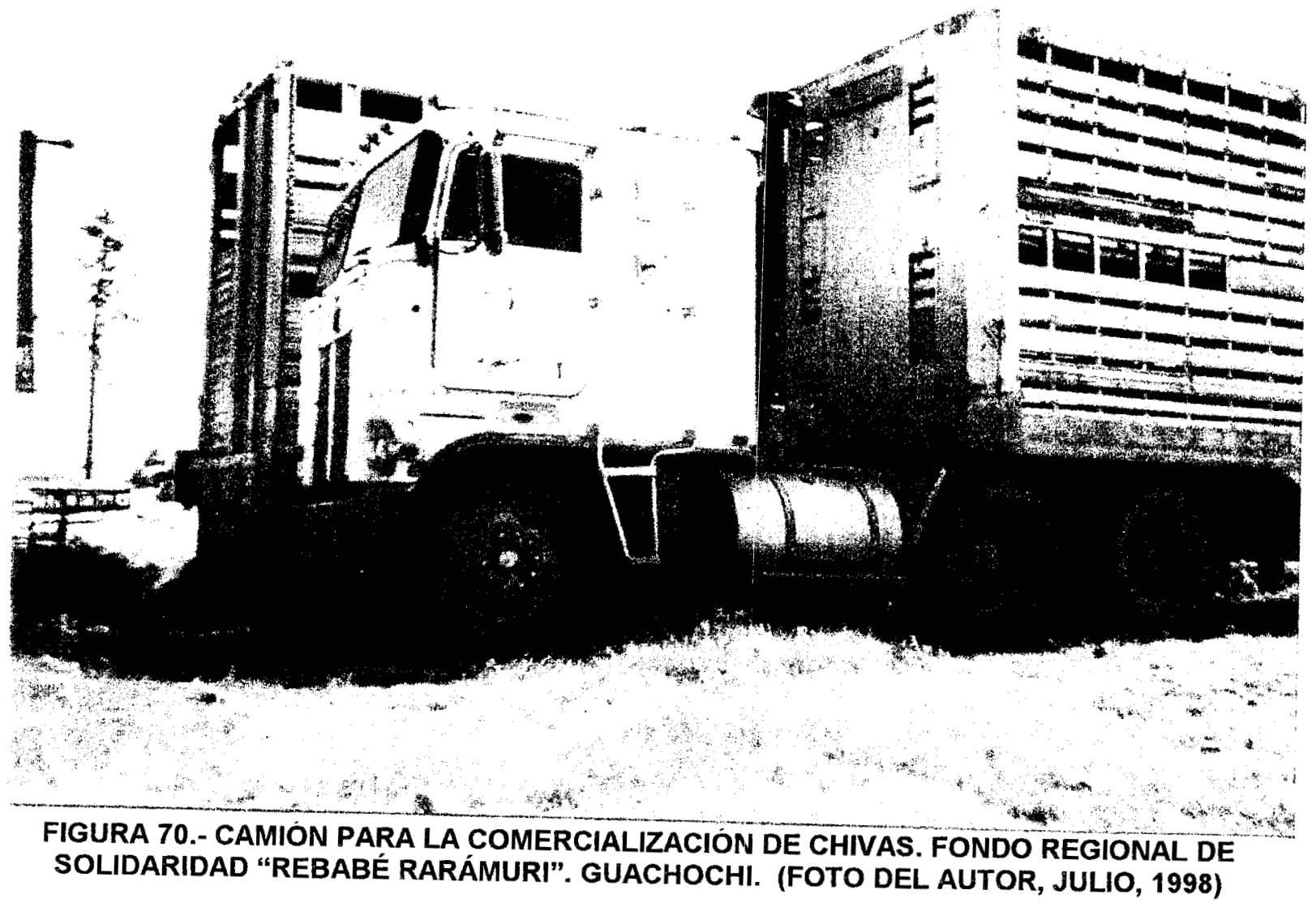


En el caso de los rarámuri (tarahumaras) se observó que la puesta en marcha de grandes proyectos regionales no se adaptaba a las formas de organización tradicional, mismos que terminarian por beneficiar únicamente a las élites mestizas. Por ello se decidió por la linea de apoyar microproyectos orientados a elevar las condiciones de vida de las familias indigenas (INI, 1994: 109 y 110)

Esta evaluación del INI, aunque tardia, corrobora lo que otros fracasos han planteado: el modelo cultural de los grupos étnicos de la Tarahumara es reacio a aceptar aquellos programas de desarrollo que se sustentan en formas comunalistas. También la lógica de la ganancia y de la reinversión de utilidades en aras de la acumulación choca abiertamente con una mentalidad indígena más proclive al autoconsumo que a la producción y venta de excedentes, a la austeridad que a la abundancia. Estos condicionantes culturales siempre han constituido una barrera infranqueable para los promotores externos de modelos de desarrollo en la Tarahumara.

En los últimos años (1994-2000) los FRS han seguido funcionando e incluso se ha creado uno nuevo - Bagai Kaikiari- integrado por un grupo de tepehuanes de la zona de Baborigame (municipio de Guadalupe y Calvo). En términos generales, puede decirse que aunque los problemas de operación y recuperación financieras que hemos señalado siguen presentes, se ha logrado encontrar un cierto modelo de proyecto que se adapta mejor a la lógica económica indígena. En particular, se observa que los proyectos que implican operaciones económicas de mediana o gran escala en términos de financiamiento, producción y comercialización tienden a fracasar, mientras que aquellos que se limitan a operar dentro de nichos microregionales o, exclusivamente, en el ámbito de las rancherías y pueblos, pueden tener un cierto éxito, como lo demuestra un relativo auge de las pequeñas tiendas de abasto. Pero quizás el fenómeno más interesante que ha derivado de la experiencia de los fondos ha sido el de la adaptación de las formas organizativas originalmente propuestos por PRONASOL a los estilos propios de los rarámuri y ódame integrados en esos fondos. Este proceso de reapropiación se expresa, por ejemplo, en la tendencia de muchas organizaciones a asimilar dentro de las instancias directivas y de contraloría de los fondos, a personas con cargos en el sistema de gobierno indigena. También he podido observar en mi experiencia de campo en 
concentrarse más los esfuerzos de las agencias gubernamentales- dificilmente pueden considerarse como propuestas de un programa integral de desarrollo que garantice, al menos, un estándar de bienestar para los indígenas serranos tal y como lo muestran las cifras de pobreza y marginalidad a las que nos referiamos al principio de este capítulo. Pero además, la más grave limitante de estos programas indigenistas es que han quedado al margen de las que parecen ser hoy las estrategias emergentes del desarrollo económico en la Tarahumara.

En las dos últimas décadas, en efecto, a la par que el paradigma indigenista ha venido decayendo, otras nuevas alternativas y estrategias de desarrollo han surgido en la Sierra de Chihuahua. Algunas proceden de instancias gubernamentales y otras tienen como origen sectores diversos del capital y la economia internacionales. En cualquier caso todas pueden ser calificadas de estrategias "emergentes" del desarrollo que, de una $u$ otra forma, están teniendo un impacto en las poblaciones de la Sierra Tarahumara y frente a las cuales el indigenismo es ajeno.

De entre estas nuevas estrategias, tres son, en concreto, las más importantes: el repunte de un nuevo modelo productivo minero, la creación de un ambicioso programa de turismo y el impacto en amplias franjas de la geografía serrana de la siembra y comercialización de estupefacientes.

\section{Nuevos perfiles de la mineria serrana}

La primera de estas alternativas obedece al interés que los inversionistas extranjeros han mostrado en fechas recientes en torno a la explotación de los recursos mineros de la Sierra. En particular asistimos recientemente a un notorio incremento de la inversión de origen canadiense en la explotación de metales preciosos. El repunte minero obedece a una serie de cambios en la reglamentación y situación fiscal de esta rama derivados de la firma del Tratado de Libre Comercio asi como al interés creciente que diferentes firmas canadienses han mostrado en los yacimientos de metales 
descubrimiento se ubica en el pueblo de Moris, también en la Sierra Tarahumara, en donde opera la empresa canadiense Manhattan Minerals Corporation que explota ya un gran yacimiento de oro. ${ }^{81}$ Junto con las empresas señaladas otras más están realizando trabajos de prospección geológica y de comprobación metalúrgica en diferentes lugares de la Tarahumara. ${ }^{82}$

Estas nuevas empresas han introducido algunas innovaciones tecnológicas como la detección de reservas a través de imágenes satélite, el minado a tajo abierto y el beneficio por lixiviación en montones (por el que se someten los minerales a la acción de reactivos con cianuro), filtración y precipitación, eliminándose los viejos sistemas de la flotación selectiva y la pirometalurgia. Se trata, en general, de sistemas de producción que están teniendo ya un primer impacto laboral y ambiental. Asi, se observan algunas incidencias en el empleo local y en afectaciones medioambientales en tierras, caminos, suelos, ríos, bosques, etc.

La presencia de estas empresas ha originado ya algunos debates y preocupaciones, en especial entre algunas organizaciones ecologistas norteamericanas, como Border Ecology Project, en torno a los posibles impactos ambientales y sociales que este repunte de la mineria serrana pueda causar. El caso del yacimiento de El Sauzal es el más preocupante puesto que se localiza en el ejido de Piedras Verdes (municipio de Urique), donde se asienta población rarámuri con la que la empresa ya ha entrado en negociaciones. De acuerdo con un estudio llevado a cabo por varios grupos ecologistas es muy factible que este proyecto minero, una vez que entre en operación,

proyecto de Dolores está todavia en fase de exploración pero augura un indudable auge de la mineria en la región de Madera.

${ }^{81}$ El yacimiento en cuestión contiene más de 4 millones de toneladas de mineral con leyes de 1.9 gramos de oro y 8.75 de plata por tonelada. Para el año de 1998 la empresa estimó una producción con un sistema de tajo abierto de 26,000 onzas de oro y 104,000 de plata a un costo de operación de 235 dólares por onza. Además, la empresa está realizando prospecciones geológicas en las zonas adyacentes de Candameña y Oribo, dos viejos poblados mineros que dejaron de ser explotados hace ya algunas décadas.

${ }^{82}$ Entre otras la Glamis Gold Ltd en la mina de La Cieneguita, la Western America Resources Inc. en Urique, la ESM Resources Ltd.. Westmount Resources asociada con la La Metálica S.A. (en la región de Maguarichi), Camblor, Cominco, Dynamic Ventures, Hemlo Gold, Pacific Island Gold, Silver Standard, USMX, Canarc, Corner Bay. Kennecott, Pheips Dodge y Tyler. 


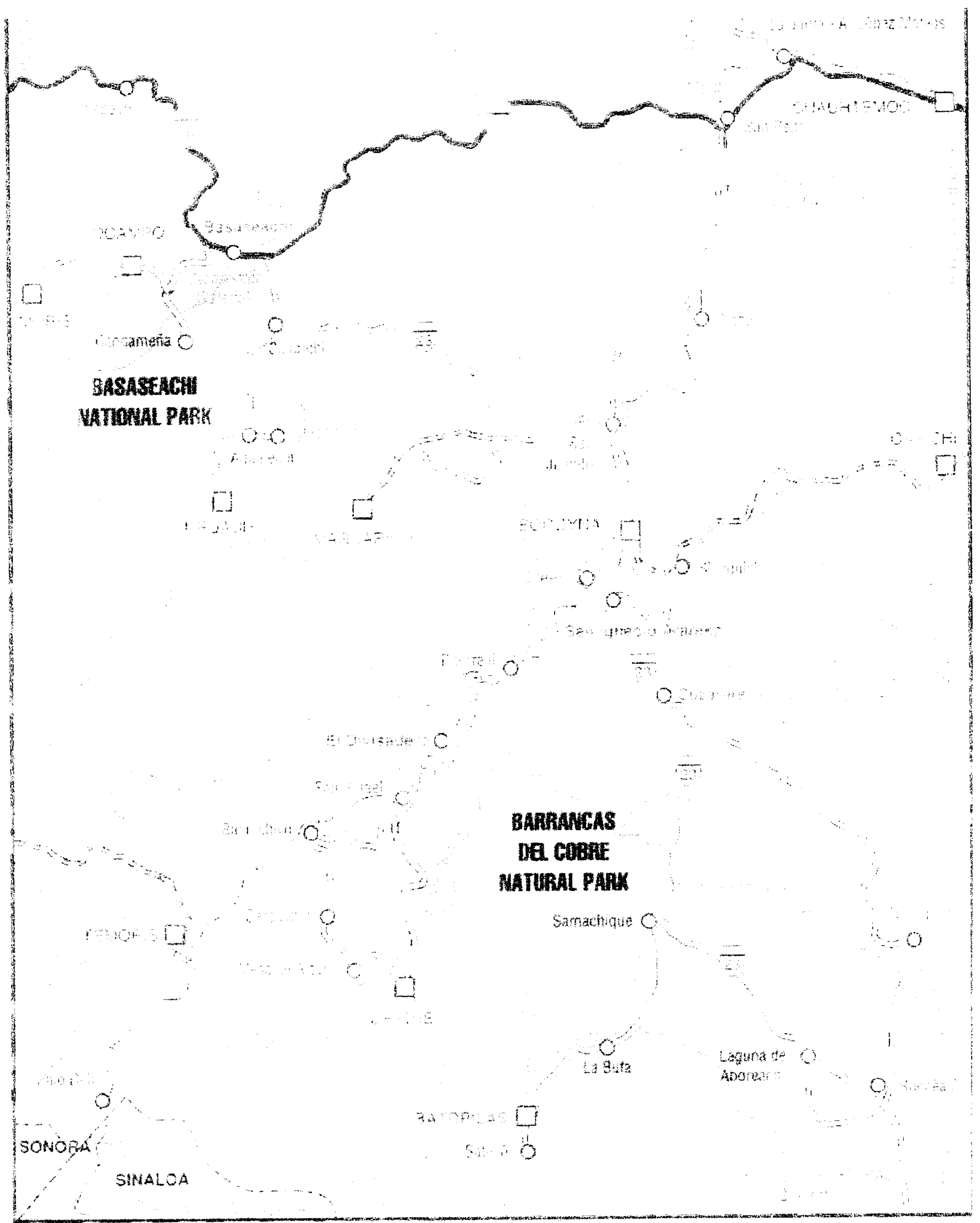

FIGURA 71.- LUGARES DE INTERÉS TURISTICO. PLAN BARRANCAS DEL COBRE

(SECRETARIA DE TURISMO-GOBIERNO DEL ESTADO DE CHIHUAHUA, s.f) 
distribuidos en poblaciones no mayores de 100 habitantes. Entre los objetivos del proyecto se plantea construir más de $300 \mathrm{kms}$. de carreteras, 2 estaciones de ferrocarril, 2 aeropuertos, sistemas de agua potable y alcantarillado, hoteles, supermercados, centros de visitantes y hasta un rancho cinegético. Aunque se prevé un gran interés del capital privado nacional y extranjero en invertir en el proyecto, la realidad es que el gobierno tuvo muchas dificultades para vender el Ferrocarril Chihuahua-Pacifico y sólo lo pudo hacer integrándolo como parte de un paquete de venta más amplio que incluía las líneas ferrocarrileras del noroeste (Secretaría de Turismo y Gobierno del Estado de Chihuahua, 1997 y Trujillo, 1996).

El 10 de agosto de 1995 y el 11 de diciembre de 1996, el presidente Zedillo inauguró el Plan y en enero de 1997 entregó al gobierno del estado de Chihuahua 28 millones de pesos para concluir la carretera Creel-Divisadero que permite a los visitantes acceder al más conocido mirador de la Barranca del Cobre. En su $1^{a}$ etapa está previsto que el Fideicomiso creado para manejar los fondos del Plan invierta en infraestructura 385'718,000 dólares: de esta suma cerca de la mitad (183'544,000 dólares) será proporcionada conjuntamente por el Banco Interamericano de Desarrollo y por el Banco Mundial. La $1^{\text {a }}$ etapa del Plan inició el 4 de enero de 1997 con una inversión de 16 millones de dólares aportados por el FONATUR (crédito del BID).

Aunque se aseguró, al inicio del proyecto, que se destinarian 2 millones y medio dólares a estudios de impacto ambiental y cultural, un grupo de expertos de la Universidad Autónoma de Chihuahua y de San José State University en California piensan que el proyecto puede acelerar la erosión derivada de la sobrexplotación forestal y aseguran que en 10 años el ecosistema de las barrancas puede acabar en un cañón totalmente erosionado como el del Colorado. Los mismos expertos estiman que, en la Tarahumara, por cada 2 árboles talados se va 1 metro cúbico de tierra al Pacifico por efecto de las lluvias y la erosión. También, varios ciéntíficos de Chihuahua han propuesto al gobierno que se plantee un programa de "Deuda por Naturaleza" (desarrollo de proyectos científicos en beneficio del medio ambiente a cambio de deuda), sin que, hasta 
la fecha, haya habido respuesta a esta solicitud (Gutiérrez, 1996:3).

En diciembre de 1996, varios diputados cenecistas en el congreso chihuahuense y los alcaldes priistas serranos, además de la mesa directiva del PRD estatal y grupos defensores de los derechos humanos, como la Comisión de Solidaridad y Defensa de los Derechos Humanos A.C. (COSYDDHAC), manifestaron abiertamente su oposición a la aprobación legislativa del Fideicomiso Barrancas del Cobre -organismo encargado de asumir la coordinación y financiamiento del plan-, aduciendo que en su Consejo Técnico estaban excluidos tanto los diputados y alcaldes serranos como los grupos étnicos que habitan en los municipios afectados. La presión obligó al gobierno del estado y a la Secretaria de Turismo a crear un Consejo Consultivo integrado por el gobernador del estado, empresarios, funcionarios estatales, 6 funcionarios federales, 9 alcaldes, 3 diputados locales, 1 representante de la Diócesis de la Tarahumara y 1 indígena, to que habla por sí mismo de la falta de interés por incluir a los grupos étnicos en la toma de decisiones del Plan Barrancas del Cobre (Salmón, 1997; Breach, 1996).

En fecha reciente y como parte del Plan Barrancas del Cobre, el gobierno estatal declaró estar interesado en promover ante la UNESCO la declaración del pueblo de Batopilas como Patrimonio cultural de la Humanidad, asi como la construcción de un desarrollo hotelero de 40 cabañas, de un hostal junto a la Barranca de La Sinforosa (en Guachochi) y de una pista de aterrizaje para aviones bimotores en Creel, obras todas ellas que fueron acordadas en la sesión del Comité Técnico del Fideicomiso Barrancas del Cobre en abril de 1999. En dicha reunión se decidió también impulsar algunos proyectos carreteros que abran la comunicación a través de la Baja Tarahumara entre Chihuahua y Sinaloa, así como obras en el campo de la piscicultura, tratamiento de aguas residuales en Guachochi y la reforestación de algunas zonas en la mesa de Guachochi.

Desde su aprobación, el Plan ha generado algunas inversiones en infraestructura de carreteras, caminos, hoteles y servicios turisticos, casi todos ellos ajenos a los 


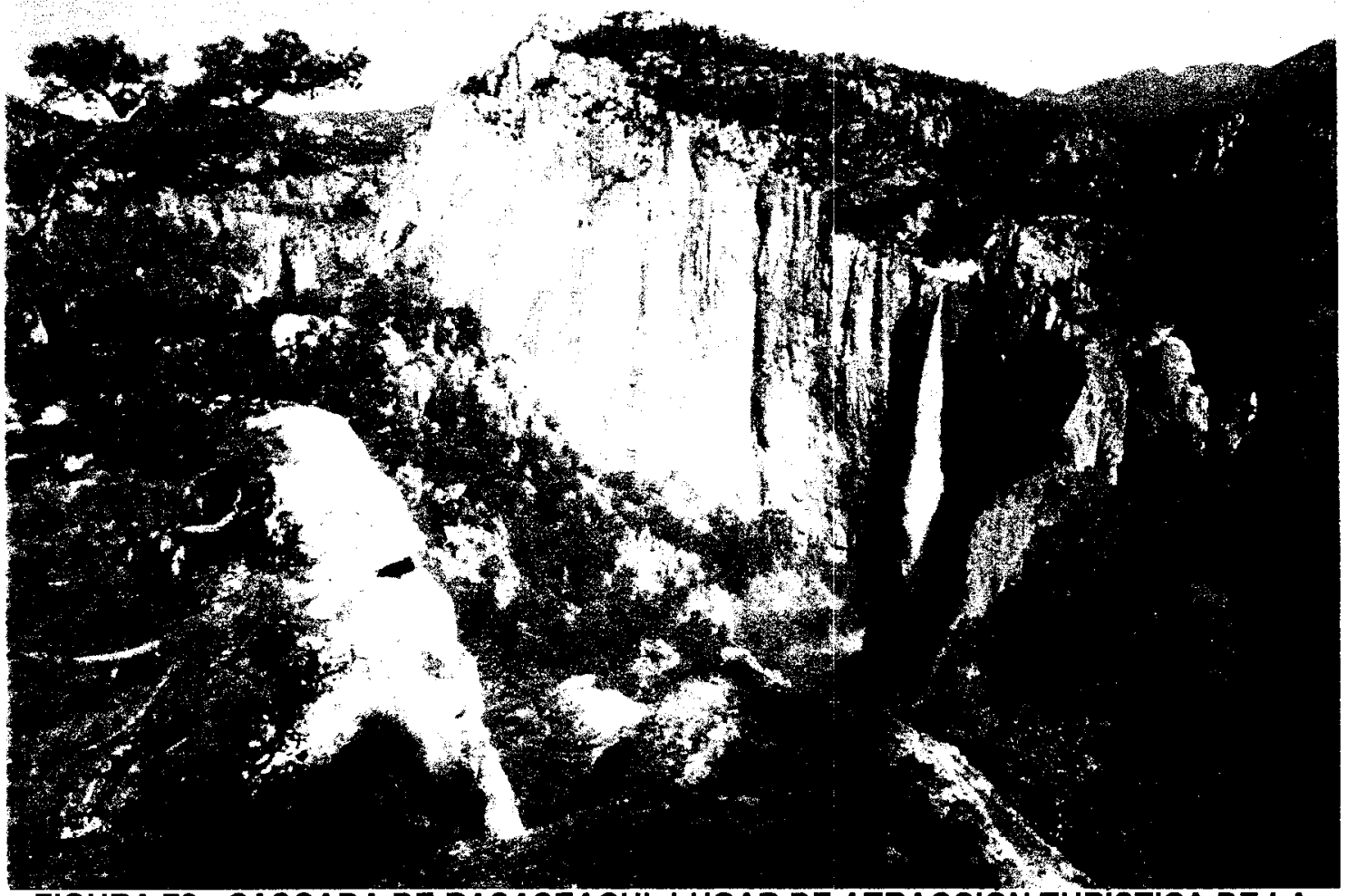

FIGURA 72.- CASCADA DE BASASEACHI, LUGAR DE ATRACCION TURISTICA DE LA TARAHUMARA (SECRETARIA DE TURISMO-GOBIERNO DEL ESTADO DE CHIHUAHUA, s.f)

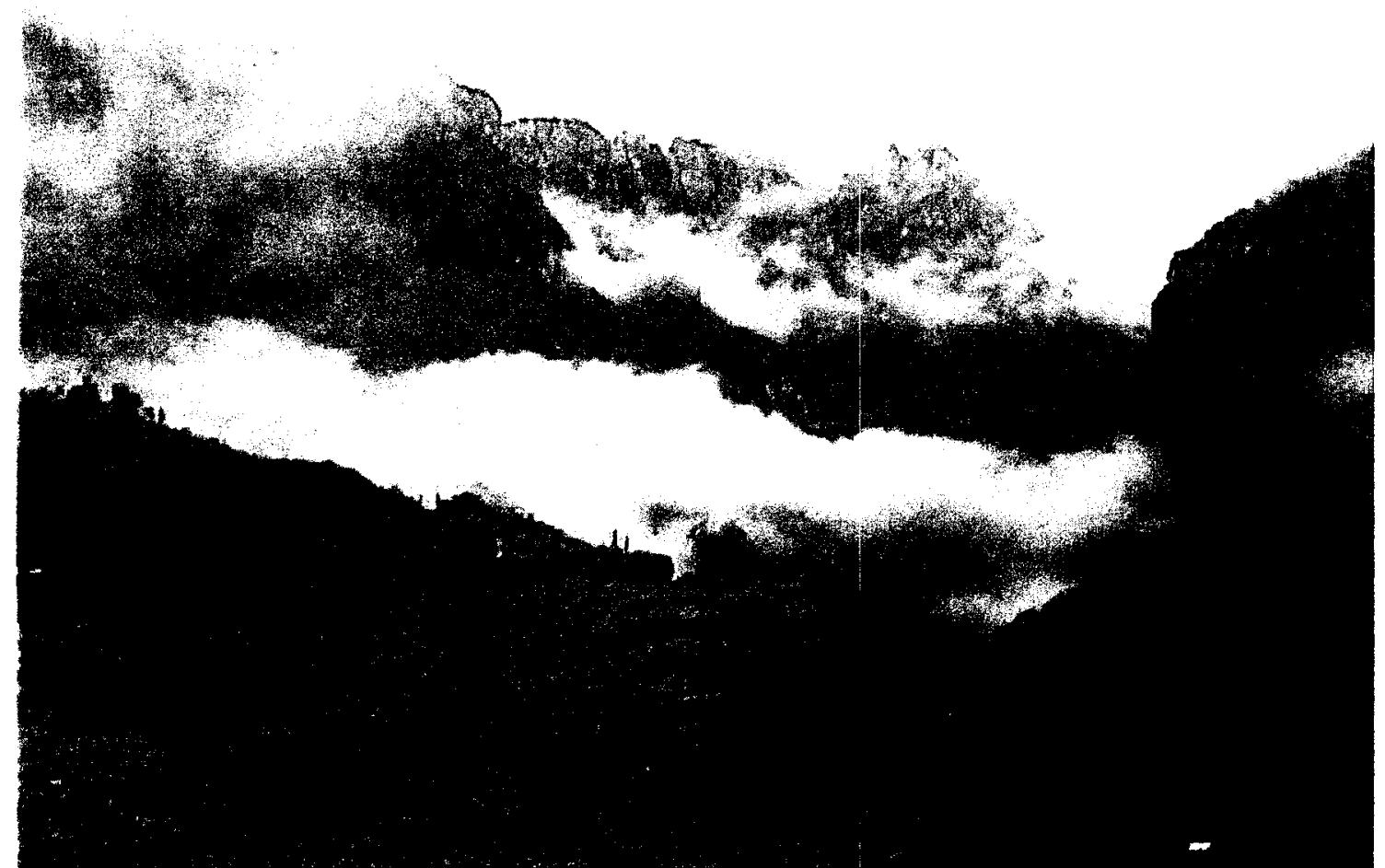


intereses de los indigenas de la Tarahumara. En algunos lugares, como El Tejabán y el ejido de San Luis de Majimachi, los intereses de los hoteleros han entrado en abierta oposición con los de los ejidatarios indigenas. ${ }^{84}$

\section{Narcotráfico y cultura de la violencia}

Finalmente existe una tercera alternativa económica en la Tarahumara, la de la siembra y comercialización organizada de estupefacientes -mariguana y amapola- que, a pesar de haber sido objeto de una persecución militar y policial sistemática en las tres últimas décadas, no ha hecho sino expandirse en amplias franjas de la Sierra, cobrando su saldo de muerte y violencia del que es un reflejo la situación de las cárceles y de algunas comunidades indígenas.

La narcoecomia es algo más que un fenómeno coyuntural en la Tarahumara. Sostiene y explica sistemas de circulación de dinero y mercancias, formas culturales de despilfarro y consumo suntuoso, asi como niveles de empleo en no pocas áreas de las barrancas de la Sierra Madre. La Tarahumara constituye oficialmente uno de los terntorios críticos del auge del narcotráfico en México durante las últimas décadas. ${ }^{85}$ Asi se desprende de los datos de la Procuraduria General de la República que, a mediados de los años noventa, situaba a Chihuahua en el segundo lugar entre los estados de la República con mayor número de plantíos de estupefacientes (cerca de 5,000 ), sólo aventajado por el de Sinaloa y seguido, en orden decreciente, por los de Guerrero, Michoacán, Durango, Jalisco, Sonora, Veracruz y Chiapas.

\footnotetext{
${ }^{84}$ En su informe de 19916-1997, sobre la situación de los derechos humanos en Chihuahua COSYDDHAC informaba:

En el ejido de San Luis de Majimachi, un empresanio sinaloense pretendió rentar una extensión de 6 hectáreas de la Mesa de Güerachi, por un pago mensual de 750 pesos por 30 años, es decir, con el pago por el hospedaje de una habitación. Finalmente en una asamblea los ejidatarios decidieron no aceptar la propuesta. Otro caso es el del Tejabán, municipio de Bocoyna, donde les fue arrebatado el predio para construir un hotel (Comisión de Solidaridad y Defensa de los Derechos Humanos A.C., 1998: 27).

${ }^{85}$ Como es obvio, no es fácil obtener datos fidedignos sobre la narcosiembra y el narcotráfico en la Sierra Tarahumara. Sin embargo, cuando uno realiza trabajo de campo en la zona no tarda en reconocer evidencias del fenómeno. Además de esto, muchas de las cifras que aportamos aqui provienen en su mayoria del estudio de Carlos Mario Alvarado, La Tarahumara: una tierra herida, uno de los pocos trabajos serios sobre el tema.
} 
Dentro de esta geografía de la narcosiembra, Chihuahua forma parte del llamado "Triángulo dorado", integrado por los estados de Chihuahua, Sinaloa y Durango, zona de cultivo de mariguana y amapola. Sólo en el estado de Chihuahua se estimaba en 1996 que estos cultivos se extendian por una superficie de $30,000 \mathrm{kms}$. cuadrados y que existian cerca de 25,000 cultivadores anuales de mariguana y amapola. Pese a ser analfabetas, la mayoria de estos productores de droga han dominado las técnicas de cultivo y siembra y, amparados por un suelo agreste, han establecido estrategias de camuflaje para salvar sus miles de microcultivos de droga de los helicópteros fungicidas ("boludos"), de las patrullas de militares, del granizo y de los extraños. No sólo eso, también han soportado por varias décadas el rigor y los excesos de la represión policiaca.

Como lo muestran los siguientes datos, una buena parte de las actividades del narcotráfico en el Triángulo Dorado se desarrollan en la Sierra: de los 663 detenidos y consignados en el estado de Chihuahua como presuntos narcotraficantes entre 1978 y $1981,24 \%$ eran campesinos e indigenas de los municipios serranos de Guadalupe y Calvo, Guazapares, Morelos, Batopilas, Guachochi, Urique y Chinipas en los que se estima que, en 1993, se sembraban en cerca de 5,000 has. mariguana y amapola y en los que se concentra una gran parte de las actividades ligadas a la narcosiembra, en especial en municipios barranqueños como el de Guadalupe y Calvo. ${ }^{86}$

\footnotetext{
${ }^{86}$ En 1992, según cifras del Programa Estatal de Control de Drogas, en Chihuahua, se destruyeron 2,706 has. de amapola ( $23.3 \%$ del total destruido en el pais) y 2,781 has. de siembras de mariguana ( $16.5 \%$ del total nacional). La mayor parte de esas actividades de erradicación se llevaron a cabo en el municipio de Guadalupe y Calvo. Se estima además que en el estado y durante 1992 se ocuparon en la producción de mariguana 13,935 personas, o sea $1 \cdot 672,260$ jornales por ciclo productivo, es decir $3 \cdot 300,000$ pesos invertidos en jomales para la producción de estupefacientes destruidos por la PGR, causando daños millonarios a los sembradores por la semilla perdida y las instalaciones hidráulicas. Según el Sistema Estadistico Uniforme para el control de Drogas, en el estado de Chihuahua, de enero de 1988 a diciembre de 1992 se destruyeron 78,882 plantios de mariguana (7,238.53 has.) y 82,062 plantíos de amapola $(72,47.64$ has.). O sea, en 4 años se destruyeron más de 160 mil plantios de mariguana y amapola con una extensión de casi 15,000 has.

En el caso particular del municipio de Guadalupe y Calvo, para ese año se calcula que alrededor de 20,842 personas (de las cerca de 35,000 con que cuenta el municipio) estaban incorporadas a la producción de la droga, es decir el $275.72 \%$ de la PEA. Eso indica que a la actividad se suman niños y migrantes, como lo confirman algunos reportes de maestros que señalan que en época de cosecha se les vacian los salones de clase. (Alvarado, 1996)
} 

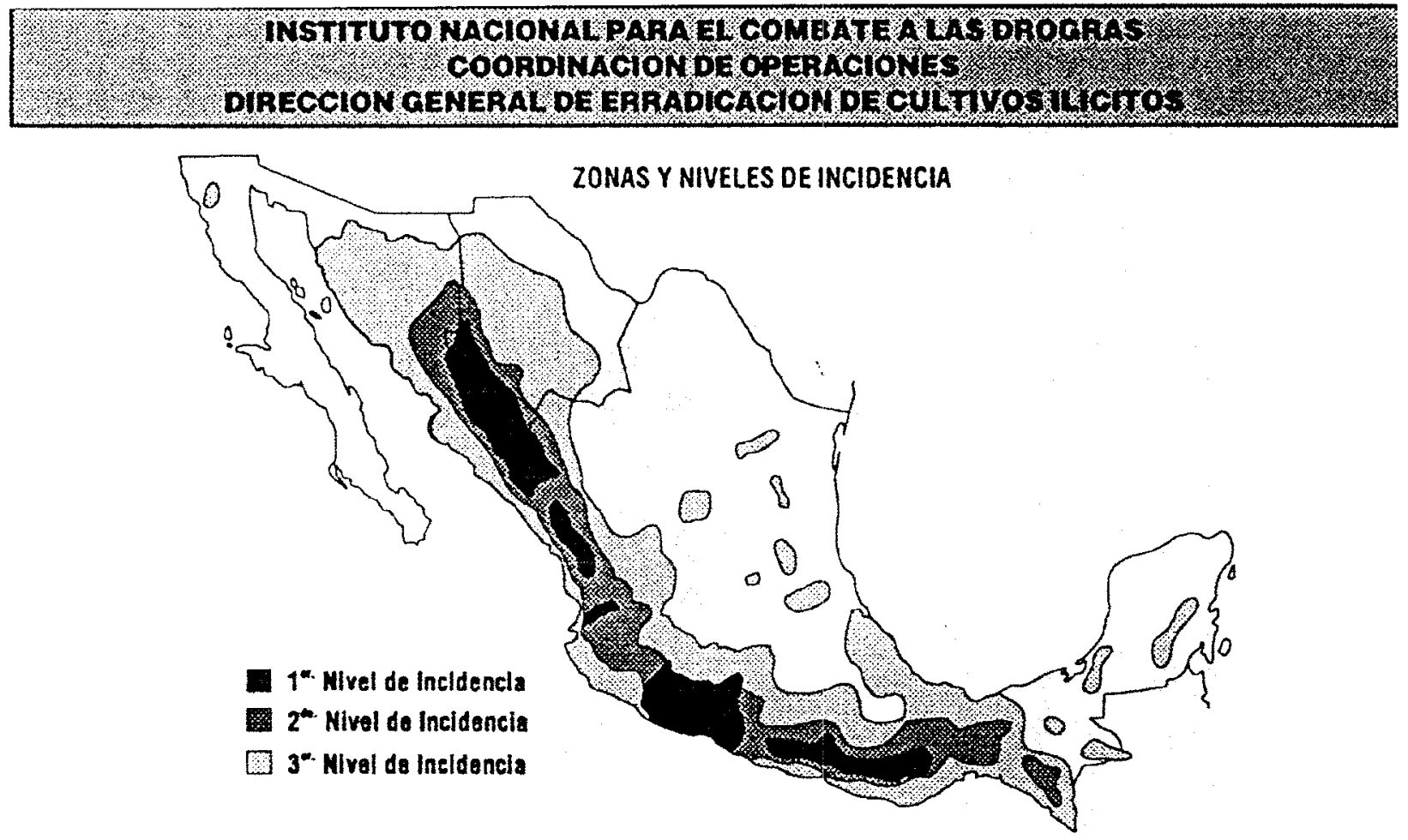

FIGURA 74.- REGIONES DE MEXICO CON MAYOR INCIDENCIA DE NARCOCULTIVOS (ALVARADO, 1996: 57)

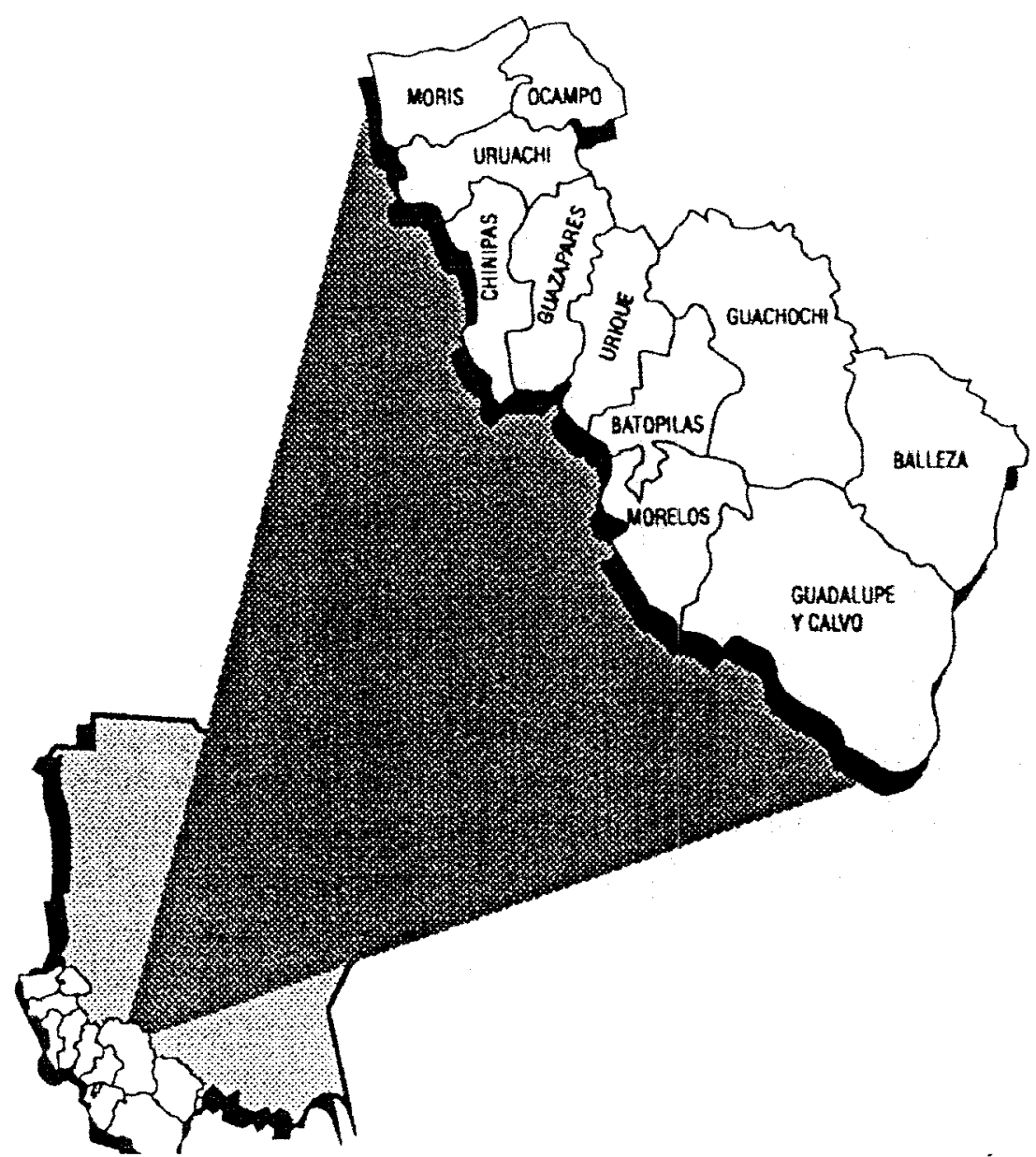

FIGURA 75.- MUNICIPIOS DEL ESTADO DE CHIHUAHUA UBICADOS EN EL TRIÁNGULO DORADO DE ESTUPEFACIENTES Y CON ALTO ÍNDICE DE HOMICIDIOS (ALVARADO, 1996: 68) 


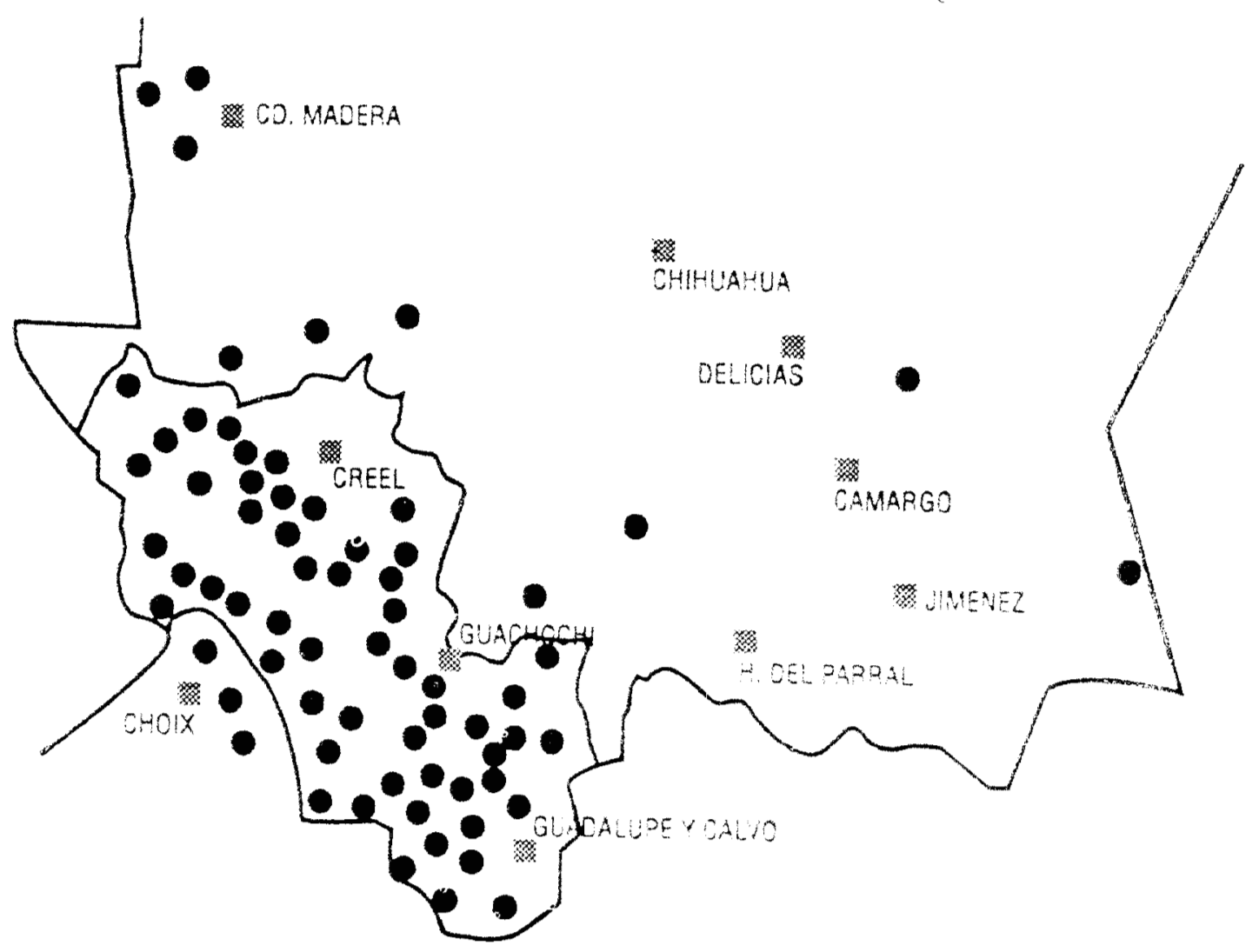

FIGURA 76.- ÁREAS REINCIDENTES DE SIEMBRA DE AMIAPOLA EN LA SIERRA TARAHUMARA( $\bullet$ ). (INSTITUTO NACIONAL PARA EL COMBATE A LAS DROGAS. COORDINACIÓN DE OPERACIONES. DIRECCIÓN GENERAL DE ERRADICACIÓN DE CULTIVOS. TOMADO DE ALVARADO, 1996:79)

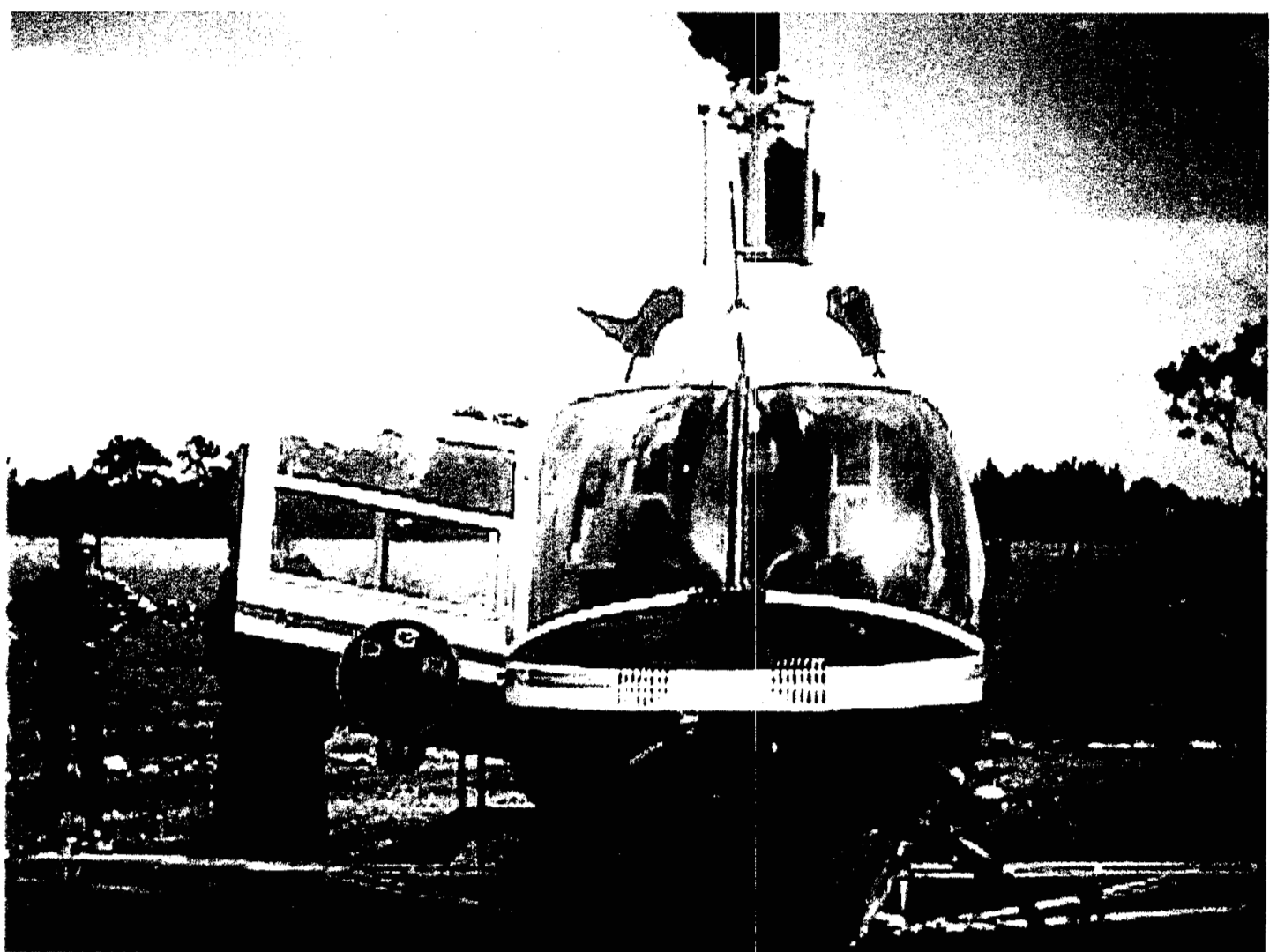

FIGURA 77.- BOLUDO O HELICOPTERO PARA FUMIGACION DE NARCOSEMBRADIOS EN LA SIERRA TARAHUMARA, AEROPUERTO DE GUACHOCHI (FOTO DEL AUTOR, JULIO, 1998) 
La más grave consecuencia de esta proliferación de la narcosiembra es la cultura de la violencia que se ha extendido en muchos lugares de la Sierra Tarahumara, en especial en los pueblos barranqueños en donde el aislamiento es mayor. Esta cultura de la violencia se expresa en delitos como el armamentismo, el consumo del licor, las violaciones, los homicidios por venganzas $y$, en general, un clima de delincuencia ${ }^{87}$ que retratan interminablemente los narcocorridos serranos. ${ }^{88}$

Para enfrentar esta situación, el aparato de justicia estatal y federal resulta a todas luces insuficiente. Pero lo más grave no es sin embargo eso, sino el hecho de que en amplios sectores de la Sierra quienes se dedican a la narcosiembra no asumen una conciencia de delincuencia. Para muchos de estos sujetos, la siembra de amapola y mariguana no es sino una actividad económica que les permite sobrevivir en medio de una tierra muy poco propicia para la agricultura y en donde las alternativas reales de empleo son muy restringidas. ¿Cómo enfrentar este grave problema que cada día toma proporciones alarmantes en la Tarahumara? ¿Bastará con incrementar las estrategias de

${ }^{87}$ De acuerdo con los datos que proporciona Alvarado los indices de homicidios en los municipios de Guachochi, Guadalupe y Calvo, Moretos, Batopilas, Urique y Chinipas representaron en promedio y entre 1988 y 1994 niveles cuatro veces superiores a los esperables de acuerdo al tamaño de su población y a la media estatal. Es constatable que la Sierra ha sido desde épocas históricas un lugar con tendencia a la marginalidad social, el bandolerismo y la delincuencia social, pero quizás sea tambièn cierto que la economia de la narcosiembra vino a afianzar aún más esta cultura de la violencia.

${ }_{88}$ Baste como ejemplo, el corrido "Pacas de a kilo" de Los Huracanes del Norte y sus alusiones directas o en doble sentido a los "costales" (de mariguana), las "vacas" (marihuana o amapola), la "cola de borrego" (variedad de mariguana altamente productiva), las "culebras" (la ley, la policia o el ejército), el "cuemo de chivo" (fusil ametrallador AK-47), y las "pacas de kilo" (fajos de dinero que se cuentan por su peso):

"Me gusta andar por la Sierra/me crié entre matorrales, ahi aprendi a hacer las cuentas/nomás contando costales/me gusta buntar las redes/que tienden los federales.

Muy pegadito a la Sierraftengo un rancho ganadero/ganado sin gamapatas/que llevo p'al extranjero/iqué chulas se ven mis vacas/con colitas de borrego.

Los amigos de mi padre/me admiran y me respetanly en dos o trescientos metros/evanto las avionetas,/de diferentes calibres manejo las metralletas [...].

Por ahi andan platicando/que un día me van a matar/no me asustan las culebrasyo sé perder y ganar./Ahi traigo un cuemo de chivo/para el que le quiera entrar[...]

Los pinos me dan la sombra/mi rancho pacas de a kilo/soy mediano de estatura/amigo entre los amigos. Perdonen que no acostumbro decirles mis apellidos.

Adiós Sierra de Coahuiladde Sinaloa y Durango/de Sonora y Tamaulipas/Chihuahua te andas quedando.Si me quieren conocer/en Juárez me ando paseando. (Tomado de Alvarado, 1996: 90-92) 
persecución y encarcelamiento de los delincuentes?. ${ }^{89}$

Las comunidades indigenas no han sido del todo ajenas a este auge de la economia de los narcocultivos y la cultura de la violencia ligada a él. Especialmente, algunos grupos étnicos serranos como los warojíos en la región de Uruachi y Arechuyvoy los tepehuanes en el área de Baborigame- han vivido desde hace al menos dos décadas los estigmas de esta cultura de la violencia.

Entre otras cosas, este auge de la delincuencia muestra los límites reales de las políticas y de los experimentos del desarrollo que la Sierra ha conocido en las últimas décadas. Carentes de tierras o de implementos para hacerlas producir, victimas de una politica depredadora de la riqueza forestal y minera que sölo beneficia a las grandes empresas, amenazados periódicamente por la sequia y la hambruna y olvidados por un sistema de gobierno que se apoya en el caciquismo, muchas poblaciones de la Baja Tarahumara se han visto orilladas a entrar en esta economía del narcocultivo y a sufrir sus efectos de violencia. Sólo pagando este alto precio, han podido acceder a ciertos niveles de consumo y bienestar que les permiten sobrevivir en sus pueblos $y$ comunidades de la Sierra de Chihuahua.

\footnotetext{
${ }^{89}$ Al respecto, un dato puede resultar esclarecédor: en caso de que se hubieran consignado y sentenciado a los 40 mil trabajadores necesarios para hacer producir esas 15,000 has. de cultivos de enervantes destruidas entre 1988 y 1992, se hubiera requerido prácticamente toda una ciudad penitenciaria, eso, sin incluir a quienes lograron cosechar y vender la droga, ni a las bandas de narcotraficantes locales asociados a los carteles internacionales de la heroina. Ante tales hechos no son extrañas reacciones como las de la Delegada de la PGR en el estado de Chihuahua, Teresa Jardi, quien proponia hacia 1990 que se despenalizara la siembra de los narcocultivos (Alvarado, 1996: 76-78).
} 


\section{CONCLUSIONES: DEL INDIGENISMO A LA AUTONOMÍA E INTERCULTURALIDAD}

A lo largo de este estudio hemos tratado de analizar criticamente cuáles fueron, a lo largo del siglo que hemos concluido, las concepciones y experiencias institucionales del indigenismo en la Sierra Tarahumara frente a los pueblos, en especial los rarámuri (o tarahumara). De este examen critico podemos concluir un recuento de las principales directrices y una propuesta de periodización del indigenismo en la Sierra de Chihuahua.

Como lo planteamos en la introducción, cuatro son los ejes alrededor de los cuales se ha movido la acción indigenista en la Tarahumara: una particular perspectiva etnográfica sobre el indio y las posibilidades de su transformación social, un discurso sobre las formas de organización social y en especial sobre la comunidad indígena, un planteamiento que trata de entender las relaciones interétnicas y superar su conflictividad y una serie de propuestas sobre el desarrollo encaminadas a resolver la grave situación de pobreza y marginación de los grupos étnicos.

La etnografía indigenista, en particular la que surgió después de la revolución (1910-1920) se encuadra dentro de las que hemos denominado miradas "reformadoras", que vieron la Tarahumara como un lugar propicio para el cambio y como un terreno apto para la práctica de experimentos de transformación social. En sus diferentes modalidades, esta etnografía ha insistido en la viabilidad de la incorporación del indio a la nación. Esta visión optimista que acerca a indigenistas y misioneros católicos se enfrenta con la que calificamos como una mirada "primitivista" sobre la Tarahumara que, no sin asombro, descubre en este territorio y en sus pueblos indios una muestra excepcional de resistencia cultural al cambio, digna de respetarse y aún de mantenerse intacta. Creo no equivocarme al pensar que es ésta última la visión consagrada desde el siglo XIX por viajeros, literatos, médicos, naturalistas y es ésta la imagen perpetuada, hasta el día de hoy, por defensores del discurso indianista y promotores del turismo internacional folclorista. 
La perspectiva del comunitarismo indígena constituye a lo largo de todo el siglo $X X$, una de las premisas y, al mismo tiempo, uno de los objetivos de la acción indigenista. Es el punto de partida, la condición y la meta última de muchos de los programas del indigenismo oficial. $Y$ sin embargo, la etnografía sistemática $y$, sobre todo, las experiencias de los fracasos del indigenismo en la Tarahumara, demuestran que, entre estos grupos étnicos, la concepción que liga a los individuos en un sistema social, un territorio y una forma de gobierno está muy lejos del arquetipo mesoamericano que se esconde detrás de muchos de los experimentos del indigenismo oficial.

La experiencia indigenista en la Tarahumara muestra también que la conflictividad interétnica es algo más que un problema de anacrónicas relaciones "de casta"; deriva de profundas diferencias culturales entre indios y mestizos, se reafirma en contextos de relaciones capitalistas y se convierte en un serio obstáculo para la integración de los indígenas a la cultura y a la economía nacionales.

Las concepciones, los modelos y los proyectos de desarrollo que el indigenismo ensayó en la Tarahumara han chocado en mayor o menor grado con las visiones, las prácticas productivas y las formas de organización social de los pueblos indígenas. En particular, la insistencia indigenista en la explotación intensiva del bosque, en la implantación de formas organizativas ligadas a la institución ejidal, en la expansión del aparato escolar y en la difusión de la medicina cientifica han topado con serios obstáculos derivados de la preferencia indígena por una diversificación productiva, por un sistema de organización territorial disperso, por un modo de socialización familiar y por un profundo arraigo de las nociones de salud-enfermedad y de las prácticas curativas autóctonas.

Pero los pueblos indígenas de la Tarahumara no han sido sujetos pasivos frente a los discursos y los experimentos que el indigenismo ha construido sobre su identidad, sus formas de organización, sus relaciones con el mundo mestizo y sus posibilidades de desarrollo. Por el contrario, los grupos étnicos han desarrollado diversas estrategias para sobrevivir, mantener y reafirmar su identidad. La gama de estas estrategias ha sido muy variada: va desde el enfrentamiento violento y la oposición declarada hasta la asimilación 352 
asumida y la aceptación forzada de imposiciones extemas. En medio de estos extremos se han situado, sin embargo, las respuestas más comunes: la resistencia pasiva $y$, especialmente, la reapropiación y reinterpretación de imposiciones externas de acuerdo con los intereses indigenas.

El cuadro 29 pretende sintetizar por etapas la historia de los discursos y experiencias indigenistas en la Tarahumara asi como de las respuestas indígenas frente a ellos. Retomo aquí las periodizaciones y los contenidos que he planteado en cada uno de los capitulos de este estudio de los que concluyo que el indigenismo en la Tarahumara ha conocido a lo largo del siglo XX cinco grandes discursos hegemónicos. El primero, que denomino proteccionista, definió a los indios como una minoría étnica en condiciones de inferioridad social, incapacidad jurídica, atraso y, por ello, necesitada de protección y tutela bajo un régimen de excepcionalidad juridica. El proteccionismo, cuyo antecedente más claro es la experiencia colonial de la "república de indios" en los pueblos de misión" instaurados por los jesuitas entre 1606 y $1767^{1}$, volvió a cobrar vigencia entre 1880 y 1910, a raiz de las medidas dictadas por el gobernador Creel con vistas a lograr la "civilización y mejoramiento de la raza tarahumara" y consistentes en la creación de colonias y escuelas para los tarahumaras. Frente a esta politica y frente a la expansión agresiva del ferrocarril, las empresas mineras, las compañias forestales y deslindadoras

\footnotetext{
' Como lo señalamos en el capitulo 2, durante todo este periodo, las 4 etnias serranas reaccionaron violentamente contra el sistema misional en una secuencia ciclica de rebeliones armadas y sumisiones forzosas. Al mismo tiempo, asimilaron de sus conquistadores ciertos elementos civilizatorios como el complejo tecnológico agricola, ganadero y forestal de raiz europea (del que, en gran medida, siguen viviendo), un sinnúmero de simbolos religiosos incorporados al ritual indigena y un sistema de gobiemo que, más tarde, se convertiria en elemento central de la identidad india. La resistencia pasiva tuvo su más clara expresión en la persistencia del patrón indigena de dispersión territorial contra el que los misioneros europeos inútilmente lucharon, hasta aceptar la imposibilidad de "reducir a los naturales".
} 


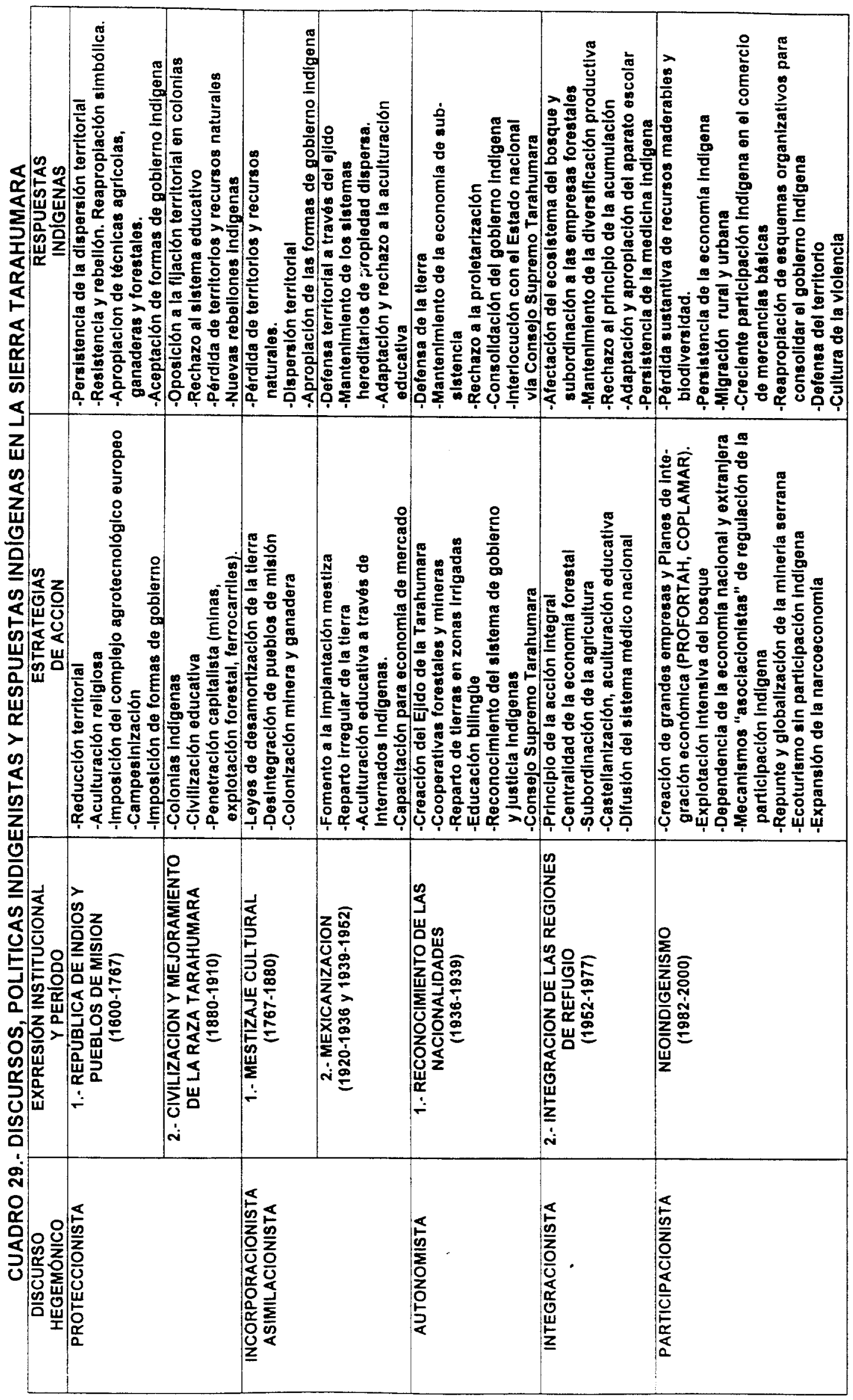


de tierras, los rarámuri se vieron forzados a aceptar una notoria pérdida de sus territorios y de sus recursos naturales. Pero el estallido de la revolución hizo inoperantes las reformas gubernamentales y propició, incluso, nuevos brotes de rebelión en la segunda década del siglo.

El segundo discurso indigenista hegemónico fue el del incorporacionismo o asimilacionismo, que postuló la necesidad de eliminar todo tipo de barreras culturales y jurídicas que llevaran a considerar al indigena como un sujeto social distinto y propugnó por su incorporación a las formas de vida mestiza y a los patrones de la cultura nacional. El antecedente más importante de esta propuesta fue la politica de mestizaje cultural que tuvo lugar en el período que va de las reformas borbónicas en 1767 (cuando los jesuitas fueron expulsados) a la consolidación del liberalismo en 1880, etapa en la que el principio de la fijación residencial del indio se relajó, fueron decretadas leyes de desamortización de las tierras de comunidad y la colonización mestiza, emprendida por mineros y ganaderos, se expandió en el territorio serrano. ${ }^{2}$

Pero la tesis del incorporacionismo volvió a tener vigencia entre 1920 y 1952 (salvo en un corto lapso que va de 1936 a 1939), cuando tanto el gobierno -y en cierta forma la iglesia- ensayaron formas aculturativas centradas en la educación y la reforma agraria con vistas a lograr la mexicanización del indio. Como ni una ni otra fueron acompañadas de reformas profundas del sistema económico serrano, no lograron modificar sustancialmente los patrones de subsistencia indígenas. La primera de estas estrategias se centró en el experimento de los internados sustentado en la pedagogía de la castellanización y enseñanza de oficios. La segunda el reparto de la tierra- tuvo efectos contradictorios porque si, por una parte, ofreció a algunos núcleos indigenas una cierta seguridad legal sobre la propiedad de sus tierras, por otra, propició el desdibujamiento de

\footnotetext{
${ }^{2}$ Fue en este tiempo cuando los rarámuri tuvieron que aceptar la pérdida del control sobre una parte importante de su territorio y cuando la presencia de los chabochi se acrecentó en los centros mineros barranqueños y en las antiguas cabeceras de los pueblos de misión. En este contexto de latente conflictividad interétnica, los tarahumaras optaron por la dispersión en zonas inhóspitas de refugio, lejos del influjo mestizo, y por una reapropiación y traducción, en contenidos indigenas, de las formas de gobiemo que les habian sido impuestas por los jesuitas.
} 
la estructura de los territorios indios y, por ende de la jurisdicción sobre ellos de las gobernadores o siriame. Además, la centralidad que las dependencias agrarias e indigenistas (el Departamento Autónomo de Asuntos indigenas) otorgaron al ejido (en particular al ejido forestal) confirió a los mestizos una serie de atribuciones políticas y un control sobre la actividad productiva que hasta entonces no habian detentado.

Los rarámuri reaccionaron ante su pretendida "mexicanización" adaptándose o resistiendo pasivamente ante la aculturación educativa y aprovechando las medidas agraristas como única altemativa para defender sus tierras del acecho de las empresas madereras, de la intromisión de nuevos colonizadores y de la expansión ganadera propiciada por grupos mestizos. Pero no siempre lograron ganar esta batalla y, cuando lo hicieron, fue a costa de una pérdida de atribuciones de su gobierno y de un desdibujamiento de los perfiles de sus territorios. En todo caso, las modalidades legales de apropiación de la tierra derivadas de la institución ejidal fueron incapaces de trastocar las formas tradicionales rarámuri de transmitir por via hereditaria y bilateral la propiedad de ranchos dispersos.

Durante un corto lapso de tiempo, en pleno período cardenista, el indigenismo asumió formas radicales en la Tarahumara, a raiz de las propuestas de algunos funcionarios gubernamentales y de un grupo de maestros agraristas centradas en torno a la autonomia de los rarámuri. De todas ellas, la única que tuvo vigencia fue la creación del Consejo Supremo Tarahumara, organismo que asumió hasta los años setenta un papel de intermediación política entre los rarámuri y el estado nacional, para pasar después a convertirse en una instancia corporativizada carente de representatividad.

Desde 1952 hasta 1977, la presencia institucional del INI en la Tarahumara estuvo formalmente ligada a la concepción oficial del indigenismo de la época que defendió la integración de los grupos étnicos a la nación, reconoćiendo algunos elementos centrales de su identidad como sus lenguas y su territorio. En la sierra de Chihuahua, el integracionismo se expresó particularmente en una estrategia de acción integral que otorgó una marcada centralidad a la explotación forestal, derivando de ella algunos 356 
beneficios en materia de educación, salud y bienestar social. Esta estrategia no logró, sin embargo, transferir a los rarámuri un control real sobre el bosque y su explotación comercial, haciéndolos cada vez más dependientes de la dinámica capitalista de las empresas forestales. Quizés por ello, la centralidad que los indigenistas otorgaron a la actividad forestal de los ejidos no trastocó sustancialmente el esquema de diversificación productiva propio del complejo agrícola indigena. La expansión del aparato escolar y de la medicina institucional, en algunos casos, encontró una abierta resistencia de parte de siriame y owirúame; en otros, trastocó los roles de socialización y pedagogía de los mayora y padres de familia y el trabajo de pastoreo de los niños y, en otros más, en fin, permitió a los rarámuri acceder a una fuente altemativa de alimentación para sus hijos así como prepararlos, a través del uso de la lengua nacional, para la difícil convivencia con los mestizos.

En las dos últimas décadas, hemos asistido a un desdibujamiento del discurso, ahora denominado, neoindigenista y a su sustitución por un conjunto de estrategias gubernamentales que, de manera uniforme, han optado por encuadrar el problema indigena dentro de los parámetros generales del combate a la pobreza y la marginalidad. Para ello se han valido de una estrategia participacionista que retoma algunos elementos de las tesis del etnodesarrollo. Las modalidades y proyectos especificos en que el principio de la participación indígena ha sido planteado resultan muchas veces incompatibles con las formas arraigadas de organización social de los rarámuri. Aun asi, éstos han sabido reprocesarlas, adaptarse y valerse de ellas para diversificar sus fuentes económicas de sobrevivencia y consolidar su manera de vivir en sociedad y su sistema de gobierno.

Pero la limitación más importante de esta nueva estrategia neoindigenista es que se mantiene al margen y en oposición, con la orientación de los programas económicos y las estrategias emergentes que el gobiemo y èl capital extranjero están planteando actualmente en la Tarahumara. En efecto, los nuevos programas económicos han asumido una actitud más agresiva frente a la autarquia indígena, al pretender integrar verticalmente la producción forestal de los ejidos a las demandas de los mercados 
nacional y extranjero. Además, la tendencia a la globalización ha tenido también otros tres impactos en la Sierra Tarahumara: el resurgimiento de la inversión extranjera en las minas barranqueñas de metales preciosos, la puesta en oferta del patrimonio natural y cultural, a través de un ambicioso programa turístico y la creciente expansión del narcotráfico y su cultura de violencia. Ninguno de estos escenarios parece el más propicio para que la pobreza y la marginalidad de los pueblos indigenas sean desterradas de la Tarahumara.

Al repasar esta larga historia, dos parecen ser los principales obstáculos que ha enfrentado la cruzada indigenista en la Sierra de Chihuahua: el primero se refiere a sus dificultades para descifrar las formas de organización social de los rarámuri, tejidas alrededor de la dispersión territorial, la atomización en ranchos y rancherías, la autonomía de los individuos, el papel central de la familia y el carácter moral del ejercicio de la autoridad y la justicia. El segundo obstáculo, aún más complejo, nos remite a una perspectiva cultural y civilizatoria profundamente arraigada entre los rarámuri y demás etnias de la Sierra, difícil de entender y definir, pero claramente distinta de las visiones sobre el desarrollo que los agentes indigenistas han tratado de imponer, a veces con la mejor voluntad. Rebasa nuestros propósito plantear aqui los contenidos de esa visión civilizatoria que versan sobre los deberes del hombre frente a Dios y la sociedad para la conservación del orden cósmico y del equilibrio de la naturaleza, pero es claro, a lo largo de la historia que hemos examinado, que esta perspectiva está lejos de ser compatible con los discursos indigenistas.

Lo que hasta aqui hemos venidos planteando nos hace pensar que, al cabo de varias décadas de formulaciones y experiencias, asistimos hoy a un desgaste en los discursos que pretendieron sustentar la acción del estado y, en general, de la sociedad nacional frente los pueblos indios de la Tarahumara. En la búsqueda de un nuevo esquema de relaciones entre éstos y el resto de la nación, resulta obligado evitar y superar los dos extremos sin salida entre los que osciló por largo tiempo el discurso sobre lo indígena: el uno, el del paternalismo indigenista y la imposición de modelos aculturativos legitimados en una supuesta preeminencia de la nación sobre los grupos 358 


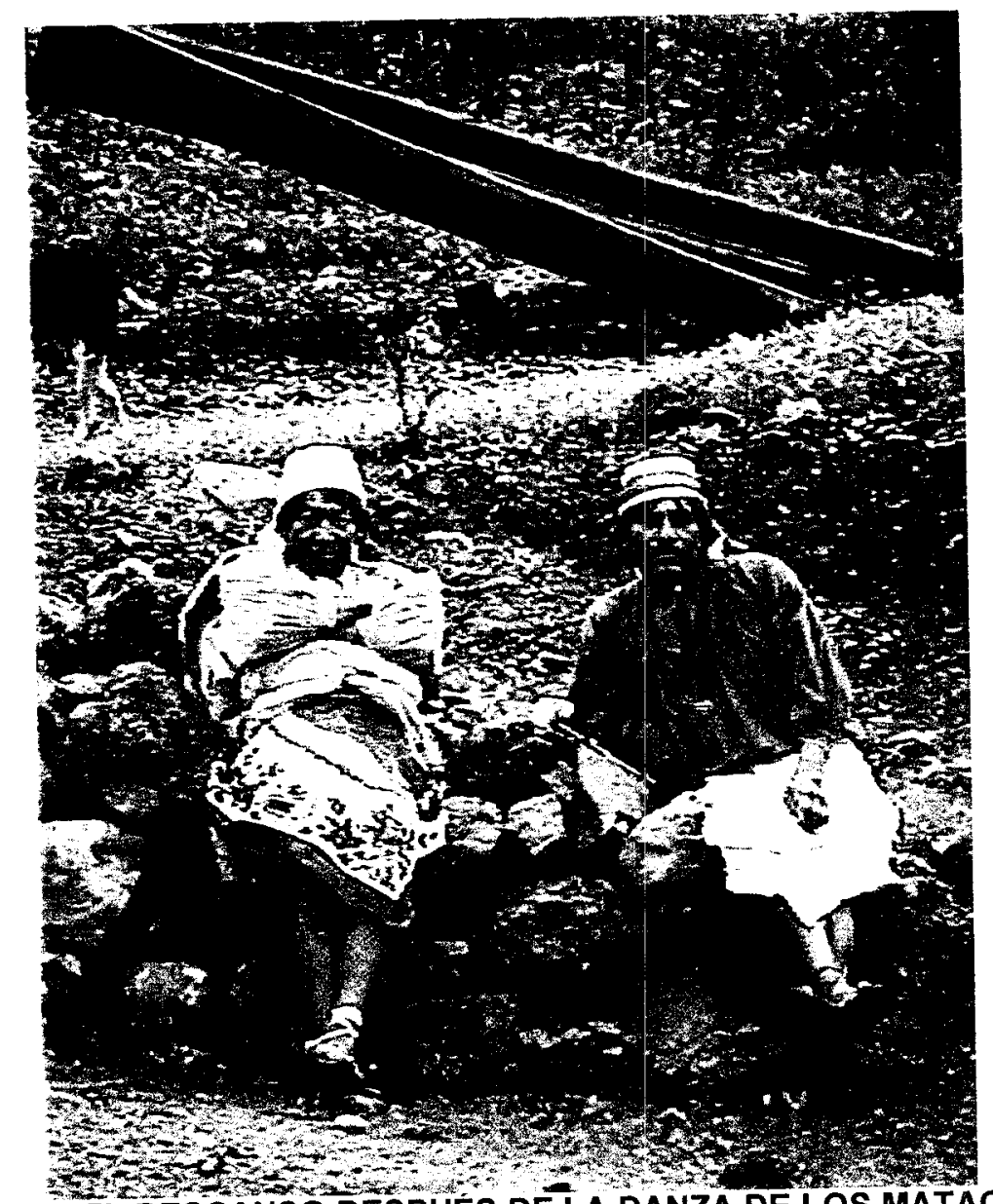

FIGURA 78.- EL DESCANSO DESPUÉS DE LA DANZA DE LOS MATACHINES.

MESA DE LA YERBABUENA (FOTO DEL AUTOR, JULIO, 1999)

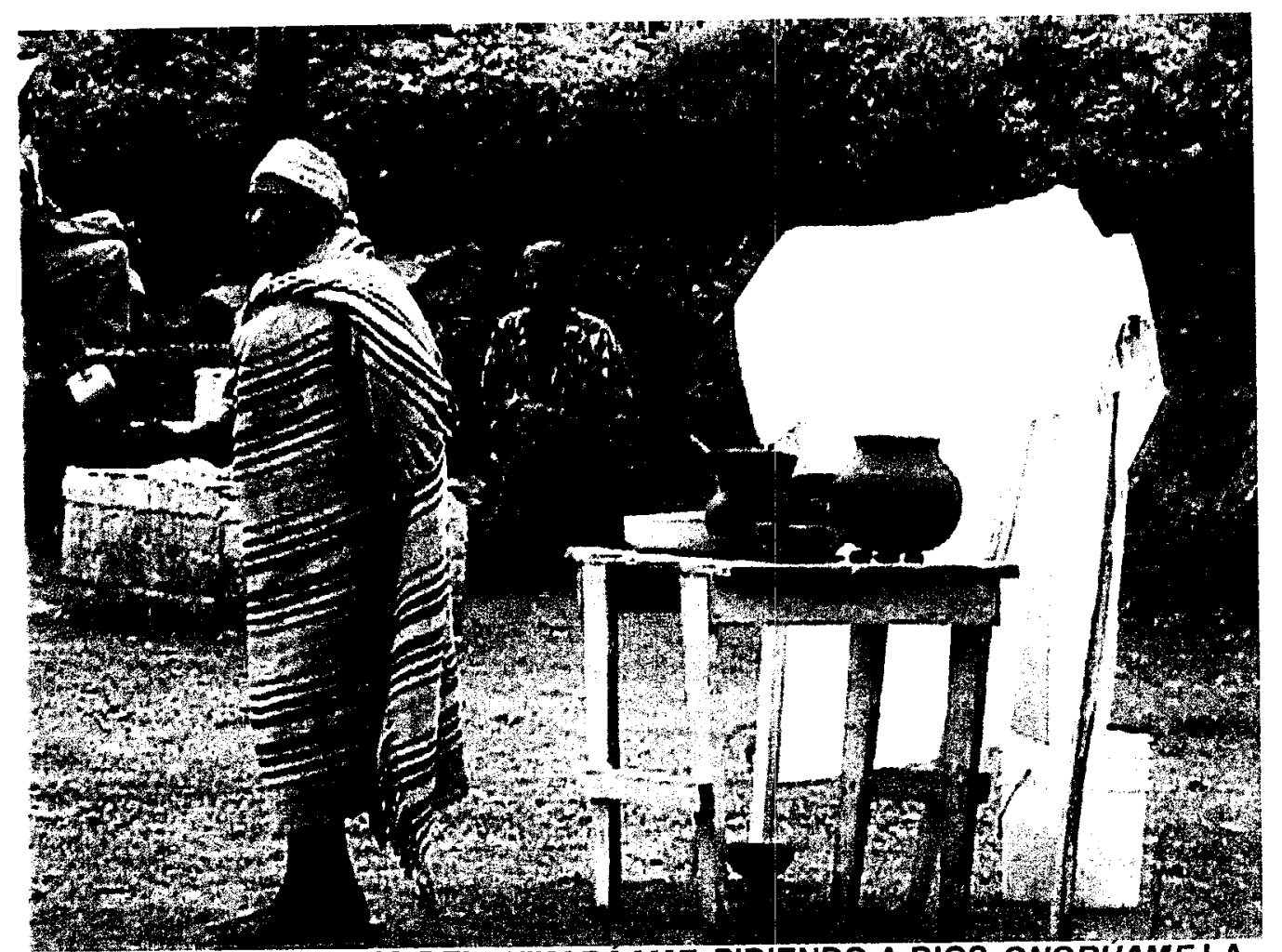


étnicos que la componen; el otro, el de una idilica neutralidad que piensa que es posible resguardar y aislar a los indigenas de los influjos del resto de la nación y aún del mundo.

\section{DEL INDIGENISMO A LA AUTONOMIA}

Al menos durante las últimos cinco décadas, la via del integracionismo nacionalista siempre estuvo presente en el pensamiento indigenista, cuya esencia más profunda quedaria manifiesta en las palabras de Aguirre Beltrán, uno de sus principales teóricos:

El indigenismo no es una politica formulada por indios para la solución de sus propios problemas sino la de los no-indios respecto a los grupos étnicos heterogéneos que reciben la general designación de indígenas [...]

El indigenismo no está destinado a procurar la atención y el mejoramiento del indigena como su finalidad última sino como un medio para la consecución de una meta mucho más valiosa: el logro de la integración y el desarrollo nacionales, bajo normas de justicia social, en que el indio y el no-indio sean realmente ciudadanos libres e iguales (Aguirre, 1992a: 25, 26 y 28).

La historia de la Tarahumara que hemos revisado exhibe sintomáticamente los caminos sin salida de esta perspectiva que conformó el substrato de la acción indigenista y que hoy ya es insostenible, en un contexto en el que la nación ha dejado de ser entendida como un bloque cultural uniforme y empieza a ser reconocida como un proyecto multicultural en continuo proceso de construcción. El reconocimiento de la diversidad y de la pluralidad vuelve obsoleto el discurso de la homogeneidad, la imposición, el paternalismo, la integración y la "mexicanización".

La pérdida de sentido del indigenismo tiene como contraparte la actualidad y pertinencia del concepto de autonomia, tema en torno al cual se plantean hoy las claves del futuro de los pueblos indios en el país. La autonomia significa el derecho reconocido a estos pueblos para construir su futuro a partir de sus propias aspiraciones, su visión del mundo, su concepción del bienestar y su particular forma de organizarse. Pero ¿cómo concebir la autonomia y formularla en el contexto particular de la Sierra Tarahumara?

En Chihuahua el debate actual sobre la autonomia indigena derivó de la reforma y aprobación de una nueva constitución estatal que entró en vigor el 2 de octubre de 1994. 
En su Título II ("De los derechos del gobernado") se incluyó un capitulo II ("De los pueblos indigenas") en el que se establece la obligación de los jueces de considerar los usos, costumbres y prácticas jurídicas indigenas en los casos donde una de las partes juzgadas sea indígena, asi como en la represión de delitos cometidos en las comunidades indígenas entre miembros de un mismo pueblo (Artículo 8). El mismo Capitulo II reconoce en su Artículo 9 la propiedad inalienable e imprescriptible de los pueblos indigenas sobre sus tierras, prohibiendo su enajenación o gravamen, asi como el de las aguas, salvo en los casos en que la ley y la práctica juridica indígena lo permitan. También se establece en el Artículo 10 que la educación indigena será objeto de atención especial, que se propiciará que sea bilingüe e impartida por los propios pueblos indigenas y que los servicios de salud proporcionados por el estado a las comunidades indigenas se planearán, teniendo en cuenta las costumbres de éstas. Además, en materia de educación, se estipula que ésta se orientará considerando la realidad pluriétnica del estado, promoviéndose la educación bilingüe en todos los niveles (Artículo 144). Finalmente, el Articulo 64 dispone que los pueblos indigenas, a través de sus representantes, deberán ser consultados por el Congreso del Estado cuando se discutan y dicten leyes relativas a su desarrollo integral.

El reconocimiento de este conjunto de derechos de los pueblos indigenas ha quedado en cierta forma trunco y empantanado, en la medida en que los diputados chihuahuenses no han llegado a consensar una Ley Reglamentaria que precise y norme el alcance de estos derechos. En 1995 y 1998 el Congreso local, a través de su Comisión de Asuntos Indigenistas, emprendió una serie de consultas públicas en torno a dos iniciativas de "Ley Reglamentaria de los Derechos de los pueblos y Comunidades Indigenas del estado de Chihuahua", sin que, hasta la fecha, ni éstas dos ni otras propuestas hayan sido formalmente aprobadas por el Legislativo estatal. Han contribuido a ello tanto la cambiante y competitiva correlación de fuerzas partidarias en la Cámara local como un dificil entorno nacional derivado de la negativa del Ejecutivo federal a aprobar y firmar los acuerdos sobre autonomía indigena que fueron discutidos con el Ejercito Zapatista de Liberación Nacional en San Andrés Larráinzar. 
Sin lugar a dudas, en todas las propuestas de Ley Reglamentaria que se han venido discutiendo en Chihuahua, el eje central del debate es el tema de la autonomía, expresada ésta en tres ámbitos primordiales: el territorio, el gobiemo y el sistema interno normativo de justicia

En cuanto al primero de estos niveles, el de la autonomia territorial, la controversia estriba en determinar si debe o no reconocerse un territorio propio entendido éste como el lugar donde los pueblos indios han desarrollado, desde tiempos ancestrales, sus actividades económicas, religiosas, jurídicas, políticas y sociales- en el que dichos pueblos tengan el derecho a ejercer su competencia jurisdiccional. Del análisis de la historia del indigenismo en la Tarahumara que hemos presentado, podemos concluir que el territorio indigena tiene un perfil claramente definido y se caracteriza por la existencia de unidades o pueblos integrados alrededor de un cabecera central (sede de la actividad ceremonial, de gobierno y de justicia) y una red o constelación de ranchos y rancherias circundantes. Esta estructura, que responde a una apropiación o "autoctonización" de un modelo de control misionero de la época colonial, se ha mantenido viva hasta nuestros dias a pesar de que nunca ha sido reconocida por el estado nacional y de que sobre ella se han impuesto otros esquemas de ordenación territorial como el ejido y el municipio.

En mi opinión el reconocimiento de la autonomia indígena debería iniciar por asumir que esta estructura tan particular y distintiva de "pueblos" es la forma que, desde hace varios siglos, las etnias de la Tarahumara se han dado a si mismas para organizarse internamente y para establecer formas de interlocución con el estado y la sociedad nacionales. El reconocimiento jurídico de este hecho no podria, por menos, de llevamos a una reforma profunda de aquellos principios constitucionales derivados de la herencia juridica española que han consagrado el ayuntamiento como núcleo básico del gobierno y de la administración pública. En la Sierra Tarahumara y en abierto contraste con lo que sucede en otras regiones indigenas del pais, la'institución municipal es ajena por completo a la tradición indígena sobre el territorio y sobre el gobierno e incluso constituye 
la expresión institucionalizada más clara de la dominación de los mestizos sobre la población indigena. $^{3}$

Si el municipio es ajeno a la idiosincrasia indigena de la Tarahumara, el ejido no lo es menos. Superpuesto sobre la estructura de ranchos, rancherias y pueblos, el ejido goza sin embargo de una virtud no desdeñable: hasta hoy es la única forma juridica reconocida -aunque no lo suficiente- de la que los indigenas pueden valerse para defender su propiedad sobre sus tierras y territorios. De no haber existido, es muy probable que la voracidad de las empresas forestales y mineras, la codicia de algunos núcleos mestizos y la ambición de los consorcios turísticos hubieran acabado ya con esos territorios. Por ello, el ejido sólo debería ser suplantado en la medida en que se asegure un reordenamiento territorial que reconozca el modelo nuclear de pueblos y rancherias garantizando el control de los pobladores indigenas sobre lo que fue, desde tiempos históricos, su territorio. Este, por cierto, aunque sólo parcialmente esté compuesto por tierras propicias para la agricultura y la ganaderia, no por ello deja de ser un patrimonio de los pueblos indios de la Tarahumara. A la luz de la historia que hemos revisado, ninguna alternativa que pretenda resolver los problemas de desigualdad de los indigenas de esta región podrá tener futuro, a nuestro juicio, si no incluye una revisión sistemática de la actual estructura de la propiedad de la tierra, derivada de errores y vicios en la aplicación de los principios de la reforma agraria pero también en su capacidad para adaptarse a las prácticas indígenas sobre el uso territorio. Eso, sin considerar la inequidad propia del sistema de relaciones interétnicas.

El segundo ámbito de la autonomía, el que se refiere al reconocimiento del gobierno indígena, está intimamente ligado al anterior porque este gobierno se ejerce dentro de jurisdicciones territoriales precisas a partir de la autoridad de los gobemadores

\footnotetext{
${ }^{3}$ El caso más distinto es probablemente el de muchos ayuntamientos de Oaxaca donde la población indigena, que constituye una mayoria, se fue históricamente apropiando de esta institución de origen español.
} 
y de un cuerpo de funcionarios y cargos subalternos escogidos todos ellos según los criterios de la costumbre, el prestigio y la altemancia. ${ }^{4}$

Este sistema de gobiemo indigena presenta algunas particularidades y diferencias en cada uno de los cuatro grupos étnicos, tanto en términos de la estructura de cargos y funciones cuanto en el grado de centralidad del poder. En la mayoria de los casos puede decirse, sin embargo, que no existe una forma de gobierno que trascienda el nivel del pueblo y sus rancherias, lo que equivale a decir que los gobernadores tienen todos la misma jerarquia y los pueblos el mismo rango y que no existe nada equivalente a un gobierno "de tribu" o a un estado centralizado o confederado. La corporativización y pérdida de representatividad del Consejo Supremo Tarahumara y de otros organismos creados coyunturalmente en las dos últimas décadas no hacen sino reforzar este planteamiento.

En sus diferentes variantes propias de cada etnia y aún de cada zona de la Tarahumara, el sistema de gobierno indígena ha mostrado su eficacia y pertinencia para asegurar formas de convivencia porque ¿cómo si no explicar que haya perdurado por cerca de cuatro siglos a pesar de su desconocimiento, rechazo y exclusión en las constituciones y códigos legales de la nación y del estado de Chihuahua?

En mi opinión una de las condiciones indispensables para que la autonomia indigena en la Tarahumara sea efectiva es que este sistema de gobierno sea legalmente reconocido, lo que tendría varias implicaciones. En primer lugar, sería preciso reconocer jurídicamente todos aquellos ámbitos de competencia y jurisdicción que tradicionalmente han sido propios de estas autoridades como lo son los problemas relacionados con la aplicación de la justicia en casos que no impliquen el homicidio y la propiedad y uso de la tierra. Además se requeriria recortar o, en su caso, eliminar las funciones que, en abierta

\footnotetext{
${ }^{4}$ Es importante recordar lo que ya hemos señalado a lo largo de este trabajo: en muchos de estos pueblos $y$, especiaimente, en sus cabeceras, los indigenas serranos conviven y comparten su territorio con los mestizos. En esto estriba quizás la diferencia más significativa con respecto a la situación de las regiones étnicas de Oaxaca y Chiapas.
} 
competencia con el sistema de gobierno indigena, detentan aquellas autoridades del sistema politico nacional (comisarios de policia, comisariados ejidales, jueces de primera instancia, etc.) si dichas funciones entran en competencia con las del gobierno indigena. Finalmente habría que insistir en que reconocer el gobierno indígena significa aceptar la existencia no sólo de un sistema tradicional de cargos sino sobre todo de toda una cultura politica permeada por concepciones sobre el poder de raices distintas a las que sustentan el sistema político hegemónico.

Los principios con que se rige y ejerce el gobierno indígena son de un orden cultural muy diferente a los de la democracia formal, división de poderes, sufragio electoral, voto directo, plebiscito, partidos políticos, representación indirecta y otros más que presiden la cultura política nacional. En el medio indigena no hay una separación formal entre el ámbito de lo civil, lo politico y lo religioso; la tradición está por encima del contrato social; los derechos individuales sólo se conciben en el marco de una colectividad, la autoridad es elegida a partir del reconocimiento del prestigio social derivado del servicio al pueblo, en la toma de decisiones nunca opera el principio de la mayoria sino el del consenso, lo que en ocasiones implica largos procesos de consulta "hasta que todos están de acuerdo", las autoridades mantienen una lealtad primaria al pueblo que los nombró y éste puede revocarles su mandato sin que existan tiempos estipulados en el ejercicio de los cargos y las decisiones del pueblo, una vez consensadas adquieren el carácter de obligatoriedad moral y de norma social y su transgresión se convierte en objeto de sanciones grupales.

Aceptar la vigencia de una cultura política distintiva de los pueblos indígenas traería como ineludible consecuencia replantear de manera radical la legislación electoral por lo que a la población indígena se refiere. En concreto, se propone abolir aquellas normas jurídicas que obliguen a los indígenas a elegir sus autoridades por algún método que no sea el acorde con su sistema de gobierno y cultura politica, en forma similar a lo que ya se ha convertido en ley en el estado de Oaxaca. 
Asi pues, reconocer el sistema de gobiemo indigena y otorgarle estatuto legal en el ámbito de las leyes locales y nacionales significaria abdicar de una vez por todas de la vieja pretensión indigenista que anheló diluir la cultura política indígena en los márgenes de la institución municipal o del poder legislativo. Por ejemplificarto con claridad, no se trataría de convertir a los siriame rarámuri en los nuevos alcaldes o diputados locales o federales "reconvirtiéndolos" al sistema político moderno nacional, sino más bien, se pretendería aceptar y reconocer juridicamente que pueden coexistir una cultura y una forma de gobierno sustentada en principios distintos -aunque no necesariamente opuestos- a los del modelo político hegemónico nacional.

El tercer espacio de definición de la autonomia es el que se relaciona con el sistema interno normativo y de justicia. Considerando que las concepciones y prácticas jurídicas de los pueblos indígenas de Chihuahua son históricamente anteriores y difieren culturalmente de los principios del derecho positivo que subyacen a las leyes y a la aplicación de la justicia en el ámbito estatal y federal, se debate hoy en torno a la conveniencia de establecer mecanismos de reconocimiento y respeto de la práctica jurídica indígena.

En mi opinión, debe ser jurídicamente reconocida y aceptada la validez del sistema normativo interno que practican los pueblos indígenas serranos para la prevención y solución de los conflictos entre individuos y grupos por la sencilla razón de que este sistema jurídico ha mostrado su utilidad desde hace varios siglos para regular la convivencia interna. También debe mantenerse operativo el principio, hecho costumbre, de reconocer que existen ciertos delitos que son de jurisdicción de la justicia indígena y otros, de orden más grave, que los propios grupos étnicos reconocen ser de competencia exclusiva del sistema judicial hegemónico.

En los tres ámbitos de la autonomía que hemos referido -la del territorio, gobierno y sistema de justicia- creo que el criterio que habrá de guiar la nueva legislación en materia de derechos indígenas en el estado de Chihuahua habrá de ser la de reconocer y plasmar en lenguaje jurídico lo que, en muchos aspectos -aunque no en todos-, ha sido la práctica 
durante mucho tiempo entre los grupos étnicos de la Tarahumara, porque en realidad y como ya lo hemos señalado y al menos en cierta forma, el territorio, el gobierno, el sistema normativo indigenas son instituciones que, desde la resistencia y la apropiación culturales, nunca han dejado de operar. Se trata pues de dar estatuto de legitimidad a estos "usos y costumbres" que siempre y a pesar no haber sido reconocidos han tenido vigencia y utilidad sociales.

La trayectoria del indigenismo nos ha permitido descubrir que la imposición de concepciones y prácticas ajenas a la idiosincrasia de los pueblos indígenas no son los mejores argumentos para superar las causas de su pobreza. Por ello resulta imperativo incluir entre los principios de la autonomía el derecho de los pueblos indios de la Tarahumara a definir su propio proyecto de futuro. Es tiempo ya de reconocer que la mayoría de los esquemas en que se han sustentado las propuestas de desarrollo introducidas en la Sierra Tarahumara por agentes mestizos, organismos públicos e instituciones indigenistas han partido del principio de la inviabilidad de los modelos indigenas de utilización y aprovechamiento sustentables del ecosistema serrano.

El derrumbe persistente en los últimos años de todas estas propuestas $y$, sobre todo, las crisis ciclicas en la producción de granos básicos, acompañadas de hambrunas y desnutrición hacen pensar en la necesidad de replantear seriamente los modelos indigenistas de desarrollo de las etnias serranas asi como de reconsiderar la viabilidad de las tradiciones silvicolas, las culturas agricolas y los saberes productivos de los pueblos indios, con vistas a resolver uno de sus problemas más graves, el de su autosuficiencia alimentaria. Sin duda, también, estas tradiciones, culturas y saberes necesitan confrontarse y enriquecerse de los avances cientificos de la cultura occidental.

En tal sentido creo que el concepto de desarrollo, que históricamente tan poco y mal se ha adaptado a la lógica indígena, deberá ser sustituido por el de bienestar. Toca a los pueblos indios, y sólo a ellos, decidir cómo conciben y planean ese bienestar a partir de su cosmovisión, su conocimiento y sentido de equilibrio e identificación con la naturaleza asi como sus propios criterios éticos. También corresponde a ellos determinar 
las estrategias y modalidades más acordes con su cultura para lograr los objetivos de bienestar que se proponen.

De cuanto hemos venido señalando, se concluye claramente que el concepto de la autonomia y su ejercicio político sólo pueden ser entendibles a nivel regional. Las visiones sobre el territorio, el ejercicio del poder y las prácticas juridicas son distintas entre los diferentes grupos étnicos del país e incluso de la Sierra Tarahumara. Por eso también la definición jurídica de esos derechos debe surgir de una debate que tenga más actores particularmente indigenas- locales y no tantos nacionales, como hasta ahora ha sucedido. Es un debate desde y para las regiones étnicas del país y el afán de volverlo homogéneo puede acabar por ahogarlo.

En el caso particular de la Tarahumara hay pruebas evidentes de que muchos de los espacios autonómicos están ya funcionando desde hace tiempo, lo que nos habla de resistencia, de apropiación y de una cierta autonomía de facto.

\section{DEL INDIANISMO A LA INTERCULTURALIDAD}

La autonomia aparece pues como el primer principio básico para redefinir la relación de los pueblos indios de la Tarahumara con el estado y la sociedad nacional. Sin embargo y para que pueda ser viable en todos sus órdenes, la autonomía necesita complementarse con el principio de la interculturalidad que busca asegurar la equidad, el respeto y la convivencia entre culturas distintas que, por razones históricas, comparten no sólo un espacio geográfico sino también un cierto destino dentro de una nación.

El contexto de la interculturalidad es por lo demás obvio: resulta impensable creer que los grupos étnicos de la Tarahumara, a pesar de su relativo aislamiento geográfico, puedan vivir ajenos a la dinámica económica y política del resto del país y aún del mundo. Concebir para ellos un futuro ajeno al de ese entorno resultaría una falsa quimera. La idea consagrada por la mirada "primitivista" sobre la Tarahumara es una falacia porque la interacción entre quienes observan ese mundo supuestamente "arcaico" y quienes lo hacen realidad no ha cesado: ayer fueron los viajeros, etnógrafos, poetas y naturalistas, 
hoy son los turistas curiosos, los defensores de la naturaleza y, de nuevo, los etnográfos. En cualquier caso la relación mutua -vestida de daños, impactos o beneficios- no ha cesado.

Hablar sólo de autonomia nos lleva quizás a pensar en islas de cultura independientes e inconexas, algo que en realidad es inviable: nadie esta aislado de nadie y el análisis de la práctica institucional indigenista nos ha mostrado hasta qué punto es impensable una economia indigena aislada de la nacional, una lógica de la justicia ajena a la de los tribunales de justicia e instituciones penitenciarias, un sistema de gobierno indigena que no tenga que interactuar con el estado, etc. El contexto de la actual globalización, del que hoy son una buena muestra el Plan turistico Barrancas del Cobre y la penetración del narcotráfico, revela claramente que la Sierra Tarahumara, nos guste o no, es un territorio de la globalidad y quizás lo ha sido desde hace ya mucho tiempo.

La relación de interculturalidad se da en primer lugar en los propios territorios indigenas donde los grupos étnicos de la Tarahumara conviven, como lo hemos documentado en este trabajo no ajenos al conflicto interétnico, con una población mestiza cada vez más numerosa. A un nivel más amplio la interculturalidad se expresa en las relaciones de los pueblos indios con la sociedad nacional y con el estado a través de las instituciones gubernamentales. El problema que se plantea entonces es cómo orientar esa obligada relación intercultural de forma tal que se aseguren el respeto y la equidad; cómo hacer compatibles las concepciones y los sistemas -indígena y occidental- de territorio, gobierno, justicia y bienestar que, por proceder de matrices culturales distintas, son por naturaleza, diferentes.

La primera estrategia para responder a este reto estriba en concebir que las relaciones interculturales, entendidas éstas en un sentido global no tienen necesariamente por qué pensarse en tériminos de competencia sino de complementariedad. Así las prácticas de la justicia entre los pueblos autóctonos de la Tarahumara pueden convivir al lado del sistema nacional de justicia mejorando las formas de relación y complementariedad que hasta ahora han mantenido sin pretender, como 
algunos legisladores y juristas to han propuesto, que la justicia indigena se sujete a un principio de convalidación por parte de los jueces y tribunales nacionales, lo que representaria un verdadero retroceso.

En mi opinión, la aceptación de las formas de gobierno indígena contribuiria no sólo a reconocer un legitimo derecho de los grupos étnicos sino también a mejorar el alcance y la calidad de los servicios de la administración pública asumiendo que no hay mejor forma de gobierno que aquella que acerca cultural y politicamente a la autoridad con sus gobernados. En este sentido habría que plantear mecanismos de articulación, entendimiento y colaboración entre los gobiernos municipal e indigena de forma tal que las autoridades estatales y municipales mantengan con el gobiemo indigena una relación de respeto, cooperación y diálogo interculturales que aseguren un mayor bienestar de la población indigena.

Mientras el principio de la autonomia conlleva el reconocimiento de la diversidad, el de la interculturalidad expresa la necesidad de la comunicación e interlocución entre sociedades con matrices culturales distintas pero que no son ni se perciben ajenas entre sí. La interculturalidad se expresa no sólo en los órdenes de gobierno, justicia y territorio sino también en todos los aspectos ligados al bienestar social de los pueblos indios tales como la educación, la salud, el uso de los recursos naturales, etc. En todos y cada uno de estos ámbitos, la interculturalidad se traduce en la necesidad de encontrar mecanismos de comunicación y complementariedad entre sociedades que conciben la justicia, la democracia, el desarrollo y el bienestar de modos distintos, sin repetir ya los viejos modelos de la imposición y la integración culturales.

Si se pretende hoy acabar con estos viejos modelos aculturativos que ahogaron la autonomia de los pueblos indigenas de la Sierra Tarahumara para imponerles, desde fuera, patrones de desarrollo ajenos a su idiosincrasia, es probable entonces que haya llegado al final la vigencia del indigenismo. Este representó la institucionalización de formas de mediación entre el estado y la sociedad nacionales, por un lado, y los grupos étnicos, por otro. El reclamo justificado de la autonomia de los pueblos indios de 369 
Chihuahua y de su relación intercultural directa con el estado y el resto de la sociedad ponen pues en entredicho la pertinencia del indigenismo y sus instituciones. A cambio de ellas se requieren hoy nuevas formas institucionales que aseguren la interlocución directa y la transferencia efectiva del poder y de las decisiones públicas relativas al futuro de la Tarahumara a sus principales protagonistas, los rarámuri, odami, o'oba y warijó.

Un nuevo paradigma de relaciones interétnicas basadas en la autonomia y la interculturalidad exigirá marcos juridicos y propuestas institucionales inéditas hasta ahora. No sólo eso. También será preciso, después de tanto tiempo de paternalismo y silenciamiento, reconstruir el perfil auténtico y oír, en su propio idioma, la voz genuina de los verdaderos interlocutores indigenas, tantas veces suplantados por falsos voceros $e$ intérpretes.

El grito desesperado de Josecito Aguirre, el viejo gobernador rarámuri de la Mesa de Guachochi, en abril de 1939, durante el acto constitutivo del Consejo Supremo Tarahumara, reclamando al gobierno y a los mestizos "Dejadnos solos; no requerimos vuestra ayuda. Dejadnos vivir nuestra vida" (Aguirre, 1994: 36 y Gómez, 1948: XIX-XX|) cobra hoy, más que entonces, una inusitada actualidad. El reclamo airado de éste y otros muchos indigenas de la Sierra de Chihuahua no ha dejado de ser cierto, está aún por atenderse y aguarda a la espera de tiempos mejores. ¿Serán éstos los del presente? 


\section{BIBLIOGRAFIA Y FUENTES}

\section{ARCHIVOS}

ACCIT: Archivo del Centro Coordinador Indigenista de la Tarahumara. Instituto Nacional Indigenista. Guachochi, Chih.

ABOITES, Luis

\section{BIBLIOGRAFIA}

1987 La irrigación revolucionaria. Historia del sistema nacional de riego del río Conchos, Chihuahua. 1927-1938. SEP/CIESAS, México.

AGHEMO, Piero et al.

1968 "Massima potenza muscolare in un gruppo di Indiani del Mexico". En: Bolletino della Societa Italiana de Biologia Sperimentale, 45, p. 458-459.

AGHEMO, Piero, L. F. PIÑERA, G.SASSI.

1971 "Maximal aerobic power in primitive Indians". En: Internationale Zeitschrift für Angewandte Physiologie Einschliesslich Arbeitsphysiologie, n. 29, p. 337-342.

AGUIRRE BELTRÁN, Gonzalo

1956 "Teoria de los Centros Coordinadores". En: Ciencias Sociales, v. VII, n.37, Unión Panamericana, Washington, p. 1-26.

1957 El proceso de aculturación. UNAM, México.

1967 Regiones de refugio. El desarrollo de la comunidad y et proceso dominical en Mestizoamérica. Instituto Indigenista Interamericano, Ediciones especiales, 46, México.

1983 Lenguas vernáculas. Su uso y desuso: la experiencia de México. CISINAH, Ediciones de la Casa Chata, México.

1988 "Formación de una teoria y una práctica indigenistas". En: Instituto Nacional Indigenista, Instituto Nacional Indigenista. 40 años. INI, México, p.11-40.

1989 Obra antropológica, XV. Crítica antropológica. Contribuciones al estudio del pensamiento social en México. Universidad Veracruzana/INI/Gobierno del Estado de Veracruz/Fondo de Cultura Económica, México.

1991 Formas de gobiemo indigena. Universidad Veracruzana/INI/Gobiemo del Estado de Veracruz/Fondo de Cultura Económica, México. (1ª edición en 1953).

1992a Obra potémica. Universidad Veracruzana/INI/Gobiemo del Estado de Veracruz/Fondo de Cultura Económica, México.

1992b Teoria y práctica de la educación indigena. Universidad Veracruzana/NI/Gobierno del Estado de Veracruz /Fondo de Cultura Económica, México.

1994 El pensar y el quehacer antropołógico en Méxíco. Universidad Autónoma de Puebla, Puebla.

AGUIRRE BELTRÁN, Gonzalo y Ricardo POZAS ARCINIEGA

1981 La política Indigenista en México. Tomo II. Métodos y resultados. INI, México. (1 $1^{\mathrm{a}}$ edición, 1954). 
ALCOCER PATIÑO, Fernando

1987 Un siglo en el bosque. Unión de Productores e Industriales Forestales de Chihuahua, Chihuahua.

ALMADA, Francisco

1945 Geografia del estado de Chihuahua. s.e., Chihuahua.

1968 Diccionario de historia, geografia y biografia chihuahuenses. Universidad Autónoma de Chihuahua, Chihuahua.

1971 El Ferrocarril de Chihuahua Pacifico. Libro-Mex, México.

ALMEIDA, Jesús Antonio

1926 Memoria del Gobemador Coronel Jesús Antonio Almeida al H. Congreso del Estado, de Octubre de 1924 a Octubre de 1926. Secretaría de Gobierno, Talleres Gráficos del Gobierno del Estado, Chihuahua.

ALVARADO, Carlos Mario

1998 La Tarahumara: una tierra herida. Análisis de la violencia en zonas productoras de estupefacientes en Chihuahua. Talleres Gráficos del Gobiemo del Estado, Chihuahua, 1996.

ANONIMO

1954 "La acción del Centro Coordinador Indigenista de la región tarahumara, hasta fines de 1953". En: Boletín Indigenista, v. XIV, n. 1, marzo, p. 50-54

1955a "En la región tarahumara". En: Acción Indigenista, n. 22, abril, p.1.

1955b "El Instituto Nacional Indigenista en la región tarahumara". En: Boletín Indigenista, v. XV, n. 4, diciembre, p. 352-358.

1956 "El bosque tarahumara". En: Acción Indigenista, n. 34, abril, p.1.

1959 "Reparto en la Tarahumara". En: Acción Indigenista, n. 78, diciembre, p. 2-3.

1971 "Ejido tarahumara de Cusárare". En: Acción Indigenista, n. 215, mayo, p. 3.

1972 "Creación de la empresa Productos Forestales de la Tarahumara". En: Acción Indigenista, n 217. mayo, p. 3.

1973 "Amplio desarrollo en la sierra Tarahumara". En: Acción Indigenista, n. 237, marzo, p. 6.

1977 "Ponencia especial que presenta el Octavo Congreso de Pueblos Tarahumaras". En: México Indigena", n. 2, mayo, p. 4-5.

1995 Relatos Tarahumaras. Ki'á ra'ichaala rarámuli. CNCA, Dirección General de Culturas Populares, Colección Lenguas de México, , n. 9, México.

ARPEE, Levon Harris

1935 "Los indios tarahumaras de Chihuahua, México". En: Anales de 1935. Museo Nacional de Arqueologia, Historia y Etnografia. Talleres Gráficos, Tomo II, Quinta época, México, p. 461477.

ARTAUD, Antonin

1984 México y Viaje al país de los Tarahumaras. Fondo de Cultura Económica, México. 
BAEZ-JORGE, Félix

1975 "Antropologia y colonialismo". En: La palabra y el hombre, nueva época, n. 15, junio septiembre, p. 85-87.

1978 "Aculturación e integración intercultural: un momento histórico del indigenismo mexicano". En: Instituto Nacional Indigenista, INI $\mathbf{3 0}$ años después. Revisión crítica, México Indígena, número especial de aniversario, INI, México, p. 291-299.

1990 "Claves de un diálogo entre la antropologia y la politica (Estudio introductorio)". En: G. Aguirre Beltrán, Obra antropológica, XV. Crítica antropológica. Contribuciones al estudio del pensamiento social en México. Universidad Veracruzana/INI/Gobiemo del Estado de Veracruz/Fondo de Cultura económica, México, p. 7-42.

BALKE, Bruno y C. SNOW

1975 "Anthropological and physiological observations on Tarahumara Endurance Runners", En: American Joumal of Physical Anthropology, v. 23 , n. 3, p. 293-301.

BANDELIER, A.F.

1923-27 Historical documents relating to New Mexico, Nueva Viscaya and approaches there to, 3 tomos, Washington.

BARTA, Roger

1974 "El pensamiento indigena y la ideologia indigenista". En: Revista Mexicana de Sociologia, año $X X X V I$, v. XXXVI, n. 3, julio-septiembre, p. 459-482.

BASAURI, Carlos

1926 "The Resistence of the Tarahumaras". En: Mexican Folkways, v. 5, n. 2.

1929 Monografia de los Tarahumaras. Talleres Gráficos de la Nación, México.

1990 "Familia pimana. Tarahumaras" . En: C.Basauri, La población indigena de México. INI/CNCA, México, Tomo II, p. 255-305.

BEALS, Ralph

1946 Cherán, A Sierra Tarascan Village. Cooper Square Publishers, Nueva York, $\left(1^{\mathrm{a}}\right.$ edición, 1946)

BENITEZ, Femando

1967 VViaje a la Tarahumara". En: F. Benitez, Los indios de México. Era, México, Tomo I, p. 75-138.

BENNETT, Wendel C. y Robert M. ZINGG

1978 Los Tarahumaras, una tribu india del Norte de México. Instituto Nacional Indigenista, México.

BERNSTEIN, Marvin D

1964 The Mexican Mining Industry. 1890-1950. A Study of the Interaction of Politics, Economics and Technology. State University of New York, Nueva York.

BONFIL, Guiliermo

1970 "Del indigenismo de la Revolución a la antropologia critica". En: Varios, De eso que llaman antropologia mexicana. Nuestro Tiempo, Mexico, p. 39-65.

1981 Utopia y revolución. El pensamiento político contemporáneo de los indios en América Latina. Nueva Imagen, México. 
1987a México profundo. Una civilización negada. SEP/CIESAS, México.

1987b "La teoria del control cultural en el estudio de procesos étnicos". En: Papeles de la Casa Chata, año 2, n. 3, p. 23-43.

1982 "El etnodesarrollo: sus premisas juridicas, politicas y de organización". En: F. Rojas Aravena, comp., América Latina: etnodesarrollo y etnocidio. FLACSO, Jan José, Costa Rica., p. 131145.

1991 a "Las culturas indias como proyecto civilizatorio". En: A. Warman y A. Argueta, coords., Nuevos enfoques para el estudio de las etnias indigenas en México. Centro de Investigaciones Interdisciplinarias, UNAM/Porrúa, México, p. 121-142.

$1991 \mathrm{~b}$ "Sobre la ideologia del mestizaje lo cómo Garcilaso Inca anunció sin saberlo muchas de nuestras desgracias)". En: Pliegos, n.3, Madrid. Reproducido en Ojarasca, 1995.

BRADING, David A.

1989 "Manuel Gamio y el indigenismo oficial en México". En: Revista Mexicana de Sociołogia, año LI, n. 2, abril-junio, p. 267-284.

BREACH, Miroslava

1996 "Aprueban fideicomiso turistico. Diputados del PRI, PAN y CDP dan luz verde al proyecto". En:

Diario de Chihuahua, 11 de diciembre, p.1.

BROUZĖS, Françoise

1991 "Migración rarámuri a Sinaloa". En: D. Gutiérrez y J. Gutiérrez, coords., El Nonoeste de México. Sus culturas étnicas. Instituto Nacional de Antropologia e Historia, México, p. 411-422.

1998 "Las politicas indigenistas y el trabajo en el medio rarámuri". En: J.L. Sariego, coord., Trabajo, territorio y sociedad en Chihuahua durante el siglo XX. Gobierno del Estado de Chihuahual Escuela Nacional de Antropologia e Historia, Unidad Chihuahua/Universidad Autónoma de Ciudad Juárez, Chihuahua, p. 459-513.

BROWN, R.B.

1996 "El papel de Adolph Francis Bandelier en la arqueologia y la antropologia de Chihuahua". En: E. Gamboa, coord., El México desconocido cien años después. Instituto Nacional de Antropologia e Historia, México, p. 29-36.

BYE, Robert

1994 "La tradición sirve" (entrevista). En: Ojarasca, n. 38-39, noviembre-diciembre, p. 50-52.

CABEZA DE VACA, Francisco

1943 Apuntes sobre la vida de los tarahumaras. Vargas Rea, México.

CAJAS CASTRO, Juan

1992 La sierra tarahumara o los desvełos de la modernidad en México. CNCA, México.

CAMPBELL, Howard and Alexandro SILVA

1996 "Robert Zingg: El Paso Anthropologist". En: Password, v.41, n. 3, Fall, p. 117-123.

1998 "Rereading Robert Zingg: Anthropology. Literacy Criticism, and Political Correctness". En: Sociological Imagination, $v .35, n .2 / 3, p .137-158$. 
CASO, Alfonso

1955 ¿Qué es el INI?. INI, México.

1958 Indigenismo. INI, Colección Culturas Indigenas, n. 1, México.

CASTELLANOS, Alicia y Gilberto LÓPEZ Y RIVAS

1992 "El reconocimiento constitucional de los Pueblos Indios de México". En: Grupo Parlamentario del Partido de la Revolución Democrática, Los derechos constitucionales de los Pueblos Indigenas. H. Cámara de Diputados, LV Legislatura, Talleres Gráficos de la Cámara de Diputados, México. p. 13-28.

CAZĖS, Daniel

1966 "Indigenismo en México: pasado y presente". En: Historia y Sociedad, n. 5, p. 66-84.

CERQUEIRO $M$.

1975 The food and nutrient intake of the Tarahumara Indians of Mexico. Tesis de doctorado, University of lowa, lowa.

CHARBONNIER, Georges

1952 Essai sur Antonin Artaud. Editions Pierre Seghers, Poètes d'Aujord hui, n. 66, Paris.

COMAS, Juan

1976 La Antropologia social aplicada en México. Instituto Indigenista Interamericano, México.

COMISION DE ASUNTOS INDIGENAS

1991 Memoria del Foro-Taller Presente y Futuro de la Tarahumara, Creel, Chihuahua, 11-13 de septiembre de 1992. LV Legislatura, Cámara de Diputados del Estado de Chihuahua, Chihuahua.

COMISIÓN DE SOLIDARIDAD Y DEFENSA DE LOS DERECHOS HUMANOS A.C. (COSYDDHAC)

1998 Situación de los derechos humanos, Chihuahua. 1996 y 1997. COSYDDHAC, Chihuahua.

CONGRESO DEL ESTADO DE CHIHUAHUA

1933 Decretos número 74 y 82 por el que se crea la Sección de Protección Indigena y se expide su Ley Reglamentaria. Diario Oficial del Estado, Chihuahua, 13 y 19 de julio.

CONNOR, William E. et al.

1978 "The plasma lipids, lipoproteins and diet of the Tarahumara Indians of Mexico. En: American Joumal of Clinical Nutrition, n. 31, p. 113-142.

CONSEJO NACIONAL DE POBLACION

1990 Indicadores socioeconómicos e indice de marginación municipal. CONAPO, México.

CONSEJO SUPREMO TARAHUMARA

1974 Consejo Supremo Tarahumara. s.e, Guachochi, Chihuahua.

COORDINACION ESTATAL DE LA TARAHUMARA

1997 La Tarahumara, proyecto a largo plazo. Gobiemo del Estado de Chihuahua, Chihuahua.

CRAMAUSSEL, Chantal

1990 La Provincia de Santa Bárbara en Nueva Vizcaya. 1563-1631. Universidad Autónoma de Ciudad Juárez, Ciudad Juárez, Chih. 
CREEL, Ennique C.

1906 Exposición de motivos que presentó el Ejecutivo del Estado sobre la civilización y mejoramiento de la Raza Tarahumara y Ley expedida acerca del asunto por la Legislatura. Imprenta del Gobiemo del Estado, Chihuahua.

1929 Agricultura y agrarismo. Estudio leido en la Sociedad Científica Antonio Alzate. Tipografia El Progreso, México.

DAY, M. James (ed.)

1979 Morris B.Parker's. Mules, Mines and me in Mexico. 1985-1932. The University of Arizona Press, Tucson.

DEDERA, Don

1974 "The Longest Joumey, One Step at a Time". En: Outdoor Arizona, 46 , 5 mayo, p. 3.

DEIMEL, CLAUS

1980 Les Indiens Tarahumaras au présent et au passé. Editions Fédérop, Paris.

DEPARTAMENTO DEL TRABAJO

1936 La Raza Tarahumara. Departamento del Trabajo, México.

DIARIO OFICIAL DE LA FEDERACION

1952 "Decreto por el que se crea el Centro Coordinador Indigenista de la Región Tarahumara". En Diario Oficial de la Federación, CXCIII, 41.

DIAZ POLANCO, Héctor

1978 "Indigenismo, populismo y marxismo". En: Nueva Antropotogia, año III, n. 9, octubre, p. 7-31.

1981a "La teoria indigenista y la integración". En Varios, Indigenismo, modernización y marginalidad. Una revisión crítica. Centro de Investigación para la Integración socialJuan Pablos Editor, México, p. 9-45.

1981b "El discreto encanto del indigenismo". En: Boletín de antropología americana, n. 4, diciembre, p. 100-113.

1991 "Cuestión étnico nacional y autonomia". En: A. Warman y A. Argueta, coords, Nuevos enfoques para el estudio de las etnias indigenas. Centro de Investigaciones Interdisciplinarias, UNAM/Porria, México, p.193-233.

DUNNE, Peter $M$

1958 Las Antiguas misiones de la Tarahumara. Jus, 2 tomos, México.

DURÁN FLORES, Sebastián

1961 "Antecedentes históricos del Ferrocarril Chihuahua al Pacifico y su influencia en la integración económica de México". En: El Economista Mexicano, n. 2, enero-febrero, p. 56-73.

EMBRIZ, Amulfo

1992 El Instituto Nacional Indigenista: Cuarenta años de trabajo en la Sierra Tarahumara, Cuademos de Trabajo, 8, Oficina Coordinadora Estatal del Instituto Nacional Indigenista/Unidad de Estudios Regionales de la Universidad Autónoma de Ciudad Juárez. Ciudad Juárez, Chih

ENRIQUEZ HERNÁNDEZ, Jorge

1988 Análisis geoeconómico del sistema regional de la Sierra Tarahumara. UNAM, México. 
FOSTER, George

1948 Empire's Children: The People of Tzintzuntzan. Smithsonian Institution of Social Anthropology, Washington.

1974 Antropología aplicada. Fondo de Cultura Económica, Breviarios, n. 232, México.

FOX, Jonathan

1994 "Targeting the Poorest: The role of the National Indigenous Institute in Mexico's Solidarity Program". En: W. Cornelius, A. L. Craig y J. Fox, Transforming State-Society Relations in Mexico. The National Solidarity Strategy. Center for U.S.-Mexican Studies, University of California, San Diego, p. 178-216

GALVEZ, Felipe

1993 "Incursión a Jordán". En: F. Jordán, El otro México. Biografía de Baja California. Secretaria de Educación Pública/Universidad Autónoma de Baja California, México. p. 7-59.

GAMBOA, Eduardo, coord.

1996 El México desconocido cien años después. Seminario en homenaje a la obra de Cart Lumholtz, El México desconocido, 1890-1990. Instituto Nacional de Antropologia e Historia, Colección Divulgación, México.

GAMIO, Manuel

1979 La población del Valle de Teotihuacán. INI, México. ( $1^{\text {a }}$ edición, La población del Valle de Teotihuacán. El medio en que se ha desarrollado. Su evolución étnica y social. Iniciativas para procurar su mejoramiento. Dirección de Talleres Gráficos de la Secretaria de Educación Pública, Tomos I y II, 1922, México).

1982 Forjando Patria. Pronacionalismo. Porrua, México. (1ª edición en 1916).

1986 Arqueología e indigenismo. Instituto Nacional Indigenista, México.

GENTRY, Howard S.

1963 "The warihio Indians of Sonora-Chihuahua. An Etnographic Survey". En: Bureau of American Ethnology, Bulletin 186, Antrophological Papers, n. 65, p. 61-144.

GERSTE, Achille

1914 "Rapport sur un voyage d'exploration dans la Tarahumara (Mexique Nord-Ouest)". En: Memoire della Pontificia Academia Romana dei Nuovi Lincei, Series 1, v. 32, p. 137-186.

GÓMEZ, Filiberto

1948 Rarámuri. Mi diario tarahumara. Talleres tipográficos de Excélsior, México.

1965 "El problema tarahumara. Sugerencias prácticas para su solución". En: Boletín de la Sociedad mexicana de geografia y estadistica, CII, enero, p. 175-218.

GÓMEZ, Magdalena

1995 Derechos indigenas. Lectura comentada del Convenio 169 de la Organización Internacional del Trabajo, INI, México.

GÓMEZ, Norma

2000 "Se reduce población serrana". En: El Diario, Chihuahua, 5, junio, p.3.

GONZALEZ CASANOVA, Pablo

1963 "Sociedad plural, colonialismo interno y desarroilo". En: América Latina, v. 6, n. 3, p. 15-32. 
GONZALEZ RODRIGUEZ, Luis

1988 "La antropologia en la Tarahumara". En: C. Garcia Mora, coord., La Antropología en México. Panorama histórico, Tomo 12, La Antropología en el norte de México. Instituto Nacional de Antropologia e Historia, México, p. 199-242.

1992 Crónicas de la Sierra Tarahumara. Camino, Chihuahua.

1993 El noroeste novohispano en la época colonial. UNAM/Porrua, México.

$1994 a$ Tarahumara: la Sierra y el hombre. Camino, Chihuahua.(1ª edición de 1982, SEP, México).

1994b "Notas históricas sobre el gobierno de los Tarahumares". En: Varios, Derechos culturales y derechos indigenas en la Sierra Tarahumara. Universidad Autónoma de Ciudad Juárez, Ciudad Juárez, Chih.

GREAVES, Cecilia

1996 "Entre la teoria educativa y la práctica indigenista. La experiencia en Chiapas y la Tarahumara (1940-1970)". En: P. Gonzalbo Aizpuru, coord., Educación rural e indígena en lberoamérica. El Colegio de México/Universidad Nacional de Educación a distancia, México, p. 161-178.

GRIGGS, John

1907 The Mines of Chihuahua. s.e. Chihuahua.

GROOM, Dale

1971 "Cardiovascular observations on Tarahumara Indian runners. The moderns Spartans". En: American Heart Joumal, v. 21, n. 81, p. 304-314.

GUERRERO, Javier, Marcela LAGARDE y Maria Elena MORALES

1978 "La cuestión étnica". En: Nueva Antropologia, n. 9, p. 79-93.

GUTIÉRREZ, Alejandro

1996 "Focos rojos en las Barrancas". En: Diario de Chihuahua, Reporte especial, 11 diciembre, p. 3A.

HARD, Robert J. y William L.MERRILL

1992 "Mobile Agriculturalists and the Emergence of Sedentism: Perspectives fron Northern Mexico". En: American Anthropologist, v. 94, n. 3, Septiembre, p. 601-620.

HERNÁNDEZ LABASTIDA, Josè y ALVAREZ, Francisco Javier

1945 Repabé Raramuri. Método de lectura. Chihuahua.

HERRERA, Rocio B. de

1983 "La politica indigenista en la actualidad". En: Boletín de Antropotogía Americana, n. 8, diciembre, p. 42-57.

HEWIT DE ALCÁNTARA, Cynthia

1988 Imágenes del campo. La interpretación antropológica del México rural. El Colegio de México, México.

HILLERKUSS, Thomas

1992 "Ecologia, economia y orden social de los Tarahumaras en la época prehispánica y colonial". En: Estudios de Historia Novohispana, v. 12, p. 9-62. 
INSTITUTO NACIONAL DE ESTADISTICA, GEOGRAFIA E INFORMÁTICA (INEGI)

1996 Chihuahua. Conteo de Población y Vivienda, 1995. Resultados definitivos. Tabulados básicos. INEGI, Aguascalientes.

INSTITUTO NACIONAL DE SOLIDARIDAD

1997 Organización, desarrollo y gobierno indigena en la Tarahumara. SEDESOL, México.

INSTITUTO NACIONAL INDIGENISTA (INI)

1964 INI. Realidades y Proyectos. 14 años de trabajo. INI, México.

$1978 a$ Bases para la acción. 1977-1982. Guía para la programación. INI, México.

1978b Instructivo para la instalación de los CCI. INI, México.

1978c INI 30 años después. Revisión crítica. México Indigena, número especial de aniversario, INI, México.

1982 Memoria de actividades. 1976-1982. INI, México.

1988 Instituto Nacional Indigenista. 40 años. INI, México

1993a Indicadores socioeconómicos de los Pueblos indigenas de México. INI, México.

1993b Pueblos indigenas y microdesarrollo en la Tarahumara. Seminario permanente sobre indigenismo. INI Delegación Chihuahua/Programa de Desarrollo Forestal ChihuahuaDurango, ms, Chihuahua.

1994 Instituto Nacional Indigenista. 1989-1994. INI, México.

s.f Perfiles de los Pueblos indigenas de México. <uww.sedesol.gob.mx/ perfiles>

IRIGOYEN, Fructuoso

1979 Cerocahui. Una comunidad en la Tarahumara. Centro Librero La Prensa, Chihuahua.

1994 Rarajipari. La carrera de bola tarahumara. Centro Librero La Prensa, Chihuahua.

JORDÁN, Femando

1948 "Invierno en la Tarahumara. II.- Ejemplares vivos de los hombres de la prehistoria". En: Mañana, 25 diciembre, p. 30-40.

1954 "¿Serán los indios el problema? Es posible que los indigenistas sean un problema mayor". En: Siempre, n. 57, 24 de julio, p. 28, 29 y 70.

1989 Crónica de un pais bárbaro. Centro Librero La Prensa, $7^{\mathrm{a}}$ edición, Chihuahua. (Edición original de la Asociación Mexicana de Periodistas, México, 1956).

KENNEDY, John G.

1970 Inápuchi. Una comunidad tarahumara gentil. Instituto Indigenista Interamericano, Ediciones especiales, n. 58 , México.

1989 The Tarahumara. Chelsea House Publishers, Nueva York.

1996 Tarahumara of the Sierra Madre. Survivors on the Canyon's Edge. Asilomar Press, Pacific Grove, California. 
KROTZ, Esteban

1998 "El Indigenismo en México". En: Enciclopedia lberoamericana de Filosofía. Consejo Superior de Investigaciones Cientificas, Trotta, Madrid, p. 163-178.

KUMMELS, Ingrid

1988 Schulerzichung für oder gegen indianische Etnhien?. Die Raramuri von Kaborachi und die Erzieizungspolitik der mexikanischen Regierung. Tesis de doctorado, Universidad de Munich.

LARTIGUE, François

1983 Indios y bosques. Políticas forestales y comunales en la Sierra Tarahumara. CISINAH, Ediciones de la Casa Chata, México.

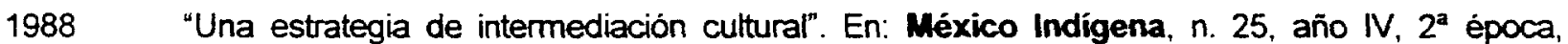
noviembre-diciembre, p. 56-60.

1989 "Los intermediarios culturales en la Tarahumara. Delegación de autoridad y elaboración del derecho consuetudinario". En: R. Stavenhagen y Diego Iturralde, comps., Entre la ley y la costumbre: el derecho consuetudinario indígena en América Latina. El Colegio de Méxicol Instituto Interamericano de Derechos Humanos, México, p. 192-204.

LEBRUN, Jorge

1933 Empresa minera Pastrana y Anexas. Batopilas, Chihuahua, México. Prospecto, informes, etc. s.e. Hermosillo.

LEON, Ricardo

1992 Misiones jesuitas en la Tarahumara. Siglo XVIII. Universidad Autónoma de Ciudad Juárez, Ciudad Juárez, Chih.

LEWIS, Oscar

1951 Life in a Mexican Village. Tepoztlan Restudied. Illinois University Press, Urbana.

1957 "Urbanización sin desorganización". En: América Indígena, v. 18, n. 3, p. 230-246. (1ª edición en 1952)

1964 Los hijos de Sánchez. Fondo de Cultura Económica, México.

1967 Pedro Martínez. A Mexican Peasant and his Family. Vintage Books, Nueva York.

1971 La cultura de la pobreza. Anagrama, Barcelona.

LIMÓN, Miguel

1988 "El indigenismo: un imperativo nacional". En: Instituto Nacional Indigenista, Instituto Nacional Indigenista. 40 años. INI, México, p. 81-101.

LISTER Florence C. y Robert H. LISTER

1979 Chihuahua. Almacén de tempestades. Gobierno del Estado de Chihuahua, Chihuahua.

LOPEZ Y RIVAS, Gilberto

1988 Antropologia, minorias étnicas y cuestión nacional. Ediciones Aguirre Beltrán, Editorial Cuicuilco, Escuela Nacional de Antropologia e Historia, México.

LUMHOLTZ, Cart

1986 El México desconocido. 2 Tomos. INI. México. (1 $1^{\text {a }}$ edición en inglés: Nueva York, 1904). 
MALINOWAKI, BronislaW y JUIIO DE LA FUENTE

1957 "La economia de un sistema de mercados en México". En. Acta Antropológica, v. 1, n.2, p. 88188 .

MANCERA, Federico, Alonso DOMINGUEZ y Arturo HERRERA

1998 Impactos culturales del Plan Maestro "Barrancas del Cobre". Instituto Chihuahuense de la Cultura, Chihuahua.

MARROQUIN, Alejandro

1957 La ciudad mercado (Tlaxiaco). UNAM, México. ( 1 a edición en 1954).

1971 "La politica indigenista en Mèxico". En: Varios, ¿Ha fracasado el indigenismo? Reportaje de una controversia (13 de septiembre de 1971). SepSetentas, México, p. 195-225.

MASFERRER, Elio

1981 "Documentos y testimonios de la acción indigenista". En: América Indigena, 40 años de Indice general. Instituto Indigenista Interamericano, México, v. 2, p. IX-X|.

MEDINA CÁRDENAS, Eduardo

1992 "El modelo región de refugio de Aguirre Beltrán. Teoria, aplicaciones y perspectivas". En: Siglo XIX. Cuadernos de Historia, año II, n. 4, octubre, p. 61-82

MEDINA, Andrés

$1974 a$ ¿Etnologia o literatura?. El caso de Benitez y sus indios". En: Anales de Antropologia, v. XI. p. $109-140$

1974b "Antropologia e indigenismo. Los compromisos introductorios de la ciencia en México". En: Revista de la Universidad de México, v. XXIX, n. 2, octubre, p. 13-20

1976 "Ortodoxia y herejia en la antropologia mexicana". En: Anales de antropologia, t. XIII, p. 217231

MEDINA, Andrés y Carlos GARCIA MORA

1983 La quiebra política de la antropología social en México. (Antologia de una polémica). I. La impugnación. UNAM, Instituto de Investigaciones Antropológicas, México.

MÉNDEZ LAVIELLE, Guadalupe

1987 "La quiebra politica (1965-1976)". En: C. Garcia Mora, coord., La Antropologia en México. Panorama histórico. 2 Los hechos y los dichos (1880-1986), Instituto Nacional de Antropología e Historia, México, p. 339-437.

MERRILL, William L.

1992 Almas rarámuris. CNCAINI, México.

1995 "La época franciscana en la Tarahumara". En: N Congreso Internacional de Historia regional comparada, 1993. Actas, v. 1, p. 157-175, Universidad Autónoma de Ciudad Juárez.

MEZA, Mayra Ciudad. Juárez, Chih.

1997 San José Baqueachi: Historia de un ejido tarahumara que se resiste al despojo de sus tierras. Tesis de licenciatura en Antropología, Escuela Nacional de Antropologia e Historia, Unidad Chihuahua, Chihuahua. 
MOLINARI, Claudia

1993 Protestantismo y explotación forestal en la Tarahumara. Tesis de licenciatura en Antropologia social. Escuela Nacional de Antropologia e Historia, México.

MUÑOZ, Maurilio

1967 "Los tarahumaras". En: Acción Indigenista, marzo, p. 3

NAHMAD, Salomón

1978 "La educación bilingüe y bicultural para las regiones interculturales de México". En: Instituto Nacional Indigenista, INI. 30 años después. Revisión critica. INI, México, p. 225-244.

1988 "Comientes y tendencias de la Antropologia aplicada en México. Indigenismo". En: Varios Teoría e investigación en la antropologia social mexicana. CIESASUUAM-lztapalapa, Cuademos de la Casa Chata, n. 160, México, p. 15-41.

NAVARRO, Luis

1964 Don José de Gálvez y la Comandancia General de las Provincias Internas del Norte de Nueva España. Escuela de Estudios Hispanoamericanos, Sevilla.

NEUMANN, Jose y Luis GONZALEZ (ed.)

1991 Historia de las rebeliones en la Sierra Tarahumara (1626-1724). Camino, Chihuahua.

OCAMPO, Manuel

1950 Historia de la Misión Tarahumara (1900-1950). Buena Prensa, México.

OLIVOS, Luis $\mathrm{N}$.

1997 Territorio étnico y proyecto nacional: el ejido y la comunidad tarahumara. Tesis de licenciatura en Antropologia social, Escuela Nacional de Antropologia e Historia, México.

OROZCO, Victor

1992 Las guerras indias en la historia de Chihuahua. Primeras fases. CONACULTA, México

OVALLE, Ignacio

1977 "Indigenismo de participación". En: México Indigena, n.1, México.

1988 "De la aldea al mundo". En: Instituto Nacional Indigenista, Instituto Nacional Indigenista. 40 años, INI, México, p. 41-80.

PALERM, Angel

1975 "La disputa de los antropólogos mexicanos: una contribución cientifica". En: América Indigena, v. XXXV n. 1, p. 161-167.

1976 "Introducción". En: G. Aguirte Beltrán, Obra polémica. Universidad Veracruzana/INI/Gobierno del Estado de Veracruz/Fondo de Cultura Económica, México, p. 7-19. (Primera edición de CISINAH, México, 1976)

PALOMARES, Noé

1994 Propietarios norteamericanos y reforma agraria en Chihuahua, 1917-1942. Universidad Autónoma de Ciudad Juàrez, Colección de Estudios Regionales, n. 4, Ciudad Juárez, Chih.

PAREDES, A. BERGER, R.L., SNOW C.C.

1970 "Biosocial adaptation and correlates of acculturation in the Tarahumara ecosystem". En: International Joumal of Social Psychiatry, v. 16, n. 3, p. 163-174. 
PENNINGTON, Campbell W.

1963 The Tarahumar of Mexico: Their Environenment and Material Culture. University of Utah Press, Salt Lake City.

1969 The Tepehuan of Chihuahua. Their Material Culture. University of Utah Press, Salt Lake City.

1983 "Tárahumara". En: A. Ortiz (ed.), Southwest, Handbook of North American Indians, v. 10, William C. Sturtevant (ed.), Smithsonian Institution, Washington, p. 276-289.

PEÑA, Guillermo de la

1988 "Gonzalo Aguirre Beltrán". En: Instituto Nacional Indigenista, Instituto Nacional Indigenista. 40 años. INI, México, p 375-382.

1998 Las politicas sociales hacia los indigenas en México, 1948-1998: actores, mediaciones y nichos de identidad, Proyecto colectivo (borrador provisional), ms, CIESAS, Guadalajara.

PEÑA, Moisés de la

1944 "Ensayo económico y social sobre el pueblo tarahumara". En: Investigación Económica, v. 4, p. 363-399.

1945 "La mexicanización del indio. Un problema económico". En: Revista de Economia, v.1, p. 3-34.

1946 "Extranjeros y tarahumares en Chihuahua". En: M. O. de Mendizábal, Obras Completas, México, Tomo I, p. 225-277

1948 Chihuahua económico. Gobierno del Estado de Chihuahua, 3 Tomos, Chihuahua.

1950 Problemas sociales y económicos de las mixtecas. Memorias del Instituto Nacional Indigenista, INI, México.

PLANCARTE, Francisco $M$.

1954 El problema indigena tarahumara. Memorias del Instituto Nacional Indigenista, INI, México.

PLETCHER, David M.

1958 "City Boss: Alexander R. Shepherd". En: D. M. Pletcher, Rails, mines and progress: Seven

American Promoters in Mexico, 1867-1911. Cornell University Press, Nueva York, p. 182-218,

PONCE DE LEÓN, José Maria

1909 Chihuahua y sus distritos. Datos Geográficos y Estadisticos del Estado de Chihuahua. s.e., Chihuahua.

PORRAS, Eugenio

1996 Indigenismo y cambio sociocultural en la Tarahumara. Elementos para el monitoreo de impactos socioculturales. Tesis de Licenciatura en Etnologia, Escuela Nacional de Antropología e Historia, México.

PORTAL, Maria Ana

1995 "Los partidos politicos mexicanos de fines del milenio frente a la cuestión indigena". En: Inventario Antropológico, v. 1, p. 130-145.

POZAS, Ricardo

Antropologia y burocracia indigenista. Tlacuilo, México. 
PRODUCTOS FORESTALES DE LA TARAHUMARA (PROFORTARAH)

1976 Productos Forestales de la Tarahumara. Un organismo para el desarrollo. Memoria. Imprenta Roa, Ciudad Juárez, Chihuahua.

RAMIREZ MORALES, César

1996 Carl. Lumholtz. Montañas, duendes, adivinos... INI, México.

RASCÓN BANDA, Victor Hugo

1996 Volver a Santa Rosa. Joaquín Mortiz, México.

REDFIELD, Robert

1973 Tepoztlan. A Mexican Village. Chicago University Press, Chicago ( $1^{\mathbf{a}}$ edición en 1930).

1941 The Folk Culture of Yucatan. Chicago University Press, Chicago.

1956 The Little Community. Peasant Society and Culture. Chicago University Press, Chicago.

ROBLES, J. Ricardo

1995 "Los Rarámuri-Pagótuame". En: M. Marzal, ed., El rostro indio de Dios. Ediciones del Centro de Reflexión Teológica/Universidad lberoamericana, México, p. 23-87.

ROBLES, J. Ricardo y C.F. VALLEJO

1995 "Los juicios en el pueblo rarámuri". En: R. Estrada y G. González, coord., Tradiciones y costumbres jurídicas en comunidades indigenas de México. Comisión Nacional de Derechos Humanos, México, p. 71-95

ROMANO, Agustín

1962 "El INI en la Tarahumara". En: Acción indigenista, n. 103, enero, p.1-4.

RONQUILLO AGUIRRE, Mario

1993 Donde volaron las garzas. s.e., México

SȦENZ, Moisés

1966 Carapan. Bosquejo de una experiencia, Lima. (1 ( $^{\text {a }}$ edición, del Gobiemo del Estado de Michoacán de 1966).

1982 México íntegro. Sep/80, México

SALMÓN, Alejandro

1997 "Instalan Consejo Consultivo Regional. Proyecto Barrancas del Cobre". En: Diario de Chihuahua, 10 de mayo, Chihuahua, p.3

SANCHEZ PAREJA, J.

1883 Reseña histórica de Batopilas. Álamos, Sonora.

SARIEGO, Juan Luis

$1995 a$ "Ideologias y modelos de desarrollo en la Sierra Tarahumara". En: M. Camberos, V. Salazar, P. $L$. Salido y S. Sandoval, comps., Las consecuencias de la modemización y el desarrolto sustentable. CIAD/UNAM, México, p. 76-86.

$1995 b$ "Aguirre Beltrán, Gonzalo, El pensar y el quehacer antropologico".
Antropológico, v. 1, México, p. 149-157.

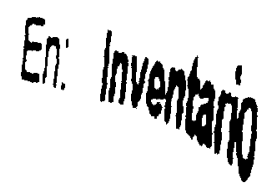


1999a "Propuestas y reflexiones para una antropologia del norte de México". En: J. L. Moctezuma y E. Villaipaldo, eds., Antropologia de la identidad e historia en el norte de México, Homenaje a Alejandro Figueroa Valenzuela. Número especial de la revista Noroeste de México, Instituto Nacional de Antropología e Historia, Centro Sonora, Hermosillo, p. 17-21.

1999b "Para una historia de la antropologia en Chihuahua". En: Inventario Antropológico, v. 5, p. 29 44.

SARIEGO, Juan Luis (comp.)

1998a El indigenismo en Chihuahua. Antologia de Textos. Escuela Nacional de Antropologia e Historia, Unidad Chihuahua, Chihuahua.

SARIEGO, J.L. (coord.)

1998b Trabajo, territorio y sociedad en Chihuahua durante el siglo XX. Historia general de Chihuahua. V. Periodo contemporáneo. Primera Parte. Gobiemo del Estado de Chihuahua/ Escuela Nacional de Antropologia e Historia, Unidad Chihuahua/Universidad Autónoma de Ciudad Juárez, Chihuahua.

SARIEGO, Juan Luis y Augusto URTEAGA

1995 "Cultura politica y participación indigena". En: Varios, El patrimonio sitiado. El punto de vista de los trabajadores. Edición del Sindicato de trabajadores académicos del INAH, México, p.141-146.

SCHNEIDER, Luis Mario

1994 "Artaud y México". En: A. Artaud, México y Viaje al pais de los Tarahumaras. Fondo de Cultura Económica, México, p. 7-93

SCHWATKA, Frederik

1893 In the Land of the Cave and Cliff Dwellers. Cassel Publishers, Nueva York.

SECRETARIA DE DESARROLLO SOCIAL (SEDESOL)

1998 Organización, desarrollo y gobiemo indigena en la Tarahumara. SEDESOL, México.

SECRETARIA DE TURISMO Y GOBIERNO DEL ESTADO DE CHIHUAHUA

1998 Plan Barrancas del Cobre, Proyecto SECTUR-Gobierno del Estado de Chihuahua. ms, México.

s/f Guia turistica de la Sierra Tarahumara. s. e., México.

SHEPHERD, Grant

1965 Batopilas (Entraña de plata). Impresora Tipográfica, Ciudad Juárez, Chih.

SONNICHSEN, C.L.

1976 Colonel Greene and The Copper Skyrocket. The University of Arizona Press, Tucson.

SOUTHWORTH, J.R.

1905 Las minas de México. s. e, México.

SPICER, Edward H.

1976 Cycles of Conquest The impact of Spain, Mexiço and the United States on the Indians of the Southwest. 1533-1960. University of Arizona Press, Tucson.

STAVENHAGEN, Rodolfo

1969 Las clases sociales en las sociedades agrarias. Siglo XXI Editores, México. 
1978 "Clase, etnia y comunidad". En: México Indigena, número especial, diciembre, p. 97-100.

1980 "Castas, Clases y proceso dominical: notas sobre la antropologia politica de Aguirre Beltrán". En: R. Stavenhagen, Problemas étnicos y campesinos, INI. México, p. 60-71.

STURTEVANT, William C. (general editor)

1983 Handbook of Noth American Indians. Smithsonian Institution, Washington.

TELLECHEA, Miguel

1826 Compendio gramatical para la inteligencia del idioma tarahumar. Imprenta de la Federación en Palacio, México.

TELLO, Marta

1994 El mismo diablo nos robó el papel. Dos estudios de educación y resistencia cultural entre mixes y tarahumaras. CNCA, México.

TERRAZAS, Joaquin

1905 Memorias del Señor Coronel Don Joaquin Terrazas. Imprenta del Agricultor mexicano, Escobar Hnos., Ciudad Juárez, Chih.

TORRES ORDOÑEZ, LUiS

1963 "Beneficios forestales obtenidos en zonas indigenas". En: Acción Indigenista, n.124, octubre, p. 3.

TRUJILLO, Eva

1996 "Sueño de las Barrancas del Cobre. Un programa turistico ambicioso en medio de grandes carencias". En. Diario de Chihuahua, Reporte especial, 23 de abril, p. 6-A.

TRUJILLO, E., M. QUEZADA y O. ARAGÓN

1996 "Firman plan turistico. Anuncia el Presidente 'cascada' de apoyos". En. Diario de Chihuahua, 12 de diciembre, p. 3-A.

URIAS, Margarita

1994 "Rarámuris en el siglo XVIII". En: Varios, Derechos culturales y derechos indigenas en la Sierra Tarahumara. Universidad Autónoma de Ciudad Juárez, Ciudad Juárez, Chih. p. 73-115.

URTEAGA, Augusto

1996 "Aspectos culturales del sistema politico rarámuri". En: E. Krotz (coord.), El estudio de la cultura política en México (Perspectivas disciplinarias y actores politicos). CNCA CIESAS, México. p. 293-323.

1997 "Narrativas etnográficas en la Sierra Tarahumara". En: Frontera Norte, n. 18, Vol. 9, juliodiciembre 1997, p. 197-208.

1998 "We Semati Ricuri: Trabajo y tesgüino en la Sierra Tarahumara" en J.L. Sariego (coord.), Trabajo, territorio y sociedad en Chihuahua durante el siglo XX. Historia general de Chihuahua. $V$. Periodo contemporáneo. Primera Parte. Gobierno del Estado de Chihuahual Escuela Nacional de Antropologia e Historia, Uniḍad Chihuahua/Universidad Autónoma de Ciudad Juárez. Chihuahua, p. 515-529.

VALVERDE, Margarita

1989 El impacto del internado en la vida de catorce indigenas tarahumaras. Tesis de Maestria en Antropologia social, Univeridad Iberoamericana, México. 
VARIOS

1970

VARIOS

1971

VARIOS

1988

VARIOS

1994

VARIOS

1999

De eso que llaman antropología mexicana. Comité de Publicaciones de los alumnos de Escuela Nacional de Antropologia e Historia, s/f, $1^{\mathrm{a}}$ edición en Editorial Nuestro Tiempo; México.

¿Ha fracasado el indigenismo? Reportaje de una controversia. SepSetentas, México

Teoria e investigación en la antropología social mexicana. CIESAS/UAM-Iztapalapa, Cuademos de la Casa Chata, n.160, México.

Derechos culturales y derechos indigenas en la Sierra Tarahumara. Universidad Autónoma de Ciudad Juárez, Ciudad Juárez, Chih.

Cuando una mina llega a una comunidad mexicana: una Guia. Fondo Norteamericano para la Cooperación Ambiental, Proyecto \# 96-98: Desarrollando Estrategias Transfronterizas para Disminuir los Impactos Sociales y Ambientales de la Mineria en México, Alliance Consulting/ Border Ecology Project/El Colegio de Sonora/Proyecto Fronterizo de Educación Ambiental, ms, Hermosillo, Son.

VATANT, Françoise

1979 Un ejido forestal de la Alta Tarahumara: Cusárare. Tesis de Maestria en Etnologia, Escuela Nacional de Antropologia e Historia, México.

1990 La explotación forestal y la producción doméstica. Un estudio de caso: Cusárare. Instituto Nacional de Antropologia e Historia, Colección Cientifica, México.

VEGA, J.

1943 "La raza tarahumara y el medio geográfico y social en que vive". En: Boletin de la Sociedad Mexicana de Geografía y Estadística, tomo LVIII, n. 1 y 2, p. 103-121.

VELASCO, Pedro de

1987 Danzar o morir. Religión y resistencia a la dominación en la cultura tarahumar. Ediciones Centro de Reflexión teológica, México.

VILLA ROJAS, Alfonso

1955 Los mazatecos y el problema indigena de la cuenca del Papaloapan. Memorias del Instituto Nacional Indigenista, INI, México.

VILLORO, Luis

1987 Los grandes momentos del indigenismo en México. Lecturas Mexicanas/Centro de Investigaciones y Estudios Superiores en Antropologia social/Secretaria de Educación Pública, México.

WAMPLER, Joseph

1978 La Barranca del Cobre de México. La Región e Historia de los Indios Tarahumaras y de los Ferrocarriles Chihuahua al Pacifico. S. e., Berkeley.

WARMAN, Arturo

1990 Políticas y tareas indigenistas. 1989-1994. En: Boletin Indigenista, año 2, v. 4, nueva época, enero-febrero, p. 11-14. 
1991 "Introducción". En: A. Warman y A. Argueta, coords., Nuevos enfoques para el estudio de las etnias indigenas. Centro de Investigaciones Interdisciplinarias, UNAM/Porrua, México, p. 7-10.

WATSON, Sereno

1886 "List of Plants Collected by Dr. Edward Palmer in Souttwestern Chihuahua, Mexico, in 1885".

En: Proceedings of the American Academy of Arts and Sciences, v. 21, p. 414-445.

WILSON, Wendell E. y C.S. PANCZNER

1986 "Batopilas. Famous Mineral Localities: The Batopilas Distict, Chihuahua, Mexico". En: The Mineralogical Record, v. 17, enero-febrero, p. 61-79.

ZINGG, Robert M.

1942 "The Genuine and Spurious Values in Tarahumara Culture". En: American Anthropologist, v. 44, p. 78-92. 